\title{
MARTIN OTTO BRAUN
}

\section{An den Wurzeln der Tugend}

Rheinischer Adel und Freimaurerei 1765-1815
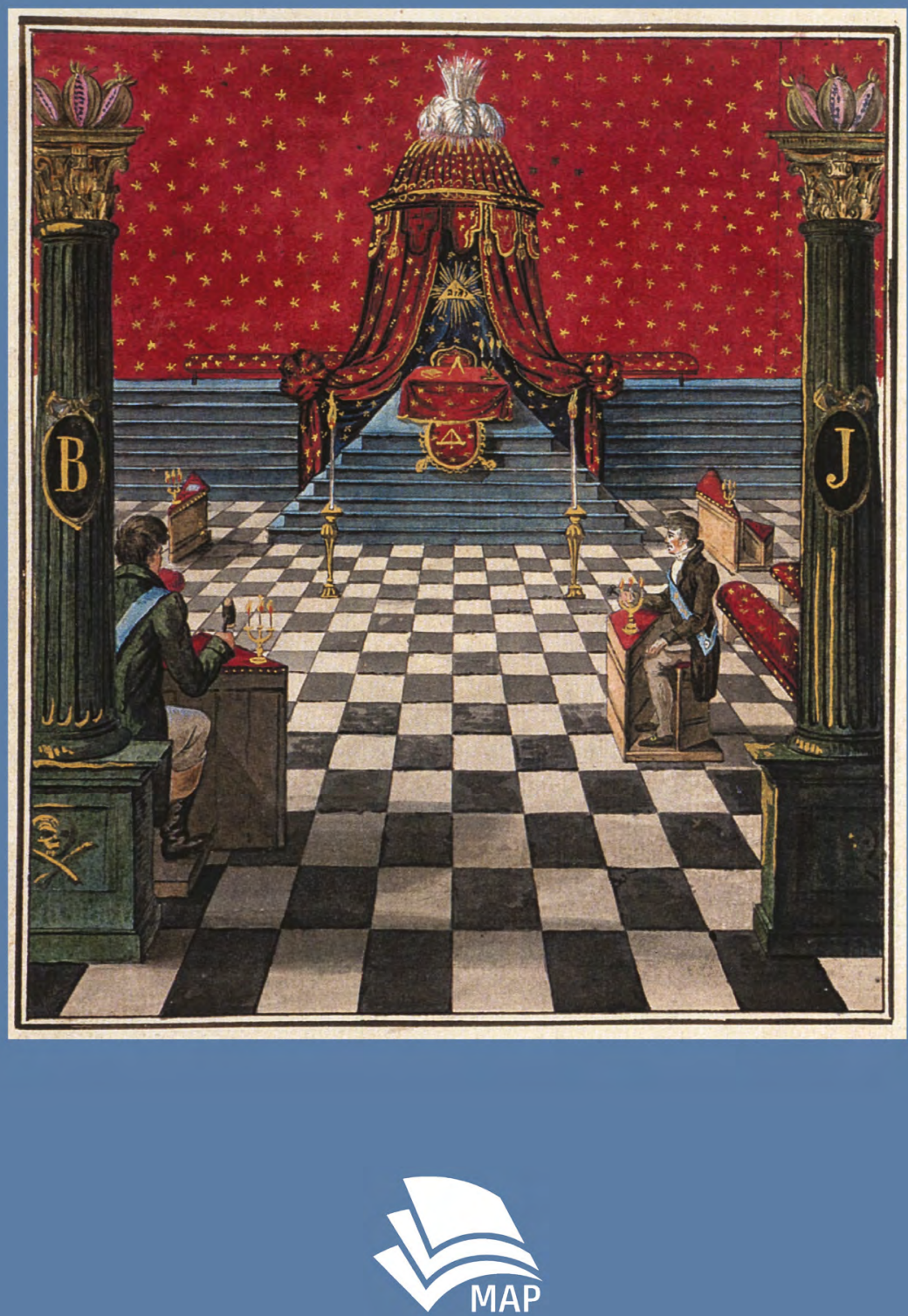
Martin Otto Braun - An den Wurzeln der Tugend 


\section{Herausgegeben von Modern Academic Publishing (MAP) 2015}

MAP (Modern Academic Publishing) ist eine Initiative an der Universität zu Köln, die auf dem Feld des elektronischen Publizierens zum digitalen Wandel in den Geisteswissenschaften beiträgt. MAP ist angesiedelt am Lehrstuhl für die Geschichte der Frühen Neuzeit von Prof. Dr. Gudrun Gersmann.

Die MAP-Partner Universität zu Köln (UzK) und Ludwig-Maximilians-Universität München (LMU) fördern die Open-Access-Publikation von Dissertationen forschungsstarker junger Geisteswissenschaftler beider Universitäten und verbinden dadurch wissenschaftliche Nachwuchsförderung mit dem Transfer in eine neue digitale Publikationskultur.

www.humanities-map.net
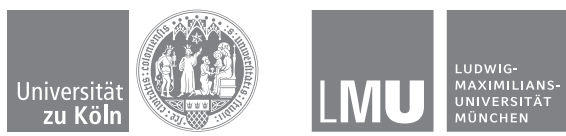
Martin Otto Braun

\section{An den Wurzeln der Tugend}

Rheinischer Adel und Freimaurerei 1765-1815 
Herausgegeben von

Modern Academic Publishing

Universität zu Köln

Albertus-Magnus-Platz

50923 Köln

Gefördert von der Universität zu Köln

Text ( Martin Otto Braun 2015

Erstveröffentlichung 2015

Zugleich Dissertation der Universität zu Köln 2013

Umschlagbild: Grade d'Apprentif, um 1800 (Bildrecht/Werk und Foto: From the collections of the Cultural Masonic Centre, The Hague).

Bibliographische Information der Deutschen Nationalbibliothek

Die Deutsche Nationalbibliothek verzeichnet diese Publikation in der Deutschen Nationalbibliografie; detaillierte bibliografische Daten sind im Internet über http:/dnb.dnb.de abrufbar.

ISBN (Hardcover): 978-3-95896-000-8

ISBN (EPUB): 978-3-95896-002-2

ISBN (Mobi): 978-3-95896-003-9

ISBN (PDF): 978-3-95896-001-5

DOI: http://dx.doi.org/10.16994/baa

Diese Arbeit ist veröffentlicht unter Creative Commons Licence BY 4.0. Eine Erläuterung zu dieser Lizenz findet sich unter http://creativecommons.org/licenses/by/4.0/. Diese Lizenz erlaubt die Weitergabe aus der Publikation unter gleichen Bedingungen für privaten oder kommerziellen Gebrauch bei ausreichender Namensnennung des Autors.

Herstellung \& technische Infrastruktur:

Ubiquity Press Ltd, 6 Windmill Street, London W1T 2JB, United Kingdom

Open Access-Version dieser Publikation verfügbar unter:

http://dx.doi.org/10.16994/baa

oder Einlesen des folgenden QR code mit einem mobilen Gerät:

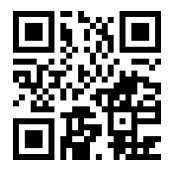




\section{Inhalt}

Danksagung und Widmung IX IX III

English Summary XIII

I. An den Wurzeln der Tugend - eine Einführung 1

I.1 Methodik 11

$\begin{array}{lll}\text { I.2 Forschungsstand } & 14\end{array}$

I.3 Gliederung und Quellenlage 23

II. Die Stammbäume der Tugend - Zur Funktion adliger Memoria um $1750 \quad 31$

II.1 Meminisse juvabit - Mythos und adlige Kavalierstour 31

II.2 »Lebens-Art« - Ausweis der Adligkeit 36

II.3 Lasterhafter Lebenswandel als Dilemma adliger "Blutsideologie» 43

II.4 Das »Esoterische» in seiner Beziehung zur adligen Memoria $\quad 49$

III. Von der Aufdeckung des Ursprungs - Ansichten über die Entstehung des Adels im Umfeld der ersten englischen Großloge

III.1 Die Geschichtsschreibung der Constitutions von 1723 als Genealogie der »Race of Noah» 53

III.2 »Royal Genealogies« - James Anderson als Adelsgenealoge 59

IV. Verborgene Wurzeln - Ars memoriae und Metempsychose 65

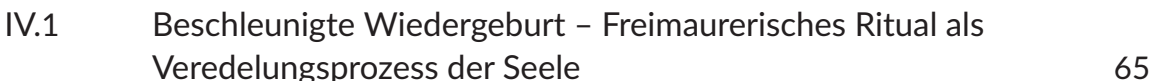

IV.2 "Feine Seelen« - Verbindungen hermetisch-alchemistischer

IV.3 Blut als ıflüssiges Gedächtnisı - Die Übertragung "geistiger

Bilder« als frühmoderne Vorstellung zur »Rassengenese» 77

IV.4 "Racines cachées» - Die Lehre der Metempsychose in ihrem

Einfluss auf die freimaurerischen Rittergrade

V. Rheinischer Adel und Freimaurerei des Ancien Régime -

Die Düsseldorfer Adelsloge La Parfaite Amitié 97

V.1 Die Loge La Parfaite Amitié und ihre Mitglieder 97

V.2 Die Beziehungen des Freiherrn Alexander von Merode-Hoffalize zur Straßburger Adelsloge La Candeur 101

V.3 Bezüge des Hochgrades eines Chevalier Rose-Croix zur Lehre der Metempsychose 
V.4 Reichsgraf Johann Ludwig Franz von Goltstein als Propagator und grenzüberschreitender Vermittler (natur-)wissenschaftlicher Forschungen

V.5 Friedrich Heinrich Jacobi und seine adligen Förderer

V.6 Die Auflösung der Parfaite Amitié und der Verbleib ihrer adligen Mitglieder

V.7 Der "Werth des Lebens" - Die Krise der aristokratischen Freimaurerei zum Ende des Ancien Régime

VI. Rahmenbedingungen: Freimaurerei in Frankreich nach 1789

VI.1 Ein Anfang vom Ende? Der Kölner Logenstreit der Jahre 1809/10 und seine karnevalistischen Ausuferungen

VI.2 Der politische Gehalt der französischen Freimaurerei nach 1789

VII. Rheinischer Adel und Freimaurerei nach 1789 - Das Beispiel Joseph zu Salm-Reifferscheidt-Dycks

VII.1 Die Familie der Altgrafen zu Salm-Reifferscheidt und ihre Beziehungen zur Wiener Freimaurerei

VII.2 Die Mitglieder des Salons der Constance de Salm und das Projekt der Idéologie

VII.3 Wissenschaftler, Künstler, Logenbrüder - Verbindungen der Idéologie in die französische Freimaurerei

VII.4 Joseph zu Salm-Reifferscheidt-Dycks Weg durch die Hochgradfreimaurerei im Paris des Premier Empire - ein Überblick 177

VII.5 Die Metempsychose als politische Fiktion - Alexandre Lenoirs Vorlesungsreihe anlässlich der Convents philosophiques des Jahres 1812

VII.6 Taxierte Seelen - Naturwissenschaftliche Analytik in ihrem Einfluss auf das zeitgenössische Verständnis des freimaurerischen Rituals in der Zeit des Premier Empire

VII.7 "... et prendre racine dans leur âme." - Das gedankliche und personale Umfeld Joseph zu Salm-Reifferscheidt-Dycks in der Pariser Loge Les Commandeurs du Mont Thabor

VII.8 Die Akademie der Weisheit - Joseph zu Salm-ReifferscheidtDyck als Vermittler des Rit écossais philosophique 
Anhang

A Tabellarische Übersicht rheinischer adliger Freimaurer 1765-1815 257

B Transkription: Discours Historique des 32. Grades des

Rite écossais ancien accepté

Freimaurerische Abkürzungen

Quellenverzeichnis

271

Literaturverzeichnis

283

Institutionen- und Logenregister

307

Personen-, Sach- und Ortsregister

309 



\section{Danksagung und Widmung}

Die vorliegende Studie wurde im Wintersemester 2013/14 von der Philosophischen Fakultät der Universität zu Köln als Dissertation angenommen und für die Veröffentlichung geringfügig überarbeitet. Bei den Forschungsarbeiten standen mir über die Jahre verschiedene Personen mit ihrem Rat und ihrer Hilfe zur Seite. Ihnen gilt mein Dank.

An erster Stelle möchte ich meiner Doktormutter, Frau Prof. Dr. Gudrun Gersmann (Köln), danken, die in zahlreichen Seminaren und Veranstaltungen an der Universität zu Köln mein Interesse für die Geschichte der Frühen Neuzeit im Allgemeinen und des Adels im Besonderen weckte. Ihre stete Förderung und das Vorbild ihrer Offenheit für neue Wege in den Geisteswissenschaften halfen mir, meine eigenen Fragen an die Geschichte zu entwickeln. Sie sowie Herr Prof. Dr. Hubertus Kohle setzten sich dafür ein, dass die Arbeit auf der Plattform Modern Academic Publishing (MAP) veröffentlicht werden konnte.

Ebenfalls danken möchte ich den Zweit- und Drittgutachtern meiner Arbeit, Frau Privatdozentin Dr. Annerose Menninger (Köln) sowie Herrn Prof. Dr. Michael Rohrschneider (Köln), die das eingereichte Manuskript einer kritischen Durchsicht unterzogen und wertvolle Anregungen für seine Überarbeitung gaben. Herr Prof. Dr. Frank Hentschel (Köln) übernahm freundlicherweise den Vorsitz der Prüfungskommission, wofür ich ihm ebenfalls herzlich danken möchte.

Die vorliegende Arbeit fußt zu großen Teilen auf den Auswertungen von Dokumenten des Familienarchivs der Fürsten und Altgrafen zu Salm-Reifferscheidt-Dyck. Ein großer Dank gilt daher der archivbesitzenden Familie der Grafen Wolff-Metternich zur Gracht. Namentlich Peter Graf Wolff-Metternich zur Gracht (†2013) und Simeon Graf Wolff-Metternich zur Gracht begegneten dem Projekt stets mit ihrer Unterstützung und gewährten mir in großzügigster Weise die Benutzung ihres Familienarchivs. In diesem Zuge ist auch den Vereinigten Adelsarchiven im Rheinland e.V. zu danken, in dessen Räumen auf Schloss Ehreshoven bei Overath das Archiv verwahrt wird und deren Bestände mir ebenso zugänglich waren.

Ein besonderer Dank gilt Herrn Dr. Hans-Werner Langbrandtner, Mitarbeiter des Archivberatungs- und Fortbildungszentrums des Landschaftsverbandes Rheinland (LVR) in Brauweiler, der stets hilfsbereit den Kontakt zu den Archivbesitzern herstellte und die Einsichtnahme vermittelte. Durch seine hervorragenden Kenntnisse der Adelsarchive gab er eine Vielzahl von wichtigen Hinweisen.

Zahlreiche Anregungen erhielt das Manuskript auch durch meine Tätigkeit als wissenschaftlicher Mitarbeiter in dem durch die Fritz Thyssen Stiftung (Köln) geförderten Projekt »Gewinner und Verlierer. Der rheinische Adel in der `Sattelzeit « 1750-1850«, in dessen Zuge in den Jahren 2012 und 2013 am Lehrstuhl für die Geschichte der Frühen Neuzeit des Historischen Instituts der Universität zu Köln eine multiperspektivische Netzbiographie zur Person des Fürsten Joseph zu 
Salm-Reifferscheidt-Dyck entstand. Ich möchte an dieser Stelle gegenüber der Fritz Thyssen Stiftung meinen aufrichtigen Dank für die Förderung und das Vertrauen ausdrücken, die sie dem Projekt angedeihen ließ. Ebenso danke ich allen beteiligten Autoren und insbesondere meinen Kollegen innerhalb des Projekts, namentlich Elisabeth Schläwe M.A. und Florian Schönfuß M.A.

Frau Prof. Dr. Gabriele Clemens (Saarbrücken) und Herrn Prof. Dr. Hillard von Thiessen (Rostock) sei für die Gelegenheit gedankt, meine Thesen in ihren Forschungskolloquien vorzustellen und zu diskutieren.

Das Deutsche Historische Institut Paris (im Folgenden DHIP) ermöglichte im Jahr 2010 durch ein Stipendium einen Forschungsaufenthalt in Paris. Mein Dank gilt insbesondere Frau Karin Förtsch und den damaligen Mitarbeitern des DHIP, Frau Dr. Christiane Coester und Herrn Dr. Stephan Geifes.

Die Benutzung freimaurerischer Bestände in französischen Bibliotheken und Archiven wären ohne die Vermittlung François Rognons, Bibliothekar der Grande Loge de France, und Sylvie Bourels, Konservatorin an der Bibliothèque nationale de France - Département des manuscrits (im Folgenden BnF) (beide Paris), nicht zustande gekommen. Ihnen möchte ich hierfür ebenfalls meinen großen Dank aussprechen. Ebenso ist Herrn Pierre Mollier, Direktor des Museums und der Bibliothek des Grand Orient de France (im Folgenden GOF) in Paris zu danken, der weitere Hinweise gab und einige Fragen zur Freimaurerei des Premier Empire mit mir diskutierte. Die Benutzung freimaurerischer Bestände der Großen NationalMutterloge $\mathrm{Zu}$ den drei Weltkugeln im Geheimen Staatsarchiv Preußischer Kulturbesitz (im Folgenden GStA PK) gewährte freundlicherweise ihr Großarchivar für Dokumentation, Dr. Klaus Röder (Berlin). Ich danke ihm sowie Frau Kornelia Lange vom GStA PK, die die Bereitstellung der Dokumente betreute. Die Recherchen in den Beständen des Cultureel Maçonniek Centrum Prins Frederik in Den Haag des Orde van Vrijmetselaren onder het Grootoosten der Nederlanden (im Folgenden GON) ermöglichten Wim van Keulen und Jacques Piepenbrock, wofür ich ebenfalls danke. Herrn Dr. Arie Nabrings, Leiter des Archivberatungs- und Fortbildungszentrums des LVR in Brauweiler, Herrn Dr. Volker Müller (Viersen) sowie Herrn Marcus Ewers, Leiter des Stadtarchivs Viersen, danke ich für die Ermöglichung der Einsichtnahmen in Archivalien der Dülkener Narrenakademie.

Verschiedene Freimaurerlogen gaben mir als »Profanem «, also außerhalb des Bundes Stehenden, die Gelegenheit, mein Projekt auf öffentlichen Logenabenden vorzustellen und die heutigen Aktivitäten des Bundes näher kennenzulernen. Ich danke hierfür Herrn Prof. Dr. Hans-Hermann Höhmann (Freimaurerloge Ver Sacrum, Köln), Herrn Kai-Henrik Wolter (Freimaurerloge Vorwärts, Mönchengladbach) sowie den Mitgliedern der Loge Freimut und Wahrheit zu Cöln.

Für die Durchführung zahlreicher Fernleihbestellungen danke ich Frau Ute Rolf, Bibliothekarin der Stadtbibliothek Viersen.

Ebenfalls schulde ich Herrn Prof. Dr. Pierre-Yves Beaurepaire (Nice), Martin Wolthaus, M.A., Mitarbeiter der Stiftung Schloss Dyck, Dr. Hanna Sonkarjävi (Köln), Dr. Martin Javor (Prešov), Monika Gussone M.A. (Aachen), Baudouin 
D’Hoore (Brüssel) sowie Dr. Alfred Whittaker für verschiedene Hinweise großen Dank. Ich danke außerdem meinen Kollegen am Historischen Institut Köln Dr. Moritz Isenmann, Dr. Michael Kaiser, Dr. Bernd Klesmann, Kim Opgenoorth, Christine Schmitt M.A. und Ulrike Schmitz M.A. für ihre Anregungen und Unterstützung.

Timothy Ellis danke ich für `Nachhilfestunden $>$ in alchemistischer Ikonographie, Panagiotis Mpeinoglou für den Beistand in der `Zeit des langen Wartens - ebenso Evangelos Stilos für seine ansteckende Zuversicht. Meinem Patenonkel Dr. Klaus Hamacher danke ich für Einblicke in die Welt der Medizin. Meiner Patentante Jutta Pitzen M.A. und Dr. Claudie Paye (München) möchte ich besonders für ihre erste Durchsicht der Arbeit danken.

Meine Mutter Brigitte Braun hielt mir unermüdlich den Rücken frei in den arbeitsameren Phasen der Manuskripterstellung und unterstützte mich in jeglicher Weise. Hierfür kann ich nicht genug danken. Nicht aufzuwiegen ist die selbstlose Unterstützung und das Vertrauen in meine Arbeit, dass ich über die Jahre durch meine Ehefrau Melanie erhalten habe. Meine Worte reichen für meinen Dank nicht aus.

Ich widme die Studie meiner Frau Melanie und meiner Tochter Mathilde, die im Februar 2012 zu unserer größten Freude das Licht der Welt erblickte. 



\section{English Summary}

\section{At the roots of virtue. Rhenish nobility and freemasonry 1765-1815}

This study focuses on the relationship between nobility and freemasonry from 1750 to 1850. It examines the specific role of an esoteric discourse surrounding the roots of the human race, centring on legendary constructions of noble genealogies in eighteenth century Europe. The aristocratic idea of blood as a type of »liquid memory of virtue « was also found in the freemason lodges frequented by the European nobility of the eighteenth century. Both groups therefore believed in educational systems that used rites, pictures and symbols to imprint the virtues in ones blood and heart respectively. The foundation of this belief - strongly combined with an interest in occult sciences and the existence of an afterlife - can be seen in the antique »art of memory«.

The example of an aristocratic lodge in Düsseldorf shows how these >research interests< overlapped within masonic and non-masonic networks of European noblemen and citizens. In the perspective of Rhenish noblemen in the mid of the eighteenth century freemasonry took the role of an educational system that improved the qualities of the noble blood to secure the leading position of nobility in the God-given »Ständegesellschaft«. The aristocratic lodge La Parfaite Amitié therefore was not only dominated by Rhenish noblemen but also by cousinship. As a consequence, it struggled to become a "provincial lodge", which had a stronger jurisdictional position in comparison with the civil lodge of Düsseldorf.

The second example is the masonic network of Joseph zu Salm-ReifferscheidtDyck (1773-1861), from the Napoleonic period. Born in the Ancient Regime to an aristocratic familiy of the lower Rhineland, Joseph zu Salm-Reifferscheidt-Dyck faced the extensive changes for the nobility of the Rhineland, caused by the French Revolution and the French occupation of the area. Together with his second wife, the Parisian Salonier Constance de Salm, he became a prominent person in the Napoleonic era. He not only acted as an influential scientist of systematic botany, as a politician and statesman but also as a high-ranking freemason in several rites, especially in the Rit écossais philosophique.

This masonic system can be seen as a `scientific $<$ one built upon the traditions of alchemistical and hermetical circles of the Ancient Regime. The Napoleonic period saw the occult sciences increasingly outdated and replaced by modern natural sciences. The methods considered as "exact « in the nineteenth century subsequently formed the perspective of civil dominated societies and its lodges on masonic rites and grades. In the masonic network of Joseph zu Salm-Reifferscheidt-Dyck, the Rit écossais philosophique was crossed with his network as a natural scientist, resulting in masonry being seen not only as an educational system but also as an exact way to uncover the "hidden roots " of the human soul and to assess the respective qualities of it. These tendencies were strongly influenced by 
the natural sciences outside the masonic sphere, which in parallel tried to uncover the »hidden roots « of the nations with the pseudo-scientific concepts of »race«.

The civil lodges of the Napoleonic era and afterwards, with their strong emphasis on the nation, could no longer be seen as a retreat for noble man and their exclusive ideology of noble blood. The majority of the Rhenish nobility therefore turned away from the lodges in order to maintain a conservative view of itself in exclusively noble circles which still believed in the quality of the noble blood and its inherited race. 


\section{An den Wurzeln der Tugend - eine Einführung}

Die Bedeutung des Stammbaums ist für dieses Verhältnis der Familien - und weiterhin der Adelsgruppe überhaupt - zu ihrem Individuum von tieferer Symbolik: die Substanz, die den Einzelnen bildet, muß durch den einheitlichen Stamm des Ganzen hindurchgegangen sein, wie die Substanz des Zweiges und der Frucht eben die ist, die auch den Stamm gebildet hat.

- Georg Simmel ${ }^{1}$

Dem Besucher des niederrheinischen Schlosses Dyck eröffnet sich in einem Nebenzimmer des Südflügels der Blick auf einen Stammbaum aus dem Jahr 1750. Das imposante Ölgemälde zeigt die Entwicklung der Familie der Altgrafen zu Salm-Reifferscheidt-Dyck und -Bedburg ${ }^{2}$ auf. Aus heutiger Sicht fast kurios erscheinen die Ursprünge der abgebildeten Ahnenreihen. Der unbekannte Maler ließ den Stammbaum bei den Leichen zweier auf Tumben aufgebahrter Stammväter entspringen. Von besonderem Interesse ist hier der linke der beiden Spitzenahnen. Dargestellt ist der Graf Salmo zu Ardennien in der Uniform eines römischen Zenturios. Den biographischen Angaben auf dem Gemälde zufolge starb Salmo im Jahr 65 vor Christus. Der in barocker Manier mit Flügeln und Sense abgebildete griechische Gott Kronos verweist in der Mitte der unteren Bildhälfte zwischen den beiden Spitzenahnen auf einen Zusatz unterhalb des Wappens der

1 Georg Simmel, Zur Soziologie des Adels. Fragment aus einer Formenlehre der Gesellschaft, in: Ders., Individualismus der modernen Zeit und andere soziologische Abhandlungen, hg. von Otthein Rammstedt, Frankfurt a.M. 2008, 257-266, hier 262.

2 Im Jahr 1204 erfolgte die Teilung des u.a. in den Ardennen begüterten Fürstenhauses der Salmen in die beiden Linien Ober- und Niedersalm. Zur Linie Obersalm zählten in späterer Zeit u.a. die Linien Salm-Salm und Salm-Kyrburg. Im Jahr 1649 kam es zu einer Erbteilung, in deren Folge die ältere niedersalmsche Hauptlinie Salm-Reifferscheidt-Bedburg von der jüngeren Hauptlinie SalmReifferscheidt-Dyck unterschieden wurde. Der älteren Linie fielen die Herrschaften Salm, Bedburg, Reifferscheidt und Alfter zu. Nach dem Tod Franz Wilhelms zu Salm-Reifferscheidt-Bedburg im Jahr 1734 teilte sie sich erneut auf. Aus dieser Teilung gingen schließlich die Linien Salm-Reifferscheidt-Bedburg (nach dem Reichsdeputationshauptschluss von 1803 Salm-Reifferscheidt-Krautheim genannt), -Hainspach sowie -Raitz hervor. Die jüngere Hauptlinie Salm-Reifferscheidt-Dyck erhielt die Herrschaften Dyck und Hackenbroich. Ihr Stammvater war Altgraf Ernst Salentin zu Salm-Reifferscheidt-Dyck (1621-1684). Die Familien Salm-Reifferscheidt-Bedburg und -Dyck waren eng verbunden mit dem Kurfürstentum Köln und bekleideten unter anderem traditionell das Amt des kölnischen Erbmarschalls, wobei die jüngere Hauptlinie die ältere Hauptlinie vertreten konnte. Die Familie der Altgrafen zu Salm-Reifferscheidt-Dyck herrschte bis zum Ende des Ancien Régime über die reichsunmittelbare Herrschaft Dyck. Vgl. zu allen hier gemachten Angaben in Bezug auf die Familiengeschichte Freiherr Leopold von Zedlitz-Neukirch, Neues preußisches Adels-Lexicon oder genealogische und diplomatische Nachrichten von den in der preussischen Monarchie ansässigen oder zu derselben in Beziehung stehenden fürstlichen, gräflichen, freiherrlichen und adeligen Häusern [...], Supplement Bd. oder des ganzen Werkes fünfter Bd., Leipzig 1839, 388-396, Permalink: http://hdl.handle.net/2027/hvd.hx3kn7 (Zugriff vom 25.05.2014); Jakob Bremer, Die reichsunmittelbare Herrschaft Dyck der Grafen und jetzigen Fürsten zu Salm-Reifferscheidt, Grevenbroich 1959, 45-84 sowie 189-206; Margit Sachse, Als in Dyck Kakteen blühten... Leben und Werk des Dycker Schlossherrn Joseph Altgraf und Fürst zu Salm-Reifferscheidt-Dyck (1773-1861), Pulheim 2005, 23-25. 
Salmen. Dieser ergänzt, dass der Ursprung des Geschlechts sich bis in das Jahr 3885 nach Erschaffung der Welt zurückverfolgen lässt. Die familiäre Memoria des Geschlechts der Altgrafen zu Salm-Reifferscheidt vermaß im Jahr 1750 die Familiengeschichte also offenbar nicht nur innerhalb der christlichen Zeitrechnung, sondern erhob den Anspruch, ihre Anciennität auch ab anno mundi, also im Verhältnis zur Schöpfungsgeschichte des Alten Testaments begründen zu können. ${ }^{3}$ Dass der zweite Spitzenahn im ebenso mythischen, jedoch deutlich jüngeren merowingischen Frankenkönig Faramund gesehen wurde, verwundert angesichts einer derartig konstruierten uralten Herkunft nur noch wenig. Dieser aus heutiger

3 Vgl. Abb. 1, 2, 3 \& 4. Für einige fachkundige Erläuterungen zur Entstehungsgeschichte des Gemäldes danke ich Herrn Martin Wolthaus, Mitarbeiter der Stiftung Schloss Dyck. Der hier beschriebene Stammbaum aus dem Jahr 1750 geht somit noch über die innerhalb der Ahnengalerie des 17. Jh.s konstruierte Ahnenreihe hinaus, die versucht, das Geschlecht in kognatischer Linie auf Kaiser Karl den Großen zurückzuführen. Zu Letzterem vgl. die Angaben bei Bremer, Die reichsunmittelbare Herrschaft Dyck (wie Anm. 2, Kap. I), 183; Hans-Werner Langbrandtner/Maria Rößner-Richarz, Genealogie und Familiengeschichte, in: Gudrun Gersmann/Hans-Werner Langbrandtner (Hg.), Adlige Lebenswelten im Rheinland. Kommentierte Quellen der Frühen Neuzeit (Vereinigte Adelsarchive im Rheinland e.V., 3), Köln/Weimar/Wien 2009, 187-192, hier 190. Karl der Große wird auch auf der »französischen Seite« des Stammbaums auf Schloss Dyck erwähnt, da die Merowinger bekanntlich die Karolinger als Herrschergeschlecht ablösten. Zur Ahnengalerie auf Schloss Dyck vgl. jüngst Martin Wolthaus, Die Ahnengalerie der Altgrafen und Fürsten zu Salm-Reifferscheidt-Dyck, aus: Netzbiographie: Joseph zu Salm-ReifferscheidtDyck (1773-1861), in: historicum-estudies.net [01.05.2014], http://www.historicum-estudies.net/ epublished/netzbiographie/ancien-regime/ahnengalerie (Zugriff vom 01.05.2014). Dass derartige Rückbezüge rheinischer adliger Familien in der Frühen Neuzeit keineswegs ungewöhnlich waren, zeigt etwa auch das Beispiel der Familie Beissel von Gymnich, die sich auf die »Legio Gemina" zurückführen wollte. Siehe zu letzterer Familie: Johannes Rogalla von Bieberstein, Adelsherrschaft und Adelskultur in Deutschland, Frankfurt a.M. [u.a.] 1989, 130. Rogalla von Bieberstein führt zudem zahlreiche weitere Beispiele aus Adelsfamilien anderer Regionen an. Er bemerkt zudem, dass diese mythischen Genealogien bis in die Zeiten eines Aeneas »wohl niemals ganz ernst genommen« worden seien. Dieser Annahme wird hier nicht gefolgt, wenngleich Rogalla von Bieberstein darin zugestimmt wird, dass allzu weit ausgreifende Stammbäume zuweilen bereits von Adligen der Frühen Neuzeit kritisch gesehen wurden. Dass dies jedoch nicht immer der Fall sein musste und etwa noch im 19. Jh. eine Abstammung des Geschlechts der Salmen von König Salomon, zumindest aber die Rückführung bis auf Salmo kolportiert wurde, illustriert folgendes Dokument: N.N., Das Schloß zur Dyk [sic!], mit der neuen botanischen Anlage, und dem alten Rittersaale, in: Gesellschaft von Freunden des Vaterlandes (Hg.), Vaterländische Blätter, den Bewohnern des Niederrheins gewidmet, Zweiter Bd., Erstes Heft, Düsseldorf 1814, 35-42, hier 40f., Permalink: http://nbn-resolving.org/urn:nbn:de:hbz:061:1-97846 (Zugriff vom 19.07.2014). Der Hinweis auf dieses Dokument fand sich bei Wolthaus, Die Ahnengalerie der Altgrafen und Fürsten zu SalmReifferscheidt-Dyck (wie Anm. 3, Kap. I). Auch ein im Dycker Archiv enthaltenes Dokument mit dem Titel »Geschichten der Salmer « aus den 1780er Jahren, das sich auf das eingangs beschriebene Gemälde bezieht, spricht durchaus für eine ernsthafte Beschäftigung des Adels des 18. Jh.s mit derartigen Theorien. Zu letzterem Dokument siehe »Geschichten der Salmer«, 1780, in: ASD, Bestände des 19. Jh.s: Allgemeine Verwaltung, Nr. 66 sowie Abb. 6. Zu den rigiden Zulassungskriterien des Hochadels in Bezug auf die »Stiftsfähigkeit« und dem hierbei gepflegten Primat der »Abstammung " gegenüber der »Reichsstandschaft« siehe zudem: Ute Küppers-Braun, Anmerkungen zum Selbstverständnis des hohen Adels - Katholische Hochadelsstifte als genossenschaftliche Kontrollinstanzen für Ebenbürtigkeit und Missheirat, in: zeitenblicke 4/3 (2005), [13.12.2005], http://nbnresolving.org/urn:nbn:de:0009-9-2438 (Zugriff vom 21.07.2014). 


\section{Sicht befremdlich anmutende Umgang adliger Familien des Ancien Régime mit familiärer Memoria ${ }^{4}$ stellt den Ausgangspunkt und zugleich roten Faden dieser}

4 Das Thema der "Memoria« stellt bekanntermaßen ein klassisches Feld der Adelsforschung dar. Insbesondere Studien zum mittelalterlichen Adel greifen diesen Aspekt auf. Unter Memoria soll in der vorliegenden Arbeit weniger das Memorialwesen, also sakrales Totengedenken und -verehrung, verstanden werden, sondern insgesamt die Bestandteile des historisch gewachsenen Bestands an selbstreferentiellen Gedächtnisgütern innerhalb einer sozialen Gruppe - hier des Adels, aber auch der Freimaurerei -, der die einzelnen Mitglieder über ihren jeweiligen zeitlichen Horizont hinweg potentiell miteinander in Beziehung setzen kann. Hierzu werden im Falle des Adels bspw. die Genealogie, die hiermit eng zusammenhängende Ahnengalerie, das Familienarchiv, aber auch sonstige selbstreferentielle Erinnerungsgüter gerechnet. Die Memoria bzw. ein sich über ihre Bestandteile definierendes Geschichtsbewusstsein wird als wichtiges Movens der Identitätsbildung ihrer Mitglieder verstanden. Es fordert diese auf, sich aktiv in das geschichtliche Werden ihres Verbandes einzuordnen. Als grundlegende Studien zum Aspekt der Memoria mit weiterführenden Literaturangaben seien hier angeführt: Dieter Geuenich/Otto Gerhard Oexle (Hg.), Memoria in der Gesellschaft des Mittelalters (Veröffentlichungen des Max-Planck-Instituts für Geschichte, 111), Göttingen 1994; Otto Gerhard Oexle (Hg.), Memoria als Kultur (Veröffentlichungen des Max-Planck-Instituts für Geschichte, 121), Göttingen 1995; Ders., Memoria in der Gesellschaft und in der Kultur des Mittelalters, in: Joachim Heinzle (Hg.), Modernes Mittelalter. Neue Bilder einer populären Epoche, Frankfurt a.M./Leipzig 1994, 297-323. Zu den Begriffen »Ursprung" und »Herkommen« in Mittelalter und Früher Neuzeit aufschlussreich ist zudem Klaus Graf, Ursprung und Herkommen. Funktionen vormoderner Gründungserzählungen, in: Hans-Joachim Gehrke, Geschichtsbilder und Gründungsmythen, Würzburg 2001, 23-36, http://nbn-resolving. org/urn:nbn:de:hebis:30-1137987 (Zugriff vom 19.07.2014). Für die Frühe Neuzeit müssen insb. die Beiträge Kilian Hecks und Bernhard Jahns erwähnt werden. Vgl. u.a. Kilian Heck/Bernhard Jahn (Hg.), Genealogie als Denkform in Mittelalter und Früher Neuzeit (Studien und Texte zur Sozialgeschichte der Literatur, 80), Tübingen 2000; Kilian Heck, Genealogie als Monument und Argument. Der Beitrag dynastischer Wappen zur politischen Raumbildung in der Neuzeit (Kunstwissenschaftliche Studien, 98), München/Berlin 2002. Elisabeth Fehrenbach bemerkte in einem Aufsatz aus dem Jahr 2006, dass die Geschichtsinteressen des Adels von der Forschung "eher selten thematisiert« werden und »das besondere Verhältnis des Adels zur Vergangenheit, wie es in der Pflege der generationenübergreifenden Familientraditionen und den Erinnerungen an eine möglichst lange Reihe verdienstvoller und ruhmreicher Ahnen zum Ausdruck kam, $[\ldots]$ als ein selbstverständlicher Bestandteil der Adelskultur, der wenig mit der Geschichtsschreibung oder gar Geschichtswissenschaft zu tun habe«, gelte. Zu Fehrenbachs Anmerkungen siehe Elisabeth Fehrenbach, Geschichtsinteressen des Adels. Freiherr vom Stein und die Gründung der "Gesellschaft für ältere deutsche Geschichtskunde», in: Dieter Hein/Klaus Hildebrand/Andreas Schulz (Hg.), Historie und Leben. Der Historiker als Wissenschaftler und Zeitgenosse, Festschrift für Lothar Gall zum 70. Geburtstag, München 2006, 645-656, hier 645. Gleichfalls zu beachten ist der von Martin Wrede und Horst Carl herausgegebene Sammelband mit dem Titel »Zwischen Schande und Ehre«. Siehe Martin Wrede/Horst Carl (Hg.), Zwischen Schande und Ehre. Erinnerungsbrüche und die Kontinuität des Hauses. Legitimationsmuster und Traditionsverständnis des frühneuzeitlichen Adels in Umbruch und Krise (Veröffentlichungen des Instituts für Europäische Geschichte Mainz, 73), Mainz 2007. Wrede setzte sich jüngst insb. mit den Mechanismen der adligen Erinnerungskulturen auseinander, wobei auch weit ausgreifende, mythische Genealogien von Adelsfamilien des französischen Hochadels in Betracht gezogen werden. Sie können so illustrieren, dass es sich bei dem oben beschriebenen Stammbaum keineswegs um ein lokales Phänomen handelte. Vgl. Martin Wrede, Zwischen Mythen, Genealogen und der Krone. Rivalisierende Familiengedächtnisse im französischen Hochadel des 17. Jh.s: die Häuser Bouillon, Noailles und Bourbon, in: Zeitschrift für Historische Forschung 32 (2005), 17-43; Ders., Ohne Furcht und Tadel. Für König und Vaterland. Frühneuzeitlicher Hochadel zwischen Familienehre, Ritterideal und Fürstendienst (Beihefte der Francia, 75), Ostfildern 2012. Eine aktuelle Studie zu der aufs Engste mit dem Geschichtsinteresse und dem frühneuzeitlichen Wissensgebiet der Genealogie 
Studie dar. Sie geht dem Interesse des rheinischen Adels an den im 18. Jahrhundert so verbreiteten Geheimbünden nach, insbesondere demjenigen der Freimaurerei. Denn sowohl im Adel als auch in dem von ihm im 18. Jahrhundert frequentierten Vergesellschaftungsraum der Freimaurerloge nahmen mythisch-legendenhafte Aspekte einen hohen Stellenwert in Bezug auf die Memoria der jeweiligen Gruppierung ein. ${ }^{5}$

Trotz der Anwesenheit des Adels in den Logen liegt gerade in den Überlieferungen der Archive des rheinischen Adels diesbezüglich eine $>$ Blindstelle vor, die - so viel darf hier vermutet werden - auch in der bis in das 20. Jahrhundert hinein äußerst angespannten Haltung der katholischen Kirche zur Freimaurerei begründet liegen dürfte. ${ }^{6}$ Dabei lassen sich auf Umwegen auch in den katholischen Adelsfamilien des Rheinlandes für das 18. Jahrhundert durchaus zahlreiche Freimaurer nachweisen. ${ }^{7}$ Untersuchungsleitende Fragen an das Thema »Rheinischer

zusammenhängenden adligen Praxis der Ahnenprobe, die gleichzeitig den Forschungsstand zu diesem Thema repräsentiert, besteht in: Elizabeth Harding/Michael Hecht (Hg.), Die Ahnenprobe in der Vormoderne: Selektion - Initiation - Repräsentation (Symbolische Kommunikation und gesellschaftliche Wertesysteme. Schriftenreihe des Sonderforschungsbereiches 496, 37), Münster 2011. Zu Ahnenproben des rheinischen Adels vgl. Hans-Werner Langbrandtner, Ahnenprobe und Aufschwörung, in: Gersmann/Langbrandtner (Hg.), Adlige Lebenswelten (wie Anm. 3, Kap. I), 178-186. Auf den Begriff des »kulturellen Gedächtnisses« und die Forschungen Jan Assmanns wird unten ausführlicher eingegangen.

5 Teilaspekte der vorliegenden Studie wurden bereits vorab an folgender Stelle in Kurzform vorgestellt: Martin Otto Braun, »Arbeit am Ideal«. Reformpotentiale freimaurerischer Vergesellschaftung in Bezug auf den Rheinischen Adel der Sattelzeit (1750-1850), in: Zeitschrift für Internationale Freimaurerforschung 28 (2012), 77-80; Ders., Mitgliedschaft in Freimaurer-Logen, aus Netzbiographie: Joseph zu Salm-Reifferscheidt-Dyck (1773-1861), in: historicum-estudies.net [01.05.2014], http://www.historicum-estudies.net/epublished/netzbiographie/franzoesische-zeit/ freimaurerei (19.07.2014). Zur freimaurerischen Memoria ist zu bemerken, dass sich Teile der englischen Freimaurerei bis weit in das 18. Jh. hinein in ihrer Geschichtsschreibung auf den biblischen Menschenvater Adam zurückführten - insb. die in dieser Studie ebenfalls behandelten sogenannten »Moderns«. Gerade hierin besteht, so Monika Neugebauer-Wölk, ihr Anschluss zu dem Themenfeld der Esoterik. Auch Rudolf Schlögl verwies bereits im Jahr 1993 auf die Wichtigkeit einer Einbeziehung des Gründungsmythos sowie des hermetischen Weltbildes in die wissenschaftliche Untersuchung der Freimaurerei. Siehe hierzu Monika Neugebauer-Wölk, Esoterik als Element freimaurerischer Geschichte und Geschichtsforschung, in: Quatuor Coronati Jahrbuch für Freimaurerforschung 40 (2003), 1-24, hier insb. 1-6, http://www.netzwerk-freimaurerforschung.de/ blog/wordpress/wp-content/uploads/2014/03/neugebauer_woelk_jahrbuch2003.pdf (Zugriff vom 25.05.2014); Dies., Esoterische Religiosität und ihre Bedeutung für die Freimaurerei, in: Quatuor Coronati Jahrbuch für Freimaurerforschung 47 (2010), 97-109, hier 105-108; Rudolf Schlögl, Ansätze zu einer Sozialgeschichte des Paracelsismus im 17. und 18. Jh., in: Peter Dilg/Hartmut Rudolph (Hg.), Resultate und Desiderate der Paracelsus-Forschung (Sudhoffs Archiv Beihefte, 31), Stuttgart 1993, 145-162, hier 155.

6 Zum Verhältnis der Katholischen Kirche zur Freimaurerei vgl. ausführlich Klaus Kottmann, Die Freimaurer und die Katholische Kirche (Adnotationes in Ius Canonicum, 45), Diss., Frankfurt a.M. 2009.

7 Vgl. die Tabelle in Anhang A dieser Studie sowie die einschlägigen Studien Dotzauers, der u.a. in Bezug auf Lüttich und Köln konstatiert, »daß sich Adelskanonikat und heimliche Logenzugehörigkeit nicht gegenseitig ausschlossen, sondern im Gegenteil im aufgeklärten Geist der Zeit insbesondere bei den adeligen Standespersonen der Germania sacra durchaus nicht Ausnahme sind.« Siehe hierzu Winfried Dotzauer, Freimaurergesellschaften am Rhein. Aufgeklärte Sozietä- 
Adel und Freimaurerei«, wie etwa nach den Gründen der Adligen des 18. Jahrhunderts für einen Beitritt in eine Freimaurerloge, der Gestaltung und Nutzung ihrer personalen Netzwerke innerhalb der Freimaurerei, der Vereinbarkeit dieser oftmals ständische Grenzen überschreitenden Form der Vergesellschaftung mit dem Selbstverständnis der adligen Personen, aber auch nach möglichen Wandlungsprozessen dieses Verhältnisses über das 18. Jahrhundert hinaus, drohen bei einer Beschränkung auf die Quellenbestände der Adelsarchive im nördlichen Rheinland nahezu unbeantwortet zu bleiben.

Auch aus diesem Grund ist der geographische Rahmen, der hier den Begriff »rheinischer Adel« konturieren soll und sich auf den nördlichen Teil der späteren preußischen Rheinprovinz konzentriert, in Bezug auf die »Adels-« wie »Logenlandschaft « von Beginn an nur als lockere Vorgabe zu sehen. ${ }^{8}$ In der genannten Region waren im Untersuchungszeitraum bedeutende Freimaurerlogen beheimatet, in denen im Ancien Régime auch Vertreter rheinischer Adelsfamilien verkehrten - wie etwa in den Städten Köln, Aachen und Düsseldorf. Die Ausweitung des Rahmens empfahl sich angesichts eines bereits früh vorhandenen kosmopolitischen Anspruchs der Freimaurerei aber von vornherein, um die oftmals grenzüberschreitenden Beziehungen der Akteure zuverlässiger beurteilen zu können. Bei den angestellten Untersuchungen standen somit wechselseitige Abhängigkeiten einzelner Individuen mit ihrem geographischen wie personalen Umfeld im Fokus.

Diese Einbeziehung des Umfeldes bedeutete jedoch keine Abkehr von den Adelsarchiven des Rheinlandes. Vielmehr bildet eine Akte des heute im Besitz der Familie der Grafen von Wolff-Metternich zur Gracht befindlichen Familienarchivs der Fürsten und Altgrafen zu Salm-Reifferscheidt-Dyck einen Angelpunkt dieser Studie. Die Akte 590 ist Bestandteil der sogenannten Blauen Bände, die der gebürtig aus Münster stammende Jurist und Genealoge Anton Fahne im 19. Jahrhundert zusammenstellte. Die in ihr enthaltenen Schriftstücke spiegeln schwerpunktmäßig das freimaurerische Engagement und Beziehungsnetzwerk des Altgrafen und im Jahr 1816 durch den preußischen König Friedrich Wilhelm III. gefürsteten Joseph zu Salm-Reifferscheidt-Dyck (1773-1861) ${ }^{9}$ in der Zeit des Premier Empire wider.

ten auf dem linken Rheinufer vom Ausgang des Ancien Régime bis zum Ende der Napoleonischen Herrschaft (Veröffentlichungen des Instituts für geschichtliche Landeskunde an der Universität Mainz, 16), Wiesbaden 1977, 96.

8 Siehe zum Begriff der »Adelslandschaft" sowie der hier erwähnten Eingrenzung in Bezug auf die preußische Rheinprovinz Rudolfine Freiin von Oer, Landständische Verfassungen in den geistlichen Fürstentümern Nordwestdeutschlands, in: Dietrich Gerhard (Hg.), Ständische Vertretungen in Europa im 17. und 18. Jh. (Veröffentlichungen des Max-Planck-Instituts für Geschichte, 27), Göttingen 1969, 94-119, hier 103; Karl Reinhold Weitz, Die preußische Rheinprovinz als Adelslandschaft. Eine statistische, sozialgeschichtliche und kulturräumliche Untersuchung zum frühen 19. Jh. Mit einer Karte, in: Rheinische Vierteljahrsblätter 38 (1974), 333-354.

9 Zur Person des Fürsten und Altgrafen Joseph zu Salm-Reifferscheidt-Dyck ist im Zuge des von der Fritz Thyssen Stiftung geförderten und an der Universität zu Köln angesiedelten Projekts »Gewinner und Verlierer. Der rheinische Adel in der `Sattelzeit $1750-1850$ « eine frei zugängliche Onlinebiographie unter Leitung von Frau Prof. Dr. Gudrun Gersmann entstanden. Siehe hierzu Gudrun 
Da eine derart umfangreiche Überlieferung der freimaurerischen Aktivitäten eines rheinischen Adligen für die napoleonische Phase des Rheinlandes als Sonderfall bezeichnet werden kann, bot sich die Akte als Kernstück der Studie an. Dies galt umso mehr, als die Lebenszeit Salm-Dycks den ins Auge gefassten Untersuchungsrahmen der Koselleckschen »Sattelzeit ${ }^{10}$ der Jahre 1750 bis 1850 weitestgehend abdeckte. Die "Sattelzeit» ist durch wissenschaftliche und gesellschaftliche Umbrüche - allen voran die Französische Revolution von 1789 - und deren Folgewirkungen geprägt. Sie kann als Phase des Übergangs von der Frühen Neuzeit zur Moderne gelten, wenngleich sich auch im Verlauf der Arbeiten zu dieser Studie andeutete, dass bestimmte Ansichten und Ideen, die tief im Weltbild und religiösem Denken der Gesellschaft der Frühen Neuzeit wurzelten, insbesondere zur Wende des 18. auf das 19. Jahrhundert an die veränderten gesellschaftlichen Rahmenbedingungen angepasst wurden.

Der Adel der Region der späteren preußischen Rheinprovinz gelangte im Zuge der Revolutionskriege und der Einrichtung des Roerdepartements - zumindest was das linke Rheinufer anbelangt - bereits mit dem Jahr 1794 unter französische Herrschaft. Die Ablösung des napoleonischen Regimes durch die Befreiungskriege der Jahre 1813 bis 1815 brachte einen erneuten Regierungswechsel mit sich, da das Rheinland fortan zum Königreich Preußen zählte. Durch die im Laufe von 20 Jahren somit mehrfach wechselnden Herrschaftsverhältnisse stand der in dieser Region ansässige Adel - sofern er sich nicht bereits 1794 durch Flucht entzogen hatte - unter einem enormen Anpassungsdruck, was seine wirtschaftliche und soziale Stellung sowie die ideellen Grundlagen der eigenen Identität anbelangte. ${ }^{11}$ Die Zeit von 1750 bis 1815 ist sowohl als ein besonders wichtiger Zeitabschnitt der

Gersmann, Vorwort, aus: Netzbiographie: Joseph zu Salm-Reifferscheidt-Dyck (1773-1861), in: historicum-estudies.net, [01.05.2014], http://www.historicum-estudies.net/epublished/netzbiographie (Zugriff vom 01.05.2014).

10 Zum Begriff der "Sattelzeit" siehe insb. Reinhart Koselleck, Einleitung, in: Otto Brunner/Werner Conze/Reinhart Koselleck (Hg.), Geschichtliche Grundbegriffe. Historisches Lexikon zur politisch-sozialen Sprache in Deutschland, Bd. 1, Stuttgart 1972, I-XXVII, insb. XV. Ergänzend hierzu sei auf die Beiträge Stefan Jordans verwiesen: Stefan Jordan, Die Sattelzeit als Epoche, in: Klaus Erich Müller (Hg.), Historische Wendeprozesse. Ideen, die Geschichte machten, Freiburg 2003, 188-203; Ders., Die Sattelzeit. Transformation des Denkens oder revolutionärer Paradigmenwechsel, in: Achim Landwehr (Hg.), Frühe Neue Zeiten. Zeitwissen zwischen Reformation und Revolution (Mainzer Historische Kulturwissenschaften, 2), Bielefeld 2012, 373-388.

11 Siehe hierzu Christof Dipper, Der rheinische Adel zwischen Revolution und Restauration, in: Helmuth Feigl/Willibald Rosner (Hg.), Adel im Wandel. Vorträge und Diskussionen des 11. Symposions des Niederösterreichischen Instituts für Landeskunde, Horn, 02.-05.07.1990 (Studien und Forschungen aus dem Niederösterreichischen Institut für Landeskunde, 15), Wien 1991, 91-116, hier insb. 91f. Die Lücken innerhalb der Forschung zum rheinischen Adel sind trotz dieser interessanten Ausgangslage nach wie vor groß. Dipper verwies daher im selben Aufsatz bereits auf den großen Forschungsbedarf. Zu einer aktuellen Einschätzung, was die Vernachlässigung des rheinischen Adels durch die Forschung angeht, siehe außerdem Michael Kaiser/Florian Schönfuß, Einführung, in: zeitenblicke 9/1 (2010), [10.06.2010], http://nbn-resolving.org/urn:nbn:de:0009-9-25200 (Zugriff vom 04.02.2013), insb. Abs. 4. 
»Sattelzeit« als auch eine bedeutende Phase der Adelsreform und des Kampfs um das gesellschaftliche ${ }$ Obenbleiben ${ }^{12}{ }^{12}$ des rheinischen Adels zu werten. ${ }^{13}$

Die vorliegende Studie geht dabei aus einem gemeinsam vom DHIP und dem Landschaftsverband Rheinland betriebenen Forschungsprojekt mit dem Titel "Aufbruch in die Moderne. Der rheinische Adel in westeuropäischer Perspektive 1750-1850 « hervor. ${ }^{14}$ Sie versteht sich in erster Linie als ein Beitrag zur Geschichte des rheinischen Adels, erhebt dabei jedoch keinen Anspruch auf Ausschließlichkeit. Dieser Umstand muss hier deshalb betont werden, weil die Untersuchung rheinischer adliger Personen innerhalb dieser Studie zwar Aussagen über Befindlichkeiten innerhalb des rheinischen Adels selbst geben soll, aber auch über historische Entwicklungen und die Beschaffenheit eines Ausschnitts ihres gedanklichen wie personalen Umfeldes zu einer bestimmten Zeit. Die Vergesellschaftungsform der Freimaurerei ist den adligen Akteuren als ein solcher Ausschnitt ihres sozialen wie gedanklichen Umfeldes zugeordnet.

An dieser Stelle soll jedoch nicht darüber hinweggetäuscht werden, dass sich ähnlich wie im Falle der Binnendifferenzierungen des frühneuzeitlichen Adels in »Hoch-« und »Niederadel« hinter dem stark generalisierenden Begriff »Freimaurerei«, insbesondere im 18. Jahrhundert, eine Vielzahl unterschiedlicher Systeme verbarg, die sich auch in ihrem jeweiligen Verständnis der >wahren` Freimaurerei deutlich voneinander unterschieden. Zum besseren Verständnis soll hier auf Grundlage der bisherigen Ergebnisse der wissenschaftlichen Forschung kurz auf die Frühgeschichte des Freimaurerbundes eingegangen werden.

Die an die Traditionen der mittelalterlichen Bruderschaften der Werkmaurer ${ }^{15}$ angelehnten Versammlungen der Freimaurer des 17. und 18. Jahrhunderts stie-

12 Zur besonderen Bedeutung dieses Zeitabschnitts in Bezug auf die »Sattelzeit« vgl. Jordan, Die Sattelzeit. Transformation des Denkens (wie Anm. 10, Kap. I), hier 384-385. Der Begriff des »Obenbleibens« wurde in der Adelsforschung durch einen Aufsatz Rudolf Brauns geprägt. Siehe Rudolf Braun, Konzeptionelle Bemerkungen zum Obenbleiben. Adel im 19. Jh., in: Hans-Ulrich Wehler (Hg.), Europäischer Adel 1750-1950 (Geschichte und Gesellschaft, 13), Göttingen 1990, 87-95. In jüngster Zeit wurde dieser Begriff jedoch auch kritisch hinterfragt. Siehe hierzu insb. Ewald Frie, Adel um 1800. Oben bleiben?, in: zeitenblicke 4/3 (2005), [13.12.2005], http://nbn-resolving.org/ urn:nbn:de:0009-9-2457 (Zugriff vom 13.10.2014). Frie plädiert dafür, insb. die begriffliche Wandlung des "Adels« in der oben angegebenen Zeit zu beachten, und weist auf die Bildung neuer "Mythen « hin, die durch die Adelsfamilien und -sozietäten des 19. Jh.s gepflegt wurden.

13 Zu der Wichtigkeit dieses Zeitabschnittes in Bezug auf die Adelsreformpläne unter Einbeziehung des rheinischen Adels siehe auch Heinz Reif, Adelserneuerung und Adelsreform in Deutschland 1815-1874, in: Elisabeth Fehrenbach (Hg.), Adel und Bürgertum in Deutschland 1770-1848 (Schriften des Historischen Kollegs, 31), München 1994, 203-230.

$14 \mathrm{Zu}$ einer Darstellung des Projekts siehe Hans-Werner Langbrandtner/Christine Schmitt, Aufbruch in die Moderne. Der Rheinische Adel in westeuropäischer Perspektive 1750-1850. Ein Forschungsprojekt des Deutschen Historischen Instituts Paris und der Archivberatung des Landschaftsverbandes Rheinland, in: Jahrbuch des Kreises Düren 2010 (2009), 119-125.

$15 \mathrm{Zu}$ einer Zusammenfassung der Theorien zu den historischen Ursprüngen der Freimaurerei siehe jüngst Helmut Reinalter, Die historischen Ursprünge und die Anfänge der Freimaurerei. Legenden - Theorien - Fakten, in: Frank Jacob (Hg.), Geheimgesellschaften: Kulturhistorische Sozialstudien (Globalhistorische Komparativanalysen, 1), Würzburg 2013, 49-83. Der kritischen Anmerkung Reinalters, dass es neben dem von Monika Neugebauer-Wölk in ihren Studien richtigerweise 
Ben sowohl in Schottland als auch in England auf das Interesse von Personen, die nicht dem Maurerberuf nachgingen, aber dennoch in die oftmals nur informell existierenden Logen aufgenommen wurden. ${ }^{16}$ Diese nicht selten gebildeten und einer vornehmen Abstammung entspringenden gentleman masons fanden über die Logen einen Zugang zu Ritualen, Symbolen und Legenden, die sich zum Teil deutlich an die bereits in der Antike gepflegte ars memoriae und die Ideen des Neuplatonismus und der Hermetik anlehnten und hierüber den Anschein machten, in direkter Verbindung mit einem Urwissen aus den Anfangstagen der Menschheit zu stehen. ${ }^{17}$ Als eigentliche, wenn auch historisch nur mangelhaft belegbare Geburtsstunde einer festere organisatorische Strukturen aufweisenden Freimaurerei gilt die Gründung der ersten Großloge von England, die sich vermutlich am 24.06.1717 im Londoner Gasthaus "Goose and Gridiron « ereignete. ${ }^{18}$ Die neu gegründete Großloge übernahm als übergeordnete Einheit die Aufsicht über die in ihr zusammengefassten vier Mitgliedslogen. Verbindungen adliger Personen mit der Freimaurerei stellten sich bereits sehr früh in der Entwicklung der englischen Großloge ein. ${ }^{19}$ So entstammte bereits der Großmeister der englischen Großloge des Jahres 1721, John Duke of Montagu, einem adligen Geschlecht. ${ }^{20}$ Dieser gab dem Dissenter-Reverend James Anderson (1680-1739)

herausgestellten »esoterischen« auch bereits früh einen »rationalen Zugang« zur Freimaurerei gegeben habe, wird in dieser Studie durch die Einbeziehung beider Ebenen Rechnung getragen und insofern ein Ausgleichsversuch unternommen.

16 Zur Entstehung der sogenannten »spekulativen Freimaurerei« liegen verschiedene Theorien vor. Hier wird der Theorie David Stevensons gefolgt, nach der die Ursprünge der spekulativen Freimaurerei im Schottland des 17. Jh.s zu finden sind. Stevenson verwies insb. auf einige definitorische Probleme, etwa in Bezug auf die Begriffe »operative mason/lodge« und »non-operative mason/lodge«. Siehe zur Geschichte David Stevenson, The Origins of Freemasonry, 12. Aufl., Cambridge 2011, insb. 1-12; Reinhold Bendel, Die Ableitung der Freimaurerei von den Steinmetzbruderschaften, Tempelritterorden und den älteren Rosenkreuzerbruderschaften, in: Joachim Berger/Klaus-Jürgen Grün (Hg.), Geheime Gesellschaft. Weimar und die deutsche Freimaurerei, (Ausstellungskatalog: Weimarer Klassik, Schiller-Museum Weimar, 21.06.-31.12.2002), München/Wien 2002, 62-74.

17 Vgl. Stevenson, The Origins of Freemasonry (wie Anm. 16, Kap. I), 77-96. Zur Geschichte der ars memoriae ist immer noch grundlegend: Frances Amelia Yates, The Art of Memory, 19. Aufl., London 2012 (Erstausgabe 1966).

$18 \mathrm{Zu}$ den Umständen der Gründung sowie deren nicht eindeutiger Belegbarkeit vgl. die Bemerkungen bei Dieter Anton Binder, Die Freimaurer. Ursprung, Rituale und Ziele einer diskreten Gesellschaft, 2. Aufl., Freiburg/Basel/Wien 2006, 31-33; Helmut Reinalter, Die Freimaurer, Sonderausgabe, München 2008, 10-12; Winfried Dotzauer, Freimaurerei global (Quellen und Darstellungen zur europäischen Freimaurerei, 11), Innsbruck 2009, 19-23; Eugen Lennhoff/Oskar Posner/Dieter Anton Binder (Hg.), Internationales Freimaurer-Lexikon, 5. überarbeitete und aktualisierte Aufl., München 2006, 254-258.

19 Siehe hierzu etwa die Erwähnungen bei Stevenson, aber auch die Großmeisterschaft des Duke of Montagu innerhalb der ersten englischen Großloge. Siehe zu adligen Personen in den frühen schottischen Logen allgemein die Angaben in: Stevenson, The Origins of Freemasonry (wie Anm. 16, Kap. I).

$20 \mathrm{Zu}$ der Großmeisterschaft des Duke of Montagu im Jahr 1721 sowie weiteren adligen Personen in der frühen Zeit der englischen Großloge vgl. die Angaben bei Lennhoff/Posner/Binder (Hg.), Internationales Freimaurer-Lexikon (wie Anm. 18, Kap. I), 49; Ric Berman, The Foundations of Modern Freemasonry. The Grand Architects: Political Change and the Scientific Enlightenment, 1714-1740, Brighton/Portland 2012, 118-163. 
den Auftrag, die sogenannten »Old Charges « oder »Alten Pflichten« zu verfassen, die fortan für alle rechtmäßig unter der Großloge konstituierten Logen Gültigkeit haben sollten und für die Großmeisterschaft auch fürderhin einen Mann von hohem Adel vorsahen. ${ }^{21}$ Die »Alten Pflichten « sind als interne freimaurerische Verfassung zu betrachten, die unter anderem die Bedingungen für die Aufnahme eines neuen Mitglieds regelten. Der Text forderte diesbezüglich etwa:

Diejenigen, welche zur Mitgliedschaft einer Loge zugelassen werden, müssen gute, wahrhafte, freigeborene Männer von reifem und verständigem Alter, keine Leibeigenen, keine Frauenzimmer, keine unsittlichen oder anstößigen Menschen, sondern von gutem Rufe sein. ${ }^{22}$

Die Aufnahme in eine Freimaurerloge erfolgte demnach im 18. Jahrhundert nicht beliebig, sondern konnte als exklusive Ehrzuweisung betrachtet werden. In den Folgejahren bildeten sich zahlreiche Logen auf dem europäischen Festland und eine Zugehörigkeit zum Bund wurde insbesondere in gehobenen Kreisen als à la mode betrachtet. ${ }^{23}$ Es ist insofern nicht übertrieben, die Freimaurerei den bedeutendsten Geheimbund des 18. Jahrhunderts zu nennen.

Was das 18. Jahrhundert anbelangt, wurde den Logen von der wissenschaftlichen Freimaurerforschung große Bedeutung für den Prozess der Entstehung der sogenannten »bürgerlichen Gesellschaft « zugesprochen. ${ }^{24}$ Die für die Freimaurerlogen typische Form der oftmals ständeübergreifenden Zusammenkunft und ihr ideeller Freundschaftskult, aber auch die quasidemokratische, geheime Abstimmungsform der ballotage über logeninterne Angelegenheiten spielten bei dieser Zuschreibung eine zentrale Rolle. Die unter den Mitgliedern einer Loge übliche gegenseitige Bezeichnung als »Bruder « bzw. ihre quasidemokratische Verfasstheit wurde vielfach als »ständische Nivellierung ${ }^{25}{ }^{2 n}$ nerhalb des Arkanraums interpretiert. ${ }^{26}$

21 Siehe hierzu ebenfalls Lennhoff/Posner/Binder (Hg.), Internationales Freimaurer-Lexikon (wie Anm. 18, Kap. I), 49.

22 Zitiert nach Dies. Internationales Freimaurer-Lexikon (wie Anm. 18, Kap. I), $19 f$.

23 Siehe hierzu Reinalter, Die Freimaurer (wie Anm. 18, Kap. I), 12; Dieter Anton Binder, Die Freimaurer. Geschichte, Mythos und Symbole, Wiesbaden 2009, 31. Binder bezieht sich, was die Freimaurerei als Modeerscheinung angeht, auf eine Äußerung Bernhard Beyers.

24 Auskunft über diese »bürgerliche« Sichtweise der Freimaurerei geben auch die Titel zweier jüngerer Studien von Stefan-Ludwig Hoffmann und Kristiane Hasselmann: Stefan-Ludwig Hoffmann, Die Politik der Geselligkeit. Freimaurerlogen in der deutschen Bürgergesellschaft 1840-1918 (Kritische Studien zur Geschichtswissenschaft, 141), Diss., Göttingen 2000; Kristiane Hasselmann, Die Rituale der Freimaurer. Zur Konstitution eines bürgerlichen Habitus im England des 18. Jh.s, Diss., Bielefeld 2009.

25 Reinalter, Die Freimaurer (wie Anm. 18, Kap. I), 96.

26 Zur gegenteiligen Interpretation siehe aber auch Winfried Dotzauer, Zur Sozialstruktur der Freimaurerei in Deutschland, in: Helmut Reinalter (Hg.), Aufklärung und Geheimgesellschaften. Zur politischen Funktion und Sozialstruktur der Freimaurerlogen im 18. Jh. (Ancien Régime, Aufklärung und Revolution, 16), München 1989, 109-150, hier 135f. Dotzauer erklärt hier: »War man schon im Blick auf Ungebildete, Frauen und Juden prämissorisch verbaliter oder von der Ideologie her indirekt uninteressiert bzw. sogar feindlich eingestellt, so galt dies auch sicher für ein demonstratives Einebnen der sozialen Unterschiede, die von den gleichen Bürgern von außen her - von 
Unterschiede zwischen den einzelnen Mitgliedern bestanden innerhalb des freimaurerischen Raums aber insbesondere durch den Grad der Einweihung in die freimaurerischen Geheimnisse. Die sogenannten Johannisgrade teilten sich auf in den Lehrlings-, Gesellen- und Meistergrad, wobei Letzterer bereits als eine in den 1720er Jahren hinzutretende Erweiterung der ursprünglich nur zwei Grade kennenden freimaurerischen Ritualformen zu sehen ist. ${ }^{27}$ Insbesondere durch den Vollzug jeweils gradspezifischer Rituale im Kreise der Logenmitglieder sollte der Rezipient stufenweise auf dem »Weg der Tugend« zur charakterlichen und sittlichen Reifung voranschreiten. Dabei sollten ihn zahlreiche Symbole an die Geschichte des Bundes sowie an die freimaurerischen Tugenden erinnern. An dieser Stelle muss zum besseren Verständnis des Folgenden vorausgeschickt werden, dass die innerhalb der Rituale vermittelten freimaurerischen Kardinaltugenden "Selbsterkenntnis, Selbstbeherrschung und Selbstveredelung" mit dem Ziel der Ausbildung einer "schönen Seele ${ }^{28}$ innerhalb dieser Studie in direkter Verbindung mit den bereits in der Antike bekannten Kardinaltugenden und insbesondere derjenigen der $"$ Klugheit " gesehen werden.${ }^{29}$ Ein weiterer Beweis dieser Reifung des Freimaurers zur Tugendhaftigkeit stellte so auch die Übernahme eines Logenamtes dar, das gewissermaßen als Beweis einer solchen seelisch-charakterlichen Veredelung gesehen werden konnte. So wurde etwa der oben bereits angesprochene Vorsteher einer Loge - auch »Meister vom Stuhl« oder im Französischen »Vénérable« genannt - durch Abstimmung unter den Logenmitgliedern einer Johannisloge gewählt. Die Ausübung aller Ämter, wie auch der Rituale, die während der freimaurerischen "Arbeit« innerhalb des $»$ Tempels $\aleph^{30}$ erfolgte, lief nach festgeschriebenen Gesetzen zur Regelung des internen Logenlebens bzw. Ritualinstruktionen ab, die durch den Meister vom

der absolutistischen Staatlichkeit legitimiert (Beamte) oder selbst aufgebaut (Fabrikanten) - in die Logen eingebracht wurden. [...] Die Berechtigung der Anrede >Bruder war damit in keiner Weise in Frage gestellt, gab es doch schon im Alten Testament, aber auch in den kinderreichen Familien der Dynastien, der Adelssippen und der Patriziergeschlechter immer rechtlich oder gefühlsmäßig bedingte Bevorzugungen und Benachteiligungen, also Unterschiede unter an und in sich Gleichen.«

27 Vgl. Lennhoff/Posner/Binder (Hg.), Internationales Freimaurer-Lexikon (wie Anm. 18, Kap. I), 394f. sowie 557.

28 Vgl. zu sämtlichen hier gemachten Zitaten bzw. zu den freimaurerischen Tugenden Lennhoff/ Posner/Binder (Hg.), Internationales Freimaurer-Lexikon (wie Anm. 18, Kap. I), 852.

29 Diese Sichtweise begründet sich in dem weiter unten erläuterten Zusammenhang zwischen der ars memoriae und dem freimaurerischen Ritual. Innerhalb der ars memoriae spielte die Kardinaltugend der »Klugheit « eine hervorgehobene Rolle. Yates zitiert zur antiken Definition der »Klugheit» eine Passage aus Ciceros De inventione: "Prudence is the knowledge of what is good, what is bad and what is neither good nor bad. Its parts are memory, intelligence, foresight [...]. Memory is the faculty by which the mind recalls what has happened. Intelligence is the faculty by which it ascertains what is. Foresight is the faculty by which it is seen that something is going to occur before it occurs. « Yates, The Art of Memory (wie Anm. 17, Kap. I), 35f.

30 »Tempel« wird innerhalb der Freimaurerei als Bezeichnung für den Versammlungsraum der Loge verwendet. Siehe Lennhoff/Posner/Binder (Hg.), Internationales Freimauer-Lexikon (wie Anm. 18, Kap. I), 832. 
Stuhl sowie die ihm beigeordneten Beamten vollzogen und auf ihre Regelmäßigkeit hin kontrolliert wurden. Die Übernahme eines Amtes setzte somit voraus, dass der Amtsinhaber bereits auf dem freimaurerischen »Weg der Tugend « weiter vorgedrungen war.

Für die vorliegende Arbeit ist die Entstehung der »Hochgrade« sowie insbesondere der in ihnen vorkommenden »Rittergrade « um das Jahr 1740 von besonderer Wichtigkeit. Finden sich doch innerhalb der während des Rituals dieser Grade verlesenen geschichtlichen Erzählungen oftmals fiktive Konstruktionen über den Ursprung und die Entwicklung der Freimaurerei, die die Sicht der Zeitgenossen auf den Bund offenbaren. Nicht selten versuchen diese eine Verbindung der Freimaurerei mit mittelalterlichen Kreuzritterorden als Hüter und Übermittler uralter mystischer Weisheiten sowie eines `wahren`Christentums zu etablieren. In Bezug auf ihre Anfänge spricht vieles für eine Vermittlung eines sogenannten »Schotten«-Grades (hier des Grades eines Maître écossais) durch die Londoner Loge L'Union im Jahr 1743 an eine aus französischen und deutschen Brüdern bestehende Berliner Loge gleichen Namens. ${ }^{31}$ Im Laufe des 18. Jahrhunderts kam es zur Ausbildung regelrechter Hochgradsysteme, die jeweils eine Vielzahl von Graden und Ritualen kannten. Die verschiedenen oftmals konkurrierenden Systeme gingen dabei zudem in ihren Ansichtsweisen über die Reihe der angenommenen Vorformen der Freimaurerei, aber auch in ihren Rekonstruktionsversuchen eines angeblich aus verschiedenen Geheimlehren ableitbaren letzten freimaurerischen Geheimnisses stark auseinander. ${ }^{32}$ Das Umfeld »Freimaurerei « und insbesondere die mit ihm verbundenen Hochgradsysteme bieten aber gerade aus diesem Grund ein großes Potenzial für die Adelsforschung.

\section{I.1 Methodik}

Mit dem Münchner Historiker Florian Maurice ist davon auszugehen, dass freimaurerische Formen der Vergesellschaftung immer »in einer Wechselbeziehung zu der sie umgebenden Außenwelt « standen und daher nur unter Berücksichtigung externer Einflüsse untersuchbar sind. ${ }^{33}$ Wichtig scheint in Bezug auf einen solchen wechselseitigen Abgleich die Ergänzung eines in unmittelbarer Nähe zur

31 Vgl. zum gesamten Komplex Pierre Mollier, La chevalerie maçonnique. Franc-maçonnerie, imaginaire chevaleresque et légende templière au siècle des Lumières, Paris 2005, 74-88. Mollier verweist hier auf die Wichtigkeit Preußens bei der Verbreitung der Freimaurerei auf dem Kontinent.

32 Zur Einführung hierzu siehe Lennhoff/Posner/Binder (Hg.), Internationales Freimaurer-Lexikon (wie Anm. 18, Kap. I), 396. Eine ältere Darstellung findet sich in: Gustav Adolf Schiffmann, Die Entstehung der Rittergrade in der Freimaurerei um die Mitte des 18. Jh.s, Leipzig 1882, Permalink: http://nbn-resolving.org/urn:nbn:de:bvb:12-bsb00066046-7 (Zugriff vom 25.05.2014). Die Darstellungen in den untenstehenden Kapiteln beziehen sich größtenteils auf: Mollier, La chevalerie maçonnique (wie Anm. 31, Kap. I).

33 Florian Maurice, Freimaurerei um 1800. Ignaz Aurelius Feßler und die Reform der Großloge Royal York in Berlin (Hallesche Beiträge zur Europäischen Aufklärung, 5), Tübingen 1997, XXIf. 
Memoria liegenden Interessenfeldes ${ }^{34}$ zu sein. Nur ein zugespitzter Blick auf ein solches sowohl im arkanen wie im nicht freimaurerischen, also profanen Bereich liegendes dynamisches Interessenfeld eines adligen Freimaurers, das zudem das Potenzial besaß, einen längerfristigen Anpassungsdruck auf die Memoria auszulösen, wird dabei die oben formulierten Fragen zufriedenstellender beantworten und die Lücke der oben beschriebenen >Blindstelle in den adligen Archiven schließen können.

In der vorliegenden Studie entspringt diese Zuspitzung dem zeit seines Lebens besonders ausgeprägten Interesse Joseph zu Salm-Reifferscheidt-Dycks an dem Wissensgebiet der Botanik ${ }^{35}$ bzw. den Naturwissenschaften, das auch in seinem freimaurerischen Umfeld zu Tage trat.

Aus Sicht der Naturwissenschaft des frühen 19. Jahrhunderts war die Nachzeichnung einer adligen $»$ Blutsideologie $\varkappa^{36}$, wie sie sich zur Mitte des 18. Jahrhun-

34 Der in dieser Studie verwendete Begriff des "Interessenfeldes« lehnt sich an den durch Kocku von Stuckrad für die Religionsgeschichte verwendeten Begriff des "Diskursfeldes« an. Stuckrad definiert diesen in Bezugnahme auf die Überlegungen Michel Foucaults, Burkhard Gladigows und Ingo Mörths zur Diskurstheorie in folgender Weise: "Diskurse sind nicht mit Traditionen identisch, vielmehr stellen sie die gesellschaftliche Organisation von Tradition, von Meinungen und Wissensbeständen dar. [...] Diskursfelder lassen sich nicht auf bestimmte Traditionen begrenzen. Vielmehr entwickeln sie sich aus gemeinsamen Fragestellungen und zeitgenössischen Interessenlagen. Mehr noch: Diskursfelder verändern religiöse Identitäten und führen mitunter zu erstaunlichen Allianzen und Parallelen zwischen vermeintlich getrennten religiösen Traditionen.« Kocku von Stuckrad, Was ist Esoterik? Kleine Geschichte des geheimen Wissens, München 2004, 16f. Die Zuspitzung auf das »Interessenfeld « erfolgt hier aufgrund der im zweiten Teil dieser Studie vorgenommenen mikrohistorischen Untersuchungen, die gezielt auch einzelne Akteure in den Blickpunkt nehmen. Der Begriff des »Interessenfeldes« soll somit stärker diesen Ansatz beim Individuum bzw. einer fest umgrenzten Gruppe von Personen zum Ausdruck bringen. Das »Interessenfeld « soll als eine Untereinheit eines übergeordneten Diskursfeldes verstanden werden. Ein übergeordnetes Diskursfeld stellt die Memoria dar, die sowohl für den Adel als auch die Freimaurerei des 18. Jh.s von großer Bedeutung war.

35 Siehe hierzu jüngst Rita Hombach, Der Park von Schloss Dyck, aus: Netzbiographie: Joseph zu Salm-Reifferscheidt-Dyck (1773-1861), in: historicum-estudies.net, [01.05.2014], http://www. historicum-estudies.net/epublished/netzbiographie/preussische-zeit/landschaftsgarten (Zugriff vom 01.05.2014); Dies., Die Pflanzensammlungen zu Dyck, aus: Netzbiographie: Joseph zu SalmReifferscheidt-Dyck (1773-1861), in: historicum-estudies.net, [01.05.2014], http://www.histori cum-estudies.net/epublished/netzbiographie/franzoesische-zeit/pflanzensammlung (Zugriff vom 01.05.2014); Dies., Botaniker, aus: Netzbiographie: Joseph zu Salm-Reifferscheidt-Dyck (17731861), in: historicum-estudies.net, [05.06.2014], http://www.historicum-estudies.net/epublished/ netzbiographie/preussische-zeit/botanik (Zugriff vom 21.11.2014); Hans-Werner Langbrandtner, Die Botanische Bibliothek auf Schloss Dyck, aus: Netzbiographie: Joseph zu Salm-ReifferscheidtDyck (1773-1861), in: historicum-estudies.net, [01.05.2014], http://www.historicum-estudies.net/ epublished/netzbiographie/preussische-zeit/botanische-bibliothek (Zugriff vom 01.05.2014).

36 Pierre Serna nutzt in einer Untersuchung den Begriff der "Blut- und Stammbaumideologie«. Auf diese Begrifflichkeit wird hier Bezug genommen. Serna führte hierzu aus: „Die Blut- und Stammbaumideologie ebenso wie die Physiognomik spiegeln ein strukturelles Mißverständnis zwischen einem Großteil des Adels und der Aufklärung wider. Ein schwerwiegendes Mißverständnis, denn die weitaus überwiegende Mehrheit der Adligen konnte dank dieses `Stammbaums` ungeniert erneut ein würdevolles Selbstverständnis einer einigen Gruppe entwickeln, die angesichts der gegen sie gerichteten Kritik solidarisch zusammenhielt. $\mathrm{Ob}$ arm oder reich, unbekannt oder berühmt, alle waren sie im Blut geeint, das von Generation zu Generation weitergegeben wurde. Die einen 
derts im Stammbaum auf Schloss Dyck findet, jedoch nur noch schwer bis gar nicht zu verteidigen - ebenso wie die bis auf Adam zurückgehenden Ursprungslegenden der Freimaurerei. Derartige Genealogien beteiligten sich aus zeitgenössischer Sicht auch an einer Debatte um die Aufdeckung der geschichtlichen Ursprünge der menschlichen »Rasse«. Aufgrund der historischen Vorbelastung des Begriffs »Rasse « in der Moderne muss hier darauf hingewiesen werden, dass seine frühneuzeitliche Bedeutung in späteren Kapiteln ausführlich erläutert wird und sich hier zunächst auf seine bereits im 16. und 17. Jahrhundert in Lexika vorzufindende Ableitung von lateinisch radix für »Wurzel « bezieht, die aus Sicht der Zeitgenossen aufs Engste mit den genealogischen Ableitungen eines Stammbaums bzw. der Ursprungsfrage verknüpft schien. ${ }^{37}$ Wenn sich ein Wandel im Verhältnis des Adels zur Freimaurerei ergeben hatte, dann, so die Grundannahme dieser Studie, maßgeblich aufgrund der Umdeutung dieses Diskurses durch den Fortschritt der Naturwissenschaften im Zuge der Aufklärung oder - um mit Wolf Lepenies zu sprechen - des »Endes der Naturgeschichte ${ }^{38}$ zum Ausgang des Ancien Régime. Die rasanten Entwicklungen im naturwissenschaftlichen Bereich stürzten im 18. Jahrhundert den Offenbarungsglauben der christlichen Religion ebenso in eine schwere Krise wie die hierauf zu großen Teilen aufbauenden Legitimationsstrategien des Adels und der ständischen Gesellschaft. Die vormodernen »Naturwissenschaften « bzw. die unter dem zeitgenössischen Begriff der »Naturgeschichte « zusammengefassten Wissensgebiete wurden daher als Zugriffspunkt der übergeordneten Analyse adlig-freimaurerischer Memoria beigeordnet.

Wie bereits angesprochen, fühlt sich eine so verstandene historische Umfeldanalyse im Kern einem mikrohistorischen Ansatz verpflichtet. Auch wenn die Diskussion über das Für und Wider einer micro-histoire anhält, scheint eine mikrogeschichtliche Herangehensweise auch in diesem Fall aus mehreren Gründen sinnvoll zu sein. ${ }^{39}$ Dabei muss vorweg bei einer Arbeit, die sich, was den geographischen Rahmen anbelangt, auch grenzüberschreitenden Verbindungen widmet, festgehalten werden, dass der Terminus »Mikrogeschichte« hier keine ein-

erblickten in ihrem Erfolg den Beweis für die Reinheit ihres Bluts, die anderen fanden im Blut einen Rückhalt, der es ihnen erlaubte, ihr geprüftes Dasein in Ehre zu tragen.« Pierre Serna, Der Adlige, in: Michel Vovelle (Hg.), Der Mensch der Aufklärung, Essen 2004, 42-97, hier insb. 92f. Auch Johannes Rogalla von Bieberstein spricht von einer adligen Ideologie. Vgl. Rogalla von Bieberstein, Adelsherrschaft und Adelskultur (wie Anm. 3, Kap. I), 115.

$37 \mathrm{Zu}$ den hier gemachten Angaben zur Etymologie des Begriffs »Rasse« siehe Antje Sommer/Werner Conze, Rasse, in: Otto Brunner/Werner Conze/Reinhart Koselleck (Hg.), Geschichtliche Grundbegriffe. Historisches Lexikon zur politisch-sozialen Sprache in Deutschland, Bd. 5, Stuttgart 1984, 135-178, insb. 138 sowie ferner Christian Geulen, Geschichte des Rassismus, München 2007, 13f.; Serna, Der Adlige (wie Anm. 36, Kap. I), 88-90.

38 Wolf Lepenies, Das Ende der Naturgeschichte. Wandel kultureller Selbstverständlichkeiten in den Wissenschaften des 18. und 19. Jh.s, Frankfurt a.M. 1978. Im Folgenden werden die Begriffe "Naturwissenschaften« und »Naturgeschichte« bis zum Ende des Ancien Régime synonym verwandt.

39 Siehe hierzu sowie zu weiterführenden Literaturangaben Otto Ulbricht, Mikrogeschichte. Menschen und Konflikte in der Frühen Neuzeit, Frankfurt a.M./New York 2009. 
seitige Verengung auf eine kleine Einheit der Betrachtung bedeuten soll, sondern durchaus den Spielraum für weitergehende Ausblicke einbezieht. In dieser Studie wird somit davon ausgegangen, dass der oftmals in der Methoden-Diskussion der Geschichtswissenschaften angeführte Gegensatz zwischen »Mikro-« und »Makrogeschichte « nicht aufrechterhalten werden kann, sondern die Betonung eines mikrohistorischen Ansatzes in der Rekonstruktion historischer Begebenheiten zwangsläufig in der Analyse auch allgemeinere historische Phänomene berücksichtigen muss. ${ }^{40}$ Die vorliegende Studie sieht in diesem Sinne einen Mittelweg zwischen mikro- und makrohistorischem Ansatz als von vornherein gegeben an. Die oben erläuterte Methodik trägt mit diesem Vorgehen - wie bereits an der Erwähnung der Studie Maurice` deutlich wird - auch Entwicklungen innerhalb der jüngeren Freimaurerforschung Rechnung.

\section{I.2 Forschungsstand}

Innerhalb der neueren Adelsforschung kann das völlige Fehlen ausführlicher, systematischer Behandlungen der Beziehungen des Adels zur Freimaurerei festgestellt werden. Auch kürzere Besprechungen des Themas erfolgen nur vereinzelt. So widmete sich etwa Heinz Reif in seiner aus den 1970er Jahren stammenden Dissertation über den westfälischen Adel innerhalb eines Kapitels den Vereinsaktivitäten des dortigen Adels. Innerhalb eines Unterkapitels hierzu erfolgt auch eine kurze Besprechung der Beziehungen zur Freimaurerei. ${ }^{41}$ Die hierin durch Reif konstatierten Befunde einer zunächst durch die westfälischen Adligen praktizierten aristokratisch ausgerichteten Form der Freimaurerei, die durchaus auch eine rangmäßige Unterordnung bürgerlicher Mitglieder in der Logengemeinschaft einschloss, sowie eines nachlassenden Interesses der adligen Personen an der Freimaurerei mit Beginn des 19. Jahrhunderts bleiben ungeachtet der Kürze der Darstellung auch für die vorliegende Studie von Wichtigkeit. Reif sieht die Freimaurerei aber noch als eine »den Augen der noch ständisch geprägten Öffentlichkeit und des Staates in starkem Maße entzogene [...] Annäherung an das Modell der antizipierten bürgerlichen Gesellschaft« an, aus der auch eine teilweise » Verbürgerlichung des Adels« zum 19. Jahrhundert hin resultiere. ${ }^{42}$ Diese Sichtweise muss aus heutiger Perspektive kritisch hinterfragt werden.

Der inzwischen bezüglich einer solchen Einschätzung eingetretene Wandel tritt in der deutlich jüngeren Studie Marko Kreutzmanns zum sächsischen Adel

40 Vgl. hierzu auch Ders., Mikrogeschichte (wie Anm. 39, Kap. I), insb. 34-37. Ulbricht betont hier auch, dass mikrogeschichtliche Untersuchungen zwar insb. auf bäuerliche Schichten angewendet wurden, sich jedoch durchaus auch für die Betrachtungen anderer Schichten der Gesellschaft eignen.

41 Heinz Reif, Westfälischer Adel: 1770-1860. Vom Herrschaftsstand zur regionalen Elite (Kritische Studien zur Geschichtswissenschaft, 35), Diss., Göttingen 1979, 405-408.

42 Ders., Westfälischer Adel: 1770-1860 (wie Anm. 41, Kap. I), 404-408, insb. 404 und 407. 
aus dem Jahr 2008 hervor. Kreutzmann greift - ähnlich wie Reif in einem Unterkapitel - das Verhältnis des Adels, hier namentlich der adligen Familien von Fritsch und von Ziegesar, zur Freimaurerei auf. Kreutzmann hebt jedoch im Sinne der weiter unten zu erläuternden Ergebnisse der jüngeren Freimaurerforschung hervor, dass die Freimaurerei keineswegs eindeutig als bürgerliche Vereinigung zu sehen sei, sondern im Geheimbundwesen der Zeit Bereiche existierten, die »anschlussfähig für verschiedenste gesellschaftliche Gruppen « waren. ${ }^{43}$ Wichtig erscheint in dieser Hinsicht insbesondere Kreutzmanns Hinweis im anschließenden Kapitel auf die Mitgliedschaft August Friedrich Carl von Ziegesars zum Ende des 18. Jahrhunderts in einer Loge und gleichzeitig im exklusiv adligen Johanniterorden. In diesem Zusammenhang verweist er unter anderem auf organisatorische und rituelle Parallelen zwischen Tempelmaurerei und dem auf einer 16erAhnenprobe bestehenden Ritterorden. ${ }^{44}$

Innerhalb der Freimaurerforschung existiert keine neuere Studie, die sich in Ausführlichkeit explizit dem Thema des Adels in der Freimaurerei widmet. ${ }^{45}$ Dabei sei zuvor darauf hingewiesen, dass die Schrift des wissenschaftlichen Mitarbeiters in der Dienststelle des Reichsführers SS Hans Riegelmann aus dem Jahr 1943 mit dem Titel »Die europäischen Dynastien in ihrem Verhältnis zur Freimaurerei« aufgrund ihrer zwar prosopographisch umfangreichen, aber dennoch grundsätzlich verfehlten Haltung im Sinne der »Gegnerforschung « des Dritten Reiches nicht als wissenschaftlich verwertbare Studie zum Thema betrachtet wird. ${ }^{46}$

43 Marko Kreutzmann, Zwischen ständischer und bürgerlicher Lebenswelt. Adel in Sachsen-Weimar-Eisenach 1770 bis 1830 (Veröffentlichungen der Historischen Kommission für Thüringen, 23), Diss., Köln/Weimar/Wien 2008, 143. Dies deckt sich mit den Untersuchungen Steven C. Bullocks für die Logen der frühen englischen Großloge. Bullock stellt fest, dass gerade aufgrund der eigenartigen Vermischung konservativer und aufgeklärter Ansichten in den Logen diese zu Vereinigungen wurden, in denen die Mitglieder der neu entstehenden Schicht der Vornehmen (genteels) aus nicht adligen Gelehrten, vermögenden Personen sowie Mitgliedern des Adels harmonisch miteinander verkehren konnten. Vgl. Steven C. Bullock, Revolutionary Brotherhood. Freemasonry and the Transformation of the American Social Order, 1730-1840, Chapel Hill/London 1998, 40f.

44 Vgl. Kreutzmann, Zwischen ständischer und bürgerlicher Lebenswelt (wie Anm. 43, Kap. I), 151f.

45 Kürzere Darstellungen finden sich u.a. in: Wilhelm Best, Die Fürstenlogen von Saarbrücken. Zur Geschichte der Freimaurerei in Nassau-Saarbrücken (Monographien zur Kunst- und Kulturgeschichte der Saarregion, 10), Walsheim 2000; Claus Heinrich Bill, Adelige Freimaurer in Mecklenburg 1750 bis 1850. Ein prosopographischer Überblick zu Logen und Edelleuten, in: Nobilitas. Zeitschrift für deutsche Adelsforschung 22 (2002), 1082-1122. Beiträge älteren Datums aus freimaurerischen Zeitschriften finden sich in: Br.[uder] Gemoll, Die Teilnahme des Adels und der Offiziere in den 3 preussischen Grosslogen, in: Schlesisches Logenblatt 20 (1900), o.S.; Reinhold Taute, Der Geburts-Adel in den deutschen Logen. Ein statistischer Beitrag von Br. R. Taute, Mitglied der Loge »Karl zu den drei Ulmen« in Ulm, in: Asträa. Taschenbuch für Freimaurer 10 (1891), 114-118. Ein interessanter Beitrag zur Rolle der Monarchien für die internationalen Beziehungen innerhalb der Freimaurerei findet sich in: Anton van de Sande, Monarchy and Aristocracy as International Factors in Freemasonry. The Case of Prince Frederick of the Netherlands, 1816-1881, in: Equinox. Journal for research into freemasonry and fraternalism 1 (2010), 23-35.

46 Vgl. Hans Riegelmann, Die europäischen Dynastien in ihrem Verhältnis zur Freimaurerei. Historisch-politische Untersuchungen auf genealogischer Grundlage (Quellen und Darstellungen zur Freimaurerfrage, 4), Diss., Berlin 1943. Zum erneuten, unkommentierten Aufgriff der Studie durch neuere Beiträge dürfte die Wiederveröffentlichung der ursprünglich 1943 im Nordland- 
Ein noch älterer, aber wissenschaftlich nutzbarer Beitrag, auf den sich die auch in jüngeren Studien erwähnte These von der Kompensation des Machtverlustes adliger Personen in der profanen Gesellschaft durch die Einrichtung der Rittergrade innerhalb der Freimaurerei zurückführen lässt, findet sich in der Schrift »Die Entstehung der Rittergrade in der Freimaurerei um die Mitte des 18. Jahrhunderts « des freimaurerischen Historikers Gustav Adolf Schiffmann. ${ }^{47}$ Schiffmann versuchte in einem Unterkapitel seiner Studie aufzuzeigen, wie ein im Gegensatz zum Bürgertum begriffener französischer Adel die Rittergrade und exklusiven Adelslogen dazu genutzt habe, sich von dem mit ihm konkurrierenden Bürgertum abzusondern. ${ }^{48}$ Wenngleich Bestandteile dieser These nicht von der Hand gewiesen werden können, zeigt die von ihm quellenmäßig nicht belegte einseitige Berufung auf eine stereotype adlige Dekadenz deutlich die Schwachstelle seiner Analyse. ${ }^{49}$ Im Zusammenspiel mit den oftmals heroisierenden Darstellungen adliger Personen in der freimaurerischen Geschichtsschreibung des 19. Jahrhunderts, wie etwa im Falle des preußischen Königs Friedrich II., zeigen sich die beiden Pole der älteren Freimaurerforschung in Bezug auf die Bewertung des Adels für die Geschichte des Bundes. Von der modernen Freimaurerforschung wurden insbesondere letztere Darstellungen zum Teil deutlich relativiert, ${ }^{50}$ doch wurde auch

verlag der SS erschienen Dissertation im Jahr 1985 im Verlag für ganzheitliche Forschung und Kultur beigetragen haben. Diese Neuauflage entbehrt u.a. des im Original wiedergegebenen Lebenslaufes Hans Riegelmanns, der bereits einen Hinweis auf die Zugehörigkeit zur nationalsozialistischen Gegnerforschung hätte geben können. Riegelmann war demnach seit dem 01.04.1938 wissenschaftlicher Mitarbeiter in der Dienststelle des Reichsführers SS. Zu einer kurzen Darstellung und Bewertung des Entstehungsprozesses der Dissertation siehe auch folgenden Beitrag: Ralf Klausnitzer, Geheimgesellschaften im Visier. Geisteswissenschaftliche »Gegnerforschung" 1933-1945 zwischen Verschwörungsparanoia und Versachlichung, in: Gerhard Kaiser/Matthias Krell (Hg.), Zwischen Resonanz und Eigensinn. Studien zur Geschichte der Sprach- und Literaturwissenschaften im 20. Jh. (Studien zur Wissenschafts- und Universitätsgeschichte, 7), Heidelberg 2005, 71-112, hier 94-98. Ähnlich antifreimaurerisch ist auch die bereits zum Ende der 1920er Jahre veröffentlichte Schrift "Deutscher Adel und Freimaurerei« zu werten. Vgl. Friedrich Bronsart von Schellendorff, Deutscher Adel und Freimaurerei, Wismar 1929. Bronsart von Schellendorff ist dem Kreis um Erich Ludendorff zuzurechnen, der ebenfalls ein erklärter Feind der Freimaurerei war. Aus selben Gründen nicht berücksichtigt wurde Heinz Gürtler, Deutsche Freimaurer im Dienste napoleonischer Politik. Die Geschichte der Freimaurerei im Königreich Westfalen, Berlin 1942.

47 Siehe Schiffmann, Die Entstehung der Rittergrade (wie Anm. 32, Kap. I), Einband. Zu dieser These als Standarderklärung siehe den Hinweis bei Monika Neugebauer-Wölk, Arkanwelten im 18. Jh. Zur Struktur des Politischen im Kontext von Aufklärung und frühmoderner Staatlichkeit, in: Dies. (Hg.), Arkanwelten im politischen Kontext (Aufklärung. Interdisziplinäres Jahrbuch zur Erforschung des 18. Jh.s und seiner Wirkungsgeschichte, 15), Hamburg 2003, 7-65, hier 42.

48 Siehe hierzu Schiffmann, Die Entstehung der Rittergrade (wie Anm. 32, Kap. I), 130-158, insb. 141-158.

49 Vgl. Ders., Die Entstehung der Rittergrade (wie Anm. 32, Kap. I), 130-158, insb. 142.

50 An dieser Stelle sei lediglich auf den jüngst erschienen Artikel von Karlheinz Gerlach in der "Zeitschrift für Internationale Freimaurer-Forschung" verwiesen. Gerlach bietet hierin auch einen Überblick über die wichtigsten Forschungsbeiträge. Siehe Karlheinz Gerlach, König Friedrich II. und die preußischen Freimaurer, in: Zeitschrift für Internationale Freimaurer-Forschung 28 (2012), 9-53, hier insb. 18-23. 
hier weniger auf ihre adlige Herkunft, das heißt ihre familiäre Abstammung, ihre Erziehung oder ihr Selbstverständnis als Adliger eingegangen als vielmehr auf ihr allgemeines Verhältnis zur Freimaurerei und ihre administrative Funktion innerhalb des Bundes.

In zwei kürzeren Beiträgen jüngeren Datums wird hingegen versucht, auch das profane Engagement der adligen Freimaurer stärker in die allgemeine Analyse einzubeziehen. ${ }^{51}$ Erwähnenswert scheint hier insbesondere die Darstellung Wilhelm Bests zu den Saarbrücker Fürstenlogen. Best verbleibt in seiner Darstellung jedoch dabei, die Freimaurerei im Sinne der älteren Forschung lediglich als Gegenpart zum »Absolutismus « und als Bildungsstätte des »aufgeklärten Fürsten « zu begreifen. ${ }^{52}$ Die Freimaurerei habe demnach zur "Nivellierung der ständischen Unterschiede« beigetragen, da sie »Mitträger des ideellen Konzepts der Aufklärung " gewesen sei. ${ }^{53}$ Insbesondere die von Best erwähnte Aufnahme des Fürsten in die Straßburger Loge La Candeur um 1763, ${ }^{54}$ deren Logengemeinschaft auch im Verlaufe der vorliegenden Studie noch näher thematisiert werden muss, lässt daran zweifeln, dass die Freimaurerei den Fürsten zwingend im Sinne einer Aufweichung der Ständeordnung beeinflusste - handelte es sich bei der Candeur doch zunächst um eine konservative Adelsloge.

Erst in jüngerer Zeit wird die Perspektive der universitären Freimaurerforschung auf den Bund als »bürgerliches Phänomen« stärker hinterfragt. Die ältere Sichtweise spricht dem Bund eine große Bedeutung für die Herausbildung der »bürgerlichen Gesellschaft» des 19. Jahrhunderts zu. Diese These lässt sich vornehmlich auf die Wirkmächtigkeit der Heidelberger Dissertationsschrift Reinhart Kosellecks aus dem Jahr 1954 mit dem Titel »Kritik und Krise - Eine Studie zur Pathogenese der bürgerlichen Welt « zurückführen. Die Überzogenheit der Koselleckschen These, dass die Freimaurerei insbesondere durch die indirekt politische

51 Es handelt sich hierbei um eine Untersuchung Wilhelm Bests zu den Saarbrücker Fürstenlogen sowie einen Beitrag Bärbel Raschkes zum Thema »Androgyne Arkangesellschaften und Freimaurerei«. Im Beitrag Bests werden auch biographische Abschnitte der betrachteten adligen Person näher erläutert. Insgesamt werden hieraus - wie bereits aus den Titeln ersichtlich wird - jedoch weniger neue Schlüsse in Bezug auf das Verhältnis "Adel/Freimaurerei« gezogen, als die lokale Struktur der freimaurerischen Logen bzw. des Hofes oder aber die Bedeutung der Freimaurerei im Verhältnis zur ausgeübten Politik des Landesherrn im Sinne der Aufklärung beleuchtet. Der Beitrag Bärbel Raschkes untersucht überblicksartig das Verhältnis hochadliger Frauen zur Freimaurerei, wobei sie insb. das Verhältnis gemischtgeschlechtlicher Orden zur männlich dominierten Freimaurerei im 18. Jh. sowie die Reaktionsweisen hochadliger Frauen auf diese männliche Dominanz untersucht. Siehe Best, Die Fürstenlogen von Saarbrücken (wie Anm. 45, Kap. I); Bärbel Raschke, Androgyne Arkangesellschaften und Freimaurerei. Entwicklungs- und Beziehungsprobleme aus der Perspektive hochadliger Frauen, in: Berger/Grün (Hg.), Geheime Gesellschaft (wie Anm. 16, Kap. I), 153-159.

52 Best, Die Fürstenlogen von Saarbrücken (wie Anm. 45, Kap. I), 8 sowie 12.

53 Ders., Die Fürstenlogen von Saarbrücken (wie Anm. 45, Kap. I), 33.

54 Siehe Ders., Die Fürstenlogen von Saarbrücken (wie Anm. 45, Kap. I), 9-11. Best behandelt eine spätere Zeit der Loge, in der sie bereits nicht mehr durch den Adel dominiert wurde. Das Aufnahmedatum des Fürsten lässt sich laut Best nicht mehr klären. Meine eigenen Nachforschungen hierzu brachten ebenfalls kein Ergebnis. 
Funktion des Logengeheimnisses und die mit ihr verbundene bürgerliche Kritik an den bestehenden Verhältnissen die Krise des »absolutistischen « Staates befördert und somit maßgeblich die moderne »bürgerliche Gesellschaft" vorbereitet habe, ist verschiedentlich kritisiert worden und muss hier nicht nochmals ausführlicher nachgewiesen werden. ${ }^{55}$ Trotz dieser Kritik bilden die Bedeutung des freimaurerischen »Geheimnisses « und seine Funktion auch für diese Studie einen wichtigen Untersuchungsgegenstand.

Nach wie vor maßgeblich für eine Studie, die sich mit der Freimaurerei des Rheinlands beschäftigt, bleiben die Studien Winfried Dotzauers aus den 1970er Jahren zur Beschaffenheit und Sozialstruktur der rheinischen Logen des Ancien Régime bis zum Ende des napoleonischen Premier Empire - auch was die Erwähnung adliger Beteiligung an den Logen angeht, da sie reichhaltige prosopographische Auswertungen einzelner Logen bieten. ${ }^{56}$ Dotzauer, der seine Studien in den 1970er Jahren noch auf einem im Vergleich zur heutigen Situation deutlich begrenzten Quellenspektrum durchführen musste, sieht den »Adel im Toleranzraum der Dynasten « bereits richtigerweise im Fokus der Freimaurerei des 18. Jahrhunderts, wobei er hierzu insbesondere die »Regenten der mittleren Teildynastien, noch typischer die Prinzen von Geblüt « zählt. ${ }^{57}$ Er relativiert in Teilen die pauschalen Aussagen Kosellecks, folgt im Großen und Ganzen aber offenbar der älteren Kompensationsthese, wenn er ausführt: »Dazu gesellt sich in den Lo-

55 Vgl. Reinhart Koselleck, Kritik und Krise. Eine Studie zur Pathogenese der bürgerlichen Welt, Frankfurt a.M. 1973, insb. 61-81. Zur Kritik an Kosellecks These siehe u.a. Michael Schwartz, Leviathan oder Lucifer. Reinhart Kosellecks `Kritik und Krise revisited, in: Zeitschrift für Religions- und Geistesgeschichte 45 (1993), 33-57; Monika Neugebauer-Wölk, Esoterische Bünde und Bürgerliche Gesellschaft. Entwicklungslinien zur modernen Welt im Geheimbundwesen des 18. Jh. (Kleine Schriften zur Aufklärung, 8), Göttingen 1995, 7f.; Dies., Zur Konzipierung der bürgerlichen Gesellschaft. Freimaurerei und Esoterik, in: Berger/Grün (Hg.), Geheime Gesellschaft (wie Anm. 16, Kap. I), 80-89, hier 82.

56 Siehe vor allem Winfried Dotzauer, Freimaurergesellschaften am Rhein. Aufgeklärte Sozietäten auf dem linken Rheinufer vom Ausgang des Ancien Régime bis zum Ende der napoleonischen Herrschaft (Veröffentlichungen des Instituts für geschichtliche Landeskunde an der Universität Mainz, 16), Wiesbaden 1977. Bereichert wird diese ausführliche Studie zudem durch die aktuellere Zusammenstellung »Die Freimaurer im Alten Preußen 1738-1806« von Karlheinz Gerlach, denen neben den prosopographischen Daten und Statistiken zur sozialen Zusammensetzung zahlreiche weitere Informationen zu den Freimaurerlogen der oben skizzierten Region entnommen werden können. Beide Studien zeichnen in dieser Hinsicht ein sehr detailliertes Bild der Entwicklung der rheinischen Freimaurerei und liefern auch in Bezug auf die Beteiligung des rheinischen Adels an den Logen zahlreiche Hinweise. Siehe Karlheinz Gerlach, Die Freimaurer im Alten Preußen 1738-1806. Die Logen zwischen mittlerer Oder und Niederrhein (Quellen und Darstellungen zur europäischen Freimaurerei, 8), Innsbruck 2007 sowie Ders., Die Freimaurer im Alten Preußen 1738-1806. Die Logen in Pommern, Preußen und Schlesien (Quellen und Darstellungen zur europäischen Freimaurerei, 9), Innsbruck 2009. Wichtig erscheint auch der Hinweis Wolfgang Hartwigs, dass »dem Anspruch der Ständeegalisierung innerhalb der Freimaurergesellschaften [...] ein ausgesprochener Eliteanspruch der Logen im Verhältnis zur bürgerlichen Gesellschaft insgesamt gegenüber « gestanden habe. Vgl. Wolfgang Hartwig, Eliteanspruch und Geheimnis in den Geheimgesellschaften des 18. Jh.s, in: Reinalter (Hg.), Aufklärung und Geheimgesellschaften (wie Anm. 26, Kap. I), 63-86, hier 67.

57 Dotzauer, Zur Sozialstruktur der Freimaurerei (wie Anm. 26, Kap. I), hier $128 f$. 
gen, zum Teil ebenfalls in Führungspositionen, der nichtdynastische Adel, der in den großen Staaten politisch entmachtet ist und neue gesamtstaatliche Dienstfunktionen übernehmen kann. ${ }^{58}$ Dessen ungeachtet bilden die Forschungsarbeiten Dotzauers eine der wichtigsten Grundlagen dieser Arbeit.

In jüngster Zeit gingen insbesondere die Untersuchungen des österreichischen Historikers Dieter A. Binder auf den Aspekt der innerhalb der Freimaurerei anzutreffenden Elemente adliger Kultur ein und kamen insofern zu interessanten Ergebnissen. Binders Untersuchungen führten ausgehend von der berechtigten Annahme der Freimaurerei als Erziehungssystem zum Konzept der »Freimaurerei als Erziehung zum Gentleman $«{ }^{59}$ Binder sieht insbesondere in der im Ritual des Lehrlingsgrades vorhandenen Reisesymbolik eine deutliche Anspielung auf die im europäischen Adel des 17. und 18. Jahrhunderts übliche Kavalierstour. ${ }^{60}$ Als Beispiel sei hier nur die durch Binder gesehene Parallele zwischen dem von einem englischen Adligen geforderten "noble seat « und seiner freimaurerischen Entsprechung im Ort der Loge genannt sowie einer gesellschaftlich geforderten "guten Abstammung « des Gentleman - einem Kriterium, das auch innerhalb der Freimaurerei vor der Aufnahme durch die Logengemeinschaft verbürgt wurde. ${ }^{61}$ Binder vermutet in der insbesondere in den freimaurerischen Hochgraden erfolgenden Anlehnung an ein »nicht mehr an die Zugehörigkeit zum Adel« geknüpf-

58 Ders., Zur Sozialstruktur der Freimaurerei (wie Anm. 26, Kap. I), hier 128. Ähnlich argumentiert auch Norbert Schindler, wenn er schreibt: »Die paradoxe, zugleich innovatorische und systemstabilisierende Funktion des deutschen Logenwesens bestand nun darin, daß es in diesem Umschichtungsprozeß einen sozialen und kulturellen Integrationsfaktor darstellte, der dysfunktionale Nebenfolgen harmonisierend auffing, Konfliktpotentiale antizipierte und so zur Assimilation der im Austausch begriffenen Führungseliten beitrug. Die komplexe sozialintegrative Aufgabe der Logen bestand also darin, zum einen den Funktionsverlust der adelsständischen Eliten zu kompensieren und soziokulturell zu verarbeiten und zum anderen dem Prestige- und Anerkennungsbedürfnis der aufsteigenden bürgerlichen Schichten entgegenzukommen. Sie mussten exklusiv genug sein, um das sozial gegenläufige, aber in der Motivation ähnliche Geltungsbedürfnis von Adel und Bürgertum abzudecken, und gleichzeitig abstrakt-egalitär genug, um langfristig bürgerlichen Verhaltensorientierungen zum Durchbruch zu verhelfen. « Norbert Schindler, Freimaurerkultur im 18. Jh. Zur sozialen Funktion des Geheimnisses in der entstehenden bürgerlichen Gesellschaft, in: Robert M. Berdahl [u.a.] (Hg.), Klassen und Kultur. Sozialanthropologische Perspektiven in der Geschichtsschreibung, Frankfurt a.M. 1982, 205-262, hier 223.

59 Vgl. Binder, Geschichte, Mythos und Symbole (wie Anm. 23, Kap. I) insb. 40-48; Ders., Freimaurerei oder die Erziehung zum Gentleman, in: Mitteilungen des Österreichischen Staatsarchivs 55 (2011), 333-353. Auch die Forschungen Pierre-Yves Beaurepaires konnten zum Teil einen deutlichen Zusammenhang zwischen der Absolvierung der Grand Tour und der Aufnahme der Kavaliere, aber auch Hofmeister in eine Freimaurerloge während der Bildungsreisen ausmachen. Siehe hierzu Pierre-Yves Beaurepaire, L’Autre et le Frère. L'étranger et la franc-maçonnerie en France au XVIII e siècle (Les Dix-Huitièmes Siècles, 23), Paris 1998, 434-443. Auch die Bemerkungen Stevensons zur Rolle der ars memoriae innerhalb der Freimaurerei sowie den Ausführungen Hasselmanns zur geforderten "reformation of manners« im Umfeld der englischen Freimaurerei des frühen 18. Jh.s weisen auf den Erziehungsaspekt hin. Siehe hierzu Stevenson, The Origins of Freemasonry (wie Anm. 16, Kap. I), 87-96; Hasselmann, Die Rituale der Freimaurer (wie Anm. 24, Kap. I), 52-55.

60 Vgl. Binder, Geschichte, Mythos und Symbole (wie Anm. 23, Kap. I), 26-30.

61 Ders., Mythos und Symbole (wie Anm. 23, Kap. I), 28f. sowie 47. 
tes »Rittertum« eine Absetzung von einer »Feminisierung der Sitten«, wie sie innerhalb der Frühen Neuzeit allgemein bemerkbar sei. ${ }^{62}$ Für das 19. Jahrhundert wertet er die entsprechenden Grade als Substitut der Bourgeoisie für die höfischen Umgangsformen. ${ }^{63}$

Bei einer »Erziehung zum Gentleman«, wie sie Binder beschreibt, der im Übrigen in Bezug auf den Adel auch der Kompensationsthese folgt, ${ }^{64}$ stellt sich jedoch aus Perspektive des Adelsforschers die Frage, weshalb die Freimaurerei dann noch auf adlige Personen attraktiv wirken konnte. Hatten viele adlige Personen doch gemeinhin im Elternhaus eine langjährige intensive »Erziehung zum Gentleman« bzw. in der höfischen Etikette genossen und diese zumeist - mal mit mehr, mal mit weniger Erfolg - während einer mehrjährigen Kavalierstour perfektioniert.

Die vorliegende Studie orientiert sich zur Beantwortung dieser Fragen an einem Paradigmenwechsel hin zu einer kulturgeschichtlichen bzw. mikrohistorischen Betrachtung freimaurerischer Vergesellschaftung, der sich in einigen jüngeren Studien der Freimaurerforschung ergeben hat. Auf deutschsprachigem Gebiet markierte insbesondere die Münchner Dissertation des oben erwähnten Historikers Florian Maurice zur Reform der Berliner Großloge Royal York dieses methodische Umdenken. Hierin standen weniger strukturgeschichtliche Analysen als vielmehr eine auf die direkte Erfahrungswelt des Individuums ausgerichtete Untersuchung im Vordergrund - hier anhand der Person des Reformators der Berliner Großloge Royal York, Ignaz Aurelius Feßler in den Jahren 1796 bis 1802. Anhand des Fallbeispiels des feßlerschen Hochgradsystems konnte Maurice eindrucksvoll aufzeigen, wie Feßler, angeregt durch die Lektüre zeitgenössischer Darstellungen zur Geschichte der antiken Gnostiker, das freimaurerische Ritual zu einem Weg der »Selbsterlösung« des Menschen umarbeiten und den Rezipienten "auf die Vernunfterkenntnis der Unsterblichkeit führen will, auf das Wissen von der Fortdauer des Geistes nach dem Tode. $«{ }^{65}$ Die These des Münchner Historikers lautet, dass die Freimaurerei vor allem als ein »Raum für Selbstverwirklichung" von Wichtigkeit war, oder anders ausgedrückt: »Die Unbestimmtheit und Vieldeutigkeit der Begriffe und Symbole machte es möglich, daß man von außen hineintrug, was man im Innern zu finden wünschte, und schließlich glauben konnte, es dort vorgefunden zu haben. ${ }^{66}$ Die Loge habe über diese Funktion nicht nur

62 Ders., Mythos und Symbole (wie Anm. 23, Kap. I), $46 f$.

63 Vgl. Ders., Mythos und Symbole (wie Anm. 23, Kap. I), 46.

64 Siehe hierzu Ders., Mythos und Symbole (wie Anm. 23, Kap. I), 41. Binder nimmt hier auf Schindler Bezug.

65 Maurice, Freimaurerei um 1800 (wie Anm. 33, Kap. I), XVf. sowie 398-400. Das hier angeführte Zitat entstammt dem Vorwort Monika Neugebauer-Wölks.

66 Ders., Freimaurerei um 1800 (wie Anm. 33, Kap. I), XVf. sowie 399; Florian Maurice, Die Mysterien der Aufklärung. Esoterische Traditionen in der Freimaurerei?, in: Monika NeugebauerWölk (Hg.), Aufklärung und Esoterik (Studien zum 18. Jh., 24), Hamburg 1999, 274-287, hier 278, http://www.netzwerk-freimaurerforschung.de/blog/wordpress/wp-content/uploads/2014/03/ maurice99_mysterien_der_auklaerung.pdf (Zugriff vom 15.07.2014). 
entscheidend zur Identitätsbildung ihrer Mitglieder beigetragen, sondern konnte letztlich auch dem frühmodernen Staat als Schule der »Verinnerlichung staatstragender Werte« von Nutzen sein. ${ }^{67}$

Diesem Ansatz folgend gilt es, verstärkt die äußeren Einflüsse zu beachten, die zu einer bestimmten Zeit auf die Freimaurerei und die ihr angehörenden Individuen einwirkten. Die mikrohistorischen Untersuchungen der vorliegenden Studie setzen jedoch nicht bei der rationalistischen Form der Freimaurerei zu Beginn des 19. Jahrhunderts an, sondern vielmehr bei ihren mystisch-okkulten Ausprägungen um die Mitte des 18. Jahrhunderts. Mit ihrer bereits erwähnten typischen Anlehnung an das Rittertum scheinen diese in besonderem Maße durch Elemente einer adligen Lebenswelt beeinflusst.

Der geographische Rahmen dieser Studie geht dabei über das Rheinland hinaus. Insbesondere mit Blick auf die Person Joseph zu Salm-Reifferscheidt-Dycks werden auch die Beziehungen rheinischer adliger Freimaurer nach Frankreich von Belang sein. Stellvertretend für die französische Freimaurerforschung sei hier daher der methodische Ansatz Pierre-Yves Beaurepaires erwähnt. Beaurepaire setzt sich ebenfalls für eine mikrohistorische Vorgehensweise bei der Betrachtung freimaurerischer Sozietäten ein. In seiner umfangreichen Studie »L'Autre et le Frère L'étranger et la franc-maçonnerie en France au XVIII ${ }^{\mathrm{e}}$ siècle « konnte Beaurepaire deutlich die keineswegs immer offene Haltung innerhalb der französischen Freimaurerlogen des 18. Jahrhunderts gegenüber »Brüdern « fremder Städte, anderer Stände, Konfessionen, Religionen und auch Hautfarbe herausstellen. ${ }^{68}$ Er widmete sich zudem in einigen kürzeren Beiträgen bereits dem Zusammenhang von Freimaurerei und Adelskultur und zeigte hierbei die Wichtigkeit der Schloss- und Hoflogen als Orte alternativer Herrschaftsausübung des Adels im 18. Jahrhundert auf. ${ }^{69}$ Diese fruchtbaren Erfolge der micro-histoire scheinen auch im Hinblick auf die Untersuchung rheinischer Adliger innerhalb der Freimaurerei beachtenswert. Zeigen sie doch nochmals, wie wichtig eine »Vergrößerung des Maßstabes « ${ }^{70}$ bei der Betrachtung sein kann.

Abschließend müssen hier in besonderem Maße die Studien Monika Neugebauer-Wölks hervorgehoben werden. Sie haben zur Fragestellung und Ausrichtung der vorliegenden Studie maßgeblich beigetragen. Neugebauer-Wölk plädiert zum einen für eine höhere Akzeptanz des »Esoterischen« als Element frühneuzeitlicher Politik und verweist zum anderen auf den Relativierungsbedarf hinsichtlich einer rein bürgerlich orientierten Forschung zu den Aufklärungsgesellschaften des 18. Jahrhunderts. In diesem Zuge betont sie, dass die freimau-

67 Maurice, Freimaurerei um 1800 (wie Anm. 33, Kap. I), XVII.

68 Vgl. Beaurepaire, L’Autre et le Frère (wie Anm. 59, Kap. I), 539-667.

69 Siehe jüngst Ders., Freimaurer. Fürstliche Protektion, Hoflogen und hugenottische Netzwerke, in: Bernd Sösemann/Gregor Vogt-Spira (Hg.), Friedrich der Große in Europa. Geschichte einer wechselvollen Beziehung, Stuttgart 2012, 97-111. Hierin werden u.a. die verwandtschaftlichen Verflechtungen Friedrichs des Großen innerhalb der preußischen Freimaurerei besprochen. 
rerischen Hochgradsysteme insbesondere dem Adel einen Raum boten, in den sich seine herrschaftliche Macht hinein verlängern ließ und in dem ein in der arkanen Praxis geschultes Bürgertum seine Karrieren in der profanen Welt vorbereitete. Auch aus diesem Grunde bedürfe es, so Neugebauer-Wölk, »einer neuen Grundhaltung des Historikers gegenüber einer Überlieferung, deren Inhalte und Ausdrucksformen sich dem unmittelbaren Verständnis durch das moderne Denken entziehen ", und die insbesondere durch die Mittel einer "neuen Religionsgeschichte der Frühen Neuzeit« erklärbar gemacht werden könnten. ${ }^{71}$ In weiteren Studien verwies Neugebauer-Wölk zudem ausdrücklich auf die Herausforderung, die die naturwissenschaftlichen Erkenntnisse des 18. Jahrhunderts für die freimaurerische Geschichtsschreibung bedeuteten. ${ }^{72}$ Sie warf die Frage auf, warum eine Freimaurerei, die im Kern wie bei Koselleck rein auf ein politisches, dem "Absolutismus « entgegengesetztes "Geheimnis« beschränkt wird, »mit dem Verschwinden von Absolutismus und ständischer Gesellschaft« nicht selbst ebenfalls obsolet erschien. ${ }^{73}$

Insbesondere an diese Fragestellung schließt die vorliegende Studie an, da sie in Teilen auf die Situation des Adels in der "Sattelzeit« übertragbar ist. Dabei stehen die im Folgenden angestellten Untersuchungen mit ihrer Konzentration auf den Aspekt der Naturwissenschaften nicht in Konflikt mit den von NeugebauerWölk erwähnten Mitteln der »neuen Religionsgeschichte der Frühen Neuzeit«. Dies begründet sich vor allen Dingen in der innerhalb der vorliegenden Studie aufgegriffenen Begriffsdefinition des "Esoterischen" durch den Religionswissenschaftler Kocku von Stuckrad. Stuckrad definiert das "Esoterische« als ein »Element kultureller Prozesse« der »Identitätsbildung", das sich gerade aus den »diskursiven Transfers zwischen einzelnen Bereichen europäischer Kultur - vor allem zwischen Religion, Naturwissenschaft, Philosophie, Literatur und Kunst «speiste und stellte so jüngst in einem Aufsatz auch »Überlegungen zur Transformation des esoterischen Diskursfeldes seit der Aufklärung« an. ${ }^{74}$ Einer solchen

$71 \mathrm{Zu}$ den gesamten in diesem Abs. gemachten Angaben: Neugebauer-Wölk, Arkanwelten im 18. Jh. (wie Anm. 47, Kap. I), hier 62-64. Vgl. in diesem Sinne auch: Dies., Religion als Thema der Geschichtswissenschaft, in: Friedrich Wilhelm Graf/Friedemann Vogt (Hg.), Religion(en) deuten. Transformationen der Religionsforschung (Troeltsch-Studien, Neue Folge, 2), Berlin/New York 2010, 259-280, insb. 279f. Zu einem Abriss über die Entwicklung historischer Religionsforschung mit der aufgeworfenen Frage, ob das 18. Jh. in religiöser Hinsicht nicht einen »Riegel, sondern eine Gelenkstelle zwischen Früher Neuzeit und Moderne«bilde, siehe Dies./Markus Meumann, Aufklärung - Esoterik - Moderne. Konzeptionelle Überlegungen zur Einführung, in: Dies./Renko Geffarth/Markus Meumann (Hg.), Aufklärung und Esoterik: Wege in die Moderne (Hallesche Beiträge zur europäischen Aufklärung, 50), Berlin/Boston 2013, 1-36; Dies., Zur Konstituierung historischer Religionsforschung 1974-2004, in: zeitenblicke 5/1 (2006), [04/04/2006] http:// nbn-resolving.org/urn:nbn:de:0009-9-2755 (Zugriff vom 08.01.2013).

72 Vgl. Dies., Esoterik als Element freimaurerischer Geschichte (wie Anm. 5, Kap. I), hier 1-6.

73 Dies., Zur Konzipierung der bürgerlichen Gesellschaft (wie Anm. 55, Kap. I), hier 82.

74 Stuckrad, Was ist Esoterik? (wie Anm. 34, Kap. I), 20-23; Ders., Überlegungen zur Transformation des esoterischen Diskursfeldes seit der Aufklärung, in: Neugebauer-Wölk/Geffarth/Meumann (Hg.), Aufklärung und Esoterik (wie Anm. 71, Kap. I), 96-112. Zu einer nützlichen Diskussion zur Schwierigkeit, eine wissenschaftlichen Ansprüchen genügende Begriffsdefinition zu geben, die 
Transformation will die vorliegende Studie nachgehen. Eine Konzentration auf die sich entwickelnden Naturwissenschaften im 18. Jahrhundert wird dabei den oben genannten Bereichen in besonderem Maße gerecht, weil der vormoderne Begriff der »Naturgeschichte« diese Aspekte zunächst einbezog. ${ }^{75}$

\section{I.3 Gliederung und Quellenlage}

Die vorliegende Studie gliedert sich daher wie folgt: Zunächst sollen die zuletzt erwähnten Forschungen Monika Neugebauer-Wölks in einem zeitlich zu Beginn der »Sattelzeit« ansetzenden Analyseteil aufgegriffen und in direktem Bezug auf die Situation des Adels zu Beginn der "Sattelzeit» vertieft werden. Da aus Sicht der Adelsforschung gerade durch die Arbeiten Josef Matzeraths pointiert herausgestellt wurde, dass die Erinnerung an und die "Binnenkommunikation« über »Adligkeit« eine wichtige Funktion für die »Kohäsion« des Adels einnahm ${ }^{76}$, sollen zunächst einige für die späteren mikrohistorischen Untersuchungen grundlegende Vorüberlegungen zu Weltbild und Selbstsicht des frühneuzeitlichen Adels angestellt werden. Dabei müssen zum besseren Verständnis auch diesbezügliche Ideen des 17. und frühen 18. Jahrhunderts zur Sprache kommen. In diesem vorgeschalteten Teil der Studie soll konkret untersucht werden: Erstens, ob und inwiefern das "Esoterische« eine Bedeutung für die Selbstsicht adliger Personen um 1750 hatte; zweitens, in welcher Form freimaurerische Geschichtsschreibung und Ritual inhaltlich hieran bzw. an Bestandteile der adligen Memoria anknüpften; drittens, welcher Einfluss der zum Ende des 18. Jahrhunderts bereits innerhalb der geheimen Aufklärungsgesellschaften nachgewiesenen eschatologischen Lehre der Metempsychose in dieser frühen Phase der Freimaurerei beigemessen werden kann, der aufs engste mit dem Thema der Memoria verknüpft zu sein scheint. ${ }^{77}$

jedoch nicht Kocku von Stuckrads Vorschlag des "Esoterischen« berücksichtigt, vgl.: Peter-André Alt/Volkhard Wels, Einleitung, in: Dies. (Hg.), Konzepte des Hermetismus in der Literatur der Frühen Neuzeit (Berliner Mittelalter- und Frühneuzeitforschung, 8), Göttingen 2010, 7-22, hier insb. 7-10.

75 Siehe zum Verhältnis "Literatur/Naturgeschichte« etwa Lepenies, Das Ende der Naturgeschichte (wie Anm. 38, Kap. I), 133-146.

76 Josef Matzerath, Adelsprobe an der Moderne: Sächsischer Adel 1763-1866. Entkonkretisierung einer traditionalen Sozialformation (Vierteljahrschrift für Sozial- und Wirtschaftsgeschichte, Beiheft 183), Habil., Stuttgart 2006, $109 f$.

77 Dieser letzte Untersuchungsschritt wird vorgenommen, da sich in den vergangenen Jahren einige Studien mit der Idee der Metempsychose beschäftigten. Siehe insb. Helmut Zander, Geschichte der Seelenwanderung in Europa. Alternative religiöse Traditionen von der Antike bis heute, Darmstadt 1999; Helmut Obst, Reinkarnation. Weltgeschichte einer Idee, München 2009. Martin Mulsow konnte bereits ihre Bedeutung für das Ritual der Illuminaten zum Ende des 18. Jh.s herausstellen. Zudem war die Lehre der Metempsychose ein von den frühmodernen Naturwissenschaften thematisiertes Problem, an dem sich auch der frühneuzeitliche Adel interessiert zeigte. Siehe hierzu insb. Martin Mulsow, Vernünftige Metempsychosis. Über Monadenlehre, Esoterik und geheime Aufklärungsgesellschaften im 18. Jh., in: Neugebauer-Wölk (Hg.), 
An diesen allgemeineren Überblick schließen sich zwei mikrohistorische Untersuchungen zum rheinischen Adel in der Freimaurerei an, die zeitlich die Jahre von 1765 bis 1815 abdecken. Die erste mikrohistorische Analyse widmet sich der bereits von dem freimaurerischen Historiker August Pauls zu Beginn des 20. Jahrhunderts untersuchten Düsseldorfer Adelsloge La Parfaite Amitié. Diese Loge wurde deshalb ausgewählt, weil sich in ihr eine besonders große Zahl adliger Familien des nördlichen Rheinlands nachweisen lässt. Anhand der mikrohistorischen Betrachtung des sozialen wie gedanklichen Umfeldes ausgewählter Mitglieder im Zeitraum von den 1760er Jahren bis zum Ausbruch der Französischen Revolution von 1789 soll hiermit zeitlich die erste Hälfte der »Sattelzeit« abgedeckt werden. In die Zeit nach 1789 fällt die mikrohistorische Analyse des gedanklichen und sozialen Umfeldes des bereits erwähnten Altgrafen und Fürsten Joseph zu Salm-Reifferscheidt-Dyck.

Die Untersuchung seines Engagements innerhalb der Freimaurerei des Premier Empire soll die veränderten Voraussetzungen und Bedingungen aufzeigen, die einen rheinischen Adligen nach der Zäsur des Jahres 1789 bzw. 1794 in der französischen Freimaurerei erwarteten. Neben der Darstellung der gesellschaftlichen Betätigungen Salm-Dycks außerhalb der Freimaurerei soll die Analyse seines freimaurerischen Netzwerks im hermetisch-alchemistischen Hochgradsystem des Rit écossais philosophique die Beschaffenheit und gedankliche Prägung seines sozialen Umfelds klären. Es wird erwartet, dass sich durch diesen Analyseschritt sowohl Aussagen über die Gründe für das Interesse Joseph zu SalmReifferscheidt-Dycks als auch für das Desinteresse des Gros seiner ehemaligen Standesgenossen an der Freimaurerei dieser Zeit treffen lassen. Ein Ausblick auf die Vergesellschaftung des rheinischen Adels in den Jahren nach dem endgültigen Zusammenbruch des napoleonischen Regimes im Jahr 1815 wird als Schlusspunkt dieser Studie dienen.

Wie bereits erwähnt, kann die vorliegende Studie auf die umfangreichen Bestände des Archivs der Fürsten und Altgrafen zu Salm-Reifferscheidt-Dyck zurückgreifen, das sich heute im Besitz der Familie der Grafen Wolff-Metternich zur Gracht befindet und in den Archivräumen der Vereinigten Adelsarchive im Rheinland e.V. auf Schloss Ehreshoven bei Overath verwahrt wird. ${ }^{78}$ In Anbetracht der in den übrigen Archiven der Vereinigten Adelsarchive im Rheinland e.V.

Aufklärung und Esoterik (wie Anm. 66, Kap. I), 211-273, insb. 226f. Der Begriff der Metempsychose wird innerhalb dieser Studie für eine Vielzahl der sich als Alternative zum insb. christlich geprägten "Himmel-Hölle«-Schema etablierenden Jenseitsvorstellungen (Seelenwanderung, Planetenwanderung etc.) der Frühen Neuzeit verwendet. Die Inhalte der unterschiedlichen Vorstellungen werden im jeweiligen Zusammenhang erläutert werden. Eine ältere französische Studie, die bereits auf den Zusammenhang zwischen den freimaurerischen Hochgraden und der Metempsychose anhand eines auch in dieser Arbeit verwendeten Manuskripts des Chevaliers Andrew Michael Ramsay verwies, besteht in: August Viatte, Les sources occultes du Romantisme. Illuminisme - Théosopohie 1770-1820, Bd. 1: Le Préromantisme, Paris 1928, insb. 31-35.

78 Eine Bestandsbeschreibung sowie Informationen über die Zugänglichkeit der Archivalien der Vereinigten Adelsarchive im Rheinland e.V. finden sich auf den Internetseiten des Archivberatungs- 
nahezu völlig fehlenden Bestände zur freimaurerischen Vergesellschaftung des rheinischen Adels in der »Sattelzeit« wurde zusätzlich auf die archivalischen Dokumente freimaurerischer Provenienz anderer Institutionen zurückgegriffen. Hierunter fällt vor allem der sogenannte Fonds maçonnique der Archives du GOF, der in der BnF in Paris verwahrt wird. Außerdem wurden verschiedene zeitgenössische Broschüren, Logenmatrikel, Ritualinstruktionen und Reden in den Bibliotheken des GOF in Paris und des Cultureel Maçonniek Centrum Prins Frederik des GON in Den Haag ausgewertet. Dokumente zur Geschichte der in dieser Studie behandelten Logen des Rheinlands fanden sich zudem in den Archivbeständen freimaurerischer Provenienz des GStA PK in Berlin. Zeitgenössische Literatur und freimaurerische Überlieferungen, die in Kommunal- und Landesarchiven sowie Universitätsbibliotheken des In- und Auslands vorhanden sind, wurden zur Rekonstruktion der Zusammenhänge ebenso herangezogen wie wissenschaftliche Quelleneditionen in gedruckter und digitaler Form.

und Fortbildungszentrums des Landschaftsverbands Rheinland unter: http://www.afz.lvr.de/de/ archivberatung/adelsarchive_1/adelsarchive_1.html (Zugriff vom 24.03.2014). 


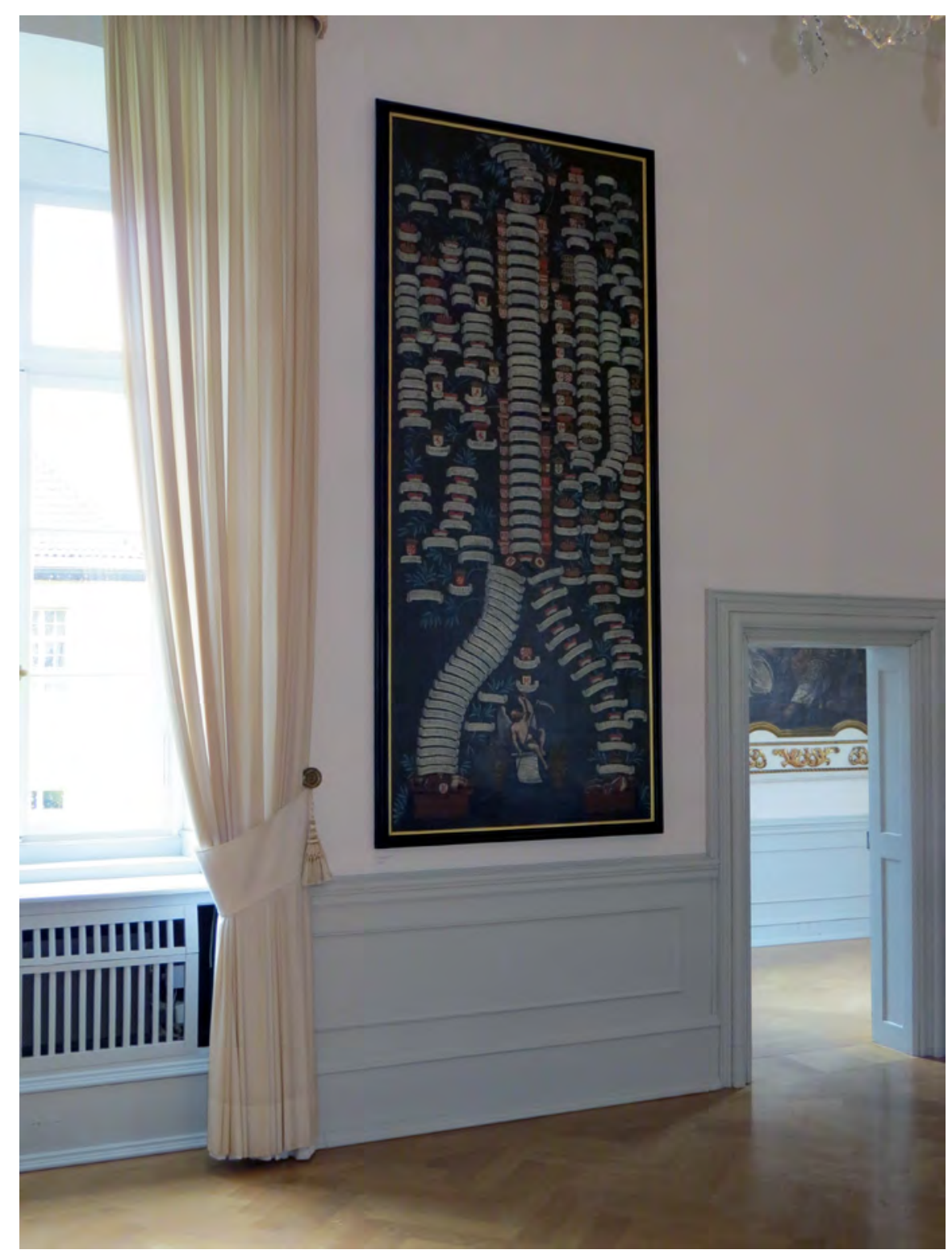

Abbildung 1: Stammbaum der uralten hochgräfflichen Salm, Schloss Dyck, 1750, Öl auf Leinwand (Bildrecht/Werk: Grafen Wolff-Metternich zur Gracht; Foto: M.O. Braun). 


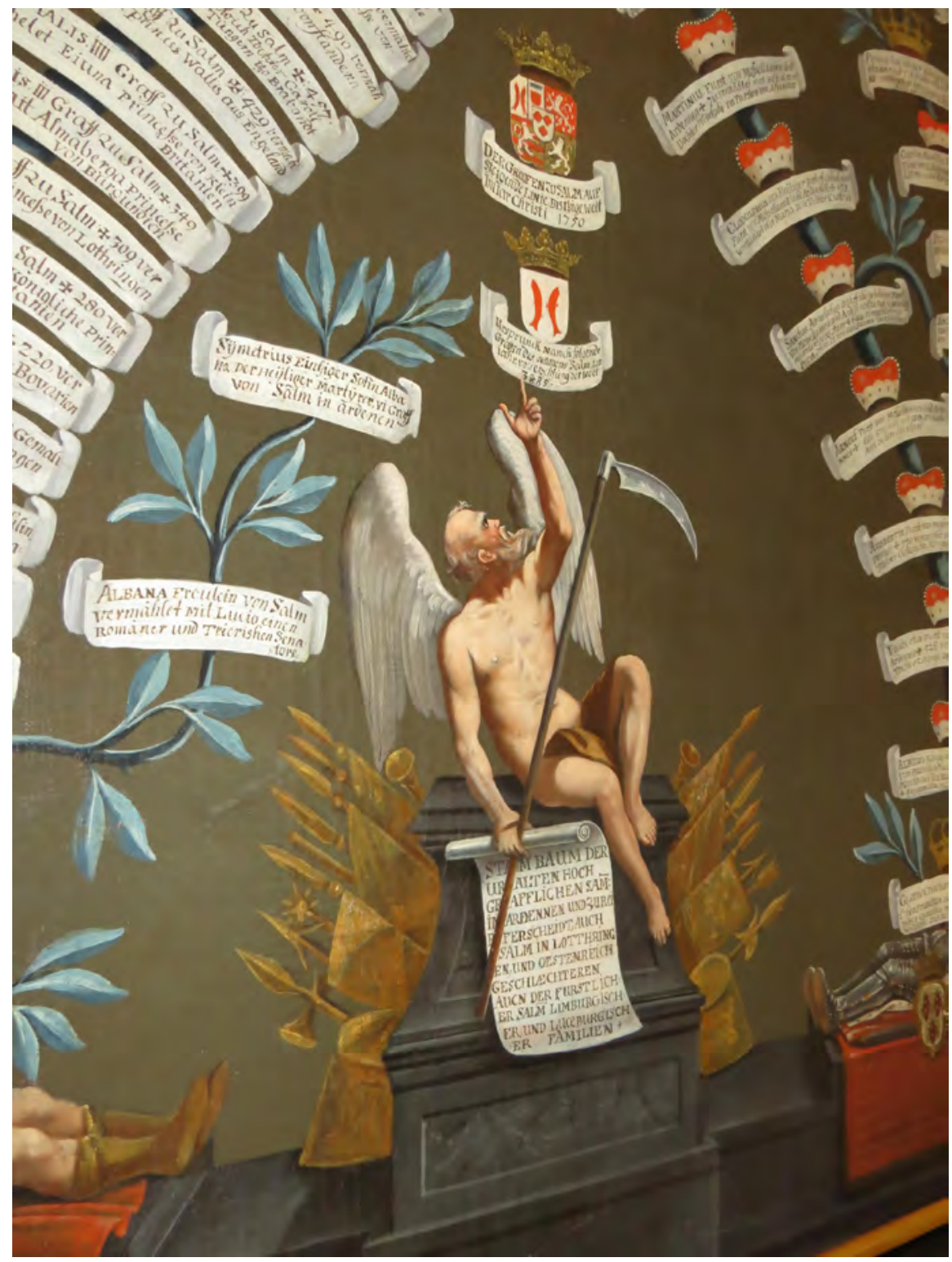

Abbildung 2: Detailaufnahme des Stammbaums auf Schloss Dyck - Kronos auf das Wappen der Grafen zu Salm verweisend (Bildrecht/Werk: Grafen Wolff-Metternich zur Gracht; Foto: M.O. Braun). 


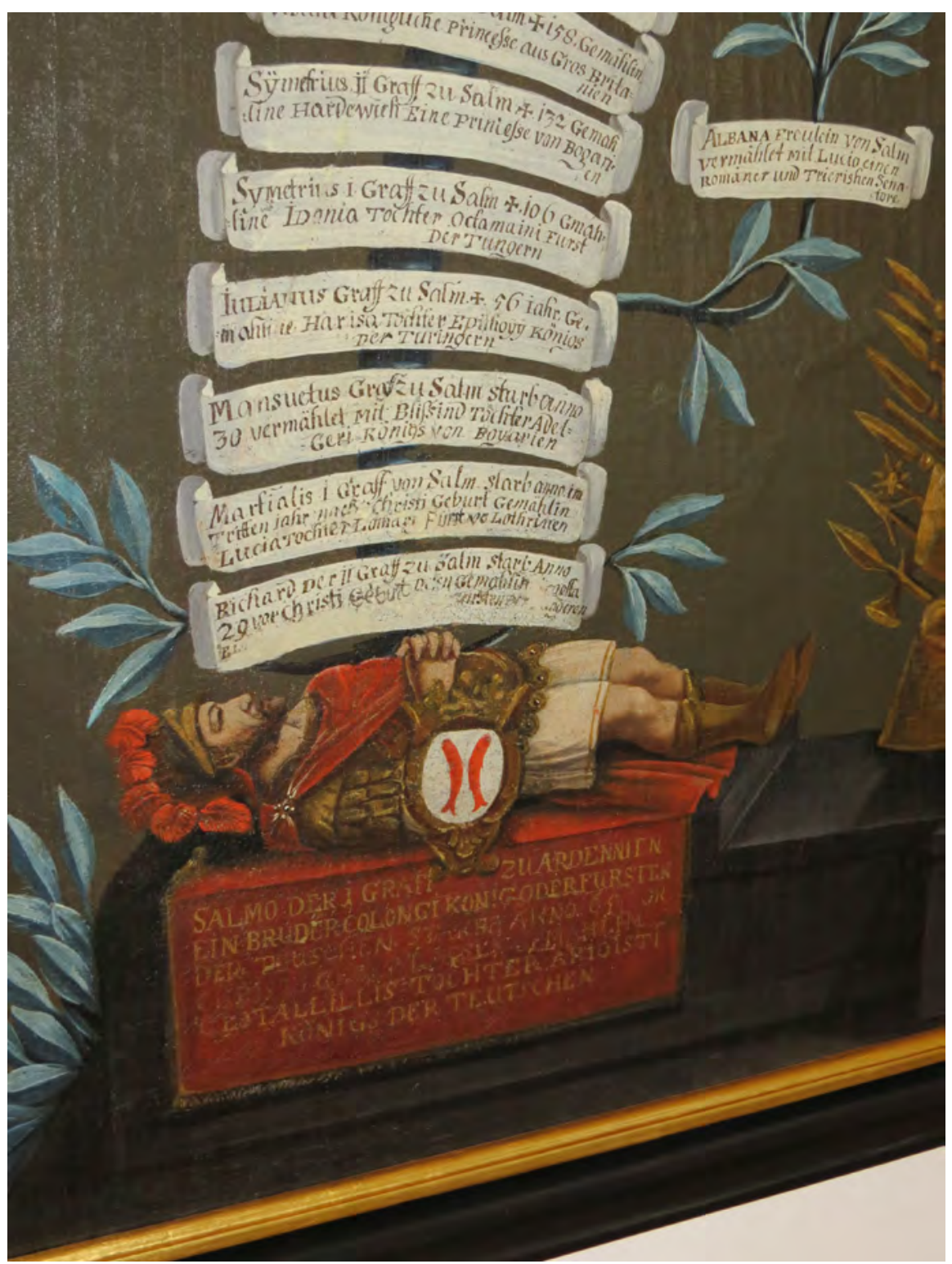

Abbildung 3: Detailaufnahme des Stammbaums auf Schloss Dyck - Salmo, der Graf zu Ardennien (Bildrecht/Werk: Grafen Wolff-Metternich zur Gracht; Foto: M.O. Braun). 


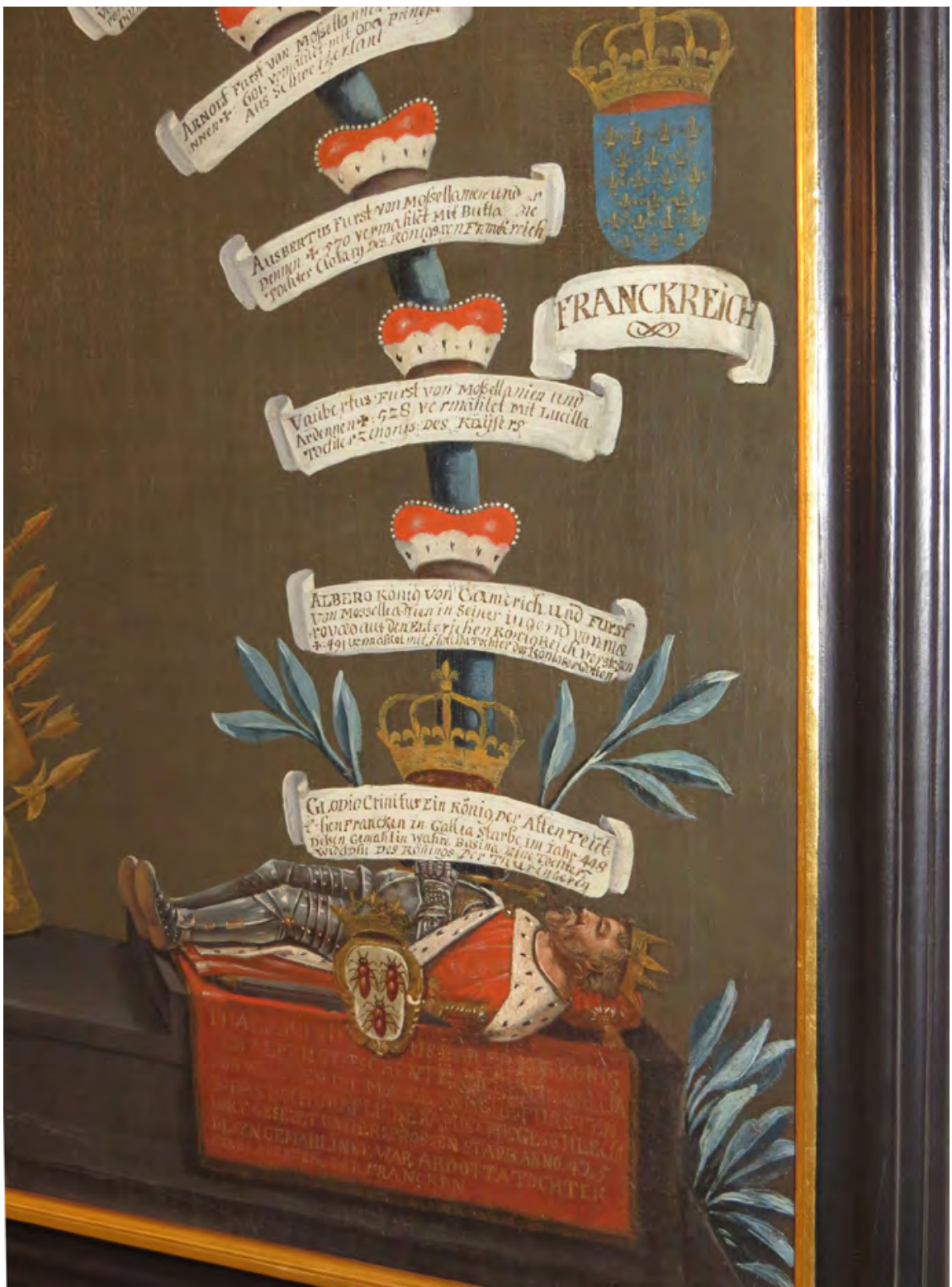

Abbildung 4: Detailaufnahme des Stammbaums auf Schloss Dyck - Faramund, König der Franken (Bildrecht/Werk: Grafen Wolff-Metternich zur Gracht; Foto: M.O. Braun). 



\section{Die Stammbäume der Tugend - Zur Funktion adliger Memoria um 1750}

\section{II.1 Meminisse juvabit - Mythos und adlige Kavalierstour}

I would think that the answer to this problem may be suggested by the history of the art of memory, that the Renaissance occult memory [...] may be the real source of a Hermetic and mystical movement which used, not the real architecture of >operative r masonry, but the imaginary or speculativer architecture of the art of memory as the vehicle of its teachings.

- Frances A. Yates ${ }^{1}$

Im Jahr 1763 kehrte der junge Reichsgraf Johann Ignaz Wolff-Metternich zur Gracht (1740-1790) von seiner dreijährigen Bildungsreise zurück auf den Stammsitz seiner Familie im Rheinland. ${ }^{2}$ Während der Reise, die ihn zunächst zum Studium in die Niederlande und später an die großen Höfe von Versailles und Wien führte, hatte er - den Erziehungsratgebern seiner Zeit entsprechend - nicht nur seine Bildung auf den Gebieten der Sprachen und Rechtswissenschaften erweitern können, sondern auch seine Umgangsformen in der Gesellschaft sowie seine Fähigkeiten in der Konversation verfeinert. Wolff-Metternich zur Gracht hatte zur Ausweitung seiner Weltkenntnis und sicherlich auch zum Nutzen der heimischen Wirtschaft Manufakturen besichtigt, zahlreiche Kontakte zu adligen Standesgenossen und Lehrenden an der Universität unterhalten oder auch gesellige Abende mit bürgerlichen Kaufleuten verlebt.

Um diese und andere Begebenheiten für sich und seine Nachkommen festzuhalten, führte er bereits während der Reise kritisch Buch über seine Erlebnisse und Kontakte. Die oftmals hastig verfasste Rohform dieser Notizen übertrug er später in ein hochwertiges, in Leder eingefasstes Journalbuch und stellte diesem das Motto Meminisse juvabit (»Sich erinnern wird nützen/erfreuen«) voran. ${ }^{3}$ Das Motto war dem Heldenepos der Aeneis des antiken Dichters Vergil ${ }^{4}$ entnommen.

1 Yates, The Art of Memory (wie Anm. 17, Kap. I), 295. Der Hinweis auf dieses Zitat fand sich bei: Stevenson, The Origins of Freemasonry (wie Anm. 16, Kap. I), 96.

2 Zur Biographie des Grafen Johann Ignaz Wolff-Metternich zur Gracht (1740-1790) sowie einer ausführlicheren Beschreibung seiner Reise siehe Martin Otto Braun, Ein Kavalier und sein soziales Netzwerk. Ausschnitte aus dem Journal der Bildungsreise des Reichsgrafen Johann Ignaz Wolff-Metternich zur Gracht (1740-1790), in: Rechtsrheinisches Köln. Jahrbuch für Geschichte und Landeskunde 35 (2010), 50-108, hier 54-62.

$3 \mathrm{Zu}$ allen hier gemachten Angaben vgl. Reisetagebuch (»Annotations et journal sur mes Voiages«) von Johann Ignaz Wolff-Metternich, 1760-1763, in: ASG, Akten, Nr. 545; Braun, Ein Kavalier und sein soziales Netzwerk (wie Anm. 2, Kap. II), 50-108. Die im Folgenden wiedergegebenen Zitate aus zeitgenössischen Quellen übernehmen die Schreibweise des Originals, auch wenn sie von der heutigen Orthographie abweichen sollte.

4 Das Motto kann vor allem durch die charakteristische Hexameter-Endung als Teil der Dichtung Vergils identifiziert werden. Es bezieht sich auf den Vers: »Forsan et haec olim meminisse juvabit.» 
Es zeigt die Bedeutung auf, die Johann Ignaz selbst einer aktiven Erinnerungsarbeit zumaß und kann stellvertretend für den Stellenwert des Erinnerns innerhalb einer adligen Familie gesehen werden. Denn die Reise des jungen Grafen war in ihrem Sinngehalt nicht allein auf die Erziehung und Bildung beschränkt. Sie stellte vielmehr die Fortsetzung einer familiären Tradition dar. Die finanziell oft aufwendigen Kavalierstouren des Adels wurden vom 17. bis weit in das 18. Jahrhundert hinein in der Regel von den heranwachsenden männlichen Mitgliedern einer adligen Familie als Übergangsritual zum Erwachsenendasein absolviert. ${ }^{5}$ Auch im Falle des Reichsgrafen Johann Ignaz Wolff-Metternich zur Gracht hatten bereits mehrere Vorfahren diesen exklusiven »rite de passage " ${ }^{6}$ vollzogen und ihre Reisejournale den Nachfahren hinterlassen. Von diesem Standpunkt aus gesehen, konnte er sich als jüngstes Glied einer langen Kette von Absolventen einer derartigen Reise betrachten.

Vgl. Vergil, Aeneis. Lateinisch-Deutsch, hg. von Johannes Götte, 5. Aufl., München 1980, Buch I, Vers 203. Zur zentralen Bedeutung des Mottos für einen Text wie zu seiner präfigurativen Funktion vgl. Jan Erik Antonsen, Text-Inseln. Studien zum Motto in der deutschen Literatur vom 17. bis 20. Jh. (Epistemata. Würzburger wissenschaftliche Schriften: Reihe Literaturwissenschaften, 258), Würzburg 1998, insb. 164-195.

5 Siehe zur Kavalierstour allgemein Antje Stannek, Telemachs Brüder. Die höfische Bildungsreise des 17. Jh. (Geschichte und Geschlechter, 33), Frankfurt a.M. 2001; Mathis Leibetseder, Die Kavalierstour. Adlige Erziehungsreisen im 17. und 18. Jh. (Beihefte zum Archiv für Kulturgeschichte, 56), Köln/Weimar/Wien 2004. Siehe im Hinblick auf ältere Reiseformen wie die perigrinatio academica des 16. Jh.s Rainer Babel/Werner Paravicini (Hg.), Grand Tour. Adeliges Reisen und europäische Kultur vom 14. bis zum 18. Jh. (Beihefte der Francia, 60), Ostfildern 2005, Permalink: http://nbn-resolving.org/urn:nbn:de:bvb:12-bsb00026833-7 (Zugriff vom 25.05.2014).

6 Zum Begriff »rite de passage« bzw. Übergangsriten allgemein vgl. Arnold van Gennep, Übergangsriten (Les rites de passage), Frankfurt a.M. 1986; Victor Witter Turner, The ritual process: structure and anti-structure, London 1969. Zur Kavalierstour als Übergangsritus im Besonderen siehe Stannek, Telemachs Brüder (wie Anm. 5, Kap. II). Es ist hier zu betonen, dass die Kavalierstour - wie Mathis Leibetseder überzeugend herausgearbeitet hat - nicht auf den Aspekt des Übergangsritus beschränkt werden kann, sondern multifunktional war. Siehe hierzu insb. Leibetseder, Die Kavalierstour (wie Anm. 5, Kap. II), 12f. sowie 205-207, aber auch jüngst Eva Bender, Die Prinzenreise. Bildungsaufenthalt und Kavalierstour im höfischen Kontext gegen Ende des 17. Jh. (Schriften zur Residenzkultur, 6), Diss., Berlin 2011, 16. Dennoch scheint eine vollkommene Negierung des rituellen Charakters der Tour auch aufgrund der hier beschriebenen memorialen Intention nicht gerechtfertigt. Sowohl Leibetseder als auch Bender kritisieren, dass kein eindeutiges Ende des »Ritus Kavalierstour« zu erkennen sei. Im Falle der reisenden Minderjährigen des rheinischen Adels im 18. Jh. ist dieses Ende jedoch mit der Reise zum Kaiserhof bzw. im Falle Minderjähriger mit der Erteilung der kaiserlichen venia aetatis perfecta (Großjährigkeitserklärung) in der Regel vorhanden. Dies zeigt sich auch im Journal Wolff-Metternichs, dessen Aufzeichnungen mit seinem Aufenthalt am Kaiserhof abbrechen. Auch die "Liminalität« als typisches Merkmal des Ritus ist gegeben, da vor Absolvierung der Tour allenfalls vorläufige Großjährigkeitserklärungen (venia aetatis imperfecta) mit wesentlichen Einschränkungen über die selbstständige Verwaltung der Familiengüter erteilt wurden. Siehe zu einer solchen Erklärung bspw.: Kaiserliche Großjährigkeitserklärung für Graf Joseph, 31. Mai 1793, Transkription Elisabeth Schläwe, aus: Netzbiographie: Joseph zu Salm-Reifferscheidt-Dyck (1773-1861), in: historicum-estudies.net, [05.06.2014], http:// www.historicum-estudies.net/epublished/netzbiographie/transkriptionen/grossjaehrigkeitserklae rung-1793 (Zugriff vom 21.11.2014). Zur Kavalierstour des Vaters Johann Ignaz Wolff-Metternichs vgl. Martin Otto Braun, Franz Joseph Graf Wolff-Metternich zur Gracht (1710-1741). Karriereweg eines rheinischen Adligen am kurkölnischen Hof, in: Jahrbuch der Stadt Erftstadt 20 (2011), 66-76. 
Seine Tour, die er auf Geheiß und mit finanzieller Unterstützung seiner Mutter im Jahr 1760 antrat, erfuhr während der Reinschrift der Notizen eine nachträgliche persönliche Ausdeutung und Bewertung. ${ }^{7}$ Mit Hilfe des Mottos eröffnete Johann Ignaz innerhalb des Journals nicht nur das persönliche Zwiegespräch über seine Reiseerlebnisse, sondern wandte sich gleichzeitig auch an seine Nachkommen. Dem Exempel seiner Vorfahren folgend gewährleistete er mit der Konservierung des Erlebten durch das "Gedächtnismedium ${ }^{8}$ der Schrift bewusst die Weitergabe seiner persönlichen Erfahrungen und vertraute darauf, dass sein tugendhaftes Exempel in dieser Form den Nachfahren von größerem Nutzen sein würde. Denn die Journale der Kavaliere und mit ihnen die auf Reisen gemachten Erfahrungen gingen nach der Verschriftlichung in die Familienbibliotheken und -archive als typische »Erinnerungsräume ${ }^{9}$ des Adels ein. ${ }^{10}$

Eine solche Überlieferung lässt sich in Anlehnung an die Arbeiten des Ägyptologen Jan Assmann als »kulturelles Gedächtnis « ${ }^{11}$ bezeichnen. Die adlige Bib-

7 Anzeichen hierfür sind zahlreiche Bemerkungen des Grafen, der die Wichtigkeit bestimmter Kontakte für die Reise nachträglich bewertet bzw. Reflektionen über Erlebnisse anstellt. Vgl. Reisetagebuch (»Annotations et journal sur mes Voiages«) von Johann Ignaz Wolff-Metternich, 1760-1763, in: ASG, Akten, Nr. 545.

8 Zur Schrift als "Gedächtnismedium« und "Gedächtnisstütze« siehe Aleida Assmann, Erinnerungsräume. Formen und Wandlungen des kulturellen Gedächtnisses, 3. Aufl., München 2006, 179-217.

9 Zum Begriff des "Erinnerungsraumes« sowie des »Erinnerungsortes« siehe Dies., Erinnerungsräume (wie Anm. 8, Kap. II), 298-303. Auf französischem Sprachgebiet sind hierzu vor allem die Studien Pierre Noras zu den »lieux de mémoire« zu erwähnen. Siehe zu Letzteren Pierre Nora (Hg.), Erinnerungsorte Frankreichs, München 2005.

10 Folgt man dem Konzept Aleida Assmanns, kommt den Archiven im Falle des Adels eine deutlich zweigeteilte Rolle zu. Zum einen stehen sie - wie im Fall der Reisejournale - für das »bewohnte Funktionsgedächtnis«, das die Identität einer Familie allgemein und in Bezug auf ihre Zugehörigkeit zur gesellschaftlichen Gruppe des Adels im Besonderen in der Gegenwart fundiert. Das Beispiel der Reisejournale illustriert in besonderer Weise die »auf Wiederholung gegründete rituelle Kommemoration« des Funktionsgedächtnisses. Zum anderen nehmen die Archive jedoch auch die Rolle des »unbewohnten Speichergedächtnisses« ein. Dies verweist auf den Bestand an Dokumenten, deren Inhalt potentiell hervorgeholt werden könnte. Das »unbewohnte Speichergedächtnis« ist dabei als »ausgelagerter Wissensspeicher« zu sehen, der die Möglichkeit zur Wiederanknüpfung bietet, jedoch nicht in regelmäßigem Gebrauch sein muss. Hierunter fällt besonders das angeführte Beispiel des Archivs als Ort der Sammlung und Lagerung des schriftlich gespeicherten Wissens. Beim Adel können diese Übergänge zwischen »bewohntem Funktionsgedächtnis« und »unbewohntem Speichergedächtnis« fließend sein und auch in den Bereich des »Verwahrensvergessens" einmünden. $\mathrm{Zu}$ den hier verwendeten Begriffen des »Funktions-« und "Speichergedächtnisses" sowie dem Bereich des "Verwahrensvergessens" siehe allgemein Assmann, Erinnerungsräume (wie Anm. 8, Kap. II), insb. 130-145 sowie 408-413. Zum "Funktions-« und »Speichergedächtnis« in Bezug auf die Herausbildung adliger Identität vgl. auch Silke Marburg/Josef Matzerath, Vom Stand zur Erinnerungsgruppe. Zur Adelsgeschichte im 18. und 19. Jh., in: Dies. (Hg.), Der Schritt in die Moderne: Sächsischer Adel zwischen 1763 und 1918, Köln/ Weimar/Wien 2001, 5-16, hier 11. Zum Archiv als »Erinnerungsraum« vgl. Assmann, Erinnerungsräume (wie Anm. 8, Kap. II), 343-347. Zur Bedeutung und Generierung der Memoria im rheinischen Adel siehe auch die entsprechenden Beiträge in: Gersmann/Langbrandtner (Hg.), Adlige Lebenswelten (wie Anm. 3, Kap. I), 171-226.

11 Jan Assmann, Das kulturelle Gedächtnis. Schrift, Erinnerung und politische Identität in frühen Hochkulturen, 6. Aufl., München 2007. 
liothek, die Ahnengalerie und das Archiv können ebenso wie der Stammsitz einer Familie gleichsam als Manifestationen eines »kulturellen Gedächtnisses" adliger Familien aufgefasst werden. ${ }^{12}$ Die Literaturwissenschaftlerin Aleida Assmann bemerkte $\mathrm{zu}$ derartigen »Familien-« oder »Generationenorten ${ }^{13}$ treffend:

An diesen Orten entschränkt sich das Gedächtnis des einzelnen in Richtung auf das der Familie; und hier verschränkt sich die Lebenssphäre des einzelnen mit jenen, die zu dieser Lebenssphäre dazugehören, aber nicht mehr da sind. An beiden Orten geht individuelle Erinnerung in einer allgemeineren Erinnerung auf. ${ }^{14}$

Mit Beginn der Frühen Neuzeit verwendeten adlige Familien mehr Mühe darauf, mit Hilfe schriftlicher Zeugnisse des Familienarchivs oder einer intensiven Beschäftigung mit Themen wie Ahnenforschung oder der gezielten Bewahrung von materiellen Relikten der Familiengeschichte eine spezifisch eigene Tradition zu kreieren. ${ }^{15}$ Rückbezüge auf mythische Helden oder andere große Gestalten der Geschichte waren hierbei durchaus üblich - wobei insbesondere im Falle der mythischen Helden die Historizität der fiktiven Figuren lange Zeit weniger in Zweifel gezogen wurde als ein heutiger Betrachter zunächst annehmen könnte. ${ }^{16}$ Der Rückbezug auf den Mythos der Aeneis im Fall des Reichsgrafen Wolff-Metternich kann somit durchaus als sein persönlicher Versuch gesehen werden, Ursprung und Sinn des Ritus der Kavalierstour auf historischer Ebene zu klären.

Die Auseinandersetzung mit dem Bestand der familiären Überlieferung zur Tour, der den Adligen in den familiären "Erinnerungsräumen", aber meist auch im persönlichen Vorbild des Vaters zur Verfügung stand, bildete für die Nachfahren die Grundlage für eine Auseinandersetzung mit der Tradition der Reise. Mit dem tatsächlichen Antritt der Tour verließ der Kavalier diese Sphäre des Theoretischen, absolvierte den Ritus und trat damit idealerweise in eine Phase ein, aus der er selbst sinnstiftend hervorgehen sollte.

Hier scheint eine interessante Parallele zu den Erinnerungs- und Gedächtnisformen nicht schriftlicher Kulturen auf, wie sie Jan Assmann für das antike

12 Siehe zur Bedeutung, die der Gedächtnisbegriff bereits im Mittelalter im höfischen Kontext spielte: Jan-Dirk Müller, Gedechtnus. Literatur und Hofgesellschaft um Maximilian I. (Forschungen zur Geschichte der älteren deutschen Literatur, 2), München 1982.

13 Assmann, Erinnerungsräume (wie Anm. 8, Kap. II), 301-303.

14 Ders., Erinnerungsräume (wie Anm. 8, Kap. II), 299 f.

15 Siehe Klaus Graf, Adel als Leitbild. Zur Geschichte eines Grundwerts in Spätmittelalter und früher Neuzeit, in: Horst Carl/Sönke Lorenz (Hg.), Gelungene Anpassung? Adelige Antworten auf gesellschaftliche Wandlungsvorgänge vom 14. bis zum 16. Jh. (Schriften zur südwestdeutschen Landeskunde, 53), Ostfildern 2005, 67-81, hier 71f., Permalink: http://nbn-resolving.org/ urn:nbn:de:bsz:25-opus-56326 (Zugriff vom 25.05.2014).

16 Vgl. hierzu bspw. im Zedlerschen Lexikon den Artikel "Aeneas", in dem die Historizität der Aeneas-Sage verteidigt wird: Johann Heinrich Zedler, Grosses vollständiges Universal-Lexicon Aller Wissenschaften und Künste, Halle/Leipzig 1732-1750, Bd. 1, 654-658, http://www.zedlerlexikon.de/ (Zugriff vom 25.05.2014). 
Ägypten untersucht hat. Assmann betont hierbei die Rolle des Ritus und des Festes als "primäre Organisationsformen des kulturellen Gedächtnisses «. ${ }^{17}$ Diese weisen laut Assmann oft enge Verbindungen zu Mythen auf. Durch dieses Zusammenspiel setzt sich die sogenannte "Mythomotorik der Erinnerung" in Gang, mit der das Potenzial eines Mythos gemeint ist, durch einen Vergangenheitsbezug "orientierend «, "selbstbildformend " und "handlungsleitend " in einer menschlichen Gesellschaft zu wirken. ${ }^{18}$ Derartige Rückbezüge auf Mythen sowie eine mythologisierte oder zumindest nachträglich idealisierte Familiengeschichte sind auch als gängige Praxis der Identitätsstiftung des frühneuzeitlichen Adels anzusehen. ${ }^{19}$

Dass der Reichsgraf Wolff-Metternich in Bezug auf seine Reise ebenfalls einen Mythos vor Augen hatte, erhellt das im Nachhinein gewählte Motto. Er verglich sich auf diese Weise mit der mythischen Gestalt des irrlichternden Aeneas, der nicht zuletzt als Begründer Alba Longas bzw. Roms galt. Der junge Graf zeigte hiermit - obgleich seine Reise im Vorhinein zweifelsfrei besser geplant war als die des fiktiven trojanischen Helden - eine direkte gedankliche Verbindungslinie zwischen der Ausfahrt des Heroen und seiner persönlichen Unternehmung auf. Eine fundierende Funktion des Mythos im Sinne der durch Assmann beschriebenen "Mythomotorik« ist somit vorhanden.

Es ist dabei von besonderer Wichtigkeit, sich die Rolle der heranwachsenden Stammhalter in Bezug auf die familiäre Memoria zu verdeutlichen. Die Stammhalter einer Familie waren der lebende Nexus zwischen Vergangenheit und $\mathrm{Zu}$ kunft, zwischen den Inhalten des innerfamiliären Gedächtnisses und dessen Aktualisierung und Anreicherung in der Gegenwart. Hier sah sich das "Arkanum» der adligen Familiengeschichte mit den wechselnden Verhältnissen - positiven wie negativen - konfrontiert, sah sich der Träger tradierter familiärer und standesinterner Vorgaben, Werte und Normen zur Interaktion mit anderen Adligen, aber auch anderen sozialen Gruppen, Lebensweisen und Weltbildern aufgefordert. Die »Binnenkommunikation" der von Matzerath beschriebenen »Erinnerungsgruppe Adel« speiste sich so auch im Falle des rheinischen Adels nicht erst

17 Assmann, Das kulturelle Gedächtnis (wie Anm. 11, Kap. II), 56-59.

18 Dies kann entweder »fundierend « geschehen, also die Gegenwart als sinnvoll und gottgewollt erscheinen lassen, oder »kontrapräsentische "Züge annehmen, indem die Vergangenheit als »Goldenes Zeitalter « und erstrebenswertes Vorbild gesehen wird. Fundierende und kontrapräsentische Funktion der »Mythomotorik « müssen dabei nicht getrennt, sondern können zuweilen auch gemeinsam auftreten. Siehe zum Begriff der »Mythomotorik « und ihren hier erläuterten Funktionen Assmann, Das kulturelle Gedächtnis (wie Anm. 11, Kap. II), 78-83.

19 Was die Kavalierstour anbelangt, sei hier etwa der häufige Rückbezug auf den auch bei Gabriele Stannek erwähnten Telemach-Mythos genannt. Dieser Bezug des Adels auf Mythen ist auch von Joachim Berger für andere Lebensbereiche konstatiert worden. Berger bespricht hierbei den vor allem bis in das erste Drittel des 18. Jh.s hinein wirksamen Herkules-Mythos in Bezug auf deutsche Fürstenhäuser. Vgl. hierzu Joachim Berger, Hercules Vinariensis. Aneignungen eines europäischen Mythos in der frühen Neuzeit, in: Hellmut Th. Seemann (Hg.), Europa in Weimar. Visionen eines Kontinents (Jahrbuch der Klassik Stiftung Weimar 2008), Weimar 2008, 77-104. 
seit $1750 \mathrm{zu}$ entscheidenden Teilen aus den Erfahrungen ihrer Mitglieder außerhalb ihrer selbst. ${ }^{20}$

Die aus der Vergangenheit herüberreichende Kette der Exempel der Vorfahren wurde um das Exempel des in der Gegenwart lebenden Ichs erweitert und der Nachwelt präsentiert. Ein Bewusstsein für Riten als Vermittler identitätsstiftender Erfahrungen und primärer, nicht materieller Träger eines bewahrenswerten Wissens der Vorfahren kann dabei für weite Teile des europäischen Adels als gegeben angenommen werden. Adlige Riten und die über sie Aufschluss gebenden Informationsträger sind hierbei als Teil einer gleichzeitig innerfamiliären wie nach außen gerichteten Selbstinszenierung ${ }^{21}$ zu sehen. Das Reisejournal des Reichsgrafen Johann Ignaz Wolff-Metternich zur Gracht, aber auch andere Träger des »kulturellen Gedächtnisses « des Adels, wie etwa der Stammbaum des salm-reifferscheidtschen Geschlechts auf Schloss Dyck, sind somit - bildlich gesprochen - Beispiele für eine zeitlich mehrdimensionale Bühne. Doch welches Bild sollte um die Mitte des 18. Jahrhunderts von einer adligen Person auf einer solchen Bühne im Idealfall inszeniert werden? Und weshalb bedurfte es überhaupt der Inszenierung?

\title{
II.2 "Lebens-Art» - Ausweis der Adligkeit
}

\begin{abstract}
Denn ein Edelmann muß Lebens=Art und ein edles Wesen haben; sonst wird man ihn gar leicht mit dem Pöbel vermengen.
\end{abstract}

- Johann Michael von Loen ${ }^{22}$

Bereits in den Theorien der Philosophen des 17. und frühen 18. Jahrhunderts, wie etwa dem Konzept der »Privat-Klugheit « eines Christian Thomasius' (1655-1728), ${ }^{23}$

20 Hier werden die bereits oben genannten Begriffe der »Erinnerungsgruppe« sowie der »Binnenkommunikation« von Josef Matzerath und Silke Marburg als Konstitutivum für das adlige Selbstverständnis aufgegriffen. Siehe hierzu Dies., Vom Stand zur Erinnerungsgruppe (wie Anm. 10, Kap. II); Matzerath, Adelsprobe an der Moderne (wie Anm. 76, Kap. I). Wichtig scheint in Bezug auf eine nicht als vollkommen undurchlässig für äußere Einflüsse verstandene »Binnenkommunikation « des Adels insbesondere der Hinweis Marburgs auf die recht gute Vereinbarkeit des Vereinswesens des 18. Jahrhunderts mit dem adligen Selbstbild: Silke Marburg, Adel und Verein in Dresden, in: Dies./Matzerath (Hg.), Der Schritt in die Moderne (wie Anm. 10, Kap. II), 45-62, hier 47. In der vorliegenden Studie soll daher gleichzeitig der Forderung Heike Düselders und Olga Weckenbrocks Rechnung getragen werden, die den Adel nicht unter dem »Diktum des geschlossenen Standes« betrachten, sondern gerade seine Interaktion mit der ihn umgebenden Umwelt thematisieren. Siehe hierzu Heike Düselder/Olga Weckenbrock, Einführung, in: Dies./Siegrid Westphal (Hg.), Adel und Umwelt. Horizonte adeliger Existenz in der Frühen Neuzeit, Köln/Weimar/Wien 2008, 1-16, hier insb. 1-5.

21 Zum freimaurerischen Ritual in diesem Sinne vgl. Hasselmann, Die Rituale der Freimaurer (wie Anm. 24, Kap. I), insb. 187-191.

22 Johann Michael von Loen, Der Adel, Ulm 1752, Abh. VI, § 14, hier 315, Permalink: http:// nbn-resolving.de/urn:nbn:de:bvb:12-bsb11100691-7 (Zugriff vom 25.05.2014).

23 Siehe hierzu etwa Christian Thomasii, Kurtzer Entwurff der Politischen Klugheit, sich selbst und anderen in allen Menschlichen Gesellschaften wohl zu rathen, und zu einer gescheid- 
waren dem Adel Wege aufgezeigt worden, auf denen eine Verinnerlichung und Weitergabe von tugendhaftem Verhalten zu erreichen war. Dem »Vorbild der Tugend «, personifiziert in der Gestalt des »Weisen«, wurde ein entscheidender Einfluss auf die Entwicklung der Gesellschaft eingeräumt. Derartige philosophische Systeme mündeten in eine Diskussion ein, die das 18. Jahrhundert prägen sollte: die Frage nach dem Ursprung menschlicher Zivilisation und einer Rechtfertigung der Ständeordnung des Ancien Régime.

Vor diesem Hintergrund ist der Artikel zum Begriff »Lebens-Art« im Zedlerschen Lexikon zu sehen, der eine auf vier Graden basierende Herausbildung einer höchsten »Lebens-Art« im Laufe der geschichtlichen Entwicklung der Menschheit nachzeichnete, die vom Jagd- und Höhlenmenschen über den Viehzüchter zum Ackerbauern und schließlich zur höchsten Ausformung in der Stufe Vita civilis sive urbana et mitior führte, die sich vor allem durch die Anlage schöner und kultivierter Bauwerke und Gärten als das Goldene Zeitalter des Menschen darstellte. ${ }^{24}$ Die Ergreifung dieser höchsten "Lebens-Art « sollte den Menschen zur »Herrschaft über die materielle Welt « führen. ${ }^{25}$ Sie beinhaltete einen praktischen Ausgleich zwischen Eigennutz und Sorge um das Fortkommen

ten Conduit zu gelangen [...], Franckfurth/Leipzig 1713, Permalink: http://nbn-resolving.de/ urn:nbn:de:gbv:3:1-341186 (Zugriff vom 25.05.2014). Kontrastierend zur »Staats-Klugheits-Lehre» des 17. Jh.s, die in erster Linie auf eine von oben nach unten vorgegebene Ordnung des gesamten Gemeinwesens zielte, hatte Thomasius sein sozialethisches »Decorum-Konzept«bzw. den Begriff der »Privat-Klugheit« entwickelt. Beide sind als Teil einer umfassenden praktischen Philosophie zu sehen, die vor allem in geselligen Zusammenkünften durch die Vorbildwirkung eines vollkommen selbstbeherrschten und durch direkte Erfahrungen gebildeten Individuums wirksam werden sollte. Siehe hierzu die Ausführungen bei Wolfram Mauser, Geselligkeit. Zu Chance und Scheitern einer sozialethischen Utopie um 1750, in: Karl Eibl (Hg.): Entwicklungsschwellen im 18. Jh., Hamburg 1990, 5-36, Permalink: http://nbn-resolving.org/urn:nbn:de:bsz:25-opus-67758 (Zugriff vom 25.05.2014); Wolfram Mauser, »Ich lasse den Freund dir als Bürgen«. Das Prinzip Vertrauen und die Freundschaftsdichtung des 18. Jh.s, in: Ute Pott (Hg.), Das Jh. der Freundschaft. Johann Wilhelm Ludwig Gleim und seine Zeitgenossen (Schriften des Gleimhauses Halberstadt, 3), Göttingen 2004, 11-20, hier 15. Zum »Decorum-Konzept«, das auf die äußerlichen Sitten und Regeln des ordentlichen Umgangs des Menschen in Gesellschaft zielt und der thomasischen "politischen Klugheit« zugrunde liegt, vgl. Stephan Sting, Freundschaft als soziale Utopie. Zur Entstehung bürgerlicher Gesellungsformen im 18. Jh., in: Meike Sophia Baader/Johannes Bilstein/Christoph Wulf (Hg.), Die Kultur der Freundschaft. Praxen und Semantiken in anthropologisch-pädagogischer Perspektive, Weinheim/Basel 2008, 60-69, hier 62f. Dieses veränderte Bild des Fürsten, das mit einer Diskussion um eine verbesserte Erziehungsweise der heranwachsenden Anwärter einherging, muss - wie Manfred Agethen gezeigt hat - auch als eines der Grundelemente des Interesses adliger Personen an Geheimgesellschaften gesehen werden. Agethen bezeichnet das sich während des 18. Jh.s herausbildende »veränderte Selbstkonzept« der Fürsten als »geradezu revolutionär« und führt Kaiser Joseph II. als Beispiel für die Durchsetzung dieses Ideals eines aufgeklärten »Absolutismus« an. Siehe hierzu Ders., Geheimbund und Utopie. Illuminaten, Freimaurer und deutsche Spätaufklärung (Ancien Régime, Aufklärung und Revolution, 11), München 1984, 26-33.

24 Vgl. zu sämtlichen in diesem Abs. gemachten Angaben zur "Lebens-Art» Mauser, Geselligkeit (wie Anm. 23, Kap. II), 5-36, hier vor allem 1lf.; Wolfram Mauser, Konzepte aufgeklärter Lebensführung: literarische Kultur im frühmodernen Deutschland, Würzburg 2000, 23-29. Mauser bezieht sich hier auf den Artikel »Lebens-Art« im Zedlerschen Lexikon. Siehe hierzu Zedler, Universal-Lexicon (wie Anm. 16, Kap. II), Bd. 16, 1272-1276.

25 Mauser, Geselligkeit (wie Anm. 23, Kap. II), hier 11. 
der Allgemeinheit. ${ }^{26}$ Es galt im Sinne der thomasischen »Privat-Klugheit «, sich selbst und seine tugendhaften Fähigkeiten zu erkennen, zu schulen und in der Praxis einzusetzen, damit die eigene Person im geselligen Umgang wiederum auf andere als Vorbild wirken konnte. ${ }^{27}$ War dies nicht die »Lebens-Art «, die der Adel seit jeher für sich beanspruchte?

Das zu Anfang dieses Kapitels angeführte Zitat des bekannten zeitgenössischen Schriftstellers Johann Michael von Loen (1694-1776), dessen Reisedarstellungen auch in der Bibliothek des Schlosses Dyck zu finden waren, ${ }^{28}$ kann nur aus dieser Perspektive verstanden werden. Es überrascht in diesem Zuge nicht, dass die Frage nach den Ursprüngen der Menschheit und ihrer natürlichen Ordnung für den Adel des Ancien Régime zur Frage nach den Ursprüngen des Standes und der Begründung seiner gesellschaftlichen Vorbildposition wurde.

So veröffentlichte Johann Michael von Loen im Jahr 1752 eine Abhandlung mit dem Titel »Der Adel «. ${ }^{29}$ Loen widmete diese rund 500 Seiten lange Schrift seinen vier "nach Tugend und Weisheit als dem wahren Adel strebenden « Söhnen Johann Michael, Johann Wolfgang, Rudolph Emmanuel und Johann Just von Loen. ${ }^{30}$ In der Abhandlung rekapitulierte Loen, der selbst an der Universität Halle bei Thomasius studiert hatte, für seine Kinder die Herkunft allen Adels und seine verschiedenen Ausprägungen. Wie Loen bereits zu Beginn für seine Söhne feststellte, hing für ihn die Herkunft allen Adels entscheidend von der Fähigkeit eines Menschen zur Tugendhaftigkeit $\mathrm{ab}^{31}$ - womit er auf einen lange gepflegten Topos des Adels zurückgriff. ${ }^{32}$

Auch das Titelkupfer des Werks illustriert diesen Vorzug: Dort ist ein nach römischer Art gekleideter Patrizier vor einer wilden Landschaft zu sehen. Ein Fluss trennt ihn von einer Rotte wilder Tiere, die von einem Löwen abwärts in ihren körperlichen Dimensionen kleiner wird und bei zwei im Dreck kriechenden Schlangen endet. Über dem Bild erscheint die Losung "Volunt sed non possunt«. Der zeitgenössische Leser konnte hieraus bereits im Vorhinein schließen, dass Adel nach gewissen Fertigkeiten verlangte, die auch von natürlichen Voraussetzungen eines Geschöpfes abhingen. In der regelmäßig abgestuften Reihung

26 Vgl. Mauser, Geselligkeit (wie Anm. 23, Kap. II), hier 11.

27 Vgl. Ders., Geselligkeit (wie Anm. 23, Kap. II), 11-13.

28 Vgl. hierzu Senator \& Hanstein, Auktion 66: Bibliothek Schloss Dyck und weitere wertvolle Bücher, Druckgraphik, Handzeichnungen, Autographen, 14.-15.09.1992, 2. Teil, Köln 1992, Nr. 156.

29 Siehe Loen, Der Adel (wie Anm. 22, Kap. II).

30 Ders., Der Adel (wie Anm. 22, Kap. II), Widmung o.S.

31 Vgl. Loen, Der Adel (wie Anm. 22, Kap. II), Abh. I, $\$ 2 f ., 3-5$. Zur Beeinflussung Johann Michael von Loens durch seinen Lehrer Thomasius sowie zum Konzept der »Lebens-Art« vgl. auch Helmuth Kiesel, »Bei Hof, bei Höll«. Untersuchungen zur literarischen Hofkritik von Sebastian Brant bis Friedrich Schiller, Tübingen 1979, 199-207.

32 Zum Topos des »Tugend-Adels« im 18. Jh. siehe auch Christian Meier/Werner Conze, Adel, in: Brunner/Conze/Koselleck (Hg.), Geschichtliche Grundbegriffe (wie Anm. 10, Kap. I), 1-48, insb. 16f.; Rogalla von Bieberstein, Adelsherrschaft und Adelskultur (wie Anm. 3, Kap. I), 117f. Graf hält fest, dass »in der frühen Neuzeit [...] die Tugendadellehre die Erörterungen des Adelsthemas« beherrschte. Graf, Adel als Leitbild (wie Anm. 15, Kap. II), 76. 


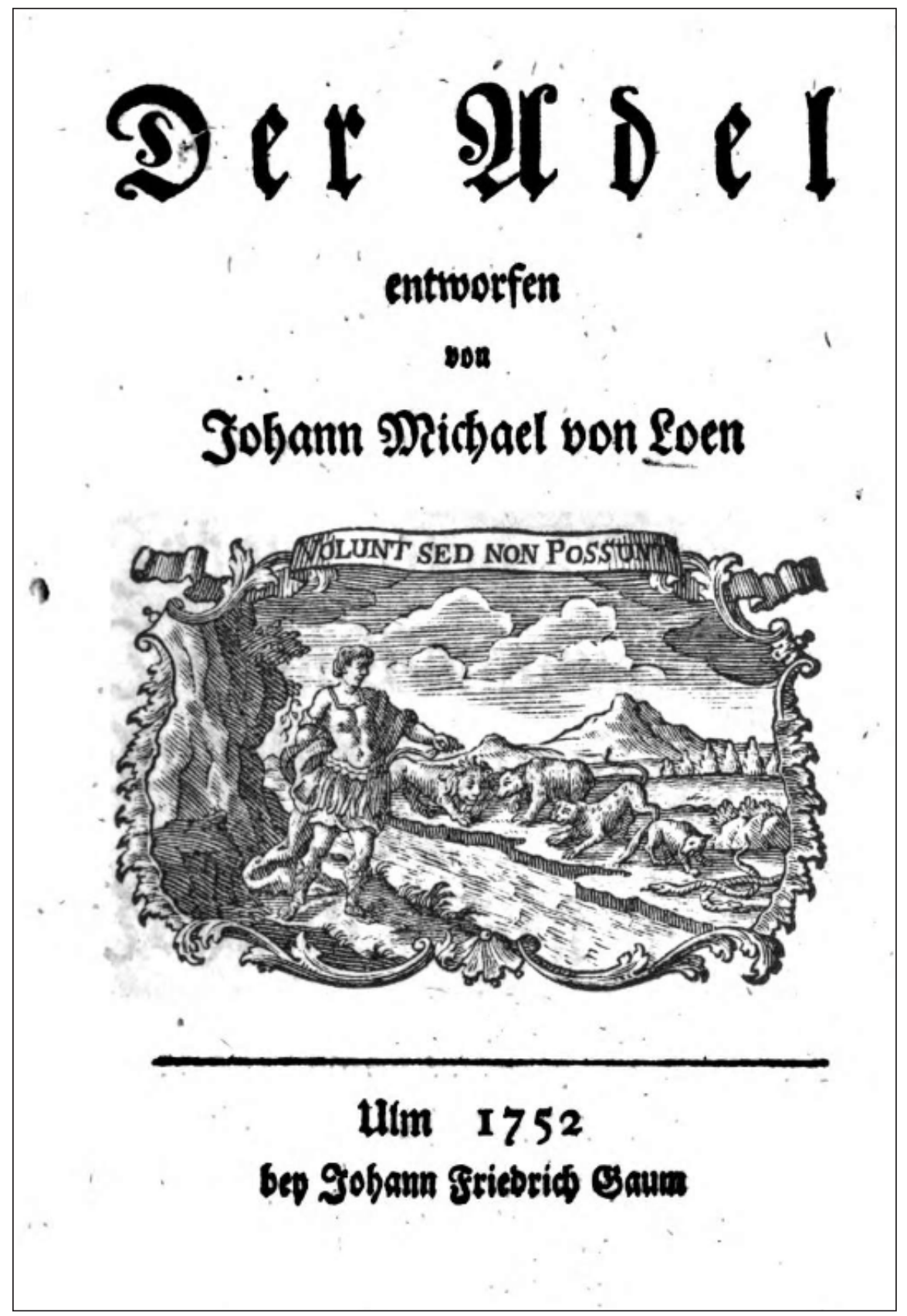

Abbildung 5: Frontispiz zu Johann Michael von Loens „Der Adel«, 1750 (Bildnachweis: BSB München, Sign. 999/Jur.589). 
des Titelkupfers drückt sich der Glaube an eine erhöhte Stellung des von Gott zur Herrschaft über seine Schöpfung auserkorenen Menschen über den weniger fähigen und geschickten Geschöpfen des Tierreichs aus. Ähnlich verhielt es sich auch in der menschlichen Gesellschaft. Der von den Vorfahren innerhalb der menschlichen Gesellschaft ererbte Adel, mahnte Loen seine Söhne aber dennoch bereits in der Zuschrift, »will nichts sagen, wann Ihr nicht denselben durch solche Sitten und durch solche Eigenschaften fortpflanzet, die wahrhaftig edel sind. ${ }^{33}$

In seiner Abhandlung ließ Loen die Gottgegebenheit der Ständeordnung keineswegs fallen. Bereits der Beginn der ersten Abhandlung des Werks »Von dem Ursprung des Adels« macht dies deutlich. Nach einem Zitat aus dem Buch Mose ${ }^{34}$ zeichnete Loen den Ausweg einer von Bosheit eingenommenen Menschheit aus der Urkatastrophe des Sündenfalls nach:

Dem ohngeachtet so keimte doch ein himlischer Saamen in ihnen unmerklich fort. Die Tugend erhielt noch immer ihr heiliges Recht. Ihre Schönheit ist allzu reitzend als daß sie nicht rühren und gefallen solte. Nichts kan ihren Handlungen den Werth, nichts ihrer Unschuld die Annehmlichkeit benehmen. [...] Die lasterhafteste Menschen müssen also in andern diejenige Tugend loben die sie selbst nicht ausüben. Einen so großen Eindruck macht das Gute in der menschlichen Seele. Alle Völcker verehren demnach die Schönheit der Tugend und ehren ihren ewigen Ruhm. ${ }^{35}$

Auf die Tugend war deshalb jeglicher Adel zurückzuführen:

Wie nun die Tugend das eintzige Mittel ist das Unheil der Menschen zu verbessern, so verdienet sie auch die gröste Ehre. Sie allein ist hochgeboren, dann sie stammet vom Himmel. Sie ist ein Strahl des göttlichen Lichts, und ein Abglantz seines Wesens; sie adelt die Seelen und macht die Menschen zu einem göttlichen Geschlecht. Diesen Adel haben alle fromme und weise Leute. $^{36}$

Die Verteilung der Tugendhaftigkeit unter den Menschen war jedoch seit alters her nicht gleichmäßig, wie Loen feststellte: "So gaben es unter dem Volck GOttes vortrefliche Männer, welche der HErr mit besonderer Weisheit und Tugend ausgerüstet hatte. ${ }^{37}$ Hierunter verstand Loen zunächst die großen Gestalten der Bibel, wie etwa den Gesetzgeber Mose oder den auch innerhalb der freimaurerischen Rituale so bedeutenden König Salomon. Letzterer »erhielt seinen hohen Adel mit

33 Loen, Der Adel (wie Anm. 22, Kap. II), Zuschrift, 3f. Zum Titelkupfer siehe Abb. 5.

34 Das Zitat lautet in der Zitation Loens: "Ein allgemeines Verderben hatte sich nach dem Verfall der ersten Menschen über den gantzen Erdboden ausgebreitet. Diese nach GOttes Ebenbild geschaffene denckende Wesen waren gäntzlich von seiner Erkentnis und der damit verknüpften Ordnung abgewichen. Ihre Bosheit war gros und alles dichten und trachten ihres Hertzens böse 1 B. Mo 6, 12.13. Loen, Der Adel (wie Anm. 22, Kap. II), Abh. I, $\$ 1$, If.

35 Loen, Der Adel (wie Anm. 22, Kap. II), Abh. I, $\$ 1,2$.

36 Ders., Der Adel (wie Anm. 22, Kap. II), Abh. I, $\$ 2,3$.

37 Ders., Der Adel (wie Anm. 22, Kap. II), Abh. I, $₫ 3,3$. 
seiner Geburt, dann er bekam eine feine und edle Seele, und übertraf an Weisheit alle Könige der Erden. $\aleph^{38}$ Als höchstes Beispiel der Tugendhaftigkeit fungierte aber Jesus Christus, in dem »die menschliche Natur mit der göttlichen vereiniget « war. ${ }^{39}$

Eine Rechtfertigung der ständischen Gesellschaftsordnung gab Loen in einer Anlehnung an Thomas Hobbes' "Leviathan " und die darin enthaltene Theorie vom bellum omnium contra omnes. Im Kapitel »Von der Einführung der Monarchien und Republicken" ist es der Tugend-Adel in Gestalt »tapferer und weiser Männer «, der die Gesellschaft ordnen und beherrschen kann. ${ }^{40}$ Die Furcht vor den Bedrohungen der Umwelt, die Liebe zum Leben und der Trieb zur Geselligkeit habe schließlich zur Bildung von Gemeinwesen verschiedener Geschlechter geführt, wobei die »Tapfersten zu ihren Beschützern und die Weisesten zu ihren Richtern " gewählt worden waren. ${ }^{41}$ In diesen beiden Funktionen musste ein Adliger des 18. Jahrhunderts zwei Grundaufgaben seines Standes erkennen: das Militärwesen und die Patrimonialgerichtsbarkeit.

Dem »Tugend-Adel« kam in dieser Urform der Gesellschaft damit die Stellung des Weisen zu, der die übrige Menschheit durch sein Beispiel zum tugendhaften Leben anleitete und somit dem Ideal des Weisen innerhalb der thomasischen Philosophie entsprach. Unter $\$ 2$ »Ursprung des Adels« fasste Loen seine Ausführungen zusammen. Der Ursprung des Adels begründete sich resultierend aus den oben zitierten Passagen demnach in der Ehre und dem Ruhm, die einem Menschen von der Gesellschaft aufgrund seiner Tugendhaftigkeit und des hieraus entspringenden Verdienstes um das Gemeinwohl zuerkannt worden waren. ${ }^{42}$ Der an Nachfahren vererbte Ruhm der Tugendhaftigkeit führte zur Entstehung des Geschlechtsadels und der Privilegien. ${ }^{43}$

Das Wissen über die Geschichte des Adels, das Loen an seine Söhne weiterzugeben suchte, entsprach dabei durchaus gängigen Vorstellungen der Aufklärungszeit. Auch die Herleitung des Zedlers aus dem Jahr 1732 ist ähnlich angelegt: »Adel, Ist ein Ehrenstand, welcher um vorhergehnder Tugenden und Verdienste willen von der höchsten Obrigkeit verliehen wird, und auf die Nachkommen erbet. ${ }^{44}$ Der Zedler setzte seine Geschichte des Adels jedoch bei den Römern an. ${ }^{45}$

Neben dieser geschichtlichen Herleitung des Adels, die deutlich auf dem durch die Aufklärer betonten Prinzip des Vorrangs qua Verdienst für die Gesellschaft beruhte, gab es jedoch auch die Berufung auf die besondere Qualität des adligen Blutes. Diese war eng mit der vorigen verwoben. So hielt auch noch ein der Aufklärung zuneigender Adliger wie Loen an dieser bei weitem konservativsten

38 Ders., Der Adel (wie Anm. 22, Kap. II), Abh. I, $\$ 3,4$.

39 Ders., Der Adel (wie Anm. 22, Kap. II), Abh. I, $₫ 3,5$.

40 Ders., Der Adel (wie Anm. 22, Kap. II), Abh. I, $\$ 5,8$.

41 Ders., Der Adel (wie Anm. 22, Kap. II), Abh. I, $₫ 5,8$.

42 Vgl. Loen, Der Adel (wie Anm. 22, Kap. II), Abh. I, \$ 7, 12f.

43 Vgl. Ders., Der Adel (wie Anm. 22, Kap. II), Abh. I, $\$ 7,13 f$.

44 Zedler, Universal-Lexicon (wie Anm. 16, Kap. II), Bd. 1, 467.

45 Vgl. Ders., Universal-Lexicon (wie Anm. 16, Kap. II), Bd. 1, 467. 
Begründung fest. Sie beruhte auf einer nicht in Frage gestellten göttlichen Ordnung der Welt, die sich bereits im Titelkupfer seines Werkes über den Adel finden ließ und auf die im 18. Jahrhundert noch wirkmächtige Vorstellung der »Großen Kette der Wesen ${ }^{46}{ }^{6}$ anspielte, denn: »Er [der Adel, Anm. d. Verf.] ist eine natürliche Folge in der Reyhe der Dinge, da GOtt ein Geschlecht auf Erden vor dem andern empor kommen lässet, um durch dieses Mittel die Ordnung der Stände zu unterhalten. ${ }^{47}$

Eine solche Argumentationsweise erlaubte dem Autor, die Vielschichtigkeit des Adels sowie die ständische Ordnung auf ein göttliches und als solches in den Dingen der Natur offenbar werdendes Prinzip der Vorsehung zurückzuführen. Denn die Tugendhaftigkeit, dies tritt unter $₫ 17$ »Wie man sich seine Vorfahren bekannt machen, und darüber ordentliche Register halten soll? « ${ }^{48}$ verstärkt hervor, wurde insbesondere durch das Blut vererbt:

Es ist kein geringes Vergnügen in einer langen Reihe von vätterlichen und mütterlichen Vorfahren besondere Spuren der göttlichen Vorsehung zu entdecken. Man siehet mit einem frommen Entzücken, wann in diesem oder jenem unsrer Vorfahren ein tugendhafter Saame aufgegangen ist, der sich hernach unter göttlichen Seegen weiter biß auf die Nachkommen fortpflanzet. Man bemercket mit einer gleich demüthigen Ehr=Furcht die göttliche Heimsuchungen, welche sich hin und wieder geäusert, indem eine Linie herunter und die andere empor kommet; Ich beobachte solches mit allem Fleis in den vielen Geschlechtern, deren Blut in dem Meinigen zusammen geflossen ist; Ich suche mir solche folgender Gestalt bekannt zu machen. Ich befleißige mich von einem jeden Geschlecht den Ursprung zu entdecken, und lasse ihre Namen in den Chronicken und Stamm=Registern fleißig nachschlagen. ${ }^{49}$

Blut und das Beispiel des Verhaltens gewährten für Loen somit eine doppelte Fortpflanzung oder Vererbung des tugendhaften Charakters - des maßgeblichen Garanten für alle »Adligkeit«. Dabei war seine Annahme eines im adligen Blut verborgenen »tugendhaften Saamens « sowie sein Bestehen auf einer adligen Heiratspraxis, die diese Qualität des Blutes bei der Wahl der Allianzen beachtete, zur Mitte des 18. Jahrhunderts keineswegs außergewöhnlich. ${ }^{50}$ Ein Adliger mit einer

Siehe hierzu vor allem Arthur O. Lovejoy, Die große Kette der Wesen. Geschichte eines Gedankens, Frankfurt a.M. 1993.

47 Loen, Der Adel (wie Anm. 22, Kap. II), Abh. I, $\$ 7,14$.

48 Vgl. Loen, Der Adel (wie Anm. 22, Kap. II), Abh. IV, \$17, 207-209.

49 Ders., Der Adel (wie Anm. 22, Kap. II), Abh. IV, \$ 17, $207 f$.

$50 \mathrm{Zu}$ Loens Kriterien zur Wahl von Ehepartnern, die - wie unten zu zeigen sein wird - nicht zufällig an eine "Zuchtwahl« erinnern, siehe Ders., Der Adel (wie Anm. 22, Kap. II), Abh. VI, \$13, 307-313. Vgl. zu den im Blut vermuteten »Samen« die Erwähnung bei André Devyver, dass eine ganze Reihe von Autoren des 18. und 19. Jh.s die Formel von der »semence occulte " des Adels aufgriffen. Ders., Le sang épuré. Les préjugés de race chez les gentilshommes français de l'Ancien Régime (1560-1720), Bruxelles 1973, 27. Zur ähnlichen Begrifflichkeit sowie Argumentation französischer Autoren des späten 17. und frühen 18. Jh.s vgl. ferner diverse andere Beispiele in: Ders., Le sang 
langen, ausnahmslos adligen Ahnenreihe genoss in einer derartigen Weltsicht von klein auf einen Vorteil, stammte er doch von tugendhaften Vorfahren ab und wurde zudem durch seinen Umgang mit vornehmen und gesitteten Leuten "mehr Exempel von erhabenen und rühmlichen Handlungen" gewahr als andere Menschen. ${ }^{51}$

\title{
II.3 Lasterhafter Lebenswandel als Dilemma adliger "Blutsideologie»
}

\begin{abstract}
Les exemples du premier tems que nous venons de toucher, font connoître l'ancienneté, l'usage \& la nécessité de la Noblesse; les périls \& les desordres d'un Etat, quand elle cesse d'y occuper le premier rang; \& la même raison qui fait comprendre ce que l'on doit à la vertu, fait sentir qu'elle est plus ordinaire dans les bonnes races que dans les autres.
\end{abstract}

- Henri de Boulainvilliers ${ }^{52}$

Die alte Diskussion um die Rechtfertigung und Möglichkeiten einer Vererbung des Adels ist im Werk Loens offensichtlich. ${ }^{53}$ Im Folgenden soll gezeigt werden, dass seine Berufung auf die adlige »Blutsideologie« im Jahr 1752 nicht zufällig war. Dabei bestritt Loen in seiner Abhandlung keinesfalls juristische oder anderweitige Begründungen des Adels - so auch die Möglichkeit, den Adelstitel mittels Geld zu erkaufen. ${ }^{54} \mathrm{Er}$ sprach sich jedoch trotz dieser Wege explizit gegen eine Abschaffung ständischer Schranken aus. ${ }^{55}$ War die Ständeordnung doch - wie oben gezeigt - göttlichen Ursprungs und als solche nicht in Frage zu stellen.

Die Klitterung der ultrakonservativen Ideologie des adligen Bluts mit Elementen des Aufklärungsdiskurses, wie sie uns hier in Loens Schrift exemplarisch entgegentritt, ist für die Zeit um 1750 weder für Deutschland noch für andere Länder ungewöhnlich. Wie der französische Historiker Pierre Serna auch für den französischen Adel dargestellt hat, handelte es sich vielmehr um einen Weg,

épuré (wie Anm. 50, Kap. II), etwa 102f.; Guillaume Aubert, Kinship, Blood and the Emergence of the Racial Nation in the French Atlantic World, 1600-1789, in: Christopher Howard Johnson [u.a.] (Hg.), Blood \& Kinship. Matter for metaphor from ancient Rome to the present, New York [u.a.] 2013, 175-195, hier insb. 178f.

51 Loen, Der Adel (wie Anm. 22, Kap. II), Abh. VI, \$ 14, 314.

52 Henri de Boulainvilliers, Essais sur la noblesse de France contenans une dissertation sur son origine \& abaissement, Amsterdam 1732, hier 7, Permalink: http://nbn-resolving.org/ urn:nbn:de:bvb:12-bsb10416687-3 (Zugriff vom 24.05.2014).

53 Siehe zu früheren Beispielen dieser Diskussion in der Frühen Neuzeit etwa Barbara Stollberg-Rilinger, Gut vor Ehre oder Ehre vor Gut? Zur sozialen Distinktion zwischen Adels- und Kaufmannsstand in der Ständeliteratur der Frühen Neuzeit, in: Johannes Burkhardt (Hg.), Augsburger Handelshäuser im Wandel des historischen Urteils (Colloquia Augustana, 3), Berlin 1996, 31-45, hier insb. 39f.

54 Siehe hierzu bspw. Loen, Der Adel (wie Anm. 22, Kap. II), Abh. VII, § 5, 337f. Eine völlige Ablehnung bürgerlicher Betätigungen war für Loen wohl aufgrund seiner Abstammung von einer niederländischen Kaufmannsfamilie nicht möglich.

55 Vgl. hierzu etwa Ders., Der Adel (wie Anm. 22, Kap. II), Abh. VII, §5, $326 f$. 
den Teile des Adels zur Mitte des 18. Jahrhunderts eingeschlagen hatten, um den Verdienstdiskurs der Aufklärung mit der althergebrachten und in Verruf geratenen Ideologie des adligen Blutes auszugleichen.${ }^{56}$ Letzterer lag die Auffassung zugrunde, dass der Adel eine »historisch privilegierte und biologisch höherstehende Gruppe « der Menschheit bilde, wobei in Frankreich die 1732 erschienene Geschichte des französischen Adels von Henri de Boulainvilliers diese Ansicht befördert hatte, indem sie einen Gegensatz zwischen den beiden "Rassen« des französischen Adels auf der einen und des französischen Volks auf der anderen Seite propagierte. ${ }^{57}$ Der Höhepunkt dieser Entwicklung war in Frankreich bereits vor der Veröffentlichung Boulainvilliers' »um die Wende zum 18. Jahrhundert« erreicht. ${ }^{58}$

Dieser auf den Adel gemünzte Rassenbegriff hatte sich in Frankreich vor allem im politischen Streit über die Stellung der noblesse de robe und der noblesse de race/noblesse de sang herausgebildet. Der Rassenbegriff wurde hierbei zunächst in erster Linie als ein »historisches Konzept « verstanden..$^{59}$ So gründete auch Boulainvilliers' Herleitung nicht auf einer modern-biologischen, sondern vielmehr einer angenommenen wesensmäßigen Nachfolge des französischen Adels von den Nachfahren des westgermanischen Stammes der Franken, die aufgrund ihres im Blut gründenden, freiheitsliebenden Charakters zur Herrschaft über die gallo-romanischen Ureinwohner des Landes bestimmt gewesen seien, welche schließlich den dritten Stand gebildet hätten. ${ }^{60}$ Abseits des historischen Konzepts scheint hier eine andere Feststellung Boulainvilliers wichtiger. Er wollte 1732 eine europäische opinio communis über die Voraussetzung des Adels ausgemacht haben, wenn er bemerkte: »TANT il est vrai que toute l'Europe Occidentale concourre dans un sentiment commun, quoique non distinctement \& uniformément exprimé, de CARACTERISER la Noblesse par l'avantage du sang \& d'une naissance illustre, aussi ancienne que la Royauté. ${ }^{61}$ Diese - wie später zu zeigen sein wird - im Kern keineswegs neue opinio communis um die Vortrefflichkeit des adligen Blutes ${ }^{62}$ so-

56 Vgl. Serna, Der Adlige (wie Anm. 36, Kap. I), hier 87-94.

57 Ders., Der Adlige (wie Anm. 36, Kap. I), hier 87; Geulen, Geschichte des Rassismus (wie Anm. 37, Kap. I), 49. Bei dem hier wiedergegebenen Zitat aus dem Text Sernas handelt es sich um eine deutsche Übersetzung einer Feststellung Devyvers zu Boulainvilliers' Einfluss. Siehe daher auch Devyver, Le sang épuré (wie Anm. 50, Kap. II), 353-390.

58 Ders., Der Adlige (wie Anm. 36, Kap. I), hier 87. Vgl. auch Wrede, Zwischen Mythen, Genealogen und der Krone (wie Anm. 4, Kap. I), hier 39-41.

59 Geulen, Geschichte des Rassismus (wie Anm. 37, Kap. I), 48f. Siehe zum Rassenbegriff bei Boulainvilliers als historischem Konzept außerdem Marco Schütz, Rassenideologien in der Sozialwissenschaft (Contacts: Sér. 2, Gallo-Germanica, 11), Diss., Bern [u.a.] 1994, 42f.

$60 \mathrm{Zu}$ sämtlichen Angaben dieses Abs. vgl. Geulen, Geschichte des Rassismus (wie Anm. 37, Kap. I), 48f.; Serna, Der Adlige (wie Anm. 36, Kap. I), hier 87. Zum Nachleben der Theorie Boulainvilliers' im 19. Jh. bei Joseph-Arthur de Gobineau vgl. Devyver, Le sang épuré (wie Anm. 50, Kap. II), 432437.

61 Boulainvilliers, Essais sur la noblesse (wie Anm. 52, Kap. II), 47.

62 Vgl. hierzu überblicksartig bzw. mit weiteren Beispielen dieser Auffassung im europäischen Adel: Devyver, Le sang épuré (wie Anm. 50, Kap. II); George L. Mosse, Die Geschichte des Rassismus in Europa, Frankfurt a.M. 1990; Ronald G. Asch, Europäischer Adel in der Frühen Neuzeit. Eine 
wie einer adligen Geburt gewann im weiteren Verlauf des 18. Jahrhunderts mit der Aufklärung und den aus ihr allmählich hervorgehenden anthropologischen Theorien um die Unterteilung der Menschheit in »Rassen" aus Sicht des Adels zunächst an Schlagkraft - obgleich insbesondere die Ideologie des adligen Blutes durch Teile des Bürgertums heftig kritisiert wurde.

In diesem Zusammenhang ist es wichtig zu betonen, dass der Rassenbegriff des 18. Jahrhunderts mehr als vage war. Noch bis zum Ende des 18. Jahrhunderts verwies er, um mit den Worten Christian Geulens zu sprechen, auf »eine Art geheimes Wissen, auf eine verborgene Wahrheit«, war »Rasse [...] Ausdruck für das im Blut liegende und damit gerade nicht unmittelbar sichtbare, sondern in den Tiefen der Herkunft und Abstammung verborgene Wesen einer bestimmten Gruppe von Menschen. ${ }^{63}$ Es lohnt daher, sich zunächst die wesentlichen Theorien des 18. Jahrhunderts zur "Rassengenese« anhand der Ausführungen bereits vorliegender geschichtswissenschaftlicher Untersuchungen in Auszügen zu vergegenwärtigen.

Für eine Entwicklung eines geschichtlich wie biologisch begründeten Rassenbegriffs war die im 18. Jahrhundert viel diskutierte Frage nach dem Ursprung der Menschheit von einiger Wichtigkeit. Im Wesentlichen standen sich zu dieser Zeit die Vertreter der Theorien des Monogenismus und des Polygenismus gegenüber - wobei die Akzeptanz des Polygenismus erst zum Ende des 18. Jahrhunderts bedeutend wurde. ${ }^{64}$ Die Monogenisten gingen davon aus, dass die Menschheit von einem einzigen Urelternpaar abstammte, wie etwa den biblischen Gestalten Adam und Eva, während ihre Gegner, die Polygenisten, an die Existenz mehrerer solcher Urelternpaare glaubten, die etwa als »Präadamiten« noch vor Adam und Eva existiert haben sollten. Von einer endgültigen Beantwortung der Ursprungsfrage erhofften sich die Zeitgenossen nicht nur eine Erklärung für das Vorhandensein

Einführung, Köln/Weimar/Wien 2008, 47-51. Zu weiteren Hinweisen und Untersuchungen zur »Blutsideologie« (»limpieza de sangre«) im Spanien der Frühen Neuzeit siehe insb. Max Sebastián Hering Torres, Rassismus in der Vormoderne: die »Reinheit des Blutes« im Spanien der Frühen Neuzeit, Frankfurt a.M. 2006, insb. 65-72. Der Autor zeigt hierin nicht nur die Bedeutung der "Blutsideologie« für den spanischen Adel in Ritterorden auf, sondern auch in anderen Lebensbereichen, wie etwa bei den Abschlüssen von Studenten an Universitäten, die auch an genealogische Qualitäten geknüpft wurden. Ein kürzerer Beitrag der jüngeren Zeit, der über Spanien hinausblickt, besteht in: Nikolaus Böttcher, Ahnenforschung in Hispanoamerika. »Blutsreinheit« und die Castas-Gesellschaft in Neu-Spanien im 18. Jh., in: Harding/Hecht (Hg.), Die Ahnenprobe in der Vormoderne (wie Anm. 4, Kap. I), 387-413. Zur Ummünzung des Rassenbegriffs auf das Bürgertum durch Augustine Thierry im postrevolutionären Frankreich vgl. Geulen, Geschichte des Rassismus (wie Anm. 37, Kap. I), 49 sowie 54.

63 Geulen, Geschichte des Rassismus (wie Anm. 37, Kap. I), 38. Siehe auch Wrede, Ohne Furcht und Tadel (wie Anm. 4, Kap. I), 19; Diego Venturino, Race et histoire. Le paradigme nobiliaire de la distinction sociale au début du XVIII ${ }^{\mathrm{e}}$ siècle, in: Sarga Moussa (Hg.), L'idée de »race« dans les sciences humaines et la littérature (XVIII et XIX ${ }^{e}$ siècles), Paris/Budapest/Torino 2003, 19-38, hier insb. 26-34.

64 Vgl. Geulen, Geschichte des Rassismus (wie Anm. 37, Kap. I), 52. 
verschiedener Völker, sondern letztlich der göttlichen Gesetze, die deren Entwicklung bestimmten. ${ }^{65}$

Die Frage, die sich den Zeitgenossen stellte, war die nach einer Erklärung für die unterschiedlichen Wesensmerkmale und Hautfarben der Menschen ${ }^{66}$ - die gängige Annahme vorausgesetzt, dass Adam und Eva hellhäutig gewesen waren. ${ }^{67}$ Ein tradiertes Modell zur Klärung dieser Frage fußte, wie bereits der Glaube an ein Urelternpaar, auf der Deutung des Buches Genesis. Nach dieser Deutung hatten sich die verschiedenen Völker nach der Sintflut aus den Nachkommen der drei Söhne Noahs - Sem, Ham und Jafet - entwickelt, wobei Sem als der Stammvater der Völker des »Nahen Ostens« galt, Ham insbesondere die afrikanischen Ethnien begründete haben sollte und schließlich Jafet zum Stammvater der Europäer erklärt wurde. ${ }^{68}$

Aus der biblischen Überlieferung ließen sich für die Zeitgenossen ergänzend hierzu moralisch-qualitative Aussagen ableiten. Da Noah Hams Geschlecht in der biblischen Überlieferung zur Knechtschaft verflucht hatte und auch die Nachfahren Sems, in Folge der Kreuzigung Jesu, als mit Makel behaftet galten, konnte hiermit lange Zeit sowohl die Versklavung dunkelhäutiger Menschen als auch eine gesellschaftliche Ächtung der Juden gerechtfertigt werden. ${ }^{69}$ Als moralisch höchststehender und durch Gott am meisten begünstigter Sohn erschien bei dieser Interpretation des biblischen Textes Jafet - der Urvater der Europäer. ${ }^{70}$ Dass sich die verschiedenen Menschenvölker in der Hautfarbe, aber auch von ihren charakterlichen Eigenschaften her unterschieden, wollten die Monogenisten des 18. Jahrhunderts in Ergänzung zur biblischen Überlieferung auf die direkten Einwirkungen der sozialen wie klimatischen Bedingungen der Umwelt zurückgeführt wissen. ${ }^{71}$

In den naturkundlichen Werken eines Georges-Louis Leclerc, comte de Buffon (1707-1788) oder des Schweden Carl von Linné (1707-1778) konnte darüber hinaus die Richtigkeit der Ständeordnung auch im Spiegel der verschiedenen

$65 \mathrm{Zu}$ allen in diesem Abs. gemachten Angaben sowie insb. den beiden Theorien des Monogenismus und Polygenismus vgl. auch Christiane Küchler Williams, Erotische Paradiese. Zur europäischen Südseerezeption im 18. Jh., Göttingen 2004, 59-66; Urs Bitterli, Die »Wilden« und die »Zivilisierten«. Grundzüge einer Geistes- und Kulturgeschichte der europäisch-überseeischen Begegnung, München 1976, 327-343.

66 Vgl. hierzu Ders., Die »Wilden« und die »Zivilisierten« (wie Anm. 65, Kap. II), 328f.

67 Vgl. Carl Jung, Kaross und Kimono. »Hottentotten« und Japaner im Spiegel des Reiseberichts von Carl Peter Thunberg (1743-1828) (Beiträge zur Kolonial- und Überseegeschichte, 85), Diss., Stuttgart 2002, 244.

68 Hering Torres, Rassismus in der Vormoderne (wie Anm. 62, Kap. II), 183f.; Bitterli, Die »Wilden« und die "Zivilisierten (wie Anm. 65, Kap. II), $340 f$.

69 Vgl. Hering Torres, Rassismus in der Vormoderne (wie Anm. 62, Kap. II), $183 \mathrm{f}$.

70 Siehe hierzu Jung, Kaross und Kimono (wie Anm. 67, Kap. II), 243f.

71 Vgl. hierzu etwa die Ausführungen des Zedler im Artikel »Volck«: Zedler, Universal-Lexicon (wie Anm. 16, Kap. II), Bd. 50, 362-375, hier insb. 370-373. 
Rangstufen der Geschöpfe in der Natur abgelesen werden. ${ }^{72}$ So hieß es etwa in der Abhandlung über das Pflanzenreich zu den Palmen: "Sie machen die Fürsten unter den Pflanzen aus, sind die Höchsten unter allen, haben einen sehr einfachen Stamm, welcher mit einer immergrünen Krone versehen ist. Sie nähren die Menschen, und besonders die Bewohner ihrer Gegenden. ${ }^{73}$ Und während die Gräser nach Linné nur das "gemeine Volk« und die »Bauern« des Pflanzenreichs darstellten, waren die Lilien "als der hohe Adel unter ihnen zu betrachten. ${ }^{74}$

Die linnésche Naturgeschichte mit ihrer Verteidigung der Präformationslehre $^{75}$ und extensiven Einteilung der Geschöpfe in Arten war somit kein Hindernis für die adlige »Blutsideologie«, zielte sie doch letztlich noch darauf, die Natur als »genealogischen Staat « zu erklären, in dem Herkunft und Abstammung entscheidende Kriterien für die gesellschaftliche Stellung eines Geschöpfes waren. ${ }^{76}$ In der linnéschen Naturbetrachtung lebte die aristotelische Idee von der »Großen Kette der Wesen « und die mit dieser verbundene Vorstellung eines konstanten und kontinuierlichen Übergangs der verschiedenen Geschöpfe in immer höhere Seins-Ordnungen fort. ${ }^{77}$ Auch wenn die Idee der »Großen Kette der Wesen« bis zum Ende des 18. Jahrhunderts wirksam bleiben sollte, verstärkte sich das bereits seit langem bestehende Dilemma ${ }^{78}$ der adligen »Blutsideologie» mit

72 Vgl. Lepenies, Das Ende der Naturgeschichte (wie Anm. 38, Kap. I), 151-160. Linné - wenn auch kein Verfechter der Klimatheorie - sprach der hellhäutigen bzw. »kaukasischen Rasse« alle positiven Eigenschaften zu, die zur Herrschaft über die Welt befähigten, und sah als unterstes Glied der Menschheit dunkelhäutige Menschen an. Vgl. hierzu etwa Mosse, Die Geschichte des Rassismus (wie Anm. 62, Kap. II), 45f. Ein Porträt Linnés (Ölgemälde von Alexander Roslin, 1775) findet sich unter: commons.wikimedia.org/wiki/File:Carl_von_Linné.jpg (Zugriff vom 07.08.2014). Ein Porträt Buffons (Ölgemälde von François-Hubert Drouais, 1753) findet sich unter: commons.wiki media.org/wiki/File:Buffon_1707-1788.jpg (Zugriff vom 07.08.2014).

73 Carl von Linné, Des Ritters Carl von Linné Pflanzensystem nach seinen Klassen, Ordnungen, Gattungen und Arten mit den Erkennungs und Unterscheidungszeichen, 14. Aufl., Wien 1786, II, Permalink: http://nbn-resolving.org/urn:nbn:de:bvb:12-bsb10302318-7 (Zugriff vom 25.05.2014).

74 Linné, Des Ritters Carl von Linné Pflanzensystem (wie Anm. 73, Kap. II), II.

75 Die Präformationslehre besagte, dass innerhalb des männlichen Samens oder der weiblichen Eizelle bereits vor der Geburt des Kindes sein Körper in Miniaturform vorgebildet sei und mithin nach der Einnistung nur noch heranwachsen musste.

76 Siehe zum Begriff des "genealogischen Staats« sowie zur Thematik allgemein Staffan Müller-Wille, Genealogie, Naturgeschichte und Naturgesetz bei Linné und Buffon, in: Heck/Jahn (Hg.), Genealogie als Denkform (wie Anm. 4, Kap. I), 109-119, hier 118f. Verwiesen sei auch auf den Aufsatz im selben Bd. von Sara Paulson Eigen, A Mother's Love, a Father's Line: Law, Medicine and the $18^{\text {th }}$-Century Fictions of Patrilineal Genealogy, in: Dies., Genealogie als Denkform (wie Anm. 4, Kap. I), 87-107.

77 Vgl. hierzu Lovejoy, Die große Kette der Wesen (wie Anm. 46, Kap. II), insb. 274-291. Aufschlussreich auch für Linnés Ansichten über die Konstanz der Arten: Hans-Peter Müller, Johann Beckmann und Carl von Linné. Anmerkungen zu einer prägenden Begegnung, in: Günter Bayerl/Jürgen Beckmann (Hg.), Johann Beckmann (1739-1811). Beiträge zu Leben, Werk und Wirkung des Begründers der Allgemeinen Technologie (Cottbuser Studien zur Geschichte von Technik, Arbeit und Umwelt, 9), Münster [u.a.] 1999, 87-104, hier insb. 93f.

78 Dass es offenbar unmöglich war, die zur Tugendhaftigkeit führenden Eigenschaften im Akt der menschlichen Fortpflanzung sicher zu vererben, wird bereits im "Adels-Spiegel « des Cyriacus Spangenberg von 1591 erwähnt. Grundsätzlich räumt Spangenberg zwar angeerbte Tugenden und Laster ein, führt jedoch ebenfalls an, dass aus tugendhaften Eltern lasterhafte Kinder hervorgehen 
dem Fortschritt der sich intensivierenden Naturforschung, wie an späterer Stelle noch zu zeigen sein wird. Mit dem zur Mitte des 18. Jahrhunderts an Linné, aber auch dem später noch zu erwähnenden Georges-Louis Leclerc, comte de Buffon, geschulten Wissen über die Natur ließen sich die scheinbar in der Welt angelegten göttlichen Ordnungsschemata aus Sicht des Adels zunächst noch zugunsten des zweiten Standes ablesen. Die Beteiligung des Adels an der Naturforschung - eine Ausbildung in Naturgeschichte und Zoologie sowie das Botanisieren waren beim Adel zur moralischen und intellektuellen Bildung in dieser Zeit sehr attraktiv ${ }^{79}$ war insofern auch der Versuch, die hergebrachte Selbstsicht des Standes mit neuen Mitteln zu bestätigen.

Denn grundsätzlich - und dies ist in Bezug auf die »Blutsideologie« des Adels entscheidend - konnte man im 18. Jahrhundert im Sinne der linnéschen Naturgeschichte annehmen, dass es verschiedene "Artungen " von Tieren und Menschen gab, die ihren Anlagen entsprechend mehr oder weniger zu Lastern neigten. ${ }^{80}$ Es hing von den persönlichen Handlungen und dem individuellen Umfeld in der Gegenwart ab, ob der Weg der Tugend abseits der Sünde beschritten werden konnte. Doch es war ebenso offensichtlich, dass die Abstammung von adligen Eltern nur schwer als alleiniger Garant für einen tugendhaften Lebenswandel gesehen werden konnte - wie sich im 18. Jahrhundert etwa bereits anhand der Kritik an den Ausschweifungen reisender Kavaliere zeigen ließ. In Bezug auf die diesbezüglich verschiedenen "Artungen" von Tieren und Menschen führt Stefan Borchers in seiner Dissertation ein aufschlussreiches Zitat Siegmund Jacob Baumgartens aus dem Jahr 1738 an, das auch hier wiedergegeben werden soll. Bei Baumgarten heißt es:

können. Grundsätzlich stellt er jedoch fest, dass das Laster eher das Laster hervorbringt und sogar noch verstärkt. Siehe hierzu Cyriacius Spangenberg, Adels-Spiegel. Historischer ausführlicher Bericht: Was Adel sey und heisse/ Woher er kome/ Wie mancherley er sey [...], Bd. 1, Schmalkalden 1591, 31v, Permalink: http://digi.ub.uni-heidelberg.de/diglit/drwspangenberg1591 (Zugriff vom 25.05.2014). Zur Einordnung der Schrift Spangenbergs als Entgegnung auf Nicodemus Frischlins Adelskritik in den 1580er Jahren siehe Horst Carl, Genossenschaft und Herrschaftsverdichtung. Zur politischen Kultur von Adelseinungen im Alten Reich, in: Ronald G. Asch/Dagmar Freist (Hg.), Staatsbildung als kultureller Prozess. Strukturwandel und Legitimation von Herrschaft in der Frühen Neuzeit, Köln 2005, 405-428, hier $425 f$.

79 Vgl. zur Beliebtheit des Botanisierens sowie der Naturgeschichte als Teil der adligen Ausbildung Heide Düselder, Vom »Botanisieren« und der »Nützlichkeit der Natur«. Naturaneignung und Herrschaftsverständnis des Adels im Kontext von Kultur, Bildung und Ökonomie, in: Dies./Weckenbrock/Westphal (Hg.), Adel und Umwelt (wie Anm. 20, Kap. II), 19-50, hier 29-38.

80 Borchers verweist hierzu etwa auf die bereits bei Augustinus gebräuchliche Analogie zwischen Pflanzenveredelung und Vererbung der menschlichen Erbsünde. Demnach konnten auch veredelte Pflanzen mitunter unedle Samen, so wie getaufte und damit von der Erbsünde reingewaschene Eltern wiederum mit der Erbsünde behaftete Kinder hervorbringen. Vgl. Stefan Borchers, Die Erzeugung des "ganzen Menschen«. Zur Entstehung von Anthropologie und Ästhetik an der Universität Halle im 18. Jh., Berlin/New York 2011, 182f. Hierzu ist zu ergänzen, dass Karl Schmid innerhalb seiner Studien zur Bedeutung des königlichen Geblüts im Mittelalter festhält, dass sich die »Blutsideologie« zu dieser Zeit ebenfalls auf das »Wort „vom guten Baum« «berief. Karl Schmid, Geblüt, Herrschaft, Geschlechterbewusstsein. Grundfragen zum Verständnis des Adels im Mittelalter (Vorträge und Forschungen, 44), Sigmaringen 1998, insb. 19-49. 
So wenig aber bey Thieren, was ihnen durch Kunst oder Gewohnheit beygebracht wird, vermittelst der Fortpflantzung auf die Jungen übergehet, weil solches nicht zur Einschränckung ihrer Natur gehört; so wenig wird die übernatürliche Besserung frommer Eltern auf ihre Kinder fortgepflantzt; obgleich bey solcher natürlichen Zeugung verschiedene Einschränckung dieses Verderbens vorgehen kan, so aus den angeerbten stärckern natürlichen Neigungen zu gewissen Lastern bey manchen Personen unläugbar ist. ${ }^{81}$

Auffallend scheint hier vor allem die »übernatürliche Besserung«. Da der gängigste Legitimationsversuch um die ursprüngliche Herkunft des Adels auf einer Ehrzuweisung an einen besonders tugendhaften Vorfahren fußte, konnten adlige Personen auch vom Stand der zeitgenössischen Naturwissenschaften her für sich in Anspruch nehmen, von ihren Anlagen her eher zur Tugend als zum Laster zu neigen. Entscheidend war in dieser Hinsicht zunächst also, welche Wege der Erziehung zu ihrer weiteren Veredelung bzw. einem Verbleib auf einem tugendhaften Pfad des Lebens eingeschlagen werden konnten, damit der edle »tugendhafte Saame« nicht zu einem unedlen wurde und eine weitere »übernatürliche Besserung« vonstattenging.

\title{
II.4 Das »Esoterische« in seiner Beziehung zur adligen Memoria
}

\begin{abstract}
Als Konsequenz aus all dem ergibt sich, dass man einen Esoterikbegriff braucht, der nicht nur Kontinuitäten abbildet, sondern der auch die Dynamik und Prozessualität von Identitätsbildung, die diskursiven Transfers zwischen einzelnen Bereichen europäischer Kultur - vor allem zwischen Religion, Naturwissenschaft, Philosophie, Literatur und Kunst - ins Kalkül zieht.
\end{abstract}

- Kocku von Stuckrad ${ }^{82}$

Das Zusammenspiel der oben dargestellten Traditions-, Meinungs- und Wissensbestände des teils auf unterschiedlichen gesellschaftlichen Ebenen ablaufenden Adelsdiskurses in der ersten Hälfte des 18. Jahrhunderts zeigt bereits typische Bestandteile des »Esoterischen« auf. Als »Dreh- und Angelpunkt aller esoterischen Traditionen « stellt Stuckrad »Erkenntnisansprüche, die auf das [...] absolute Wissen abheben, und die Modi, dieses Wissen verfügbar zu machen«, heraus. ${ }^{83} \mathrm{Er}$ fasst zusammen:

Die Modi, in denen sich ein Diskurs absoluter Erkenntnis entfaltet, haben mit der Dialektik von Verborgenem und Offenbartem zu tun, also durchaus mit `Geheimnis`, jedoch nicht in dem Sinne, dass die esoterische Wahrheit nur Eingeweihten zugänglich ist. Was einen Diskurs esoterisch macht, ist

81 Zitiert nach Borchers, Die Erzeugung des "ganzen Menschen« (wie Anm. 80, Kap. II), 183.

82 Stuckrad, Was ist Esoterik? (wie Anm. 34, Kap. I), 20.

83 Ders., Was ist Esoterik? (wie Anm. 34, Kap. I), 21. 
die Rhetorik einer verborgenen Wahrheit, die auf einem bestimmten Weg enthüllt werden kann und gegen andere Deutungen von Kosmos und Geschichte - nicht selten die der institutionalisierten Mehrheit - in Stellung gebracht wird. ${ }^{84}$

Gerade die letztgenannte Eigenschaft stellt sich als zutiefst verwoben mit den oben dargestellten Rechtfertigungsversuchen der "Adligkeit « dar, wie sie sich noch in der ersten Hälfte des 18. Jahrhunderts zeigten. Denn die historische bzw. naturgeschichtliche Erforschung des Themas ist als der zeitgenössische Modus zu sehen, durch den die sewige Wahrheit des Adels etwa in Erziehungsschriften oder mit Hilfe der Genealogie enthüllt und insbesondere ihren Kritikern als gerechtfertigt präsentiert werden sollte.

Es galt dabei aus Sicht der Elterngeneration den jungen Adligen mit Hilfe der Memoria darzulegen, dass der Adel immer schon Teil der menschlichen Gesellschaft gewesen war. Sowohl die oben erläuterten Umstände bei der Weitergabe von familieninternem Wissen im adligen Umfeld als auch die Ansichten und Herleitungsversuche zum Ursprung und der Vererbbarkeit von »Adligkeit « in den oben beschriebenen Kontexten erfüllen aus diesem Grund den für das »Esoterische« ebenfalls typischen Modus der "Mediation « des Wissens über eine »Kette von >Eingeweihten und Weisen $«{ }^{85}$ Dieser Umstand tritt um das Jahr 1750 im adligen Ritus der Kavalierstour und seiner mythologische Gestalten einbeziehenden Form der Memorierung ebenso hervor wie in den Erziehungsschriften und den ebenso weit ausgreifenden adligen Stammbäumen. Durch die hiermit zusammenhängenden geblütsmagischen Vorstellungen konnte der Adlige dieser Zeit nicht nur den göttlichen Willen zur Beherrschung der Gesellschaft durch eine >ewige Eliteくvon tugendhaften »Weisen « in seiner Person erneut zur Ausprägung gelangt sehen, sondern sich auch als jüngstes Glied einer langen Kette von ähnlich tugendhaften Vorfahren begreifen. Die Aufgabe dieser Elite sollte es sein, ihre Vorbildwirkung auf die folgende Generation der Familie sowie auf die Gesellschaft im Allgemeinen zu entfalten und gleichzeitig die Akzeptanz dieses offenbarten >Geheimnisses der Adligkeit ‘ zu erhalten. ${ }^{86}$

Was eine solche esoterische Position der Adelsbegründung anbelangte, zielte bereits um 1750 alles auf eine »Veredelung des Adels«, wie sie auch noch zum Ende des 18. Jahrhunderts diskutiert wurde. ${ }^{87}$ Wie im Folgenden gezeigt werden soll, nahmen Teile des Adels wie auch des Bürgertums in Ergänzung zu der oben dargestellten Form der Adelsbegründung das Bestehen einer philosophia perennis an.

84 Ders., Was ist Esoterik? (wie Anm. 34, Kap. I), 21.

85 Vgl. zu den hier angeführten Begrifflichkeiten Ders., Was ist Esoterik? (wie Anm. 34, Kap. I), $21 f$.

86 Die treffende Bezeichnung Reifs für den Adel des 19. Jh.s als »Meister des Sichtbaren « trifft so wohl verstärkt auch auf den Adel der Frühen Neuzeit zu. Vgl. zu dieser Bezeichnung Reifs: Heinz Reif, Einleitung, in: Ders. (Hg.), Adel und Bürgertum in Deutschland, Bd. 1: Entwicklungslinien und Wendepunkte im 19. Jh. (Elitenwandel in der Moderne, 1), 2. Aufl., Berlin 2008, 7-28, hier 14.

87 Zur Hoffnung des Bürgertums auf eine »Veredelung des Adels« zum Ende des 18. Jh.s bzw. zu Beginn des 19. Jh.s siehe Ders., Adel im 19. und 20. Jh. (Enzyklopädie deutscher Geschichte, 55), München 1999, 100. 
Von dieser glaubte man, dass sie auf den Weisheiten adliger Urväter beruhte und eine stetig fortschreitende seelisch-charakterliche Veredelung eines Eingeweihten herbeiführen konnte. Von diesem ewigen Wissen nahmen nicht nur die gebildeten Teile des Bürgertums an, dass es seit den Urzeiten der Menschheit mehr und mehr in Vergessenheit geraten war. Die Rückentdeckung des mit der Zeit korrumpierten Wissens einer solchen Urreligion verband daher zunächst jene Teile der adligen und bürgerlichen Gesellschaft, die sich als eine "geistige Elite« betrachteten, die von Gott dazu auserwählt worden sei, das Wissen der Vorväter erneut in Gänze zu erlangen und ein Goldenes Zeitalter herbeizuführen. Hiermit sollte sich zunächst auch die esoterische Position der Adelsbegründung verknüpfen lassen und den Glauben an eine Erneuerung des Adels befeuern.

Eine solche Klitterung verschiedenster Einflüsse innerhalb adliger Memoria vermochte aus Sicht des Adels nicht nur aus der Vergangenheit des Standes übernommene Vorstellungen von »Adligkeit« in Bruchstücken in die historische Gegenwart zu retten, sondern setzte sich auf Grundlage der aktuellen philosophischen und (natur-) wissenschaftlichen Diskussionen der Aufklärungszeit auch aktiv mit der Frage einer Aktualisierung dieser Traditionen auseinander: Welche

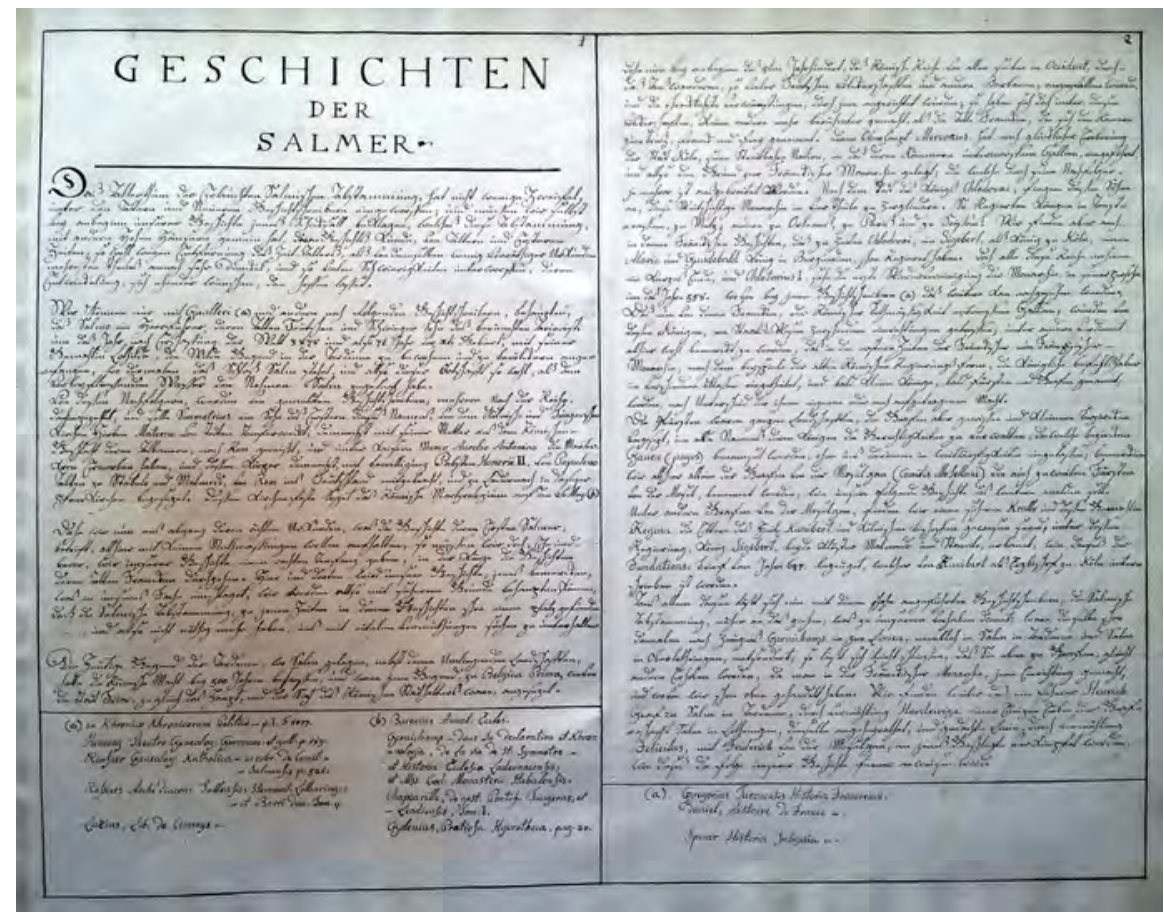

Abbildung 6: Beginn der "Geschichten der Salmer« mit historischen Erläuterungen zum Leben des Grafen Salmo, 1780 (Bildnachweis: ASD, Bestände des 19. Jahrhunderts: Allgemeine Verwaltung, Nr. 66; Bildrecht/Werk: Grafen Wolff-Metternich zur Gracht; Foto: M.O. Braun). 
Voraussetzungen und Mittel waren den Stammhaltern, aber auch den kommenden Generationen der Familien bereits von den Vorfahren gegeben worden, um die Tugendhaftigkeit als Urelement und Garant der Anerkennung ihres Adels zur vollen Ausprägung zu bringen? Welche Anpassungen dieser Mittel waren unter Berücksichtigung des Erkenntniszuwachses durch die Wissenschaften möglich und nötig - die zeitgenössische Annahme immer vorausgesetzt, dass es sich auch hierbei lediglich um ein wiederentdecktes Wissen handelte?

Bevor die Wandlungen dieser esoterischen Position der Adelsbegründung nach 1750 am Beispiel des rheinischen Adels in den Blick genommen werden können, soll hier zunächst auf der Grundlage des oben Erarbeiteten danach gefragt werden, inwiefern die Freimaurerei Adlige in der ersten Hälfte des 18. Jahrhunderts in dieser Selbstsicht bestärkte und welche Verbindungen sich zur adligen $»$ Blutsideologie« ergaben. 


\section{Von der Aufdeckung des Ursprungs - Ansichten über die Entstehung des Adels im Umfeld der ersten englischen Großloge}

\section{III.1 Die Geschichtsschreibung der "Constitutions" von 1723 als Genealogie der »Race of Noah»}

Indeed, following the work of Margaret Jacob, the question these days is more of science's influence on contemporary Freemasonry rather than the other way around.

- James E. McClellan III $^{1}$

Im Jahr 1723 legte der Reverend und Dissenter James Anderson² der Londoner Großloge eine Schrift vor, die den Titel »The Constitutions of the Free-Masons. Containing the History, Charges, Regulations, \&c. of that most Ancient and Right Worshiphful FRATERNITY« trug. Sie erfuhr bereits im 18. Jahrhundert mehrere Auflagen $^{3}$ und ist bis heute der wohl zentralste Text der freimaurerischen Geschichte. Anderson unternahm in den "Constitutions « unter anderem den Versuch, die Geschichte des Bundes aus den ältesten ihm zur Verfügung stehenden Dokumenten zusammenzustellen, wie etwa dem im 15. Jahrhundert entstandenen Cooke-Manuskript. ${ }^{4}$ Er handelte dabei im offiziellen Auftrag der Großloge. Diese hatte ihn im September 1721 ausgewählt, die verschiedenen überlieferten Formen der Konstitutionen der Freimaurerei zu einer neuen Fassung zusammenzufügen, »da sie Mängel in allen Abschriften der alten gotischen Konstitutionen beanstandete «. ${ }^{5}$ Das Ergebnis wurde von einer Kommission der Großloge, bestehend aus 14 Brüdern, abgenommen und offenbar für gut befunden. ${ }^{6}$ Zumindest

1 James E. McClellan III, Colonialism \& Science. Saint Domingue in the old regime, 2. Aufl., Chicago 2010, 186.

2 Zur Biographie James Andersons und zu seinem freimaurerischen Wirken vgl. Douglas Knoop/G. P. Jones, Die Genesis der Freimaurerei. Ein Bericht vom Ursprung und der Entwicklung der Freimaurerei in ihren operativen, angenommenen und spekulativen Phasen (Veröffentlichungen der Freimaurerischen Forschungsgesellschaft Quatuor Coronati e.V., Bayreuth), Bayreuth 1968, 166-174.

3 Die Andersonschen »Constitutions« erschienen 1738 in zweiter Auflage. Daneben kursierten kürzere Varianten anderer Autoren. Vgl. hierzu Dies., Die Genesis der Freimaurerei (wie Anm. 2, Kap. III), 170.

4 Das Cooke-Manuskript stellt eine mittelalterliche Sammlung von Pflichten englischer Maurer dar und enthält auch eine Geschichtsdarstellung. Zum Cooke-Manuskript siehe den entsprechenden Eintrag in: Lennhoff/Posner/Binder (Hg.), Internationales Freimaurer-Lexikon (wie Anm. 18, Kap. I), 193.

5 Zitiert nach Knoop/Jones, Die Genesis der Freimaurerei (wie Anm. 2, Kap. III), 167. Vgl. auch Dies., Die Genesis der Freimaurerei (wie Anm. 2, Kap. III), 166-174 im Gesamten zur Datierung des Auftrags an Anderson, für eine ausführliche Besprechung seiner Qualitäten als Historiker sowie zum Stellenwert seiner Autorschaft in Bezug auf das neue Manuskript.

6 Vgl. hierzu Dies., Die Genesis der Freimaurerei (wie Anm. 2, Kap. III), 169. 
hob der Deputierte Großmeister, John Theophilus Desaguliers, in seiner Widmung an den amtierenden Großmeister, John Duke of Montagu, lobend den hohen >wissenschaftlichen « Anspruch hervor, den Anderson an das Werk gestellt hatte. ${ }^{7}$

In Bezug auf die im 18. Jahrhundert viel diskutierte Frage nach den Ursprüngen der Menschheit bzw. ihrer gesellschaftlichen Ordnung ist es bemerkenswert, dass die Gründung der Londoner Großloge zu Beginn des 18. Jahrhunderts offenbar auch durch den Willen motiviert war, historische Forschungen ${ }^{8}$ über die Ursprünge des Bundes anzustellen. Das Vorgehen hierbei enthielt indirekt eine Stellungnahme zu der übergeordneten Diskussion. So hatten die Nachforschungen der "Moderns«, wie die Freimaurer der ersten englischen Großloge in späterer Zeit von ihren Gegnern, den "Antients «, ${ }^{9}$ aufgrund ihrer Reformen genannt werden sollten, bereits vor 1721 begonnen. Während seiner unmittelbar an die vermutlich um 1717 erfolgte Gründung der Großloge anschließenden Großmeisterschaft hatte George Payne seinen Brüdern aufgetragen, historische Zeugnisse zur Geschichte der Maurerei zu sammeln und der Großloge vorzulegen. ${ }^{10}$

Bereits um die Zeit der Jahrhundertwende vom 17. auf das 18. Jahrhundert war nach den Angaben Knoops und Jones' in England Kritik an der freimaurerischen Geschichtsschreibung laut geworden. Diese zielte vor allem auf die in den älteren Fassungen der »Constitutions « angegebenen historischen Verbindungen der Freimaurerei mit biblischen Gestalten, wie etwa dem weisen König Salomon. ${ }^{11}$ Auch wenn sich derartige Stimmen zur Zeit der Veröffentlichung der "Constitutions" von 1723 noch wenig Gehör verschaffen konnten, wie Knoop und Jones in ihren Untersuchungen ebenfalls betonten, ${ }^{12}$ scheint die Kritik bereits vor Andersons Neufassung in freimaurerischen Kreisen selbst wahrgenommen worden zu sein. Tatsächlich stellte Andersons Geschichte der Freimaurerei jedoch immer noch eine an mittelalterliche Chroniken erinnernde Universalgeschichte dar, ${ }^{13}$ die - so ihre Einleitung - zu jeder Aufnahme eines neuen Bruders in eine Loge

7 Vgl. The Constitutions of the Free-Masons Containing the History, Charges, Regulations, \&c. of that most Ancient and Right Worshipful FRATERNITY, London 5723/1723 (Faksimile: New York 1855), Dedication o.S., Permalink: http://n2t.net/ark:/13960/t22b8xx16 (Zugriff vom 18.07.2014).

8 Bereits Koselleck hat in »Kritik und Krise« die Wichtigkeit der Geschichtsphilosophie im freimaurerischen Denken betont und insb. für den Bund der Illuminaten, der die Freimaurerei lediglich als »Pflanzschule betrachtete, eingehender untersucht. Die Betonung der Bedeutung historischer Entwürfe über die Ursprünge der Freimaurerei aus der Zeit des 18. Jh.s innerhalb der vorliegenden Arbeit ist - wie bereits im Forschungsstand bemerkt - insofern keineswegs neu. Vgl. Koselleck, Kritik und Krise (wie Anm. 55, Kap. I), insb. 105-114.

9 Vgl. zu der Aufteilung in "Moderns« und »Antients« die Angaben etwa bei Jan A.M. Snoek, Initiating Women in Freemasonry. The Adoption Rite (Aries book series, 13), Leiden 2012, $2 \mathrm{f}$.

10 Vgl. Knoop/Jones, Die Genesis der Freimaurerei (wie Anm. 2, Kap. III), $201 \mathrm{f}$.

11 Vgl. hierzu zusammenfassend Ders., Die Genesis der Freimaurerei (wie Anm. 2, Kap. III), 2f. Eine ausführlichere Wiedergabe der kritischen Beiträge zur frühen freimaurerischen Geschichtsschreibung sowie zu Andersons Überarbeitung findet sich in: Douglas Knoop/G. P. Jones/Douglas Hamer (Hg.), Early Masonic Pamphlets, Manchester 1945, 10-12.

12 Vgl. Knoop/Jones, Die Genesis der Freimaurerei (wie Anm. 2, Kap. III), 2.

13 Vgl. zur chronikalen Form die kritische Einschätzung bei Lennhoff/Posner/Binder (Hg.), Internationales Freimaurer-Lexikon (wie Anm. 18, Kap. I), 39. 
verlesen werden sollte. Sie beschrieb nicht nur die Entstehungsgeschichte der Baukunst, sondern auch die Ursprünge der verschiedenen Völker der Menschheit. Es verwundert daher nicht, dass sich hierin indirekt auch eine Aussage zur Herkunft des Adels finden lässt. Zum besseren Verständnis der späteren Untersuchungen sollen hier die Andersonschen Ausführungen zusammengefasst und auf die Rolle des Adels hin analysiert werden.

Anderson begann seine Geschichte der Freimaurerei mit einem biblischen Bezug $^{14}$ und entwickelte diesen konsequent bis in die Gegenwart fort. Ausgehend vom biblischen Urvater Adam, der nach dem Abbild Gottes bzw. dem "great Architect of the Universe " geschaffen worden war und die Geometrie in seinem Herzen eingeschrieben trug, versuchte Anderson die Geschichte der Weitergabe dieser Grundlage der Maurerkunst und noble Science ${ }^{15}$ aufzuzeigen. ${ }^{16}$ Die Kunst der Maurerei habe demnach bereits bei Adams erstem Sohn Kain zur Errichtung der biblischen Stadt Enoch geführt. Anderson fügte in Bezug auf Kain hinzu: »[...] becoming the Prince of the one Half of Mankind, his Posterity would imitate his royal Example in improving both the noble Science and the useful Art. ${ }^{17}$ Gleiches galt auch für Adams dritten Sohn Seth, den Herrscher über die andere Hälfte der Menschheit, wobei auch ihm das Beispiel Adams vorstand. ${ }^{18}$

Da Kain und Seth Söhne Adams waren und hier als Prinzen bezeichnet wurden, kann für Adam der Titel eines Königs vorausgesetzt werden. Der »König Adam « der freimaurerischen Geschichtsschreibung war somit - als erster König der Menschheit überhaupt - für die Weitergabe der göttlichen Gabe »Geometrie» verantwortlich, aus der sich schließlich alle anderen Künste und insbesondere die Maurerei entwickelt haben sollten. Dieser adamitische »Uradel« war, nach Andersons Ausführungen, auch verantwortlich für die allmähliche Höherentwicklung des Kulturzustandes der menschlichen Zivilisation unmittelbar nach dem Sündenfall. An anderer Stelle sprach Anderson daher ausdrücklich von der Maurerei als der »Königlichen Kunst« und meinte dies in Anbetracht der bis hierher gemachten Ausführungen wohl wortwörtlich. ${ }^{19}$

14 Auch in den älteren Manuskripten liegen biblische Bezüge vor. Im Cooke-Manuskript ist es bspw. der biblische König Nimrod, der den Maurern die Konstitutionen gab. Zu einer älteren, online verfügbaren Transkription siehe: http://en.wikisource.org/wiki/Matthew_Cooke_Manuscript (Zugriff vom 15.07.2014). Anderson geht mit seiner Rückverlegung in adamitische Zeiten zeitlich noch über das Cooke-Manuskript hinaus. Vgl. Lennhoff/Posner/Binder (Hg.), Internationales Freimaurer-Lexikon (wie Anm. 18, Kap. I), 35.

15 Siehe zu den hier gemachten Zitaten: Constitutions (wie Anm. 7, Kap. III), If.

16 Die Betonung der »liberal science« Geometrie als Grundlage aller Künste ist dabei ebenfalls als Reminiszenz an das Mittelalter zu sehen, das zuweilen die Geometrie als Grundlage der septem artes liberales annahm. Vgl. hierzu Knoop/Jones, Die Genesis der Freimaurerei (wie Anm. 2, Kap. III), 66-68.

17 Constitutions (wie Anm. 7, Kap. III), 2.

18 Vgl. Constitutions (wie Anm. 7, Kap. III), 2f.

19 Constitutions (wie Anm. 7, Kap. III), 4f. Hier heißt es: "In these Parts, upon the Tygris and Euphrates, afterwards flourish'd many learned Priests and Mathematicians, known by the Names of CHALDEES and MAGI, who preserv'd the good Science, Geometry, as the KINGS and great Men 
Die Kunst der Könige und »Großen« bestand neben ihrer eigenen gesellschaftlichen Funktion als >lebende Symbole der Tugend demnach auch darin, die Gelehrten zu fördern und das Wissen um die Geometrie mit Hilfe des Logengeheimnisses zu bewahren. Anderson führte als Beispiele eine Reihe von Königen des Altertums und der biblischen Geschichte an, wie etwa die Könige Nimrod oder Salomon. Unter ihrer Herrschaft sei es laut Anderson möglich gewesen, die eindrucksvollsten Gebäude der Welt zu errichten, wie die ägyptischen Pyramiden oder den salomonischen Tempel. Aus dem Kontext der Darstellungen wird deutlich, dass der Bau dieser herrschaftlichen Gebäude bzw. die Gebäude selbst für Anderson nicht nur das Wissen der jeweiligen Herrscher um die »Königliche Kunst «, sondern auch die gute Ordnung der von ihnen beherrschten Gemeinwesen versinnbildlichten.

Dass spätere Könige wie Nimrod oder Salomon überhaupt noch in den Besitz dieses auf der Geometrie basierenden adamitischen Herrscherwissens gelangen konnten, erklärte Anderson durch eine Tat eines Nachkommen Seths. Dieser habe vor der Sintflut zwei Säulen mit Inschriften über die Freien Künste geschaffen. Diese transportierten das vorsintflutliche Wissen der Adamiten über das Diluvium hinaus. ${ }^{20}$ Das Material Stein war in der freimaurerischen Geschichtsschreibung also - modern ausgedrückt - Träger des »kulturellen Gedächtnisses« der Adamiten. ${ }^{21}$

Im oben erläuterten Kontext der Ursprungsdiskussionen ist es wichtig, dass auch dem neunten Nachfahren Seths, dem biblischen Patriarchen Noah, bei der Weitergabe des Wissens von Anderson große Bedeutung zugeschrieben wurde:

[...] NOAH, the ninth from Seth, was commanded and directed of God to build the great Ark, which, tho' of Wood, was certainly fabricated by Geometry, and according to the Rules of Masonry. NOAH, and his three Sons, JAPHET, SHEM, and HAM, all Masons true, brought with them over the Flood the Traditions and Arts of the Ante-deluvians, and amply communicated them to their growing Offspring; for about 101 Years after the Flood, we find a vast Number of 'em, if not the whole Race of Noah, in the Vale of Shinar, employ'd in building a City and large Tower, in order to make to themselves a Name, and to prevent their Dispersion. ${ }^{22}$

encourag'd the Royal Art. But it is not expedient to speak more plain of the Premises, except in a formed Lodge."

20 Anderson berechnete das Alter der Welt vor dem Diluvium auf 1656 Jahre - ohne dabei, wie er betonte, unsichere Angaben heranzuziehen. Constitutions (wie Anm. 7, Kap. III), 3.

21 Die Flut bzw. die Überflutung mit barbarischen Volksstämmen ist auch in der Andersonschen Geschichte eine »Metapher des Vergessens«. Siehe zur Flut als »Metapher des Vergessens« insb. Rémi Brague, Völkerwanderungen und Überschwemmungen. Die Flut als Metapher des Vergessens, in: Martin Mulsow/Jan Assmann (Hg.), Sintflut und Gedächtnis. Erinnern und Vergessen des Ursprungs, München 2006, 117-127.

22 Constitutions (wie Anm. 7, Kap. III), 3. 
Neben der Voranstellung Jafets, der in der Aufzählung vor seinen Brüdern Sem und Ham genannt wird, fällt hier wiederum die ordnende Funktion der Baukunst ins Auge, die der Zerstreuung der Völker zunächst entgegenwirkt habe. Sie wird als wichtiges überzeitliches Machtsymbol der Herrscher dargestellt. Im Zuge des Turmbaus zu Babel, der Gott aufgrund mangelnder menschlicher Demut missfiel, zerstreuten sich nach der biblischen Überlieferung bekanntlich die Völker. Und so schrieb auch Anderson über die »Race of Noah «: $»[\ldots]$ and upon their Dispersion carry'd the mighty Knowledge with them into distant Parts, where they found the good use of it in the Settelment of their Kingdoms, Commonwealths, and Dynasties. ${ }^{23}$ Auch die Nachfahren Noahs nutzten somit die »Königliche Kunst«, um ihre Herrschaften einzurichten. So habe sich die Maurerei durch Hams zweiten Sohn Mizraim in Ägypten und von hier ausgehend auch in anderen Teilen Afrikas verbreitet. ${ }^{24} \mathrm{Zu}$ Jafet äußerte sich Anderson zu Beginn seiner historischen Erläuterungen nur wenig, wobei der hier erwähnte Ausdruck »Isles of the Gentiles « ${ }^{25}$ jedoch bereits auf Europa verwies.

Die Hochphase der Maurerei der Nachkommen Sems lag nach Anderson in der Zeit der Herrschaft des weisen Königs Salomon und der Errichtung des salomonischen Tempels. Dieser sei trotz seiner gewaltigen Ausmaße in nur sieben Jahren und sechs Monaten »without the Noise of Work-mens Tools « ${ }^{26}$ und mit Hilfe des König Hiram von Tyrus sowie seines Baumeisters Hiram Abiff, dem »most accomplish'd Mason upon Earth $\aleph^{27}$ als »House of Prayer for all Nations ${ }^{28}$ erbaut worden. In der freimaurerischen Geschichte wurde der salomonische Tempel als prägendes Vorbild seiner Zeit dargestellt: Die Völker, deren Künstler nach Jerusalem gereist waren, um bei seiner Errichtung zu helfen oder nur um das fertige Bauwerk zu bewundern, verbesserten demnach bei ihrer Rückkehr die Maurerei ihres Heimatlandes. ${ }^{29}$ Die Exklusivität des Wissens sei jedoch gewahrt worden, da die Künstler ihr Wissen nur an »free born Sons of eminent Persons« weitergaben, »by whose Dexterity the Kings, Princes, and Potentates, built many glorious Piles, and became the GRAND MASTERS, each in his own Territory, and were emulous of excelling in this Royal Art «. ${ }^{30}$ Spätestens hier vollendete sich in Andersons

24 Constitutions (wie Anm. 7, Kap. III), 5 f.

25 Constitutions (wie Anm. 7, Kap. III), 6f. Hier heißt es: "And surely the fair and gallant Posterity of JAPHET, (the eldest Son of Noah) even such as travell'd into the Isles of the Gentiles, must have been equally skill'd in Geometry and Masonry; tho' we know little of their Transactions and mighty Works, until their original Knowledge was almost lost by the Havock of War, and by not maintaining a due Correspondence with the polite and learned Nations; for when that Correspondence was open'd in After-Ages, we find they began to be most curious Architects."

26 Constitutions (wie Anm. 7, Kap. III), 10.

27 Constitutions (wie Anm. 7, Kap. III), 11.

28 Constitutions (wie Anm. 7, Kap. III), 13.

29 Vgl. Constitutions (wie Anm. 7, Kap. III), 14.

30 Constitutions (wie Anm. 7, Kap. III), 14 f. 
Geschichtsschreibung das Bild einer seit Urzeiten durch den Adel dominierten elitären Vereinigung.

Als neue Hochform pries Anderson schließlich den augusteischen Stil der Römer - womit auch ihr Herrschaftsstil impliziert war. ${ }^{31}$ Die innerhalb der römischen Garnisonen entstandenen Militärlogen seien für die Übermittlung dieses hochentwickelten Wissens an die im Norden und Westen Europas lebenden Völker verantwortlich gewesen. ${ }^{32}$ In Britannien, das nach dem Abzug der römischen Garnisonen von den kriegerischen Angeln und Sachsen eingenommen worden war, sei die Maurerei in Folge der Ereignisse zunächst nahezu in völlige Vergessenheit geraten. ${ }^{33}$ Allmählich sei dort aber insbesondere den Königen und dem Adel die Wiederentdeckung und erneute Förderung der Maurerei in Britannien gelungen, die zu einer erneuten Blüte der Kunst unter den gegenwärtigen Königen Englands geführt habe. ${ }^{34}$ Auch an vielen weiteren Stellen betonte Anderson die Beteiligung des britischen Adels. ${ }^{35}$ Zum Ende seiner Darstellung nannte Anderson die Freimaurerei zudem eine »ancient fraternity«, die durch ihre Gebräuche die Gesellschaften und Orden der »Warlike Knights«, aber auch solche religiöser Natur beeinflusst habe. ${ }^{36}$

Festzuhalten bleibt hier, dass die englische Freimaurerei des frühen 18. Jahrhunderts sich als ein durchaus exklusiver, insbesondere durch den Adel angeleiteter Bund ansah, der eine Vereinigung aus »several Noblemen and Gentlemen of the best Rank, with Clergymen and learned Scholars oft most Professions and Denominations $«^{37}$ darstellte. Sie beanspruchte für sich nichts weniger als in direkter Linie Teile des Urwissens der noachidischen Fürsten der Menschheit in sich zu bergen. Betrachtet man die Adelsgenealogien im zeitlichen Umfeld der englischen Großloge, wird deutlich, dass die freimaurerische Geschichtsdarstellung dem Adel dieser Zeit keineswegs abwegig erscheinen musste, sondern durchaus für die Möglichkeit sprechen konnte, tatsächlich ein Wissensreservoir direkter Vorfahren zu entdecken.

31 Vgl. Constitutions (wie Anm. 7, Kap. III), $24 \mathrm{f}$.

32 Siehe Constitutions (wie Anm. 7, Kap. III), 27f. Anderson sagt hierzu: "And while the Roman Empire continu'd in its Glory, the Royal Art was carefully propagated, even to the Ultima Thule, and a Lodge erected in almost every Roman Garrison; whereby they generously communicated their Cunning to the northern and western Parts of Europe, which had grown barbarous before the Roman Conquest, though we know not certainly how long; because some think there are a few Remains of good Masonry before that Period in some Parts of Europe, raised by the original Skill that the first Colonies brought with them, as the Celtic Edifices, erected by the ancient Gauls, and by the ancient Britains too, who were a Colony of the Celtes, long before the Romans invaded this Island."

33 Vgl. Constitutions (wie Anm. 7, Kap. III), 29 f.

34 Constitutions (wie Anm. 7, Kap. III), 29.

35 Siehe hierzu etwa Constitutions (wie Anm. 7, Kap. III), 35-37.

36 Vgl. Constitutions (wie Anm. 7, Kap. III), 46.

37 Constitutions (wie Anm. 7, Kap. III), 48. 


\title{
III.2 "Royal Genealogies» - James Anderson als Adelsgenealoge
}

\begin{abstract}
As for the following Tables, the only Merit they pretend to, Sir, is that of their being the first Attempt in the English Language, and the compleatest yet extant in any, for reducing this extensive and confused Study to Method [...].
\end{abstract}

- James Anderson ${ }^{38}$

Das Jahr 1723 der christlichen Zeitrechnung war innerhalb der englischen Großloge gleichbedeutend mit dem freimaurerischen Jahr 5723. Letzteres war eine Angabe über den verstrichenen Zeitraum nach Erschaffung der Welt, die durchaus mit den Ansichten vieler Zeitgenossen Andersons über ein mögliches Alter der Erde übereinstimmte. Die in der Geschichte der Freimaurerei sowohl mit Hilfe der christlichen Zeitrechnung als auch mit der Angabe anno mundi vorgenommene Datierung von Ereignissen dürfte ihnen daher keineswegs ungewöhnlich erschienen sein. Auch Andersons zu nicht geringen Teilen an der Faktizität der Überlieferungen des Alten Testaments festhaltende Darstellung der Geschichte der Freimaurerei spiegelte offenbar die Sichtweise der übrigen Mitglieder der Großloge wider.

An dieser Stelle verdient der Einfluss des bereits erwähnten John Theophilus Desaguliers (1683-1744), Sohn eines 1685 nach dem Edikt von Nantes von Frankreich nach England geflohenen hugenottischen Geistlichen, auf die gedankliche Ausrichtung der Großloge besondere Beachtung. ${ }^{39}$ Wie sein Vater war auch Desaguliers Geistlicher und gilt innerhalb der Freimaurerforschung als Initiator und "geistiger Vater ${ }^{40}{ }^{0}$ des Reformprojekts der Constitutions «. In einer Studie, die sich mit dem Thema des Adels in der Freimaurerei beschäftigt, muss er in seiner Funktion als >Mittelsmann $`$ zwischen Adel und Freimaurerei besonders hervorgehoben werden. ${ }^{41}$ Auch in der Folge der Großmeisterschaft des Herzogs von Montagu im Jahr 1721 riss die adlige Beteiligung an der administrativen Leitung der Freimaurerei nicht ab, sodass auch weiterhin Personen des englischen Hochadels bzw. des englischen Königshauses die Führung der Großloge übernahmen. ${ }^{42}$ Desaguliers bekleidete dabei noch mehrfach das Amt des Deputierten Großmeisters. ${ }^{43}$ Er stand außerdem den Deputationslogen vor, die den Herzog Franz Ste-

38 James Anderson, Royal Genealogies: Or, The Genealogical Tables of Emperors, Kings and Princes, From ADAM to these Times, In Two Parts, London 1732, Widmung o.S., http://books.google.de/ books?id=yrqeY839bMwC\&dq (Zugriff vom 15.07.2014).

$39 \mathrm{Zu}$ seiner Person bzw. Biographie vgl. die Angaben in: Lennhoff/Posner/Binder (Hg.), Internationales Freimaurer-Lexikon (wie Anm. 18, Kap. I), 211.

40 Dies. (Hg.), Internationales Freimaurer-Lexikon (wie Anm. 18, Kap. I), 211.

41 Vgl. Dies. (Hg.), Internationales Freimaurer-Lexikon (wie Anm. 18, Kap. I), 211.

42 Vgl. hierzu Dies. (Hg), Internationales Freimaurer-Lexikon (wie Anm. 18, Kap. I), 255.

43 Vgl. hierzu die Angaben in Knoop/Jones, Die Genesis der Freimaurerei (wie Anm. 2, Kap. III), $178-180$. 
phan von Lothringen $1731 \mathrm{im} \mathrm{Haag}^{44}$ sowie Friedrich Ludwig von Hannover, den Prinzen von Wales, im Jahr 1737 in Kew Palace bei Richmond in die Freimaurerei aufnahmen. ${ }^{45}$ Und auch die Großmeisterschaft des Duke of Montagu war wohl maßgeblich durch die Verbindungen Desaguliers initiiert worden, da beide gemeinsam in der Royal Society engagiert waren. ${ }^{46}$

Die historischen Untersuchungen einer weiteren prominenten Bekanntschaft Desaguliers aus dieser Gelehrtengesellschaft dürften nicht unerheblich für die starken Rückbezüge der freimaurerischen »Constitutions« von 1723 auf die biblische Überlieferung gewesen sein. Desaguliers, selbst ein begabter Naturforscher, der nicht nur zahlreiche wissenschaftliche Werke vom Französischen ins Englische übersetzte, sondern auch wichtige Entdeckungen auf dem Gebiet der Elektrizität machte, pflegte freundschaftlichen Kontakt mit Sir Isaac Newton (16421727). ${ }^{47}$ Die `historischen Forschungen Newtons mündeten in einer im Jahr 1728 posthum veröffentlichten Schrift mit dem Titel »The Chronology of Ancient Kingdoms Amended «. ${ }^{48}$ Wie der Titel bereits andeutet, entbehrte diese Schrift nicht eines Bezugs zur Adelsgeschichte. Newton hatte sie ursprünglich für die Prinzessin von Wales angefertigt. ${ }^{49}$ In seiner Studie wollte Newton die Ursprünge der frühen Monarchien der Menschheitsgeschichte darstellen und verwendete dabei die Bibel im Sinne einer historisch verlässlichen Quelle. Auch die Geschichte der Sintflut mit Noah als König und Begründer einer Urreligion erfuhren hierin eine Besprechung, wobei die Baukunst - etwa in Form des salomonischen Tempels durch den Autor als Träger überlieferter Wissensbestände dieser noachidischen Urreligion vorgestellt wurde. ${ }^{50}$ Die freimaurerische Geschichtsschreibung Andersons befand sich insofern in guter Gesellschaft - zumal auch andere im London

44 Zur Aufnahme Franz Stephans in den Freimaurerbund sowie zu seinem freimaurerischen Werdegang siehe Lennhoff/Posner/Binder (Hg.), Internationales Freimaurer-Lexikon (wie Anm. 18, Kap. I), $526 f$.

45 Zur Aufnahme Friedrich Ludwigs sowie weiterer Mitglieder des englischen Königshauses in den Freimaurerbund vgl. die Angaben in Dies. (Hg.), Internationales Freimaurer-Lexikon, 262-264.

46 Siehe Dies. (Hg.), Internationales Freimaurer-Lexikon (wie Anm. 18, Kap. I), 211.

47 Newton war unter anderem auch Pate eines Sohnes Desaguliers'. Zur Beeinflussung Desaguliers durch die wissenschaftlichen Erkenntnisse und die Weltsicht Isaac Newtons vgl. insb. Bullock, Revolutionary Brotherhood (wie Anm. 43, Kap. I), 36. Für ein Porträt Newtons (Radierung von G. Kneller, 1849) siehe: commons.wikimedia.org/wiki/Images_from_the_Chemical_ Heritage_Foundation\#mediaviewer/File:Sir_Isaac_Newton_1849_RGNb10408769.17.tif (Zugriff vom 02.08.2014).

48 Sir Isaac Newton, The Chronology of Ancient Kingdoms Amended, London 1728, Permalink: http://hdl.handle.net/2027/mdp.39015007005500 (Zugriff vom 25.05.2014). Verwiesen sei auch auf die diversen Transkriptionen und Digitalisate auf der Homepage des Newton Projects, http://www. newtonproject.sussex.ac.uk/prism.php?id=1 bzw. der Cambridge Digital Library: http://cudl.lib. cam.ac.uk/view/MS-ADD-03988/7 (Zugriff vom 25.05.2014).

49 Vgl. Klaus-Dietwardt Buchholtz, Isaac Newton als Theologe. Ein Beitrag zum Gespräch zwischen Naturwissenschaft und Theologie, Witten 1965, $28 \mathrm{f}$.

50 Vgl. hierzu Mandelbrote, Isaac Newton and the Flood, in: Mulsow/Assmann (Hg.), Sintflut und Gedächtnis (wie Anm. 21, Kap. III), hier 340f. Zu Newtons Besprechung der Geschichte Noahs sowie der Abstammung der Europäer von Jafet siehe bspw. Newton, The Chronology of Ancient Kingdoms (wie Anm. 48, Kap. III), 184-190. 
des frühen 18. Jahrhunderts veröffentlichte Schriften zum Adel diese Theorien erfolgreich aufgriffen. ${ }^{51}$

Den »Constitutions« schob Anderson nach siebenjähriger Arbeit im Jahr 1732 ein genealogisches Werk mit dem Titel »Royal Genealogies: Or, The Genealogical Tables of Emperors, Kings and Princes, From ADAM to these Times « nach. $\mathrm{Zu}$ den Subskribenten gehörten zahlreiche Vertreter des englischen Adels sowie seine Logenbrüder Desaguliers und der Duke of Montagu. ${ }^{52}$ Anderson unterteilte seine rund 800 Seiten umfassende Schrift in zwei Teile und widmete sie dem bereits genannten Prinzen von Wales, Friedrich Ludwig von Hannover, Sohn König Georgs II. von Großbritannien.

Wie Anderson selbst zu Beginn des Werks angab, entnahm er die Informationen für seine Genealogie nicht nur aus der Heiligen Schrift. Er zog darüber hinaus die Untersuchungen anderer europäischer Genealogen heran, wie André du Chesne und Francis Sandford oder auch Humphrey Prideaux' Werk » The Old and the New Testament connected in the history of the Jews and the Neighbouring Nations«. Vor allem stützte er sich aber auf die Arbeit des deutschen Genealogen Johann Hübner ${ }^{53}$ - was in Anbetracht der Widmung an einen Vertreter des Hauses Hannover nicht überraschen muss. Festzuhalten bleibt, dass seine Rezeption der genealogischen Literatur durchaus international ausgerichtet war.

Bereits in seiner Widmung an den Prinzen von Wales ging Anderson auf die verwandtschaftlichen Verhältnisse der Menschheit im Allgemeinen und des Adels im Besonderen ein. Anderson fühlte sich dazu berufen, durch sein Werk Gottes Weisheit zu verehren und das Wunder seiner Schöpfung darzulegen. Dieses bewirkte Gott demnach unter anderem durch die Fortpflanzung der

various Nations of the Earth from one common Parentage, and in strengthening this original Relation by subsequent Ties and Renewals of Consanguinity; in making both the Union and Dispersion of Mankind, the Rise and Fall of Empires, the Virtues, and even the Vices of Rulers, with all the numerous Vicissitudes and seeming Inconsistencies of human Affairs, subservient to the steady Prosecution of one regular Plan of unerring Wisdom and Goodness, to the exact Accomplishment of the Predictions of the Old and New Testament. ${ }^{54}$

51 Siehe hierzu insb. eine Schrift des Autors Maurice Shelton mit dem Titel »An Historical and Critical Essay on the True Rise of Nobility, Political and Civil« aus dem Jahr 1718. Diese wurde bereits im Jahr 1720 in zweiter Auflage veröffentlicht. Shelton ging hierin in stetigem Bezug auf die Überlieferungen der Bibel den Ursprüngen des Adels nach. Deutlich lässt sich in seiner Beschreibung der Glauben an eine "Große Kette der Wesen« bzw. eine regelmäßig gestufte Himmelsleiter als ordnendes Prinzip im Universum erkennen. Maurice Shelton, An Historical and Critical Essay on the True Rise of Nobility, Political and Civil, London 1718, insb. IV-VI, Permalink: http://hdl. handle.net/2027/mdp.39015002445073 (Zugriff vom 25.05.2014).

52 Vgl. Anderson, Royal Genealogies (wie Anm. 38, Kap. III). Die Subskribentenliste findet sich im vorderen Teil des Werkes o.S.

53 Vgl. hierzu auch bereits die kritischen Bemerkungen bei Knoop/Jones, Die Genesis der Freimaurerei (wie Anm. 2, Kap. III), 166. Anderson wies hierauf teilweise selbst in seinen Angaben im Vorwort hin, vgl. Anderson, Royal Genealogies (wie Anm. 38, Kap. III), Vorwort o.S.

54 Ders., Royal Genealogies (wie Anm. 38, Kap. III), Widmung o.S. 
Anderson zeigte sich deshalb gegenüber Friedrich Ludwig davon überzeugt, dass eine "Stability of Families, and the Welfare of Kingdoms, next under the Blessing of God, depend on the Wisdom, the Application and personal Vertues of Princes «. ${ }^{55}$ Durch seine Erläuterungen zum richtigen Gebrauch der Tafeln ${ }^{56}$ präsentierte sich Anderson als ein genauer Kenner des auf der Einprägung von Bildern beruhenden Erziehungssystems der ars memoriae, wobei die Erwähnung des Wortes $» \operatorname{method} \aleph^{57}$ als Anzeichen hierfür gelten kann:

As for the following Tables, the only Merit they pretend to, Sir, is that of their being the first Attempt in the English Language, and the compleatest yet extant in any, for reducing this extensive and confused Study to Method, and for connecting and embellishing the dry Skeleton of Names and Dates with the proper Ligaments and Colourings of History. Regular Disposition and Order (which are the great Aids of Memory and the true Secret of Learning, or of dispatching Business of any Kind) are as peculiarly requisite in this Science as in that of Astronomy, where tho' the Objects which the Eye is conversant about are the brightest and most distinct, yet their Multiplicity would make our Attention despair of comprehending, and our Memory of retaining them, with the respective Times of their shining and disappearing were they not distributed into separate Constellations, and diversifify'd with some enlivening Circumstances from History [...]. ${ }^{58}$

Der Nutzen, den er für den Prinzen im Studium seiner genealogischen Tafeln sah, bestand in der genauen Kenntnis der Familiengenealogie sowie der damit einhergehenden Rückverfolgung des Blutes bis zu seinen Ursprüngen:

As these Thoughts will naturally arise in Your Royal Highness's Mind on a general Survey of this Work, so the examining the particular Tables of your own Familiy, your tracing your Blood to the dear and venerable Sources of its high Original, the observing it for so many Ages and Descents transmitted and refin'd through the uncorrupt Hearts of Great and Good PRINCES, Fathers of their Country and Friends to Mankind, beloved in their Lives and unfeignedly regretted at their Deaths, renowned above all the Heroes of Europe for that distinguish'd fraternal Union which constitutes the real, instrinsick Strength of Families, and blessed, almost all of 'em, with that Length of

55 Vgl. Ders., Royal Genealogies (wie Anm. 38, Kap. III), Widmung o.S.

56 Vgl. zum Aufkommen der im Gegensatz zum Stammbaum sehr viel abstrakter ausfallenden Stammtafeln in der Genealogie der Frühen Neuzeit: Volker Bauer, Die gedruckte Ahnentafel als Ahnenformular. Zur Interferenz von Herrschafts-, Wissens- und Medienordnung in der Universalgenealogie des 17. Jh.s, in: Harding/Hecht (Hg.), Die Ahnenprobe in der Vormoderne (wie Anm. 4, Kap. I), 125-156. Demnach war das Aufkommen der Ahnentafeln auch eine Anpassung an die neuartigen Buchdruckverfahren.

57 Zur Bedeutung des Begriffs "method « in der ars memoriae als Erziehungssystem vgl. Yates, The Art of Memory (wie Anm. 17, Kap. I), 13 sowie 228-232. Zu den Ausführungen Andersons ist ebenfalls zu bemerken, dass die ars memoriae tatsächlich auch Sternbilder als Gedächtnisstützen verwendete. Siehe hierzu Ders., The Art of Memory, 210-212.

58 Anderson, Royal Genealogies (wie Anm. 38, Kap. III), Widmung o.S. 
Days and Encrease of Possessions, which seem the peculiar Rewards promised by Heaven to Filial Piety. ${ }^{59}$

Hier spiegelte sich auch bei Anderson der Glaube an das Blut als Träger der Tugend wider. Die »instrinsick Strength of Families « bestand in einer hierin gründenden »fraternal Union« aller adligen Vorfahren - ein Begriff, der im Übrigen durchaus an die Nennung der »ancient fraternity« im Geschichtsteil der »Constitutions" erinnern konnte. Für Anderson galt ihre Rekonstruktion bis zu den Ursprüngen als möglich. Da die auf diese Weise sichtbar gemachten tugendhaften Beispiele der Vorfahren den Nachfahren auf dem Weg der Tugend hielten, war auch Friedrich Ludwig für Anderson ein »Prince framed by Nature and Education to be the Inheritor of the Vertues as well as Titles of his Royal Progenitors «. ${ }^{60}$

Die genealogischen Herleitungen der einzelnen Adelshäuser, die Anderson im Innenteil anstellte, brauchen hier nicht näher betrachtet zu werden. Sie deckten sich mit den bereits vorgestellten Rückführungsversuchen adliger Geschlechter auf biblische Vorfahren. So konnten den Prinzen etwa die Tafeln der »most ancient Kings of the Germans « auf Seite 441 interessieren, in denen ihr Geschlecht von Gomer, einem Sohn Jafets, abgeleitet und in aufsteigender Ahnenreihe weiter verfolgt wurde - eine Ableitung, die sich im Übrigen bereits bei Johann Hübner finden ließ. ${ }^{61}$ Ähnlich verfuhr Anderson mit verschiedenen anderen »Volksstämmen « und Nationen. »Race« bildete in diesem Zuge ein Äquivalent zum Adelsgeschlecht - wie das englische Wort in der deutschen Übersetzung sowohl »Rasse« als auch »Geschlecht « bedeuten kann. So leiteten sich etwa die Könige Frankreichs zunächst aus einer trojanischen »Königsrasse « und später aus den »three principal races « der Merowinger, Karolinger und Kapetinger ab. ${ }^{62}$ Die »Rasse« war hier also im Sinne der oben angeführten Definition Christian Geulens als ein im Blut und der Abstammung inbegriffenes >Geheimnis der Adligkeit` zu verstehen oder anders ausgedrückt als »Wurzel der Tugend «.

Dass genealogische Herleitungen im Stile der Andersonschen »Royal Genealogies« noch ein Jahrzehnt später im rheinischen Adel rezipiert wurden, kann ein bereits oben angeführtes Beispiel illustrieren. So findet sich in Andersons Genealogien auch eine Tafel, die die Daten des bereits oben erwähnten Stammbaumes der Familie Salm-Reifferscheidt auf Schloss Dyck nahezu exakt wiedergibt. ${ }^{63}$ Die Jahre bis zur Existenz des Fürsten Salmo hätten mit Hilfe der anderen Tafeln der

59 Ders., Royal Genealogies (wie Anm. 38, Kap. III), Widmung o.S.

60 Ders., Royal Genealogies (wie Anm. 38, Kap. III), Widmung o.S.

61 Vgl. Ders., Royal Genealogies (wie Anm. 38, Kap. III), 441. Zur selben Ableitung bei Hübner vgl. Johann Hübner, Kurze Fragen aus der Genealogie, Nebst denen darzu gehörigen Tabellen, zur Erläuterung Der Politischen Historie zusammen getragen, Und bey dieser zweyten Auflage bis auf gegenwärtige Zeit continuieret, Leipzig 1712, 9, Permalink: http://nbn-resolving.org/ urn:nbn:de:bvb:12-bsb10428228-2 (Zugriff vom 25.05.2014).

62 Vgl. Anderson, Royal Genealogies (wie Anm. 38, Kap. III), 611-613.

63 Vgl. zur genealogischen Tafel des Geschlechts Salm-Reifferscheidt bei Ders., Royal Genealogies (wie Anm. 38, Kap. III), 566. Das Geschlecht leitet sich hier ebenfalls aus den Nachfahren des französischen Königs »Pharamund « - eines heute zu den »Falschen Merowingern« zählenden 
»Royal Genealogies« sogar noch bis in die Zeiten der Einwanderung Jafets in Europa und die Anfänge der Schöpfung zurückgeführt werden können - wenngleich um 1750 gute Gründe bestanden, dies nicht mehr zu tun.

Vor dieser Zeit war über die Gestalt des Noachiden Jafet aber potentiell ein gedanklicher Brückenschlag zwischen der Geschichtsschreibung der Andersonschen »Constitutions« und den zeitgenössischen Genealogien des Adels bzw. der esoterischen Position der Adelsbegründung möglich. Die Geschichte der »Königlichen Kunst«, wie sie Anderson aus alten Dokumenten in `kritischer Manier zusammengestellt hatte, konnte dem Adel seiner Zeit als verbürgte Realität erscheinen. Sie stützte auf diese Weise das auf Anciennität bedachte Selbstverständnis der Familien. Das geschichtliche Konstrukt einer ewigen Beziehung der Freimaurerei zum Adel und zu den geistigen Eliten der Gesellschaft war jedoch nicht der einzige Brückenschlag zum »Uradel ${ }^{64}{ }^{64}$ Da die Freimaurerei vielmehr den Anspruch erhob, das Wissen einer Urreligion, wie sie auch ein Isaac Newton zu rekonstruieren versuchte, ${ }^{65}$ zumindest in Teilen in ihren Gebräuchen bewahrt zu haben, ist danach zu fragen, worin das Wissen dieser Urreligion aus der Sicht der Zeitgenossen Andersons bestanden haben könnte und inwiefern es mit der adligen »Blutsideologie« bzw. den »Wurzeln der Tugend « verknüpft zu sein schien.

Königs - ab. Auf diesen wäre die Abstammungslinie der französischen Könige anzuwenden, die letztlich zur Abstammung von der »Trojanischen Königsrasse« und Jafet führt.

64 Der Begriff des Uradels kam erst in späterer Zeit auf, ist aber, wie oben gezeigt, in Grundzügen bereits deutlich früher angelegt. Vgl. zur Entwicklung des Begriff des Uradels, der erstmals 1788 vom Göttinger Professor Christoph Meiners verwendet wurde: William D. Godsey, Vom Stiftsadel zum Uradel. Die Legitimationskrise des Adels und die Entstehung eines neuen Adelsbegriffs im Übergang zur Moderne, in: Anja Victorine Hartmann/Małgorzata Morawiec/Peter Voss, Eliten um 1800. Erfahrungshorizonte Verhaltensweisen Handlungsmöglichkeiten (Veröffentlichungen des Instituts für Europäische Geschichte Mainz, Abteilung für Universalgeschichte, 183), Mainz 2000, 371-391, hier insb. 379.

65 Vgl. hierzu etwa Robert Markley, Newton, Corruption, and the Tradition of Universal History, in: James E. Force/Richard H. Popkin (Hg.), Newton and Religion. Context, Nature and Influence (Archives internationales d'histoire des idées, 161), Dordrecht 1999, 121-143; Klaus Fischer, Isaac Newton und das verlorene Wissen der Alten. Auf der Suche nach den inneren Kräften der Natur, in: Richard van Dülmen/Sina Rauschenbach (Hg.), Denkwelten um 1700. Zehn intellektuelle Profile, Köln/Weimar/Wien 2002, 41-62; Tessa Morrison, Isaac Newton's Temple of Solomon and his Reconstruction of Sacred Architecture, Basel 2011. 


\title{
IV. Verborgene Wurzeln - Ars memoriae und Metempsychose
}

\author{
IV.1 Beschleunigte Wiedergeburt - Freimaurerisches Ritual als \\ Veredelungsprozess der Seele
}

\author{
Er lebt im Sohn. \\ — Meisterwort $»$ Macbenac ${ }^{1}$
}

Wie bereits erwähnt, ließ sich niemand Geringerer als der Prinz von Wales 1737 für den Freimaurer-Bund gewinnen. Auch andere Vertreter des europäischen Adels ließen sich um 1740 in die Geheimnisse des Bundes einweihen. Es ist anzunehmen, dass neben der Vorstellung einer langen Kette eingeweihter Vorfahren auch die Hoffnung auf eine besonders erlesene Gesellschaft und nicht zuletzt auf die Einweihung in die Gegenstände einer Geheimwissenschaft dieses Anbändeln beförderte. Bereits Steven C. Bullock stellte die Wichtigkeit der intensiven Beschäftigung einer Geistesgröße wie Isaac Newton mit Alchemie heraus. Demnach erhoffte sich Newton von einer Entschlüsselung der seiner Meinung nach chiffrierten alchemistischen Allegorien innerhalb der Bibel die Rekonstruktion des Wissens einer Urreligion, die ihm eine tiefere Einsicht in den göttlichen Schöpfungsplan ermöglichen sollte. ${ }^{2}$ Derartige Interessen fielen auch in der Gründergeneration der ersten Großloge auf fruchtbaren Boden. ${ }^{3}$ So ist es wenig

1 Es handelt sich hierbei um eine der möglichen Übersetzungen des freimaurerischen Meisterworts »Macbenac« nach: Lennhoff/Posner/Binder (Hg.), Internationales Freimaurer-Lexikon (wie Anm. 18, Kap. I), 535.

2 Vgl. insb. Bullock, Revolutionary Brotherhood (wie Anm. 43, Kap. I), 14 f.

3 Vgl. Ders., Revolutionary Brotherhood (wie Anm. 43, Kap. I), 10f. Bullock verweist bereits anhand der Geringschätzung, die Stukeleys Forschungen zur Urreligion in späterer Zeit in der Royal Society entgegengebracht wurde, darauf, dass derartige Interessen allmählich einen schwereren Stand hatten. Zu Bezügen des freimaurerischen Rituals zur Alchemie und Magie vgl. August Wolfstieg, Werden und Wesen der Freimaurerei. 2. Abt.: Die Philosophie der Freimaurerei, Bd. 1, Berlin 1922, insb. 38-41 sowie 77f.; Oswald Wirth, Le symbolisme hermétique dans ses rapports avec l'alchimie et la franc-maçonnerie, 2. Aufl., Paris 1931; Hans Biedermann, Das verlorene Meisterwort. Bausteine zu einer Kultur- und Geistesgeschichte des Freimaurertums, 3. Aufl., Wien/Köln/ Weimar 1999, 124-143; Karl R.H. Frick, Die Erleuchteten. Gnostisch-theosophische und alchemistisch-rosenkreuzerische Geheimgesellschaften, Wiesbaden 2005, insb. 209-213. Zum Einfluss von Alchemie und Magie auf das freimaurerische Ritual und insb. auf die junge Großloge von England vgl. insb. die Einträge »Alchimie (Alchemie, auch Alchymie) «, »Magie« und »Magische Maurerei« im Internationalen Freimaurer-Lexikon: Lennhoff/Posner/Binder (Hg.), Internationales Freimaurer-Lexikon (wie Anm. 18, Kap. I), 61f. sowie 537f.; jüngst auch: Wouter J. Hanegraaff, Esotericism and the Academy. Rejected Knowledge in Western Culture, Cambridge 2012, 210-212. Die Verfasser des Internationalen Freimaurer-Lexikons argumentieren hier, was die Beteiligung des Adels an magisch-alchemistischen Praktiken innerhalb der Freimaurerei und des Gold- und Rosenkreuzertums zum Ende des 18. Jh.s angeht, vor allem im Eintrag »Magische Maurerei« im Sinne eines bloßen materiellen Interesses an Geld bzw. Gold. Biedermann sieht zwar richtigerweise keine direkte Ableitung, jedoch durchaus eine ideelle Verbindung der Freimaurerei um 1717 mit den Rosenkreuzern. Er führt die Einbringung alchemistischer und rosenkreuzerischer Ideen in 
verwunderlich, dass das freimaurerische Ritual ähnlich wie magische und alchemistische Prozeduren auf stark symbolisch aufgeladenen Handlungen beruhte. Ziel war es hierbei aus Sicht der Zeitgenossen, eine moralisch-sittliche Reifung des Adepten mit Hilfe starker Sinneseindrücke hervorzurufen - ein Anliegen, das im Übrigen durchaus gut mit den empiristischen und sensualistischen Strömungen der zeitgenössischen Philosophie in Einklang zu bringen war.

Insbesondere durch Frances A. Yates und David Stevenson erfolgte der Hinweis, dass im Hintergrund des freimaurerischen Rituals die Praktiken der ars memoriae der Antike und Renaissance walteten. ${ }^{4}$ Die ars memoriae wurde, wie oben bereits erwähnt, seit der Antike als Bestandteil der Tugend der Klugheit gesehen. ${ }^{5}$ Durch die Hilfsmittel der ars memoriae ist es möglich, das Erinnerungsvermögen auszuweiten. So führt etwa Stevenson das Beispiel eines Redners an, der mit Hilfe des gedanklichen Durchschreitens der Räume eines imaginierten Gebäudes die einzelnen Argumente seiner Rede memorieren kann, indem jeder Raum bzw. die in ihm befindlichen Objekte jeweils bildlich für bestimmte Argumente stehen. ${ }^{6}$ Dieses Prinzip war auch im Hintergrund des alle Sinne einbeziehenden freimaurerischen Rituals vorzufinden, das die architektonische Figur des salomonischen Tempels sowohl gedanklich als auch materiell auf einem zentral im Logenraum platzierten Tapis oder auch regelrechten Kulissen während des Rituals vor den Augen der »Brüder « inszenierte. ${ }^{7}$

Bereits in den Darstellungen der "Verräterschriften« des frühen 18. Jahrhunderts zum Aufnahmeritual in den Lehrlingsgrad kann dieser sinnlich erfahrbare "Veredelungsprozess" anhand bestimmter Aspekte erkannt werden. Hierzu gehörte bereits das Warten des sogenannten "Suchenden « vor seiner Aufnahme in die Loge in der »chambre obscure«. Die dunkle Kammer diente der Meditation und sollte die geistige Unreife des Adepten andeuten. Von einem Bruder geleitet, traten ihm daraufhin während seiner mit verbundenen Augen durchgeführten »Reisen« durch den Logenraum symbolisch einige Gefahren des Lebens entgegen.

die Freimaurerei vor allem auf die Person Elias Ashmoles (1617-1692) zurück. Vgl. hierzu Biedermann, Das verlorene Meisterwort (wie Anm. 3, Kap. IV), 135f. sowie ferner Roland Edighoffer, Die Rosenkreuzer, Sonderausgabe, München 2008, 95-100.

4 Vgl. Stevenson, The Origins of Freemasonry (wie Anm. 16, Kap. I), 77-96; Yates, The Art of Memory, (wie Anm. 17, Kap. I).

5 Siehe Yates, The Art of Memory (wie Anm. 17, Kap. I), 35f. Yates bespricht hier insb. Ciceros Ausführungen zur Rhetorik in Ciceros De inventione.

6 Vgl. Stevenson, The Origins of Freemasonry (wie Anm. 16, Kap. I), 87.

7 Für die Ausstattung der Logen lagen auch visuelle Vorschriften vor. Siehe diesbezüglich auch die Abb. 7, 12, 13, 14, 15, 22, 23, 24, 25, 28, 29, 30. Das freimaurerische Ritual setzte neben visuellen Eindrücken u.a. auch auf musikalische Untermalung. Neben den bereits für das frühe 18. Jh. nachweisbaren Liedern, die zu bestimmten feierlichen Anlässen von den Brüdern einer Loge gesungen wurden, sowie den eigens für die Freimaurerei komponierten Werken Mozarts scheint hier vor allem das Beispiel der Pariser Adelsloge La Candeur erwähnenswert. Ihr Logentableau weist etwa im Jahr 1776 ausschließlich adlige Mitglieder auf. Sie unterhielt jedoch zudem ein eigenes Orchester mit 14 Musikern, die sämtlich aus dem dritten Stand stammten. Vgl. hierzu Loge La Candeur, Paris, Tableaux 1775-1782, in: BnF, FM2 58bis, fol. 57. Zum »Tapis« siehe den entsprechenden Eintrag in Lennhoff/Posner/Binder (Hg.), Internationales Freimaurer-Lexikon (wie Anm. 18, Kap. I), 836. 


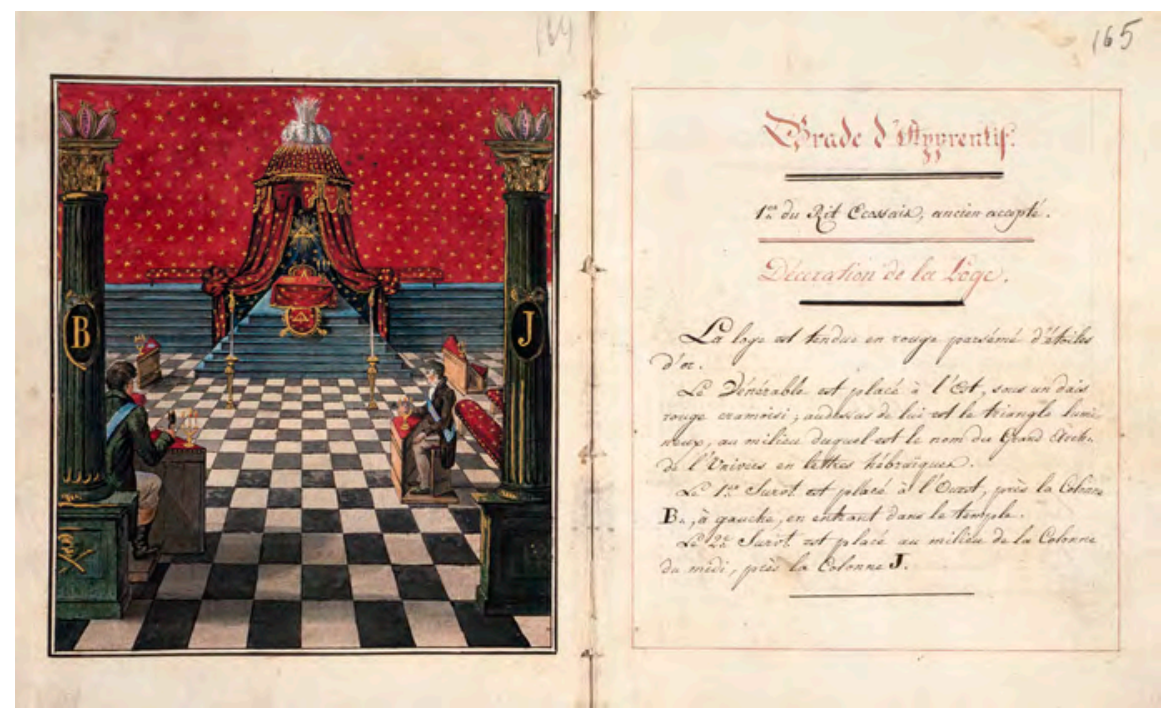

Abbildung 7: Grade d'Apprentif (= Logenraum im Lehrlingsgrad mit »musivischem Pflaster" und den beiden Säulen Jachin und Boaz im Vordergrund), um 1800 (Bildrecht/Werk und Foto: From the collections of the Cultural Masonic Centre, The Hague).

So wurde er etwa durch lärmende Geräte, das Zublasen der Hitze einer Flamme und andere Hindernisse, die sich seinem Weg in der Blindheit entgegenstellten, in Furcht versetzt. Die jeweilige Bedeutung dieser Proben für die sittliche Reifung des Adepten eröffnete ihm der Meister vom Stuhl in kurzen Vorträgen zum Ende jeder Reise. Schließlich erfolgte die Abnahme der Augenbinde im Kreise der neuen Brüder und damit die "Lichterteilung « als Freimaurer. In einer Verräterschrift hieß es zu den Auswirkungen, die diese Reisen auf den Rezipienten hatten, unter anderem: »On est aussi fatigué lorsqu'elle est fini, que si l'on avoit fait un long voyage. $\varkappa^{8}$

Dieser stufenweise erfolgende quasialchemistische Veredelungsprozess mit dem Ziel einer fortschreitenden geistigen `Erfahrung`setzte sich zunächst lediglich im Gesellengrad fort. Im Laufe der Reformen der "Moderns" trat um das Jahr 1724 der Meistergrad hinzu, in den im Laufe des 18. Jahrhunderts auch die meisten der rheinischen adligen Freimaurer eingeweiht werden sollten. ${ }^{9}$ Im Ritual

8 Siehe zu einer frühen Beschreibung des Ritualablaufs im Sinne der obigen Darstellung sowie dem hier angeführten Zitat Gabriel Louis Calabre Pérau/Johann Leuchtbecher/Johann Erich Biester, L'Ordre des Francs-Maçons trahi, et le secret des Mopses revelé, Amsterdam 1745, 54-73, Permalink: http://nbn-resolving.org/urn:nbn:de:bvb:12-bsb10435606-1 (Zugriff vom 25.05.2014). Das Zitat findet sich auf 60. Eine Illustration des Aufnahmerituals (Gravur, nach Gabanon, 1745 bzw. um 1800) findet sich unter: commons.wikimedia.org/wiki/File:Freimaurer_Initiation.jpg (Zugriff vom 07.08.2014).

9 Zu dieser Datierung vgl. die Angaben bei Heinrich Boos, Geschichte der Freimaurerei. Ein Beitrag zur Kultur- und Literatur-Geschichte des 18. Jh.s, 2. Aufl., Aarau 1906, 110 sowie 165. Zur Einweihung der rheinischen Adligen siehe die Tabelle in Anhang A dieser Arbeit. 
dieses dritten Grades wurde neben der Reisesymbolik eine Legende um den Mord an dem bereits erwähnten Baumeister des salomonischen Tempels Hiram Abiff aufgegriffen. Demnach habe Salomon nach dem spurlosen Verschwinden Hirams 15 Maurer beauftragt, diesen zu suchen. Das Ritual des Meistergrades stellte diese Geschichte um den Tod Hirams und die Auffindung seines Leichnams nach, wobei der Rezipient symbolisch die Rolle des ermordeten Hiram einnahm. ${ }^{10}$ Nachdem dieser durch seine Brüder - dem Ablauf des Rituals gemäß - aufgefunden und vom Boden des Logenraums als »neugeborener « Meister emporgehoben worden war, wurde ihm das Meisterwort "Macbenac « erteilt. ${ }^{11}$ Im Hinblick auf die magisch-alchemistischen Anklänge innerhalb der freimaurerischen Rituale ist die Erteilung dieses angeblich uralten $»$ Meisterworts ${ }^{12}{ }^{2}$ sowie die hiermit zusammenhängende Wiedergeburtsthematik von besonderem Interesse.

Verschiedene Worte und Zeichen wurden in der spekulativen Freimaurerei bereits den Lehrlingen und Gesellen als Erkennungszeichen bei ihrer Einweihung bzw. Beförderung gegeben. Das körperliche Erkennungszeichen der sogenannten »Fünf Punkte« (Fuß an Fuß, Knie an Knie, Brust an Brust, Wange an Wange, Hand in Hand), mit denen der "neugeborene« Meister emporgehoben wurde, und die Bedeutung des Meisterworts sind für das Ritual des dritten Grads von Wichtigkeit. So rankte sich um die Herkunft des körperlichen Erkennungszeichens der Fünf Punkte noch in den 1720er Jahren in der englischen Freimaurerei eine eigenartige Legende, die von dem Auffinden des Leichnams Noahs durch seine drei Söhne Sem, Ham und Jafet berichtete. ${ }^{13}$ Knoop und Jones verwiesen bereits auf die deutlichen nekromantischen Züge der Noah- bzw. Hiramslegende sowie des

10 Vgl. Samuel Prichard, Masonry Dissected, 20. Aufl., London 1770 [?] (Erstausgabe 1730), 18-22, Permalink: http://n2t.net/ark:/13960/t4sj3xj9c (Zugriff vom 25.05.2014).

11 Ders., Masonry Dissected (wie Anm. 10, Kap. IV), 21. Eine Illustration der Erhebung des Meisters während des Rituals (Gravur, nach Gabanon, 1745 bzw. um 1800) findet sich unter: commons. wikimedia.org/wiki/File:Freimaurer_Erhebung.jpg (Zugriff vom 07.08.2014).

12 Bereits in den frühen schottischen Logen der Werkmaurer diente ein sogenanntes "Maurerwort" sowie andere Geheimzeichen der gegenseitigen Erkennung der Mitglieder. Einige schottische Freimaurer des späten 17. Jh.s nahmen an, dass sowohl das Maurerwort als auch die geheimen körperlichen Erkennungszeichen der Werkmaurer bis auf die Zeiten des Turmbaus zu Babel, zumindest aber der Erbauung des salomonischen Tempels zurückgingen. Vgl. hierzu die Ausführungen bei Knoop/Jones, Die Genesis der Freimaurerei (wie Anm. 2, Kap. III), 92.

13 Vgl. zu sämtlichen hier gemachten Angaben Dies., Die Genesis der Freimaurerei (wie Anm. 2, Kap. III), 93. Diese ursprünglich im sogenannten Graham-Manuskript aus dem Jahr 1726 enthaltene Geschichte um Noah sei hier in der Zusammenfassung Knoops und Jones' wiedergegeben: "Alles, was die neue Welt dringend brauchte, war in Noahs Arche gewesen. Nun gingen dessen drei Söhne, die etwas zu finden begehrten, das sie zu dem wertvollen Geheimnis in ihres Vaters Besitz führte, zu Noahs Grab und machten vorher aus, wenn sie nicht die Sache selbst fänden, so sollte das erste Ding, auf das sie stießen, als das Geheimnis gelten. Sie fanden im Grabe nichts weiter als den toten Leib; als man den Finger ergriff, löste er sich ab; dasselbe geschah mit Handgelenk und Ellenbogen. Darauf richteten die Söhne den toten Körper auf und stützten ihn dabei, indem sie Fuß an Fuß und Knie an Knie setzten und Brust an Brust, Wange an Wange und die Hand auf den Rücken legten. Danach sagte einer: Hier in diesem Knochen ist noch Mark. Und der andere sagte: Nein, es ist nur ein trockener Knochen. Der dritte: Er stinkt. Und so kamen sie überein, ihm einen Namen zu geben, wie er der Freimaurerei noch bis zum heutigen Tage bekannt ist. « In 
Meister-Rituals. ${ }^{14}$ Sie bemerkten, dass der »Knochen, der nach der Noaherzählung das erste [sic!] war, was man fand, [...] eine ganz bestimmte Bedeutung « haben müsse. ${ }^{15}$ Sie maßen zudem dem bereits in einem Manuskript aus dem Jahr 1700 erwähnten Meisterwort einige Bedeutung zu, ohne seine Verwendung erklären zu können. ${ }^{16}$

Das »Internationale Freimaurer-Lexikon« führt mehrere Übersetzungen des Meisterwortes an, wobei letztlich alle die Gegenüberstellung von »Leben « und »Tod « aufzeigen bzw. das »Fortleben des Vaters im Sohn« beinhalten. ${ }^{17}$ Hans Biedermann gibt in seiner Studie mit dem Titel »Das verlorene Meisterwort « ergänzend hierzu als Übersetzung "Sohn der Verwesung " an und schließt sich nach einer ausführlichen Besprechung der auf die Alchemie verweisenden Aspekte des freimaurerischen Rituals unter anderem der Ausdeutung Otto Wolfskehls an, dass das Meisterwort bzw. der hierin angesprochene Verwesungsprozess auf einen geistigen Erneuerungsprozess des Rezipienten im Anschluss an dessen symbolischen Tod hindeuten soll. ${ }^{18}$ Nach Biedermann ist im alchemistischen Prozess der Metallveredelung die Stufe der »>Putrefactio< (Verfaulung, Verwesung) oder >Nigredo< (Schwärzung) eine Voraussetzung « für die »Vervollkommnung « des unedlen Metalls zu Gold. ${ }^{19}$ Das freimaurerische Meisterwort wäre, so darf hier geschlossen werden, somit einem magischen Zauberspruch oder dem alchemistischen lapis philosophorum gleichzusetzen, der im jeweiligen gedanklichen Kontext einen Umwandlungsprozess - hier also des Freimaurergesellen zum Freimaurermeister - in Gang setzen soll. ${ }^{20}$ In Ergänzung hierzu wird in der vorliegenden Studie davon ausgegangen, dass es insbesondere der in der Legende dem Knochen entströmende Verwesungsgeruch bzw. - aus zeitgenössischer Perspektive gedeu-

abgewandelter Form findet sich diese Legende laut Knoop und Jones noch im selben Jahr auf den Baumeister des salomonischen Tempels, Hiram Abiff, bezogen.

14 Vgl. Dies., Die Genesis der Freimaurerei (wie Anm. 2, Kap. III), 95. Knoop und Jones wiesen insb. auf die in der Bibel überlieferten Praktiken der Totenerweckung hin, die den Fünf Punkten deutlich ähneln. Die Nekromanten legten sich demnach der Länge nach auf die leblosen Körper und atmeten den Toten ins Gesicht.

15 Dies., Die Genesis der Freimaurerei (wie Anm. 2, Kap. III), 95.

16 Vgl. Dies., Die Genesis der Freimaurerei (wie Anm. 2, Kap. III), 96.

17 Vgl. Lennhoff/Posner/Binder (Hg.), Internationales Freimaurer-Lexikon (wie Anm. 18, Kap. I), 535. Die hier wiedergegebenen Übersetzungen lauten in der Reihenfolge ihrer Erwähnung: »Er lebt im Sohn «, »Der Sohn des toten Meisters«, »Schlachtfeld «/»Ende«, "Sohn«/»Tod«, »Sohn«/»Witwe«, "Mit dir ist dein Sohn« sowie »Der Tod ist das Ende des Fleisches, die Seele wird ewig bestehen!«.

18 Vgl. Biedermann, Das verlorene Meisterwort (wie Anm. 3, Kap. IV), 83-85 sowie 124-143. Hierzu ist außerdem zu erwähnen, dass Biedermann auch die »schöpferische Kraft des Logos« in der Magie bzw. im freimaurerischen Ritual ausführlich bespricht. Vgl. Ders., Das verlorene Meisterwort, 91.

19 Ders., Das verlorene Meisterwort (wie Anm. 3, Kap. IV), 85.

20 Vgl. zur auslösenden Kraft des lapis philosophorum: Lawrence M. Principe, Lapis philosophorum, in: Claus Priesner/Karin Figala (Hg.), Alchemie. Lexikon einer hermetischen Wissenschaft, München 1998, 215-220, hier 215f. Siehe außerdem zum Wort im magischen Kontext Biedermann, Das verlorene Meisterwort (wie Anm. 3, Kap. IV), 87-109. 
tet - die entweichenden Lebensgeister sind, die einen entscheidenden Hinweis zur Klärung des Problems geben.

Die oben stehende Interpretation des freimaurerischen Rituals im Sinne der Gedankenwelt der Magie bzw. Alchemie sowie ihre Prägung durch die ars memoriae ist unter Berücksichtigung der Interessen vieler Freimaurer und Adliger ${ }^{21}$ des 18. Jahrhunderts keinesfalls abwegig und wird im Folgenden noch von größerer Wichtigkeit in Bezug auf die weitere Untersuchung des Zusammenhangs zwischen adliger »Blutsideologie« und freimaurerischem Ritual sein. Zunächst sei hier lediglich erwähnt, dass in diesen archaisch anmutenden Elementen des freimaurerischen Rituals ein Aspekt enthalten ist, der am meisten auf ein für die Moderne allgemein als typisch angesehenes Charakteristikum verweist: die »Beschleunigung der Zeit «. ${ }^{22}$ So besaß etwa die Alchemie aus Sicht vieler Zeitgenossen des 17. und 18. Jahrhunderts das Wissen, den sonst nur langsam im Inneren der Berge ablaufenden Prozess der Reifung unedler Metalle zu Gold im Laboratorium rasant verkürzen zu können. ${ }^{23}$

Bei der Betrachtung eines solchen alchemistischen Experiments sollte der Laborant eine seelisch-charakterliche Reifung erfahren. Ähnliches konnte auch für das freimaurerische Ritual mit seiner Betonung bestimmter sinnlich erfahrbarer Eindrücke angenommen werden. In einer auf Analogien ausgerichteten Weltsicht konnten die freimaurerischen Reisen im `Mikrokosmos des Logenraums somit den Anspruch erheben, in wenigen Stunden die erfahrungsmäßigen Essenzen jahrelanger Erziehungsreisen vermitteln zu können. Das Ziel eines solchermaßen verkürzten seelischen Läuterungsprozesses war eine beschleunigte »geistige Wiedergeburt « des Adepten. ${ }^{24}$

21 Als prominentes Beispiel darf hier wiederum der alchemistisch laborierende Franz Stephan von Lothringen erwähnt werden. Vgl. zum Interesse der Habsburger an Alchemie und insb. der Transmutationsalchemie: Rudolf Werner Soukup, Chemie in Österreich: Bergbau, Alchemie und frühe Chemie. Von den Anfängen bis zum Ende des 18. Jh.s, Bd. 1, Wien/Köln/Weimar 2007, 527. Soukop äußert hier u.a. seine Überraschung über das »lückenlose Interesse« der Habsburger an der Alchemie. Er bezeichnet zudem die »engen Verflechtungen des österreichischen und böhmischen Adels in Sachen Alchemie« als »Normalzustand «.

22 Zur zentralen Bedeutung der "Beschleunigung der Zeit« in Magie und Alchemie der Frühen Neuzeit siehe die entsprechende These bei Maximilian Bergengruen, Nachfolge Christi - Nachahmung der Natur. Himmlische und Natürliche Magie bei Paracelsus, im Paracelsismus und in der Barockliteratur (Scheffler, Zesen, Grimmelshausen) (Paradeigmata, 26), Hamburg 2007, 38-159, insb. 104-159. Die Ausführungen Bergengruens zur Verbindung von Astrologie und Tugendvorstellungen im Paracelsismus (»Impressio«) scheinen ebenfalls aufs Engste mit dem hier behandelten Thema in Verbindung zu stehen, müssen jedoch weiteren Forschungsarbeiten vorbehalten bleiben.

23 Biedermann, Das verlorene Meisterwort (wie Anm. 3, Kap. IV), 127.

24 Vgl. zu der in diesem Abs. wiedergegebenen Beziehung des alchemistischen Laborierens zur Psyche auch Ders., Das verlorene Meisterwort (wie Anm. 3, Kap. IV), 127f. Siehe zum Begriff "geistige Wiedergeburt" sowie zur Bedeutung der Ideen von Wiedergeburt und Unsterblichkeit im freimaurerischen Ritual die Einträge »Wiedergeburt«, "Unsterblichkeit» und insb. »Mysterien « im Internationalen Freimaurer-Lexikon: Lennhoff/Posner/Binder (Hg.), Internationales FreimaurerLexikon (wie Anm. 18, Kap. I), 588f., 863 sowie 903. 
Ein »verlorenes Wort «blieb abseits des Meistergrads insbesondere in den um die Mitte des 18. Jahrhunderts entstehenden Hochgradsystemen weiterhin von Bedeutung. Das Gedankengut der Alchemie und Hermetik erfuhr bei diesen Fortsetzungen der Johannisgrade - entgegen allen in der Freimaurerei ebenfalls vorhandenen rationalistischen Tendenzen - verstärkte Aufmerksamkeit. Dies ausschließlich mit dem Standardargument der Gier nach Gold und Reichtum insbesondere einiger adliger Freimaurer abzutun, greift dabei deutlich zu kurz. Inwiefern sich die Gedankenwelt der Alchemie vielmehr bereits seit Längerem direkt mit der adligen »Blutsideologie« verknüpfen ließ, soll in den folgenden Kapiteln dargestellt werden.

\title{
IV.2 "Feine Seelen« - Verbindungen hermetisch-alchemistischer Vorstellungen zur adligen "Blutsideologie»
}

\begin{abstract}
Et tout ainsi que les alchimistes disent, que l'or se change trois fois auant qu'acquerir sa qualité, aussi la troisiesme mutation \& generation purifie le sang \& la race, \& en efface tout vestige de roture.
\end{abstract}

- Charles Loyseau ${ }^{25}$

Bereits Ernst Kantorowicz sprach in seiner Studie »Die zwei Körper des Königs« Grundlagen der adligen »Blutsideologie» aus der Zeit des Mittelalters an und fasste sie in der Formel natura et gracia zusammen. ${ }^{26}$ Die Geburt eines Erben wurde demnach etwa im Königtum des 11. Jahrhunderts als ein Gottesurteil aufgefasst. Kantorowicz führte in Bezug auf die Prinzenerziehung des Sohns des Stauferkönigs Friedrich II. ein interessantes Zitat aus einem Dokument des 13. Jahrhunderts an. Hierin heißt es: ») Unwissende Prinzen tragen einen um so größeren Makel als Privatleute, als der Adel des [königlichen] Blutes sich auszeichnet durch die Verbindung mit einer feinen und edlen Seele, die Prinzen mehr als andere Menschen für Lehren empfänglich macht. « ${ }^{27}$

Die Erwähnung einer mit dem Blut verbundenen »feinen und edlen Seele«, die zur besonders leichten Aufnahme von Lehren befähigt, gleicht in der Begrifflich-

25 Charles Loyseau, Cinq livres du droict des offices, avec le livre des seigneuries, et celui des ordres, 2. Aufl., Paris 1613, 108, Permalink: http://gallica.bnf.fr/ark:/12148/bpt6k118300j (Zugriff vom 22.05.2014). Zu einer ähnlichen Bemerkung Loyseaus siehe auch Devyver, Le sang épuré (wie Anm. 50, Kap. II), 213.

26 Ernst H. Kantorowicz, Die zwei Körper des Königs. Eine Studie zur politischen Theologie des Mittelalters, 2. Aufl., München 1994, 332f. Eine Ergänzung zu Kantorowiczs Studie stellt in gewisser Weise auch die ebenso berühmte Studie Marc Blochs zu den »wundertätigen Königen« dar. Marc Bloch, Die wundertätigen Könige, München 1998 (Erstausgabe 1924). In Bezug auf jüngere Studien zu den religiösen Vorstellungen zum menschlichen Blut in Mittelalter und Früher Neuzeit sei insb. auf Caroline Walker Bynum verwiesen: Caroline Walker Bynum, Wonderful Blood. Theology and Practice in Late Medieval Northern Germany and beyond, Philadelphia 2007.

27 Zitiert nach Kantorowicz, Die zwei Körper des Königs (wie Anm. 26, Kap. IV), 333. Bei der Angabe in Klammern handelt es sich um eine Ergänzung Kantorowiczs. 
keit durchaus der Beschreibung des weisen Königs Salomon durch Johann Michael von Loen im 18. Jahrhundert. ${ }^{28}$ Das von Kantorowicz aufgegriffene Zitat gibt uns insofern indirekt einen Hinweis bezüglich des Bedeutungsgehalts der adligen "Blutsideologie" des 17. und 18. Jahrhunderts. Kantorowicz vermutete in dem Glauben an eine besonders »feine Seele« der Prinzen den Niederschlag hermetischer Lehren, deren Bekanntheit er für das 13. Jahrhundert jedoch nur in geringem Maß nachweisen konnte. Anders als für das 13. Jahrhundert kann eine höhere Bekanntheit der Schriften des Corpus Hermeticum für das 17. und 18. Jahrhundert jedoch vorausgesetzt werden. ${ }^{29}$

Eine vertiefte Ausdeutung des oben angeführten Zitats des bedeutenden französischen Rechtsgelehrten Charles Loyseau (1566-1627) ist daher vor diesem Hintergrund möglich. Nicht nur der in Bezug auf die Nobilitierungspraxis seiner Zeit durchaus kritische Loyseau, ${ }^{30}$ sondern auch Cardin Le Bret (1558-1655) hatten im Frankreich des 17. Jahrhunderts bereits die anthropomorphe Metallurgie Platons im Zuge der Rechtfertigung der Existenz einer adligen »Rasse « aufgegriffen. ${ }^{31}$ Wie bereits gesehen, verband sich diese antike Vorstellung im Fall Loyseaus direkt mit

28 Loen, Der Adel (wie Anm. 22, Kap. II), Abh. I, $₫ 3$, 4. Dieser alte Glauben an das »beseelte Blut« ließe sich durch die einschlägigen Erwähnungen in der Bibel sowie weitere Beispiele aus dem Mittelalter und der Frühen Neuzeit erweitern. Vgl. hierzu die Beispiele bei Gia Toussaint, Blut im Flakon. Orientalische Fläschchen zur Präsentation des Blutes Christi im Mittelalter, in: Christine Knust/Dominik Groß (Hg.), Blut. Die Kraft des ganz besonderen Saftes in Medizin, Literatur, Geschichte und Kultur (Studien des Aachener Kompetenzzentrums für Wissenschaftsgeschichte, 7), Kassel 2010, 191-206. Zu frühneuzeitlichen Beispielen siehe im selben Bd. auch Christine Knust, Von Armsündertüchlein und Liebestränken. Blut als Heil- und Zaubermittel in Volksmedizin und Volksglauben, in: Dies., Blut (wie Anm. 28, Kap. III), 209-228.

29 In einer längeren Anmerkung zu den möglichen Einflüssen verwies er sowohl auf das zu den Schriften des Hermetismus zählende Kore Kosmou als auch auf pythagoreische Vorstellungen zum Königtum. Kantorowicz erwähnte außerdem bereits eine Kontinuitätslinie derartiger Vorstellungen bis in die Zeit des »Absolutismus«. Vgl. Kantorowicz, Die zwei Körper des Königs (wie Anm. 26, Kap. IV), 333-335.

30 Vgl. hierzu Devyver, Le sang épuré (wie Anm. Anm. 50, Kap. II), 213f. Loyseau hatte demnach Zweifel an der Praxis der Nobilitierung durch den französischen König, wenngleich er ihm dieses Recht - aufgrund seiner nicht in Frage gestellten göttlichen Gnade - nicht absprach. Devyver betont jedoch: "Est-ce sous l'influence du >racisme social latent de son époque qu'il [Loyseau, Anm. d. Verf.] ajoute (et cet aveu n'pas échappé à l'observateur sagace que fut Alés de Corbet): >Cet abolition de roture n'est qu'une effaçure dont la marque demeure. Elle semble même plutôt une fiction qu'une réalité, le Prince ne pouvant, par effet, rendre l'être au non être?«« Devyver ergänzt hiernach: „Comment donner un passé à ceux qui en étaient dépourvus, comment faire couler dans les veines d'une personne de mérite un sang autre que celui d'un geniteur qui appartenait au commun de l'humanité? Nous n'affirmons pas que Loyseau ait pensé que cela était impossible, et toute son œuvre a meme été construite pour établir le contraire [...], mais, esprit logique, il se rendait parfaitement compte que quelque chose clochait dans le raisonnement de ceux qui, par la force meme de l'oubli, s'imaginaient pouvoir corriger la nature et changer la `race «. " Ders., Le sang épuré (wie Anm. Anm. 50, Kap. II), 213f. Wie im Folgenden gezeigt werden soll, scheinen gerade die alchemistischen Äußerungen Loyseaus einen Ausweg aus diesem hier von Devyver aufgezeigten Paradoxon zu sein.

31 Siehe zum Vergleich der Stellungnahmen Loyseaus und Le Brets in der Diskussion um die Voraussetzungen der »Adligkeit« im 17. Jh. mit dem Hinweis auf Le Brets ähnliche Argumentation Elie Haddad, The Question of the Imprescriptibility of Nobility in Early Modern France, in: Matthew P. 
der Gedankenwelt der Alchemie. Eine ähnlich alchemistisch geprägte Ideenwelt war auch noch im Umfeld der englischen Freimaurerei des frühen 18. Jahrhunderts wirksam. ${ }^{32}$ Zwar wurde der »Vater der Alchemie « und fiktive Verfasser der hermetischen Schriften in den Andersonschen »Constitutions « bereits nicht mehr unter dem Namen »Hermes Trismegistos« erwähnt, dafür jedoch sein oftmaliges Äquivalent » Moses«. ${ }^{33}$

Die Entstehungsgeschichte des Corpus Hermeticum kann an dieser Stelle nicht ausführlich besprochen werden. Die wichtigsten Fakten sollen hier zum besseren Verständnis dennoch anhand der Ausführungen Kocku von Stuckrads und Florian Ebelings zusammengefasst werden. Das Corpus Hermeticum ist eine Zusammenstellung griechischer Schriften, deren Ursprünge bis ins 3. Jahrhundert n. Chr. zurückgehen. Bei seiner Auffindung im 15. Jahrhundert hielt man es jedoch für die Übermittlung eines Wissens aus den Urzeiten der Menschheit. Vom Inhalt her stellte es eine Mischung christlicher, neuplatonistischer und ägyptischer Lehrtraditionen dar, die unter anderem um das Thema der »Erkenntnisfähigkeit des Menschen « kreisten, wobei im Sinne der platonischen Philosophie davon ausgegangen wurde, dass die menschliche Seele einen zur Erkenntnis fähigen göttlichen Funken beinhalte und sich von ihrem Körper durch ein gerechtes Leben befreien und in ihre »Lichtheimat « bei Gott zurückkehren könne. ${ }^{34}$ Mit der Kritik des Philologen Isaac Casaubon im Jahr 1614 war die Datierung der Entstehung des Corpus Hermeticum auf vorsintflutliche Zeiten zwar anzweifelbar, ${ }^{35}$ jedoch hatte sich noch 1678 Ralph Cudworth, der Mitglied der Royal Society war und zu der Gruppe der Cambridger Neuplatonisten zählte, für eine Einschränkung der casaubonschen Kritik ausgesprochen und dessen Argumentationsweise sogar gegen ihn verwendet. ${ }^{36}$ Aus dieser Perspektive blieb es also beim hohen Alter des Corpus Hermeticum.

Romaniello/Charles Lipp (Hg.), Contested Spaces of Nobility in Early Modern Europe, Farnham 2011, 147-166, hier 156-158.

32 Die vorliegende Arbeit stimmt insofern nicht mit der Meinung Florian Ebelings überein, dass

Hermes Trismegistos erst für die spätere Freimaurerei des 18. Jh.s von größerer Relevanz war. Dem ist entgegenzuhalten, dass bereits das von Anderson genutzte Cooke-Manuskript Hermes Trismegistos gemeinsam mit Pythagoras als Übermittler des noachidischen Wissens direkt in einer Schlüsselposition benennt. Zu Ebelings Einschätzung vgl. Florian Ebeling, Das Geheimnis des Hermes Trismegistos. Geschichte des Hermetismus von der Antike bis zur Neuzeit, 2. Aufl., München 2009, 161.

33 Zur Schwierigkeit, die die zeitliche Einordnung der beiden Personen in der Vormoderne machte, und der zeitweiligen Austauschbarkeit der beiden Namen vgl. Cesare Vasoli, Der Mythos der "Prisci Theologi« als »Ideologie« der »Renovatio«, in: Martin Mulsow (Hg.), Das Ende des Hermetismus. Historische Kritik und neue Naturphilosophie in der Spätrenaissance (Religion und Aufklärung, 9), Tübingen 2002, 17-60, hier 47 sowie Martin Mulsow, Epilog: Das schnelle und das langsame Ende des Hermetismus, in: Martin Mulsow (Hg.), Das Ende des Hermetismus. Historische Kritik und neue Naturphilosophie in der Spätrenaissance (Religion und Aufklärung, 9), Tübingen 2002, 305-312, hier 307. Ebenfalls in diesem Sinne: Ebeling, Das Geheimnis des Hermes Trismegistos (wie Anm. 32, Kap. IV), 93; Hanegraaf, Esotericism and the Academy (wie Anm. 3, Kap. IV), 211.

34 Siehe zu sämtlichen bis hierher in diesem Abs. gemachten Angaben und angeführten Begrifflichkeiten die Ausführungen bei Stuckrad, Was ist Esoterik? (wie Anm. 34, Kap. I), 37-41.

35 Vgl. hierzu Ebeling, Das Geheimnis des Hermes Trismegistos (wie Anm. 32, Kap. IV), 126-128.

36 Vgl. Ders., Das Geheimnis des Hermes Trismegistos (wie Anm. 32, Kap. IV), 128-130. 
Kantorowicz verwies bereits auf die Wichtigkeit des Kore Kosmou, ${ }^{37}$ einer Schrift des Corpus Hermeticum, deren wesentliche Inhalte hier - wiederum den Ausführungen Stuckrads und Ebelings folgend - zusammengefasst werden sollen. Das Kore Kosmou stellt einen fiktiven Dialog der Göttin Isis mit ihrem Sohn Horus dar. Hierin wurde unter anderem die Erschaffung der Seelen und des Menschen aus verschiedenen Stoffen abgehandelt, wobei erwähnt wurde, dass Gott nach dem Grad der Reinheit 60 Abstufungen bei den Seelen einrichtete. Da diese zunächst nicht zur Erkenntnis fähig waren und sich daher aus ihrem Stolz heraus gegen Gott erhoben, versetzte er sie in materielle Körper und erschuf somit den zur Selbsterkenntnis fähigen Menschen. Auch den Planeten kam hierbei als Gottheiten eine prägende Aufgabe zu, indem sie den Menschen je nach ihrer eigenen Qualität zu Tugenden oder Lastern beeinflussten. Bei Gehorsam gegenüber den Aufgaben im göttlichen Plan war eine Rückkehr der Seele in den nicht materiellen Zustand und die Nähe Gottes möglich. Zu ihrer Läuterung war jedoch auch eine Wiedergeburt im menschlichen Körper oder ein als schwerste Strafe begriffener Abstieg bis in den Körper eines Tieres vorgesehen. ${ }^{38}$

Eine Untersuchung der Schrift im Hinblick auf Elemente, die einen Bezug zum Thema »Adligkeit« bzw. der göttlichen Ordnung der Gesellschaft besitzen, scheint hier aufgrund der oben gemachten Ausführungen sinnvoll. Da im Kore Kosmou die Vorstellung von möglichen Wiedergeburten vorausgesetzt war, stellte eine hervorgehobene Stellung eines Menschen in der Gesellschaft - ganz im Sinne der Idee der »Großen Kette der Wesen« - die Belohnung für die Gerechtesten bzw. diejenigen dar, die am meisten für die Erfüllung des göttlichen Plans auf Erden gewirkt hatten. Hiermit war unweigerlich der Gedanke einer Prüfung der Seelen im Leben verbunden. Zur besseren Verständlichkeit sei im Folgenden ein Abschnitt des Kore Kosmou, in dem diese von Gott zum Menschen bis hin zu den Tieren absteigende »Kette der Wesen« durch die Göttin Isis beschrieben wird, in der Übertragung André-Jean Festugières ausführlicher zitiert:

Ayant ainsi parlé, mon fils Horus, Dieu les gratifia toutes de soufflés, puis il reprit: ১Cependant, ce n'est pas non plus au hazard et à l'aventure que j’ai statué sur les changements de votre état, mais de même que vous changerez en pire si vous commettez quelque action vilaine, de même changerez-vous en mieux si vous prenez une résolution digne de votre origine: car c'est moi-même, et nul autre, qui serai votre surveillant et votre inspecteur. Reconnsaissez donc que c'est pour vos fautes antérieures que vous subissez ce châtiment de l'in-

37 Kantorowicz, Die zwei Körper des Königs (wie Anm. 26, Kap. IV), 334. Kantorowicz bemerkt hier: »Der Gedanke einer besonders verfeinerten ıvornehmen`Seele, ,fein und edelı, die dem Blut der Prinzen innewohnt, erinnert eher an die hermetische Lehre von der Erschaffung der Seele der Könige. Freilich ist es fraglich, ob diese Lehre damals bekannt war.«

$38 \mathrm{Vgl}$. zu den sämtlichen in diesem Abs. gemachten Angaben in Bezug auf den Inhalt des Kore Kosmou wiederum die Ausführungen bei Kocku von Stuckrad und besonders bei Florian Ebeling, auf dessen Zusammenfassung ein Großteil der hier gemachten Angaben beruht: Stuckrad, Was ist Esoterik? (wie Anm. 34, Kap. I), 40f.; Ebeling, Das Geheimnis des Hermes Trismegistos (wie Anm. 32, Kap. IV), 37-40. 
corporation. Ainsi donc, la diversité de la renaissance consistera pour vous, comme je l'ai dit, en une diversité de corps, et la séparation d'avec le corps sera bienfait et bonheur comme auparavant. Mais votre entendement sera aveuglé, si vous jugez pouvoir commettre quelque action indigne de moi, en sorte que vous penserez le contraire, et que vous subirez le châtiment comme un bienfait, le passage à un état meilleur comme un déshonneur et une violence. Les plus justes d'entre vous, capables de recevoir le changement qui mène au divin, entrant en des corps humains seront des rois justes, des philosophes authentiques, des fondateurs et législateur [...], des devins du moins véridiques, d'authentiques herboristes, d'insignes prophètes des dieux, des musiciens expérimentés des astronomes à l'esprit alerte, des augures perspicaces, des sacrificateurs exacts, et toutes autres fonctions excellentes dont vous soyez dignes; entrant en des volatiles, elles seront des aigles, parce que ceux-ci ne chasseront à grands cris aucun de leurs congénères ni ne se repaîtront de leur chair, bien plus, dans leur voisinage, un animal d'une autre sorte ne sera même pas libre d'en maltraiter un plus faible que lui, car l'aigle, plus soucieux de justice, le poursuivra; entrant en des quadrupèdes, elles seront des lions, car cet animal est plein de force, il a été doué d'une nature qui d'une certaine manière se passe de sommeil, et, dans un corps mortel, il s'excerce à la nature immortelle: les lions en effet ni ne se fatiguent ni ne dorment; entrant en des reptiles, elles seront des dragons, car c'est un animal vigoureux, à longue vie, sans malice et de quelque façon ami des hommes: il se laissera apprivoiser, n'aura pas de venin, et, quand il aura vieilli, reprendra une nouvelle jeunesse, comme la race des dieux; entrant en des poissons, elles seront des dauphins, car ces animaux auront pitié des naufragés en mer: ceux qui respirent encore, ils les transporteront à terre, mais ils ne toucheront absolument jamais aux morts, bien que la race des êtres aquatiques doive être de toutes la plus vorace. ${ }^{39}$

Wie Stuckrad betont, waren alchemistische und magische Vorstellungen innerhalb des Corpus Hermeticum im Gegensatz zu diesen philosophisch-moralischen Gedanken zunächst nur wenig von Belang. Die in ihm enthaltene platonische Seelenlehre ließ sich jedoch mit anderen religiösen Erlösungsvorstellungen wie etwa des Christentums verbinden. ${ }^{40}$ Mit den Schriften des Gelehrten Zosimos aus Panopolis, die zwischen dem 4. und 5. Jahrhundert nach Christus entstanden, wurde auch die Verbindung des Hermes Trismegistos zur Alchemie verstärkt. ${ }^{41}$ Diese im Sinne Stuckrads höchst dynamische Vermischung verschiedenster religiöser, philosophischer und naturwissenschaftlicher Traditionen, die schließlich auch die Verbindung der hermetischen Schriften mit der Alchemie ermöglichte, setzte

39 Corpus Hermeticum, Bd. 4: Fragments extraits de Stobée (XXIII-XXIX), hg. und übers. von André-Jean Festugière, Paris 1954, 13f. Die Auslassung in eckigen Klammern stammt von Festugière. Die innerhalb dieses Zitats wiedergegebenen Zuschreibungen an Tiere erinnern dabei durchaus an die Naturgeschichte eines Buffon oder die oben geschilderten Auszüge über das Pflanzenreich bei Linné.

40 Vgl. hierzu insgesamt Stuckrad, Was ist Esoterik? (wie Anm. 34, Kap. I), 36f.

41 Vgl. hierzu die Ausführungen bei Florian Ebeling: Ebeling, Das Geheimnis des Hermes Trismegistos (wie Anm. 32, Kap. IV), 48. 
sich bis in das Mittelalter und bis weit in das 18. Jahrhundert hinein fort. ${ }^{42}$ Auch in der adligen »Blutsideologie« lässt sich ihr Niederschlag finden, wie im Folgenden gezeigt werden soll.

Wie bereits erwähnt kann eine Bekanntheit der Schriften des Corpus Hermeticum für das 17. und 18. Jahrhundert vorausgesetzt werden, da sowohl französische und italienische als auch für das 17. Jahrhundert englische und niederländische Übertragungen vorlagen. ${ }^{43}$ Eine deutsche Übersetzung bewerkstelligte im Jahr 1706 der aus einem brandenburgischen Zweig des rheinischen Adelsgeschlechts Metternich stammende Wolf Freiherr von Metternich (nicht zu verwechseln mit der oben genannten Familie Wolff-Metternich) unter dem Pseudonym Aletophilus - dies also auch ein direkter Beweis für das Interesse des Adels an der Vorstellungswelt des Hermetismus zu Beginn des 18. Jahrhunderts. ${ }^{44}$ In Bezug auf die Vermischung hermetisch-alchemistischer Vorstellungen mit der adligen »Blutsideologie«, wie sie bereits bei Loyseau in Erscheinung trat, muss an dieser Stelle eine Schrift der Rosenkreuzer besondere Aufmerksamkeit erfahren: die 1616 in Straßburg erschienene »Chymische Hochzeit: Christiani Rosencreutz Anno 1459 «. ${ }^{45}$

In der fiktiven, anonym veröffentlichten Schrift Johann Valentin Andreaes (1586-1654) wird der seelische Läuterungsprozess des Protagonisten, Christian Rosenkreuz, und dessen anschließende Aufnahme in den Ritterorden vom »Goldenen Stein « beschrieben. ${ }^{46}$ Rosenkreuz ist nach einer Initiationsreise Gast bei einer »blutigen Hochzeit«, bei der zunächst drei Königspaare enthauptet werden. Nach dieser Enthauptung beobachtet Rosenkreuz als Adept einen mehrstufigen alchemistischen Prozess, bei dem die aufgelösten Körper der Königspaare schrittweise zu einem sich aus ihrem Blut nährenden Pelikan bzw. Phönix umgewandelt werden, aus dessen Asche schließlich zwei Königskinder, ein Junge und ein Mädchen, künstlich bereitet werden ${ }^{47}$ Nachdem die Königskinder wiederum mit Hilfe des Blutes des Phönix beschleunigt zu Erwachsenen aufgezogen worden

42 Hierzu insgesamt Ders., Das Geheimnis des Hermes Trismegistos (wie Anm. 32, Kap. IV), $154-171$.

43 Siehe die Angaben bei Ders., Das Geheimnis des Hermes Trismegistos (wie Anm. 32, Kap. IV), 157.

44 Vgl. Ders., Das Geheimnis des Hermes Trismegistos (wie Anm. 32, Kap. IV), 157.

45 N.N., Chymische Hochzeit: Christiani Rosencreutz Anno 1459, Straßburg 1616, Permalink: http:// resolver.sub.uni-goettingen.de/purl?PPN661910350 (Zugriff vom 24.05.2014).

46 Vgl. zu einer Wiedergabe und Deutung der Erzählung, der auch hier in Teilen gefolgt wird: Edighoffer, Die Rosenkreuzer (wie Anm. 3, Kap. IV), 34-57. Ein Porträt Andreaes (Radierung von Melchior Küsel, vor 1683) mit diversen Wappen findet sich unter: commons.wikimedia.org/wiki/ File:Johann_Valentin_Andreae_mit_Wappen.jpg (Zugriff vom 02.08.2014).

47 Siehe Edighoffer, Die Rosenkreuzer (wie Anm. 3, Kap. IV), 34-57; Chymische Hochzeit (wie Anm. 45, Kap. IV), insb. 93-129. Es können hier durchaus Bezüge zur alchemistischen Kunst der Destillation gezogen werden, bei der man davon ausging, dass sie den Geist jeglicher Dinge den Körpern entziehen könne. Siehe hierzu etwa Sergius Kodera, The Art of the Distillation of `Spirits as a Technological Model for Human Physiology. The Cases of Marsilio Ficino, Joseph Duchesne and Francis Bacon, in: Manfred Horstmanshoff/Helen King/Claus Zittel (Hg.), Blood, Sweat and Tears. The Changing Concepts of Physiology from Antiquity into Early Modern Europe (Interdisciplinary Studies in Early Modern Culture, 25), Leiden/Boston 2012, 139-170. Zu einer frühneuzeitlichen Abbildung einer Apparatur zur Destillation aus dem in Straßburg im Jahr 1512 veröffentlichten »Liber de arte Distillandi« Hieronymus Brunschwigs siehe: commons.wikimedia.org/ 
sind, findet ihre wundersame dreifache Beseelung statt, bei der ihnen die Seele durch ein Rohr dreimal in Gestalt einer Flamme in den noch unbelebten Körper eingegeben wird. ${ }^{48}$ Roland Edighoffer vermerkt in seiner Ausdeutung der »Chymischen Hochzeit « zum Beseelungsprozess: »Also werden sie nach der Wiedergeburt nicht nur ihre eigene Seele, sondern auch die Seelen ihrer Ahnherren in sich haben, und so werden sie mit dieser verdreifachten, tief verwurzelten Lebenskraft ihre Hochzeit feiern können. « ${ }^{49}$

Die Verbindung der adligen »Blutsideologie« zur Alchemie, wie sie bei Loyseau erwähnt wurde, findet sich literarisch umgewandelt somit auch in der dreifachen Beseelung der vollendeten Königskinder der »Chymischen Hochzeit: Christiani Rosencreutz«. Diese literarisch von Andreae dargestellte alchemistische Generierung eines höheren Geistes bzw. einer höheren Seele aus dem Blut der Ahnen ähnelt stark den Annahmen Loyseaus zum adligen Blut, wobei Letztere jedoch eine deutlich längere Zeit für die Umwandlung der `bäuerlichen Reste` innerhalb des Blutes vorsahen. Eine Veränderung der geistig-seelischen Qualität ergab sich jedoch nicht nur bei den Königskindern, sondern auch beim Hauptprotagonisten der literarischen Fiktion Andreaes. Allein durch die Teilnahme bzw. Beobachtung der »blutigen Hochzeit« gelangte Christian Rosenkreuz nahezu abrupt zur »geistigen Wiedergeburt «.

In Anbetracht der oben getroffenen Feststellungen zum freimaurerischen Ritual ist deshalb danach zu fragen, inwiefern Alchemisten des 17. Jahrhunderts sinnlichen Eindrücken einen Einfluss auf die Seele einräumten und welche Rolle dem Blut in diesem Verhältnis zukam.

\title{
IV.3 Blut als ıflüssiges Gedächtnis` - Die Übertragung "geistiger Bilder« als frühmoderne Vorstellung zur »Rassengenese»
}

\begin{abstract}
Diese Leidenschaften verändern nämlich insbesondere Blut und Geist, indem sie entweder entzünden oder abkühlen. Wenn sich daher Blut und Geist entzünden, werden die im Gedächtnis zu bewahrenden Bilder ausgelöscht, nicht anders als ein in Wachs gepreßtes Bild, das sofort verschwindet, wenn man das Wachs dem Feuer nähert. Und wie umgekehrt durch Kälte härter gewordenes Wachs kein Bild oder zumindest nur ein undeutliches annimmt, so nimmt das Gehirn, wenn die Lebensgeister von der Kälte des Bluts betäubt sind, entweder kein Bild an oder nur ein undeutliches.
\end{abstract}

- Johann Heinrich Alsted ${ }^{50}$

wiki/Images_from_the_Chemical_Heritage_Foundation?\#mediaviewer/File:Hieronymus_Brunschwig_Liber_de_arte_Distillandi_CHF_AQ13x3.jpg (Zugriff vom 03.08.2014).

48 Siehe Edighoffer, Die Rosenkreuzer (wie Anm. 3, Kap. IV), 34-57; Chymische Hochzeit (wie Anm. 45, Kap. IV), 93-129.

49 Edighoffer, Die Rosenkreuzer (wie Anm. 3, Kap. IV), 53.

50 Johann Heinrich Alsted, Encylopædia, in: Jörg Jochen Berns/Wolfgang Neuber (Hg.), Documenta Mnemoncia. Enzyklopädie- und Lexikonartikel zur Mnemonik, Bd. 2: Das enzyklopädische 
Der Anblick und Gestank eines verwesenden Körpers, wie er etwa in der Hirams-Legende des Meistergrades vor das geistige Auge tritt, ist gemeinhin eine schreckliche Vorstellung. Es dürfte jedoch weniger eine Vorliebe für das grausige Ende der körperlichen Existenz menschlichen Lebens gewesen sein, die den Maler des Stammbaums des salmschen Geschlechts dazu bewog, den Beginn der Ahnenreihe bei den Leichen Salmos und Faramunds entspringen zu lassen. Vielmehr zeigt sich hierin eine im Vergleich zur Moderne gänzlich andere Vorstellungswelt, die sich in der Frühen Neuzeit mit einer in Verwesung begriffenen Leiche verbinden konnte. Verwesung und Fäulnis mussten hier nicht ausschließlich für einen als endgültig begriffenen Tod stehen, mit ihnen verband sich auch der Gedanke einer ewigen Wandlung des Lebens, der sich gerade aus Sicht der Alchemisten in den gärenden Verwesungsprozessen eines toten, aber durchaus auch in den Verdauungsvorgängen des noch lebenden menschlichen Körpers beobachten ließ. ${ }^{51}$

Fast zwangsläufig verknüpft mit den Themen Tod und Sterben war die Frage nach der Beschaffenheit der menschlichen Seele. Auch den im Jahr 1614 im Flämischen geborenen Alchemisten Franciscus Mercurius van Helmont trieb diese Frage Zeit seines Lebens um. Er war im Jahr 1651 an den Hof des in religiöser Hinsicht toleranten Wittelsbacher Herzogs und Pfalzgrafen Christian August von Sulzbach (1622-1708) gelangt. ${ }^{52}$ Auf Helmonts Initiative kam auch der jüdische Gelehrte Knorr von Rosenroth (1636-1689) an den Sulzbacher Hof, der von hier aus eine Reihe wichtiger kabbalistischer Schriften veröffentlichte. Rosenroth zeichnete unter anderem für die zweibändige Übersetzung der Kabbala denudata aus dem Hebräischen ins Lateinische (veröffentlicht 1677 und 1684) verantwortlich, deren zweiter Teil die Schrift »De revolutionibus animarum» des berühmten jüdischen Kabbalisten Isaak ben Luria (1534-1572) enthielt. ${ }^{53}$

Gedächtnis der Frühen Neuzeit, Tübingen 1998, 143-188, hier 151-153. Bei dem hier wiedergegebenen Zitat handelt es sich um einen Auszug eines Enzyklopädieartikels Johann Heinrich Alsteds (1588-1638) zur Mnemonik aus seiner 1630 veröffentlichten »Encyclopædia Cursus Philosophici«.

51 Deutlicher noch als im Falle des Salmschen Stammbaums findet sich dieser Gedanke etwa in einem Kupferstich aus dem 17. Jh. der Familie von Nesselrode, der sich im Lesesaal der Archivräume des Schlosses Ehreshoven befindet. Hier entspringt dem Leichnam eines Herrn von Nesselrode eine in den Himmel wachsende Pflanze. An der linken Seite ist vermutlich die Abbildung eines »Lebensbildes« zu sehen. Siehe hierzu Abb. 9.

$52 \mathrm{Zu}$ den in diesem Abs. gemachten Angaben zu Christian August von Sulzbach vgl. Zander, Geschichte der Seelenwanderung (wie Anm. 77, Kap. I), $257 f$.

53 In "De revolutionibus animarum« entwarf Luria ein kabbalistisches Konzept der Seelenwanderung, das hier - den Ausführungen Otto Zanders folgend - verkürzt wiedergegeben werden soll: Luria ging demnach von einer Gesamtseele aus, die im Urmenschen Adam Kadmon vorgelegen hatte. Diese Gesamtseele bestand ihrerseits wiederum aus einer Vielzahl von »Seelenfunken «, die der gegenseitigen Ähnlichkeit nach in »Seelenfamilien« zusammengefasst wurden. Durch eine himmlische Katastrophe wurde die Ordnung dieser Urseele zerstört und einige Seelenfunken fielen aus der geistigen in die materielle Welt hinab. Diese gefallenen Seelenfunken konnten den Wiederaufstieg vor allem durch die "Seelenwanderung", eine stufenweise erfolgende Reinkarnation, erreichen. Da die Seelenfunken untereinander nach Art ihrer Familienzugehörigkeit eine sympathische Kraft besitzen, können die Seelenfunken einer Familie in der Lehre Lurias ihren 
Franciscus Mercurius van Helmont und Knorr von Rosenroth vermochten einer breiteren Leserschaft derartige jüdisch-kabbalistische Seelenwanderungsvorstellungen erfolgreich zu vermitteln und in Teilen mit dem christlichen Glauben auszugleichen. Helmonts 1684 anonym in London veröffentlichte Schrift "200 Quaestiones de renovatione animarum ${ }^{54}$ stellte - um mit den Worten Helmut Zanders zu sprechen - ein »reinkarnatorisches« Standardwerk « dar, das seinen Verfasser zum »Referenzpunkt der Seelenwanderungsdebatte« seiner Zeit werden ließ.$^{55}$ Diese Renaissance der Seelenwanderungsvorstellung hatte ihre Ursache in der vor allem durch den Calvinismus radikalisierten Höllenvorstellung: die Hölle eines unerbittlich strafenden Gottes war nach dieser Auffassung für alle Menschen unumgänglich geworden. ${ }^{56}$

Die Lehre der Seelenrevolution des Franciscus Mercurius van Helmont ist von Helmut Zander und anderen Autoren ausführlich besprochen worden und braucht daher hier nicht im Detail vorgestellt zu werden. Entscheidender für die Fragestellung der vorliegenden Studie ist zunächst die Wirkung der durch Franciscus Mercurius van Helmont angestoßenen Seelenwanderungsdebatte zum Ende des 17. Jahrhunderts auf zeitgenössische Gelehrte und adlige Personen. So wurden verschiedene Wiedergeburtsvorstellungen nicht nur bei den bereits erwähnten Cambridger Platonisten in England intensiv diskutiert, ${ }^{57}$ sondern in weiten Kreisen der gelehrten und adligen Gesellschaft Europas. ${ }^{58}$ So führte etwa Gottfried Wilhelm Leibniz, ${ }^{59}$ der in freundschaftlichem Kontakt mit dem zu einiger Berühmtheit gelangten Franciscus Mercurius van Helmont stand, eine intensive Korrespondenz über diesen Gegenstand mit Herzogin Sophie von Hannover (1630-1714), der späteren englischen Thronerbin. Laut eigener Auskunft der Herzogin hatte Helmont ihr bereits 1670 persönlich über seine Theorie berichtet. ${ }^{60}$

Wiederaufstieg gegenseitig unterstützen. Die Schule Lurias legte infolge dieser Annahmen auch Stammbäume an, die die Ursprünge und Wanderungen der Seelenfunken seit Adam nachzeichneten und diese fortschreitende Entwicklung bis in die Zeit Lurias aufführten. Vgl. hierzu sowie zu Knorr von Rosenroth am Sulzbacher Hof: Zander, Geschichte der Seelenwanderung (wie Anm. 77, Kap. I), 187-192 sowie 259.

54 Zur ungeklärten Verfasserschaft bzw. zu den Hinweisen auf Franciscus Mercurius van Helmont vgl. Ders., Geschichte der Seelenwanderung (wie Anm. 77, Kap. I), 259. Laut Zander bekannte sich Helmont zu seiner Verfasserschaft.

55 Ders., Geschichte der Seelenwanderung (wie Anm. 77, Kap. I), 259.

56 Vgl. Ders., Geschichte der Seelenwanderung (wie Anm. 77, Kap. I), 262. Die bei Helmont ausgearbeitete Vorstellung der »Seelenrevolutionen " geht hingegen von einem liebenden Gott aus, der Leid und Tod des Menschen nur herbeiführt, um die Perfektionierung seiner Seele hin zu einem höheren Zustand durch zwölf aufeinanderfolgende Wiedergeburten in einem Zyklus von 333 1/3 Jahren herbeizuführen. Vgl. hierzu Ders., Geschichte der Seelenwanderung, 257-273.

57 Vgl. Ders., Geschichte der Seelenwanderung (wie Anm. 77, Kap. I), 254-257.

58 Vgl. hierzu die jeweiligen Kapitel zu einzelnen Ländern: Ders., Geschichte der Seelenwanderung (wie Anm. 77, Kap. I), 284-318.

$59 \mathrm{Zu}$ der Beeinflussung der Monadenlehre eines Leibniz durch die Theorien Helmonts siehe vor allem Mulsow, Vernünftige Metempsychosis (wie Anm. 77, Kap. I), 211-273.

60 Siehe hierzu Zander, Geschichte der Seelenwanderung (wie Anm. 77, Kap. I), 260. 
Wie weit die Vorstellungen der Zeitgenossen in Bezug auf die Vorstellungen um Seelenwanderung und Wiedergeburt reichten, zeigt sich an einem bei Zander zitierten Brief der Herzogin Elisabeth Charlotte von Orléans, der unter dem Namen Liselotte von der Pfalz bekannten Schwägerin Ludwigs des XIV., an Sophie von Hannover. In diesem Brief berichtet die Herzogin über die Cousine van Helmonts - eine Baronin von Merode-Motzfeld - folgende Geschichte:

Undt wie er gefühlt [Franciscus Mercurius van Helmont, Anm. d. Verf.], daß er nahe bey seinem todt were, hette er dieße dame [die Baronin von MerodeMotzfeld, Anm. d. Verf.] kommen laßen, umb ihr seinen Geist zu geben, hette ihr gesagt, ihren mundt auff den seinen zu thun, hatt ihr damitt ins Maul gehaucht undt gesagt: >Ich erlaße euch meinen geist , hette sich darauff gewendt undt were gleich gestorben. Die dame aber glaube jetzt fest, sie hette Helmonts geist in sich. ${ }^{61}$

Diese `Schauergeschichte enthielt bei näherer Betrachtung eine subtile Anspielung auf die adlige »Blutsideologie«, die sich für die Zeitgenossen aus den Forschungen des bekannten Alchemisten, Iatromediziners und Entdeckers der Gase Johann Baptist van Helmont (1579-1644), des Vaters des Franciscus Mercurius, ergab. Es lohnt sich, diese ausführlicher zu betrachten, da davon ausgegangen wird, dass sie unerlässlich zum Verständnis der adligen »Blutsideologie» des 17. und 18. Jahrhunderts sind.

In dem im Jahr 1683 in Übersetzung erschienen Werk »Der Aufgang der Artzney-Kunst « (lateinische Erstausgabe 1648) ${ }^{62}$ behandelt Johann Baptist van Helmont unter anderem die Beschaffenheit der menschlichen Seele. In seiner Seelen-Lehre ging er von der Umhüllung einer unsterblichen inneren Seele, die er »Gemüth « nannte, mit einem vergänglichen sinnlich-tierischen Seelenteil aus. ${ }^{63}$ Das Gemüt existierte nach Helmonts Theorie vor dem Sündenfall daher zunächst allein und war Adam durch Gott »eingeblasen « worden ${ }^{64}$ - hatte also einen gasförmigen Zustand. Das Gemüt hatte vorerst das Regiment über den Körper übernommen, dessen Bildung es durch seine schöpferische Kraft selbst angeregt hatte. Es war zur vollkommenen Erkenntnis der Schöpfung und ihrer Ziele ohne die Hilfsmittel der Sinne oder des Gedächtnisses fähig. ${ }^{65}$ Helmont verstand dieses Gemüt daher

61 Zitiert nach Ders., Geschichte der Seelenwanderung (wie Anm. 77, Kap. I), 271.

62 Eine Ausgabe des Jahres 1652 ist online einsehbar: Ioanne Baptista van Helmont/Francisco Mercurio van Helmont, Ortus Medicinæ. Id est, Initia physicæ inaudita. Progressus medicinæ novus, in morborum ultionem, ad vitam longam, Amsterdam 1652, Permalink: http://nbn-resolving.org/urn:nbn:de:bvb:12-bsb10055180-6 (Zugriff vom 25.05.2014).

63 Vgl. Johann Baptista von Helmont, Aufgang der Artzney-Kunst, Sulzbach 1683, 860, Permalink: http://nbn-resolving.org/urn:nbn:de:bvb:12-bsb10869856-0 (Zugriff vom 24.05.2014). Siehe zu dieser Unterscheidung auch Berthold Heinecke, The Mysticism and Science of Johann Baptista van Helmont (1579-1644), in: Ambix 42 (1995), 65-78, hier 67.

64 Helmont, Aufgang der Artzney-Kunst (wie Anm. 63, Kap. IV), 834.

65 Ders., Aufgang der Artzney-Kunst (wie Anm. 63, Kap. IV), 834. Vgl. zu allen hier gemachten Ausführungen zu Helmonts Lichtspekulationen bzw. zum »Gemüth« auch: Heinecke, The Mysticism 


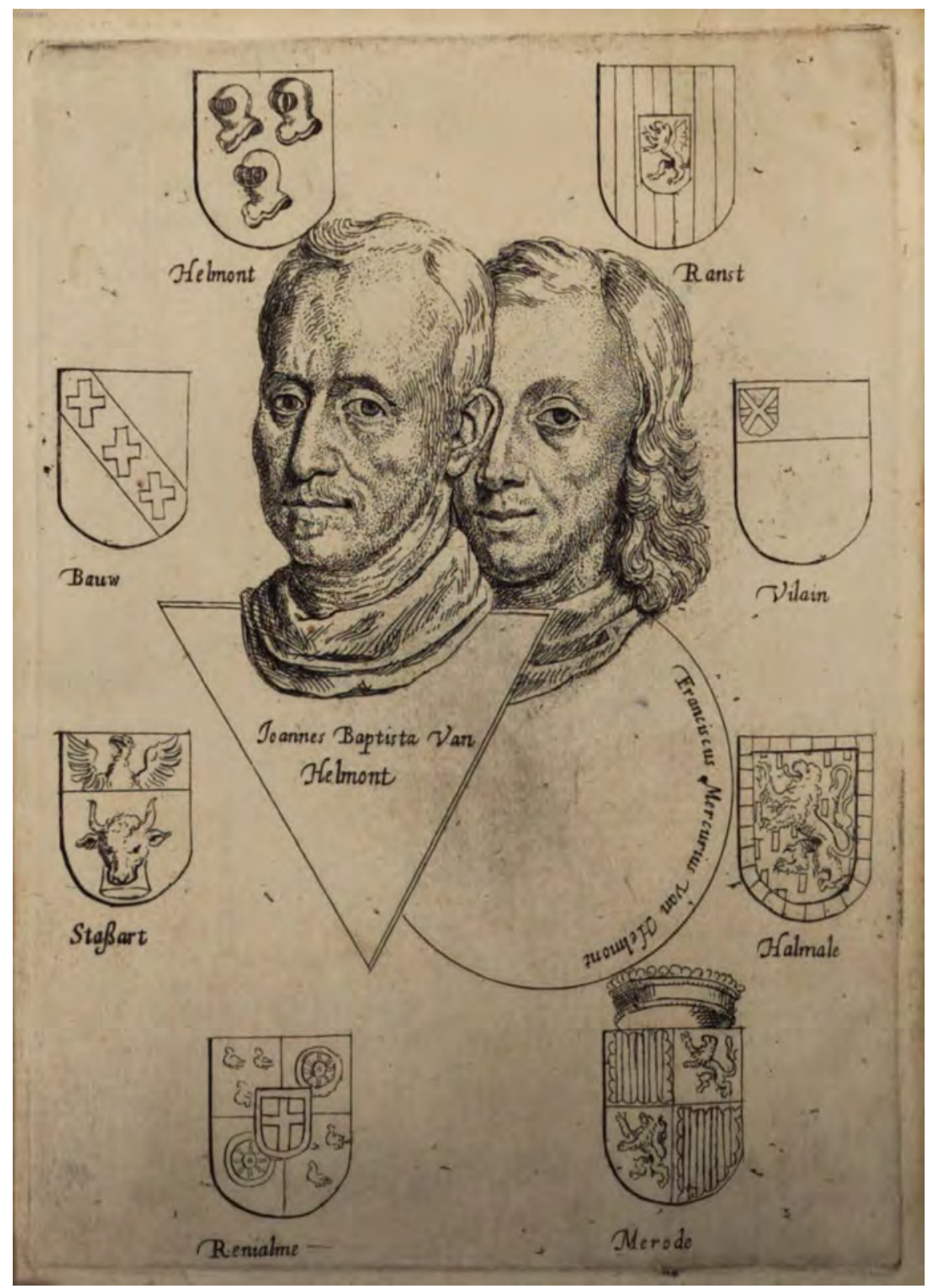

Abbildung 8: Abbildung des Johann Baptist und Franciscus Mercurius van Helmont aus der Schrift "Ortus medicinae» mit dem Wappen der Merode, 1652 (Bildnachweis: BSB München, Sign. 4 Med.g. 218). 
auch als Funken Gottes und sah es als durch das göttliche Licht gespeiste sowie mit Hilfe von Licht und Feuer mit Gott kommunizierende leuchtende Substanz an. ${ }^{66}$ Als Sitz des Gemüts machte Helmont den Magen aus, den er mit der Wurzel eines Baumes verglich. ${ }^{67}$ Der Magen stellte laut Helmont vor dem Sündenfall durch den Bezug einer bereits bei Paracelsus Archeus genannten ausführenden Lebenskraft aus den Speisen und in Verbindung mit der schöpferischen Kraft des Gemüts das ewige Leben des gottgleichen Menschen sicher. ${ }^{68}$ Seit dem Sündenfall hatte sich dieses Gemüt jedoch immer mehr zurückgezogen und der Mensch wurde nun vom neu hinzugetretenen sinnlich-tierischen Seelenteil beherrscht, der als sündhaft begriffen wurde und zur Sterblichkeit verdammt war. ${ }^{69}$

Da das Gemüt in der Helmontschen Theorie wie ein Kern von dem sinnlichtierischen Seelenteil umgeben war, war der Zugang zur Bilderwelt des göttlichen Schöpfungsplans ab diesem Zeitpunkt nur durch die von der äußeren Welt herrührenden Gegebenheiten und Vorbilder möglich. ${ }^{70}$ Wie Helmont im 54. Traktat über die Krankheiten am Beispiel körperlich deformierter Kinder, am Verhalten schwangerer Frauen und der Beschaffenheit des männlichen Samens belegen wollte, konnten besonders intensive sinnliche Eindrücke, die menschlichen »Leidenschaften " sowie starke bildhafte Vorstellungen der Phantasie die schöpferische Kraft des inneren Gemütes anregen und über den ausführenden Archeus körperliche Folgen zeitigen. ${ }^{71}$ Auf diese Weise ließ sich daher auch die von Helmont angenommene Wirksamkeit von - im wahrsten Sinne des Wortes - >eindrücklichen Zeichen, Worten und Handlungen innerhalb magischer Prozeduren erklären. Dem menschlichen Blut kam hierbei als Botensubstanz die Rolle einer

and Science (wie Anm. 63, Kap. IV), hier 67.

66 Vgl. Ders., The Mysticism and Science (wie Anm. 63, Kap. IV), hier 66. Womöglich sind auch die späteren Licht-Spekulationen Newtons noch durch die Theorien Johann Baptist van Helmonts beeinflusst. Siehe zu Letzteren Fischer, Isaac Newton und das verlorene Wissen der Alten (wie Anm. 65, Kap. III), 54f.

67 Siehe Helmont, Aufgang der Artzney-Kunst (wie Anm. 63, Kap. IV), 831. Ob dieses Bild des im Magen wurzelnden Gemüts mit dem oben erwähnten etymologischen Ursprung des Wortes »Rasse« aus lateinisch »radix « zusammenhängt, kann hier nicht gesagt werden.

68 Vgl. Ders., Aufgang der Artzney-Kunst (wie Anm. 63, Kap. IV), 834.

69 Siehe zu sämtlichen hier gemachten Angaben Ders., Aufgang der Artzney-Kunst (wie Anm. 63, Kap. IV), 833. Hier spricht sich Helmont auch für verschiedene Arten von Seelen aus.

70 Vgl. hierzu auch die Ausführungen in der Studie Jochen Büchels, die Anlass zu den hier gemachten Forschungen und Folgerungen zum Blut gab: Jochen Büchel, Psychologie der Materie. Vorstellungen und Bildungsmuster von der Assimilation von Nahrung im 17. und 18. Jh. unter besonderer Berücksichtigung des Paracelsismus (Epistemata. Würzburger Wissenschaftliche Schriften, Reihe Philosophie, 375), Diss., Würzburg 2005, 81-104, aber auch 187.

71 Vgl. hierzu insb. das 15. Kapitel des 54. Traktats bei Helmont: Ders., Aufgang der Artzney-Kunst (wie Anm. 63, Kap. IV), 1035-1040. Der bei Christoph Wulf modern-wissenschaftlich ausgedeutete kulturelle Zusammenhang zwischen »Ritual «, »Imaginärem « und dem »Blut « konnte von den frühneuzeitlichen Zeitgenossen also nicht nur als eine rein ästhetisch-metaphorische Verbindung, sondern als theoretisch fundierter Zusammenhang aufgefasst werden, der erst in der rituellen Praxis seine tiefste Wirksamkeit entfalten konnte. Zu den Anmerkungen Wulfs siehe Christoph Wulf, Blut, Ritual und Imagination, in: Christina von Braun/Ders. (Hg.), Mythen des Blutes, Frankfurt a.M./New York 2007, 16-27. 


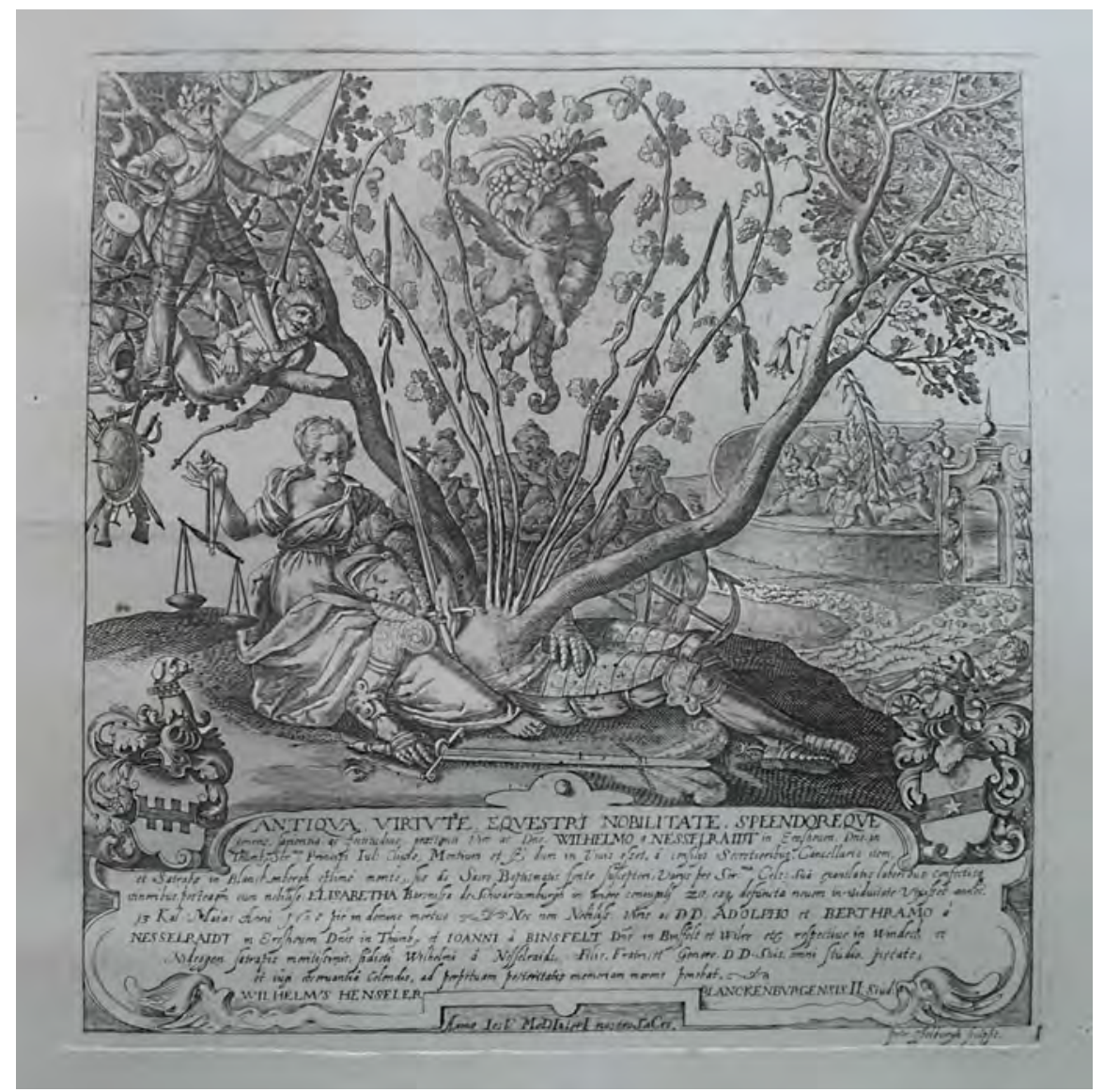

Abbildung 9: Peter Asselburgh, Wilhelm von Nesselrode-Ehreshoven (†1608), gestiftet durch Wilhelmus Henseler, um 1610, Kupferstich. Aus der Magengegend Nesselrodes entspringt ein Baum, in dessen Zweigen vermutlich ein »Lebensbild« zu sehen ist. Die Darstellungsweise erinnert dabei an die mittelalterlichen Darstellungen der "Wurzel Jesse». (Bildrecht/Werk: Rheinische Ritterschaft, Schloss Ehreshoven; Foto: M.O. Braun).

Art >flüssigen Gedächtnisses` zu, das die verschiedenen, im Herzen in das Blut eingeprägten Gedanken und Eindrücke zum Sitz des Gedächtnisses im Gehirn bzw. von diesem zurück zum Sitz der tierischen Seele im Herzen beförderte. ${ }^{72}$ Der letztgenannte Vorgang war die Erinnerung.

72 Vgl. zur »Erinnerungsfähigkeit« des Blutes insb. Helmonts Schilderungen von Leichen, die in Gegenwart ihres Mörders von selbst anfingen zu bluten: Helmont, Aufgang der Artzney-Kunst (wie Anm. 63, Kap. IV), 1032f. sowie 1039f. Helmont spricht sich hier auch für die Wahrhaftigkeit des Hexenglaubens aus. Es scheint daher angebracht, den Einfluss der Helmontschen Medizin auch in Beziehung zum durchaus langwierigen Hexenglauben in der Frühen Neuzeit zu setzen. 
Dieses Prinzip der Einprägung von »geistigen Bildern« in das Blut hatte auch auf die Vorstellungen über die Beschaffenheit des männlichen Samens Einfluss, da dieser in der Frühen Neuzeit ebenfalls als aus Blut und Lebensgeist gebildet begriffen wurde. ${ }^{73}$ Deshalb pflanzte er nach Helmonts Meinung nicht nur körperliche, sondern auch sittlich-moralische Eigenschaften fort. Hierin lag für Helmont auch die Richtigkeit der adligen »Blutsideologie« begründet:

Und hat demnach das Blut seine gewisse Einbildung / und weil solche sich darinnen viel stärcker hervor thut als in andern Dingen; so nennet die Schrifft / in ihren hoch=nachdenklichen Verboten das Blut beseelet; wenn es gleich schon gekochet und zum Essen zugerichtet ist. [...] Und weil eine solche Bildungs-Krafft auch in dem Samen steckt / und mit demselben fortgepflanzet wird / so lassen sich offtmals in einem / der nach des Vaters Tode geboren worden / die Sitten / die Geberden und die Beschaffenheiten des Groß-Vaters spüren. [...] Nemlich der Adel hat seinen Ursprung genommen von solchen Tugenden / damit einer sich wohl verdienet gemacht: Und wäre demnach eine vergebliche Vermuthung / daß der Adel sich durch eine beständige Fortpflanzung des Stamms vermehren liesse / wann nicht die Sitten und Tugenden der Vorfahren sich in denen Nachkommen über lange Zeit hervor thäten. ${ }^{74}$

Im Hintergrund dieses eigenartigen biologistischen Konzepts der »Rassengenese« ist die bereits bei Paracelsus zu findende und in der Folge auch von den Alchemisten des 17. Jahrhunderts aufgegriffene Ansicht des Wassers als »Saat-Bett « der Lebensgeister zu sehen sowie der bereits oben erwähnte Glaube an eine Beseelung des Blutes ${ }^{75}$ - durch derartige Annahmen erklärt sich im Übrigen nicht nur die

73 Vgl. Ders., Aufgang der Artzney-Kunst (wie Anm. 63, Kap. IV), 1035f. sowie die Ausführungen bei Büchel, Psychologie der Materie (wie Anm. 70, Kap. IV), 90-92. Siehe hierzu ferner den Eintrag "Geburts-Same, sonst auch Zeugungs-Same, männlicher Same« im Zedlerschen Lexikon: Zedler, Universal-Lexicon (wie Anm. 16, Kap. II), Bd. 10, 545-550 sowie Kodera, The Art of the Distillation (wie Anm. 47, Kapitel IV), hier 145.

74 Helmont, Aufgang der Artzney-Kunst (wie Anm. 63, Kap. IV), 1039 f.

75 Vgl. hierzu Walter Pagel, Joan Baptista van Helmont reformer of science and medicine (Cambridge Monographs on the history of medicine), Cambridge 2002, 53. Pagel zitiert hier u.a. aus einer Schrift des Freimaurers Elias Ashmole: ")Water...mevying causyth both Deth and Lyfe..ys the secret and lyfe of every thing... for of the Water eche thyng hath begynning.... « Pagel ergänzt: »The outstanding position of water in alchemy was endorsed by Paracelsus. He regarded it as the matrix in which there were created heaven and earth. Water is the receptacle of the seed from which man grows; elementum aquae is seed-bed. « Die Bezüge zum Beginn des Buches Genesis der Bibel sind hier offensichtlich (»[...] und Gottes Geist schwebte über dem Wasser.«). Bei Helmont heißt es daher auch: »Und also wird das Blut durch die Bewegung/ die Hitze und den Urheb verwandelt in eine Himmlische Natur / welches die unmittelbare Herberge ist des Lebens-Liechtes. Und dannenhero sind Blut / Wasser / und Geist / eins. " Helmont, Aufgang der Artzney-Kunst (wie Anm. 63, Kap. IV), 233. Büchel sieht Ursprünge bereits in der "Trinitätspekulation« bei Augustinus. Siehe hierzu Büchel, Psychologie der Materie (wie Anm. 70, Kap. IV), 222. Guillaume Aubert weist ferner auf die Einflüsse der galenischen und hippokratischen Medizin bzw. der Lehren des Aristoteles hin. Siehe Aubert, Kinship, Blood and the Emergence of the Racial Nation (wie Anm. 50, Kap. II), insb. 178f. Einen hilfreichen Überblick über die Bedeutung des Spiritus in Bezug auf die Seele bei verschiedenen Gelehrten von der Antike bis zur Frühen Neuzeit bieten Michael Sonntag, „Ge- 
oben bei Loen beschriebene Annahme »tugendhafter Samen « innerhalb des adligen Blutes, sondern auch die Argumentation eines noch vor der Veröffentlichung der Helmontschen Schriften lebenden Charles Loyseau.

Das Blut übertrug hier eben nicht die kompletten Seelen der Eltern oder Vorfahren, sondern vielmehr nur ihre sgeistigen Samen`. Genauer gesagt, handelte es sich bei den Samen also insbesondere um starke sinnlich erfahrene Eindrücke, die sich in das Blut einprägen und mit den übrigen ererbten Eindrücken der Vorfahren vermischen konnten. Von diesen guten wie schlechten Einbildungen nahm man folglich an, dass sie fortan gemeinsam im Blut eines Geschlechts existierten und bei einem neuen Menschen gleicher Linie jeweils potentiell erneut zur Ausprägung gelangen konnten. Das gute Vorbild der Eltern und die richtige Erziehungsmethode regten das Gemüt zur Ausprägung der tugendhaften Anlagen an und waren gleichzeitig Ausgangspunkt neuer Einprägungen. Das eingangs dieses Kapitels angeführte Zitat aus der 1630 veröffentlichten »Encyclopædia Cursus Philosophici« Johann Heinrich Alsteds (1588-1638) zeigt, dass derartige Verbindungen von Blut, geistigen Einbildungen und Gedächtnis in der Frühen Neuzeit durchaus verbreitet waren. Alsted galt die Beherrschung der Affekte, die ja auch das Ideal des »honnête homme« auszeichnete, als Hilfsmittel eines guten Gedächtnisses, das insbesondere auf der Qualität und der durch die Affekte beeinflussten Temperatur des Blutes beruhte - womit er offenbar auch noch die Theorien der Humoralpathologie des Mittelalters berücksichtigte. ${ }^{76}$

In Bezug auf das oben erwähnte Gerücht um das Fräulein von Merode sei hier zudem erwähnt, dass nach den Ansichten Johann Baptist van Helmonts derartige "Geister« innerhalb des Blutes durch Fäulnis oder Zersetzung desselben - wie etwa in der Lunge - nicht verloren gingen, sondern vielmehr weiterhin wirksam waren: »Nemlich / weil die Wesenheiten der Dinge und deroselben Lebens=Geister nicht faulen können; so brechen dieselbigen mit voller Krafft heraus / wenn ihre untersten Bande aufgelöset sind. " $^{77}$ Da Johann Baptist van Helmont die Annahme

fährte der Seele, Träger des Lebens«. Die medizinischen Spiritus im 16. Jh., in: Gerd Jüttemann/ Michael Sonntag/Christoph Wulff (Hg.), Die Seele. Ihre Geschichte im Abendland, Weinheim 1991, 165-179 sowie Gerhard Klier, Die drei Geister des Menschen. Die sogenannte Spirituslehre in der Physiologie der Frühen Neuzeit (Sudhoffs Archiv, Beihefte, 50), Diss., Stuttgart 2002. Zu beachten sind auch ähnliche Theorien im Umfeld arabischer Mediziner des 13. Jh.s. Vgl. hierzu Rainer Brömer, The Nature of the Soul and the Passage of Blood through the Lungs. Galen, Ibn al-Nafīs, Servetus, İtaki, 'Ațțār, in: Horstmanshoff/King/Zittel (Hg.), Blood, Sweat and Tears (wie Anm. 47, Kap. IV), 339-362 sowie Catrien Santing, ’For the Life of a Creature is in the Blood (Leviticus 17:11). Some Considerations on Blood as the Source of Life in Sixteenth-Century Religion and Medicine and their Interconnections, in: Horstmanshoff/King/Zittel (Hg.), Blood, Sweat and Tears (wie Anm. 47, Kap. IV), 415-441.

76 Vgl. Alsted, Encyclopædia (wie Anm. 50, Kap. IV), hier 152f. Zu Theorien des Mittelalters in Bezug auf die Herkunft der menschlichen Tugenden bzw. einen grundsätzlich angenommenen moralischen Unterschied zwischen Mann und Frau vgl. jüngst Joseph Ziegler, The biology of the virtues in medieval and early Renaissance theology and physiognomy, in: Mariacarla Gadebusch Bondio/ Andrea Bettels (Hg.), Im Korsett der Tugenden. Moral und Geschlecht im kulturhistorischen Kontext, Hildesheim [u.a.] 2013, 3-23, hier insb. $18 f$.

77 Helmont, Aufgang der Artzney-Kunst (wie Anm. 63, Kap. IV), 1027. 


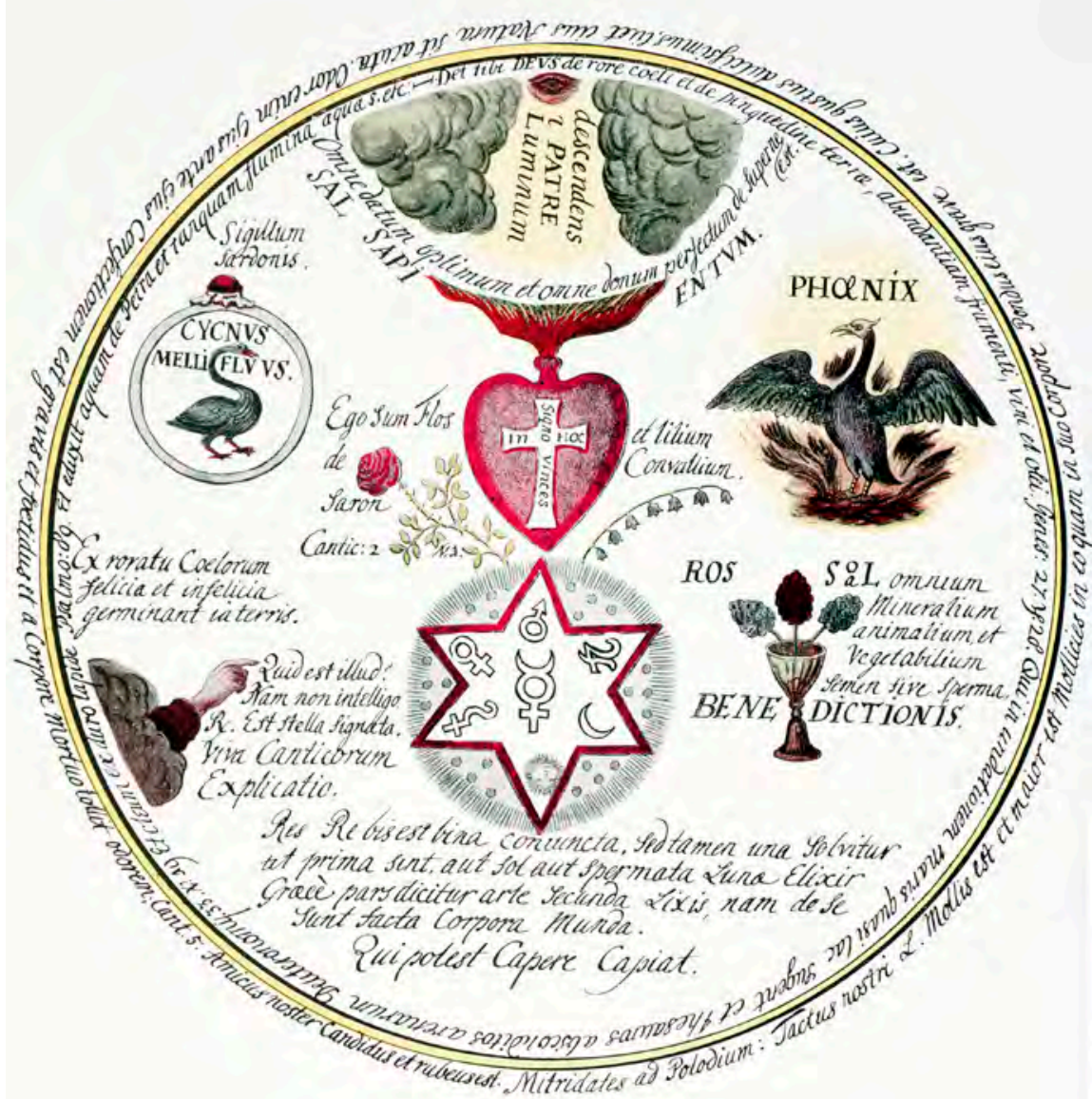

Abbildung 10: Tafel mit Symbolen der Rosenkreuzer aus einem unpublizierten Manuskript des 18. Jahrhunderts, nach 1700 (Bildrecht/Werk und Foto: From the collections of the Cultural Masonic Centre, The Hague).

vertreten hatte, das Blut des Menschen werde in den Lungen zu einem volatilen, also gasförmigen "Salz« umgewandelt und ausgeatmet, ${ }^{78}$ ging mit dem Atem des sterbenden Franciscus Mercurius somit aus Sicht der Zeitgenossen auch ein Teil seiner »Lebensgeister« auf das Fräulein Merode über. In Verbindung mit dieser Annahme der volatilen Salze war es kein besonders weiter Gedankenschritt zur

78 Vgl. Anna Marie Roos, The Salt of the Earth. Natural Philosophy, Medicine, and Chemistry in England, 1650-1750 (History of Science and Medicine Library, 3), Leiden 2007, insb. 47-154. 
Beschwörung von Ahnengeistern, die sich aus verwesenden Knochen verflüchtigten oder in der Luft schwebten. ${ }^{79}$

Es verwundert in Bezugnahme auf die positive Einschätzung Johann Baptist van Helmonts hinsichtlich der adligen »Blutsideologie» nicht, dass seine Lehren vor allem unter englischen Aristokraten im Umkreis des 1660 wiederhergestellten Königtums Karls II. von England Zuspruch fanden, der die Helmontsche Medizin protegierte. So gründete sich bereits 1665 unter Förderung zahlreicher englischer hoher Geistlicher und Adliger, wie etwa des Duke of Buckingham oder des Erzbischofs von Canterbury, die »Noble Society for the advancement of Hermetick Physick «. ${ }^{80}$ Interessanterweise zählten aber auch Gelehrte mit mehr oder weniger starken Verbindungen zur Freimaurerei zu den Befürwortern der Helmontschen Medizin, wie der »wohl [...] älteste, berühmte `spekulative` Freimaurer « und Rosenkreuzer Elias Ashmole (1617-1692) oder John Locke. ${ }^{81}$

Die freimaurerischen Rituale zu Beginn des 18. Jahrhunderts mit ihrer starken Betonung der sinnlichen Komponente und ihrem Bezug zur ars memoriae mussten in Verbindung mit den weit verbreiteten Theorien eines Johann Baptist bzw. Franciscus Mercurius van Helmont durchaus als elaboriertes Erziehungssystem

$79 \mathrm{Zu}$ einem Beispiel für eine freimaurerische Geisterbeschwörung, die hier auch mit dem Begriff der »Palingenesie« direkt verknüpft wird, in adligem Umkreis zum Ende des 18. Jh.s vgl. Geisterbeschwörungen, in: Winfried Dotzauer (Hg.), Quellen zur Geschichte der deutschen Freimaurerei im 18. Jh. unter besonderer Berücksichtigung des Systems der Strikten Observanz (Schriftenreihe der Internationalen Forschungsstelle »Demokratische Bewegungen in Mitteleuropa 1770-1850«, 3), Frankfurt a.M. [u.a.] 1991, 289-298. Es ist bekannt, dass noch die Bewegung des Mesmerismus gegen Ende des 18. Jh.s von ihren Gegnern als Abkömmling der Lehren eines Paracelsus und Johann Baptist van Helmont diskreditiert wurde. Siehe hierzu Robert Darnton, Der Mesmerismus und das Ende der Aufklärung in Frankreich, Frankfurt a.M./Berlin 1986, 23. Der Glaube an eine »Wiedergeburt der Seele« lässt sich auch in der Wiener Freimaurerei zum Ende des 18. Jh.s noch belegen. Siehe hierzu Wilgert te Lindert, Aufklärung und Heilserwartung. Philosophische und religiöse Ideen Wiener Freimaurer (1780-1795) (Schriftenreihe der Internationalen Forschungsstelle »Demokratische Bewegungen in Mitteleuropa 1770-1850«, 26), Frankfurt a.M. [u.a.] 1998, insb. 78-88.

80 Siehe hierzu P. M. Rattansi, The Helmontian-Galenist Controversy in Restoration England, in: Ambix 12 (1964), 1-23, hier 13. Rattansi erwähnt die Unterstützung der Noble Society durch die wichtigsten geistlichen und weltlichen Persönlichkeiten Englands dieser Zeit und führt eine Reihe weiterer Mitglieder an, wie etwa den Bischof von London sowie Adlige aus dem direkten Umfeld des Königs sowie des Duke of York. Siehe auch Harold J. Cook, The Society of Chemical Physicians, the New Philosophy, and the Restoration Court, in: Bulletin of the History of Medicine 61 (1987), 61-77, hier 77.

$81 \mathrm{Zu}$ Ashmoles Biographie wie dem hier angeführten Zitat siehe Lennhoff/Posner/Binder (Hg.), Internationales Freimaurer-Lexikon (wie Anm. 18, Kap. I), 89. Ashmole arbeitete selbst alchemistisch. Allison Coudert erwähnt, dass das heraldische Motto Ashmoles (»ex uno omnia«) direkt an das Motto Johann Baptist van Helmonts ("philosophus per Unum in Quo omnia«) angelehnt war. Vgl. hierzu die Angaben bei Allison Coudert, The impact of the Kabbalah in the seventeenth Century. The Life and Thought of Francis Mercury van Helmont (1614-1698), Leiden [u.a.] 1998, 142. Zu John Locke vgl. Peter R. Anstey, John Locke and Helmontian Medicine, in: Charles T. Wolfe/Ofer Gal (Hg.), The Body as Object and Instrument of Knowledge. Embodied Empiricism in Early Modern Science (Studies in History and Philosophy of Science, 25), Dordrecht [u.a.] 2010, 93-120. 
erscheinen. ${ }^{82}$ Mit Hilfe der graduellen Einweihung und ihrer symbolischen Worte und Handlungen durfte eine Aktivierung der schöpferischen Kraft des Gemüts erhofft werden, die die tugendhaften Samen innerhalb des Blutes zur Ausprägung brachte bzw. ihm neue eindrückte und hierüber die Seele läuterte. Da im neu hinzugetretenen Meistergrad das Thema der »Wiedergeburt « aufgegriffen wurde, ist danach zu fragen, inwiefern auch die durch Franciscus Mercurius van Helmont angestoßene Seelenwanderungsdebatte auf die Freimaurerei einwirkte.

Es kann durchaus angenommen werden, dass der Ruhm des Vaters der Etablierung der Schriften des Sohnes in der feinen und gelehrten Gesellschaft zuträglich war. Sie schalteten sich im Vergleich zu den Schriften des Vaters jedoch auch sehr viel direkter in die Diskussion um eine Wiederentdeckung der Urreligion ein, da Franciscus Mercurius die "Ensomati oder leibliche Wiedergeburt « als älteste religiöse Wahrheit begriffen wissen wollte, die auch Jesus Christus in seinen Predigten erwähnt habe. ${ }^{83}$ Da Franciscus Mercurius' Hauptanliegen in den 200 Fragen« darin bestand, den Gedanken der Wiedergeburt als vereinbar mit dem Christentum darzustellen, bestand wohl auch für die Freimaurerei des frühen 18. Jahrhunderts sowie den ihr nahestehenden zeitgenössischen Adel zunächst kein Hindernis, sich dieser »ältesten aller Wahrheiten« zu nähern.

So übte die Lehre der Metempsychose noch bis weit in das 18. Jahrhundert hinein eine große Faszination auf den Adel aus. ${ }^{84}$ Eine Erklärung ist simpel: Die Wahrheit der Metempsychose vorausgesetzt, war eine Geburt als Adliger als Gnade Gottes anzusehen, die aus einem zuvor geführten gottgefälligen Leben resultierte. In Verbindung mit der Annahme der besonders großen Anzahl »tugendhafter Samen« der Vorfahren innerhalb des adligen Blutes durfte man als Adliger darauf hoffen, kurz vor der Erlösung aus dem irdischen Leben bzw. der vollendeten Läuterung der Seele zu stehen. Dem Adel konnte aufgrund dieser Qualitäten jedoch auch eine besondere Kompetenz bei der Beherrschung der "Gemüther" zugetraut werden.$^{85}$ Die Hoffnung auf eine kurz bevorstehende gesellschaftliche

82 Auch in den Schriften Johann Baptist van Helmonts kam das Thema der Erziehung zur Sprache, wobei auch bei ihm kabbalistische Bezüge nachweisbar sind. So heißt es etwa im »Aufgang der Artzney-Kunst «, dass die inneren magischen Kräfte des Gemüts mit Hilfe des Heiligen Geistes bzw. durch »dessen Gabe, die Cabbala«, erweckt werden können. Vgl. Helmont, Aufgang der ArtzneyKunst (wie Anm. 63, Kap. IV), 1031 und 1039.

83 Siehe hierzu etwa Helmonts 195. und 200. Frage: Franciscus Mercurius van Helmont, Zweyhundert mit gebührender Bescheidenheit vorgestellte Fragen/ Betreffend die Lehre von der Wieder=Kehr der menschlichen Seelen/ und wie solche mit der Wahrheit des Christentums überein komme, o.O. 1686, 198-206, Permalink: http://resolver.staatsbibliothek-berlin.de/SBB000063F600000000 (Zugriff vom 25.05.2014).

84 Vgl. hierzu auch Neugebauer-Wölk, Arkanwelten im 18. Jh. (wie Anm. 47, Kap. I), hier 54f. Es ist hierbei hinsichtlich etwa des Engagements des Königshauses Preußen im freimaurerischen Umkreis und im Orden der Gold- und Rosenkreuzer nochmals wichtig, zu erwähnen, dass die Freimaurerei die adlige »Blutsideologie« offenbar zunächst nicht ablehnte.

85 Siehe in diesem Sinne etwa eine Freimaurer-Rede aus dem Jahr 1743 auf Friedrich II. von Preußen: Jakob Friedrich Lamprecht, Rede, welche am Johannisfeste in der großen Loge der Freimäurer zu Berlin gehalten worden, in: Karlheinz Gerlach (Hg.), Berliner Freimaurerreden 1743-1804 (Schriftenreihe der Internationalen Forschungsstelle »Demokratische Bewegungen in Mitteleuropa 1770- 
wie geistige Wiedergeburt bzw. Erlösung machte mehr denn je ein Erziehungssystem erforderlich, das zur Vollendung beitrug. Im folgenden Kapitel soll daher danach gefragt werden, inwiefern davon ausgegangen werden kann, dass die Freimaurerei des 18. Jahrhunderts die Lehre der Metempsychose als Wissensinhalt der Urreligion vermitteln wollte.

\title{
IV.4 "Racines cachées" - Die Lehre der Metempsychose in ihrem Einfluss auf die freimaurerischen Rittergrade
}

\author{
Tel est le malheur des Esprits vrayement Metaphisiques; on les \\ regarde souvent comme visionnaire, parcequ'ils voyent plus loin que \\ les autres.
}

- Andrew Michael Ramsay ${ }^{86}$

Als die hora mortis des Chevaliers Andrew Michael Ramsay (1686-1743) im Jahr 1743 heranrückte, diktierte er einem heute unbekannten Schreiber seine Lebensgeschichte. Ramsay erwähnte hierin unter anderem seine adlige Abstammung und betonte seine Liebe zu Gott und den Wissenschaften. Gerade in Bezug auf seine adlige Herkunft lagen die biographischen Tatsachen jedoch etwas anders: Geboren als Sohn eines Bäckers im schottischen Dorf Ayr kämpfte er nicht nur während der Spanischen Erbfolgekriege als Offizier auf Seiten der englischen Armee, sondern wurde - wohl auch aufgrund der fälschlicherweise angenommenen Abstammung vom schottischen Clan der Ramsays of Dalhousie - 1723 als Chevalier in den französischen Ritterorden Saint Lazare aufgenommen. ${ }^{87} \mathrm{Ab}$ dem Jahr 1724 fungierte er vor allem als Erzieher adliger Söhne, unter anderem des im französischen Exil lebenden »Young Pretender«, Charles Edward Stuart (1720-1788). Er verfasste außerdem mehrere Bücher pädagogischen Inhalts, die sich stark an sein Vorbild, den Erzbischof Fénelon, anlehnten, den Verfasser des berühmten

1850«, 22), Frankfurt a.M. [u.a.] 1996, 11-16, hier 14. Hier wird die besondere Qualität des Blutes König Friedrichs II. hervorgehoben und er selbst als ein König bezeichnet, der sich »sowohl der Gemüter als Reiche zu bemeistern weiß«.

86 Andrew Michael Ramsays "Dissertation sur l'âme des bêtes « findet sich in: Anecdotes de la vie de messire André de Ramsay, chevalier, baron, ou plus tost baneret d'Écosse, dictés par lui-même peu de jours avant sa mort, pressé par les instances réitérées de son épouze, o.O., o.D., in: BM, MS 1188 (417), http://www.e-corpus.org/eng/ref/88281/Ms_1188_(417)/ (Zugriff vom 16.07.2014), hier fol. 165. Die Folioangabe bezieht sich hier und im Folgenden auf die handschriftliche Seitenangabe innerhalb des digitalisierten Originals in der numerisch korrekten Reihenfolge.

87 Vgl. zu allen hier gemachten und folgenden Ausführungen in Bezug auf die Biographie Andrew Michael Ramsays: Mollier, La Chevalerie maçonnique (wie Anm. 31, Kap. I), 166-176; Lennhoff/ Posner/Binder (Hg.), Internationales Freimaurer-Lexikon (wie Anm. 18, Kap. I), 689f.; George David Henderson, Chevalier Ramsay, London 1952 sowie die umfangreiche Dissertation Georg Eckerts, »True, Noble, Christian Freethinking «. Leben und Werk Andrew Michael Ramsays (16861743), Diss., Münster 2009. 
Reiseromans "Abenteuer des Telemachs ${ }^{88}{ }^{8}$ In seiner sehr erfolgreichen Erziehungsschrift "Les Voyages de Cyrus « von 1727/1728 ließ Ramsay etwa seinen Protagonisten Cyrus, den späteren König von Babylon, eine Reise - ähnlich einer Kavalierstour - vollführen. Diese machte den Königssohn mit den verschiedenen Kulturen der Antike und ihren Weisheiten vertraut, bevor Cyrus schließlich auf die Spur einer einzigen, ewigen Wahrheit aller Lehren gelangen sollte. ${ }^{89}$

In der Geschichte der Freimaurerei trat der Chevalier Ramsay vor allem durch seinen 1736 erstmals nachweisbaren »Discours « in Erscheinung. ${ }^{90}$ In dieser Rede setzte Ramsay die Freimaurerei mit den mittelalterlichen Ritterbünden der Kreuzzugszeit in Verbindung und trug so indirekt zur Entwicklung der Legende um den templerischen Einfluss innerhalb des Bundes bei. So ging Ramsay hierin unter anderem davon aus, dass sich die von den Kreuzrittern nach ihren Kriegszügen in ganz Europa gestifteten Logen lediglich in Großbritannien bzw. - nach einer sgenaueren Äußerung Ramsays aus dem Jahr 1737, die Alain Bernheim in einer Studie anführt - in Schottland über die folgenden Jahrhunderte erhalten hatten. In Schottland sollte demnach »ean Lord Steward ou Grand maitre de la Maison du Roy d'Écosse « im Jahr 1286 eine Loge im Ort »Kilwinn « gestiftet haben. ${ }^{91}$ Das im 18. Jahrhundert als besonders ursprünglich geltende Schottland, in das sich nach späteren Erzählungen freimaurerischer Hochgradsysteme auch die Templer geflüchtet hätten, wurde auf diese Weise zu einem ständigen Referenzpunkt derartiger Geschichtskonstruktionen und klang auch in den Benennungen einzelner Systeme und ihrer Grade immer wieder an. ${ }^{92}$

Der Chevalier Ramsay stand durch den »Discours« mit der Entwicklung einer bestimmten Hochgradform in besonderer Verbindung, den sogenannten Rittergraden. Wie Pierre Mollier in seiner Studie "La Chevalerie maçonnique «üngst anschaulich nachweisen konnte, kam ihm eine entscheidende Rolle bei der Entwicklung des ersten Rittergrades zu. Vermutlich ist Ramsay sogar der alleinige Urheber des frühesten in Frankreich nachweisbaren Rittergrades, des um 1745 erstmals belegbaren Chevalier de l'Orient/Chevalier de l'Épée. ${ }^{93}$ Wie er im Jahr 1741 gegenüber einem deutschen Adligen namens Geusau angab, verfolgte Ramsay

88 Siehe hierzu Lennhoff/Posner/Binder (Hg.), Internationales Freimaurer-Lexikon (wie Anm. 18, Kap. I), $689 f$.

89 Mollier, La Chevalerie maçonnique (wie Anm. 31, Kap. I), 94. Vgl. auch Andrew Michael Ramsay, Les Voyages de Cyrus, avec un Discours sur la Mythologie, 2 Bde., Luxembourg/Amsterdam 1728, Permalink: http://nbn-resolving.org/urn:nbn:de:bvb:12-bsb10748484-6 bzw. http://nbn-resolving. org/urn:nbn:de:bvb:12-bsb10096583-7 (Zugriff vom 25.05.2014).

90 Siehe hierzu die Edition der verschiedenen Versionen bei Alain Bernheim, Ramsay et ses deux discours, Paris 2011.

91 Vgl. zu diesen Angaben sowie den hier angeführten Zitaten aus dem Original: Ders., Ramsay et ses deux discourses (wie Anm. 90, Kap. IV), 86. Bernheim legt hier eine Transkription eines Briefes Ramsays an den Marquis de Caumont vom 16.04.1737 vor.

92 Vgl. hierzu ausführlich Mollier, La chevalerie maçonnique (wie Anm. 31, Kap. I), 115-118.

93 Siehe hierzu Ders., La chevalerie maçonnique (wie Anm. 31, Kap. I), 89-105. 
das Ziel, Rituale zu rekonstruieren, wie sie bei den »Alten « gewesen sein könnten - wobei mit den »Alten « die Ritter der Kreuzzugszeit gemeint waren. ${ }^{94}$

Bereits in seinem »Discours" verteidigte Ramsay das hohe Alter des in der Freimaurerei enthaltenen Wissens, indem er feststellte: „Nôtre Science est aussy ancienne que le genre humain [...]. ${ }^{95}$ Vor seiner Überlieferung der »anciennes traditions« des Ordens, unter die Ramsay die Geschichte der Übermittlung des Urwissens durch mythische Großmeister wie Noah, Abraham, Moses, aber auch den oben erwähnten Cyrus verstand, hatte er bereits Anspruch darauf erhoben, die wahre Geschichte des Ordens auf Grundlage der Dokumente in den ältesten Archiven Großbritanniens zu kennen. ${ }^{96}$ Mit der Erwähnung einer durch die Kreuzritter reaktivierten Geheimsprache und -symbolik aus den Zeiten König Salomons gab Ramsay hier die Möglichkeit, an das Thema einer wiederentdeckten Urreligion anzuknüpfen, zumal er an anderer Stelle die Meinung vertrat, dass es sich bei dieser Kunst der allegorischen Verhüllung von religiösen Geheimnissen um eine philosophia perennis aller großen `Kulturvölker` der Menschheit handelte. ${ }^{97}$ Dieses geheime Wissen war nach Ramsays Ansicht nun über Großbritannien nach Frankreich gelangt. ${ }^{98}$ Wichtiger noch als diese Weitergabe des Wissens war jedoch der entscheidende Vorteil, der den Franzosen hiermit zuteilwurde und der Frankreich in aller Welt zu großem Ansehen verhelfen sollte: „C'est dans nos Loges a lavenir que les françois verront sans voyager, Comme dans un tableau racourcy les Caracteres de toutes les nations [...]. «99

In diesem letzten Satz des Ramsayschen »Discours" zeigt sich nochmals in konzentrierter Weise der oben herausgearbeitete Zusammenhang zwischen freimaurerischem Ritual und beschleunigter Erziehung. Die in die Königliche Kunst eingeweihten Freimaurer mussten nicht wie der fiktive Prinz Cyrus im Roman eine mühselige Reise bewältigen, um die Weisheiten aller Völker der Erde zu erfahren. Vielmehr bot ihnen die Freimaurerei im »Erinnerungsraum» der Loge die Essenz dieser Weisheiten durch eine einprägsame Symbolsprache bzw. den Stufenweg eindrücklicher Rituale an. Doch worin bestand für Ramsay die höchste Weisheit dieser beim Turmbau zu Babel mit den Menschenvölkern verstreuten und in den Freimaurerlogen wiedergeborenen Urreligion?

Ein Hinweis auf diese Frage findet sich im Anhang der bereits erwähnten Lebensbeschreibung Ramsays, die sich heute in den Beständen der Bibliothek Méjanes in Aix-en-Provence befindet. In diesem Anhang findet sich Ramsays Schrift "Dissertation sur l'âme des bêtes«, in welcher der Chevalier nicht nur - wie der Titel bereits vermuten lässt - die Beschaffenheit der Seele der Tiere, sondern auch

94 Vgl. Ders., La chevalerie maçonnique (wie Anm. 31, Kap. I), 96-98.

95 Zitiert nach der Transkription in: Bernheim, Ramsay et ses deux discours (wie Anm. 90, Kap. IV), 80. Bernheim gibt hier die Version »d'Epernay« vom 26.12.1736 wieder.

96 Vgl. Ders., Ramsay et ses deux discours (wie Anm. 90, Kap. IV), 82.

97 Siehe Ders., Ramsay et ses deux discours (wie Anm. 90, Kap. IV), 74.

98 Vgl. Ders., Ramsay et ses deux discours (wie Anm. 90, Kap. IV), $89 f$.

99 Zitiert nach Ders., Ramsay et ses deux discours (wie Anm. 90, Kap. IV), 90. 
der des Menschen behandelt. ${ }^{100}$ Seine Zielrichtung hierbei ist klar: Ramsay geht es ähnlich wie seinem Zeitgenossen Newton um die Abwehr der Philosophie Descartes' und der Gefahr eines aus ihr erwachsenden Materialismus und Atheismus. Für Ramsay war ein vollkommenes Verständnis der innersten »Essenz« der Wesen, hier der Tiere, mit den Mitteln des menschlichen Verstandes nicht möglich. ${ }^{101} \mathrm{Um}$ sich einer solchen Erkenntnis zumindest zu nähern, galt es verschiedene Theorien über die Seele der Tiere miteinander zu vergleichen.

Die Lehre der Metempsychose war der Punkt, auf den Ramsay in seiner »Dissertation « immer wieder zu sprechen kam. Für ihn waren die Tiere zwar grundsätzlich auf bestimmte instinktive Verhaltensweisen und Kenntnisse zur Erhaltung ihrer selbst bzw. ihrer Art angelegt, ${ }^{102}$ es ließen sich jedoch zwischen den Arten durchaus Unterschiede in Bezug auf das intellektuelle Vermögen und die Erkenntnisfähigkeit ausmachen. ${ }^{103}$ Nach der bereits in der Antike bekannten Lehre der Metempsychose waren Tiere laut Ramsay »Intelligences dégradées, qui expient le crime qu'elles ont commis, par l'humiliation, les peines et les maux qu'elles souffrent dans la prison des corps brutes. ${ }^{104}$ Auch der Mensch galt demnach als Gefangener seines Körpers. Für alle Wesen bestand nach Ramsay jedoch Hoffnung, dieses Gefängnis früher oder später zu verlassen: »[...] elles en Sortiront tôt ou tard, après plusieurs Révolutions et Métempsycoses. Celle est la Doctrine de toute l'antiquité tant sacrée que prophane. ${ }^{105}$

Durch einige griechische und römische Dichter sei, so Ramsay, die Lehre zwischenzeitlich verfälscht und in Misskredit gebracht worden, da sie behaupteten, die Lehre gelte universell für alle Seelen und würde bis in alle Ewigkeit andau-

100 Der Hinweis auf dieses Dokument fand sich bei Helmut Zander, der fälschlicherweise auf »Allan Ramsay« verweist, aber eindeutig Andrew Ramsay meint. Zander fand den Hinweis seinerseits bei Daniel P. Walker. Siehe hierzu Zander, Geschichte der Seelenwanderung (wie Anm. 77, Kap. I), 293.

101 Vgl. Anecdotes de la vie de messire André de Ramsay, chevalier, baron, ou plus tost baneret d'Écosse, dictés par lui-même peu de jours avant sa mort, pressé par les instances réitérées de son épouze, o.O., o.D., in: BM, MS 1188 (417), http://www.e-corpus.org/eng/ref/88281/Ms_1188_(417)/ (Zugriff vom 16.07.2014), hier fol. 106f.

$102 \mathrm{Vgl}$. Anecdotes de la vie de messire André de Ramsay, chevalier, baron, ou plus tost baneret d'Écosse, dictés par lui-même peu de jours avant sa mort, pressé par les instances réitérées de son épouze, o.O., o.D., in: BM, MS 1188 (417), http://www.e-corpus.org/eng/ref/88281/Ms_1188_(417)/ (Zugriff vom 16.07.2014), fol. 123f.

103 Siehe Anecdotes de la vie de messire André de Ramsay, chevalier, baron, ou plus tost baneret d'Écosse, dictés par lui-même peu de jours avant sa mort, pressé par les instances réitérées de son épouze, o.O., o.D., in: BM, MS 1188 (417), http://www.e-corpus.org/eng/ref/88281/Ms_1188_(417)/ (Zugriff vom 16.07.2014), fol. 124f.

104 Anecdotes de la vie de messire André de Ramsay, chevalier, baron, ou plus tost baneret d'Écosse, dictés par lui-même peu de jours avant sa mort, pressé par les instances réitérées de son épouze, o.O., o.D., in: BM, MS 1188 (417), http://www.e-corpus.org/eng/ref/88281/Ms_1188_(417)/ (Zugriff vom 16.07.2014), fol. 137.

105 Anecdotes de la vie de messire André de Ramsay, chevalier, baron, ou plus tost baneret d'Écosse, dictés par lui-même peu de jours avant sa mort, pressé par les instances réitérées de son épouze, o.O., o.D., in: BM, MS 1188 (417), http://www.e-corpus.org/eng/ref/88281/Ms_1188_(417)/(Zugriff vom 16.07.2014), fol. 139. 
ern. Ramsay verwehrte sich gegen diese Ansicht, wobei dies nicht nur die Überzeugung eines baldigen Beginns des Millenniums mit einschloss, sondern auch von der Existenz einer philosophia perennis, die Platon, Sokrates, Pythagoras, den Ägyptern, den Arabern und den Hebräern gemein gewesen sei. ${ }^{106}$ Seine hinzugezogenen Beweise aus der Bibel bezogen sich auf Moses und Salomon sowie die in den Evangelien nach Matthäus und Lukas geschilderte Austreibung von Dämonen aus dem Körper eines Besessenen. ${ }^{107}$ Sie brauchen hier nicht näher angeführt zu werden. Das hinter dem Begriff der Metempsychose liegende Prinzip der Beschaffenheit der Seele glich in Ramsays Darstellung dem oben erwähnten Auszug aus dem Kore Kosmou des Corpus Hermeticum: Ein allmächtiger Gott war der Schöpfer der Seelen, wobei er deren Auflehnung gegen ihn mit der Einkörperung in verschiedenartige Körper bestrafte. Er entzog und schenkte ihnen nach dem Grad ihrer Schuld die Sinne, mit denen sie die Welt erfahren und ihn erkennen konnten. Durch das Abbüßen ihrer Schuld durch ein tugendhaftes Leben wurden diese Sinne im Laufe des Prozesses der Metempsychose perfektioniert bzw. erweitert. Die Einteilung der Arten, die Ramsay hierbei erwähnte, glich frappierend denjenigen, die etwa auch Naturforscher wie Linné oder später Buffon vornahmen. Ramsay ging von Metamorphosen zu einem nächsthöher gelegenen Zustand aus. ${ }^{108}$

Er fasste das Ergebnis seiner »Dissertation« schließlich in vier Punkten zusammen, wobei hier vor allem der dritte Punkt von Interesse ist. Dieser lautete: „Comme chaque portion de Matiere est divisible à l'Infini, et peut renfermer des Beautés, et des merveilles Inépuisables, de même chaque Esprit peut se developper à l'infini, par une progression continuelle de connoissances et de sentimens. ${ }^{109}$ Nur geistig besonders fortgeschrittene Menschen erkannten daher laut Ramsay die Lehre der Metempsychose als einzig wahren Kern aller Religionen an. Dies stellte er ausdrücklich im Resümee seiner Abhandlung fest:

106 Vgl. Anecdotes de la vie de messire André de Ramsay, chevalier, baron, ou plus tost baneret d'Écosse, dictés par lui-même peu de jours avant sa mort, pressé par les instances réitérées de son épouze, o.O., o.D., in: BM, MS 1188 (417), http://www.e-corpus.org/eng/ref/88281/Ms_1188_(417)/ (Zugriff vom 16.07.2014), hier fol. 139f.

107 Vgl. Anecdotes de la vie de messire André de Ramsay, chevalier, baron, ou plus tost baneret d'Écosse, dictés par lui-même peu de jours avant sa mort, pressé par les instances réitérées de son épouze, o.O., o.D., in: BM, MS 1188 (417), http://www.e-corpus.org/eng/ref/88281/Ms_1188_(417)/ (Zugriff vom 16.07.2014), fol. 145-162. Die Angaben Ramsays beziehen sich auf das Evangelium nach Matthäus, Kapitel 8, Vers 29 sowie das Evangelium nach Lukas, Kapitel 8, Vers 31.

$108 \mathrm{Vgl}$. Anecdotes de la vie de messire André de Ramsay, chevalier, baron, ou plus tost baneret d'Écosse, dictés par lui-même peu de jours avant sa mort, pressé par les instances réitérées de son épouze, o.O., o.D., in: BM, MS 1188 (417), http://www.e-corpus.org/eng/ref/88281/Ms_1188_(417)/ (Zugriff vom 16.07.2014), hier fol. 149-151.

109 Anecdotes de la vie de messire André de Ramsay, chevalier, baron, ou plus tost baneret d'Écosse, dictés par lui-même peu de jours avant sa mort, pressé par les instances réitérées de son épouze, o.O., o.D., in: BM, MS 1188 (417), http://www.e-corpus.org/eng/ref/88281/Ms_1188_(417)/ (Zugriff vom 16.07.2014), fol. 163. 
Cette Doctrine de la Métempsycose doit choquer d'abord les Imaginations foibles et paroître absurde à ceux qui ne connoissent point le Plan General dela Providence. C'est ainsi que les verités les plus Lumineuses et les plus Sublimes paroissent quelques fois chimériques aux ames vulgaires, qui sont incapables d'en approfondir les racines cachées [...]. Tel est le malheur des Esprits vrayement Metaphisiques; on les regarde souvent comme visionnaire, parcequ'ils voyent plus loin que les autres. ${ }^{110}$

Auch in dem den "Voyages de Cyrus" angehängten »Discours sur la Mythologie» hatte Ramsay die Lehre der Metempsychose bereits in Form hinduistischer Wiedergeburtsvorstellungen erwähnt. ${ }^{111} \mathrm{Da}$ die Freimaurerei - wie oben gesehen für den Chevalier ein Ort war, an dem der Adept der Weisheiten aller Völker ohne zu reisen, wie auf einem »tableau racourcy«, in Kürze durch Allegorien gewahr werden konnte, begegnete sie dem freimaurerischen Adepten ebenfalls im Ritual des Chevalier de l'Orient in Gestalt der Tempelallegorie:

Tous les grades depuis l'apprentif jusques au grand Écossais, ne retracent que ce qui s'était fait lors de la construction du temple ancien. Le grade de Chevalier de l'Orient est pour renouveller la maçonnerie morte. Leur but était de rebâtir le temple, lorsque l'éternel voudrait leur en procurer les moyens. Car la maçonnerie renouvellée parmi les chrétiens, n'a d'autre fin dans son principe que de réédifier ce S. [aint] édifice sur ses anciens fondemens [...] Ce second temple a été aussi détruit. Les maçons d'aujourd'hui sont censés être descendus de ceux qui le bâtirent, aussi doivent-ils les imiter, et à leur exemple tâcher, sous la conduite d'un nouveau Zorobabel, de bâtir un troisième temple au vrai dieu. ${ }^{112}$

Interessanterweise folgte hier der Hinweis »faute de terrain nous les élevons [les temples] dans notre cour. ${ }^{113}$ Die Freimaurerei bediente sich somit in ihrem Erziehungssystem einer uralten Symbolsprache, die bereits Salomon und Cyrus beim Bau ihrer Tempel verwandt hatten. Diese Symbolsprache vermochte die Leidenschaften und hierüber das Gemüt des Menschen direkt zu berühren und über die Erkenntnis der Wahrheit der Metempsychose zur seelischen Läuterung zu führen. Der Plan der göttlichen Vorsehung bzw. das Goldene Zeitalter vollzog

110 Anecdotes de la vie de messire André de Ramsay, chevalier, baron, ou plus tost baneret d'Écosse, dictés par lui-même peu de jours avant sa mort, pressé par les instances réitérées de son épouze, o.O., o.D., in: BM, MS 1188 (417), http://www.e-corpus.org/eng/ref/88281/Ms_1188_(417)/(Zugriff vom 16.07.2014), hier fol. 164f.

111 Vgl. hierzu Ramsay, Les Voyages de Cyrus (wie Anm. 89, Kap. IV), Bd. 2, 128 f.

112 Zitiert nach Mollier, La chevalerie maçonnique (wie Anm. 31, Kap. I), 91. Bei den eingeklammerten Wörtern und Auslassungen handelt es sich um Ergänzungen und Auslassungen Molliers.

113 Zitiert nach Ders., La chevalerie maçonnique (wie Anm. 31, Kap. I). Bei den eingeklammerten Wörtern handelt es sich um Ergänzungen Molliers. Zur ähnlichen Deutung der Tempelsymbolik als wiederzuerrichtender "Innerer Tempel« siehe Cornelia Limpricht, Platzanlage und Landschaftsgarten als begehbare Utopien. Ein Beitrag zur Deutung der Templum-SalomonisRezeption im 16. und 18. Jh. (Europäische Hochschulschriften, Reihe 28, Kunstgeschichte, 202), Frankfurt a.M. [u.a.] 1994, 110-117. 
sich also nicht nur über die sich immer wieder ereignende Zerstörung und Neuaufrichtung der Tempel und Zivilisationen, sondern auch über die Wiederverkörperung und Perfektionierung der Seelen.

Die Freimaurer - insbesondere die Freimaurermeister und Inhaber der Rittergrade - konnten sich vor dem Hintergrund dieser als ursprünglichste aller religiösen Wahrheiten aufgefassten Lehre als seelisch höherstehende Wesen begreifen. Ihnen war somit ein Sinn für das Metaphysische gegeben. Nach dem Tod Ramsays nahm die Entwicklung von Hochgradsystemen, die letztlich als Rekonstruktionsversuche der Urreligion zu sehen sind, insbesondere auf dem europäischen Festland rasant an Fahrt auf. ${ }^{114}$ Innerhalb vieler Systeme wurden die Adepten nicht nur - wie in den folgenden Kapiteln gezeigt werden soll - zu aktivem alchemistischem Laborieren angehalten, sondern absolvierten regelrechte Ausbildungen in verschiedenen Geheimlehren wie Magie, Kabbala oder Alchemie. ${ }^{115}$ Nicht selten jedoch gaben Scharlatane und »Unbekannte Obere « zum eigenen finanziellen Nutzen vor, das letzte "Geheimnis « der Freimaurerei bereits zu besitzen. ${ }^{116}$ Nach den oben gemachten Ausführungen ist davon auszugehen, dass für die Beteiligten die »Gier nach Gold « in den meisten dieser Fälle deutlich hinter der Frage des künftigen Seelenheils bzw. einem 'philosophischen Gold` zurückstand, die sich aufs Engste mit der Praxis der Transmutation in den verschiedenen Kontexten verband.

Die in den späteren Kapiteln folgenden mikrohistorischen Beispiele widmen sich der Frage, auf welche Weise rheinische Adlige an einer derartigen freimaurerischen Vergesellschaftung teilnahmen und welchen Stellenwert die adlige »Blutsideologie« sowie die Lehre der Metempsychose im Verlauf der »Sattelzeit« unter dem Eindruck der fortschreitenden naturwissenschaftlichen Erkenntnisse innerhalb des Arkanraums genoss.

114 Lennhoff/Posner/Binder (Hg.), Internationales Freimaurer-Lexikon (wie Anm. 18, Kap. I), 396 sowie 605.

115 Vgl. Dies. (Hg.), Internationales Freimaurer-Lexikon (wie Anm. 18, Kap. I), 396 sowie 605.

116 Vgl. zum Begriff der »Unbekannten Oberen« bzw. »Geheimen Oberen« Dies. (Hg.), Internationales Freimaurer-Lexikon (wie Anm. 18, Kap. I), 332. 



\section{Rheinischer Adel und Freimaurerei des Ancien Régime - Die Düsseldorfer Adelsloge La Parfaite Amitié}

\section{V.1 Die Loge La Parfaite Amitié und ihre Mitglieder}

Am 17. Tag des ersten Monats des wahren Lichts $5765^{1}$ protokollierten die hohen Amtsträger der Großloge der Sieben Vereinigten Niederlande die Aufrichtung einer neuen Loge in Düsseldorf namens La Parfaite Amitié, zu deren Befugnissen sie vermerkten:

Accordons en outre aux Frères Membres de cette Loge, le pouvoir et l'autorité de conferer le Grade d'Apprentif Maçon, à tout honnête homme, recommandable par la vertu, probité, régularité de Mœurs et bonne conduite; et d'avancer les Frères, qui le meritent par leur application et zèle, aux Grades de Compagnon et de Maître. ${ }^{2}$

Die Großloge war erst kurze Zeit zuvor im Jahr 1756 von zehn niederländischen Logen im Haag gegründet worden ${ }^{3}$ und stand seit 1759 unter der Großmeisterschaft des Barons Carl van Boetzelaer. ${ }^{4}$ Die Düsseldorfer Freimaurer der Parfaite Amitié hatten zunächst in einem förmlichen Brief mit folgenden Worten dem Großmeister Respekt gezollt und ihre Unterwerfung unter das Regelwerk der niederländischen Großloge bezeugt:

C'est avec tout la Soumission due à vos Rangs et caracteres que les sousignés /: guidés par la zêle le plus ardent:/ se présentent pour vous supplier très Respectueusement d'agréer la maniere reglée, qui nous pousse à travailler avec tout l'ordre qu'exige l'Art Royale; et de vouloir pour cet Effet, nous accorder

1 Nach christlicher Zeitrechnung: 17.01.1765.

2 Zum Eingangsdatum sowie zum Zitat siehe Concept Constitutie voor de Loge La Parfaite Amitié te Dusseldoorp opgeregt 17. Jan. 1765, Den Haag, 17. Tag des ersten Monats des wahren Lichts 5765 (17.01.1765), in: GON, 2402-23, Schriften zur Konstituierung der Loge La Parfaite Amitié, Düsseldorf, 1765-1767, o.S. Es muss darauf hingewiesen werden, dass hier die freimaurerische Zeitrechnung offenbar nicht - wie im Fall der später zu behandelnden Logen des Premier Empire - mit dem Monat März, sondern mit dem Monat Januar begann. Die Zeitrechnung ist teilweise von den Zeitgenossen in die profane Zeitangabe aufgelöst. Vgl. zum Brief auch August Pauls, Düsseldorfer Freimaurerei im 18. Jh. Mit einer Einleitung über die rheinische Freimaurerei während des 18. Jh.s, Leipzig 1927, 39. Die Originale der Archivalien befinden sich sämtlich in den Beständen des Archivs des Orde van Vrijmetselaren onder het Grootoosten der Nederlanden. Zudem wurden die Notizen Pauls gesichtet, die im GStA PK verwahrt werden. In diesen finden sich einige Abschriften weiterer Dokumente, die nicht mehr im Original aufgefunden werden konnten. Siehe hierzu Mitgliederlisten Loge La Parfaite Amitié, Düsseldorf, 1765-1769, in: GON, 2336-10; Düsseldorfer Freimaurerei im 18. Jh. nach den Akten des Groß-Orients der Niederlande, in: GStA PK, FM 5.2.D48, Nr. 165.

3 Vgl. hierzu Lennhoff/Posner/Binder (Hg.), Internationales Freimaurer-Lexikon (wie Anm. 18, Kap. I), 605.

$4 \mathrm{Zu}$ seinem freimaurerischen Wirken siehe C. Lenning, Allgemeines Handbuch der Freimaurerei, Bd. 1, Leipzig 1822, 47f. 
un Acte de Constitution, àfin qu'animés par cet Esprit d'ordre, nous puissions avancer avec force, et cultiver de plus en plus cette noble science qui fait tant d'honneur à notre Société. ${ }^{5}$

Nicht nur die hier erwähnte "noble science« ist in Hinblick auf die Mitglieder der Düsseldorfer Loge wortwörtlich zu nehmen, auch der Name des Ateliers ist in diesem Sinne zu verstehen, der mit dem aus antiken Schriften abgeleiteten Ideal der "Seelenverwandtschaft» auf eine besondere Form des Freundschaftskultes im 18. Jahrhundert anspielte.

Wie bereits der dem Freimaurerbund angehörende Historiker August Pauls in seiner im Jahr 1927 erstellten Untersuchung der Loge festgestellt hat, befanden sich unter ihren Mitgliedern zahlreiche Vertreter rheinischer Adelsfamilien, sämtlich katholischer Konfession. So zählten zu den 14 Gründern die niederadligen Familien von Hompesch, von Lemmen, von Nesselrode-Hugenpoett, von Berghe, Berghe von Trips, von Goltstein, von Blanckart, von Merode und von Gymnich. ${ }^{6}$ Lediglich Bernhard von Longueval entstammte einer Familie mit französischen Wurzeln. ${ }^{7}$ Wie sich anhand der Untersuchungen Pauls sowie der im Archiv des Grootoostens der Niederlande vorhandenen Logenmatrikel zeigen lässt, nahm die Loge auch in den Jahren nach ihrer Gründung zahlreiche weitere Vertreter des rheinischen Adels, aber auch Adelsfamilien anderer Regionen auf. Ergänzend zu den bisher genannten rheinischen Geschlechtern finden sich etwa die Familien von Mirbach, von Loë, von Spee, von Schaesberg und von Hatzfeld unter den Mitgliedern der Parfaite Amitié. ${ }^{8}$ Insgesamt bestand die Loge zur Zeit ihres größten Mitgliedsbestandes im Mai des Jahres 1769 aus 37 Brüdern, davon 35 Adlige. ${ }^{9}$ Wie bereits August Pauls daher richtig bemerkt, handelte es sich bei der Parfaite Amitié um eine »Feudalloge [...] aus den ersten adeligen Geschlechtern des jülich-bergischen und kurkölnischen Landes «. ${ }^{10}$

Es verwundert bei dieser weitgehenden regionalen Beschränkung nicht, dass neben dem propagierten Ideal der Seelenverwandtschaft unter den Mitgliedern

5 Düsseldorfer Loge La Parfaite Amitié an Großloge der Sieben Vereinigten Niederlande, Düsseldorf, 08.01.1765, in: GON, 2402-23, o.S. Das Regelwerk der niederländischen Großloge orientierte sich an den Andersonschen "Constitutions« Siehe hierzu wie zu einem Abriss der Geschichte der Freimaurerei in den Niederlanden Dotzauer, Freimaurerei global (wie Anm. 18, Kap. I), 32-35.

6 Vgl. zu sämtlichen in diesem Abs. gemachten Angaben die Ausführungen bei Pauls, Düsseldorfer Freimaurerei (wie Anm. 2, Kap. V), 39-44 sowie 55. Zu den entsprechenden Namen sei außerdem auf die Tabelle in Anhang A dieser Studie verwiesen.

7 Siehe Ders., Düsseldorfer Freimaurerei (wie Anm. 2, Kap. V), 42-44.

8 Vgl. hierzu Ders., Düsseldorfer Freimaurerei (wie Anm. 2, Kap. V), 55-58 sowie 60 und 67.

9 Bei der hier vorgenommen Zählung wurden die nicht vollberechtigten bürgerlichen Mitglieder - der Clerc de Loge Sissonet sowie Friedrich Heinrich Jacobi - zunächst für die Gesamtzahl der Mitglieder mitgerechnet. Sissonet war - wie bereits bei Pauls erwähnt - offenbar nur bei der Loge angestellt. Zu Jacobis Stellung vgl. das folgende Kapitel zu seiner Person. Zu den gemachten Angaben vgl. Mitgliedertableau der Loge La Parfaite Amitié, Düsseldorf, 01.04.1769, in: GON, 2336-10. Pauls gibt für das Ende des Jahres 1769 einen Bestand von 36 Personen an. Vgl. Pauls, Düsseldorfer Freimaurerei (wie Anm. 2, Kap. V), 70. Siehe auch Abb. 11.

10 Ders., Düsseldorfer Freimaurerei (wie Anm. 2, Kap. V), 44. 


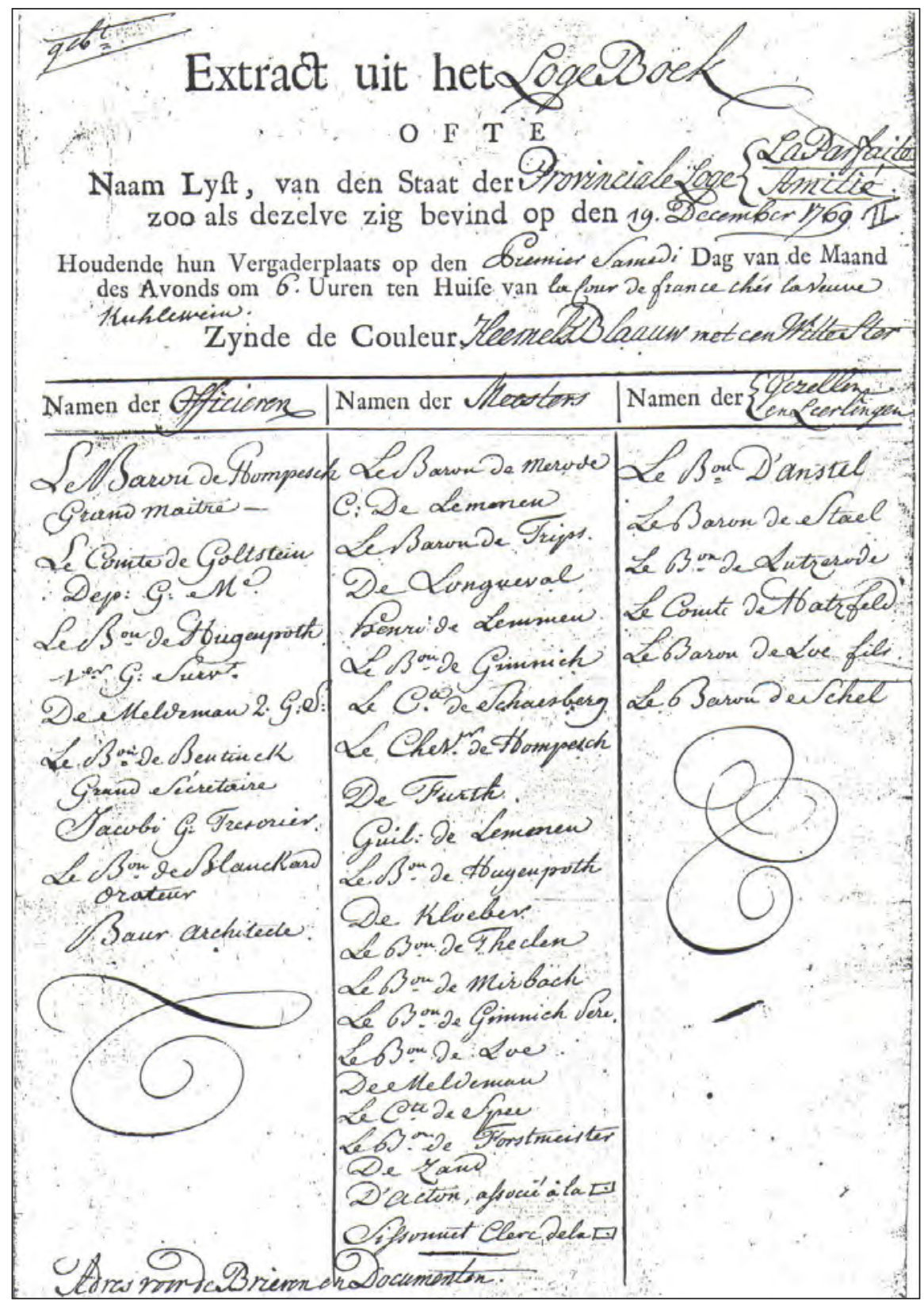

Abbildung 11: Mitgliedertableau der Düsseldorfer Adelsloge La Parfaite Amitié, Mai 1769 (Bildrecht/Werk und Foto: From the collections of the Cultural Masonic Centre, The Hague). 
der Loge auch tatsächliche verwandtschaftliche Verflechtungen vorlagen. Pauls vermerkt hierzu: »In der Loge >La parfaite amitié s sind jedenfalls Familienbeziehungen vielfach maßgebend für den Beitritt zu der auf gute Abstammung das Hauptgewicht legenden Bauhütte gewesen. ${ }^{11}$ So sind nicht nur, wie im Fall der Familien von Loë, von Staël-Holstein, von Hompesch, von Gymnich und von Lemmen direkte Angehörige, wie Sohn und Vater, in der Loge vertreten, sondern auch entferntere Verwandtschaftsgrade durch Heiratsverbindungen feststellbar. So ist zum Beispiel der 1768 zum kurpfälzischen Statthalter von Jülich-Berg ernannte Johann Ludwig Franz Reichsgraf von Goltstein mit der Schwester des Mitgründers der Loge Karl Franz Alexander Freiherr von Blanckart verheiratet. Seine Mutter war zudem eine geborene Gräfin von Schaesberg - der später in die Loge aufgenommene Graf August von Schaesberg war somit sein Vetter. ${ }^{12}$ Die Familie von Hompesch stellte mit dem später unter Kurfürst Max IV. zum bayrischen Finanzminister ernannten Franz Karl von Hompesch (1735-1800) den Meister vom Stuhl der Loge. Neben ihm waren seine beiden Brüder Karl Arnold (geboren 1736), Domherr zu Lüttich und Münster, sowie Ferdinand (1744-1805), der spätere letzte Großmeister der Malteserritter vor der Eroberung Maltas durch Napoleon, Mitglied der Loge. ${ }^{13}$ Die freimaurerische Familien-Metaphorik war hier somit gelebte Realität und ist durchaus bezeichnend im Hinblick auf den Stellenwert der adligen »Blutsideologie« bzw. eine esoterische Position der Adelsbegründung. Die Mitglieder der Parfaite Amitié konnten sich innerhalb der Loge nicht nur in einem Kreis tugendhafter adliger Vorbilder wähnen, sondern vielfach auch in einem Kreis blutsverwandter Personen.

Dieser Umstand muss - neben der starken Orientierung des rheinischen und westfälischen Adels in bildungsmäßigen Belangen in Richtung der Vereinigten Niederlande - auch in Bezug auf die Angliederung der Loge an die niederländische Großloge beachtet werden. In der Düsseldorfer Loge waren durchaus Geschlechter vertreten, deren verwandtschaftliche Netzwerke bis in die Vereinigten Niederlande und nach England reichten bzw. deren Familiengüter in diese Territorien fielen, wie im Falle der Geschlechter von Merode, von Hompesch, der Grafen von Schaesberg oder der Familie von Bentinck. So spiegelt der kurz nach der erfolgten Konstituierung der Loge vorgenommene Wechsel im Amt des Sekretärs diese

11 Pauls, Düsseldorfer Freimaurerei (wie Anm. 2, Kap. V), 56.

12 Vgl. zu sämtlichen Angaben innerhalb dieses Abs. in Bezug auf die verwandtschaftlichen Verhältnisse der Mitglieder der Parfaite Amitié: Ders., Düsseldorfer Freimaurerei (wie Anm. 2, Kap. V), 42, 44 und 55 sowie zu den Namenszusätzen einzelner Mitglieder (»pere«, "fils«, »le sécond «, »1'aine« etc.) allgemein: Mitgliederlisten Loge La Parfaite Amitié, Düsseldorf, 1765-1769, in: GON, 2336-10.

13 Vgl. zu sämtlichen hier gemachten Angaben zur Familie Hompesch: Pauls, Düsseldorfer Freimaurerei (wie Anm. 2, Kap. V), 55; Ernst von Oidtman und seine genealogisch-heraldische Sammlung in der Universitäts-Bibliothek zu Köln, bearb. von Herbert M. Schleicher (Veröffentlichungen der Westdeutschen Gesellschaft für Familienkunde e.V., 58-110), Bd. 8, Köln 1991-1998, Mappe 646, 597-633, hier 608f. Ein Porträt Ferdinands findet sich unter: commons.wikimedia.org/wiki/ File:Fra_Ferdinand_von_Hompesch_G.M._Palace.jpg (Zugriff vom 02.08.2014). 
Verflechtungen wider. Der neu in die Loge getretene und zum Sekretär gewählte Bruder Freiherr von Bentinck zu Limbricht ${ }^{14}$ verfügte über beste verwandtschaftliche Kontakte in die niederländische Freimaurerei. Der Name Bentinck ist in der Geschichte der Freimaurerei der Vereinigten Niederlande vor allem mit dem zweiten Großmeister der niederländischen Großloge Graf Christian Friedrich von Bentinck $^{15}$ sowie Willem Graaf Bentinck van Rhoon (1704-1774) verknüpft. ${ }^{16}$

Die in die Düsseldorfer Loge hineinreichenden verwandtschaftlichen Beziehungen wie die Exklusivität ihrer Mitgliedschaft waren unter Berücksichtigung der eingangs dargestellten esoterischen Form der Adelsbegründung sowie der Andersonschen Geschichtsschreibung bereits ein deutlicher Hinweis auf den konkreten Hoheitsanspruch des rheinischen Adels innerhalb des Arkanraums. Dass sich die Parfaite Amitié mit einem solchen Anspruch in guter Gesellschaft befand und sich auf direkte Vorbilder bezog, kann im Folgenden der freimaurerische Werdegang eines Gründungsmitgliedes illustrieren.

\section{V.2 Die Beziehungen des Freiherrn Alexander von Merode-Hoffalize zur Straßburger Adelsloge La Candeur}

Über den Anlass zur Gründung der Düsseldorfer Loge La Parfaite Amitié sowie den Werdegang der Gründungsmitglieder innerhalb der Freimaurerei konnte bislang nur wenig in Erfahrung gebracht werden. August Pauls vermutete in Bezug auf die für einige Mitglieder im Konstitutionsgesuch der Loge angeführten Hochgrade, dass ihre Aufnahme in französische Logen während der Absolvierung einer Reise oder eines Militäreinsatzes im Zuge des Siebenjährigen Krieges geschehen sein könnte. ${ }^{17}$ Tatsächlich lassen sich heute in Bezug auf die Düsseldorfer Loge La Parfaite Amitié abseits der bereits von Pauls angeführten französischen Sprache der verbliebenen Logen-Dokumente Indizien für enge Verbindungen $\mathrm{zu}$ französischen Logen finden.

Die Schlüsselfigur hierzu ist einer der Gründer der Loge: Freiherr Alexander von Merode-Hoffalize (gestorben 1792), Domprobst zu Hildesheim, Domherr zu Trier und Münster sowie Inhaber des freimaurerischen Rittergrades eines Chevalier Rose-Croix. ${ }^{18}$ Er sowie sein ebenfalls der Düsseldorfer Adelsloge angehörender

14 Laut Pauls handelt es sich bei dem Vertreter der Familie von Bentinck um den Freiherrn Adrian Konstanz von Bentinck zu Limbricht (1700-1779). Vgl. Pauls, Düsseldorfer Freimaurerei (wie Anm. 2, Kap. V), 55. Er bekleidete nach den Angaben bei Pauls die Ämter eines kurpfälzischen und jülich-bergischen Geheimen Rats und war Präsident des jülich-bergischen Hofrats-Dikasteriums. Vgl. zu den Familien der Freiherren von Bentinck zu Limbricht auch Oidtman und seine genealogisch-heraldische Sammlung (wie Anm. 13, Kap. V), Bd. 1, Mappe 69, 637-654, hier 648.

15 Lennhoff/Posner/Binder (Hg.), Internationales Freimaurer-Lexikon (wie Anm. 18, Kap. I), 605.

16 Vgl. zu den freimaurerischen Aktivitäten Willem Bentinck van Rhoons: Margaret C. Jacob, The Radical Enlightenment. Pantheists, Freemasons and Republicans, London/Worcester 1981, 236.

17 Vgl. Pauls, Düsseldorfer Freimaurerei (wie Anm. 2, Kap. V), $39 f$.

18 Vgl. zu den hier angeführten Titeln Pauls, Düsseldorfer Freimaurerei (wie Anm. 2, Kap. V), $39 \mathrm{f}$. sowie die Unterschrift Merodes in Düsseldorfer Loge La Parfaite Amitié an Großloge der Sieben 
Bruder, Freiherr Balduin Karl Franz von Merode-Hoffalize (1740-1803), Kaiserlicher Kammerherr sowie unter anderem Herr der Herrschaften Frenz, Frankenberg, Drove und Sechtem, ${ }^{19}$ entstammten der Ehe zwischen Gottfried Arnold von Merode-Hoffalize zu Frenz, Herr zu Frankenberg, und Karolina Maria Gräfin von Nesselrode-Ehreshoven. ${ }^{20}$ Das weitverzweigte Geschlecht derer von Merode zählt zum rheinischen Uradel, wobei im Falle des Zweiges Hoffalize zu Frenz insbesondere die verwandtschaftlichen Verflechtungen in den niederländischen und flämischen Raum für die weitere Darstellung von Bedeutung sind.

Für den 23.01.1762 ist die Aufnahme des »Alexandre Baron de Merode D' Hoffalitze« in die Matricula Serenissimorum et Illustrissimorum der Universität Straßburg bezeugt. ${ }^{21}$ In einer Studie Pierre Yves Beaurepaires wird in einem Quellenzitat zur Straßburger Adelsloge La Candeur für den 10.01.1763 ein Vorschlag zur Beförderung eines Adligen namens "de Merode" in den Grad des Meisters erwähnt. ${ }^{22}$ Hierbei handelt es sich mit großer Sicherheit um den oben erwähnten Alexander von Merode-Hoffalize. Merode unterzeichnete kurz zuvor auch das an den "Comte de Clermont Prince du Sang Grand Maître« der französischen Grande Loge gerichtete Gründungsgesuch der Candeur, da er in deren »Registre des Procès-Verbaux" unter dem Datum vom 07.01.1763 neben anderen Brüdern als Unterzeichnender aufgeführt wird. ${ }^{23}$ Er gelangte innerhalb der Candeur, die von ihren Mitgliedern als "mère loge de la noblesse ${ }^{24}$ bezeichnet wurde, nicht

Vereinigten Niederlande, Düsseldorf, 08.01.1765, in: GON, 2402-23, o.S.

19 Siehe zu den hier angeführten Titeln die Ausführungen bei Pauls, Düsseldorfer Freimaurerei (wie Anm. 2, Kap. V), 44.

20 Vgl. hierzu sowie zu den in diesem Abschnitt angegebenen weiteren Nachweisen zur Familie die Angaben bei Christian Quix, Die Frankenburg insgemein Frankenberg genannt und die Vogtei Burtscheid, Aachen 1829, 78f., Permalink: http://nbn-resolving.org/urn:nbn:de:bvb:12-bsb10013978-2 (Zugriff vom 25.05.2014); Anton Fahne, Geschichte der Grafen, jetzigen Fürsten zu Salm-Reifferscheidt, sowie ihrer Länder und Sitze: nebst derjenigen Familien, aus denen sie ihre Frauen genommen, Bd. 1, 2. Abt., Cöln 1866, 120f., Permalink: http://nbn-resolving.org/urn:nbn:de:bvb:12-bsb10624325-0 (Zugriff vom 25.05.2014).

21 Siehe hierzu Die alten Matrikeln der Universität Strassburg: 1621 bis 1793, bearb. von Gustav C. Knod, Bd. 1: Die allgemeinen Matrikeln und die Matrikeln der philosophischen und theologischen Fakultät, Strassburg 1897, 37.

22 Vgl. zu diesem Hinweis Pierre-Yves Beaurepaire, L’espace des francs-maçons. Une sociabilité européenne au XVIII ${ }^{e}$ siècle, Rennes 2003, 103. Siehe hierzu insb. Logenbuch der La Candeur, Straßburg, Eintrag vom 3. Tag der 2. Woche [sic!] des 10. Monats 5763 (10.01.1763), in: BnuS, MS 5437, fol. 4f. Die Zeitrechnung beginnt hier offenbar mit dem Monat April und wird innerhalb des Dokuments jeweils in die profane Zeit aufgelöst. Die Aufnahme bestätigt nachträglich den von Beaurepaire und Binder im Zuge ihrer Untersuchungen herausgearbeiteten Zusammenhang zwischen Grand Tour und Freimaurerei. Vgl. zu diesem Zusammenhang bei Beaurepaire: Beaurepaire, L'Autre et le Frère (wie Anm.59, Kap. I), 434-443.

23 Logenbuch der La Candeur, Straßburg, Eintrag vom 7. Tag des 10. Monats 5765 (07.01.1763), in: BnuS, MS 5437, fol. 2f. Siehe zum Engagement des Comte de Clermont in der französischen Freimaurerei sowie sein aristokratisches Verständnis derselben die Ausführungen bei Lennhoff/Posner/Binder (Hg.), Internationales Freimaurer-Lexikon (wie Anm. 18, Kap. I), 183.

24 Logenbuch der La Candeur, Straßburg, Eintrag vom 4. Tag der 4. Woche des 11. Monats 5763 (26.02.1763), in: BnuS, MS 5437, fol. 7. 
nur in den Grad des Meisters ${ }^{25}$ und den Hochgrad eines Élu, ${ }^{26}$ sondern auch am 26.02.1763 in das Logenamt eines Maître de ceremonies. ${ }^{27}$ Dieser war für die Vorbereitung der Logenarbeiten zuständig. ${ }^{28}$ Merode musste also zu diesem Zeitpunkt bereits durchaus zuverlässige Kenntnisse der freimaurerischen Gepflogenheiten erlangt haben. Nach dieser Erwähnung findet sich kein weiterer Eintrag, der den Namen Merodes nennt. Es kann davon ausgegangen werden, dass er seinen Studienort Straßburg wieder verlassen hatte.

Hierdurch bestätigt sich die von August Pauls geäußerte Annahme, dass die Gründung der Parfaite Amitié auch auf französische Einflüsse zurückzuführen sei, die auf den rheinischen Adel insbesondere in der Zeit des Siebenjährigen Krieges wirkten. Wichtiger scheint jedoch, dass die Stadt Straßburg, die von Beaurepaire aufgrund ihrer geographischen Lage und ihrer Frequentierung durch reisende Kavaliere verschiedener Nationalitäten auch als eine "carrefour maçonnique de rang européen ${ }^{29}$ bezeichnet wurde, mit der Adelsloge La Candeur eine Art französisches Pendant zur Düsseldorfer Loge beheimatete. Es lohnt sich deshalb, die Straßburger Loge La Candeur näher in Bezug auf ihre Sichtweise der Freimaurerei einzuordnen.

Die Loge La Candeur war auf Initiative des Grafen Friedrich Aloys von Brühl gestiftet worden, ${ }^{30}$ vertrat eine explizit aristokratische Auffassung der Freimaurerei und konnte in ihrer Mitgliedsstruktur durchaus als Vorbild für die Düsseldorfer Parfaite Amitié herhalten, die sich zwar der in Fragen der überständischen Vergesellschaftung als legerer geltenden niederländischen Großloge anschloss, jedoch in Bezug auf ihre interne Mitgliedsstruktur ebenfalls eine eher strengere »französische Linie « vertrat. ${ }^{31}$ Diese von der Candeur und der Parfaite Amitié bezeugte Strenge kann dabei als Ergebnis einer kritischen Haltung zur der oben erwähnten

25 Vgl. Logenbuch der La Candeur, Straßburg, Eintrag vom 4. Tag der 3. Woche des 10. Monats 5763 (18.01.1763), in: BnuS, MS 5437, fol. 4f.

26 Vgl. Logenbuch der La Candeur, Straßburg, Eintrag vom 5. Tag der 2. Woche des 11. Monats 5763 (12.02.1763), in: BnuS, MS 5437, Straßburg, fol. 8f. Zu den verschiedenen Ausformungen des Grades eines Élu vgl. Lennhoff/Posner/Binder (Hg.), Internationales Freimaurer-Lexikon (wie Anm. 18, Kap. I), 96 sowie 251. Womöglich erlangte Merode in späterer Zeit auch den Grad eines Illustre Élu de quinze des Conseil des Empereurs d'Orient et d'Occident. Siehe hierzu Pauls, Düsseldorfer Freimaurerei (wie Anm. 2, Kap. V), 59.

27 Logenbuch der La Candeur, Straßburg, Eintrag vom 4. Tag der 4. Woche des 11. Monats 5763 (26.02.1763), in: BnuS, MS 5437, Straßburg, fol. 7.

28 Vgl. zum Amt eines Maître de ceremonies den Eintrag "Zeremonienmeister« in: Lennhoff/Posner/ Binder (Hg.), Internationales Freimaurer-Lexikon (wie Anm. 18, Kap. I), 928.

29 Vgl. Pierre-Yves Beaurepaire, Un creuset maçonnique dans l'Europe des Lumières: La Loge de la Candeur, orient de Strasbourg, in: Revue d'Alsace 124 (1998), 89-120, hier 89. Ich bedanke mich bei Herrn Beaurepaire für die Übersendung eines Exemplars seines Artikels in der in Deutschland nicht aufzufindenden Zeitschrift »Revue d'Alsace».

30 Vgl. hierzu Winfried Dotzauer, Freimaurergesellschaften im Rheingebiet. Die Anfänge der Freimaurerei im Westen des Alten Reiches, in: Helmut Reinalter (Hg.), Freimaurer und Geheimbünde im 18. Jh. in Mitteleuropa, 4. Aufl., Frankfurt a.M. 1993, 140-176, hier 144.

31 Siehe zu dieser Einschätzung der niederländischen bzw. französischen Freimaurerei sowie zur Besprechung der Straßburger Loge La Candeur Margaret C. Jacob, Living the Enlightenment. Freemasonry and Politics in Eighteenth-Century Europe, Oxford 1991, 195f.; Dies., Money, Equality, Fraternity. Freemasonry and the Social Order in Eighteenth-century Europe, in: Thomas L. Has- 
»Nivellierung ständischer Grenzen« gesehen werden und entbehrte nicht eines direkten Bezugs zur adligen »Blutsideologie «. ${ }^{32}$ Innerhalb der Loge La Candeur schlug sich dieses Festhalten an der adligen »Blutsideologie» in der Suche nach einem mystischen inneren Weg zur Vereinigung des Menschen mit Gott sowie in einem katholisierenden Sprachgebrauch nieder. ${ }^{33}$ Wie Margaret C. Jacob in diesem Zuge richtigerweise feststellte, barg der dabei ebenfalls vorgenommene Rekurs auf den Tugend-Adel-Diskurs zwar eine egalisierende Option, konnte und wurde hier jedoch im freimaurerischen Raum zu einem Moment adliger Exklusivität. ${ }^{34}$ Die Gründe für ein solches Zusammengehen konnten oben bereits erläutert werden.

Die hier nur skizzierte Atmosphäre innerhalb der Straßburger Loge La Candeur ist - wie später noch ausführlicher gezeigt werden soll - auch geeignet, um die Mitgliedsstruktur der sich hauptsächlich aus Vertretern katholischer Adelsfamilien des Rheinlandes zusammensetzenden Loge La Parfaite Amitié sowie ihre Frontstellung in den 1760er Jahren gegenüber der bürgerlichen Loge Düsseldorfs La Paix du Bas-Rhin zu erklären. Aus der Verbindung einer scheinbar seit jeher adlig dominierten Freimaurerei mit dem Glauben an eine besondere Qualität des adligen Blutes ließ sich direkt ein Suprematie-Anspruch der adligen Freimaurer ableiten, wie er sich im Fall der Parfaite Amitié und der Candeur nicht nur in Form einer exklusiven Mitgliedsstruktur ersehen lässt. Wie bereits August Pauls zeigen konnte, bemühte sich die Parfaite Amitié nach ihrer Konstituierung erfolgreich beim niederländischen Groß-Orient um die Konstituierung als Provinzial-Loge, wodurch ihr schließlich die Jurisdiktion und Oberaufsicht über die Logen eines zuvor festgelegten Distriktes zuerkannt wurden - auch wenn dieser Anspruch von der bürgerlichen Loge La Paix du Bas-Rhin aufgrund der abweisenden Haltung der Parfaite Amitié gegenüber anderen Logen nicht anerkannt wurde. ${ }^{35}$

Hinsichtlich eines solchen Suprematie-Anspruches des Adels innerhalb der Freimaurerei und seines Zusammenhangs mit der adligen »Blutsideologie« muss hier nochmals auf die Entwicklung des Hochgradwesens eingegangen werden. Die Straßburger Loge La Candeur ist in einen Kreis von deutsch-französischen Logen einzuordnen, die sich eingehend mit Mystik und Alchemie beschäftigten

kell/Richard F. Teichgraeber III (Hg.), The culture of the market. Historical Essays, Cambridge 1996, 102-135, hier 114.

32 Margaret C. Jacob führt ein Zitat aus einer Logenrede der Loge La Candeur in Übersetzung an. Hierin heißt es: »[...] the egoism became so general in this century, aggravating ... even and spreading its poison until the unions of the most sacred blood [du sang] are dissolved, making all too often the closest relatives into irreconcilable enemies. « Zitiert nach Jacob, Living the Englightenment (wie Anm. 31, Kap. V), 195. Bei den Anmerkungen in Klammern handelt es sich um einen Hinweis Jacobs.

33 Siehe hierzu die Angaben bei Dies., Living the Englightenment (wie Anm. 31, Kap. V), 196.

34 Vgl. hierzu Dies., Living the Englightenment (wie Anm. 31, Kap. V), 196.

35 Siehe zur Erhebung der Parfaite Amitié zur Provinzialloge sowie zum angespannten Verhältnis zur Düsseldorfer Schwesterloge La Paix du Bas-Rhin die ausführlichen Erläuterungen bei Pauls, Düsseldorfer Freimaurerei (wie Anm. 2, Kap. V), 59-68. 
und insofern als »alchemistisch-rosenkreuzerisch « ${ }^{36}$ bezeichnet werden können. In diesen Logen spielten die Lehren der Hermetik eine bedeutende Rolle.

So stand die La Candeur in den Folgejahren ihrer Gründung in engem Kontakt mit der explizit christlich ausgerichteten Freimaurerei Lyons, die sich um die beiden Brüder Jean-Baptiste und Pierre-Jacques Willermoz organisiert hatte. ${ }^{37}$ Beachtenswert ist hier die Rolle des Mediziners und Alchemisten Pierre-Jacques Willermoz, der seinen Bruder Jean-Baptiste bei der Errichtung eines Hochgradsystems namens »Orient de la Métropole d'Écosse« stark beeinflusste, das als höchsten Grad den »Ritter vom Degen und vom Rosenkreuz« beinhaltete. ${ }^{38}$ JeanBaptiste, der intensiv die Geschichte der Freimaurerei erforschte, stand darüber hinaus seinerseits seit 1762 in engem Kontakt mit einem Kreis freimaurerischer Alchemisten in Metz, die sich »Hermetische Brüder « nannten und mit ihm ebenfalls über Alchemie, Astrologie und Magie korrespondierten. ${ }^{39}$

Auf die Freimaurerei Lyons, die sich schließlich als eigene Großloge ansah und deshalb in Auseinandersetzungen mit der französischen Grande Loge dieser Zeit geriet, sowie die Beeinflussung Jean-Baptiste Willermoz' durch die illuministischspiritistischen Lehren eines Martinez de Pasqually, Louis Claude de Saint-Martin oder des an späterer Stelle noch zu erwähnenden Antoine Joseph Pernety kann hier nicht näher eingegangen werden. ${ }^{40}$ Es sollte jedoch in Hinblick auf die Straßburger Beförderung des Freiherrn Alexander von Merode-Hoffalize in den Grad eines Élu beachtet werden, dass diese in einem freimaurerischen Umfeld geschah, das nicht nur exklusiv aristokratisch geprägt, sondern zudem durch mystische und hermetisch-alchemistische Vorstellungen geleitet war.

So existierte auch in der Straßburger Loge ein Hochgradkapitel namens Conseil Privé, das wie die "Hermetischen Brüder" in seinen Ritualen die Templerlegende und alchemistisch-rosenkreuzerische Elemente aufgriff. ${ }^{41}$ Es überrascht insofern nicht, dass der für Alexander von Merode-Hoffalize auf dem Gründungspatent der Parfaite Amitié im Jahr 1765 erwähnte Grad eines Chevalier Rose-Croix bereits im Jahr 1760 in Straßburg erstmals sicher nachweisbar ist. ${ }^{42}$ Der Freiherr von Merode befand sich also mit seinem Aufenthaltsort Straßburg in einem Zentrum, in dem sich der Grad eines Ritters vom Rosenkreuz um die 1760er Jahre in

36 Siehe hierzu die Ausführungen bei Frick, Die Erleuchteten (wie Anm. 3, Kap. IV), 551-553.

37 Vgl. hierzu Ders., Die Erleuchteten (wie Anm. 3, Kap. IV), 540-550. Zur christlichen Ausrichtung vgl. ferner Jan A.M. Snoek, On the Creation of Masonic Degrees: A Method and its Fruits, in: Antoine Faivre/Wouter J. Hanegraaf (Hg.), Western Esotericism and the Science of Religion (Gnostica, 2), Leuven 1998, 145-190, hier 174.

38 Vgl. hierzu Frick, Die Erleuchteten (wie Anm. 3, Kap. IV), 540-543.

39 Vgl. hierzu Ders., Die Erleuchteten (wie Anm. 3, Kap. IV), 542-550.

40 Vgl. hierzu ebenfalls die Ausführungen von Frick zu Willermoz: Ders., Die Erleuchteten (wie Anm. 3, Kap. IV), 540-550.

41 Vgl. hierzu Ders., Die Erleuchteten (wie Anm. 3, Kap. IV), 551.

42 Das Originalmanuskript des Straßburger Grades befindet sich in den Beständen des Archivs des GON. Siehe Chevalier de l'Aigle du Pélican de Rose-Croix de St. André, ou le Parfait Maçon, c'est-à-dire: le Chev. de l'Aigle Souv. de Rose-Croix de Strasbourg 1760, Straßburg, 1760, in: GON, 240.C.53. 
engem Austausch mit hermetisch-alchemistischen Zirkeln der Umgegend entwickeln konnte. Doch welchen rituellen Inhalt vermittelte der Grad?

\section{V.3 Bezüge des Hochgrades eines Chevalier Rose-Croix zur Lehre der Metempsychose}

Nach der Meinung Pierre Molliers transportierten die ursprünglichen, aus Frankreich stammenden Versionen des Grades eines Ritters vom Rosenkreuz ausschließlich christliches Gedankengut und seien erst zum Ende des 18. Jahrhunderts mit alchemistischer Symbolik aufgeladen worden. ${ }^{43}$ Entgegen der Meinung Molliers wird hier gerade vor dem Hintergrund des Straßburger Manuskripts angenommen, dass eine Verbindung dieses Grades zu hermetisch-alchemistischem Gedankengut von den Zeitgenossen durch die christliche Symbolik der frühen Versionen zum Ausdruck kam.

Der Titel des Straßburger-Manuskripts führt als Namen des Grades nicht nur die Bezeichnung Chevalier Rose-Croix an. Er lautet im gesamten: „Chevalier de l'Aigle du Pélican de Rose-Croix de St. André, ou le Parfait Maçon, c'est-à-dire: le Chev. de l'Aigle Souv. de Rose-Croix de Strasbourg 1760. " ${ }^{44}$ Wie ein Zusatz bemerkt, enthält es auch das geheime Alphabet der Provinzialloge zu Metz. ${ }^{45}$ Dieser Bezug zum Zentrum der »Hermetischen Brüder « ist bereits als deutlicher Hinweis auf eine Einordnung des Manuskripts in ein hermetisch-alchemistisches Umfeld zu werten.

Nach den Angaben im Manuskript handelte es sich um den siebten und letzten Grad, der unmittelbar auf den bereits oben erwähnten Grad des Chevalier de l'Orient folgte. Innerhalb des Rituals nahm der Adept die Rolle Jesus von Nazareths ein. Es wurde in der Version von 1760 in zwei Kammern vollzogen: »[...] le $1 .^{\text {er }}$ represente le mont calvaire et le $2 .^{\text {e }}$ [...] le tombeau du fils de l'homme; le tout pour rendre allégoriquement ce qui est passé à la mort et la réssurection de

43 Siehe zu Hinweisen auf eine Existenz des Rosenkreuzergrades in den 1750er Jahren die Angaben bei Mollier, der auch auf die starke alchemistische Prägung der späteren deutschen Rosenkreuzergrade verweist: Pierre Mollier, Le grade maçonnique de Rose-Croix et le christianisme: enjeux et pouvoir des symboles, in: Politica Hermetica 11 (1997), 85-118, insb. 116; Ders., Le grade maçonnique de Rose-Croix et le christianisme: enjeux et pouvoir des symboles, in: Alain de Keghel/ Bernard Moisy (Hg.), Deux Siècles de Rite Écossais Ancien Accepté en France: 1804-2004, Paris 2004, 170-193, hier 172. Mollier verweist hier auf die Erwähnung eines Dokuments aus dem Jahr 1757 in den Schriften Gustave Bords als ältestes Zeugnis für den Grad des Chevalier Rose-Croix. Dieses Dokument kann heute jedoch nicht mehr aufgefunden werden. Als chronologisch folgend erwähnt er einen Brief aus dem Jahr 1761 der Freimaurer Lyons an ihre Brüder in Metz. Das Straßburger Dokument aus dem Jahr 1760 wird von Snoek erwähnt. Snoek verweist jedoch in Bezug auf die Forschungen Piquets darauf, dass alle Versionen des Grades im Zeitraum zwischen 1760 und 1786 in großen Teilen identisch sind. Siehe hierzu Snoek, On the Creation of Masonic Degrees (wie Anm. 37, Kap. V), 145-190, hier 174.

44 Chevalier de l'Aigle du Pélican de Rose-Croix de St. André, ou le Parfait Maçon, c'est-à-dire: le Chev. de l'Aigle Souv. de Rose-Croix de Strasbourg 1760, Straßburg, 1760, in: GON, 240.C.53.

45 Chevalier de l'Aigle du Pélican de Rose-Croix de St. André, ou le Parfait Maçon, c'est-à-dire: le Chev. de l'Aigle Souv. de Rose-Croix de Strasbourg 1760, Straßburg, 1760, in: GON, 240.C.53, fol. 2. 


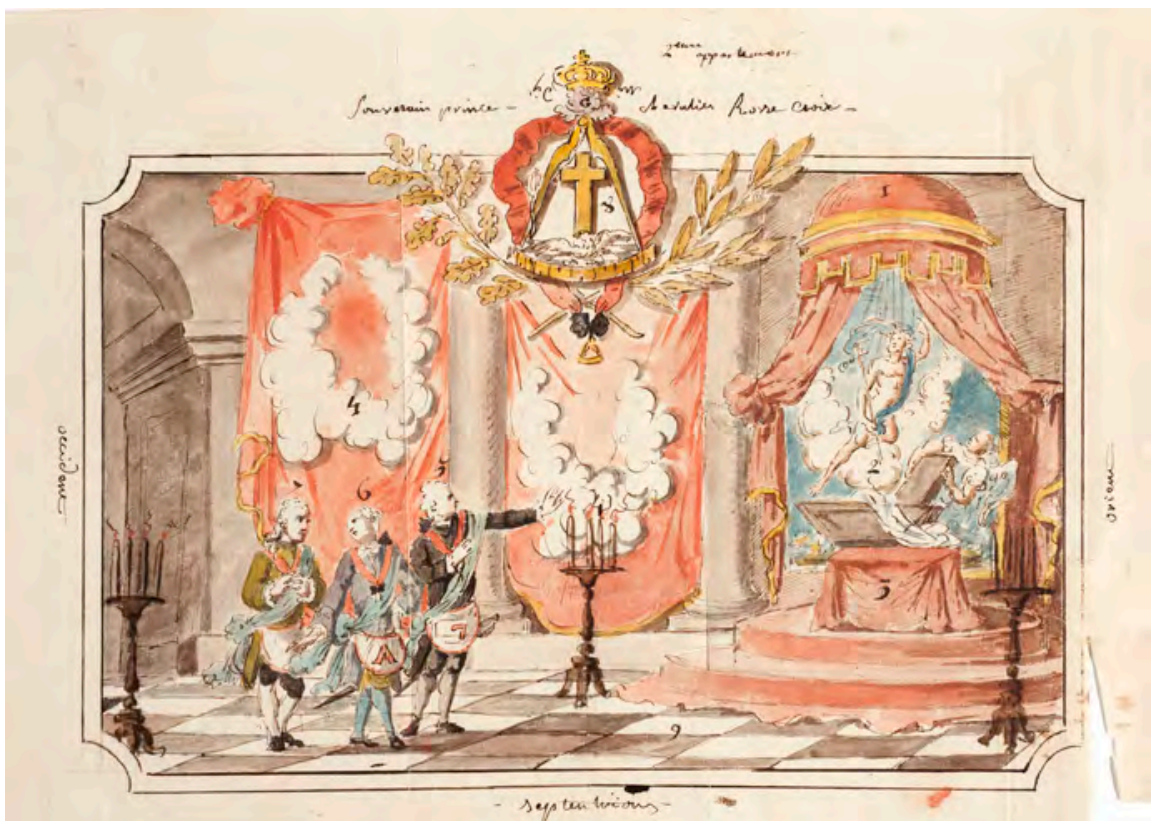

Abbildung 12: Maçonnerie des Hommes: Tweede Kamer van voorbereiding voor de graad van Souverain Prince-Chevalier Rose-Croix, 1782 (Bildrecht/Werk und Foto: From the collections of the Cultural Masonic Centre, The Hague).

Jesus Christ. ${ }^{46}$ Es soll hier nicht auf den gesamten Ablauf und die Symbolik des Rituals eingegangen werden, die bereits an anderer Stelle ausführlich beschrieben wurde. ${ }^{47}$ Es muss vielmehr danach gefragt werden, weshalb der Grad von den Hochgradfreimaurern dieser Zeit zunächst als Abschluss der Freimaurerei gesehen werden konnte.

Ein Hinweis hierauf findet sich in einer Bemerkung zur Benennung des Grades als »Parfait Maçon ${ }^{48}$ Im Straßburger-Manuskript wird die Vergabe des Grades an bestimmte Bedingungen geknüpft. Der Autor sprach sich somit zunächst gegen eine Vergabe an Freimaurer aus, die nicht den Meistergrad innehatten und somit nicht über die Bedeutung des salomonischen Tempels sowie der Hiramslegende aufgeklärt waren. Vielmehr war die Kenntnis der Vorgänge um die Errichtung des ersten und zweiten Tempels aus dem Ritual des Meistergrades sowie des Chevalier de l'Orient zwingende Voraussetzung, um die Errichtung des lebenden, dritten

46 Chevalier de l'Aigle du Pélican de Rose-Croix de St. André, ou le Parfait Maçon, c'est-à-dire: le Chev. de l'Aigle Souv. de Rose-Croix de Strasbourg 1760, Straßburg, 1760, in: GON, 240.C.53, fol. 10.

47 Chevalier de l'Aigle du Pélican de Rose-Croix de St. André, ou le Parfait Maçon, c'est-à- dire: le Chev. de l'Aigle Souv. de Rose-Croix de Strasbourg 1760, Straßburg, 1760, in: GON, 240.C.53.

48 Chevalier de l'Aigle du Pélican de Rose-Croix de St. André, ou le Parfait Maçon, c'est-à- dire: le Chev. de l'Aigle Souv. de Rose-Croix de Strasbourg 1760, Straßburg, 1760, in: GON, 240.C.53, fol. 9. 


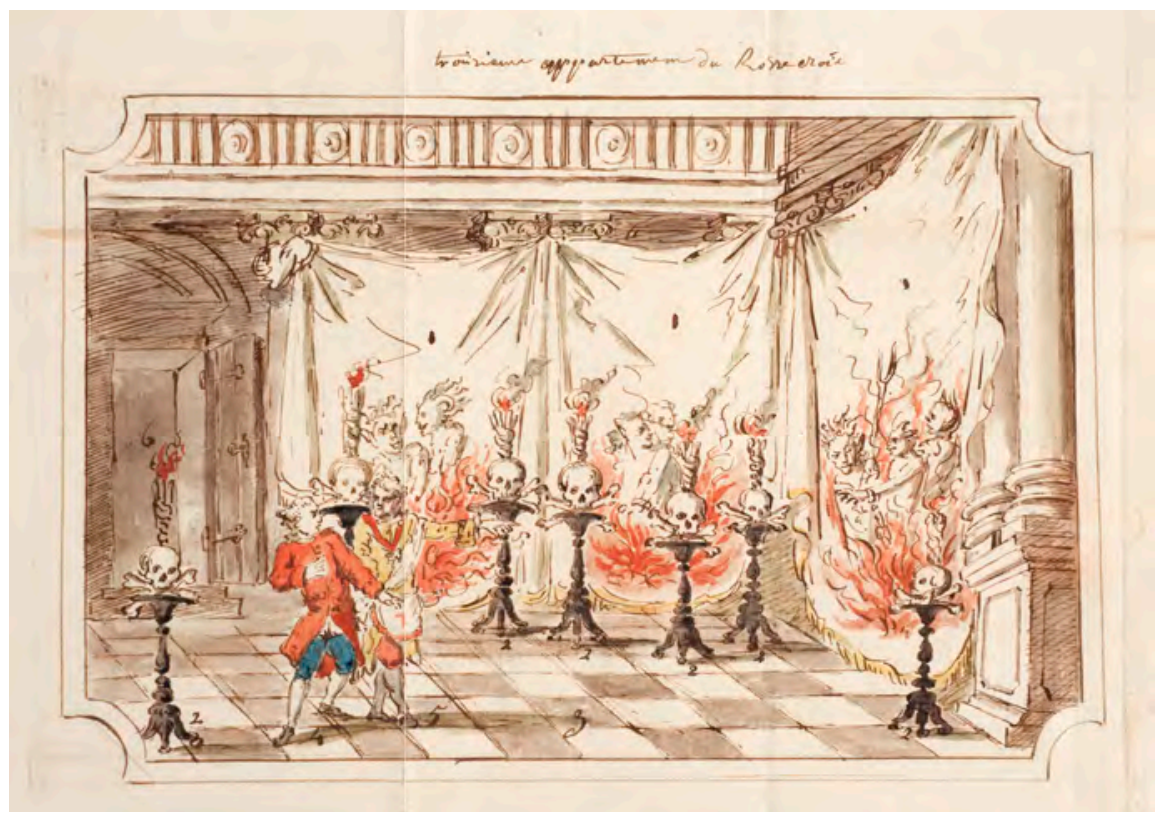

Abbildung 13: Maçonnerie des Hommes: Derde Kamer van Voorbereiding voor de graad van Chevalier Rose-Croix, 1782 (Bildrecht/Werk und Foto: From the collections of the Cultural Masonic Centre, The Hague).

Tempels in Gestalt des Erlösers Jesus Christus bzw. des eingeweihten Freimaurers, der sich den christlichen Geboten unterwarf, richtig einordnen zu können. ${ }^{49}$

So wurde auch der zukünftige Chevalier Rose-Croix im Ritual des Grades erneut mit der völligen Zerstörung der Freimaurerei bzw. des Tempels konfrontiert und sollte sich wie bereits zuvor in der Hiramslegende auf die Suche nach einer "parole perdue« machen. ${ }^{50}$ Diese war nach den Ausführungen im Ritual mit dem Tod Jesu Christi verloren gegangen bzw. in der Stunde, in der der kubische Stein, der Jesus symbolisierte, Blut und Wasser schwitzte. ${ }^{51}$ Als wiedergefundenes Wort fungierte schließlich das Notarikon am Kreuze Jesu: INRI. ${ }^{52}$ Das Leiden des Ster-

49 Vgl. Chevalier de l'Aigle du Pélican de Rose-Croix de St. André, ou le Parfait Maçon, c'est-à-dire: le Chev. de l'Aigle Souv. de Rose-Croix de Strasbourg 1760, Straßburg, 1760, in: GON, 240.C.53, fol. 9 f.

50 Vgl. Chevalier de l'Aigle du Pélican de Rose-Croix de St. André, ou le Parfait Maçon, c'est-à-dire: le Chev. de l'Aigle Souv. de Rose-Croix de Strasbourg 1760, Straßburg, 1760, in: GON, 240.C.53, fol. 16.

51 Chevalier de l'Aigle du Pélican de Rose-Croix de St. André, ou le Parfait Maçon, c'est-à-dire: le Chev. de l'Aigle Souv. de Rose-Croix de Strasbourg 1760, Straßburg, 1760, in: GON, 240.C.53, fol. 17.

52 Chevalier de l'Aigle du Pélican de Rose-Croix de St. André, ou le Parfait Maçon, c'est-à-dire: le Chev. de l'Aigle Souv. de Rose-Croix de Strasbourg 1760, Straßburg, 1760, GON, 240.C.53, fol. 27. 
bens war somit die lösende Kraft, die die Seele vom Körper löste und dem Tod bzw. der anschließenden Erneuerung zuführte.

Es muss hier darauf hingewiesen werden, dass das Notarikon insbesondere bei den Alchemisten und Rosenkreuzern nicht für »Jesus Nazarenus Rex Judaeorum« stand, sondern vielmehr für die Formel »Igne Natura Renovatur Integra« (»Durch Feuer wird die reine Natur erneuert«) bzw. »Igne Roris Nitrum Invenitur (»Durch Feuer wird das Salz [Natron] des Taus gefunden«). ${ }^{53}$ Im übertragenen Sinne bedeutete dies, dass die durch das freimaurerische Ritual erweckten Leidenschaften (»Feuer») das Blut (»Tau«) des Rezipienten erhitzen und so die darin enthaltenen Lebensgeister (»Salz«) zum Vorschein bringen bzw. das Blut mit neuen Lebensgeistern prägen konnten.

Hierüber wird bereits deutlich, dass auch die Leidensgeschichte Jesu im Sinne der Metempsychose bzw. im Sinne des hermetisch-alchemistischen Weltbildes gedeutet werden konnte. Noch deutlicher wird dies im Manuskript in den geschichtlichen Ausführungen des Redners im Anschluss an das Ritual:

Les Maçons depuis la Réedification du temple ayant négligé leurs travaux, abandonnerent aux rigueurs et aux vicissitudes des tems les Edificiers qu'ils avaient avec tant de peine relevé, leurs ouvrages n'étoient plus que des œuvres remplies de corruption, la Sagesse de l'ouvrier, la force des materiaux et la beauté de l'architecture firent place au desordre à la confusion et au vice; le G. A. d. L. determina pour manifester sa gloire d'abandonner le reste des temples pour en elever des Spirituels, dont l'existence serait inattaquable aux puissances humaines et dont la durée subsisterait dans une Éternité de Siècles, c'est pour cette resolution que les hommes ont vu le phénomène Miraculeux le prodige des prodiges, la pierre cubique suant Sang et Eau et souffrir les angoiser de l'ame $[\ldots]^{54}$

Die Aussage, die das auf Jesus Christus bezogene Ritual traf, bestand somit darin, dass das besonders starke, weil unvergängliche Symbol des lebenden »Tempel« Jesu durch sein Vorbild die tugendhaften Geister der Menschen durch alle noch kommenden Zeitalter hindurch emporzuheben vermochte. Das Urchristentum zielte daher aus Sicht der Zeitgenossen direkt auf den Fortschritt der Metempsychose. Für einen alchemistisch gebildeten Adepten stellte sich die im Anschluss an die Ausführungen des Redners vollzogene Eucharistiefeier um die zentralen Symbole des bei der Speisung gespendeten Leibes und Blutes Christi nun als ein allegorisch verhüllter Hinweis auf die Vorstellungen um die »Blutsideologie« sowie die Lehre der Metempsychose dar. ${ }^{55}$

53 Lennhoff/Posner/Binder (Hg.), Internationales Freimaurer-Lexikon (wie Anm. 18, Kap. I), $416 f$. Im Morgentau vermuteten die Alchemisten ebenfalls Lebensgeister.

54 Chevalier de l'Aigle du Pélican de Rose-Croix de St. André, ou le Parfait Maçon, c'est-à-dire: le Chev. de l'Aigle Souv. de Rose-Croix de Strasbourg 1760, Straßburg, 1760, in: GON, 240.C.53, fol. $28 \mathrm{f}$.

55 Chevalier de l'Aigle du Pélican de Rose-Croix de St. André, ou le Parfait Maçon, c'est-à-dire: le Chev. de l'Aigle Souv. de Rose-Croix de Strasbourg 1760, Straßburg, 1760, in: GON, 240.C.53, 


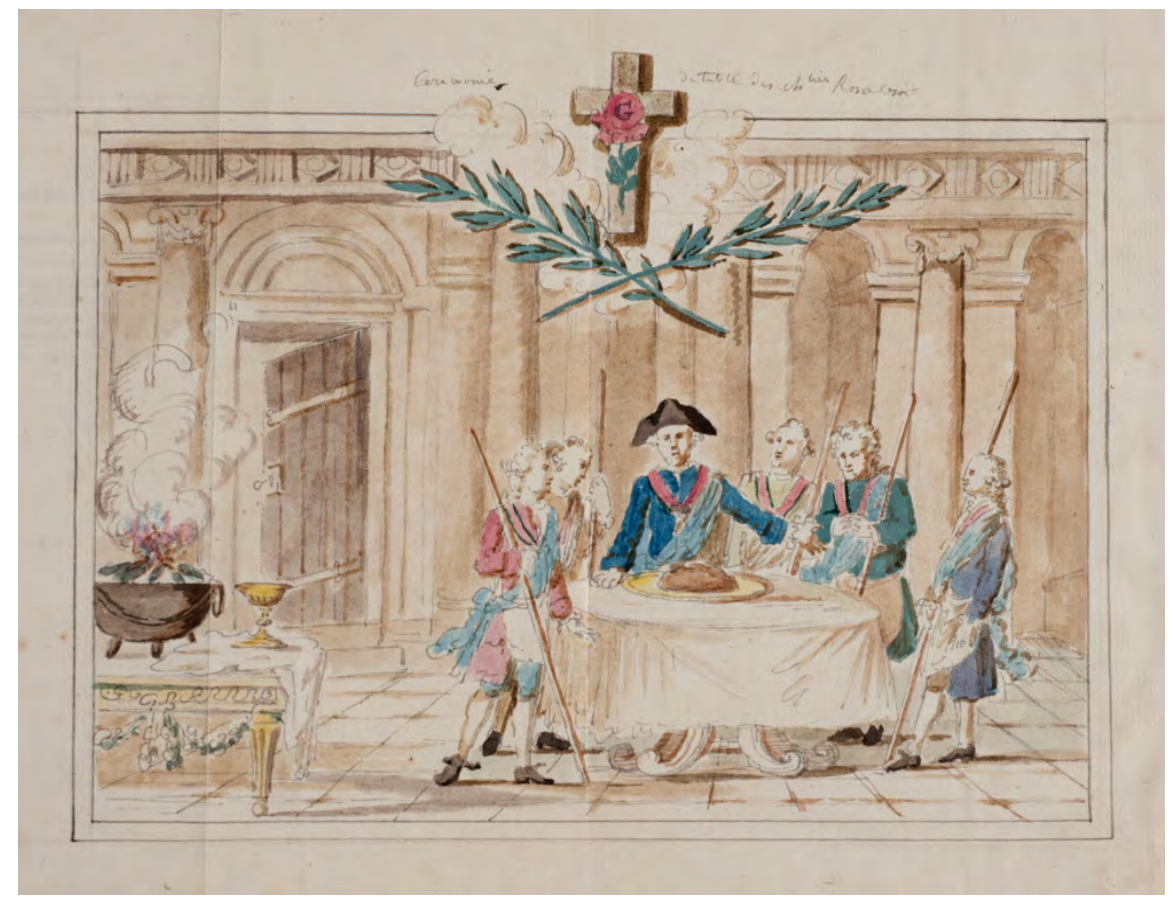

Abbildung 14: Maçonnerie des Hommes: Ceremonie in de graad van Chevalier Rose-Croix, 1782 (Bildrecht/Werk und Foto: From the collections of the Cultural Masonic Centre, The Hague).

Die in den vorangegangenen Ritualen vermittelten freimaurerischen Tugenden wurden innerhalb des Chevalier Rose-Croix durch die göttlichen Tugenden Glaube, Hoffnung und Liebe ergänzt und der Grad selbst aus einer derartigen Perspektive von den Zeitgenossen auch als nec plus ultra der Freimaurerei angesehen. ${ }^{56}$ Nach der persönlichen Teilnahme an der Wandlung des Weines in das "Blut Christi« schien für sie der »tugendhafte Samen« des leibhaftigen Messias bildhaft in das Blut des Adepten eingeprägt worden zu sein. Der Grad des Chevalier Rose-Croix versuchte somit ebenso wie die Schriften eines Franciscus Mercurius van Helmont die »uralte« Lehre der Metempsychose mit dem christlichen Glauben auszugleichen. Die Überlieferungen der Bibel wurden hierbei - noch ganz der Manier eines Sir Isaac Newton ähnlich - als alchemistische Allegorien gedeutet.

fol. 31-33. Siehe auch Abb. 14. Hierzu sei erwähnt, dass nicht nur das Blut bzw. der Wein in der Alchemie als beseelt galt, sondern auch das Brot. Siehe hierzu die besondere Bedeutung des Sauerteigs für den Prozess der Fermentation in der Alchemie bei Karin Figalla, Gärung, in: Priesner/ Dies. (Hg.), Alchemie (wie Anm. 20, Kap. IV), $143 f$.

56 Chevalier de l'Aigle du Pélican de Rose-Croix de St. André, ou le Parfait Maçon, c'est-à-dire: le Chev. de l'Aigle Souv. de Rose-Croix de Strasbourg 1760, Straßburg, 1760, GON, 240.C.53, fol. 22. 
Mollier bemerkt mit Verwunderung, dass der "Discours historique« des Chevalier Rose-Croix in seinen späteren Versionen immer weniger Bezüge zum Christentum herstellte, sondern vielmehr die Freimaurer als direkte Erben einer Weisheit darstellte, die bereits den Rittern vom Rosenkreuz, den Ägyptern, Zoroaster, Moses, Salomon, Pythagoras oder Platon bekannt gewesen war. ${ }^{57}$ Es muss hier aufgrund der oben gemachten Ausführungen nicht näher erläutert werden, dass es sich bei dieser Weisheitslehre um die Metempsychose handelte, die ein Andrew Michael Ramsay als philosophia perennis aller Religionen angesehen hatte.

Die im Straßburger-Manuskript als älteste Namen des Grades erwähnten Bezeichnungen Chevalier de l'Aigle und Chevalier du Pélican ließen diese Zweideutigkeit ebenso zu. Beide konnten sowohl in einem biblischen bzw. christlichen Kontext als auch aus alchemistischer Perspektive gedeutet werden. Der Titel Chevalier de l'Aigle war laut dem Manuskript die älteste Bezeichnung. Die hierin gegebene Ausdeutung für das Symbol des Adlers ähnelte der im Kore Kosmou. ${ }^{58}$ In Bezug auf die "Blutsideologie« verdient jedoch das Symbol des Pelikans besondere Aufmerksamkeit, wurde vom Pelikan doch aufgrund der Beschreibungen des Physiologus angenommen, dass er seine Jungen töte und sie nach Ablauf von drei Tagen mit dem eigenen Herzblut wieder zum Leben erwecke. ${ }^{59}$ Er stand im Christentum für Jesus Christus, war jedoch auch wie der Adler in alchemistischen Ikonographien der Herstellung des Steins der Weisen präsent bzw. fungierte als Namensgeber für eine alchemistische Apparatur, deren kreisförmig geleiteter Destillationsvorgang »mystische Geheimnisse« bergen sollte. ${ }^{60}$ Aus beiden Perspektiven verknüpfte sich mit ihm die geistig-seelische Erneuerung durch die heilsbringende Wirkung der tugendhaften Lebensgeister im »sang illustre«.

Auch in anderen alchemistisch-freimaurerischen Zirkeln dieser Zeit traten diese Bezüge zur Blutsideologie deutlich hervor. So hatte sich etwa in Paris im Jahr 1762 ein neues Hochgradsystem gebildet. ${ }^{61}$ Dieses System nannte sich Conseil des Chevaliers de l'Orient und praktizierte den kabbalistisch-hermetisch geprägten "adonhiramitischen Ritus", der aus insgesamt sieben Graden bestand und durch den aus Metz stammenden Baron Théodore-Henri de Tschudi (1724-1769)

57 Vgl. zum rituellen Inhalt sowie den Inhalten des "Discours historique«: Mollier, Le grade maçonnique de Rose-Croix (wie Anm. 43, Kap. V), 170-193, hier 176f.; Michel Piquet, Le grade de RoseCroix: les sources du »Nec plus Ultra«, in: Renaissance Traditionelle. Revue d'études maçonniques et symboliques 110-111 (1997), 159-196.

58 Chevalier de l'Aigle du Pélican de Rose-Croix de St. André, ou le Parfait Maçon, c'est-à-dire: le Chev. de l'Aigle Souv. de Rose-Croix de Strasbourg 1760, Straßburg, 1760, in: GON, 240.C.53, fol. 4.

59 Der Physiologus ist ein frühchristliches Naturkundewerk, dass vor allem eine symbolische Ausdeutung der Natur enthielt. Es beinhaltet sowohl eine Beschreibung des Pelikan als auch des Adlers. Siehe Otto Schönberger (Hg.), Physiologus, Stuttgart 2001, 11-15. Vgl. Lennhoff/Posner/Binder (Hg.), Internationales Freimaurer-Lexikon (wie Anm. 18. Kap. I), 645.

60 Siehe hierzu Manuel Bachmann/Thomas Hofmeier, Geheimnisse der Alchemie, Basel 1999, 68f.

61 Siehe Karl R. H. Frick, Licht und Finsternis. Okkulte Geheimgesellschaften bis zur Wende des 20. Jh.s, Bd. 2: Geschichte ihrer Lehren, Rituale und Organisationen, Wiesbaden 2005, 255f. 
erarbeitet worden war. ${ }^{62}$ Der siebte Grad war auch hier der Grad des Chevalier Rose-Croix, der innerhalb des Systems gleichbedeutend war mit dem Grad des sogenannten Philosophe Inconnu. ${ }^{63} \mathrm{Da}$ Tschudi 1766 eine zweibändige Schrift mit dem Titel "L'étoile flamboyante, ou la société des Francs-Maçons, Considérée sous tous les aspects « veröffentlichte, in der auch ein Text mit dem Titel »Catéchisme ou instruction pour le grade d'Adepte ou Apprentif Philosophe sublime \& innconu « enthalten war, sind wir über die Wechselrede des Meisters mit dem zu befördernden Adepten dieses Grades sehr gut informiert. ${ }^{64}$ In ihr spiegeln sich ebenfalls deutlich die oben geschilderten Bezüge dieser Strömung der Freimaurerei zur gedanklichen Welt des Rosenkreuzertums sowie damit zusammenhängend zu Hermetismus, Alchemie und Metempsychose wider.

So wurde der Rezipient innerhalb dieser Wechselrede nicht nur auf die Wichtigkeit der Erforschung der Natur eingeschworen, sondern auch auf sein theoretisches hermetisch-alchemistisches Wissen geprüft, wie die Kunst der Metallveredelung. In der Schrift Tschudis finden sich durchaus auch Hinweise auf eine starke Verankerung in der adligen »Blutsideologie« unter dem Eindruck der Helmontschen Theorien und einer damit einhergehenden exklusiven Sichtweise der Freimaurerei. So hieß es etwa in der Schilderung einer Aufnahme eines anonym bleibenden Grafen in die Freimaurerei aus dem Jahr 1765:

[...] la noblesse du sang n'est point un présent inutile, celui qui coule dans vos veines, naturellement consacré pour l'honneur, est le plus beau gage, le garant le plus solide de vos promesses. Instruit par une raissonable éducation à vaincre les préjugés, guidé par un Mentor éclairé, dans les routes de la sagesse, accoutumé à marcher sur les traces de votre Chef, aussi rapidement dans celles-ci, que dans les sentiers de la gloire, je ne m'étonne pas que vous soyez avancé d'un pas ferme vers le sanctuaire des Maçons: puissé-je au berceau de l'Art Royal, ou vous êtes encore, imprimer assez fortement dans votre ame, les vérités essentielles de l'Ordre [...]. ${ }^{65}$

Die hermetisch-alchemistisch geprägten Rosenkreuzergrade, die sich offenbar in einem deutsch-französischen Austauschprozess entwickelt hatten, waren letztlich auch nicht ohne Folgen für die im Jahr 1777 offiziell erfolgte Gründung des Ordens der Gold- und Rosenkreuzer, dessen inoffizielle Zirkel bereits im Jahrzehnt

62 Vgl. hierzu die Angaben bei Ulrich Neumann, Rosenkreuzertum, in: Priesner/Figala (Hg.), Alchemie (wie Anm. 20, Kap. IV), 306-308, hier 307; Rolf Christian Zimmermann, Das Weltbild des jungen Goethe. Studien zur hermetischen Tradition des deutschen 18. Jh.s, Bd. 1: Elemente und Fundamente, 2. Aufl., München 2002, Habil., 184-190; Edighoffer, Die Rosenkreuzer (wie Anm. 3, Kap. IV), 105f.; Claus Priesner, Geschichte der Alchemie, München 2011, 83f.

63 Vgl. hierzu die Angaben bei Zimmermann, der sich seinerseits auf Arthur Edward Waite bezieht: Zimmermann, Das Weltbild des jungen Goethe (wie Anm. 62, Kap. V), 184.

64 Siehe zu diesem Katechismus Baron Théodore-Henri de Tschudi, Létoile flamboyante, ou la société des Francs-Maçons, Considérée sous tous les aspects, Bd. 2, À l'Orient 1785 (Erstausgabe 1766), 179-246, Permalink: http://gallica.bnf.fr/ark:/12148/bpt6k29010v (Zugriff vom 26.05.2014).

65 Tschudi, L'étoile flamboyante (wie Anm. 64, Kap. V), 25 f. 
zuvor regen Zulauf aus freimaurerischen Kreisen genossen. ${ }^{66}$ Auch in diesem Orden, der sich in Deutschland, Österreich, Ungarn, Böhmen, BrandenburgPreußen und Russland ausbreitete und vor allem in Wien florierte, pflegte man das Andenken an Alchemie und Kabbala, um zu einer höheren Selbst- und Gotteserkenntnis zu gelangen. ${ }^{67}$

Auch wenn der ultrakonservative Orden der Gold- und Rosenkreuzer sich nicht mit der Freimaurerei gemeinmachen wollte, sondern sie im Gegenteil lediglich als »Pflanzschule« und Rekrutierungsfeld verstand, ${ }^{68}$ ist die zur Mitte des 18. Jahrhunderts durch das freimaurerische Ritual bereits gedanklich vorbereitete Verbindung zu einem erneuerten Rosenkreuzertum in Bezug auf den Adel beachtlich. Der Adel fand in den Zirkeln der Rosenkreuzer nicht nur ein Forum, in dem alchemistische und magische Experimente erprobt wurden, sondern auch eine Verbindung - dies ist in Bezug auf die theoretische Fundierung der »Blutsideologie» nicht unwichtig - zu einer großen Anzahl von Medizinern, die sich ebenfalls dem Orden anschlossen. Interessanterweise war auch bereits einer der wichtigsten Propagatoren des oben erwähnten »adonhiramitischen Ritus« in Deutschland, der kurpfälzische Hofrat Bernhard Joseph Schleis von Löwenfeld (1731-1800), Mediziner und Leibarzt der Pfalzgräfin Franziska Dorothea von Sulzbach (1724-1794), ein engagiertes Mitglied des Ordens der Gold- und Rosenkreuzer. ${ }^{69}$

$\mathrm{Ob}$ die kurpfälzischen Verbindungen um Schleis von Löwenfeld auch für die zahlreichen Mitglieder der Düsseldorfer Parfaite Amitié in Diensten des Kurfürsten von der Pfalz, Karl Theodor von Pfalz-Sulzbach, von Bedeutung waren, kann hier nicht ermessen werden, ist jedoch nicht völlig auszuschließen. Wichtiger ist die Feststellung, dass innerhalb der Düsseldorfer Parfaite Amitié für Mitglieder Johannis- und Hochgrade nachweisbar sind, die hermetisch-alchemistisches Gedankengut bzw. die Idee der Metempsychose beinhalteten.

Diese Feststellung führt uns direkt zur Frage des Stellenwerts der Seelenwanderungsdebatte im Umfeld der Düsseldorfer Loge. Diese Frage stellt sich umso dringlicher, wenn die verwandtschaftlichen Beziehungen in Betracht gezogen werden. Die Düsseldorfer Logenmitglieder Alexander von Merode und sein Bruder Balduin Karl entstammten dem gleichen Familienzweig Merode-Hoffalize wie die oben innerhalb des Gerüchts um Franciscus Mercurius van Helmont er-

66 Vgl. zu dieser Datierung wie zur Ordensgeschichte insgesamt insb.: Renko D. Geffarth, Religion und arkane Hierarchie. Der Orden der Gold- und Rosenkreuzer als Geheime Kirche im 18. Jh., Leiden 2007, 55 und 63.

67 Vgl. zur Verbreitung die Angaben bei Renko Geffarth, Zirkel, Brüder, Unbekannte Obere. Zur inneren Struktur des Gold- und Rosenkreuzerordens in Mittel- und Norddeutschland, in: Holger Zaunstöck/Markus Meumann (Hg.), Sozietäten, Netzwerke, Kommunikation. Neue Forschungen zur Vergesellschaftung im Jh. der Aufklärung (Hallesche Beiträge zur Europäischen Aufklärung, 21), Tübingen 2003, 159-175, hier 159-161.

68 Siehe hierzu Geffarth, Religion und arkane Hierarchie (wie Anm. 66, Kap. V), 55.

69 Vgl. hierzu die Ausführungen bei Zimmermann, Das Weltbild des jungen Goethe (wie Anm. 62, Kap. V), 184-190; Frick, Die Erleuchteten (wie Anm. 3, Kap. IV), 336f. 
wähnte Baronin Merode-Motzfeld. ${ }^{70}$ Noch Johann Baptist van Helmont hatte sich als Herr von Merode bezeichnet, da er sich mütterlicherseits auf die Verwandtschaft zu diesem Geschlecht berief. ${ }^{71}$ So wurde das Wappen derer von Merode auf den Titelkupfern der Helmontschen Schriften angeführt. ${ }^{72}$ Es ist aufgrund dieser Zusammenhänge davon auszugehen, dass den beiden Logenmitgliedern die Lehren der beiden Helmonts durchaus bekannt gewesen sein dürften.

Der Boden für eine Auseinandersetzung mit dem auf hermetisch-alchemistischen Vorstellungen beruhenden Weltbild, wie es etwa in den oben beschriebenen Freimaurerlogen im Umfeld des Freiherrn Alexander von Merode ersichtlich ist, war innerhalb der Familie Merode-Hoffalize - und auch in der weiteren Adelslandschaft - somit bereits lange vor dem Eintritt in die Freimaurerei über den Umweg der Lehren eines Johann Baptist van Helmont bereitet. Die in der Freimaurerei aufkommenden hermetisch-alchemistischen Strömungen sowie später der Orden der Gold- und Rosenkreuzer boten einen vom »Pöbel« und von dessen Unverständnis abgeschotteten Raum, die Erkenntnisse über den Sinn und das Ziel der Schöpfung zu erweitern und sich selbst auf dem Weg zum Seelenheil zu perfektionieren - ein metaphysisches, aber auch politisches Ziel, wie unter anderem am zeitweilig großen Einfluss der Gold- und Rosenkreuzer auf die Politik Friedrich Wilhelms II. von Preußen gesehen werden kann. Die im freimaurerischen Geheimraum vorgenommenen Spekulationen über die Lehre der Metempsychose und eine seinprägsame Erziehungsmethode trugen im Falle der Adelslogen zu einer Verschärfung gesellschaftlicher Gegensätze bei.

Im Zusammenspiel mit dem Festhalten des Adels an der adligen »Blutsideologie« verstärkten sie eine distanziert-kontrollierende Haltung gegenüber den bürgerlichen Eliten - selbst denen, die innerhalb der Freimaurerei mit ihnen verbrüdert waren. Dieses in den Quellen oft nur zwischen den Zeilen aufscheinende Spannungsverhältnis, das von bürgerlichen Kreisen wie in der Düsseldorfer

70 Die Baronin Isabella von Merode-Motzfeld war die Tochter des Franz Ignatz von Merode-Hoffalize und seiner zweiten Frau, Maria-Henrica von Rolshausen. Nach den Angaben Anton Fahnes war Isabella vor ihrer Heirat mit Heinrich von Motzfeld zunächst Nonne gewesen, entfloh aber dem Klosterleben und »schwor zu Cleve den [sic!] Glauben ab«. Isabellas Vater, Franz Ignatz, war 1655 mit dem Gut Frankenberg belehnt worden. Nachdem Isabellas Bruder dieses Lehen 1717 übernommen hatte, ging Frankenberg 1728 zunächst an den Großvater, 1746 dann an den Vater der beiden Logenmitglieder der Parfaite Amitié, Gottfried Arnold von Merode-Hoffalize, über. Das Logenmitglied der Parfaite Amitié Balduin Karl konnte sich schließlich ebenfalls als Herr über die Herrschaft Frankenberg bezeichnen. Auch in dieser Hinsicht bestand also eine Verbindung. Vgl. zu den Verwandtschaftsverhältnissen Fahne, Geschichte der Grafen, jetzigen Fürsten zu SalmReifferscheid (wie Anm. 20, Kap. V), 121; Georges Martin, Histoire et généalogie de la Maison de Merode, Lyon 1999, 171. Für den Hinweis auf die Angaben im Buch Georges Martins danke ich Herrn Baudouin D’ hoore. Vgl. zu allen Angaben betreffend die Herrschaft Frankenberg Quix, Die Frankenburg (wie Anm. 20, Kap. V), $78 f$.

71 Laut den Angaben bei E. de Beer war die Mutter Johann Baptist van Helmonts, Margaretha von Ranst, eine Urenkelin des Reichsfreiherrn Arnold von Merode. Vgl. hierzu E. de Beer (Hg.), The Correspondence of John Lock, Bd. 5, Oxford 1979, 244.

72 Siehe hierzu Abb. 8 bzw. das Titelkupfer in Helmont, Ortus Medicinæ (wie Anm. 62, Kap. IV), Titelkupfer. 
Loge La Paix du Bas-Rhin nicht ohne Weiteres hingenommen wurde, lässt sich auch innerhalb des Personenkreises der Parfaite Amitié direkt nachweisen und soll in einem späteren Kapitel anhand des einzigen vollwertigen bürgerlichen Mitglieds, des bekannten Philosophen Friedrich Heinrich Jacobi, illustriert werden. Zunächst muss hier jedoch anhand der Person des Düsseldorfer Statthalters, des Reichsgrafen Johann Ludwig Franz von Goltstein, auf den möglichen Stellenwert der Erziehung und naturwissenschaftlicher Forschungen im Umkreis der Loge eingegangen werden, da sie das Rückgrat für die Verteidigung genealogischer Abstammungslinien bildeten und auch eine Brücke zur Debatte um die Beschaffenheit der menschlichen bzw. tierischen Seele in das Rheinland schlugen.

\section{V.4 Reichsgraf Johann Ludwig Franz von Goltstein als Propagator und grenzüberschreitender Vermittler (natur-)wissenschaftlicher Forschungen}

Neben den oben erwähnten verwandtschaftlichen Verflechtungen der Familien van Helmont und Merode-Hoffalize macht auch das nahe gelegene Berleburg unter der Herrschaft des im halleschen Adelspädagogium ausgebildeten Grafen Casimir von Sayn-Wittgenstein-Berleburg (1687-1741) das Ankommen der Seelenwanderungsdebatte im Rheinland zu Beginn des 18. Jahrhunderts wahrscheinlich. ${ }^{73}$ Berleburg stellte einen Brennpunkt des »radikalen Pietismus « dar, in dessen Hoheitsgebiet mit der Berleburger Bibel eine der wichtigsten Bibelübersetzungen des 18. Jahrhunderts in deutscher Sprache erschien. ${ }^{74}$ Wie Martin Mulsow herausstellte, hatten die Theorien Franciscus Mercurius van Helmonts auch die rradikale Speerspitze des Pietismus beeinflusst. ${ }^{75}$ So ist es nicht verwunderlich, dass auch die Autoren der Berleburger Bibel bis zum Jahr 1735 insofern zu der Debatte Stellung bezogen, als sie zwar nicht direkt von der Metempsychose sprachen, aber offenbar die Helmontschen Vorstellungen von einer »Seelenrevolution« übernahmen und ebenfalls mit dem Christentum in Ausgleich bringen wollten. ${ }^{76}$ Diese ersten Anspielungen im regionalen Umfeld der katholisch geprägten Loge La Parfaite Amitié führen zu der Frage, inwieweit sich ihre Mitglieder für die naturwissenschaftlichen Debatten ihrer Zeit interessierten - mit denen die aus al-

73 Siehe zu Berleburg und den Grafen von Sayn-Wittgenstein-Berleburg Martin Brecht/Friedhelm Ackva (Hg.), Geschichte des Pietismus, Bd. 2: Der Pietismus im 18. Jh., Göttingen 1995, 160-162; Zander, Geschichte der Seelenwanderung (wie Anm. 77, Kap. I), 326-328; Obst, Reinkarnation (wie Anm. 77, Kap. I), 115-117.

74 Vgl. Zander, Geschichte der Seelenwanderung (wie Anm. 77, Kap. I), 326-328; Brecht/Ackva, Geschichte des Pietismus (wie Anm. 73, Kap. V), 160-162; Obst, Reinkarnation (wie Anm. 77, Kap. I), 115-117.

75 Vgl. Mulsow, Vernünftige Metempsychosis (wie Anm. 77, Kap. I), hier 213.

76 Vgl. hierzu Zander, Geschichte der Seelenwanderung (wie Anm. 77, Kap. I), 327f.; Obst, Reinkarnation (wie Anm. 77, Kap. I), 115-117. 
chemistisch laborierenden Kreisen heraus angestoßene Seelenwanderungsdebatte eng zusammenhing.

Dass ein Interesse an aktuellen naturwissenschaftlichen Erkenntnissen und Diskussionen im Umfeld der Loge bestand, lässt sich über ein Mitglied zeigen, das wie Friedrich Heinrich Jacobi dem dritten Stand angehörte. So war ein Bruder namens Anton Sissonet als Schreiber (Clerc de la Loge) bei der Parfaite Amitié angestellt. ${ }^{77}$ Über Sissonets Person ergibt sich bereits eine Beziehung zu dem auch für die adlige Memoria grundlegenden Thema der adligen Erziehung. Bereits August Pauls verwies darauf, dass der französischstämmige Sissonet im Jahr 1749 im Düsseldorfer Pagenhaus ein Adelspädagogium nach französischem Vorbild errichtet hatte. ${ }^{78}$ Als Unterrichtsfächer der Kavaliere des jülich-bergischen Adels wurden Sprachen, Mathematik, Geographie und Geschichte, Arithmetik, Fechten und Tanzen genannt, doch auch »les sentiments du cœur et de l'esprit«standen im Fokus des Erziehungsprogramms. ${ }^{79}$ Sissonet warb zwar bei den Landständen und der Ritterschaft für sein Projekt, das bis zu seinem Tod im Jahr 1774 bestehen sollte, mit dem Hinweis auf die wirtschaftlichen und moralischen Risiken der herkömmlichen Kavaliersausbildung auf Reisen. ${ }^{80}$ Seine Akademie stieß von dieser Seite jedoch auf wenig finanzielle Unterstützung und musste schließlich auch bürgerliche Vertreter zulassen ${ }^{81}$ Offenbar war der jülich-bergische Adel nicht gewillt, in Erziehungsfragen des Nachwuchses von althergebrachten repräsentativen Verfahrensweisen abzurücken.

Sissonets Name wird in der Düsseldorfer Stadtgeschichte auch im Zusammenhang mit einem anderen wichtigen Projekt erwähnt: der 1770 erfolgten Einrichtung einer öffentlichen Bibliothek. ${ }^{82}$ Auch hier übernahm er die Sekretärsfunktion..$^{83}$ Die Idee zur Einrichtung der Bibliothek ging auf das zeitweilig wohl prominenteste Mitglied der Düsseldorfer Parfaite Amité, den Statthalter der Herzogtümer Jülich und Berg Reichsgraf Johann Ludwig Franz von Goltstein, zu-

77 Vgl. Pauls, Düsseldorfer Freimaurerei (wie Anm. 2, Kap. V), 66.

78 Vgl. hierzu die Angaben bei Ders., Düsseldorfer Freimaurerei (wie Anm. 2, Kap. V), 66.

79 Ders., Düsseldorfer Freimaurerei (wie Anm. 2, Kap. V), 66.

80 Siehe die Angaben bei Klaus Müller, Unter pfalz-neuburgischer und pfalz-bayerischer Herrschaft, in: Hugo Weidenhaupt [u.a.] (Hg.), Düsseldorf: Geschichte von den Ursprüngen bis ins 20. Jh., Bd. 2, Düsseldorf 1988, 244.

81 Vgl. zur finanziellen Situation der Akademie Müller, Unter pfalz-neuburgischer und pfalz-bayerischer Herrschaft (wie Anm. 80, Kap. V), 244. Zum Hinweis auf die Zulassung bürgerlicher Vertreter aufgrund der finanziellen Engpässe vgl. Marcus Bernhardt, »Es sollten gleichsam Krieges=Schulen seyn vor dem Adel, daß man geschickte Krieges=Officierer hätte. « Die Gründung militärischer Bildungsanstalten im Rheinland des 18. Jh.s, in: Frank Günter Zehnder/Werner Schälke, Eine Gesellschaft zwischen Tradition und Wandel: Alltag und Umwelt im Rheinland des 18. Jh.s (Der Riss im Himmel. Clemens August und seine Epoche, 3), Köln 1999, 96.

82 Siehe zur Einrichtung dieser Bibliothek die Erläuterungen bei Manfred von Stosch, Düsseldorfs »öffentliche Bibliotheque« 1770-1809, in: Gerhard Kurz (Hg.), Düsseldorf in der deutschen Geistesgeschichte (1750-1850), Düsseldorf 1984, 37-53; Müller, Unter pfalz-neuburgischer und pfalzbayerischer Herrschaft (wie Anm. 80, Kap. V), $244 \mathrm{f}$.

83 Vgl. Stosch, Düsseldorfs »öffentliche Bibliotheque« (wie Anm. 82, Kap. V), hier 42. 
rück. ${ }^{84}$ Sie ergänzte ihren Bestand auch durch private Schenkungen, und so lässt es in Bezug auf die eingangs erwähnten Diskussionen um den Einfluss der Umwelt auf charakterliche Eigenschaften, aber auch die Klimatheorie aufhorchen, wenn Sissonet im Katalog der Bibliothek als Beiträger einiger Schriften des Franzosen Pierre-Louis Moreau de Maupertuis (1698-1759) erwähnt wird. ${ }^{85}$ Maupertuis, der unter anderem in den Jahren 1746 bis 1753 Präsident der Königlich Preußischen Akademie der Wissenschaft war, vertrat in Bezug auf die Einteilung des Menschen in »Rassen « die Ansichten der Klimatheorie, wobei er sich mit Christoph Meiners darüber stritt, „ob das vollkommenste Exemplar des europäischen Musterprodukts im nördlichen Deutschland oder an den Ufern der Seine zu finden sei. ${ }^{86}$

In Maupertuis' Stellungnahme ist eine weitere Variation der bereits weiter oben dargestellten Theorien um die Entwicklung der menschlichen »Rassen « zu sehen, wobei sich diese neuartigen Ansichten zwar im Kern gegen die im 18. Jahrhundert allgemein noch anerkannte Präformationslehre wandten, jedoch nicht die Vortrefflichkeit einer "weißen Ursprungsrasse« vor allen anderen »Rassen« oder gar die adlige »Blutsideologie» ad acta legten. Bei Maupertuis ist jedoch eine allmähliche Transformation des Begriffs »Rasse« zu beobachten, der nicht mehr in erster Linie auf einen historischen Prozess hindeuten sollte, sondern stärker biologistisch aufzufassen war. Der zivilisierte Mensch war aus Sicht eines Zeitgenossen wie Maupertuis, der auch aus heutiger Sicht abschreckende Überlegungen zum Thema der >Menschenzucht anstellte, ${ }^{87}$ dazu befähigt, sich die Prozesse der Natur zu seiner eigenen Vervollkommnung zu Nutze zu machen. ${ }^{88}$ Gerade seine

84 Vgl. die Angaben bei Ders., Düsseldorfs »öffentliche Bibliotheque« (wie Anm. 82, Kap. V), hier 37; Müller, Unter pfalz-neuburgischer und pfalz-bayerischer Herrschaft (wie Anm. 80, Kap. V), 244.

85 Vgl. Stosch, Düsseldorfs »öffentliche Bibliotheque« (wie Anm. 82, Kap. V), hier 42.

86 Bitterli, Die »Wilden« und die »Zivilisierten« (wie Anm. 65, Kap. II), $352 \mathrm{f}$.

87 Wichtig ist hier, dass Maupertuis als Folge seiner »Dissertation sur le nègre blanc«, die den für das 18. Jh. als Kuriosum geltenden Fall eines von dunkelhäutigen Eltern abstammenden Albinos behandelte und Maupertuis in der Annahme einer weißen Urmutter zu bestätigten schien, in seiner 1745 erschienenen Schrift »Venus physique « sich näher über die Vererbung der Eigenschaften bestimmter »Rassen« äußerte. Die Entstehung von Kindern, die zu ihren Eltern phänotypisch ungleich waren, erklärte er wie folgt: „Ces productions ne sont d'abord qu'accidentelles: les parties originaires des ancêtres se retrouvent encore les plus abondantes dans les semences: après quelques générations, ou dès la génération suivante, l'espèce originaire reprendra le dessus; et l'enfant, au lieu de ressembler à ses père et mère, ressemblera à des ancêtres plus éloigné. «Zitiert nach den Auszügen aus dem Original in: Émile Callot, Maupertuis: Le Savant et le Philosophe. Présentation et Extraits, Paris 1964, 79. Um diese "accidents « zu verhindern, sprach Maupertuis eine Empfehlung aus: »Pour faire des espèces des races qui se perpétuent, il faut vraisemblablement que ces générations soient répétées plusieurs fois; il faut que les parties propres à faire les traits originaires, moins nombreuses à chaque génération, se dissipent, ou restent en si petit nombre qu'il faudrait un nouveau hasard pour reproduire l'espèce originaire. Au reste quoique je suppose ici que le fonds de toutes ces variétés se trouve dans les liqueurs séminales mêmes, je n'exclus pas l'influence que le climat et les aliments peuvent y avoir. "Zitiert nach den Auszügen aus dem Original in: Ders., Maupertuis: Le Savant et le Philosophe, 79.

88 Inge Baxmann erwähnt, dass die Überlegungen zur Menschenzucht bzw. -kreuzung zum Teil tatsächlich durchgeführt wurden. Siehe hierzu Inge Baxmann, Monströse Erfindungskunst, in: Inge 
Ausführungen zur $>$ Menschenzucht $\triangleleft$ konnten somit indirekt auch als Rechtfertigung einer Praxis wie der adligen Ahnenprobe verstanden werden.

$\mathrm{Zu}$ einem der bekanntesten und vom Adel hoch geschätzten Naturforscher seiner Zeit wurde jedoch der französische Adlige Georges Louis Leclerc, comte de Buffon (1707-1788). Seine seit 1749 erscheinende »Histoire Naturelle« wurde während des 18. Jahrhunderts geradezu populär. Buffon war wie Maupertuis Anhänger der Theorie des Monogenismus und im Sinne der Klimatheorie noch stärker als dieser davon überzeugt, dass »Charakter und Fähigkeiten eines Menschen durch seine Herkunft bestimmt wurden. $\aleph^{89}$ Buffons Histoire Naturelle« stellte Naturgeschichte aus adliger Perspektive dar und glich hierin - trotz aller sonstigen, auch persönlich gepflegten Gegensätze zwischen den beiden Forschern - den oben erwähnten Darstellungen Linnés. In Buffons Naturgeschichte war das Pferd ein edles Tier, herrschte der Löwe aufgrund der natürlichen unverrückbaren Ordnung aller Dinge königgleich über die Tierwelt. ${ }^{90}$ Wie bereits erwähnt hat Pierre Serna jüngst darauf verwiesen, wie der von Linné, Buffon und Maupertuis geprägte wissenschaftliche Diskurs nicht nur »auf eine Klassifizierung der lebenden Arten und der Menschen sowie auf die Festlegung einer Rangordnung zwischen ihnen, vom Wilden bis hin zum hochzivilisierten Menschen ${ }^{91}$ zustrebte, sondern auch vom Adel dazu genutzt wurde, seine traditionelle Stellung als oberes Glied der »Großen Kette der Wesen « auf naturwissenschaftlicher Basis zu legitimieren.

Die durch Sissonet an die Düsseldorfer Bibliothek gelangten Bücher Maupertuis' vermittelten eine derartige Sichtweise auf die Natur. Neben Sissonets Eingaben trug jedoch auch der Initiator des Projekts, Reichsgraf Johann Ludwig Franz von Goltstein, zum Anwachsen des Buchbestandes bei. Der Graf zeigte sich dabei nicht nur an der deutschen und französischen Geschichte interessiert. ${ }^{92}$ Beachtung verdient auch sein offenbar großes Interesse an naturwissenschaftlichen Fragestellungen und eine sich hierüber ergebende Verbindung in das direkte Umfeld des Comte de Buffon.

Eine aus heutiger Sicht fast banal erscheinende, aus zeitgenössischer Sicht jedoch durchaus sensationelle Erfindung des Detmolder Naturforschers Stephan

Baxmann/Michael Franz/Wolfgang Schäffner (Hg.), Das Laokoon-Paradigma. Zeichenregime im 18. Jh., Berlin 2000, 404-417, hier 413.

89 Asch, Europäischer Adel (wie Anm. 62, Kap. II), 278.

$90 \mathrm{Zu}$ allen hier gemachten Angaben vgl. Lepenies, Das Ende der Naturgeschichte (wie Anm. 38, Kap. I), 161-168. Das schwierige, weil mannigfaltige Studium der Naturgeschichte besaß für Buffon dabei insb. den Zweck einer geistig-seelischen Bildung, die sich vor allem über dauerhafte visuelle Eindrücke (»impressions durables«) derartiger Zusammenhänge in der Natur ergab. Vgl. Georges Louis Leclerc, Comte de Buffon/Louis Jean Marie Daubenton, Histoire Naturelle, Générale et Particulière, avec la description du Cabinet du Roi, Bd. 1, Paris 1749, 5f., Permalink: http://gallica.bnf. fr/ark:/12148/bpt6k97490d (Zugriff vom 24.05.2014).

91 Serna, Der Adlige (wie Anm. 36, Kap. I), hier 89.

92 Vgl. Stosch, Düsseldorfs »öffentliche Bibliotheque« (wie Anm. 82, Kap. V), hier 41. Stosch erwähnt, dass Goltstein Joseph Barre de Beaumarchais' »Histoire générale d'Allemagne« sowie Paul François Vellys »Histoire de France depuis l'établissement de la monarchie jusqu'au règne de Louis XIV « der Bibliothek gestiftet habe. 
Ludwig Jacobi ${ }^{93}$ (1711-1784) zur künstlichen Besamung von Fischrogen bzw. ihre publizistische Bekanntmachung, bezeugt diesen Kontakt. ${ }^{94}$ Stephan Ludwig Jacobi hatte - soweit heute bekannt - zunächst keinen Versuch unternommen, seine Forschungsergebnisse selbst zu publizieren. ${ }^{95}$ Einen Grund hierfür sieht sein Biograph Meyer-Waarden auch in religiösen Bedenken, aufgrund der »Erweckung< tierischen Lebens « ${ }^{96}$ Diese Vorbehalte sind auch bei den letztendlich doch erfolgten Publizierungen der Theorie um das Jahr 1765 in der Zeitschrift »Hannoverisches Magazin« teilweise bemerkbar. ${ }^{97}$ Jacobis Entdeckung war, nach den Angaben Meyer-Waardens, jedoch bereits 1764 Diskussionsgegenstand in der Berliner Akademie der Wissenschaft und - dies ist hier von größerem Belang - wurde auch in verschiedenen französischen naturkundlichen Schriften abgedruckt. ${ }^{98}$

Bislang stand von Seiten der Jacobi-Forschung lediglich die Vermutung im Raum, dass der Graf von Goltstein für die Vermittlung der Jacobischen Theorie an adlige französische Naturforscher, wie den Comte de Buffon oder den zu Buffons engem Umkreis zählenden Henri Louis Duhamel du Monceau (1700-1782) gesorgt habe. ${ }^{99}$ Meyer-Waarden, der in seiner Jacobi-Biographie der Frage eine ausführliche Darstellung widmete, führte zu dieser Vermutung zwar mehrere Belege aus dem 19. Jahrhundert an, die den Grafen von Goltstein immer wieder als Vermittler erwähnten, konnte jedoch keine zeitgenössische Quelle hierzu ausmachen, obgleich er auch eine 1773 erschienene Ausgabe des Werkes »Traité Général des Pesches « von Duhamel du Monceau einsah. ${ }^{100}$ In einer früheren Ausgabe dieses letztgenannten Werkes aus dem Jahr 1772 findet sich in einer Anmerkung jedoch ein direkter Beweis für die Mittlertätigkeit des Grafen von Goltstein, der zudem weitestgehend identisch ist mit den bei Meyer-Waarden zitierten Äußerungen des 19. Jahrhunderts. In der Ausgabe von 1772 heißt es:

Ce Mémoire fut remis à M. Fourcroy en Allemand à Dusseldorff en 1758, par M. le Comte de Golstein [sic!], aujourd'hui Grand-Chancelier des Duchés de Bergues \& de Juliers pour S. A. E. Palatine. Ce Seigneur, aussi instruit que curieux en Histoire naturelle, rendoit par son excellente Maison \& son accueil honnête, le séjour de Dusseldorff très agréable aux Officiers François pendant la derniere guerre. M. Fourcroy dit qu'il se rappelle qu'il lui dit avoir toute confiance aux faits de ce Mémoire, comme les tenant de très-bonne main. Comme M. Fourcroy trouva des difficultés à traduire ce Mémoire, M.

93 Stephan Ludwig Jacobi ist nicht zu verwechseln mit den Vertretern der oben bereits genannten Düsseldorfer Familie Jacobi.

94 Zu Stephan Ludwig Jacobis Biographie vgl. Paul Friedrich Meyer-Waarden, Stephan Ludwig Jacobi: Begründer der künstlichen Besamung in der Fischzucht. Leben und Werk, Berlin 1972. Auf diese Biographie stützen sich im Wesentlichen die folgenden Angaben.

95 Vgl. Ders., Stephan Ludwig Jacobi (wie Anm. 94, Kap. V), 64-67.

96 Ders., Stephan Ludwig Jacobi (wie Anm. 94, Kap. V), 64.

97 Vgl. hierzu Ders., Stephan Ludwig Jacobi (wie Anm. 94, Kap. V), 64 sowie den Abdruck der Zeitschrift auf 71-78 und ihre Besprechung auf 132f.

98 Vgl. Ders., Stephan Ludwig Jacobi (wie Anm. 94, Kap. V), 132-137.

99 Vgl. Ders., Stephan Ludwig Jacobi (wie Anm. 94, Kap. V), $137 f$.

100 Vgl. Ders., Stephan Ludwig Jacobi (wie Anm. 94, Kap. V), 135-138. 
Le Comte de Golstein voulut bien le lui faire remettre en Latin, \& cette version François, montrée depuis à plusieurs personnes qui savoient bien les deux Langues, a été trouvée exacte. ${ }^{101}$

Bei dem hier erwähnten Vertreter der adligen Familie Fourcroy handelte es sich um Charles-René Fourcroy de Ramecourt (1715-1791). Fourcroy de Ramecourt fiel vor allem durch seine Leistungen als militärischer Ingenieur auf und nahm während des Siebenjährigen Krieges an drei Feldzügen in Deutschland teil. ${ }^{102}$ Gemeinsam mit Duhamel du Monceau veröffentlichte er auch Schriften über handwerkliche Themen - ein Interesse, das wie die Freimaurerei zu dieser Zeit im französischen Adel recht verbreitet war und auch durch den späteren König Ludwig XVI. gepflegt werden sollte. ${ }^{103}$ Das oben angeführte Zitat gewinnt durch die persönliche Zusammenarbeit Duhamel du Monceaus mit Fourcroy an Glaubwürdigkeit. Dessen Kontakt zu dem Grafen von Goltstein dürfte, wie sich im Zitat bereits andeutet, durch das beide Männer verbindende naturwissenschaftliche Interesse zustande gekommen sein.

Der Graf von Goltstein hatte somit während des Siebenjährigen Krieges nicht nur Kontakt zu französischen Offizieren, was im Hinblick auf die oben bereits angeführte Theorie August Pauls über mögliche Aufnahmen der Mitglieder der Parfaite Amitié in die Freimaurerei von Bedeutung sein könnte. Wichtiger ist hier sein eigenes, offenbar stark ausgeprägtes Interesse an naturwissenschaftlichen Fragestellungen und insbesondere der Tierzucht. Der Kontakt zu französischen adligen Naturwissenschaftlern, die zum direkten Umkreis Buffons zählten, bestätigt nur diese Neigung. Gemeinsam erforschten sie in der europäischen république des lettres die Entstehung und Entwicklung des Lebens. Zwar geriet die Fischzuchtmethode Jacobis bald wieder in Vergessenheit. Kritische Anmerkungen, aber auch die Aufforderung zu ihrer weiteren Erforschung, enthielt bereits Duhamel du Monceaus Schrift. ${ }^{104}$

Dass die Methode zuvor jedoch durch den Grafen von Goltstein aufgegriffen und bekannt gemacht wurde, ist ein weiterer Beleg für das starke Interesse von Teilen des Adels, hier des rheinischen Adels, an neuartigen naturwissenschaftlichen Erkenntnissen. Über eine andere Beziehung Goltsteins lässt sich zeigen, dass im

101 Henri Louis Duhamel du Monceau, Traité Général des Pesches, et Histoire des Poissons qu'elles fournissent, tant pour la subsistance des hommes, que pour plusieurs autres usages qui ont rapport aux Arts et au Commerce, Bd. 2, Paris 1772, 213, Permalink: http://gallica.bnf.fr/ark:/12148/ btvlb8626558w (Zugriff vom 25.05.2014).

102 Siehe zu diesen Angaben sowie seiner Biographie Louis Gabriel Michaud (Hg.), Biographie Universelle Ancienne et Moderne, ou Histoire, par ordre alphabétique, de la vie publique et privée de tous les hommes qui se sont fait remarquer par leurs écrits, leurs actions, leurs talents, leurs vertus ou leurs crimes, Bd. 14, Paris 1856, 523, Permalink: http://gallica.bnf.fr/ark:/12148/bpt6k51654t (Zugriff vom 25.05.2014).

103 Siehe hierzu etwa Henri Louis Duhamel du Monceau [u.a.], Descriptions des arts et métiers, faites ou approuvées par Messieurs de l'Académie royale des sciences de Paris, Bd. 4: L'Art du Tuilier et du briquetier, Paris 1763, http://books.google.de/books?id=xkO2-sSfR10C (Zugriff vom 25.05.2014).

104 Monceau, Traité Général des Pesches (wie Anm. 101, Kap. V), $213 f$. 
Zuge dieser Forschungen auch das Thema der Entstehung bzw. Beschaffenheit der Seele eine Rolle spielte. Gemeint ist hier sein Logenbruder Friedrich Heinrich Jacobi.

\section{V.5 Friedrich Heinrich Jacobi und seine adligen Förderer}

Der Name des bekannten Düsseldorfer Philosophen Friedrich Heinrich Jacobi (1743-1819) ist erstmals im Dezember 1765 mit der Amtsbezeichnung Tresorier in der Mitgliederliste der Parfaite Amitié aufgeführt. ${ }^{105}$ August Pauls erwähnt, dass der 22-jährige Jacobi »in persönlichem, freundschaftlichem Verkehr« mit dem Reichsgrafen von Goltstein sowie dem Meister vom Stuhl der Loge, Franz Karl Freiherr von Hompesch stand. ${ }^{106}$ Bevor diese Feststellung Pauls hinterfragt wird, soll hier zunächst auf die Zeit unmittelbar vor dem Beitritt Jacobis in die Kette der Brüder der Parfaite Amitié eingegangen werden.

Jacobi war der Sohn des Kommerzienrates Johann Conrad Jacobi (1715-1788), der in Pempelfort eine Zucker- und Stärkefabrik besaß und um die Gunst des Kurfürsten bemüht war, der ihn nach einem Brand der Manufaktur im Mai 1766 bei finanziellen Engpässen auch tatsächlich förderte. ${ }^{107}$ Seinen Sohn, Friedrich Heinrich, bereitete der Vater zunächst auf die Übernahme des Geschäfts vor. ${ }^{108}$ Dessen Interessen lagen jedoch bereits früh im religiösen und philosophischen Bereich, was etwa sein Anschluss an eine pietistische Gemeinschaft am Niederrhein mit dem Namen »Die Feinen belegt. $^{109}$

Ob er hierüber bereits mit der Seelenwanderungsdebatte in Berührung kam, ist nicht belegt. Der Jacobi-Biograph Kurt Christ, der sich intensiv mit dem Frühwerk Jacobis auseinandergesetzt hat, zitiert jedoch mehrfach Ausschnitte aus Briefen Jacobis, in denen die Seele und die Frage nach ihrer Unsterblichkeit thematisiert werden. Christ kommt zu der Feststellung, dass »die Unsterblichkeitsfrage und alle daraus resultierenden religiösen und philosophischen Probleme [...] gleichsam zum Grundaffekt der biographischen Existenz wie seines [Jacobis, Anm. d. Verf.] Werkes« wurden. ${ }^{110}$ Christ führt ergänzend eine Selbstcharakterisierung Jacobis aus seinem Roman »Alwill« an, die Jacobis Beschlagenheit in den Vorstel-

Siehe hierzu das Tableau der Loge La Parfaite Amitié, Düsseldorf, 27.12.1765, in: GON, 2336-10. Vgl. auch Pauls, Düsseldorfer Freimaurerei (wie Anm. 2, Kap. V), 54f. Ein Porträt Jacobis (Kupferstich von Christian Gottlieb Geyser, vor 1819) findet sich unter: commons.wikimedia.org/wiki/ File:Friedrich_Heinrich_Jacobi.jpg (Zugriff vom 02.08.2014).

106 Pauls, Düsseldorfer Freimaurerei (wie Anm. 2, Kap. V), 54.

107 Vgl. hierzu die entsprechenden Ausführungen bei Kurt Christ, Friedrich Heinrich Jacobi: Rousseaus deutscher Adept. Rousseauismus in Leben und Frühwerk Friedrich Heinrich Jacobis, Würzburg 1998, 16.

108 Vgl. Ders., Friedrich Heinrich Jacobi (wie Anm. 107, Kap. V), 22.

109 Ders., Friedrich Heinrich Jacobi (wie Anm. 107, Kap. V), 22f.

110 Ders., Friedrich Heinrich Jacobi (wie Anm. 107, Kap. V), 23. Zur großen Bedeutung der Unsterblichkeitsfrage in der Literatur des 18. Jh.s siehe auch die gesammelten Einschätzungen bei Carmen Götz, Friedrich Heinrich Jacobi im Kontext der Aufklärung. Diskurse zwischen Philosophie, Medizin und Literatur (Studien zum achtzehnten Jh., 30), Hamburg 2008, 43. 
lungen seiner Zeit über die Seele bezeugt. Hier schlägt Jacobi dem Leser vor, »sich unter dem Herausgeber einen Mann vorzustellen, dem es von seiner zartesten Jugend an, und schon in seiner Kindheit ein Anliegen war, daß seine Seele nicht in seinem Blute, oder ein bloßer Athem seyn möchte, der dahin fährt « ${ }^{111}$ Jacobi zeigte hier selbst den Kernpunkt seiner philosophischen Arbeiten an und gab zudem kritisch die gängigen Vorstellungen über den Sitz und die Beschaffenheit der Seele wieder. Diese Kritik ist es, die im Weiteren von Bedeutung sein wird.

Hinsichtlich seiner wissenschaftlichen Bildung waren für Jacobi seine »Genfer Jahre « (1759-1762) prägend. ${ }^{112}$ Er unternahm die Reise sowie seine wissenschaftliche `Nebentätigkeit mit ausdrücklicher Erlaubnis des Vaters. ${ }^{113}$ Einen Fürsprecher fand er dabei in dem Physiker und Mathematiker Georges-Louis Le Sage (1724-1803), der mit den Geistesgrößen rund um Genf, wie etwa Voltaire, in engem Kontakt stand und Jacobi mit ihnen zusammenführte. ${ }^{114}$ Hier interessiert jedoch in erster Linie seine Beeinflussung durch den Genfer Biologen Charles Bonnet (1720-1793), dessen Werk ihn auch in der gesamten Zeit seiner Logenmitgliedschaft beschäftigte. ${ }^{115}$ Jacobi hatten die Schriften Bonnets derartig beeindruckt, dass er sie nach eigenen Angaben $»$ beinah auswendig gelernt hatte«. ${ }^{116}$

Bonnet war 1745 mit der Untersuchung »Traité d'Insectologie« an die Öffentlichkeit getreten, in der er im Anschluss an das Vorwort eine »Echelle des Êtres Naturels" abbilden ließ, die aufsteigend von den vier Elementen über die Salze, Metalle und Steine die Hierarchie der Wesen von den Pflanzen bis zum Menschen als höchste Sprosse der Leiter anzeigte. ${ }^{117}$ Bonnet ging hierbei von der Kontinuitätsvorstellung dieser "Großen Kette der Wesen" aus, die in unmerklichen Abstufungen nach dem Grad ihrer Vollkommenheit miteinander verbunden waren. ${ }^{118}$ Ein Nutzen dieser Wissenschaft bestand laut Bonnet darin, »de nous montrer qu'il y a une gradation entre toutes les parties de cet univers; verité sublime, \& bien

111 Zitiert nach Ders., Friedrich Heinrich Jacobi (wie Anm. 107, Kap. V), 23.

$112 \mathrm{Zu}$ den Jahresangaben sowie einer zusammenfassenden Besprechung der »Genfer Jahre« siehe Nicole Schumacher, Friedrich Heinrich Jacobi und Blaise Pascal: Einfluss - Wirkung - Weiterführung, Würzburg 2003, Diss., 27f.

113 Vgl. Christ, Friedrich Heinrich Jacobi (wie Anm. 107, Kap. V), $25 f$.

114 Siehe Schumacher, Friedrich Heinrich Jacobi (wie Anm. 112, Kap. V), 27; Christ, Friedrich Heinrich Jacobi (wie Anm. 107, Kap. V), 33-35.

115 Vgl. hierzu die noch im Jahr 1768 erfolgte Erwähnung gegenüber dem Amsterdamer Verleger Marc-Michel Rey, in der Jacobi angab, Bonnets Schriften immer wieder zu lesen. Zitiert bei: Christ, Friedrich Heinrich Jacobi (wie Anm. 107, Kap. V), 48.

116 Friedrich Heinrich Jacobi, Über die Lehre des Spinoza in Briefen an den Herrn Moses Mendelssohn, bearb. von Marion Lauschke (Philosophische Bibliothek, 517), Hamburg 2000, 41. Jacobis hier zitierte Äußerung aus seinen Briefen an Moses Mendelssohn findet sich ebenfalls in einer Anmerkung bei Christ. Vgl. hierzu die Angaben bei Ders., Friedrich Heinrich Jacobi (wie Anm. 107, Kap. V), 48.

117 Vgl. hierzu Charles Bonnet, Traité d'Insectologie, ou Observations sur les Pucerons, Bd. 1, Paris 1745, I-XXXII, Permalink: http://nbn-resolving.org/urn:nbn:de:bvb:12-bsb10306750-6 (Zugriff vom 24.05.2014). Ein unvollständiges Digitalisat der Leiter findet sich unter letztgenanntem Link im Anschluss an S. XXXII.

118 Vgl. Ders., Traité d'Insectologie (wie Anm. 117, Kap. V), XXVII-XXXII. 
digne de devenir lobjet de nos méditations! « ${ }^{119}$ Hierin klingt bereits an, dass Bonnet ein Fortschreiten der Leiter über die Sprosse des Menschengeschlechts hinaus hin zu himmlischen Wesen in unendlich ansteigenden Arten der Perfektion erwartete. ${ }^{120}$ In den folgenden Jahren setzte sich Bonnet in seinem »Essai sur la psychologie« (1754) sowie »Essai analytique sur les facultés de lâme« (1760) eingehender mit der Beschaffenheit der menschlichen Seele auseinander.

Neben den 1762 erschienenen »Considerations sur les corps organisées « und der »Contemplation de la nature (1764 und 1765) erregte vor allem seine 1769 erschienene Schrift »Palingénésie philosophique Aufsehen und ist auch hier von besonderem Interesse. In dieser griff Bonnet das oben erwähnte Bild der Kette bzw. Leiter wieder auf und vertrat die Lehre der Planetenwanderung. ${ }^{121}$ Diese ging von der Untrennbarkeit der menschlichen Seele von ihrem Körper aus und nahm von daher eine gemeinsame Auferstehung in stufenweise aufeinanderfolgenden Planetenwelten an, mit der sich gleichzeitig eine Höherentwicklung der Erkenntnisse und Sinne verbinden sollte. ${ }^{122}$ Wie Helmut Zander feststellte, handelte es sich hierbei jedoch nicht im strengen Sinne um eine Seelenwanderungs- bzw. Reinkarnationsvorstellung, da Bonnet nicht an eine Trennung von Körper und Geist glaubte. ${ }^{123}$

Wie bereits erwähnt rezipierte der junge Jacobi die Schriften Bonnets eifrig. Noch im Jahr 1785 - Jacobi war zu dieser Zeit bereits unter dem Ordensnamen »Sully« dem Orden der mittlerweile durch fürstlichen Erlass verbotenen Illuminaten beigetreten, deren Geschichtsphilosophie ebenfalls stark auf der Idee der Metempsychose beruhte ${ }^{124}$ - waren Bonnets Schriften Gegenstand der Briefkorrespondenz des nunmehr 42-jährigen mit Moses Mendelssohn, in der er über ein Treffen mit Gotthold Ephraim Lessing berichtete. ${ }^{125}$ Jacobi war im Jahr 1780 mit Lessing in Wolfenbüttel zusammengetroffen. Lessing hatte im selben Jahr die Schrift "Die Erziehung des Menschengeschlechts « veröffentlicht, in der er sich in den letzten Paragraphen ( $\$ \$ 90-100)$ mit der Seelenwanderungslehre auseinandersetzt. ${ }^{126}$ Lessing hatte sich kritisch mit der »Palingénésie philosophique«

Ders., Traité d'Insectologie (wie Anm. 117, Kap. V), XXVII.

Vgl. Ders, Traité d'Insectologie (wie Anm. 117, Kap. V), XXIX-XXXII.

Siehe zu diesen Erläuterungen Zander, Geschichte der Seelenwanderung (wie Anm. 77, Kap. I), $362 \mathrm{f}$.

Siehe hierzu Ders., Geschichte der Seelenwanderung (wie Anm. 77, Kap. I), $362 \mathrm{f}$.

Vgl. Ders., Geschichte der Seelenwanderung (wie Anm. 77, Kap. I), 362f.

Vgl. hierzu die Ausführungen bei Mulsow, Vernünftige Metempsychosis (wie Anm. 77, Kap. I), hier insb. 225-264. Mulsow erläutert hier ausführlich die Beeinflussung Adam Weishaupts durch die Philosophie Charles Bonnets und kommt auch auf Jacobi zu sprechen.

Vgl. Jacobi, Über die Lehre des Spinoza (wie Anm. 116, Kap. V), $40 \mathrm{f}$.

Vgl. hierzu Zander, Geschichte der Seelenwanderung (wie Anm. 77, Kap. I), 343-352; Obst, Reinkarnation (wie Anm. 77, Kap. I), 122-126. Zu Lessings Vorstellungen sowie den gedanklichen Bezügen zu Bonnet vgl. auch Manfred Beetz, Lessings vernünftige Palingenesie, in: NeugebauerWölk (Hg.), Aufklärung und Esoterik: Rezeption - Integration - Konfrontation (Hallesche Beiträge zur Europäischen Aufklärung, 37), Tübingen 2008, 131-148. Die innerhalb der vorliegenden Studie geschilderten medizinischen Zusammenhänge sind sicherlich auch in Beziehung auf seine bekannte Theatertheorie zu beachten. 
Bonnets beschäftigt und war im Urteil über sein eigenes System zu einer Ansicht gelangt, die nicht weit entfernt von den Vorstellungen eines Andrew Michael Ramsay war, wie die von Lessing bereits im Herbst 1778 verfasste Schrift »Dass mehr als fünf Sinne für den Menschen sein können« zu erkennen gibt. ${ }^{127}$

Die Bekanntschaft Jacobis zu Lessing resultierte auch aus seiner engen Beziehung zum Meister vom Stuhl der Parfaite Amitié, Franz Karl von Hompesch. Der Freiherr von Hompesch hatte im Jahr 1777 den vergeblichen Versuch unternommen, Lessing für das neugeschaffene Nationaltheater in Mannheim zu gewinnen. ${ }^{128}$ Zur Zeit dieses Engagements bestand die Düsseldorfer Loge bereits nicht mehr. Wie weiter unten zu erläutern sein wird, erlosch sie, wie schon von August Pauls angenommen, in den 1770er Jahren. Es lohnt sich dennoch, auf diese späteren Jahre einzugehen, da sie die Bedingungen der Förderung Jacobis durch den Reichsgrafen von Goltstein und Franz Karl von Hompesch verdeutlichen. Die Konstellation offenbart das relative Abhängigkeitsverhältnis Jacobis. Diese Abhängigkeit wird insbesondere innerhalb seiner Tätigkeit für die Finanzverwaltung der Ländereien des Kurfürstentums ersichtlich, die im Folgenden kursorisch anhand der Untersuchungen Klaus Hammachers und Hans Hirschs nachgezeichnet werden soll.

Diese Förderung Jacobis beruhte ganz offensichtlich auf den finanzwirtschaftlichen Fähigkeiten des Schatzmeisters der Loge. Im Jahr 1772 wurde Jacobi zum "wirklichen jülich-bergischen Hofkammerrat mit Sitz und Stimme« ernannt und erhielt durch den Einsatz des Grafen von Goltstein, der Jacobis kaufmännisches Geschick würdigen wollte, ein jährliches Gehalt von 600 Gulden. ${ }^{129} \mathrm{Da}$ sich die Zuckermanufaktur des Vaters spätestens seit dem Brand im Mai 1766 in finanziellen Engpässen befand, dürfte dieses Gehalt gern gesehen worden sein und die Gunst des Reichsgrafen von Goltstein war ein ebenso wichtiges Gut. ${ }^{130}$ Jacobi übernahm für das oben erwähnte Gehalt arbeitsreiche Tätigkeiten im Finanzressort und war dem kurfürstlichen Statthalter und nicht zuletzt dem Kurfürsten selbst bei der Erfassung der Landesfinanzen sowie der Ordnung des Zollwesens von großem

127 Gotthold Ephraim Lessing, Werke, Bd. 8: Theologiekritische Schriften III. Philosophische Schriften, hg. von Herbert G. Göpfert, Darmstadt 1979, 557-561. Vgl. zur Frage der Entstehung Ders., Werke, Bd. 8, 744. In der Schrift Lessings heißt es: »Dieses mein System ist gewiß das älteste aller philosophischen Systeme. Denn es ist eigentlich nichts als das System von der Seelenpräexistenz und Metempsychose, welches nicht allein schon Pythagoras und Plato, sondern auch vor ihnen Ägyptier und Chaldäer und Perser, kurz alle Weisen des Orients, gedacht haben. Und schon dieses muß ein gutes Vorurteil dafür wirken. Die erste und älteste Meinung ist in spekulativen Dingen immer die wahrscheinlichste, weil der gesunde Menschenverstand sofort darauf verfiel." Ders., Werke, Bd. 8, 557-561, hier 560f. Der Hinweis auf dieses Zitat fand sich bei: Obst, Reinkarnation (wie Anm. 77, Kap. I), 125.

128 Vgl. hierzu Günther Ebersold, Louise von Hompesch (1775/1777-1801) und ihre Familie. Eine Frau zwischen Tradition und Revolution (Mannheimer historische Schriften, 2), Ubstadt-Weiher [u.a.] 2009, 29.

129 Klaus Hammacher/Hans Hirsch, Die Wirtschaftspolitik des Philosophen Jacobi (Fichte-Studien Supplementa, 1), Amsterdam/Atlanta 1993, 21.

130 Vgl. hierzu auch die Ausführungen bei Klaus Hammacher und Hans Hirsch, die auf Briefe Jacobis aus dem Jahr 1774 verweisen: Dies., Die Wirtschaftspolitik des Philosophen Jacobi (wie Anm. 129, Kap. V), 23. 
Nutzen. ${ }^{131}$ Wiederum unter Fürsprache des Grafen wurde er 1775 in Mannheim zum Zollkommissar ernannt, was ihm erneut jährliche finanzielle Zuwendungen einbrachte. ${ }^{132}$ Für verschiedene Projekte konnte er im Jahr 1777 zudem auch auf die Fürsprache des jülich-bergischen Hofkammerpräsidenten Ludwig Anton von Blanckart und des Hofkammervizepräsidenten Graf Ambrosius Franz von Spee bauen. ${ }^{133}$ Es ist nicht unwahrscheinlich, dass die persönliche Bekanntschaft zum Grafen von Spee aus der Düsseldorfer Loge hier nutzte.

Aufgrund interner Querelen am Hof reichte Jacobi im Jahr 1778 ein Entlassungsgesuch ein, das Hompesch jedoch zurückwies. ${ }^{134}$ Der Freiherr, der mittlerweile kurpfalz-bayerischer Finanzminister in München geworden war, hatte ihn noch während des Jahres 1779 nach München geholt, seit der Verlagerung des Hofes aus Mannheim Residenz des Kurfürsten. ${ }^{135}$ Hier sollte Jacobi bei der Planung und Organisation des erbstaatlichen Kommerzialverbandes unterstützen und wurde zwischenzeitlich zum »Titular-Geheimen Rat ohne Sitz und Stimme«, jedoch mit einem Gehalt von 1000 Gulden ernannt. ${ }^{136}$ Er wurde zum wichtigsten Ratgeber des Finanzministers Hompesch und versuchte, physiokratisch-liberale Reformen des Wirtschaftssystems durchzusetzen. ${ }^{137}$ Noch im Jahr 1779 musste Jacobi, der auch öffentlich die Wirtschaftspolitik der Regierung kritisiert hatte, auf Wunsch des Fürsten aus München abreisen und sich zurück auf seinen Sitz nach Pempelfort begeben. ${ }^{138}$ Die im Großen und Ganzen gegen Jacobis Reformen gesinnte jülich-bergische Hofkammer erwirkte 1780 sogar die Einstellung sämtlicher Gehaltszahlungen an ihn. ${ }^{139}$ Freiherr Franz Karl von Hompesch, der mehr und mehr an Einfluss verlor, konnte diese allmähliche $>$ Kaltstellung $<$ Jacobis nicht verhindern. ${ }^{140}$

Die Förderung Jacobis und nicht zuletzt seine Aufnahme in die Loge dürften jedoch auch auf seine Bildung in den Naturwissenschaften und der Philosophie zurückzuführen sein. Es ist bekannt, dass sich Franz Karl von Hompesch und Jacobi vor der Münchener Zeit auch auf Schloss Bollheim, dem Familiensitz Hompeschs, trafen, um etwa die pädagogischen Reformschriften des zum Münsterischen Kreis des Salons der Fürstin Anna Amalia von Gallitzin zählenden Franz Friedrich Freiherr von Fürstenberg (1729-1810) zu diskutieren. ${ }^{141}$ Letzterer gehörte selbst nicht Vgl. Dies., Die Wirtschaftspolitik des Philosophen Jacobi (wie Anm. 129, Kap. V), 27. Vgl. Dies., Die Wirtschaftspolitik des Philosophen Jacobi (wie Anm. 129, Kap. V), 28. Siehe Dies., Die Wirtschaftspolitik des Philosophen Jacobi (wie Anm. 129, Kap. V), $29 f$. Dies., Die Wirtschaftspolitik des Philosophen Jacobi (wie Anm. 129, Kap. V), 29 f. Vgl. Dies., Die Wirtschaftspolitik des Philosophen Jacobi (wie Anm. 129, Kap. V), 35-38. Siehe Dies., Die Wirtschaftspolitik des Philosophen Jacobi (wie Anm. 129, Kap. V), 36. Siehe Dies., Die Wirtschaftspolitik des Philosophen Jacobi (wie Anm. 129, Kap. V), $28 f$. Vgl. Dies., Die Wirtschaftspolitik des Philosophen Jacobi (wie Anm. 129, Kap. V), 36.

141 Siehe hierzu Christ, Friedrich Heinrich Jacobi (wie Anm. 107, Kap. V), $160 \mathrm{f}$. 
der Freimaurerei an, besaß innerhalb seiner Bibliothek jedoch eine große Anzahl von Schriften freimaurerischer Provenienz. ${ }^{142}$

Besonders die Erziehung galt für Jacobi als das Mittel, das den Menschen zu einem tugendhaften Wesen zu formen vermochte. Der Mensch als »Leib-SeeleWesen« kam nicht vollkommen zur Welt, sondern - hier stimmte Jacobi vollkommen mit den Ansichten innerhalb der Freimaurerei überein - bedurfte auf seinem Weg der Läuterung. ${ }^{143}$ In seinem Roman »Woldemar « drückte Jacobi dies in fast alchemistisch wirkender Manier aus:

So weit die Geschichte reicht, sehen wir Tugend und Laster in wunderlicher Vermischung, in einer Vermischung, die wie ein Vergleich aussieht; beyde überall mit gewissen äusserlichen Formen der Lebensart, der Gesetzgebung und der Religion gleich unzertrennlich verknüpft; nirgend Tugend in eigener Gestalt. - Die bloßen Triebe zum Guten und Edeln, ungeläutert und sich selbst überlassen, diese Triebe mit ihren unmittelbaren zufälligen Aeusserungen, sind noch nicht die Tugend; sie machen nur ihren Stoff aus. Diesen Stoff hat die Zeit analysirt, eine Menge Scheidungen damit vorgenommen, mit dem Geschiedenen allerhand Mischungen versucht. Jede dieser Mischungen erhielt ihr eigenes Gefäß und Siegel. Einige läuterten sich schon. Zerbrach nun aber das Gefäß, oder bekam es eine Oefnung; so verflog der Geist, und hinterließ wenig mehr, als Gestank. Mit allen bisherigen Formen der Menschheit ist es so ergangen. ${ }^{144}$

Die Parallelen zum Grundschema der freimaurerischen, aber auch der illuminatischen ${ }^{145}$ Geschichtskonstruktionen sind hier offensichtlich, wobei Jacobi hier nicht Gott, sondern den Faktor »Zeit« als entscheidend hervorhebt. Eine solche Philosophie wirft jedoch unweigerlich Fragen auf, was das Verhältnis Jacobis zum Adel und dessen »Blutsideologie« anbelangt.

Die Schriften Bonnets konnten dem Adel durch ihre Befürwortung der Präformationslehre sowie der Planetenwanderung, innerhalb der der Mensch nicht die Krone der Schöpfung, aber zumindest ein Mittelglied ${ }^{146}$ war, durchaus noch einen Platz am ıoberen Ende dieser Mitte zusprechen. Größeres Augenmerk verdient hingegen die Begeisterung Jacobis für adelskritische Schriften wie Rousseaus

142 Vgl. Hans-Werner Langbrandtner/Monika Gussone, Bibliotheken und Musikalien als Spiegel adliger Bildung. Auf Spurensuche in rheinischen Adelsbibliotheken und -archiven, in: zeitenblicke 9/1 (2010), [10.06.2010], http://nbn-resolving.org/urn:nbn:de:0009-9-25171 (Zugriff vom 26.02.2012), insb. Abs. 40; Bertram Haller, Aus der Bibliothek Fürstenberg-Stammheim, (Ausstellungskatalog: Stadtsparkasse Münster, 16.05.-27.05.1988) (Schriften der Universitätsbibliothek Münster, 1), Münster 1988, 110f. In selbiger Bibliothek befanden sich auch die innerhalb dieser Studie zum Teil erwähnten Schriften Buffons, Linnés, Lavaters sowie Bonnets.

143 Vgl. hierzu die Besprechung von Jacobis Roman »Woldemar« bei Christ, Friedrich Heinrich Jacobi (wie Anm. 107, Kap. V), 312.

144 Friedrich Heinrich Jacobi, Woldemar, Erster Theil, Königsberg 1794, 128f., Permalink: http:// resolver.staatsbibliothek-berlin.de/SBB00006BFB00010000 (Zugriff vom 25.05.2014). Der Hinweis auf dieses Zitat fand sich bei: Christ, Friedrich Heinrich Jacobi (wie Anm. 107, Kap. V), 312.

145 Siehe hierzu die Ausführungen bei Koselleck, Kritik und Krise (wie Anm. 55, Kap. I), insb. 68-81.

146 Vgl. Zander, Geschichte der Seelenwanderung (wie Anm. 77, Kap. I), 364. 
»Nouvelle Hélo $\square$ se«, deren Amsterdamer Verleger Marc-Michel Rey - ebenfalls Freimaurer - zu Jacobis engen Korrespondenzpartnern zählte, oder die Schrift »Le Noble« der niederländischen Adligen Isabelle de Charrière (1740-1805), auch Belle van Zuylen genannt - dieses Werk erhielt Jacobi ebenfalls über Rey. ${ }^{147}$

Insbesondere in letztgenannte Schrift hatte sich Jacobi nach eigenen Äußerungen »verliebt «. ${ }^{148}$ Die sarkastische Geschichte, die den in der vorliegenden Studie untersuchten Konflikt der Memoria brennglasartig aus zeitgenössischer Sicht zusammenzufassen scheint, handelt von dem Baron d'Arnonville, dessen Tochter sich in den Sohn einer >neuadligen Pariser Familie namens Valaincourt verliebt. ${ }^{149}$ Der Baron d'Arnonville, dessen ganzer Stolz der bis auf das Jahr 456 n. Chr. zurückverfolgbare Stammbaum seines Adelsgeschlechts ist, fällt in Ohnmacht, als er der drohenden Mesalliance seiner Tochter gewahr wird. ${ }^{150}$ Erst als der besonders liederlich dargestellte Stammhalter eine Tochter aus altadligem Hause heiratet, kann sich der Vater im Überschwang der Gefühle mit der Tochter versöhnen und ihrer unstandesgemäßen Heirat zustimmen. ${ }^{151}$

Jacobi war derartig begeistert von dieser Schrift, dass er sie 1770 auch in Deutschland edieren und verbreiten wollte. ${ }^{152}$ Für diese Neuauflage verfasste er - vermutlich mit Hilfe seines Bruders - ein Vorwort, dessen Original zwar verschollen ist, jedoch in einer Version von 1771 vorliegt. ${ }^{153}$ Dieses anonym veröffentlichte Vorwort gibt zu erkennen, wie sehr Jacobi der Ahnenstolz und die »Blutsideologie« des Adels verhasst waren. Über Zuylens Schrift heißt es hier:

Il paroit avoir été composé principalement pour cette partie de l'Europe, où le ridicule qu'il attaque est dans sa plus grande vigueur. Personne n'ignore qu'aucune sorte de mérite n'y tient lieu d'ancêtres. Ayez sur un homme à Seize-Quartiers la supériorité d'esprit \& de sentiment la plus décidée, qu'il soit même assez heureusement né pour la sentir \& la reconnoître, malgré cela il vous regardera toujours comme son inférieur, puisque vous n'avez pas reçu comme lui en naissant le privilége de marcher sur des échasses. La plûpart des Barons \& des Comtes d'Empire estiment qu'Apollon fait le métier d'un manant, \& traitent les Muses en petites Bourgeoises qui ne sont pas faites pour être reçues dans la bonne compagnie. La barbarie, où une partie consi-

Vgl. hierzu Christ, Friedrich Heinrich Jacobi (wie Anm. 107, Kap. V), insb. 36f. und 144-151.

Ders., Friedrich Heinrich Jacobi (wie Anm. 107, Kap. V), 145.

Madame de Charrière, Lettres Neuchâteloises. Mistriss Henley. Le Noble, Genf 1908, 163-194, Permalink: http://n2t.net/ark:/13960/t8jd5p53z (Zugriff vom 18.07.2014).

50 Siehe hierzu Dies, Lettres Neuchâteloises (wie Anm. 149, Kap. V), 164, insb. 173f. sowie 192-194. Die auf Seite 173f. geschilderte Szene erinnert dabei nicht nur an die oben geschilderten Stammbäume, sondern scheint auch auf die Wichtigkeit des visuellen Eindrucks durch die Erwähnung des Zusammenhangs der Ahnengalerie, des Stammsitzes und der Herausbildung der Tugend durch das Studium der Familiengeschichte zu verweisen.

Siehe hierzu Dies., Lettres Neuchâteloises (wie Anm. 149, Kap. V), 192-194.

Vgl. hierzu die Angaben bei Christ, Friedrich Heinrich Jacobi (wie Anm. 107, Kap. V), 144.

Zur Verfasserfrage siehe Ders., Friedrich Heinrich Jacobi (wie Anm. 107, Kap. V), 145-147. 
dérable de cette nation, d'ailleurs si éclairée, est encore plongée à cet égard, passe toute croyance. ${ }^{154}$

Jacobi versuchte in dieser Vorrede interessanterweise, den Adel auch durch eine Anekdote über dessen Jenseitsvorstellungen zu diskreditieren ${ }^{155}$ - ein Hinweis, wie sehr sich »Blutsideologie» und Erlösungsglaube bedingten. Jacobi gab an, noch mehr solcher Anekdoten zu kennen, sie jedoch aus Ekel vor ihnen nicht niederschreiben zu können. ${ }^{156}$ Ein sehr spitzer Angriff und eine überdeutliche Adressierung der Neuedition folgte - in dem wohlgemerkt in französischer Sprache verfassten Vorwort - auf dem Fuße: »Les personnes de distinction en Allemagne voudroient l'être en tout point. Ils ne parlent pas la langue de leur pays pour n'avoir pas un idiome commun avec la canaille qui les entoure $[\ldots] .{ }^{157}$ Dies traf auch auf die ehemaligen Mitglieder der in französischer Sprache arbeitenden Parfaite Amitié zu - und das Zielpublikum seiner Vorrede.

Handelte es sich angesichts derartig provokanter Ansichten bei dem Verhältnis Jacobis zu dem Grafen von Goltstein und dem Freiherrn von Hompesch also tatsächlich um ein freundschaftliches Verhältnis im modernen Sinne? Empfanden sich der zum dritten Stand zählende Jacobi und die Vertreter des zweiten Standes als vollkommen gleichrangig, weil sie Freimaurer waren und der Name ihrer Loge das Ideal der Seelenverwandtschaft suggerierte?

Im Falle des Reichsgrafen von Goltstein darf aufgrund des Kontakts zu adligen französischen Naturwissenschaftlern angenommen werden, dass das Thema einer "adligen Rasse« in seinem Denken eine Rolle gespielt haben dürfte. Für den Freiherrn Franz Karl von Hompesch sind wir dank einer Studie Günther Ebersolds über die Tochter des Freiherrn, Louise von Hompesch (1775-1801), zuverlässig informiert, was seine Einstellung zu »Adligkeit« anbelangt. ${ }^{158}$ Der Freiherr war demnach »ein adelsstolzer Mann, dem Ehre und guter Ruf seiner Familie über alles gingen « und dessen Interessen vor allem auf den Gebieten Philosophie, Erziehung und Glauben lagen. ${ }^{159}$ Ebersold sieht in ihm auch aus diesem Grund zwar

154 Friedrich Heinrich Jacobi, Discours Préliminaire zu Le Noble (1771), in: Ders., Kleine Schriften I: 1771-1783, hg. von Catia Goretzki/Walter Jaeschke (Friedrich Heinrich Jacobi: Werke, 4,1), Hamburg 2006, 9f., hier 9.

155 Ders., Discours Préliminaire zu Le Noble (wie Anm. 154, Kap. V), 9. Hier heißt es: »Une Dame [...] s'entretenant avec un Eccléssiastique, homme d'esprit \& connu par d'excellens Ouvrages, lui dit: sseroit-il bien vrais, Monsieur, que dans l'autre monde tous les rangs seront confondus? Mon Dieu! On est si peu habitué à voir toute sorte de gens, comment s'y [f]eroit-on? Tranquillisez-vous, Madame, reprit l'Ecclésiastique, il y aura des balcons pour les Dames. « Vgl. zu den hier gemachten Angaben auch die Erwähnung bei Christ, Friedrich Heinrich Jacobi (wie Anm. 107, Kap. V), 148.

156 Vgl. Ders., Friedrich Heinrich Jacobi (wie Anm. 107, Kap. V), 148f. Im Original heißt es hierzu: "Je m'abstiens de rapporter un plus grand nombre d'anecdotes de cette nature, que j'ai recueilles en parcourant l'Allemagne, parce qu'elles sont trop révoltantes \& que je ne pourrois les écrire sans dégoût." Siehe zu diesem Zitat Ders., Discours Préliminaire zu Le Noble (wie Anm. 154, Kap. V), hier 9.

157 Ders., Discours Préliminaire zu Le Noble (wie Anm. 154, Kap. V), 9.

158 Vgl. Ebersold, Louise von Hompesch (wie Anm. 128, Kap. V).

159 Ders., Louise von Hompesch (wie Anm. 128, Kap. V), 36-38. 
durchaus einen frankophilen Anhänger der Aufklärung, aber keinesfalls eine grenzenlos liberale Persönlichkeit mit Sympathien für Revolutionen. ${ }^{160}$

Aufschlussreich in Bezug auf den hier behandelten thematischen Komplex ist eine von Ebersold in den Dokumenten des Familienarchivs der Hompeschs in Brünn aufgefundene Aussage Franz Karl von Hompeschs anlässlich der bevorstehenden Heirat seines Sohnes Karl, die den »Adelsstolz« des Vaters zweifelsfrei belegt. Diese stammt aus dem Jahr 1796 und zeigt seine Kenntnis des aus England herüberreichenden Rassenvergleichs "Adel/Pferd $\aleph^{161}$ ebenso in aller Deutlichkeit auf wie sein Festhalten an der Vorstellung einer auf dem Vorzug des Bluts gründenden adligen »Rasse« im Allgemeinen. In Bezug auf Vermählungen bemerkte er: »Die Rasse macht hier viel [...] für die Menschen wie für die Pferde, und wenn ich noch vor hätte, mich zu verheiraten, würde ich eine Frau vorziehen mit einem Viertel Blut mehr, hätte sie auch zwei Drittel Vermögen weniger. ${ }^{162}$ Das reale Verhältnis des Freiherrn zu seinen Kindern ähnelte dabei kurioserweise der bei van Zuylen beschriebenen literarischen Szenerie. ${ }^{163}$ Hompeschs Tochter Louise lehnte sich laut Ebersold gegen Ahnenstolz und die als "Eisenketten " empfundenen Blutsbindungen des Adels auf. ${ }^{164}$ Das durchaus ernsthafte Anbändeln Louises mit dem französischen General Dieudonné Louis Antoine Klein (1761-1845), Sohn des Kaufmanns Jacques Louis Klein, wusste Hompesch bis zu seinem Lebensende im Jahr 1800 zu verhindern - Louise starb im darauffolgenden Jahr. ${ }^{165}$

Abschließend lässt sich festhalten, dass die Interessenlagen und persönlichen Einstellungen der beiden hier vorgestellten adligen Logenbrüder Goltstein und Hompesch es mehr als unwahrscheinlich erscheinen lassen, dass es sich in Bezug auf den jungen Kaufmann Friedrich Heinrich Jacobi - der nicht davon überzeugt war, dass die Seele im Blut, geschweige denn im Atem lag - um ein freundschaftliches Verhältnis im modernen Sinne handelte. Sicherlich: Die gemeinsame Mitgliedschaft in der Freimaurerei stellte eine engere Verbindung her, da sie alle drei Personen spätestens im Meistergrad mit dem für alle gleichermaßen bedrohlichen Thema des persönlichen Todes konfrontierte und zur gedanklichen wie gefühlsmäßigen Auseinandersetzung im Ritual aufforderte. Die hierin vermittelte Vorstellung einer Auferstehung - in welcher Form auch immer - drängte das Thema der Erziehung in den Mittelpunkt, das sowohl innerhalb als auch außerhalb des freimaurerischen Raums behandelt wurde. Das einigende Band stellte die mit dem Eintritt in die Freimaurerei bezeugte Bekundung dar, die eigene Seele zu vervollkommnen, aber auch aufgrund einer allmählichen tieferen Einsicht in die Ge-

160 Vgl. hierzu Ders., Louise von Hompesch (wie Anm. 128, Kap. V), 38-41.

161 Zur Wichtigkeit der Pferdezucht in Bezug auf die adlige »Blutsideologie« vgl. die Ausführungen bei Serna, Der Adlige (wie Anm. 36, Kap. I), 89 f.

162 Zitiert nach Ebersold, Louise von Hompesch (wie Anm. 128, Kap. V), 44.

$163 \mathrm{Zu}$ einer eingehenderen Beschreibung des Vater/Sohn-Verhältnisses siehe Ders., Louise von Hompesch (wie Anm. 128, Kap. V), 46-69.

164 Ders., Louise von Hompesch (wie Anm. 128, Kap. V), 93.

165 Vgl. Ders., Louise von Hompesch (wie Anm. 128, Kap. V), 77-136, hier insb. 82, 84 und 87. 
heimnisse eines angenommenen göttlichen Plans anderen aus dem letztlich recht egoistischen Motiv des Seelenheils heraus bei ihrem Aufstieg zu helfen.

Die eher im Hintergrund des freimaurerischen Rituals schwelende Debatte um die Seelenwanderung stellte in Ergänzung hierzu ein theoretisches Gerüst dar, dessen vielfache Facetten auch außerhalb des arkanen Raums diskutiert wurden. Dies bedeutete nicht zwangsläufig, dass mit einem Eintritt in die Freimaurerei an die Lehre der Metempsychose zu glauben war - jedoch bezeugte die Mitgliedschaft idealerweise den Sinn für das Metaphysische. Hier ist wohl auch der Anknüpfungspunkt für die Mitgliedschaft eines Anton Sissonet oder Friedrich Heinrich Jacobi in der Düsseldorfer Adelsloge zu sehen. Aufgrund ihres vorfreimaurerischen Werdegangs durfte von ihnen durchaus angenommen werden, diesen Sinn zu besitzen. Das spekulative Wissen, das sie über Pädagogik, aber auch die Beschaffenheit der Seele und in Jacobis Fall die Lehre der Metempsychose besaßen, machte sie für die Adelsloge zusätzlich zu ihren praktischen Fähigkeiten attraktiv.

Was sich letztlich hieraus ergab, war jedoch ein Abhängigkeitsverhältnis, dessen schwächeres Ende zweifellos noch auf der Seite des dritten Standes zu finden war. Sowohl Jacobi als auch Sissonet waren auf die Gunst der vornehmen Familien des Landes angewiesen, um gesellschaftlich zu reüssieren bzw. ihre Stellung zu halten. Dies beweist auch die - wohlgemerkt anonym geäußerte - Adelskritik Jacobis in den 1770er Jahren. Diese erfolgte zu einem Zeitpunkt, an dem er hoffen durfte, in seiner gesellschaftlichen Stellung bereits weitestgehend gefestigt zu sein. Die Loge schaffte in seinem Fall somit zwar den Raum zur Annäherung an die herrschenden Geschlechter, überwand jedoch keinesfalls die Grenze der »Rasse ${ }^{166}$ Vielmehr ist hier im Sinne des durch Wolfgang Reinhard erarbeiteten »Verflechtungskonzepts« von einer Form der »Patronage« zu sprechen. ${ }^{167}$ Der Begriff der »amitié«, wie er im Logennamen anzutreffen war, ging zwar durchaus mit einer gewissen Form der zwischenmenschlichen Verbundenheit einher, diese hatte sich jedoch - für die Frühe Neuzeit nicht ungewöhnlich - stets den Gepflogenheiten ständischer Schranken zu unterwerfen. Während Jacobi sich zwar durchaus auch auf eine Beziehung zu seinen adligen Logenbrüdern im Sinne der »Landsmannschaft« berufen konnte, fehlte ihm doch das für die Loge so eminent

166 Bezüglich des Karrieremusters gleicht der Fall Jacobi den Karrierestrukturen im bzw. außerhalb des Ordens der Gold- und Rosenkreuzer bzw. den Ergebnissen Beaurepaires für die frühe Freimauerei Berlins. Vgl. zu diesen Karrieremustern Geffarth, Religion und arkane Hierarchie (wie Anm. 66, Kap. V), 141-162, insb. 147f.; Beaurepaire, Freimaurer (wie Anm. 69, Kap. I), hier insb. 109.

167 Siehe zum »Verflechtungskonzept« sowie den »vier Gattungen persönlicher Beziehungen« in Form von »Verwandtschaft«, "Landsmannschaft«, »Freundschaft" und »Patronage» Wolfgang Reinhard, Freunde und Kreaturen. »Verflechtung " als Konzept zur Erforschung historischer Führungsgruppen. Römische Oligarchie um 1600 (Schriften der Philosophischen Fachbereiche der Universität Augsburg, 14), München 1979, 35-41. 
wichtige Kriterium der »Verwandtschaft«. ${ }^{168}$ Zudem war seine Position für eine vollwertig reziproke $"$ Freundschaft ${ }^{169}$ durch die angespannte finanzielle Situation seiner Familie grundsätzlich untergraben.

Die Freimaurerei, in deren Umkreis sich lange Zeit Gerüchte über verborgenes Wissen »Geheimer Oberer « hielten, stellte für den in derartigen Logen verkehrenden Adel im Ancien Régime ein weiteres Forum dar, in dem der dritte Stand mit seinen Diensten den zweiten Stand in seiner Ausübung der Herrschaft unterstützte. Die Herrschaft bezog sich hier auf die `Herrschaft über die Gemüter «. Nur insofern war auch der bereits erwähnte Suprematie-Anspruch der Brüder der Parfaite Amitié über die sich vorwiegend aus Mitgliedern des dritten Standes zusammensetzende Düsseldorfer Loge La Paix du Bas-Rhin zu verstehen. Gerade die Vielzahl der Facetten der Lehre der Metempsychose und die Unsicherheit über den Entstehungsprozess der Seele wie die Vererbbarkeit von charakterlichen Eigenschaften - dies war den Zeitgenossen bereits bewusst - bargen einen großen Interpretationsspielraum in sich, der gesellschaftlich prekär werden konnte. Es galt somit nicht nur für den in den Logen vertretenen Adel, das gesamte verfügbare Wissen hierüber wie über die Geschichte der freimaurerischen Vereinigungen zu sammeln, aber auch im Ritual oder spiritistischen Séancen zu erproben und die Korrumpierung der Ur- bzw. Vernunftsreligion weiter aufzuheben. Die gemeinsame Wissenserweiterung im pädagogischen und naturwissenschaftlichen Bereich konnte sich gleichzeitig positiv in anderen Facetten der außerhalb der Freimaurerei stattfindenden adligen Herrschaftsausübung auswirken. Dies beweist beispielsweise die Einrichtung der öffentlichen Bibliothek Düsseldorfs durch den Reichsgrafen von Goltstein. Die Lehre der Metempsychose ist dabei, neben sicherlich auch vorhandenen wirtschaftlichen Hintergedanken, als der hauptsächliche Antrieb für derlei Projekte zu sehen.

Die Krux lag jedoch darin, dass auch die derartig gebildeten und in die Geheimbünde aufgenommenen Schichten des dritten Standes, die wie Jacobi die adlige »Blutsideologie« negierten, durch ihre jeweils eigene Interpretation der Metempsychose für sich in Anspruch nehmen konnten, ebenfalls mit einer höheren Form der seelischen Beschaffenheit ausgestattet zu sein. Das freimaurerische Erziehungssystem konnte somit indirekt zu einer deutlichen Verhärtung der Fronten zwischen Adel und Bürgertum beitragen. Als Abschluss der Untersuchungen zur Düsseldorfer Adelsloge La Parfaite Amitié soll daher auf ihre Auflösung und den Werdegang einiger Brüder in den Folgejahren eingegangen sowie die Krise dieser aristokratischen Form der Freimaurerei in der Inkubationsphase der Französischen Revolution besprochen werden.

168 Vgl. zum Kriterium der "Landsmannschaft« sowie zur "Verwandtschaft« Ders., Freunde und Kreaturen (wie Anm. 167, Kap. V).

169 Siehe Ders., Freunde und Kreaturen (wie Anm. 167, Kap. V). 


\section{V.6 Die Auflösung der Parfaite Amitié und der Verbleib ihrer adligen Mitglieder}

Wann die Düsseldorfer Adelsloge La Parfaite Amitié ihre Arbeit einstellte, kann nicht mit Sicherheit gesagt werden. August Pauls verwies bereits darauf, dass die niederländische Großloge im Jahr 1771 den Übergang der von ihr konstituierten Ateliers unter die Aufsicht der englischen Großloge verhandelte und die Parfaite Amitié in diesem Zuge aus ihrem Verband ausgeschieden und unter die englische Direktion geraten sein könnte. ${ }^{170}$ Aufgrund einer Liste, die sich in einem Brief des Gelehrten Rijklof Michael van Goens (1748-1810) an den Grafen von Rechteren, Meister vom Stuhl der Loge L'Indissoluble im Haag, findet, kann nun bestätigt werden, dass die Parfaite Amitié zumindest bis in das Jahr 1771 noch in Kontakt mit der niederländischen Großloge gestanden haben muss. Hierfür spricht auch, dass Goens in persönlichem Kontakt mit Jacobi stand, was seine Informationen als zuverlässig erscheinen lässt. ${ }^{171}$

In der besagten Liste mit dem Titel "Liste de toutes les Loges legitimement constituées dependant à la Grande Maitrise en Hollande, suivant leur état en 1771« wird für Düsseldorf neben der Loge Paix du Bas-Rhin die Parfaite Amitié angeführt. ${ }^{172}$ Als Meister vom Stuhl der Parfaite Amitié wird der »Baron de Hompesch" sowie als Sekretär »Baron de Bentinck« erwähnt. Auch eine von Beaurepaire in einem anderen Zusammenhang zitierte Anmerkung eines Mitglieds der englischen Großloge aus dem Jahr 1773 macht ein Fortbestehen der Loge nach 1771 als selbstständige Provinzialloge unter englischer Aufsicht plausibel. ${ }^{173}$

Trotz dieses offenbaren Fortbestands der Loge über das Jahr 1769 hinaus gibt es gute Gründe für die Annahme, dass die Loge sich zur Mitte der 1770er Jahre auflöste. Die genauen Gründe für die Auflösung der Loge bleiben weiterhin unklar. Neben der immer kritischer werdenden Stellung des Kurfürsten Karl Theodor zur Freimaurerei in den 1770er Jahren sollte jedoch beachtet werden, dass sich die

170 Siehe hierzu die Angaben bei Pauls, Düsseldorfer Freimaurerei (wie Anm. 2, Kap. V), 68f. In den Abschriften der ursprünglichen Logendokumente, die heute im GStA PK lagern, findet sich als letzte Abschrift Pauls ein Brief der Parfaite Amitié an die niederländische Großloge, der auf Dezember 1769 datiert. Unterzeichnender Sekretär ist Bentinck. Vgl. hierzu Düsseldorfer Freimaurerei im 18. Jh. (wie Anm. 2, Kap. V), fol. 93f.

171 Zum Kontakt Goens zu Jacobi vgl. etwa Jan U. Terpstra, Eine niederländische Woldemar-Übersetzung. Ein Beitrag zum Problem der Rezeption Friedrich Heinrich Jacobis in den Niederlanden, in: Klaus Hammacher (Hg.), Friedrich Heinrich Jacobi. Philosoph und Literat der Goethezeit (Studien zur Philosophie und Literatur des 19. Jh.s, 11), Frankfurt a.M. 1971, 301-318, hier 302.

172 Siehe den Abdruck dieser Liste in W. H. de Beaufort, Brief van V. Goens aan den Graaf van Rechteren, in: Bijdragen en mededeelingen van het Historisch Genootschap, Tiende Deel, Utrecht 1887, 458-461, hier 461, http://www.dbnl.org/tekst/_bij005188701_01/_bij005188701_01_0016.php (Zugriff vom 25.05.2014).

173 Siehe Pierre-Yves Beaurepaire, Quand les francs-maçons signent des traités diplomatiques: circulations et échanges maçonniques entre France et Angleterre (1765-1775), in: Ann Thomson [u.a.] (Hg.), Cultural Transfers. France and Britain in the long eighteenth century, London/Paris 2010, 71-84, hier 76. Die Datierung des Dokuments auf den 18.06.1773 findet sich bei Beaurepaire in Anm. 11 . 
Residenzstadt des Kurfürsten von Mannheim nach München verlagerte und Düsseldorf sowie die rheinischen Gebiete des Kurfürstentums mehr und mehr ins Abseits gerieten. ${ }^{174}$ Die bereits in den 1760 er Jahren durch die Mitglieder der Parfaite Amitié gegenüber der niederländischen Großloge als Entschuldigung für Verzögerungen im schriftlichen bzw. persönlichen Informationsaustausch geäußerten zeitlichen Engpässe aufgrund der zahlreichen Verpflichtungen durch landesherrliche Ämter ${ }^{175}$ dürften sich aufgrund der Verlegung des Hofes nach München entschieden vergrößert haben. Reichsgraf Johann Ludwig Franz von Goltstein war bereits im September 1776 verstorben. Zudem war der führende Kopf der Parfaite Amitié, der Freiherr Franz Karl von Hompesch, spätestens 1779 durch sein Amt als bayerischer Finanzminister völlig nach München gezogen worden. Die Auflösung manifestiert sich - wie bereits Pauls erwähnte - in den Quellen durch das Auftauchen einiger Mitglieder der Parfaite Amitié in den Logenmatrikeln anderer Logen, worauf noch näher einzugehen sein wird. Es ist hier zunächst danach zu fragen, welchen Stellenwert der »Blutsideologie» die ehemaligen Mitglieder der Parfaite Amité außerhalb ihres exklusiven Zirkels erwarten konnten.

Innerhalb der `aristokratischen Sphäre` der Freimaurerei zählte die gedanklich mit der Qualität des Blutes verbundene Ehre der profanen Welt als Maßstab fort. So stellte etwa auch der bereits erwähnte Baron Tschudi in seinem »Étoile flammboyante« ein solches Verständnis der Freimaurerei, das die konservative Idee der »Blutsideologie« nicht ad acta legte, gegenüber einem adligen Bruder heraus:

L'égalité établie entre nous, ce niveau équitable qui place l'homme de Cour à côté du simple Citoyen, le Général sur la même ligne que le patriote ignoré, le Magistrat d'un ordre supérieur sans aucune distinction près du modeste cultivateur ou de l'artisan honnête, les rend membres d'un même corps, unis pour le même but, occupés du même objet, ils sont assujettis aux mêmes regles, le mêrite seul peut introduire ou autoriser des différences. Ne pensez pas, mon cher Frere, que nous ignorions les égards qu'un sang illustre détermine en général dans la société, ou que rebelles aux usages reçus, les Maçons s'écartent jamais de la légitime portion de déférence due à ceux qui, comme vous, portent un nom respectable \& respecté: plus ils sembleront en oublier le prestige, plus nous affecterons de nous en souvenir. ${ }^{176}$

Die Wahrheit dieser Äußerungen wurde für ihren Verfasser durch die freimaurerische Geschichtsschreibung bestätigt, die vor allem in den Hochgraden die Kon-

174 Für die kritischer werdende Haltung des Kurfürsten spricht etwa die Ablehnung der Neugründung einer Loge in Mannheim im Jahre 1776, aber auch das 1784 im Zuge der Wirren um den Illuminatenorden vorgenommene Verbot aller Geheimgesellschaften. Vgl. hierzu Reinhard Graf von Neipperg, Kaiser und Schwäbischer Kreis (1714-1733). Ein Beitrag zu Reichsverfassung, Kreisgeschichte und kaiserlicher Reichspolitik am Anfang des 18. Jh.s (Veröffentlichungen der Kommission für Geschichtliche Landeskunde in Baden-Württemberg, Reihe B, 119), Stuttgart 1991, 78.

175 Vgl. Pauls, Düsseldorfer Freimaurerei (wie Anm. 2, Kap. V), $52 f$.

176 Tschudi, L'étoile flamboyante (wie Anm. 64, Kap. V), $49 f$. 
tinuität mit den alten Kreuzrittern hochhalten und eine direkte Verbindungslinie zu den Adelsfamilien schlagen sollte. ${ }^{177}$

Es ist jedoch ebendiese Geschichtsschreibung, die im letzten Drittel des 18. Jahrhunderts gemeinsam mit zahlreichen weiteren Herausforderungen die aristokratischen Formen der Hochgradfreimaurerei mehr und mehr in Bedrängnis brachte. Verfolgt man in dieser Hinsicht den Weg einiger Gründungsmitglieder nach Erlöschen der Parfaite Amitié zur Mitte der 1770er Jahre, so wird ersichtlich, dass eine aristokratische Auffassung der Freimaurerei und die Nähe zu alchemistisch laborierenden Hochgradsystemen noch in diesen Krisenjahren zum Ende des Jahrhunderts für sie in Bezug auf ihrer freimaurerische Vergesellschaftung eine Bedeutung gehabt haben muss. Hierauf verweist bereits die Mitgliedschaft des kurpfälzischen Rittmeisters Karl von Lemmen ${ }^{178}$ sowie Bernhard von Longuevals in der 1778 durch den kurkölnischen Hofrat Peter Joseph von Buschmann gegründeten Kölner Strikten Observanz-Loge Maximilian zu den drei Lilien. ${ }^{179}$ Der Meister vom Stuhl dieser Loge war der ebenfalls zuvor der Parfaite Amitié angehörende Wilhelm von Lemmen. ${ }^{180} \mathrm{Ihr}$ gehörten außerdem noch weitere Mitglieder des Adels, zum Teil aus fürstlichen und gräflichen Häusern an. ${ }^{181}$

177 Dies wird in der Folge des oben angeführten Zitats deutlich, wenn es heißt: »La partie de notre histoire que je puis vous communiquer à present, vous prouvera cette vérité; vous y verrez par là la vénération que l'Ordre a pour les personnages illustres qui sont consacrés dans ses fastes, que nous savons apprécier ce qui mérite de l'être, \& vous conviendrez peut-être avec moi, que le nom du premier baron chrétien, dont le vôtre perpétuera la gloire, n’est pas déplacé dans la liste brillante de ceux dont les Croisades font mention. C'est à cette époque précise qu'il faut fixer celle de notre établissement en Europe, \&c.« Siehe zu diesem Zitat Ders., L'étoile flamboyante (wie Anm. 64, Kap. V), 50f.

178 Karl von Lemmen wurde bereits auf dem in den Beständen des GON enthaltenen Gründungspatent der Parfaite Amitié mit dem Grad eines Chevalier Kadosh angeführt, dessen Ritual das Zusammengehen der Freimaurerei mit den Tempelrittern konstruiert. Der Ritualtext dieses Grades aus dem Jahr 1764 findet sich bei Mollier. In der Einleitung dieses Textes wird der Rezipient auch auf mehrere zeitgenössische Geschichtsdarstellungen zum Thema der Kreuzzüge hingewiesen. Vgl. hierzu Mollier, La chevalerie maçonnique (wie Anm. 31, Kap. I), 191-217. Zu Karl von Lemmen als Inhaber des Grades eines Chevalier Kadosh siehe auch Pauls, Düsseldorfer Freimaurerei (wie Anm. 2, Kap. V), 40.

179 Zur Mitgliedschaft Karl von Lemmens sowie Bernhard de Longuevals in dieser Loge vgl. die Angaben bei Pauls, Düsseldorfer Freimaurerei (wie Anm. 2, Kap. V), 42. Zu weiteren Mitteilungen über diese Loge siehe auch Friedrich Mahlert, Nachrichten über die Loge »Maximilian zu den drei Lilien« im Or. Cöln 1778-1784, in: Bundesblatt: Organ der Großen National-Mutterloge »Zu den Drei Weltkugeln« 15 (1915), 97-103; Winfried Dotzauer, Die Mitglieder der Kölner Freimaurerloge der Loge »Le Secret des trois Rois « vom Ende des alten Reiches bis zu den Freiheitskriegen: Ein Beitrag zur Entwicklung der städtischen Gesellschaft vom Ancien régime zum Zeitalter Napoleons, in: Jahrbuch des kölnischen Geschichtsvereins 44 (1973), 123-231, hier 127, http://www. ub.uni-koeln.de/cdm4/document.php?CISOROOT=/_RHPER\&CISOPTR=17662\&REC=14 (Zugriff vom 25.05.2014).

180 Vgl. die Angabe bei Pauls, Düsseldorfer Freimaurerei (wie Anm. 2, Kap. V), 55.

181 Siehe hierzu die Angaben bei Joseph Hansen, Quellen zur Geschichte des Rheinlandes im Zeitalter der Französischen Revolution 1780-1801, Bd. 1, Bonn 1931, 60-62. Hansen führt etwa als Mitglieder den Vizegouverneur der Stadt Bonn, Oberst Klemens August von Kleist, den früheren General in spanischen Diensten, Prinzen Emanuel zu Salm-Salm, den Domherren zu Köln, Straßburg und Salzburg, Fürst Johann Christian von Hohenlohe zu Bartenstein sowie zwei Gra- 
Um diesen Übergang richtig einordnen zu können, ist es wichtig, sich die Vorgänge um die Gründung der Loge Maximilian zu den drei Lilien (1778-1786?) zu verdeutlichen, die sich in ihrem Namen auf den neuen Kölner Kurfürsten Maximilian Friedrich von Königsegg-Rothenfels bezog. ${ }^{182}$ Wilhelm von Lemmen hatte vor der Gründung der Lilien-Loge das Amt des Redners in der im Ancien Régime bereits aristokratisch geprägten Kölner Loge Le Secret de trois Rois bekleidet. ${ }^{183}$ Auch für die Secret de trois Rois lassen sich enge Verbindungen adliger Domherren nach Straßburg nachweisen, ${ }^{184}$ sodass das in der Parfaite Amitié anzutreffende aristokratisch-freimaurerische Milieu Straßburger Prägung auch in der Dreikönigs-Loge nicht unbekannt war. Die Kölner Loge, die seit 1775 unter der Aufsicht des französischen GOF arbeitete, ${ }^{185}$ hatte sich im Jahr 1778 gespalten, da ihr Meister vom Stuhl, der später auch zu einem Rosenkreuzerzirkel zählende Peter Joseph von Buschmann, sie gegen den Widerstand einiger Mitglieder in das System der Strikten Observanz überführen wollte. ${ }^{186}$

Die Strikte Observanz oder der »Hohe Orden vom Heiligen Tempel zu Jerusalem« hatte sich ab den 1750er Jahren zunächst unter maßgeblicher Leitung des Freiherrn Karl Gotthelf von Hund und Altengrotkaus (1722-1776) herausgebildet und stellte schließlich die »bedeutendste und wirkungsvollste freimaurerische Organisation im Deutschland des 18. Jahrhunderts ${ }^{187}$ dar. Dies unter anderem

fen von Königseck an. Prinz Emanuel zu Salm-Salm nimmt später auch an den Konventen der Philaleten in Paris teil.

182 Siehe Lennhoff/Posner/Binder (Hg.), Internationales Freimaurer-Lexikon (wie Anm. 18, Kap. I), 470.

183 Vgl. die Angaben bei Pauls, Düsseldorfer Freimaurerei (wie Anm. 2, Kap. V), 55; Lennhoff/Posner/Binder (Hg.), Internationales Freimaurer-Lexikon (wie Anm. 18, Kap. I), 470. Wie Lennhoff/ Posner/Binder bemerken, waren unter den Mitgliedern der Loge auch Vertreter der Familie Königsegg. Zur aristokratischen Prägung dieser Loge vgl. die Aussage bei Dotzauer, Freimaurergesellschaften am Rhein (wie Anm. 56, Kap. I), 95.

184 Vgl. hierzu die prosopographischen Angaben bei Dotzauer, Die Mitglieder der Kölner Freimaurerloge (wie Anm. 179, Kap. V). Dotzauer verweist ausdrücklich darauf, dass die Mitgliedschaft adliger Domherren in einer Freimaurerloge sehr häufig war. Dieser Umstand kann wohl nur mit der Suche nach einer Urreligion bzw. der Hoffnung auf ein daraus resultierendes besseres Verständnis von der christlichen Religion gedeutet werden. Siehe Ders., Die Mitglieder der Kölner Freimaurerloge, 134-137, insb. 137.

185 Vgl. hierzu die Angaben bei Lennhoff/Posner/Binder (Hg.), Internationales Freimaurer-Lexikon (wie Anm. 18, Kap. I), 470.

186 Vgl. hierzu Dotzauer, Die Mitglieder der Kölner Freimaurerloge (wie Anm. 179, Kap. V), hier 127f.

187 Hermann Schüttler, Geschichte, Organisation und Ideologie der Strikten Observanz, München 1987, 1. Zu den maßgeblichen Studien Schüttlers, die den aktuellen Forschungsstand zum Thema repräsentieren, siehe auch Hermann Schüttler, Zum Verhältnis von Ideologie, Organisation und Auswanderungsplänen im System der Strikten Observanz, in: Monika Neugebauer-Wölk/ Richard Saage (Hg.), Die Politisierung des Utopischen im 18. Jh. Vom utopischen Systementwurf zum Zeitalter der Revolution (Hallesche Beiträge zur Europäischen Aufklärung, 4), Tübingen 1996, 143-168; Hermann Schüttler, Zwei freimaurerische Geheimgesellschaften des 18. Jh.s im Vergleich: Strikte Observanz und Illuminatenorden, in: Erich Donnert (Hg.), Europa in der Frühen Neuzeit: Festschrift für Günter Mühlpfordt, Bd. 4: Deutsche Aufklärung, Köln/Weimar 1997, 521-544. Daneben sind auch in den Schriften René Le Forestiers sowie Christian M. Baumgartners nützliche Hinweise enthalten. Siehe René Le Forestier, Die templerische und okkultistische 
auch deshalb, weil ihr mehrere Vertreter regierender Fürstenhäuser Deutschlands angehörten, namentlich etwa ihr späterer Großmeister Herzog Ferdinand von Braunschweig-Wolffenbüttel (1721-1792) und sein Stellvertreter Prinz Karl von Hessen-Kassel (1744-1836). Sie wurde nachträglich aufgrund ihrer stark hierarchisch geprägten und auf dem Prinzip des absoluten Gehorsams gegen die Oberen beruhenden Struktur als System der »Strikten Observanz « bezeichnet ${ }^{188}$ und verfolgte das Ziel, die Organisation des Tempelherrenordens wiederaufzurichten und den zeitgenössischen Verhältnissen anzupassen. ${ }^{189}$

Sie reaktivierte und aktualisierte somit tatsächliche Bestandteile des »kulturellen Gedächtnisses« einer längst vergangenen Phase adligen Rittertums, reicherte sie aber darüber hinaus vor allem über die freimaurerische Templerlegende mit mythischem Gehalt an. Die adligen Mitglieder der Strikten Observanz konnten etwa im sogenannten »Inneren Orden « zu Rittertiteln gelangen und erhielten die Führung über die Mitglieder aus dem dritten Stand, die als "Armige« ohne Ritterschlag aufgenommen wurden. ${ }^{190}$ Wie Hermann Schüttler zeigen konnte, wurden die in den Rittergraden Aufgenommenen in das letztendliche Ziel der Strikten Observanz eingeweiht, das adelsreformistische Züge trug: Der Operationsplan sah die Errichtung eines demokratisch-aristokratischen Adelsstaats in Nordamerika (Labrador) bzw. Russland (Saratow) vor, fern von dem Zugriff bereits existierender Herrschaften. ${ }^{191}$ Wie Schüttler herausstellte, war die Organisationsform der Freimaurerei in der adlig dominierten Strikten Observanz für derlei letztlich Utopie bleibende Pläne nur ein Mittel zum Zweck. ${ }^{192}$

Maurerei im 18. und 19. Jh., Bd. 1: Strikte Observanz, Leimen 1987; Christian M. Baumgartner, Die Strikte Observanz. Der hohe Orden vom heiligen Tempel zu Jerusalem. Ein vergangenes templerisches und freimaurerisches System. 1751-1782. Aufstieg und Fall, Jarplund/Weding 2007.

188 Der Rezipient schwor, wie Schüttler erwähnt, in einer Eidesformel bei seiner Aufnahme etwa den Logen »later Observanz« ab. Schüttler, Geschichte, Organisation und Ideologie (wie Anm. 187, Kap. V), 21.

189 Vgl. hierzu die von Winfried Dotzauer edierte Quelle »Die wahre Idee, welche man sich von der Natur und Endzweck des O[rden]s nach der Lage der Zeiten, worinnen wir leben, machet [vor 1772, Strikte Observanz] « in: Dotzauer, Quellen zur Geschichte der deutschen Freimaurerei (wie Anm. 79, Kap. IV), 59-64.

190 Siehe hierzu die Ausführungen bei Klaus C. Feddersen, Rituale des hohen Ordens zum heiligen Tempel zu Jerusalem, auch Strikte Observanz genannt, weltlicher Zweig nebst Ordensregeln und vielen Abbildungen aus dem Jahr 1764, Flensburg 1999, 29; Gerhard Müller, Von der arkanen Sozietät zum bürgerlichen Verein. Die Freimaurerei in Weimar-Jena als Medium bürgerlicher Wertevermittlung (1744-1844), in: Hans-Werner Hand/Dieter Hein (Hg.), Bürgerliche Werte um 1800: Entwurf - Vermittlung - Rezeption, Köln 2005, 167-192, hier 173.

191 Vgl. zur Geschichte des Ordens und seiner Organisation Schüttler, Zum Verhältnis von Ideologie, Organisation und Auswanderungsplänen (wie Anm. 187, Kap. V), hier 159-168; Schüttler, Geschichte, Organisation und Ideologie (wie Anm. 187, Kap. V), 20-26.

192 Schüttler gibt das Verhältnis von Adligen zu Vertretern des dritten Standes mit einem Prozentanteil von 56\% (Adel) zu 44\% (dritter Stand) an. Insgesamt gehörten demnach 41 Personen aus regierenden Häusern, 227 Personen des höheren Adels und 496 Personen des niederen Adels der Strikten Observanz an. Vgl. hierzu die Angaben bei Schüttler, Zum Verhältnis von Ideologie, Organisation und Auswanderungsplänen (wie Anm. 187, Kap. V), hier 147 sowie 168. 
Ab 1776 existierte auch in Bonn eine Strikte Observanz-Loge, die durch den aus einem westfälischen Adelsgeschlecht stammenden Freiherrn Franz Wilhelm von Spiegel zum Diesenberg geleitet und durch den Kurfürsten Maximilian von Königsegg-Rothenfels offenbar gefördert wurde. Dieser schlossen sich unter anderem der Hofratspräsident des kurkölnischen Hofes Baron Otto von Gymnich sowie der kurfürstliche Oberstallmeister Friedrich Karl von Forstmeister (seit 1767 in den Listen der Düsseldorfer Loge angeführt) an. ${ }^{193}$ Auch der kurfürstliche Geheimrat Joseph von Leerodt war Mitglied der Bonner Loge. Er war zwar kein ehemaliges Mitglied der Parfaite Amitié, entstammte aber einem rheinischen Adelsgeschlecht. In späterer Zeit besuchte er bis zum Jahr 1801 mit seinen beiden Söhnen die Kölner Dreikönigs-Loge. ${ }^{194}$

Der Übergang einiger Brüder aus der Parfaite Amitié in die adlig dominierten Strikten Observanz-Logen des Rheinlands zeigt, dass sie auch weiterhin der aristokratischen Auffassung der Freimaurerei und der Templerlegende zugeneigt waren. Obgleich der Gründer des Ordens von Hund alchemistischen und okkultistischen Lehren kritisch gegenüberstand, sickerten derartige Ansichten doch in den 1760er Jahren in den Orden ein, der schließlich wohl auch einen eigenen »Alchemistengrad " kannte, der Aufnahmewillige in ihren naturwissenschaftlichen Kenntnissen prüfte. ${ }^{195}$ Es verwundert insofern nicht, dass sich etwa zwischen den vornehmlich adligen Mitgliedern der Lilien-Loge von den adligen Brüdern protegierte und besonders naturwissenschaftlich interessierte bürgerliche Mitglieder finden, wie etwa der Kölner Verleger Louis-François Mettra, Mitglied der Münchener Akademie der Wissenschaften sowie der Straßburger Société des Philanthropes. ${ }^{196}$ Die genannten ehemaligen Brüder der Parfaite Amitié blieben somit auch in dieser Hinsicht in einem Umfeld, in dem das Weltbild hermetischalchemistischer Lehren eine Rolle spielte und mit Bestandteilen des »kulturellen Gedächtnisses« des Adels wie der »Blutsideologie« in Zusammenhang gebracht werden konnte.

193 Zur Mitgliedschaft in der Parfaite Amitié siehe die Logenlisten in: GON, 2336-10, Mitgliederlisten Loge La Parfaite Amitié, Düsseldorf, 1765-1769. Zur Mitgliedschaft in der Bonner Strikten Observanz-Loge siehe Hansen, Quellen zur Geschichte des Rheinlandes (wie Anm. 181, Kap. V), 60-62; Winfried Dotzauer, Bonner aufgeklärte Gesellschaften und geheime Sozietäten bis zum Jahr 1815 unter besonderer Berücksichtigung des Mitgliederbestandes der Freimaurerloge »Frères courageux « in der napoleonischen Zeit, in: Bonner Geschichtsblätter 24 (1971), 78-142, hier 80-82; Ders., Freimaurergesellschaften am Rhein (wie Anm. 56, Kap. I), 83f.

194 Siehe zu sämtlichen Angaben dieses Abschnitts bezüglich der Person Joseph von Leerodts Anm. 7 bei Hansen, Quellen zur Geschichte des Rheinlandes (wie Anm. 181, Kap. V), 60.

195 Vgl. hierzu die Ausführungen und Abbildungen Christan M. Baumgartners zum sogenannten »Adeptengrad«: Feddersen, Rituale des hohen Ordens zum heiligen Tempel (wie Anm. 190, Kap. V), 29. Siehe ferner auch Baumgartner, Strikte Observanz (wie Anm. 187, Kap. V), 148-150. $\mathrm{Zu}$ seiner Person vgl. die Biographie von: Karin Angelike, Louis-François Mettra. Ein französischer Zeitungsverleger in Köln (1770-1800) (Rheinisches Archiv, 145), Diss., Köln/Weimar/Wien 2002, insb. 75-93. Angelike zeigt auch hier Tendenzen auf, die ein geschäftliches Interesse Mettras an der Verbindung zu adligen Brüdern innerhalb der Freimaurerei nahelegen. 


\section{V.7 Der "Werth des Lebens» - Die Krise der aristokratischen Freimaurerei zum Ende des Ancien Régime}

Bereits mit dem großen Freimaurerkonvent von Wilhelmsbad im Jahr 1782 war eine kritische Absage weiter Teile der Freimaurerei in Bezug auf die templerischen Theorien erfolgt, die letztendlich die Destruktion des Ordens der Strikten Observanz nach sich zog. ${ }^{197}$ Inhärent konnte die $>$ Herrschaft über die Gemüter ${ }^{198}$ spätestens jetzt - und gravierender noch mit der Entlarvung des Ingolstädter Professors Adam Weishaupt als Ordensoberhaupt der Illuminaten - als eine nicht mehr explizit adlig besetzte Domäne gewertet werden.

Besonders deutlich wird dieser sich zum Ende des 18. Jahrhunderts vollziehende Wandel in einer »Über den Werth des Lebens« betitelten Logenrede zum Tod des Herzogs Leopold Maximilian von Braunschweig-Lüneburg aus dem Jahr 1785. Der nicht genannte Verfasser war davon überzeugt, dass »der ganze zahlreiche Haufen der Thoren aller Classen, welche auf Geburt, Stand, Vermögen, Schönheit, Puz und ähnliche Dinge einen übertriebenen Werth legen, gewiss mehr Mitleyd und Belehrung, als Hass oder Spot [sic!] « ${ }^{199}$ verdienten, und sah das Ziel der Freimaurerei darin

[...] den Bau unserer eigenen sowohl, als der allgemeinen Menschen Glückseligkeit jenem erhabenen Plane anzupassen, den der ewige Baumeister im Weltall ausgeführet hat: da wir wissen, dass jedes Geschlecht der Dinge, ja jedes einzelne Wesen, einen von der Meinung des Menschen ganz unabhängigen Werth in der Reihe der vorhandenen Dinge habe, welcher darauf beruht, wieviel jedes zur Vollkommenheit des Ganzen auf seiner Stelle beitragen solle, und wie viel es würklich dazu beiträgt $[\ldots] .{ }^{200}$

Den Wert eines Menschen erkennen konnte dabei, laut dem Verfasser, wohlgemerkt nur derjenige, der sich selbst und die Natur bereits in den »blauen Graden« der Freimaurerei studiert hatte:

197 Siehe hierzu vor allem René Le Forestier, Die templerische und okkultistische Freimaurerei im 18. und 19. Jh., Bd. 3: Das System von Wilhelmsbad, Leimen 1990; Ludwig Hammermayer, Der Wilhelmsbader Freimaurer-Konvent von 1782. Ein Höhe- und Wendepunkt in der Geschichte der deutschen und europäischen Geheimgesellschaften (Wolfenbütteler Studien zur Aufklärung, V/2), Heidelberg 1980.

198 Jakob Friedrich Lamprecht, Rede, welche am Johannisfeste in der großen Loge der Freimäurer zu Berlin gehalten worden (wie Anm. 85, Kap. IV).

199 Rede »Über den Werth des Lebens bei Gelegenheit des Todes des Hochwürdigsten B $\therefore$ Leopold Maximilian Herzog von Braunschweig Lünebourg«, o.O., 1785, in: BnF, FM1 289 (MF 33610), fol. 337. Das Entstehungsjahr der Rede wurde aus den Lebensdaten des Herzogs Leopold von Braunschweig-Lüneburg (1752-1785) gefolgert.

200 Rede »Über den Werth des Lebens bei Gelegenheit des Todes des Hochwürdigsten B $\therefore$ Leopold Maximilian Herzog von Braunschweig Lünebourg", o.O., 1785, in: BnF, FM1 289 (MF 33610), fol. 337. 
Da nun die erste Stufe unserer Königlichen Kunst Selbsterkenntnis ist, so werden schon unsere sehr ehrwürdigen Brüder Lehrlinge und Gesellen, durch Vergleichung des Menschen mit den leblosen Mineralien mit den organisierten Pflanzen, und mit den empfinden der Thieren gefunden haben, dass der Mensch über das Thier, wenigstens eben soweit, als das Thier über die Pflanze erhaben sey. Denn wenn das Mineralreich zur Summe des vorhandenen Guten und Schönen bloß Körperlichen Stoff liefert; wenn das Pflanzenreich durch seine bewunderungswürdige Organisation den Stoff nach unzähligen Schönen regelmäßigen Formen umbildet; Wenn das Thierreich mit Empfindung genießt; so wirckt der Mensch mit Bewusstseyn und Vorsatz zur Vervollkommnung der Dinge und zur Vermehrung des Guten und Schönen in der Welt; indem seine körperlichen organischen und thierischen Kräfte durch höhere geistige Fähigkeiten unterstützt werden. Er baut absichtlich am Wohl der Schöpfung in dem Wirckungskreise, den ihm der große Baumeister angewiesen, und nach demselben Plane, den Dieser im Weltall befolgt; das ist: er arbeitet unaufhörlich daran, sich selbst und alles worauf er wircket, immer besser und vollkommener zu machen. Dies ist der Werth des Menschen Geschlechts in der Reihe der Dinge, und zugleich der einzige Maasstab, nach welchem der Werth einzler Menschen untereinander richtig bestimmt werden kann. ${ }^{201}$

Hinter diesem durch den zeitgenössischen Verfasser skizzierten Bewertungsschema des Menschen sind bereits Anleihen bei den taxonomischen Bestimmungsverfahren eines Linné zu erkennen. Wie im weiteren Verlauf der Untersuchungen gezeigt werden soll, sollte dieser Zusammenhang zwischen modernen naturwissenschaftlichen Verfahren und freimaurerischer Vergesellschaftung sich bis in das 19. Jahrhundert hinein halten. In diesem Zuge ist zu beachten, dass der Wert des Menschen hierbei aus seinem jeweils aktuellen, also nicht mehr auf den Taten der Vorfahren beruhenden Verdienst für die Allgemeinheit resultieren sollte - neben einer offenbar immer noch als vorhanden und in unterschiedlichem Maße bei den einzelnen Menschen vorliegend angesehenen inneren Anlage zur Erkenntnis eines göttlichen Planes. Auch im arkanen Raum schritt die Auflösung des Bedeutungsgehalts der adligen »Blutsideologie» gegen Ende des 18. Jahrhunderts mehr und mehr voran.

Diese Auflösung war dabei auch durch den interpretativen Spielraum ermöglicht worden, den die verschiedenen zeitgenössischen Theorien um die Entstehung der menschlichen "Rassen« und insbesondere die Lehre der Metempsychose den verschiedenen, auch in den Logen verkehrenden Eliten in Hinblick auf die Begründung einer gesellschaftlichen Vorrangstellung ließen. Anders gelagerte Interpretationen negierten zwar nicht die göttliche Stufenleiter, stellten aber dennoch den Stellenwert adliger Geburt nachhaltig in Zweifel. Der Verfasser der Rede

201 Rede »Über den Werth des Lebens bei Gelegenheit des Todes des Hochwürdigsten B. Leopold Maximilian Herzog von Braunschweig Lünebourg«, o.O., 1785, in: BnF, FM1 289 (MF 33610), fol. 338 . 
wollte aus diesem Grund »nicht auseinander setzen, wie niedrig auf dieser Stufenleiter manches gekrönte und berühmte Haupt und wie hoch dagegen mancher unbekannte und dürftige Erdensohn zu stehen käme: Wenn Gott oder die Vernunft die Rangordnung in den Staaten bestimmen sollte. ${ }^{202}$ Im Hintergrund dieser Ausweitung stand trotz der offenbaren Ohnmacht Gottes immer noch - und dies ist hier entscheidend - die Lehre der Metempsychose:

Das Leben ist nichts anders, als die Zahl der Stunden, Tage und Jahre, die uns die Göttliche Vorsehung bestimmt, unser eben beschriebenes menschliches Geschäft auf der Erde zu treiben, das ist, Vollkommenheit in und um uns zu stiften, auf dem Platze, wo es dem grossen Baumeister gefällt, uns ans Werck zu stellen. Man sollte hier Leben genauer von Daseyn oder Existenz unterscheiden, als es gewöhnlich geschieht. Was ich eben gesagt habe ist eigentlich die Absicht unseres Daseyns unter den erschaffenen Dingen. Dieses begreift die ganze Fortdauer unseres Wesens von der ersten Entwicklung des Keims an bis in die unbegränzte Ewigkeit hinaus. Dagegen begreift das Leben blos die Zeit, die uns zu Erfüllung jener Absicht hier auf der Erde angewiesen ist. Der Todt macht unsrem Leben ein Ende, aber nicht unserm Daseyn; die-

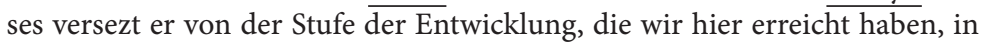
ein anders Leben, das ist, an eine andere Stelle in dem Weltgebäude, wo wir die hier angefangene Arbeit weiter fortsetzen. [...] Die Natur und ihr weiser Meister fordern von einem jeden Wesen, dass es in der jedes maligen Lage, in der es sich befindet, die Absicht seines Daseyns so gut erfülle, als es nach seinen Kräften und nach Beschaffenheit der Umstände möglich ist. ${ }^{203}$

Dass eine solche Lebensweise auch bei einem Adligen anzutreffen war, stand außer Zweifel und war für den Verfasser durch das Beispiel des verstorbenen Herzogs bewiesen. ${ }^{204}$

Die Frage um das Seelenheil und mit ihr um die Metempsychose - dies wird hier deutlich - waren damit verständlicherweise keinesfalls nach 1782 ad acta gelegt. Sie war nach wie vor von Interesse, da einige Zeitgenossen immer noch daran glaubten, sie durch die eine (Geheimwissenschaften) oder andere (moderne Naturwissenschaften) Weise klären zu können. Etwa zeitgleich zum Wilhelmsbader Konvent berief so etwa das Hochgradsystem der Philaleten ${ }^{205}$ im Jahr 1785 in Paris einen Konvent ein, der nach eigener Aussage »das eigentliche Wesen der

202 Rede »Über den Werth des Lebens bei Gelegenheit des Todes des Hochwürdigsten B $\therefore$ Leopold Maximilian Herzog von Braunschweig Lünebourg«, o.O., 1785, in: BnF, FM1 289 (MF 33610), fol. 339.

203 Rede »Über den Werth des Lebens bei Gelegenheit des Todes des Hochwürdigsten B $\therefore$ Leopold Maximilian Herzog von Braunschweig Lünebourg«, o.O., 1785, in: BnF, FM1 289 (MF 33610), fol. 339f.

204 Rede »Über den Werth des Lebens bei Gelegenheit des Todes des Hochwürdigsten B $\therefore$ Leopold Maximilian Herzog von Braunschweig Lünebourg«, o.O., 1785, in: BnF, FM1 289 (MF 33610), fol. 341 .

205 Siehe zum Hochgradsystem der Philaleten auch Lennhoff/Posner/Binder (Hg.), Internationales Freimaurer-Lexikon (wie Anm. 18, Kap. I), 650. 
freimaurerischen Wissenschaften $\aleph^{206} \mathrm{zu}$ definieren suchte. Nach René Le Forestier standen hierbei auch die Fragen nach der »Immaterialität und Unsterblichkeit der Seele« sowie nach der »Realität von Lohn und Strafe >in einem anderen Leben«" im Mittelpunkt des Konvents, dessen Initiatoren von den Geheimwissenschaften eine Lösung dieser Fragen erhofften. ${ }^{207}$

Die Geschichte der jeweiligen Konvente braucht hier nicht ausführlich dargestellt zu werden. Ludwig Hammermayer konstatiert für den großen Wilhelmsbader Konvent »auf ihrem >rechten`, d.h. hermetisch-alchymistischen und christlich-kabbalistischen Flügel [...] die sog. Neuen Gold-und Rosenkreuzer sowie die Asiatischen Brüder; auf dem >linken`, dem rationalistischen bis radikal-aufklärerischen Flügel [...] « den Illuminatenorden. ${ }^{208}$ Die Übergänge zwischen diesen einzelnen »esoterisch-ideologischen Strömungen" - hierauf verweist Hammermayer nachdrücklich - waren dabei fließend. ${ }^{209}$

Es hat in Bezug auf die Geheimgesellschaften des Ancien Régime den Anschein, als habe gerade die vom dritten Stand dominierte ${ }^{210}$ rationalistische Strömung um den Illuminatenorden den rheinischen Adel der Gründergeneration der Parfaite Amitié nicht mehr erreicht. Es darf vermutet werden, dass dies auch auf einer dem Rationalismus entspringenden skeptischen Einschätzung der alchemistischen Lehren, die die adlige "Blutsideologie» lange befeuert hatten, seitens der Illuminaten beruhte. So finden sich unter den Illuminaten bezeichnenderweise nur wenige und zur Folgegeneration zählende jüngere Vertreter des rheinischen Adels, wie etwa beide Söhne des Freiherrn Franz Karl von Hompesch, Karl und Johann Wilhelm. ${ }^{211}$

Es ist in diesem Zusammenhang interessant zu sehen, dass beide Söhne ebenfalls Mitglied der bekannten Loge Zur wahren Eintracht um den Hofrat Ignaz

206 Zitiert nach René Le Forestier, Die templerische und okkultistische Freimaurerei im 18. und 19. Jh., Bd. 4: Die letzten Templer, Leimen 1992, 117f.

207 Ders., Die templerische und okkultistische Freimaurerei (wie Anm. 206, Kap. V).

208 Hammermayer, Der Wilhelmsbader Freimaurer-Konvent (wie Anm. 197, Kap. V), 12.

209 Ders., Der Wilhelmsbader Freimaurer-Konvent (wie Anm. 197, Kap. V), 37.

210 Vgl. hierzu die Angaben bei Schüttler, der ein Verhältnis von 65\% (Dritter Stand) zu 35\% (Adel mit Fürsten) im Orden der Illuminaten angibt: Schüttler, Zwei freimaurerische Geheimgesellschaften (wie Anm. 187, Kap. V), hier 535.

211 Hermann Schüttler führt neben Karl von Hompesch (1758-1812) und Johann Wilhelm Graf von Hompesch (1761-1809) den Domherrn Graf Hugo Franz von Hatzfeld-Wildenburg (1755-1830) sowie August Clemens Graf von Hatzfeld (1754-1787) an. Es wird hier im Gegensatz zu Schüttler davon ausgegangen, dass es sich bei »Karl von Hompesch« um den Sohn Franz Karl von Hompeschs handelt. Die biographischen Erläuterungen bei Schüttler zur Person Karl von Hompeschs beziehen sich somit auf den Vater und Gründer der Parfaite Amitié, wobei die Angabe bei Schüttler »letzter Großmeister des Malteserordens« auch in Bezug auf den Senior falsch ist. Letzter Großmeister des Malteserordens im Ancien Régime war - wie oben erwähnt - Ferdinand von Hompesch. Siehe Hermann Schüttler, Die Mitglieder des Illuminatenordens 1776-1787/93 (Deutsche Hochschuledition, 18), München 1991, 68 sowie 75f.; Heinz Schuler, Die St. JohannisFreimaurerloge »Zur wahren Eintracht«. Die Mitglieder der Wiener Elite-Loge 1781-1785, in: Genealogisches Jahrbuch 31 (1991), 5-41, hier 21. 
Edler von Born in Wien waren, ${ }^{212}$ die ebenfalls starke Verbindungen zum Orden der Illuminaten aufwies und bis 1785 arbeitete. ${ }^{213}$ Born prangerte etwa nach dem kaiserlichen Freimaurer-Verbot von 1785, das vor allem aus dem Aufruhr um die zwar harmlosen, aber dennoch von der zeitgenössischen Presse aufgebauschten Umtriebe der Illuminaten resultierte, bei Kaiser Joseph II. die »Verfälschung des Wesensinhaltes der Freimaurerei durch asiatische Brr., Magier, Alchimisten usw." an. ${ }^{214}$ Die hiermit zusammenhängende stärkere Betonung einer rationalistischen Variante bedeutete gleichzeitig eine stärkere Hinwendung zu den sich deutlicher herausbildenden modernen Naturwissenschaften. Die deutliche Absage an Magie und Alchemie bedeutete zwar eher eine kritische Einstellung zur adligen »Blutsideologie«, aber keine zwangsläufige Verneinung der Lehre der Metempsychose. ${ }^{215}$

Dies gilt es auch in Hinblick auf eine sehr viel konkretere 'Seelenrevolution bzw. »Gärung der Geister « ${ }^{216}$ zu bedenken: die Französische Revolution des Jahres 1789. Aufgrund der Revolution und ihrer Folgen für das Rheinland blieben viele Mitglieder des rheinischen Adels den Logen fern. ${ }^{217}$ Der Einmarsch der französischen Revolutionstruppen in das Rheinland zwang sie entweder zur Emigration oder zog den Verzicht auf Privilegien und Adelstitel nach sich ${ }^{218}$ - die Abkehr oder zumindest öffentliche Negierung der adligen »Blutsideologie« inbegriffen. Dieser Wechsel der Zeiten sollte sich auch im Geheimraum der Loge niederschlagen.

212 Siehe hierzu Hans-Josef Irmen (Hg.), Die Protokolle der Wiener Freimaurerloge »Zur wahren Eintracht (1781-1785) (Schriftenreihe der Internationalen Forschungsstelle »Demokratische Bewegungen in Mitteleuropa 1770-1850«, 15), Frankfurt a.M. [u.a.] 1994, 327. Ein Porträt Borns durch einen unbekannten Künstler findet sich unter: commons.wikimedia.org/wiki/File:Ignaz_ von_Born2.jpg (Zugriff vom 11.08.2014).

213 Siehe hierzu Irmen, Die Protokolle der Wiener Freimaurerloge »Zur wahren Eintracht (wie Anm. 212, Kap. V), 15; Lennhoff/Posner/Binder (Hg.), Internationales Freimaurer-Lexikon (wie Anm. 18, Kap. I), $146 f$.

214 Lennhoff/Posner/Binder (Hg.), Internationales Freimaurer-Lexikon (wie Anm. 18, Kap. I), $146 f$. Siehe ferner Irmen, Die Protokolle der Wiener Freimaurerloge "Zur wahren Eintracht« (wie Anm. 212, Kap. V), 15.

215 Siehe auch Mulsow, Vernünftige Metempsychosis (wie Anm. 77, Kap. I), hier insb. 226-240.

216 Mit diesem Ausdruck wird Bezug genommen auf einen Aussage des Hofmeisters der Grafen zu Salm-Reifferscheidt-Dyck anlässlich ihres Aufenthaltes im Paris des Jahres 1789. Sachse zitiert hier in Bezug auf die Angaben bei Heinke Wunderlich folgenden Auszug aus einem Brief des Abbé Jacob zur bevorstehenden Abreise der Suite aus Paris vom 26.06.1789: "car il regnoit à Versailles et à Paris une fermentation prête à faire explosion. "Zitiert nach Sachse, Als in Dyck Kakteen blühten (wie Anm. 2, Kap. I), 62 sowie insb. 225.

217 Siehe hierzu etwa auch die Bemerkungen Winfried Dotzauers, dass der Adel sich nur allmählich mit dem napoleonischen Regime anfreunden konnte und in französischer Zeit nur in geringer Zahl etwa in der Kölner Loge Le Secret de trois Rois vertreten war. Bei Dotzauer wird bereits der Name Joseph zu Salm-Reifferscheidt-Dycks erwähnt, wobei dieser nicht Mitglied der Dreikönigsloge, sondern in der unten noch zu behandelnden Kölner Loge La Naissance du Roi de Rome war. Vgl. Dotzauer, Die Mitglieder der Kölner Freimaurerloge (wie Anm. 179, Kap. V), hier 134-137.

218 Siehe hierzu Dipper, Der rheinische Adel (wie Anm. 11, Kap. I), 92. 


\section{Rahmenbedingungen: Freimaurerei in Frankreich nach 1789}

\section{VI.1 Ein Anfang vom Ende? Der Kölner Logenstreit der Jahre 1809/10 und seine karnevalistischen Ausuferungen}

Es war der vierte Tag des neunten Monats im freimaurerischen Jahr des wahren Lichts $5809^{1}$, als Erique Henry Verkenius, Sekretär der Kölner Freimaurerloge Le Secret des trois Rois und Inhaber des Hochgrades eines Élu des Quinze, den Text eines seit Längerem fälligen Briefes an den GOF vervollständigt hatte. In der profanen Welt außerhalb des freimaurerischen Tempels hatte Napoleon Bonaparte, der - zwischenzeitlich zum Kaiser gekrönt - auch über die im Roerdepartement liegende Stadt Köln herrschte, vor wenigen Monaten einen, wie es schien, entscheidenden Sieg bei Wagram über Kaiser Franz I. von Österreich errungen und seinen Gewinn im Frieden von Schönbrunn besiegeln lassen. Der Inhalt des Briefes, den Verkenius verfasst hatte, war für die Loge ebenfalls von größter Wichtigkeit, und so unterschrieben nacheinander der Meister vom Stuhl, Charles Léonore Belling, der Großmeister des Kapitels, Henry Joseph Weyer, sowie die beiden Aufseher der Loge, Jean Philippe Heimann und François Xavier Schirmer, bevor Verkenius selbst nach dem obligatorischen »Par mandement de la $[\therefore] \ll$ das Dokument unterzeichnete. ${ }^{2}$

In dem von Verkenius verfassten Schreiben entschuldigten sich die Beamten der Loge stellvertretend für die Gesamtheit ihrer Logenbrüder für die verspätete Einsendung des regelmäßig an den Grand Orient als verwaltende freimaurerische Oberbehörde des Premier Empire abzuführenden »don gratuit«. Außerdem war die Übermittlung eines aktuellen Mitglieder-Tableaus der Dreikönigsloge ausgeblieben, sodass die Beamten sich ferner dazu veranlasst sahen, nicht nur schnellstmöglich die ausstehenden Gelder und das Tableau einzureichen, sondern den Grand Orient auch über die Gründe für diese Verspätung aufzuklären. Nach Auskunft des Schreibens war demnach nicht etwa Nachlässigkeit in der Beachtung der freimaurerischen Pflichten der Grund für das Versäumnis. Vielmehr war die Verzögerung durch den Tod des bisherigen Repräsentanten der Loge beim Grand Orient, Pierre Nicolas Riffe de Caubray, ${ }^{3}$ verursacht worden. ${ }^{4}$

Doch noch ein zweiter Grund bereitete den Mitgliedern der Dreikönigsloge seit einiger Zeit große Mühe. Bereits in einem Schreiben vom 25. Tag des ach-

1 Nach christlicher Zeitrechnung: 04.11.1809.

2 Zu allen Angaben vgl. Kölner Dreikönigsloge an Grand Orient, Köln, 4. Tag des 9. Monats 5809 (04.11.1809), in: BnF, FM2 535 (MF 4589), fol. 99f.

3 Zu seiner Person siehe Pierre Mollier/Pierre-François Pinaud, L'état-major maçonnique de Napoléon. Dictionnaire biographique des dirigeants du Grand Orient de France sous le Premier Empire, À l’Orient 2009, 245; Dotzauer, Die Mitglieder der Kölner Freimaurerloge (wie Anm. 179, Kap. V), hier 180.

4 Vgl. Kölner Dreikönigsloge an Grand Orient, Köln, 4. Tag des 9. Monats 5809 (04.11.1809), in: BnF, FM2 535 (MF 4589), fol. 99f. 
ten Monats $5809^{5}$ hatte man den Grand Orient über die Zwangsversteigerung des Hauses auf der "Rue Kloeckersgass No. 4972 « in Köln unterrichtet, in dem die Loge bislang ihr Domizil gefunden hatte. ${ }^{6}$ Seitdem mussten die freimaurerischen Arbeiten ersatzweise im Haus eines Logenbruders stattfinden. Über ein neues Lokal als festen Sitz der Loge hatte man sich nicht einigen können, sodass das Schreiben außerdem die Bitte der Logenbeamten an den Grand Orient enthielt, einem Beschluss zuzustimmen, der die Aufteilung der Logengemeinschaft in zwei Sektionen vorsah. ${ }^{7}$ Nach den Angaben in diesem Brief zu urteilen, der fast apologetisch mit einem Hinweis auf das hohe Alter der Freimaurerei in Köln und die seit jeher große Gewissenhaftigkeit der Kölner Freimaurer beginnt, scheint die Schwierigkeit zunächst darin bestanden zu haben, eine neue Bleibe für die Loge zu finden, die sowohl der großen Zahl der Logen-Mitglieder Raum bot als auch finanzierbar war. Über die korrekte Vorgehensweise herrschte unter den Brüdern der Loge große Uneinigkeit.

Wie der Inhalt des Briefes zu erkennen gibt, hatten sich während der Beratungen zwei Lager gebildet - resultierend aus den gegenläufigen Stellungnahmen des Vénérable Belling auf der einen und des Bruders Théodore François Thiriart ${ }^{8}$ auf der anderen Seite. Die maurerische Einigkeit der Loge drohte durch Parteigeist zerstört zu werden, ${ }^{9}$ vor dem bereits James Anderson die Freimaurerei 1723 in den "Constitutions « zu schützen gesucht hatte. Die zunächst getroffenen Regelungen sowie die Aufspaltung der Loge in zwei Sektionen - "Agrippina « und »Charlemagne« benannt - erscheinen folglich in einem zwiespältigen Licht und geben bereits ein erstes Zeugnis über den offensichtlichen Bruch innerhalb der Logengemeinschaft. ${ }^{10}$

5 Nach christlicher Zeitrechnung: 25.10.1809.

6 Vgl. Kölner Dreikönigsloge an Grand Orient, Köln, 25. Tag des 8. Monats 5809 (25.10.1809), in: BnF, FM2 535 (MF 4589), fol. 101-104. Zur Adresse des ehemaligen Sitzes der Loge vgl. die Angabe in Kölner Dreikönigsloge an Grand Orient, Köln, 10. Tag des 11. Monats 5809 (10.01.1810), in: BnF, FM2 535 (MF 4589), fol. 107.

7 Vgl. Kölner Dreikönigsloge an Grand Orient, Köln, 4. Tag des 9. Monats 5809 (04.11.1809), in: BnF, FM2 535 (MF 4589), fol. 99f. Zur Aufspaltung der Loge siehe auch Leopold Böhmer, Geschichte der Freimaurerei in Köln am Rhein von 1815 bis 1872 nebst Rückblicken auf ältere Epochen, Köln 1873, 27f.; Klaus Müller, Köln von der französischen zur preußischen Herrschaft $1794-1815$ (Geschichte der Stadt Köln, 8), Köln 2005, 90 sowie 261f. Böhmer gibt an, dass die Loge La Naissance du Roi de Rome im Jahr 1811 in Köln konstituiert wurde und keine weiteren Nachrichten oder Urkunden zu ihr vorliegen, außer einem Schwert in roter Samtscheide mit französischem Adler, einem kölnischen Wappen mit der Jahreszahl 1811 und der Aufschrift: ")Je défends le F $\therefore$ fidèle, Je punis le parjure.«

$8 \mathrm{Zu}$ seiner Person siehe Dotzauer, Die Mitglieder der Kölner Freimaurerloge (wie Anm. 179, Kap. V), hier 229.

9 Vgl. Kölner Dreikönigsloge an Grand Orient, Köln, 25. Tag des 8. Monats 5809 (25.10.1809), in: BnF, FM2 535 (MF 4589), fol. 103.

10 Die Regelungen sahen vor, dass die Loge in die beiden genannten Sektionen geteilt wurde, wobei jede Sektion ihre eigene Verwaltung und Korrespondenzführung selbstständig übernahm. Sofern es Sachverhalte von allgemeinem Interesse zu beraten gab, konnten sich Abordnungen beider Sektionen versammeln oder die jeweiligen Meister vom Stuhl gemeinsam tagen. Der Beschluss sah nach diesem Modus auch eine Abfassung von allgemeingültigen Regeln für die Logengemein- 
So führten die Brüder der Sektion Agrippina unter dem Vorsitz François Xavier Schirmers in einem Schreiben an den Grand Orient vom 9. Tag des 11. Monats $5809^{11}$ bittere Klage über die freimaurerischen Vergehen der nun in der Sektion Charlemagne zusammengefassten Brüder. Das Problem des Domizils wird zwar auch in diesem Schreiben als Auslöser erwähnt, die beiden Parteien innerhalb der Loge werden jedoch wie folgt umschrieben:

L'un pour la conservation et la rigoureuse observance des formes et des Statuts. Lautre pour un Relachement non Seulement attentatoire aux maximes de La Maçonnerie, mais préjudiciable, aux mœurs et aux Vertus sociales qui doivent constituer une Réunion d'honneur dont les vues ne tendent qu’à faire le bien. ${ }^{12}$

Was die durchaus auf Exklusivität bedachten Brüder der Sektion Agrippina hier als schädlich für die freimaurerischen Maximen und eine tugend- und ehrenhafte Zusammenkunft ansahen, wird in ihrem Schreiben ebenfalls geschildert. Gegen sie - die in ihren Augen einzig wahren Mitglieder der ehrwürdigen Loge Le Secret des trois Rois - standen jene, die die »arche sainte« der Freimaurerei verlassen hatten, um sich von nun an Prahlerei, Unordnung und Orgien hinzugeben. Die Vorwürfe der Agrippinen gegen die als »dissidents« bezeichneten >Abtrünnigen` gipfelten in folgender Anschuldigung:

[...] ils ont aggrégé six Frères par forme d'affiliation, ils ont organisé une société profane qui est nommée Société Secondaire laquelle est annexée et lient ses assemblées dans le Local et Notamment dans la Salle du Banquet de leur Loge. Les Sociétaires sont tous Profanes et payent chacun Neuf Francs qui sont versés dans la caisse de leur Loge et contribuent aux Batisses qu'ils ont projetées. Ils ont permis par un contrat formel Stipulé pour quinze Ans, à leur concierge, de Tenir une Bastringue pendant Trois jours du Carnaval et Trois jours de la Kermes. Dans cette Bastringue se Réunit ordinairement, Tous ce que la ville de Cologne recèle de plus abject et des plus Crapuleux. Enfin, ils ont tenu déjà plusieurs Banquets aux quels ils ont admis des profanes et méprisant les Formes Maçonniques, les ont tournées en ridicule et les parodiant et donnant aux présidents de ce Banquet des dénomminations de Professions et de métiers profanes. ${ }^{13}$

schaft vor. Jedem Mitglied stand es unter Einhaltung einer Frist bis zum 30.11.1809 frei, seine Sektion selbst zu wählen, wobei automatisch eine Ehrenmitgliedschaft in der nicht gewählten Sektion vorgesehen war. Die Beamtenwahlen und freimaurerischen Arbeiten sollten von jeder Sektion autonom durchgeführt werden. Der Beschluss sah außerdem vor, dass jede Sektion eine Kommission mit der Abwicklung der finanziellen Angelegenheiten beauftragte sowie eine weitere Kommission für die Feststellung der aktiven und passiven Mitglieder einrichtete. Als Letztes folgte der Beschluss zur Vorlage und Ratifizierung des Erlasses beim Grand Orient. Vgl. Kölner Dreikönigsloge an Grand Orient, Köln, 25. Tag des 8. Monats 5809 (25.10.1809), in: BnF, FM2 535 (MF 4589), fol. 103f.

11 Nach christlicher Zeitrechnung: 09.01.1810.

12 Kölner Dreikönigsloge an Grand Orient, Köln, 10. Tag. des 11. Monats 5809 (10.01.1810), in: BnF, FM2 535 (MF 4589), fol. 108.

13 Kölner Dreikönigsloge an Grand Orient, Köln, 10. Tag des 11. Monats 5809 (10.01.1810), in: BnF, FM2 535 (MF 4589), fol. 108f. In einem weiteren Brief, der auf den 22.02.1810 datiert, heißt es in 
Es ist wenig verwunderlich, dass die beiden Sektionen der Dreikönigs-Loge wenige Zeit später gänzlich voneinander getrennte Wege gehen sollten. Die Mitglieder der Sektion Agrippina verblieben unter dem Logennamen Le Secret des trois Rois und suchten sich gegen die legere Auslegung der freimaurerischen Arkanpflicht fortan in ihren Statuten zu schützen. ${ }^{14}$ Der zahlenmäßig weitaus größere Teil, ${ }^{15}$ der sich in der Sektion Charlemagne zusammengefunden hatte, gründete eine neue Loge unter dem Namen La Naissance du Roi de Rome. Diese wurde durch Entscheidung der Gr $\therefore$ L $\therefore$ symbolique général des GOF - trotz der Querelen und Anschuldigungen der Agrippinen - am 03.07.1811 gemäß den Satzungen als rechtmäßige Loge anerkannt. Sie fand ihr Domizil zwischenzeitlich am Neumarkt. ${ }^{16}$

Im Logentableau dieser neuen Kölner Loge La Naissance du Roi de Rome aus dem Jahr 1813 finden sich unter den Mitgliedern des Ateliers die Namen so bekannter rheinischer Familien wie Herstatt, Lenné, Dumont-Schauberg, Farina oder Mumm. ${ }^{17}$ Unter den Ehrenmitgliedern wird neben dem Präfekten des Roerdepartements, Charles de Ladoucette, auch der Name Joseph zu Salm-Reifferscheidt-Dycks angeführt. ${ }^{18}$ Salm-Dyck zählte zu den Personen adliger Abstam-

Ergänzung hierzu: »Nous n'avons point de pièces écrites à produire pour justifier que la section établie chez le nommé Hittorff, s'est assosciée une société Profane, mais cela est connu de toute la ville, et vous pouvez sur ma parole de Maçon et celles des autres frères de Notre atelier, le certifier au G $\therefore \mathrm{O} \therefore$ cette société s'occupe à jouer aux cartes, à boire et manger, à lire les journaux, enfin, en amusements utiles dans toutes les Sociétés ordinaires. Le V $\therefore$ ble et L.L $\therefore$ S $\therefore$, sont les commissaires et les Directeurs Nés de la Société. [...] Parsuite de L'évacuation du local de Hittorff la on [Abkürzung für »Section«, Anm. d. Verf.] charlemagne obligée de maintenir la Société profane qu'elle s'est adjointe dont elle a reçu d'avance l'abonnement d'une année, viens de prévenir par une circulaire ses abonnés, qu'elle s'est établie ailleurs (encore dans un Cabaret! ou des profanes même non abonnés sont admis). «Siehe zu diesem Zitat Kölner Dreikönigsloge an Grand Orient, Köln, 22. Tag des 12. Monats 5809 (22.02.1810), in: BnF, FM2 535 (MF 4589), fol. 116f.

14 Astrid Küntzel erwähnt die Einführung einer »Domizilspflicht«. Vgl. Astrid Küntzel, Fremde in Köln. Integration und Ausgrenzung zwischen 1750 und 1814 (Stadt und Gesellschaft. Studien zum rheinischen Städteatlas, 4), Diss., Köln/Weimar/Wien 2008, 119.

15 Dass es sich um den zahlenmäßig größeren Teil handelte, geht ebenfalls aus dem Schreiben der Sektion Charlemagne vom 09.01.1810 hervor. Hier heißt es: »[...] mais le Comble de leur part est de vouloir traiter comme Scissionnaires la partie des Ffr $\therefore$ qui ont à leur tête le Ven $\therefore$ de la L $\therefore$, le premier Surv $\therefore$ La plupart des dignitaires, et qui constituent le plus grand nombre.« Vgl. Kölner Dreikönigsloge an Grand Orient, Köln, 9. Tag. des 11. Monats 5809 (09.01.1810), in: BnF, FM2 535 (MF 4589), fol. 105f.

16 Das Logentableau kann in der Bibliothek des GON in Den Haag eingesehen werden. Siehe hierzu Tableau des Off. Dign $\therefore$ et des FF $\therefore$ Qui composent la R $\therefore \square$ de St.-Jean d'Écosse, sous le Titre distinctif de la Naissance du Roi de Rome à l'Or.: de Cologne, Cologne 5813 (1813), in: GON, 212.D.33. Das Gründungsdatum sowie das Konstitutionspatent des Grand Orient im Wortlaut gibt Hermann Weiland in seiner Chronik der Johannisloge Minerva an. Vgl. Hermann Weiland, Chronik der vereinigten Johannisloge Minerva zum vaterländischen Verein und Rhenana zur Humanität im Or. Köln 1852-1902, Köln 1902, 4f. Zum Domizil vgl. auch Müller, Köln von der französischen zur preußischen Herrschaft (wie Anm. 7, Kap. VI), 262.

17 Vgl. Tableau des Off. Dign $\therefore$ et des FF $\therefore$ Qui composent la R $\therefore \square$ de St.-Jean d'Écosse, sous le Titre distinctif de la Naissance du Roi de Rome à l'Or $\therefore$ de Cologne, Cologne 5813 (1813), in: GON, 212.D.33.

18 Vgl. Tableau des Off. Dign $\therefore$ et des FF $\therefore$ Qui composent la R $\therefore \square$ de St.-Jean d'Écosse, sous le Titre distinctif de la Naissance du Roi de Rome à l'Or $\therefore$ de Cologne, Cologne 5813 (1813), in: GON, 212.D.33. 
mung, die 1794 nicht vor den Franzosen geflohen waren, sondern sich dem neuen Regime und den damit einhergehenden Veränderungen ihrer Lebenswelt - auch unter Verlust ihrer Titel und Privilegien - gestellt hatten. ${ }^{19}$ Die seinem Namen im Logentableau beigefügten profanen und freimaurerischen Titel, Comte de l'Empire, Membre du Conseil général du département, Grand Inspecteur Inquisiteur Commandeur, Deputé Grand Inspecteur dans les departements de la Roër, de la Meuse-Inférieure, de l'Ourthe et de Rhin-et-Moselle, beweisen nicht nur sein großes freimaurerisches wie politisches Engagement, sondern auch eine soziale Flexibilität, die ihm eine erfolgreiche Anpassung an die neuen Gegebenheiten und den Aufstieg in die neugeschaffene Noblesse d'Empire Napoleons ermöglicht hatte. Eine Phase, die noch Jahrzehnte später durch einige Logenchronisten des späteren 19. Jahrhunderts abwertend als eine Zeit der aus Frankreich herrührenden freimaurerischen Verfehlungen beschrieben werden sollte. ${ }^{20}$

In ebenjener Zeit genoss Salm-Dyck unter den Freimaurern der neuen Kölner Loge hohes Ansehen. Dies unterstreichen nachdrücklich die Vorgänge um deren Eingliederung in ein prestigeträchtiges französisches Hochgradsystem. Die Loge La Naissance du Roi de Rome, deren Name auf den Titel des am 20.02.1811 geborenen Sohns Napoleons anspielt und als Ehrenbekundung gegenüber diesem zu sehen ist, erhielt am 28.03.1812 ein Dekret der Mère Loge Écossaise de France, ${ }^{21}$ das ihr erlaubte, von nun an das Hochgradsystem des sogenannten Rit écossais philosophique zu bearbeiten. Die Beamten der Loge richteten daher, angeleitet durch den Vénérable der Loge, Jean Philippe Heimann, am 12.08.1812 (12. Tag des 6. Monats 5812) ein Schreiben an Joseph zu Salm-Reifferscheidt-Dyck, in dem sie ihn darum baten, die Installation am 30. Tag des laufenden Monats durchzuführen. Warum gerade seine Person als geeignet erschien, die Zeremonie durchzuführen, begründeten sie wie folgt: »Les hauts Gr $\therefore$ que Vous possedez $\operatorname{tr} \therefore$ ill $\therefore$ et Ch $\therefore$ Fr $\therefore$ les qualités eminent qui vous distinguent, Vos Vertus et lumieres maçonniques Vous ont donné depuis longtemps les plus justes Titres à notre estime et affection. ${ }^{22}$

19 Siehe hierzu Sachse, Als in Dyck Kakteen blühten (wie Anm. 2, Kap. I), 67-80; Martin Otto Braun, »Quel titre font-il que j’y prenne?« Die Entscheidung gegen die Emigration im Jahr 1794 und ihre langfristigen Folgen, aus: Netzbiographie: Joseph zu Salm-Reifferscheidt-Dyck (17731861), in: historicum-estudies.net, [05.06.2014], http://www.historicum-estudies.net/epublished/ netzbiographie/franzoesische-zeit/emigration (Zugriff vom 21.11.2014).

20 Siehe hierzu etwa Böhmer, Geschichte der Freimaurerei in Köln (wie Anm. 14, Kap. VI), Einleitung o.S.

21 Vgl. Weiland, Chronik der vereinigten Johannisloge Minerva (wie Anm. 16, Kap. VI), 5. Weiland erwähnt hier die Verleihung eines »Rite écossais« an die Loge La Naissance du Roi de Rome. Zur Umbenennung siehe auch François Collaveri, La franc-maçonnerie de Bonaparte, 2. Aufl., Paris 2007, 124.

22 Kölner Loge La Naissance du Roi de Rome an Joseph Salm-Dyck, Köln, 12. Tag des 6. Monats 5812 (12.08.1812), in: ASD, Blaue Bände, Bd. 590, fol. 70f. Es liegt keine Nachricht darüber vor, ob Joseph zu Salm-Reifferscheidt-Dyck die Installation der neuen Kölner Loge tatsächlich vorgenommen hat. Die Auflistung seiner Person unter den Ehrenmitgliedern des Ateliers im Logentableau von 1813 lässt diesen Schluss jedoch durchaus zu. 
Dieses Ansehen Salm-Dycks innerhalb der freimaurerischen Sphäre ist - gerade für die doch anscheinend an einer konservativen Auslegung freimaurerischer Verhaltensweisen desinteressierte Loge - bemerkenswert. Ein Grund hierfür mag auch in der enormen gesellschaftlichen Präsenz Joseph zu Salm-ReifferscheidtDycks gelegen haben, von der zahlreiche offizielle Zeugnisse im Familienarchiv vorliegen und die hier nur durch einige ausgewählte Beispiele illustriert werden soll: So wirkte Salm-Reifferscheidt bereits ab 1800 im Departementsrat des Roerdepartements. Er saß ab 1804 als Deputierter des Roerdepartements in der Gesetzgebenden Körperschaft in Paris, gehörte ab 1808 im Rang eines Chevalier und 1809 als Comte zur Noblesse d'Empire und zählte von 1808 bis 1814 zu den 30 meistbesteuerten Personen des Roerdepartements. ${ }^{23}$ Wie der eingangs erwähnte Stammbaum der Familie Salm-Reifferscheidt bereits verdeutlichte, entstammte er einem Adelsgeschlecht, das sich traditionell auf sein hohes Alter und eine Nähe zu Frankreich berief. ${ }^{24}$ Jedoch spiegelt die oben geschilderte Episode um die Kölner Loge wie die nahezu reibungslose Eingliederung in die neuen politischen Verhältnisse die relative Freizügigkeit bezüglich seiner gesellschaftlichen Kontakte wider, die zunächst nicht recht zu der standesbewussten Darstellung des Stammbaums aus dem Ancien Régime passen will. Salm-Dyck ergriff im Kölner Logenstreit Partei für die »dissidents«. Er zeigte sich damit offen gegenüber ihren karnevalesken Sitzungen, die das freimaurerische Geheimnis profanierten, indem er ihre Angliederung an das System des Rit écossais philosophique unterstützte.

Vor einer näheren Beschäftigung mit der freimaurerischen Biographie SalmDycks ist es zur richtigen Einordnung jedoch erforderlich, sich zunächst einige wichtige Entwicklungen der französischen Freimaurerei zum Anfang des 19. Jahrhunderts zu verdeutlichen, wobei vor allem die enge Verflechtung der napoleonischen Freimaurerei mit der politischen Sphäre des Premier Empire zu besprechen sein wird.

\section{VI.2 Der politische Gehalt der französischen Freimaurerei nach 1789}

Nicht nur in der Kölner Loge äußerten Freimaurer ihren Unmut über Gepflogenheiten, die im Premier Empire Einzug in die Logen gehalten hatten. Auch außerhalb des Roerdepartements beschwerten sich Logenmitglieder bei Gelegenheit über die große Zahl der Aufnahmen in den Maurerbund während des Premier Empire. So stießen sich etwa die Mitglieder der Brüsseler Loge Amis Philantropes

23 Siehe Roger Dufraisse, Les notables de la rive gauche du rhin à lépoque napoléonienne, in: Revue d'histoire moderne et contemporaine 17 (1970), 758-776, hier 762; Sachse, Als in Dyck Kakteen blühten (wie Anm. 2, Kap. I), 81-87; Florian Schönfuß, Zur Aufnahme in Napoleons Noblesse d'Empire, aus: Netzbiographie: Joseph zu Salm-Reifferscheidt-Dyck (1773-1861), in: historicumestudies.net, [05.06.2014], http://www.historicum-estudies.net/epublished/netzbiographie/franzoe sische-zeit/noblesse-dempire (Zugriff vom 21.11.2014).

24 Vgl. hierzu Sachse, Als in Dyck Kakteen blühten (wie Anm. 2, Kap. I), 17. 
an den zahlreichen »Gewalteintritten der großen Beamten « in die Bauhütten; die »Liebe zum Spielzeug« habe »Frankreich überschwemmt« und der Bund zähle »mehr verlorene Kinder als wahre Ordensanhänger $«{ }^{25}$ Eine Kritik, die einen Eindruck von der Ohnmacht eines Teils der Freimaurer gegenüber den Entwicklungen innerhalb des Bundes speziell unter der Herrschaft Napoleons vermittelt.

Entgegen den Konstruktionen zeitgenössischer Verschwörungstheorien - deren bekannteste und einflussreichste wohl die in den »Mémoires pour servir à l'histoire du Jacobinisme« des Abbé Barruel enthaltene darstellt - hatte die Freimaurerei in Frankreich nicht aktiv zum eigentlichen Ausbruch der revolutionären Ereignisse von 1789 beigetragen. ${ }^{26}$ Allenfalls hatten die Logen die Verbreitung der Ideen der Aufklärung befördert. ${ }^{27}$ Unter der Terreur stellten beide französische Großlogen ihre Arbeit komplett ein, Freimaurer wurden durch den Wohlfahrtsausschuss zum Teil verfolgt. Nach diesem absoluten Tiefpunkt, während dessen in Paris nur drei Logen ihre freimaurerischen Arbeiten fortgesetzt haben sollen, ${ }^{28}$ gestaltete sich die Wiederbelebung der Freimaurerei in Frankreich - ganz im Gegensatz zur Zeit des Ancien Régime, in der mehrere Großlogen miteinander konkurrierten - zunächst überraschend einhellig. Ab dem Jahr 1796 nahm der GOF seine Arbeiten wieder auf, wobei der maßgebliche Initiator, Roëttiers de Montaleau, selbst während der Terreur in Gefangenschaft geraten war. ${ }^{29}$ Wenige Monate vor der Beseitigung des Direktoriums durch Napoleon war der GOF zwar zunächst die einzige freimaurerische Großloge in Frankreich. ${ }^{30}$ Die Zahl der französischen Logen war im Jahr 1800 jedoch deutlich dezimiert: von vormals 1.000 Logen in Frankreich waren nur noch 74 aktiv, 23 davon in Paris. ${ }^{31}$ Der Grand Orient schaffte es zunächst, die politischen und rituellen Gräben zu überbrücken, die nach wie vor zwischen ihren Mitgliedern in und außerhalb der Loge bestanden. ${ }^{32}$

Doch bald traten altbekannte Probleme auf den Plan. Mit der Gründung der Grande Loge Générale Écossaise de France im Oktober des Jahres 1804 entstand

25 Zitiert nach Paul Rousseau, Der französische Ritus und die linksrheinischen Logen am Anfang des 19. Jh.s, in: Quatuor Coronati Jahrbuch für Freimaurerforschung 22 (1985), 261-280, hier $273 f$. Auch Dotzauer sieht diesen Übergang der Logen in die Öffentlichkeit während der Französischen Zeit des Rheinlandes und sieht ihn in dem Umstand begründet, dass die »laizistischen Anschauungen« der französischen Freimaurerei nach 1800 sich weitgehend mit den politischen Prinzipien der Revolutionsregierung deckten - also nicht mehr im Verborgenen praktiziert werden mussten. Siehe hierzu Dotzauer, Freimaurergesellschaften am Rhein (wie Anm. 56, Kap. I), 235.

$26 \mathrm{Zu}$ Verschwörungstheorien allgemein unter besonderer Beachtung der Freimaurerei siehe Johannes Rogalla von Bieberstein, Der Mythos von der Verschwörung. Philosophen, Freimaurer, Juden, Liberale und Sozialisten als Verschwörer gegen die Sozialordnung, Wiesbaden 2008.

27 Vgl. hierzu Reinalter, Die Freimaurer (wie Anm. 18, Kap. I), 18.

28 Vgl. Georg Kloss, Geschichte der Freimaurerei in Frankreich aus ächten Urkunden dargestellt. (1725-1830), Bd.1, Darmstadt 1852, 347, Permalink: http://hdl.handle.net/2027/hvd.32044105550289 (Zugriff vom 25.05.2014).

29 Siehe hierzu Kloss, Geschichte der Freimaurerei (wie Anm. 28, Kap. VI), 345; Rousseau, Der französische Ritus (wie Anm. 25, Kap. VI), hier 267.

30 Vgl. Mollier/Pinaud, L'état-major maçonnique (wie Anm. 3, Kap. VI), 14.

31 Vgl. die Angaben bei: Roger Dachez, Histoire de la franc-maçonnerie française, Paris 2003, 79.

32 Vgl. Mollier/Pinaud, L'état-major maçonnique (wie Anm. 3, Kap. VI), 14f. 
schließlich eine konkurrierende Großloge für die verschiedenen schottischen Hochgradsysteme des französischen Raums, die zwar durch ein Konkordat bald dem Grand Orient angegliedert werden konnte, jedoch in der Zeit des Premier Empire weitgehend in einer jurisdiktionellen Unabhängigkeit verblieb. ${ }^{33}$ Innerhalb der Schotten-Maurerei dieser Zeit wurde dabei vor allem der sich zu dieser Zeit aus dem amerikanischen Charleston her etablierende, 33 Grade umfassende Rite écossais ancien accepté sehr prominent, da er mit dem Anspruch auftrat, verschiedene wichtige Hochgradsysteme der schottischen Freimaurerei zu einem geschlossenen System vereinigen zu können. ${ }^{34}$ So ergab letztlich das Konkordat die Zuständigkeit des GOF für die 18 ersten Grade bis zum Chevalier Rose-Croix und des leitenden Suprême Conseil des Rite écossais ancien accepté für den 19. bis 33. Grad, wobei den Inhabern der letzten drei Grade - insbesondere dem Kollegium der Mitglieder im 33. Grad - die Leitung des Systems des Alten und Angenommen Schottischen Ritus an der Ordensspitze vorbehalten blieb. ${ }^{35}$

Die wichtigsten Hochgradsysteme innerhalb des Rite écossais ancien accepté waren dabei der bereits im Ancien Régime entstandene, hermetisch-alchemistisches Gedankengut aufgreifende Rit écossais philosophique sowie der Royal Ordre d'Heredom de Kilwinning. ${ }^{36}$ Die Vehemenz, mit der die Auseinandersetzungen um die administrative und rituelle Aufsicht auch in den folgenden Jahren geführt wurde, kann etwa daran abgelesen werden, dass die prominent besetzte Pariser Loge des philosophischen Ritus Commandeurs du Mont Thabor, der auch Joseph zu Salm-Reifferscheidt-Dyck angehörte und die neben dem philosophischen auch den Ritus von Kilwinning bearbeiten durfte, im Jahr 1809 bekannt gab, dass sie "nur diejenigen für Rosecroix erkenne, welche in einem regelmäßigen Kapitel des großen und erhabenen Ordens von Kilwinning aufgenommen worden seien. ${ }^{37}$ Hierbei ist es wichtig, die bereits bei Ramsay erwähnten Ursprungskonstruktionen der schottischen Maurerei im schottischen Kilwinning

33 Vgl. Lennhoff/Posner/Binder (Hg.), Internationales Freimaurer-Lexikon (wie Anm. 18, Kap. I), 297f.; Pierre Mollier, Naissance et essor du Rite Écossais Ancien Accepté en France 1804-1826, in: Keghel/Moisy (Hg.), Deux Siècles de Rite Écossais (wie Anm. 43, Kap. V), 71-113, hier 84-89.

34 Siehe zu diesen Angaben Lennhoff/Posner/Binder (Hg.), Internationales Freimaurer-Lexikon (wie Anm. 18, Kap. I), 298. Für eine detaillierte Darstellung vgl. jedoch vor allem die Angaben bei Mollier, Naissance et essor (wie Anm. 33, Kap. VI), hier 84-89.

35 Siehe die Angaben bei Mollier, Naissance et essor (wie Anm. 33, Kap. IV), hier $92 \mathrm{f}$.

$36 \mathrm{Zu}$ beiden Systemen vgl. die Ausführungen bei Frick, Licht und Finsternis (wie Anm. 61, Kap. V), 28-58.

37 Ders., Licht und Finsternis (wie Anm. 61, Kap. V), 32 sowie 35. Die Bemerkung im Original fand sich in: Commandeurs du Temple du Mont Thabor Rit Écossais Philosophique a l'O $\therefore$ de Paris, Paris 5809 (1809), in: GOF, 5311, 109. Hier heißt es unter der Überschrift »Observation importante.«: »Enfans de la mère Loge du rit écossais philosophique en France, les Commandeurs du M $\therefore$ Thabor ne reconnaissent pour Rose-Croix que ceux qui ont été admis dans un chapitre régulier du grand et sublime Ordre de Kilwining. C'est au chapitre seul de la mère Loge écossaise de Saint-Alexandre, $\mathrm{O} \therefore$ de Paris, que les Commandeurs qui n'en font pas partie, doivent avoir recours, pour accroître leurs moyens de force et de sagesse.« 


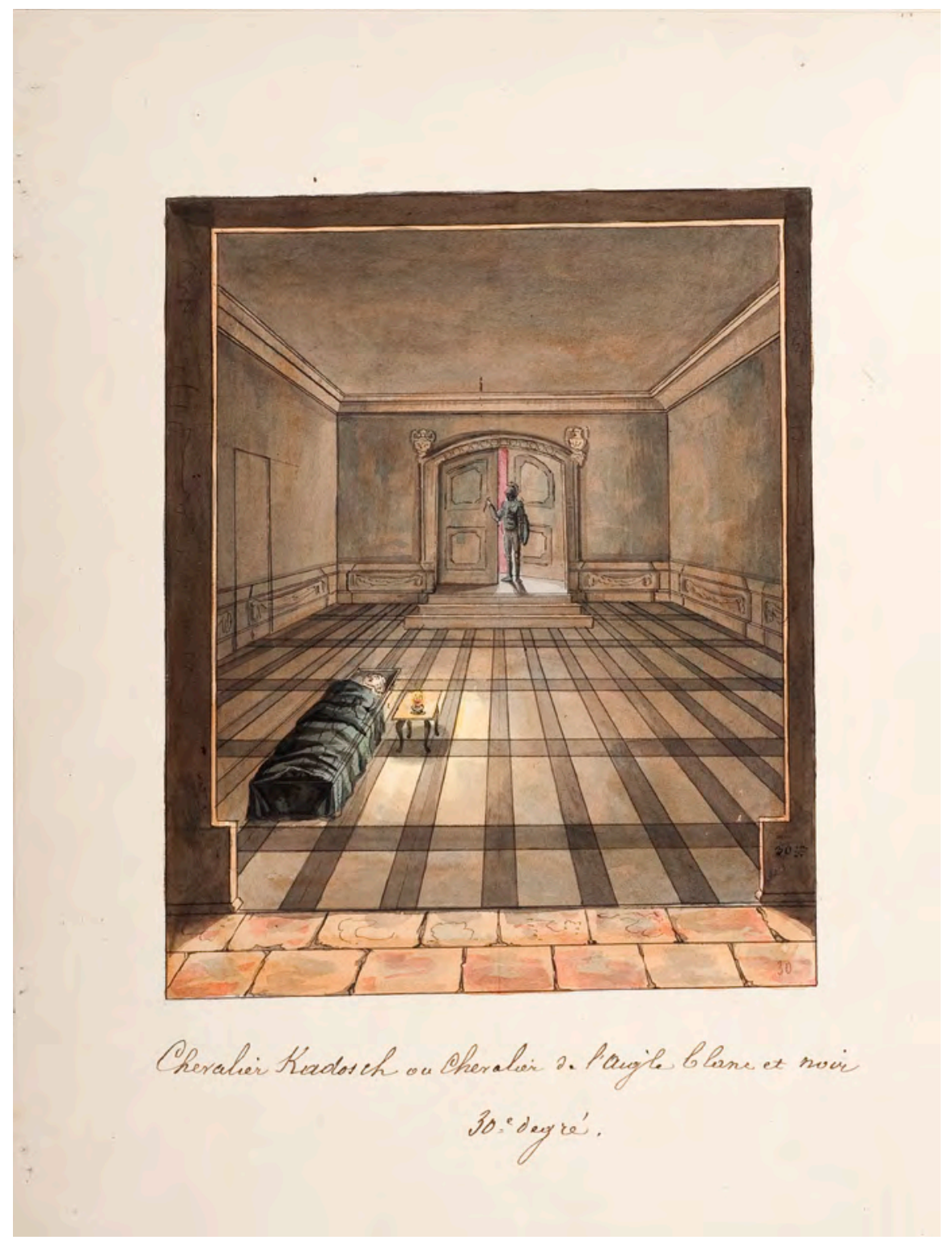

Abbildung 15: Rite Écoss. Anc. et Acc.: Décorations et Costumes II: Chevalier Kadosch ou Chevalier de l'Aigle blanc et noir, 30 degré (= Dekoration des Logenraums im 30. Grad), um 1800 (Bildrecht/Werk und Foto: From the collections of the Cultural Masonic Centre, The Hague). 
zu bedenken. Im Premier Empire wurde die Templerlegende somit zum Teil wieder aufgegriffen.

Die enge Anbindung des Grand Orient sowie der schottischen Hochgrade an das napoleonische Regime erfolgte nicht zuletzt über eine zentrale Personalie. Ab 1805 stand Archichancellier Jean-Jacques-Régis de Cambacérès (1753-1824) an der Spitze des Grand Orient und ab 1806 auch des Suprême Conseil des Rite écossais ancien accepté. ${ }^{38}$ Zudem wurde er unter anderem Grand-Maître d'Honneur der Grande Loge Provinciale de Hérédom (ebenfalls 1806) sowie Grand-Maître der Mère Loge du Rit écossais philosophique (1807). ${ }^{39}$ Die Leitung des Grand Orient bzw. durch zahlreiche personelle Überschneidungen auch des Suprême Conseil, dessen officiers in verschiedenen Kollegien über die allgemeinen administrativen und rituellen Fragen berieten und über Abgeordnete der Einzellogen das freimaurerische Netzwerk des Premier Empire unter Führung seines Archichancelliers beaufsichtigten, war von ihrer personalen Aufstellung her sehr stabil und rekrutierte sich aus der Schicht der Notabeln. ${ }^{40}$ Es verwundert in dieser Hinsicht und im Hinblick auf die Einführung der Noblesse d'Empire durch Napoleon nicht, dass die im Ancien Régime übliche Verleihung von Ehrenmitgliedschaften - ebenfalls ein durchaus aristokratisches Moment der Freimaurerei - in dieser Zeit wieder eingeführt wurde. Sie beruhte beispielsweise innerhalb des Grand Orient auf einer direkten Ernennung durch Cambacérès. ${ }^{41}$ Die Effizienz dieses Systems schlug sich in der immens wachsenden Zahl der Logen während des Premier Empire nieder. ${ }^{42}$

Von dem Ausschluss politischer Themen aus den Logen konnte spätestens ab dem Zeitpunkt des Antritts Napoleons als erster Konsul keine Rede mehr sein. Besaß die Freimaurerei, wie oben gezeigt, bereits im Ancien Régime einen indirekten politischen Gehalt, so hatte dieser unter den veränderten gesellschaftlichen Bedingungen direkter seinen Einzug in die sich neu gründenden Logen Frankreichs gehalten - ein deutliches Indiz ist hierbei etwa auch die führende Rolle der leiblichen Brüder Napoleons innerhalb des Bundes. ${ }^{43}$ Eine Mitgliedschaft der Beamten in einer Freimaurerloge wurde wie in Brüssel daher die Regel.

$38 \mathrm{Zu}$ diesen Angaben vgl. Lennhoff/Posner/Binder (Hg.), Internationales Freimaurer-Lexikon (wie Anm. 18, Kap. I), 168 sowie 298.

39 Siehe zu diesen Angaben sowie Cambacérès' Rolle in der Freimaurerei des Premier Empire Collaveri, La franc-maçonnerie de Bonaparte (wie Anm. 21, Kap. VI), 68-74. Ein Porträt Cambacérès (Öl auf Leinwand, unbekannt, 19. Jh.) findet sich unter: commons.wikimedia.org/wiki/ File\%3AJean-Jacques_R\%C3\%A9gis_Cambac\%C3\%A9r\%C3\%A8s_(Conseil_d'Etat).jpg (Zugriff vom 11.08.2014).

40 Siehe Mollier/Pinaud, L'état-major maçonnique (wie Anm. 3, Kap. VI), insb. 28-34.

41 Vgl. hierzu Dies., L’état-major maçonnique (wie Anm. 3, Kap. VI), 30f.

42 Mollier und Pinaud führen für 1804 die Zahl von 300 Zivil-Logen an. Im Jahr 1810 hatte sich diese Zahl auf 667 ausgeweitet, wobei 626 in den Departements lagen. Siehe hierzu Dies., L'état-major maçonnique (wie Anm. 3, Kap. VI), 21.

43 Lennhoff/Posner/Binder (Hg.), Internationales Freimaurer-Lexikon (wie Anm. 18, Kap. I), 298. Siehe ferner etwa den aufschlussreichen Aufsatz von Yves Hivert-Messeca über Jean Étienne Portalis (1746-1807): Yves Hivert-Messeca, Portalis, Ministre des Cultes et des Rites ou la Théorie du 
Auch in der Kölner Dreikönigsloge, die am 19.05.1775 durch den GOF gestiftet worden war, ${ }^{44}$ ist dies zu bemerken. Astrid Küntzel bemerkt in ihrer Untersuchung zum Thema der Integration und Ausgrenzung Fremder im Köln der Jahre zwischen 1750 und 1814 zusammenfassend: »Im Jahre 1801 befanden sich unter den 186 Mitgliedern der Loge 96 Auswärtige, darunter viele französische Offiziere und Beamte [...]. Fast völlig verschwanden die Angehörigen des Adels sowie der Klerus aus der Loge, während der Anteil der Beamten und Militärangehörigen stark anstieg. ${ }^{45}$

Bereits im Jahr 1797 hatten staatliche Einrichtungen in den durch Frankreich annektierten Gebieten des Rheinlandes zur Gründung von Gesellschaften aufgerufen, mit dem Ziel, die Bevölkerung den neuen Machthabern anzunähern. ${ }^{46}$ Die Logen des linken Rheinufers in der napoleonischen Zeit wurden somit - wie bereits Winfried Dotzauer treffend feststellte - zu Orten der gezielten »Französisierung «, die eine sozial-integrative Funktion erfüllten, ${ }^{47}$ indem sie insbesondere die lokalen Eliten der annektierten Gebiete mit den französischen `Eroberern` zusammenbrachten. Mit den bereits etablierten Freimaurerlogen konnte auch die napoleonische Regierung auf eine gesellschaftliche Formation zurückgreifen, die lediglich - falls nicht bereits wie im Fall der Kölner Dreikönigsloge schon im Ancien Régime geschehen ${ }^{48}$ - dem Grand Orient administrativ unterstellt werden musste. Napoleon beschritt mit der Nutzung der Freimaurerlogen zu politischen Zwecken somit einen Weg, der sich bereits in direktem Anschluss an die nachrevolutionären Entwicklungen abgezeichnet hatte.

Mit der Kaiserkrönung Napoleons, dessen eigene Zugehörigkeit zum Bund umstritten ist, ${ }^{49}$ wird die politische Nutzbarmachung der Logen überdeutlich. Es

Licol Doré, in: Pierre Mollier (Hg.), La franc-maçonnerie sous l'Empire: Un âge d'or?, Paris 2007, 15-39, hier 37.

44 Vgl. zum Stiftungsdatum Rousseau, Der französische Ritus (wie Anm. 25, Kap. VI), hier 265.

45 Küntzel, Fremde in Köln (wie Anm. 14, Kap. VI), 118.

46 Vgl. etwa zur Einrichtung von Lesegesellschaften und dem sogenannten »Konstitutionellen Zirkel« in Köln: Gisela Mettele, Bürgertum in Köln 1775-1870. Gemeinsinn und freie Association (Stadt und Bürgertum, 10), München 1998, 92.

47 Vgl. Dotzauer, Freimaurergesellschaften am Rhein (wie Anm. 56, Kap. I), 237. Zur wichtigen Funktion der Sozietäten für die Integration Fremder siehe insb. Küntzel, Fremde in Köln (wie Anm. 14, Kap. VI), 116-125; Müller, Köln von der französischen zur preußischen Herrschaft (wie Anm. 7, Kap. VI), 258-260.

48 So arbeiteten etwa die Kölner Loge Le Secret des trois Rois bereits seit 1775, die Aachener Loge La Constance seit 1799 unter der Aufsicht des Grand Orient. Siehe hierzu die Ausführungen bei Dotzauer, Freimaurergesellschaften am Rhein (wie Anm. 56, Kap. I), 93, 106f. sowie 199.

49 Zur Erörterung dieser Frage siehe vor allem François Collaveri, Napoléon franc-maçon?, 2. Aufl., Paris 2003. Collaveri bleibt in seinem Resümee unentschieden. Ein von Jacques Tuchendler wiederentdecktes Schreiben des zur damaligen Zeit innerhalb der Freimaurerei sehr prominenten Archivars des Rit écossais philosophique, Claude Antoine Thory, aus dem Jahr 1818 schildert die Anbändelung der damaligen Freimaurerei mit dem napoleonischen Regime und negiert indirekt eine Mitgliedschaft Napoleons. Vgl. hierzu Jacques Tuchendler, À propos des archives de Claude Antoine Thory: de la légende à l'histoire, in: Renaissance Traditionelle. Revue d'études maçonniques et symboliques 145 (2006), 32-72, hier 43f.; Mollier/Pinaud, L'état-major maçonnique (wie Anm. 3, Kap. VI), 59-61. 
ist gerade für diese Zeit nicht übertrieben, von einem programmatischen Zweck der Logen zu sprechen, der mit den oben geschilderten Befunden des vermehrten Eintritts von Beamten einhergeht. Pierre Mollier und Pierre-François Pinaud verwiesen auf die große Bedeutung, die die Logen deshalb für den sozialen Austausch und die Korrespondenz der Elite des Premier Empire spielten. Die Freimaurerei war von Napoleon als probates Mittel erkannt worden, mit dem das gesellschaftliche Gefüge der französischen Nation durch eine ordensmäßig zusammengefasste Elite, die innerhalb des sozialen Raums der Loge miteinander kommunizierte und gemeinsam freimaurerisch arbeitete, gefestigt werden konnte. ${ }^{50}$ Im Folgenden wird der These Molliers und Pinauds gefolgt, die in der Freimaurerei des Premier Empire einen "appareil idéologique« sehen, der - und hierzu fügt sich der gelegentlich in der deutschen Freimaurerforschung gebrauchte Begriff von der "unsichtbaren Kirche« - eine gemeinsame »Ideologie « vermitteln konnte.${ }^{51}$ Es ist hier hinsichtlich der durchaus in Teilen ebenfalls aristokratische Züge tragenden Freimaurerei des Premier Empire allerdings die Frage, um welche »Ideologie« es sich dabei handelte. Dies gilt vor allem, wenn man innerhalb der Freimaurerei den durch die Ereignisse der Revolution zwangsläufig verstärkten Ablösungsprozess von der »Blutsideologie« des Adels beachtet und nicht leichtfertig unterstellen will, es handele sich hierbei lediglich um den in den Logenreden der Zeit immer wieder aufscheinenden Kult um Napoleon selbst. ${ }^{52}$

Es wäre hinsichtlich des in den Logen betriebenen Personenkultes um den Herrscher im Übrigen falsch, davon auszugehen, dass Napoleon durch seine Protektion der Freimaurerei eine dauerhafte Kontrolle über seine Eliten gewann, ${ }^{53}$ wenngleich bekannt ist, dass die Logen unter Napoleon mit Polizeispitzeln durchsetzt waren. Die anfängliche Anhänglichkeit der französischen Freimaurer ließ nicht nur im Kernland des Premier Empire seit 1811/12 spürbar nach und spiegelte so auch die öffentliche Meinung wider. ${ }^{54}$ Je tiefer der Stern Napoleons sank, desto mehr bröckelte auch der Rückhalt des Kaisers in den Logen.

Muss in den Vorgängen in der Kölner Loge La Naissance du Roi de Rome deshalb auch eine Form der Kritik am napoleonischen Regime gesehen werden? Hierfür spricht, dass die Loge im Krisenjahr 1814 eine Namensänderung in Amis de la patrie bei der Mère Loge du Rit écossais philosophique beantragte, die durchaus doppeldeutig zu verstehen sein konnte und eine Vorläuferform ihres späteren

50 Vgl. Mollier/Pinaud, L'état-major maçonnique (wie Anm. 3, Kap. VI), insb. 15-17.

51 Siehe hierzu Dies., L'état-major maçonnique (wie Anm. 3, Kap. VI), 64f. Zum Begriff der »unsichtbaren Kirche«, der auf Lessing zurückgeht, siehe etwa Maurice, Freimaurerei um 1800 (wie Anm. 33, Kap. I), 45-51, insb. 48f.

52 Siehe zum Kult um den Kaiser der Franzosen etwa Collaveri, La franc-maçonnerie de Bonaparte (wie Anm. 21, Kap. VI), 80-89.

53 Hierfür spricht etwa die Aussage Molliers und Pinauds, dass sich ab dem Jahr 1811 in den Logen Querelen und offene Gegnerschaft zum Regime bzw. zum Kaiser zeigten. Vgl. Mollier/Pinaud, L'état-major maçonnique (wie Anm. 3, Kap. VI), 17. In diesem Sinne siehe auch Collaveri, La franc-maçonnerie de Bonaparte (wie Anm. 21, Kap. VI), $127 \mathrm{f}$.

54 Vgl. Mollier/Pinaud, L'état-major maçonnique (wie Anm. 3, Kap. VI), 17. 
Namens in preußischer Zeit Zum vaterländischen Verein darstellte. ${ }^{55}$ Handelte es sich bei Joseph zu Salm-Reifferscheidt-Dyck aus freimaurerischer Sicht nur um ein weiteres der »verlorenen Kinder«, über die sich die Brüsseler Loge so beklagte?

Wie im Laufe der Untersuchungen zu Joseph zu Salm-Reifferscheidt-Dyck zu zeigen sein wird, muss in den karnevalesken Betätigungen der Kölner Loge jedoch nicht ausschließlich eine Verballhornung der Freimaurerei gesehen werden - wenngleich dieser Charakter zweifellos in Teilen vorhanden war. Der legere Umgang mit dem freimaurerischen Geheimnis muss vielmehr als ein direktes Produkt ernsthafter Bemühungen innerhalb der historischen Diskussion um die und in der Freimaurerei betrachtet werden, bei der auch die Lehre der Metempsychose durchaus noch eine Rolle spielte und einer aristokratischen Gesellschaftsform entgegenkommen konnte. Dieser Aspekt ist insofern auch hinsichtlich der von Dotzauer im Zuge seiner Untersuchung zu den Logen des Rheinlandes erwähnten "Aussöhnung « einer geringen Zahl von rheinischen Adligen der Kölner Loge mit dem napoleonischen Regime zu bedenken..$^{56}$ Die Fragestellung der Untersuchung muss im Folgenden auch dahin zielen, welches gesellschaftliche Ideal eine Person wie Joseph zu Salm-Reifferscheidt-Dyck verfolgte, der aus einer altadligen Familie des Rheinlandes stammte und sich nun - auch in freimaurerischer Hinsicht - in einem deutlich gewandelten Umfeld bewegte. Zur besseren Beurteilung lohnt es sich, nicht nur die freimaurerische Karriere des späteren Fürsten, sondern auch die zeitlich unmittelbar vor seinem freimaurerischen Engagement liegenden Lebensabschnitte zu untersuchen.

55 La Naissance du Roi de Rome an Bouquairol, Köln, 3. Tag des 3. Monats 5812 (03.05.1812), in: BnF, FM2 535 (MF 4589), fol. 1-3 (ohne Folioangabe im Dokument). Hierzu bereits Müller, Köln von der französischen zur preußischen Herrschaft (wie Anm. 7, Kap. VI), 262.

56 Vgl. Dotzauer, Die Mitglieder der Kölner Freimaurerloge (wie Anm. 179, Kap. V), hier 134-137. 



\title{
VII. Rheinischer Adel und Freimaurerei nach 1789 - Das Beispiel Joseph zu Salm-Reifferscheidt-Dycks
}

\author{
VII.1 Die Familie der Altgrafen zu Salm-Reifferscheidt und ihre \\ Beziehungen zur Wiener Freimaurerei
}

In den Jahren 1785 bis 1791 unternahm Joseph zu Salm-Reifferscheidt-Dyck gemeinsam mit seinem Bruder Franz Joseph und dem Hofmeister Abbé Jacob eine ausgedehnte Kavalierstour. Diese ist noch als Fortsetzung der Traditionen des Adels im ausgehenden Ancien Régime zu sehen. Sie führte die Brüder unter anderem in die Städte Brüssel, Paris und Wien. ${ }^{1}$ Neben zahlreichen Schriften zu historischen Themen finden sich in ihrer Studienbibliothek viele auf der Höhe der zeitgenössischen Wissenschaft stehende naturgeschichtliche Werke, aber auch Andrew Michael Ramsays "Les voyages de Cyrus « ist noch vertreten. ${ }^{2}$ Aus dem Nachweis der Schriften Ramsays lässt sich selbstverständlich nicht auf eine freimaurerische Beeinflussung oder gar eine frühe Mitgliedschaft des Altgrafen Joseph innerhalb des Bundes schließen. Dennoch sollte in Hinblick auf sein späteres Engagement in der Freimaurerei beachtet werden, dass durchaus prominente Freimaurer direkt an der Ausbildung des jungen Grafen beteiligt waren. So unterrichtete etwa der bekannte französische Astronom Jérôme Lefrançais de Lalande (1732-1807) die beiden Brüder in Paris in der Wissenschaft der Astronomie. ${ }^{3}$ Auf Lalande, der zur berühmten Pariser Intellektuellen-Loge Les Neuf Sœurs zählte, wird weiter unten im Zuge der Untersuchungen zu Joseph zu Salm-ReifferscheidtDycks zweiter Ehefrau, Constance de Salm, und ihrem Pariser Salon noch nä-

1 Siehe zur Kavalierstour Heinke Wunderlich, Studienjahre der Grafen Salm-Reifferscheidt (17801791). Ein Beitrag zur Adelserziehung am Ende des Ancien Régime (Beiträge zur Geschichte der Literatur und Kunst des 18. Jh.s, 8), Heidelberg 1984; Sachse, Als in Dyck Kakteen blühten (wie Anm. 2, Kap. I), 53-66; Bernd Klesmann, Erfahrungen in Paris am Vorabend der Revolution, aus: Netzbiographie: Joseph zu Salm-Reifferscheidt-Dyck (1773-1861), in: historicum-estudies. net, [01.05.2014], http://www.historicum-estudies.net/epublished/netzbiographie/ancien-regime/ paris-um-1789 (Zugriff vom 01.05.2014) sowie Elisabeth Schläwe, Der junge Graf als Reiseliterat auf Kavalierstour, aus: Netzbiographie: Joseph zu Salm-Reifferscheidt-Dyck (1773-1861), in: his toricum-estudies.net, [05.06.2014], http://www.historicum-estudies.net/epublished/netzbiographie/ ancien-regime/kavalierstour (Zugriff vom 21.11.2014).

2 Vgl. die Angaben bei Wunderlich, Studienjahre der Grafen Salm-Reifferscheidt (wie Anm. 2, Kap. I), 143 sowie 172-212. Unter den naturwissenschaftlichen Werken ist auch Bonnets "La Contemplation de la nature " vorhanden. Aufgrund des später zu erläuternden personalen Zusammenhangs ist es wichtig zu erwähnen, dass auch Bernard-Germain-Etienne de la Ville Comte de Lacépèdes "Exposition de l'Electricité« sowie Joseph Jérôme Le Français de Lalandes »Abrégé d'Astronomie« den jungen Grafen vorlagen. Zudem erwähnt Wunderlich auf Seite 148, dass die jungen Grafen Antoine Joseph Pernetys "Discours sur la physionomie« lasen. Es muss hierbei erwähnt werden, dass Antoine Joseph Pernety der Begründer des Rit écossais philosophique ist, dem Joseph Salm-Reifferscheidt-Dyck später angehören sollte.

3 Siehe hierzu Ders., Studienjahre der Grafen Salm-Reifferscheidt (wie Anm. 2, Kap. I), 99. Ein Porträt Lalandes (Kupferstich, unbekannt, o.D.) findet sich unter: commons.wikimedia.org/wiki/ File:J\%C3\%A9r\%C3\%B4me_Lalande.jpg (Zugriff vom 11.08.2014). 
her einzugehen sein. ${ }^{4}$ Wichtiger ist hier zunächst der Aufenthalt der Kavaliere in Wien ab September 1789, der aus einer durchaus richtigen Einschätzung der angespannten Lage im Paris des Sommers 1789 durch den Hofmeister resultierte. ${ }^{5}$

Bei dem Aufenthalt in Wien gilt es zu beachten, dass bereits seit Längerem eine Verknüpfung des Geschlechts der Salm-Reifferscheidts mit der Freimaurerei in den habsburgischen Landen bestand. Bereits 1742 wird in der ersten in Wien gegründeten Loge $\mathrm{Zu}$ den drei Kanonen, die alchemistisch arbeitete und der neben zahlreichen anderen Adligen und Militärs auch Franz Stephan von Lothringen angehört haben soll, ein Graf Salm erwähnt. ${ }^{6}$ Lajos Abafi, der bekannte Historiograph der österreichischen und ungarischen Freimaurerei, vermutete, dass es sich hierbei um Karl Anton Josef zu Salm-Reifferscheidt-Bedburg (1697-1755) handelte $^{7}$ - also ein Mitglied jenes Zweiges der Familie Salm-Reifferscheidt, der ebenfalls auf dem Stammbaum auf Schloss Dyck abgebildet war. Diese Zuordnung Abafis ist insofern wahrscheinlich, als die Familie der Altgrafen zu SalmReifferscheidt-Bedburg zu dieser Zeit ihren Lebensmittelpunkt wohl aufgrund ihrer Nähe zum Kaiser noch in Wien hatte und erst der Sohn Karl Anton zu SalmReifferscheidt-Bedburgs, Sigismund, seinen Sitz nach Bedburg verlagerte. ${ }^{8}$

Wichtiger noch als dieses recht frühe Zeugnis der Familie Salm-Reifferscheidt in Verbindung mit der Freimaurerei sind die spätere Verknüpfung des Zweiges Salm-Reifferscheidt-Raitz mit der Geschichte der Strikten Observanz sowie der Nachweis des Einflusses der Gold- und Rosenkreuzer auf Mitglieder dieses Familienzweiges. So ist hier der Name des Grafen Karl Anton zu Salm-ReifferscheidtRaitz (1750-1838) zu erwähnen, der in der Geschichtsschreibung der Freimaurerei mit dem sogenannten Brünner Fund verbunden ist. ${ }^{9}$ Der Graf war Meister vom Stuhl der Loge Zur aufgehenden Sonne, die in den Jahren von 1782 bis 1785 im mährischen Brünn arbeitete und sich unter dem Einfluss der Gold- und Rosenkreuzer auch mit Magie befasste. ${ }^{10}$ Er war zudem stark in der Strikten Observanz

4 Siehe zur Mitgliedschaft Lalandes in der Loge Neuf Sœurs Robert Bied, Le rôle d'un salon littéraire au début du XIX ${ }^{\mathrm{e}}$ siècle: les amis de Constance de Salm, in: Revue de l'Institut Napoléon 113 (1977), 121-160, insb. 135-139.

5 Siehe zu der angeführten Einschätzung des Abbé Jacob sowie den angeführten Reisedaten Sachse, Als in Dyck Kakteen blühten (wie Anm. 2, Kap. I), $62 \mathrm{f}$.

$6 \mathrm{Zu}$ diesen Angaben siehe Lajos Abafi, Geschichte der Freimaurerei in Österreich-Ungarn, Bd. 1, Budapest 1890, 85-87; Frick, Die Erleuchteten (wie Anm. 3, Kap. IV), 350.

7 Vgl. Abafi, Geschichte der Freimaurerei in Österreich-Ungarn (wie Anm. 6, Kap. VII), 86.

8 Vgl. hierzu den Quellenbeleg bei Heinrich Helmut Dunkhase, Das Fürstentum Krautheim. Eine Staatsgründung um Jagst und Tauber 1802-1806 (1839), Diss., Würzburg 1967, 2. Auf dem Stammbaum der Familie auf Schloss Dyck ist der letzte genannte Bedburger Franz Wilhelm zu SalmReifferscheidt-Bedburg. Fälschlicherweise ist hier das Jahr 1600 als Todesjahr für ihn oder seine Frau Marie Agnes Slavata angegeben. Franz Wilhelm starb 1734 in Wien, seine Frau war 1718 ebenda verstorben.

9 Vgl. hierzu den entsprechenden Eintrag bei Lennhoff/Posner/Binder (Hg.), Internationales Freimaurer-Lexikon (wie Anm. 18, Kap. I), 156.

10 Siehe zu diesen Angaben Dies. (Hg.), Internationales Freimaurer-Lexikon (wie Anm. 18, Kap. I), 156; Martin Javor, Slobodomurárske Hnutie V Českých Krajinách A V Uhorsku V 18. Storočí, Prešov 2009, insb. 47-49. 
engagiert und nahm als Vertreter der Provinzialloge von Österreich am Wilhelmsbader Konvent teil. ${ }^{11}$ Das Archiv der Loge Zur aufgehenden Sonne versteckte der Graf Karl Anton nach Erlöschen der Loge in einem Geheimfach seiner Bibliothek auf dem Schloss Raitz, das unweit von Brünn gelegen ist. ${ }^{12}$ Es kann davon ausgegangen werden, dass auch er die Freimaurerei als eine aristokratische Vergesellschaftungsform auffasste, deren Pforten sich nur für einen kleinen, ausgesuchten Kreis öffnen sollten. ${ }^{13}$

Auch die Bestände der Familienbibliothek der Grafen zu Salm-ReifferscheidtRaitz spiegeln eine eher konservative Haltung wider. Die umfassende Bibliothek beinhaltete neben einer großen Zahl alchemistischer Schriften zahlreiche Werke aus den Naturwissenschaften sowie Schriften freimaurerischer und rosenkreuzerischer Provenienz und der Dämonologie. ${ }^{14}$ Der Sohn Karl Antons, Altgraf Hugo Franz zu Salm-Reifferscheidt-Raitz (1776-1836), war ebenfalls noch stark an der Alchemie interessiert, da er die Familienbibliothek um einen großen alchemistischen Bestand aus der Hand des Grafen von Küenburg erweiterte. ${ }^{15}$ In dem Altgrafen Hugo finden wir - ebenso wie bei Joseph zu Salm-Reifferscheidt-Dyck - eine starke Begeisterung für naturwissenschaftliche Themen. Nebenbei sei bemerkt, dass Hugo einem Gerücht zufolge selbst Geisterbeschwörungen durchgeführt hatte und während einer Reise nach Straßburg, die Nachforschungen über den Mesmerismus diente, mit Jérôme Lefrançais de Lalande Bekanntschaft machte. ${ }^{16}$

11 Vgl. Lennhoff/Posner/Binder (Hg.), Internationales Freimaurer-Lexikon (wie Anm. 18, Kap. I), 737; Hammermayer, Der Wilhelmsbader Freimaurer-Konvent (wie Anm. 197, Kap. V), 94. Die Teilnahme als Abgeordneter der österreichischen Provinzialloge und des Strikten Observanz-Kapitels von Hermannstadt ist zweifelsfrei bei Hammermayer nachgewiesen.

12 Vgl. hierzu Lennhoff/Posner/Binder (Hg.), Internationales Freimaurer-Lexikon (wie Anm. 18, Kap. I), 156. Für die Bereitstellung einiger Informationen zum freimaurerischen Bestand des Archivs der Familie Salm-Reifferscheidt-Raitz in Brünn bedanke ich mich bei Herrn Martin Javor.

13 Hierfür spricht eine durch Salm-Reifferscheidt auf dem Wilhelmsbader Konvent vorgebrachte Beschwerde über die »große Anzahl derer, die sich Freimaurer nennen. « Zitiert nach Eva Huber, Zur Sozialstruktur der Wiener Logen im Josephinischen Jahrzehnt, in: Reinalter (Hg.), Aufklärung und Geheimgesellschaften (wie Anm. 26, Kap. I), 173-188, hier 182.

14 Siehe hierzu die Angaben bei Luboš Antonín, Rájec nad Svitavou [Raitz], in: Handbuch der historischen Buchbestände in Deutschland. Digitalisiert von Günter Kükenshöner, hg. von Bernhard Fabian, Hildesheim 2003, [2003], http://fabian.sub.uni-goettingen.de/?Rajec_Nad_Svitavou (Zugriff vom 31.08.2012), hier Abs. 1.2.

15 Vgl. Ders., Rájec nad Svitavou [Raitz] (wie Anm. 14, Kap. VII), Abs. 2.3.

16 Vgl. hierzu die Ausführungen bei N.N., Hugo Franz Altgraf von Salm-Reifferscheidt-Krautheim, in: Joseph Freiherr von Hormayr (Hg.), Taschenbuch für die vaterländische Geschichte, 29. Jahrgang der gesammten und 11. der neuen Folge, Leipzig 1840, 523-596, hier 551f., Permalink: http:// nbn-resolving.org/urn:nbn:de:bvb:12-bsb10009920-5 (Zugriff vom 21.07.2014). Der Bericht über die Straßburg-Reise findet sich ferner in: Archiv für Geographie, Historie, Staats- und Kriegskunst 7 (1816), 341, Permalink: http://nbn-resolving.org/urn:nbn:de:bvb:12-bsb10530589-8 (Zugriff vom 25.05.2014). Für mich war eine Mitgliedschaft Hugo zu Salm-Reifferscheidt-Raitz' in einer Freimaurerloge nicht nachweisbar. Ein Porträt Hugos (Kupferstich, unbekannt, um 1830) findet sich auf: commons.wikimedia.org/wiki/File:Hugo_Salm_starohrab\%C4\%9B.gif (Zugriff vom 02.08.2014). 
Der Vater Hugos, Karl Anton, war zudem Mitglied der Loge Zur Gekrönten Hoffnung in Wien. Bei der Loge Zur Gekrönten Hoffnung handelte es sich um eine durch den Adel dominierte Loge, der mit Maximilian von Kempis im Jahr 1782 auch ein rheinischer Adliger während seiner Studienreise angehört hatte. ${ }^{17}$ Das am 11.12.1785 veröffentlichte Freimaureredikt Kaiser Josephs II. richtete sich nicht allein gegen den Orden der Illuminaten, sondern nahm auch das alchemistische Laborieren in den Blick, wie es auch in der Gekrönten Hoffnung nachzuweisen ist - und traf hiermit den konservativen Adel ins Mark. ${ }^{18}$ Neben dem Einfluss der Illuminaten war die Freimaurerei Wiens in den 1780er Jahren stark durch die Gold- und Rosenkreuzer sowie das Hochgradsystem der Asiatischen Brüder geprägt. ${ }^{19}$ Die Vorstellungswelten der Alchemie, aber auch der Glaube an Mesmerismus und Geisterbeschwörung waren im Wien der Jahrhundertwende also noch aktuell. Das kaiserliche Handbillett zeitigte aber größere Wirkung als die diversen päpstlichen Bullen des 18. Jahrhunderts. Für Wien bedeutete dies konkret auch eine Zurückdrängung des Hochgradwesens. ${ }^{20}$

In Wien verblieben in der Folge des Edikts anstelle der acht ursprünglichen Logen nur noch zwei sogenannte Sammellogen. ${ }^{21}$ Da die erste dieser Sammellogen, die sich Zur Wahrheit nannte, nur bis 1789 arbeitete, bestand zur Zeit des Aufenthalts Joseph zu Salm-Reifferscheidt-Dycks anlässlich seiner Kavalierstour in Wien nur noch die Sammelloge Zur neugekrönten Hoffnung, die 1786275 Mitglieder zählte und sich im Jahr 1793 auflöste. ${ }^{22}$ Karl Anton zu Salm-Reifferscheidt-

17 Siehe zur Mitgliedschaft Karl Anton zu Salm-Reifferscheidt-Raitz' die Angaben bei Huber, Zur Sozialstruktur der Wiener Logen (wie Anm. 13, Kap. VII), hier 174-175. Im Archiv Burg Kendenich hat sich lediglich die Mitgliedsurkunde Maximilian von Kempis' erhalten, die bereits von Joseph Hansen angeführt wurde. Maximilian von Kempis wurde demnach anlässlich seiner Studienreise 1782 in die Wiener Loge aufgenommen. Vgl. Hansen, Quellen zur Geschichte des Rheinlandes (wie Anm. 181, Kap. V), 60. Zu den durchaus liberalen Einstellungen Maximilian von Kempis' bezüglich seines Begräbnisses sowie des Totengedenkens vgl. Maria Rößner-Richarz, Selbstzeugnisse als Quellen adliger Lebenswelten in der Sattelzeit. Eine Bestandsaufnahme, in: zeitenblicke 9/1 (2010), [10/06/2010], http://nbn-resolving.org/urn:nbn:de:0009-9-21027 (Zugriff vom 13.10.2014), hier Abs. 22.

18 Siehe hierzu vor allem Frick, Die Erleuchteten (wie Anm. 3, Kap. IV), 350f. Ferner die Einschätzung bei Biedermann, der einen Auszug aus einer Anleitung der Loge aus dem Jahr 1780 zur Einrichtung eines alchemistischen Laboratoriums zitiert. In dem alchemistischen Laborieren der adligen Mitglieder der Gekrönten Hoffnung vermutet Biedermann die Gier nach Gold. Siehe Biedermann, Das verlorene Meisterwort (wie Anm. 3, Kap. IV), 142. In Bezug auf die Deutbarkeit der Alchemie hinsichtlich der Blutsideologie scheint jedoch gerade ein Nebensatz in der bei Biedermann zitierten Anleitung zu stehen. Dieser lautet: »[...] gleich wie das Vollkommene selbsten aus dem Vollkommensten gezeiget [gezeugt] worden ist «. Zitiert nach Ders., Das verlorene Meisterwort (wie Anm. 3, Kap. IV), 142.

19 Zur Dominanz von Illuminaten, Rosenkreuzern und Asiatischen Brüdern in den Logen Wiens vgl. die Feststellung bei Huber, Zur Sozialstruktur der Wiener Logen (wie Anm. 13, Kap. VII), hier 173; Jacob Katz, Der Orden der Asiatischen Brüder, in: Reinalter (Hg.), Freimaurer und Geheimbünde (wie Anm. 30, Kap. V), 240-283; Frick, Die Erleuchteten (wie Anm. 3, Kap. IV), 350f.

20 Vgl. Huber, Zur Sozialstruktur der Wiener Logen (wie Anm. 13, Kap. VII), hier 184.

21 Vgl. hierzu Ders., Zur Sozialstruktur der Wiener Logen (wie Anm. 13, Kap. VII), hier 185.

22 Vgl. hierzu die Angaben bei Ders., Zur Sozialstruktur der Wiener Logen (wie Anm. 13, Kap. VII), hier $185 f$. 
Raitz war Mitglied der Loge, er engagierte sich jedoch stärker in der Freimaurerei Brünns. Die Loge Zur Gekrönten Hoffnung bzw. Zur neugekrönten Hoffnung führte ihn in ihren Mitgliedslisten von 1781 bis 1790 als »abwesend « auf. ${ }^{23}$

Alfred Whittaker verwies in seinen Studien zu dem Geologen und Forschungsreisenden Karl Ludwig Giesecke auf die Mitgliedschaft Joseph zu Salm-Reifferscheidt-Dycks in der Loge Zur neugekrönten Hoffnung. ${ }^{24}$ Joseph zu Salm-Reifferscheidt-Dyck reiste zwar erst im Frühjahr des Jahres 1791 aus Wien ab, ${ }^{25}$ was eine Mitgliedschaft in der Loge Zur neugekrönten Hoffnung ermöglicht hätte, anhand der Logenlisten aus den Jahren 1790 bis 1792 lässt sich eine solche dennoch nicht nachweisen. ${ }^{26}$ Der von Whittaker angeführte Kontakt zum Mitglied der Neugekrönten Hoffnung Karl Ludwig Giesecke um das Jahr 1800 ist jedoch zweifelsfrei belegt und für beide Studien weit wichtiger als der eigentliche Aufnahmeort des Altgrafen, der vorerst weiter ungeklärt bleibt. ${ }^{27}$

In den Stammbüchern Gieseckes findet sich laut den Angaben bei Whittaker und Edward Dent ein Autograph Joseph zu Salm-Reifferscheidt-Dycks. Der Altgraf zitiert hier eine Passage aus dem Libretto von Mozarts "Zauberflöte«. Diese lautet: »Nur der Freundschaft Harmonie mildert die Beschwerden, ohne diese Simpathie gibt's kein Glück auf Erden. $\aleph^{28}$ Die Anlehnung an die "Zauberflöte» Mozarts ist dabei wohl nicht zufällig, wie auch Whittaker erläutert. Wolfgang Amadeus Mozart war bis zu seinem Tod im Jahr 1791 Mitglied der Loge Zur neugekrönten Hoffnung. ${ }^{29}$ Giesecke gab nach Mozarts Tod an, am Libretto der

23 Vgl. hierzu die Angaben bei Eva Huber, Sozialstruktur der Wiener Freimaurer 1780-1790, 2. Teil, Diss., Wien 1991, o.S.

24 Es handelt sich hier offenbar um eine Verwechslung mit Karl Anton zu Salm-ReifferscheidtRaitz, der u.a. auch den Vornamen Joseph trug. Siehe hierzu Alfred Whittaker, Karl Ludwig Giesecke, His Life, Performance and Achievements, in: Mitteilungen der Österreichischen Mineralogischen Gesellschaft 146 (2001), 451-479, hier 459f., http://www.uibk.ac.at/mineralogie/oemg/ bd_146/146_451-479.pdf (Zugriff vom 25.05.2014); Ders., Karl Ludwig Giesecke: His Albums and his likely involvement in the writing of the Libretto of Mozart's Opera The Magic Flute, in: Mitteilungen der Österreichischen Mineralogischen Gesellschaft 155 (2009), 321-332, hier insb. 324-327, http://www.uibk.ac.at/mineralogie/oemg/bd_155/155_321-332.pdf (Zugriff vom 25.05.2014). Ich bedanke mich bei Herrn Whittaker für die freundliche Auskunft zu den von ihm gemachten Angaben.

25 Diese Angabe findet sich bei: Sachse, Als in Dyck Kakteen blühten (wie Anm. 2, Kap. I), 65.

26 Die Mitgliedsliste aus dem Jahr 1790 findet sich in: Tadeusz Krzeszowiak, Freihaustheater in Wien 1787-1801. Wirkungsstätte von W. A. Mozart und E. Schikaneder, Wien/Köln/Weimar 2009, 410416, hier insb. 416. Siehe zur Mitgliederliste von 1791 Gerald Fischer-Colbrie, Die Mitgliederliste der Freimaurerloge "Zur gekrönten Hoffnung « aus Mozarts Sterbejahr aufgefunden, in: Mitteilungen der Internationalen Stiftung Mozarteum 3-4 (1993), 35-47, hier 41-47. Ebenfalls wurde herangezogen: Verzeichnis der Mitglieder der Gerechten und vollkommenen St. Johannes $\square$ Zur Gekrönten Hoffnung im Orient von Wien, Wien 1792.

27 Siehe den Abdruck des Autographs bei Whittaker, Karl Ludwig Giesecke: His Albums (wie Anm. 24, Kap. VII), hier 325.

28 Hier wird der Wiedergabe des Autographs bei Edward Dent gefolgt. Siehe Edward Joseph Dent, Mozarts Opern, Berlin 1922, 210.

29 Zu Mozart als Freimaurer siehe Hans-Josef Irmen, Mozart. Mitglied geheimer Gesellschaften, Zülpich 1988, hier vor allem 180-183; Fischer-Colbrie, Die Mitgliederliste der Freimaurerloge "Zur gekrönten Hoffnung (wie Anm. 26, Kap. VII), 35-47. 
»Zauberflöte« mitgewirkt zu haben. ${ }^{30}$ Unabhängig vom Wahrheitsgehalt dieser Aussage Gieseckes ist es entscheidend, die Verwobenheit des Autographs Joseph zu Salm-Reifferscheidt-Dycks mit verschiedenen Interessenfeldern zu erkennen, die die Biographie des jungen Altgrafen wie Gieseckes gleichermaßen betrafen und insofern zur Verbindung der beiden Männer beitrugen. In Bezug auf das hier bearbeitete Thema ist die von Assmann aufgezeigte Verbindung der »Zauberflöte« zum »Wiener Mysterienprojekt « der Loge Zur wahren Eintracht von Bedeutung. ${ }^{31}$

Assmann erläutert in seiner Studie das große Interesse der Gebildeten zum Ende des 18. Jahrhunderts an einer Erforschung der antiken Mysterien, welches auch durch die vernichtenden Ergebnisse des Wilhelmsbader Konvents weiter forciert wurde. ${ }^{32}$ Das Ziel dieser Mysterienforschung war die Entlarvung der antiken Götter-Religionen als durch die geistigen Eliten einer Gesellschaft kreierte Fiktionen. Diese sollten das Volk über die Vorstellung göttlicher Autoritäten zur Einhaltung der Gesetze des Gemeinwesens anleiten. ${ }^{33}$ Diese »Kleinen Mysterien « stellten den Aberglauben des »Pöbels« dar, wohingegen die »Großen Mysterien« der "geistigen Elite« vorbehalten blieben und ihrem Adepten durch eine »emotionale Schocktherapie« die Fiktionalität der Göttergestalten, die Wahrheit des »einen Gottes « sowie das Geheimnis von Tod und Wiedergeburt offenbaren sollten. ${ }^{34}$ Assmann kommt für die Handlung der "Zauberflöte« zu dem Schluss, dass Mozart und Schikaneder das Ziel verfolgten, den »starren Antagonismus zwischen Volksreligion und Elitereligion" aufzubrechen und sich in der "Zauberflöte» eine »freimaurerische Aufklärung « zeige. ${ }^{35}$ Das Beispiel der »Zauberflöte« ist insofern sehr gut geeignet, das Vorhandensein einer Strömung innerhalb der Freimaurerei zum Ende des 18. Jahrhunderts zu illustrieren, die in einem Wechselspiel aus Scherz und Ernst in Teilen auf eine Popularisierung der »Großen Mysterien « als >politisches Allheilmittel zielte.

An dieser Stelle muss im Hinblick auf die oben erfolgten Schilderungen zur »Blutsideologie« danach gefragt werden, wie weit eine solche in der Kunst idealiter vorgezeichnete Allianz zwischen »Pöbel « und »geistiger Elite« um 1800 innerhalb der Freimaurerei tatsächlich bereits existierte. Ein auch für die Freimaurerei wirkmächtiger Katalysator dieser Verbindung ist dabei bereits in der Beziehung des Altgrafen Joseph zu Karl Ludwig Giesecke bereits offenkundig. Für beide stellten neben Musik und Kunst die Naturwissenschaften das mit Abstand wichtigste Inte-

30 Diese Beteiligung ist jedoch nicht erwiesen, wobei Giesecke als junger Mann in der Schauspieltruppe Schikaneders im Wiener Freihaustheater spielte und auch als Autor von komödiantischen

Theaterstücken agierte. Siehe hierzu eine Besprechung bei Irmen, Mozart (wie Anm. 29, Kap. VII), hier vor allem 264-269.

31 Siehe Jan Assmann, Die Zauberflöte. Oper und Mysterium, München/Wien 2005, 155-160.

32 Vgl. Ders., Die Zauberflöte (wie Anm. 31, Kap. VII), 155.

33 Vgl. zu den in diesem Abs. gemachten Ausführungen Ders., Die Zauberflöte (wie Anm. 31, Kap. VII), 161f.

34 Vgl. zu den hier gemachten Angaben und Zitaten Ders., Die Zauberflöte (wie Anm. 31, Kap. VII), 162f. sowie 220-230.

35 Vgl. Ders., Die Zauberflöte (wie Anm. 31, Kap. VII), 166. 


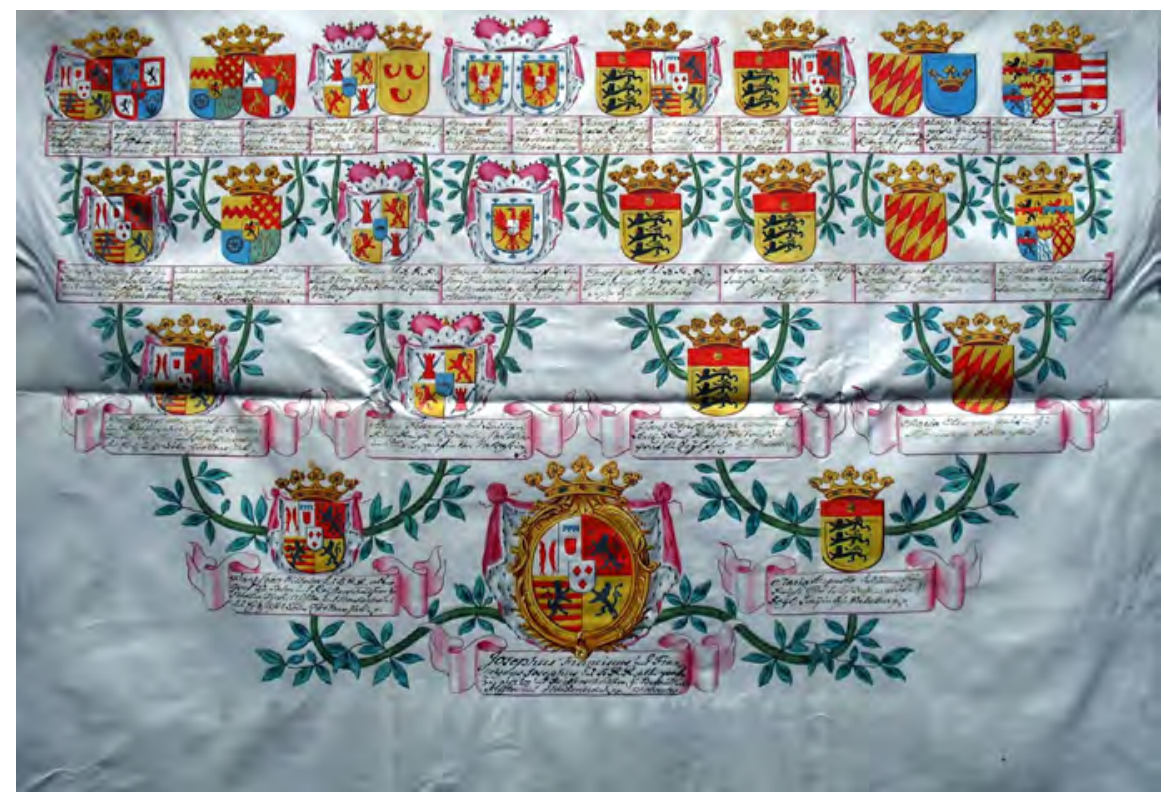

Abbildung 16: Ahnenprobe für den Altgrafen Joseph zu Salm-Reifferscheidt-Dyck und seinen Bruder Franz Joseph, um 1780 (Bildnachweis: ASD; Bildrecht/Werk: Grafen Wolff-Metternich zur Gracht; Foto: M.O. Braun).

ressenfeld dar. Es ist jedoch von Vornherein klar, dass das Interesse des unter französischer Regierung lebenden »Bürgers Salm-Dyck « an den Naturwissenschaften um 1800 nicht mehr dazu dienen konnte, die auf göttlicher Fügung beruhende adlige »Blutsideologie « zu stützen. ${ }^{36}$ Es ist daher zwingend erforderlich, die weitere Vergesellschaftung Joseph zu Salm-Reifferscheidt-Dycks auf eine Alternative zur »Blutsideologie« zu untersuchen.

36 Dieser partielle Bruch mit der familiären Memoria spiegelt sich auch in der vorübergehenden Vernachlässigung des »kulturellen Gedächtnisses« der Familie sowie einer distanzierten Haltung zur katholischen Kirche wider. Letztgenannter Umstand illustriert etwa der bei Margit Sachse erwähnte Verfall und Abriss der Michaelskapelle. Diese war von der Familie Salm-ReifferscheidtDyck erbaut worden. Vgl. zu diesen Angaben Sachse, Als in Dyck Kakteen blühten (wie Anm. 2, Kap. I), 148; Monika Gussone, Einstellung zu den sakralen Monumenten seiner Vorfahren, aus: Netzbiographie: Joseph zu Salm-Reifferscheidt-Dyck (1773-1861), in: historicum-estudies.net, [05.06.2014], http://www.historicum-estudies.net/epublished/netzbiographie/franzoesische-zeit/ monumente (Zugriff vom 21.11.2014). 


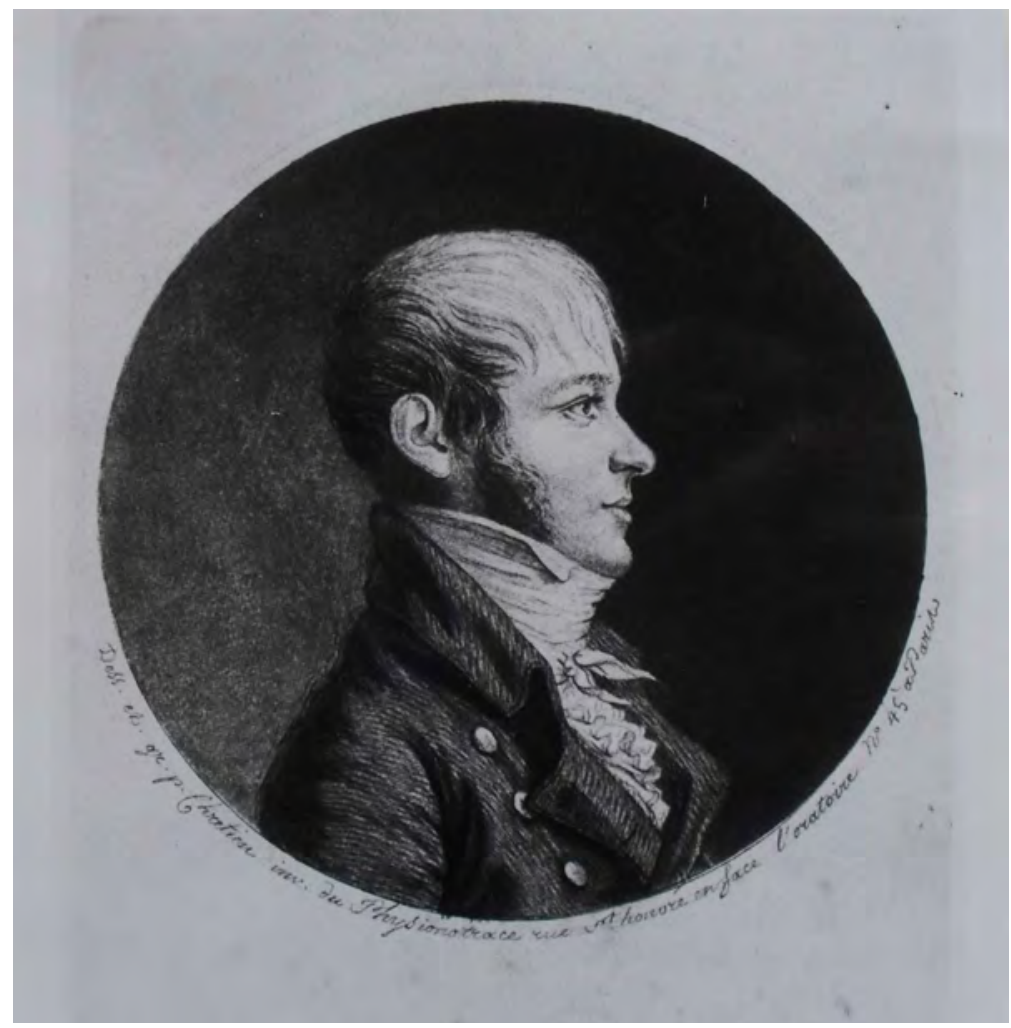

Abbildung 17: Chretien, Porträt Joseph zu Salm-Reifferscheidt-Dycks, Stich, Paris, um 1800 (Bildnachweis: ASD; Bildrecht/Werk: Grafen Wolff-Metternich zur Gracht, Foto: M.O. Braun).

\section{VII.2 Die Mitglieder des Salons der Constance de Salm und das Projekt der Idéologie}

Der Pariser Salon der Constance de Salm (1767-1845) war im nachrevolutionären Paris einer der Anziehungspunkte für Schöngeister und Gelehrte. ${ }^{37}$ Die auch »Muse de la raison " genannte Constance de Salm war in der damals noch zur Bretagne zählenden Stadt Nantes in die adlige Familie de Théis geboren worden. Sie hatte bereits als junge Frau mit dem 1785 im »Almanach de Muses« erschienenen Gedicht »Bouton de rose« als femme de lettres auf sich aufmerksam gemacht. In diesem Gedicht thematisierte Constance auch mit folgenden Worten

37 Siehe hierzu jüngst Gudrun Gersmann, Postrevolutionäre Netzwerke, aus: Netzbiographie: Joseph zu Salm-Reifferscheidt-Dyck (1773-1861), in: historicum-estudies.net, [01.05.2014], http:// www.historicum-estudies.net/epublished/netzbiographie/franzoesische-zeit/netzwerke (Zugriff vom 01.05.2014). 


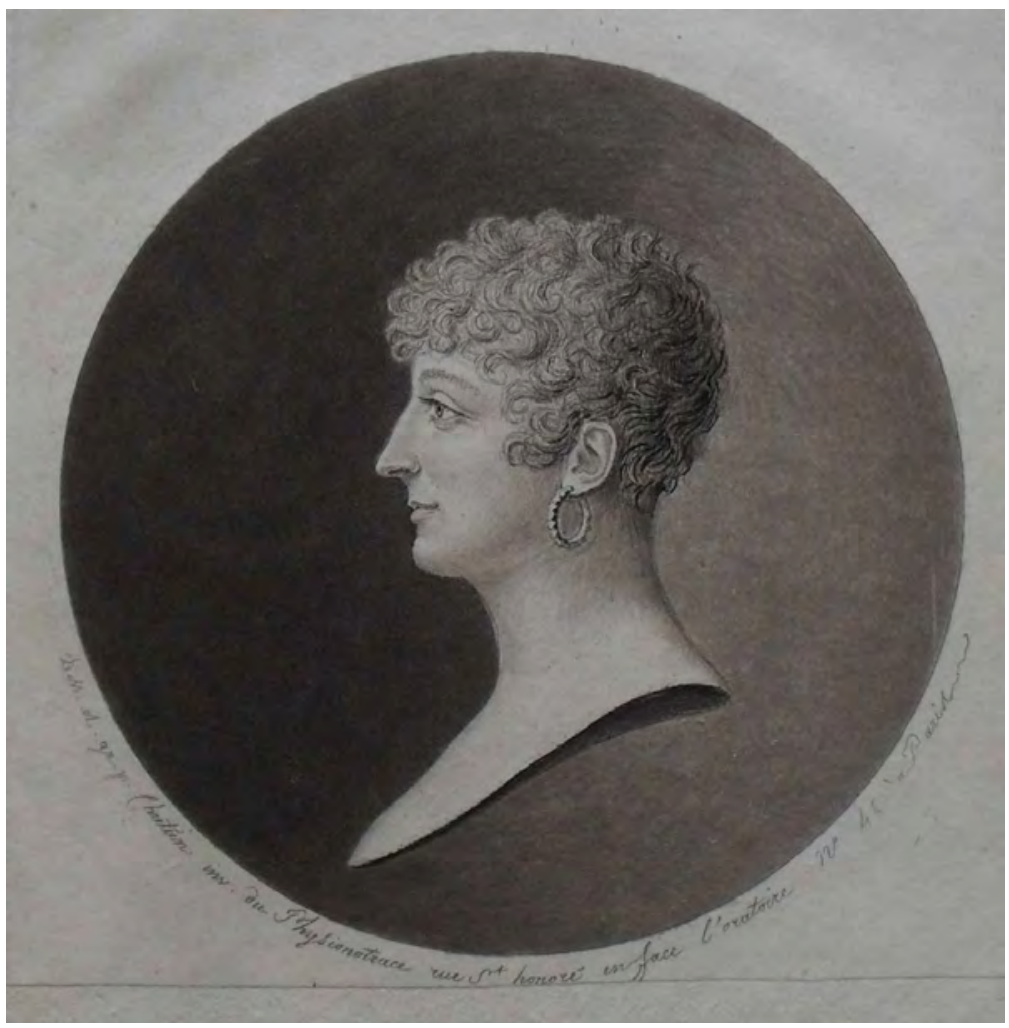

Abbildung 18: Chretien, Porträt Constance de Salms, Stich, Paris, um 1800 (Bildnachweis: ASD; Bildrecht/Werk: Grafen Wolff-Metternich zur Gracht, Foto: M.O. Braun).

die Lehre der Metempsychose: „Bouton de rose,/ Adieu, Rose vient, je la voi:/ S’il est une métempsycose,/ Grands dieux! par pitié rendez-moi/ Bouton de rose. ${ }^{38}$ Neben dem antikisierenden Anruf der Götter wird hier die Metempsychose mit dem Symbol der Rose in Verbindung gebracht, das ebenfalls für die Wiedergeburt stehen kann. ${ }^{39}$ Die Metempsychose wird durch das konditionale »si « jedoch deutlich in den Bereich des Unergründlichen verwiesen. Diese Schwebe im Verhältnis zur Lehre der Metempsychose barg zum Ende des 18. Jahrhunderts auch eine politische Konnotation in sich, die in der folgenden Besprechung zu beachten ist. Zunächst sei hier aber auf einige Aspekte der Biographie der Dichterin und ihres sozialen Umfeldes eingegangen, da sie für die freimaurerische Verge-

38 N.N., Poésies de Madame La Princesse Constance de Salm, Bd. 2, 3. Aufl., Paris 1835, 209f., hier 210, Permalink: http://gallica.bnf.fr/ark:/12148/bpt6k5601159q (Zugriff vom 25.05.2014).

39 Siehe hierzu die Eintragungen zum Thema "Rose" sowie »Rosenkreuz« bei Lennhoff/Posner/ Binder (Hg.), Internationales Freimaurer-Lexikon (wie Anm. 18, Kap. I), $715 f$. 
sellschaftung ihres späteren Ehemannes aus dem Rheinland nicht unerheblich sein sollten.

Im Jahr 1803 heiratete Constance Joseph zu Salm-Reifferscheidt-Dyck. ${ }^{40}$ Ebenso wie für den nun offiziell unter französischer Regierung lebenden »Citoyen Joseph de Salm-Dyck«, der sich im Jahr 1800 von seiner ersten Frau, der Gräfin Marie Therese von Hatzfeld (1776-1838), getrennt hatte, war dies für sie die zweite Ehe. ${ }^{41}$ Wie bereits oben gesehen, war die Mitgliedschaft von Medizinern in Freimaurerlogen des Ancien Régime nicht ungewöhnlich. Dies traf etwa auch auf den ersten Ehemann der Constance, Jean-Baptiste Pipelet de Leury (1759-1823), zu. Pipelet entstammte einer begüterten Pariser Chirurgen-Familie, die auch in den Pariser Freimaurerlogen des Ancien Régime verkehrte. So gehörten Jean-Baptiste und sein Bruder vor der Revolution der Loge L'Innocence Reconnue an. ${ }^{42}$ Der Vater, François Pipelet, war Mitglied der Hochgrad-Loge Saint-Alexandre d'Écosse, die im Jahr 1806 als sogenannte Mère Loge die Leitung des später in Bezug auf Joseph zu Salm-Reifferscheidt-Dyck noch ausführlicher zu behandelnden hermetisch-alchemistischen Rit écossais philosophique übernehmen sollte. ${ }^{43}$

Salm-Dyck war zwar kein Chirurg, teilte aber mit vielen Besuchern des Salons das Interesse für die schönen Künste, die Philosophie und die Naturwissenschaf-

40 Vgl. Sachse, Als in Dyck Kakteen blühten (wie Anm. 2, Kap. I), 111.

41 Vgl. Dies., Als in Dyck Kakteen blühten (wie Anm. 2, Kap. I), 109-111; Monika Gussone, Hochzeit in der Familie, aus: Netzbiographie: Joseph zu Salm-Reifferscheidt-Dyck (1773-1861), in: historicum-estudies.net, [05.06.2014], http://www.historicum-estudies.net/epublished/netzbio graphie/ancien-regime/hochzeit (Zugriff vom 21.11.2014); Gudrun Gersmann, Die Ehen, aus: Netzbiographie: Joseph zu Salm-Reifferscheidt-Dyck (1773-1861), in: historicum-estudies.net, [05.06.2014], http://www.historicum-estudies.net/epublished/netzbiographie/franzoesische-zeit/ ehen (Zugriff vom 21.11.2014); Hannah Schneider, „Unvergängliche Werke des Geistes und der Wissenschaft « - die Schriftstellerin Constance de Salm und ihr Ehemann, aus: Netzbiographie: Joseph zu Salm-Reifferscheidt-Dyck (1773-1861), in: historicum-estudies.net, [01.05.2014], http:// www.historicum-estudies.net/epublished/netzbiographie/preussische-zeit/werke (Zugriff vom 01.05.2014); Kopie der Reichskammergerichtsakten, April 1798 (in Auszügen), Transkription Elisabeth Schläwe, aus: Netzbiographie: Joseph zu Salm-Reifferscheidt-Dyck (1773-1861), in: his toricum-estudies.net, [01.05.2014], http://www.historicum-estudies.net/epublished/netzbiogra phie/transkriptionen/prozessakten-in-auszuegen-1798 (Zugriff vom 01.05.2014). Erklärung des Friedensrichters zur Flucht der Maria Theresia von Hatzfeld, August 1801, Transkription Elisabeth Schläwe, aus: Netzbiographie: Joseph zu Salm-Reifferscheidt-Dyck (1773-1861), in: his toricum-estudies.net, [01.05.2014], http://www.historicum-estudies.net/epublished/netzbiographie/ transkriptionen/erklaerung-des-friedensrichters-1801 (Zugriff vom 01.05.2014).

42 Vgl. hierzu Alain Le Bihan, Francs-maçons parisiens du Grand Orient de France (Fin du XVIII siècle) (Commission d'Histoire Économique et Sociale de la Révolution Française, Mémoires et Documents, 19), Paris 1966, 398. Die Einträge Le Bihans lauten: »PIPELET fils (Jean-Baptiste) (1759-1823). Avocat. Chirurgien en 1786. - L'Innocence Reconnue, 1784. PIPELET (Nicolas) $\left(\right.$ PIPELET $\left.2^{\mathrm{e}}\right)$. Chirurgien de la Ville de Paris, depuis 1757. - L'Innocence Reconnue, 1785. PIPELET l'aîne (François) (PIPELET 1 1er). Maître en chirurgie, depuis 1750. - Saint-Alexandre d'Ecosse, 1784-86. PIPELET de MONTIZEAUX (François-Marie). Avocat en Parlement. - Saint-Alexandre d'Ecosse, 1784-89. Souv. Chap. De la R.M.L.E., 1785-87...«

43 Vgl. Le Bihan, Francs-maçons parisiens (wie Anm. 42, Kap. VII), 398. Zur Leitung des Rit écossais philosophique durch die Loge Saint-Alexandre d'Ecosse siehe die Angaben bei Frick, Licht und Finsternis (wie Anm. 61, Kap. V), 35. 
ten. Laut einer Aussage ihres Bruders, Alexandre, hatte auch Constance bereits während der Revolution Kontakte mit Wissenschaftlern und Künstlern gepflegt, wie dem bereits im Zusammenhang mit der Familie Salm-Reifferscheidt erwähnten Astronomen Joseph-Jérôme de Lalande, dem Geographen und Schriftsteller Edme Mentelle (1730-1815) ${ }^{44}$ oder dem Komponisten Jean Paul Martini (17411816). ${ }^{45}$ In den Jahren nach der Heirat mit Joseph Salm-Dyck stießen weitere Personen zu diesem Kreis, wobei hier als prominente Beispiele nur der Natur- und Altertumsforscher Aubin-Louis Millin (1759-1818) und Alexander von Humboldt - ebenfalls Freimaurer - (1769-1859) genannt seien. ${ }^{46}$

Wie schon im Verhältnis Josephs zu Karl Ludwig Giesecke ist die Verbindung der Interessenfelder »Kunst « und »Naturwissenschaften « also auch beim Ehepaar Joseph und Constance de Salm-Dyck von Wichtigkeit. Auffällig ist hier, wie sehr das Thema der Memoria in den jeweiligen Arbeitsgebieten der Salonmitglieder von Belang war. Welche Bedeutung die Memoria auch im nachrevolutionären Paris noch hatte, wird etwa im Verhältnis Joseph-Jérôme de Lalandes zu Constance de Salm ersichtlich. Der berühmte Astronom hatte Constance dazu auserkoren, nach seinem Ableben einen Nekrolog auf ihn zu halten. Der Schriftstellerin kam somit die Aufgabe zu, sein Lebenswerk nachträglich in einer aus seiner Sicht angemessenen Weise zu würdigen. Dass sie dies erfolgreich tat, beweist ihre am 19.05.1809 in der Athénée des arts gehaltene »Eloge Historique de M. De La Lande $\ll .{ }^{47}$

Auch Lalande hatte während seines Lebens zahlreiche Elogen auf verdiente Persönlichkeiten des literarischen oder wissenschaftlichen Metiers gehalten. Constance maß diesen Lobreden große Bedeutung bei, da sie ihrer Meinung nach

44 Mentelle verstand sich selbst vor allem als Schriftsteller und betonte in seinem Werk stark die pädagogische Bedeutung der Geographie. Zu seiner Biographie und seinem wissenschaftlichen Werk siehe den Aufsatz von Michael Heffernan, Edme Mentelle's Geographies and the French Revolution, in: David N. Livingstone/Charles W.J. Whithers (Hg.), Geography and Revolution, Chicago 2005, 273-303, hier insb. zu seiner Beziehung zu Constance de Salm, 295. Ein Porträt Mentelles (Kupferstich von Conrad Westermayr und Jean Henri Cless, 1801) findet sich unter: commons. wikimedia.org/wiki/File:Edme_Mentelle_AGE_V08_1801.jpg (Zugriff vom 02.08.2014).

45 Vgl. zu den Kontakten der Constance während der Revolution: Bied, Le rôle d'un salon littéraire (wie Anm. 4, Kap. VII), hier 123.

46 Vgl. hierzu die Angaben bei Ders., Le rôle d'un salon littéraire (wie Anm. 4, Kap. VII), hier $123 f$.

47 Constance de Salm, Eloge Historique de M. De La Lande; par M. ${ }^{\text {me }}$ la C. ${ }^{\text {tesse }}$ Constance de Salm, Paris 1810, Permalink: http://gallica.bnf.fr/ark:/12148/bpt6k5613408b (Zugriff vom 17.07.2014). Zur Zeitangabe sowie zum Brief Lalandes mit der Bitte an Constance, den Nekrolog zu halten, vgl. Préface. Was Lalande sich von diesem Nekrolog erhoffte, scheint in einer Anrede auf, die er innerhalb eines auf den 01.07.1805 datierten Briefes für Constance benutzte. Hier bezeichnete er die Dichterin als »chere garant de mon immortalité«. Siehe hierzu Marie-Thérèse Pallot-Raguet, Correspondance de Constance de Salm (1795-1811). Édition critique, Diss. (unveröffentlicht), 257. Ich danke Frau Pallot-Raguet für die Bereitstellung ihres Manuskripts. Ein Erschließungsprojekt des DHIP widmete sich in den vergangenen Jahren unter Leitung von Frau Florence de PeyronnetDryden der Digitalisierung und Inventarisierung des umfangreichen Korrespondenz-Nachlasses der Constance de Salm, der durch die Société des Amis du Vieux Toulon et de sa Région verwahrt wird. Das Inventar ist online einsehbar unter http://www.constance-de-salm.de (Zugriff vom 25.05.2014). 
eine Vorbildfunktion für die nachfolgenden gens de lettre et gens du monde $«^{48}$ erfüllten. Wie in einer Familie das generationenübergreifende Verantwortungsbewusstsein durch die Vorbildfunktion der einzelnen Mitglieder aufrechterhalten werden musste, so mussten diese Vorbildfunktion auch alle "gens de mérite" erfüllen, denn: »Les gens de mérite de tout l'univers sont comme une immense famille, unie par les lumières de l'esprit, et qui éprouve sans cesse le besoin impérieux de se voir et de se communiquer. ${ }^{49}$ Der Kern der bereits im Ancien Régime durch die Philosophie der Aufklärer vermittelten Erziehungslehren, wie etwa der des Christian Thomasius, klang also auch hier noch nach. Die Ehre und damit die Aufnahme in die illustre Familie der "gens de mérite « hingen für Constance fast zwangsläufig mit der Begabung für die Wissenschaft, Literatur oder Kunst sowie dem Drang zusammen, sich in exklusiven Zirkeln zu vergesellschaften.

Um diese Ansicht Constance de Salms zu verstehen, ist es wichtig zu erwähnen, dass eine nicht geringe Zahl von Mitgliedern des Salons der Constance der Gruppe der sogenannten Idéologues oder zumindest ihrem Umfeld zuzurechnen war, wie beispielsweise Pierre Louis Ginguené (1748-1816), einer der Gründer der wichtigsten Zeitschrift der Idéologues, der »Décade philosophique, littéraire et politique ${ }^{50}{ }^{50}$ Mit Destutt de Tracy und Pierre-Jean-Georges Cabanis (1757-1808) an ihrer Spitze zielten die Idéologues besonders in den Jahren des Direktoriums auf ein programmatisches Zusammenwirken der Künste und Wissenschaften, welches die Errungenschaften der Revolution durch die politische wie moralische Bildung der französischen Nation verfestigen sollte. In diesem Zuge wollte allen voran Destutt de Tracy das neue Wissensgebiet der Idéologie etablieren. ${ }^{51}$ Diesem war letztlich die Aufgabe zugedacht, den Staat über die Erkenntnis der Entstehungsbedingungen des menschlichen Denkens und Handelns mit Hilfe der Methoden der zeitgenössischen Wissenschaft bei der Gesetzgebung zu unter-

48 Salm, Eloge Historique de M. De La Lande (wie Anm. 47, Kap. VII), 22.

49 Dies., Eloge Historique de M. De La Lande (wie Anm. 47, Kap. VII), $27 \mathrm{f}$.

50 Vgl. Bied, Le rôle d'un salon littéraire (wie Anm. 4, Kap. VII), hier insb. 135. Siehe außerdem François Picavet, Les Idéologues. Essai sur l'histoire des idées et des théories scientifiques, philosophiques, religieuses, etc. en France depuis 1789, Diss., Paris 1891, Permalink: http://gallica.bnf.fr/ ark:/12148/bpt6k108222f (Zugriff vom 25.05.2014); Marc Regaldo, Un milieu intellectuel: la Décade philosophique (1794-1807), 5 Bde., Diss., Paris 1976, hier insb. Bd. 1, 26 sowie 28f. Ob der Name "Décade« dabei auch durch den Stellenwert der "Dekade« im Corpus Hermeticum als Zahl der Vollendung interpretiert werden kann, kann hier nicht gesagt werden. Vgl. zur »Dekade« im Corpus Hermeticum etwa Stuckrad, Was ist Esoterik? (wie Anm. 34, Kap. I), $40 \mathrm{f}$.

51 Zum Begriff der »Idéologie« vgl. die Ausführungen bei Ulrich Dierse, Die Anfänge der >science sociale bei den französischen Ideologen und in ihrem Umkreis, in: Gudrun Gersmann/Hubertus Kohle (Hg.), Frankreich 1800. Gesellschaft, Kultur, Mentalitäten, Stuttgart 1990, 104-121, hier insb. 113. Laut Ulrich Dierse teilte sich die Wissenschaft der Ideologie in vier verschiedene Bereiche auf: »[...] auf die Untersuchung der Entstehung der menschlichen Vorstellungen (`idées $`$ ) folgt die Wissenschaft, wie diese nach einem Regelsystem mitgeteilt werden (`grammaire`), wie sie miteinander kombiniert werden (`logique $\triangleleft$ ) und wie schließlich unser Wille und seine Wirkungen vernünftig gelenkt werden (`traité de la volonté et ses effets ).« Ders., Die Anfänge der >science sociale bei den französischen Ideologen, 112. 


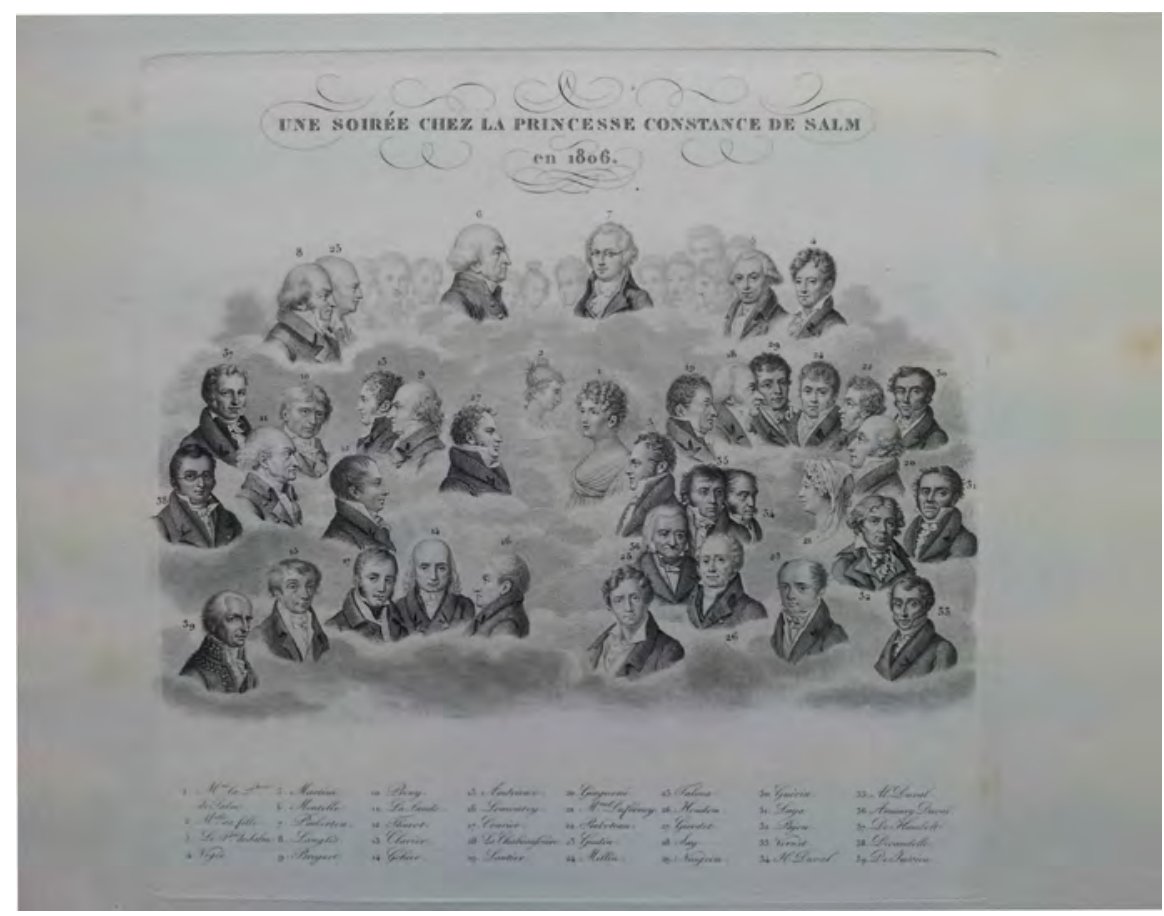

Abbildung 19: Une soirée chez la princesse de Salm en 1806, Stich, o.J. (Bildnachweis: ASD; Bildrecht/Werk: Grafen Wolff-Metternich zur Gracht; Foto: M.O. Braun).

stützen und hierüber zum Allgemeinwohl beizutragen. ${ }^{52}$ Es wurde angenommen, dass Geist und Körper des Menschen sich gegenseitig bedingten und insofern nur gemeinsam erforschbar waren und nach der wissenschaftlichen Erkenntnis der Funktionsweise beider Bereiche der Mensch als Ganzes zu moralischem Handeln anleitbar war. ${ }^{53}$

Die Theorien des Mediziners Cabanis spielten hierbei eine nicht zu unterschätzende Rolle. Cabanis' Theorieentwurf zielte darauf, die Einheit von Seele und Körper zu beweisen, um sie so mit den Mitteln der exakten Naturwissenschaften untersuchbar und formbar zu machen. ${ }^{54}$ Auch für Cabanis, der noch Anspielun-

52 Vgl. Ders., Die Anfänge der >science sociale` bei den französischen Ideologen (wie Anm. 51, Kap. VII), hier insb. 111-114.

53 Siehe hierzu auch Thomas Kirchner, Physiognomie als Zeichen. Die Rezeption von Charles Le Bruns Mensch/Tier-Vergleichen um 1800, in: Gersmann/Kohle (Hg.), Frankreich 1800 (wie Anm. 51, Kap. VII), 34-48, hier 35.

54 Vgl. Jean-Luc Chappey, La Société des Observateurs de l'homme (1799-1804). Des anthropologues au temps de Bonaparte, Diss., Paris 2002, 56-67. Es scheint in diesem Zusammenhang bedeutsam zu sein, dass Chappey erwähnt, dass Cabanis' Ansichten mit auf Reform drängenden medizinischen Lehren, wie sie an den Universitäten in Paris, Straßburg und Montpellier gelehrt wurden, einhergingen. Hierzu ist anzumerken, dass alle drei Städte durchaus bedeutsame Zentren der schottischen Maurerei darstellten. 
gen auf die "Große Kette der Wesen " machte, stand hier die in den Kreisen der Idéologues nicht unumstrittene Möglichkeit der Perfektionierung der menschlichen »Rasse« im Vordergrund, wobei das Mitleid mit anderen Wesen und die Nächstenliebe den höchsten Grad der Perfektionierung darstellten und durch die staatliche Erziehung erreicht werden sollten. ${ }^{55}$ Die Künste, aber auch die Wissenschaften waren für ihn Mittel, um diese Erziehung mit Hilfe von einprägsamen Darstellungen zu bewerkstelligen, wie er etwa innerhalb eines Beitrags in der »Décade« vom 30. Germinal des Jahres VII (19.04.1799) bemerkte. ${ }^{56}$

Der Entwurf dieses neuen umfassenden Wissensgebiets der Idéologie ist deutlich dem enzyklopädischen Charakter des Wissenschaftsverständnisses dieser Zeit verpflichtet, das sich noch stark am Leitbild Diderots und der Aufklärung orientierte und bei relativ starker Betonung der naturwissenschaftlichen Methoden letzten Endes auf die Verknüpfung der Erkenntnisse unterschiedlicher Wissensgebiete - wie hier der Medizin und der Philosophie - drängte. Die loi Dannou vom 3. Brumaire des Jahres IV (25.10.1795) hatte dieses Prinzip gewissermaßen mit der Schaffung eines neuen Bildungssystems institutionalisiert, da es neben der Abhaltung von Festen zum Zwecke der politischen und moralischen Bildung des Volkes auch mit der Schaffung des Institut national des sciences et arts als Sammelpunkt aller Erkenntnisse bzw. Treffpunkt der Intellektuellen Frankreichs als »encyclopédie vivante« vorsah. ${ }^{57}$

55 Vgl. Picavet, Les Idéologues (wie Anm. 50, Kap. VII), 218-220 sowie insb. die Besprechung einer Verteidigung der "perfectibilité « in der "Décade philosophique« durch Cabanis auf 219. Zum Original der Besprechung siehe: Pierre-Jean Georges Cabanis, Lettre sur un passage de la Décade Philosophique, et en général sur la Perfectibilité de l'esprit humain, in: La Décade philosophique, littéraire et politique, 21/an VII de la République Française, 30. Germinal, hier 149-159, Permalink: http://gallica.bnf.fr/ark:/12148/bpt6k423985j (Zugriff vom 25.04.2014). Der Hinweis auf den Autor findet sich, wie bereits von Picavet angemerkt, im Inhaltsverzeichnis der »Décade«.

56 In dem oben angemerkten Beitrag Cabanis in der "Décade« heißt es: »Non, l'espoir de perfectionner l'homme, de le rendre plus sensé, meilleur, plus heureux, n'est point chimérique. Cet espoir que confirment tous les faits bien vus, ne peut être écarté que par une philosophie bornée et chagrine, par une expérience incomplète et resserrée dans quelques détails Il ne fut pas seulement le mobile et le flambeau des sages et des savants de l'antiquité; il fut encore le guide secret et l'âme des efforts de ces génies brillants qui la couvrirent de gloire par les arts. Dans ces belles époques de la Grèce, les poètes, les musiciens, les peintres, les sculpteurs passaient leur vie avec les philosophes: ils ne se bornaient pas à puiser dans leurs conversations des vues propres à diriger le talent; ils s'y nourrissaient encore des modèles du beau moral, par l'étude plus approfondie des passions; ils aspiraient à donner eux-mêmes des leçons utiles aux hommes, à fortifier l'empire des vertus, en prêtant à la vérité le charme du sentiment, et l'associant aux émotions puissantes qui maîtrisèrent les imaginations et les cœurs. Et c'est ainsi que les arts sont véritablement divins; car le génie s'honore lui-même bien plus encore par le but que par l'éclat de ses travaux." Cabanis, Lettre sur un passage de la Décade Philosophique (wie Anm. 55, Kap. VII), hier 150f.

$57 \mathrm{Zu}$ dieser Ordnung sowie dem ebenfalls von Cabanis geäußerten Begriff der »encyclopédie vivante« vgl. die Angaben bei Claude Jolly, Destutt de Tracy éducateur, in: Ders. (Hg.), Destutt de Tracy: Premiers écrits. Sur l'éducation et l'instruction publique, CEuvres complètes I, Paris 2011, 102f. Die Bedeutung des Instituts nationale innerhalb des Systems erscheint mir jedoch bedeutender als die der von Jolly als "Gravitationszentren « des Systems beschriebenen »écoles centrales des départements«. Interessant scheint auch der Briefwechsel Destutt de Tracys mit dem bereits 
Wie bereits gesehen, war in den deutschen Freimaurer-Logen der 1780er Jahre die graduelle Bewertung menschlichen Daseins innerhalb einer Gesellschaftsform aufgegriffen worden. Durch die starke Verwobenheit dieses Denkens mit der Vorstellung einer Ablesbarkeit einer historischen Höherentwicklung am >menschlichen und kulturellen Phänotyp`, die die graduelle Auf- und Abwertbarkeit eines Menschen oder einer Nation letztlich mehr oder weniger unbewusst vom subjektiven Eindruck des Betrachters abhängig machte, etablierte sich die Vorstellung einer wissenschaftlich exakten Messbarkeit des Kulturzustandes fußend auf der Bewertung von Gütern der intellektuellen bzw. künstlerischen Produktion. Diese Ansicht sollte vor allem in Europa eine enorme Konkurrenzsituation zwischen den verschiedenen Nationen hervorrufen und ist neben allen materiellen Interessen auch für die Anhäufung von Kunstgütern fremder Nationen in Kriegszeiten nicht zu unterschätzen. Auch das Denken der Idéologues erforderte in letzter Konsequenz diesen Maßstab als Bewertungskriterium des zivilisatorischen Fortschritts einer Nation sowie ordnendes Prinzip der innergesellschaftlichen Rangfolge ihrer Mitglieder.

Das fruchtbare Zusammengehen verschiedener Wissensgebiete unter der Programmatik der Idéologues wurde auch in der Tätigkeit Aubin-Louis Millin de Malmaisons, eines bereits genannten Mitglieds des Salons und Korrespondenzpartners der Constance de Salm, sichtbar. Millin gilt als einer der herausragenden europäischen Intellektuellen des frühen 19. Jahrhunderts - ein Ruf, den er auch seinen ambitionierten wissenschaftlichen Projekten zu verdanken hatte. Millin trat im Jahr 1795 sein Amt als Conservateur du Cabinet des antiques, médailles et pierres gravées de la Bibliothèque nationale an und hatte zudem eine Professur für Geschichte der École centrale du département de la Seine inne. ${ }^{58}$ Gemeinsam mit André Barthélemy verfolgte er ab 1795 das ambitionierte Projekt, die Geschichte der Menschheit mit Hilfe der Ausstellung von Monumenten in einem einzigen Museum zusammenzufassen, um - ganz im Sinne der sich formierenden science sociale - die Sitten und Gebräuche der verschiedenen Völker der Vergangenheit abzubilden und sie gleichzeitig den Erkenntnissen über die Völker der Gegenwart zuzugesellen. ${ }^{59}$

Doch die spezialisierten und durch die Methodik der Naturwissenschaften beeinflussten archäologisch-antiquarischen Studien waren in der enzyklopädischen Programmatik der Idéologues nicht das einzige Wirkungsgebiet Millins. Durch sein Engagement in der Société d'histoire naturelle de Paris sowie der bis 1804

in Verbindung mit Jacobi erwähnten Joseph Rey. Siehe hierzu Claude Jolly (Hg.), Destutt de Tracy. Lettres à Joseph Rey 1804-1814 (Hautes Études Médiévales et Modernes, 82), Genève 2003.

58 Vgl. zu diesen Angaben die tabellarische Biographie bei Geneviève Espagne/Bénédicte Savoy (Hg.), Aubin-Louis Millin et l'Allemagne: Le Magasin encyclopédique. Les lettres à Karl August Böttiger (Europaea Memoria. Studien und Texte zur Geschichte der europäischen Ideen, Reihe 1: Studien, 41), Hildesheim/Zürich/New York 2005, 557-560.

59 Vgl. hierzu die Ausführungen bei Thomas Nutz, Varietäten des Menschengeschlechts. Die Wissenschaften vom Menschen in der Zeit der Aufklärung, Köln/Weimar/Wien 2009, 289. 
bestehenden Société des Observateurs de l'homme ließ er seine große Wertschätzung der Naturwissenschaften erkennen. Die histoire de l'homme, deren Erforschung letztlich die Observateurs verfolgten, ist dabei sowohl als Bezug auf die in Verruf geratene Naturgeschichte des 18. Jahrhunderts als auch auf die moderneren Theorien Destutt de Tracys zu sehen. ${ }^{60}$ Nur aus seinem Wirken innerhalb dieser Gesellschaften heraus ist es verständlich, weshalb Millin die Archäologie vor allem mit Hilfe eines an Linné orientierten Klassifizierungssystems systematisieren wollte. $^{61}$

Die Sociéte des Observateurs de l'homme löste sich jedoch im Jahr 1804 auf. Wie Jean-Luc Chappey aufzeigen konnte, hing dies mit dem großartigen Erfolg der Schriften des Mediziners Franz Joseph Gall zusammen, der die Pseudo-Wissenschaft der Phrenologie begründete, die davon ausging, dass das Gehirn das zentrale Organ des Körpers sei, das die moralischen Neigungen des Menschen mehr oder weniger unbeeinflussbar durch jede Erziehungsarbeit als Anlage in sich trage, und die Vermessung von Schädeln zu einer Art Mode werden ließ. ${ }^{62} \mathrm{Um}$ das Jahr 1802 erfolgte auch aus diesem Grund die schrittweise Abkehr des napoleonischen Regimes vom enzyklopädisch-pädagogischen oder modern ausgedrückt interdisziplinären Wissenschaftssystem im Stil der Idéologues und seine Ersetzung durch eine höhere Spezialisierung und Abgrenzung der Einzeldisziplinen, wie in den Akademien des Ancien Régime, die direkt an das `Hirn des Staates`, also die Regierung berichteten. ${ }^{63}$ Im Hinblick auf die Mitglieder des Salons der Constance de Salm, die, wie oben gezeigt, vielfach der Gruppe der Idéologues zuzurechnen waren oder zumindest mit ihnen sympathisierten, ist danach zu fragen, wie sie mit dieser Abweisung durch den ersten Mann im Staate umgingen.

Abschließend bleibt an dieser Stelle festzuhalten, dass Joseph zu Salm-Reifferscheidt-Dyck im Salon seiner Frau engen Kontakt zu der Gruppe der Idéologues besaß. Eine gedankliche Beeinflussung durch ihre Ansichten kann daher im Folgenden für den Dycker Schlossherrn vorausgesetzt werden.

60 Vgl. hierzu die Ausführungen bei Hans-Dietrich Dräxler, Die Idéologie in Deutschland. Versuch der Rekonstruktion der Rezeption einer französischen wissenschaftlichen Theorie im Deutschland des frühen 19. Jh.s, Münster 1996, 24 f.

61 Vgl. hierzu Chappey, La Société des Observateurs de l'homme (wie Anm. 54, Kap. VII), $174-179$. In diesem Sinne ebenfalls: Claude Rétat, Revers la science. Aubin-Louis Millin, Alexandre Lenoir, in: Éric Perrin-Saminadayar (Hg.), Rêver l'archéologie au XIX ${ }^{\mathrm{e}}$ siècle: de la science à l'imaginaire (Mémoires, 23), Saint-Étienne 2001, 97-122, hier 99-101.

62 Vgl. Chappey, La Société des Observateurs de l'homme (wie Anm. 54, Kap. VII), 455f.

63 Siehe hierzu Ders., La Société des Observateurs de l'homme (wie Anm. 54, Kap. VII), 401-407. Zum Einfluss medizinischer Erkenntnisse bzw. den Vorstellungen des Vitalismus auf die französische Kunst seit Mitte des 18. Jh.s sowie deren Ausweitung in andere Bereiche des gesellschaftlichen bzw. politischen Lebens siehe jüngst auch Tomas Macsotay, Suffering Bodies, Sensible Artists. Vitalist Medicine and the Visualising of Corporeal Life in Diderot, in: Horstmanshoff/King/Zittel (Hg.), Blood, Sweat and Tears (wie Anm. 47, Kap. IV), 267-291, insb. 269-272. 


\section{VII.3 Wissenschaftler, Künstler, Logenbrüder - Verbindungen der Idéologie in die französische Freimaurerei}

Die Vielfalt der aufgezeigten Themen, die Constance de Salm in ihrer Korrespondenz mit Schriftstellern, Gelehrten und Künstlern verhandelte, deutet auf ein Festhalten an einem enzyklopädischen Wissenserwerb und somit auch an der Rolle des wissenschaftlich gebildeten Künstlers wie des künstlerisch gebildeten Wissenschaftlers als vorbildhafte moralische Leitinstanzen der Gesellschaft hin. Ob Botanik, Schriftstellerei oder Medizin, alle Bereiche sollten sich im Denken der Idéologues zum Zwecke der einigenden Erkenntnis gegenseitig befruchten und mussten ihre Qualität nach wissenschaftlicher Regelhaftigkeit unter Beweis stellen. Dieser breitangelegte Wissensdrang berührte daher in der Korrespondenz gelegentlich Themenbereiche, die auch der Freimaurerei nicht fremd waren. So war Constance über die Korrespondenz mit dem Orientalisten Louis-Mathieu Langlès (1763-1824), Edme Mentelle sowie Amaury Duval etwa bestens über die künstlerische Verarbeitung der Templerlegende in dem von François Raynouard (1761-1836) geschriebenen Theaterstück »Les Templiers « unterrichtet, ${ }^{64}$ das am 24. Floréal des Jahres XIII (14.05.1805) im Théâtre français in Paris erstmalig aufgeführt wurde und Napoleon nachhaltig beeindruckt hatte. ${ }^{65}$ Deutlicher noch tritt diese Nähe in einem Brief des bereits erwähnten Geographen Edme Mentelle aus dem Jahr 1806 hervor. ${ }^{66}$ Er berichtete Constance über seine Bekanntschaft mit Charles-François Dupuis (1742-1809): »[...] l'auteur de l'Origine des cultes, et membre de l'Institut. C'est un philosophe très érudit, et dont le génie a percé très avant dans l'antiquité des temps. Il va publier un morceau très précieux sur les zodiaques de l'Inde, et de la Chine, de l'Egypte etc. ${ }^{67}$

Mit dem Namen Charles-François Dupuis ist einer der wichtigsten zeitgenössischen Religionsforscher angesprochen. Seine Schriften führen mitten ins Zentrum der Debatten über die Mysterien und Religion der Alten im Frankreich der Jahrhundertwende und lagen so auch in Reichweite der Tätigkeit eines Aubin-Louis Millin. Als Schüler und Freund Lalandes nahm die Astronomie im

64 Siehe hierzu die Transkription der Briefe vom 4., 7. und 11. Prairial XIII in Pallot-Raguet, Correspondance de Constance de Salm (wie Anm. 47, Kap. VII), 234-238, 239f. sowie 242f.

65 Siehe zu diesem Theaterstück, seinem Vergleich mit der freimaurerischen Templerlegende bzw. dem Grad eines Chevalier Kadosh sowie dem Interesse Napoleons: François Cavaignac, Légende templière et imaginaire maçonnique dans le théâtre profane en France au XIX ${ }^{\mathrm{e}}$ siècle, in: Keghel/Moisy (Hg.), Deux Siècles de Rite Écossais (wie Anm. 43, Kap. V), 143-161, hier insb. 147-150.

66 Mentelle war im Übrigen auch Gründer der ebenfalls auf eine breite öffentliche Vermittlung ihrer Erkenntnisse drängenden Société statistique de Paris, der Constance de Salm ebenfalls angehörte. Vgl. hierzu Chappey, La Société des Observateurs de l'homme (wie Anm. 54, Kap. VII), 451. Zur Mitgliedschaft Constances vgl. die Angabe bei Pallot-Raguet, Correspondance de Constance de Salm (wie Anm. 47, Kap. VII), 15.

67 Zitiert nach Dies., Correspondance de Constance de Salm (wie Anm. 47, Kap. VII), 306. 
Denken Dupuis' einen wichtigen Platz ein. ${ }^{68}$ Mit den »Origines de tous les cultes« wollte er eine Beschreibung aller religiösen Kulte der Menschheit erstellen und lieferte dabei eine universale Erklärung jeglicher Gottesvorstellungen im Altertum ab. Dupuis vertrat hierin die Ansicht, dass alle Gottesvorstellungen des Altertums, aber auch des Christentums, dem Sternenhimmel nachempfunden waren und in engem Zusammenhang mit den Jahreszeiten und dem Ackerbau standen, ${ }^{69}$ wobei die Hauptgottheiten - wie etwa im alten Ägypten - durch die Sonne und den Mond vorgestellt wurden. Dies war für Dupuis der Grund zu der Ansicht, dass auch die in der Bibel überlieferte Auferstehung Christi lediglich eine allegorische Verkleidung dieses alten Glaubens an den Sternenlauf war. Es ist daher nicht verwunderlich, dass ebenso wie im Fall der Idéologues mit der zunehmenden Annäherung des napoleonischen Regimes an die katholische Kirche sein Verhältnis zu Napoleon schwieriger wurde.

Mit der Erwähnung Dupuis' lässt sich somit aber auch die Kenntnis der zeitgenössischen Forschungen zu den Mysterien im Umkreis des literarischen Salons der Constance de Salm aufzeigen. Robert Bied verwies in seiner Untersuchung des Salons bereits darauf, dass rund die Hälfte der insgesamt 39 Besucher des Salons einer Freimaurer-Loge angehörten. ${ }^{70}$ Auch Lalande und Millin zählten zu dieser Gruppe des Salons. Es gilt unter den veränderten Bedingungen zunächst nach der Bedeutung dieser Verbindung »Kunst - Wissenschaft - Freimaurerei« $\mathrm{zu}$ fragen. Es sollte jedoch ferner beachtet werden, dass Dupuis der Lateinlehrer Joseph Salm-Reifferscheidt-Dycks während der Pariser Jahre seiner eingangs erwähnten Kavalierstour war. ${ }^{71}$ Joseph zu Salm-Reifferscheidt-Dyck war Dupuis daher persönlich bekannt und durchaus vertraut.

Wie bereits im ersten Teil dieser Studie gesehen, wurde der Sinn für die Kunst und die Wissenschaft - auch in der Freimaurerei - des Öfteren als Ausdruck des Zivilisationsstandes der Menschheit bzw. eines Volkes gesehen. Diese Ansicht fand sich auch in der von Jerôme de Lalande noch während des Ancien Régime gegründeten Künstler-Loge Les Neuf Sœurs wieder, die ebenfalls eine enge Verbindung zu dem schöngeistigen Salon einer Pariser Dame - dem Salon der Minette Helvetius - aufwies, der gleichzeitig als eine Wiege der Idéologues zu betrachten ist. $^{72}$ Der bereits mehrfach aufgezeigte Bezug zum Thema der Memoria war in der Loge Les Neuf Sœurs bereits durch die Namensgebung vorhanden, da die neun Musen der griechischen Mythologie die Kinder der Göttin der Erinnerung, Mne-

68 Vgl. Jed Z. Buchwald/Diane Greco Josefowicz, The Zodiac of Paris. How an Improbable Controversy over an Ancient Egyptian Artifact Provoked a Modern Debate between Religion and Science, Princeton/New Jersey 2010, 48.

69 Vgl. Dies., The Zodiac of Paris (wie Anm. 68, Kap. VII), 47.

70 Vgl. hierzu die Angaben bei Bied, Le rôle d'un salon littéraire (wie Anm. 4, Kap. VII), hier 138.

71 Vgl. hierzu Wunderlich, Studienjahre der Grafen Salm-Reifferscheidt (wie Anm. 1, Kap. VII), 99.

72 Siehe hierzu die Einschätzung bei Dräxler, Die Idéologie in Deutschland (wie Anm. 60, Kap. VII), 21. 
mosyne, waren. ${ }^{73}$ Die Musen waren in der Antike die Förderinnen der Künste und Wissenschaften, und so galten auch für die Loge diesbezügliche Aufnahmebedingungen für Mitglieder. ${ }^{74}$ Neben »aspirants distingués par leur rang ou par les postes honorables" sollten lediglich Personen aufgenommen werden, deren künstlerisches bzw. wissenschaftliches Talent durch eine öffentliche Probe erwiesen war. ${ }^{75}$ Unter den Mitgliedern fanden sich so nicht nur Voltaire, La Fayette, Georg Forster und Benjamin Franklin, sondern auch berühmte Mediziner wie Joseph-Ignace Guillotine oder der bereits erwähnte Cabanis. Die Loge sah sich in diesem Sinne selbst als eine Art `Elfenbeinturm`der mit dem Sinn für das Schöne und die Wissenschaften >begabten< Personen aller europäischen Nationen. ${ }^{76}$

Einige Mitglieder des Salons der Constance de Salm hatten die Freimaurerei demnach bereits im Ancien Régime als ein Forum genutzt, um naturwissenschaftliche und künstlerische Themen im Verband zu diskutieren. Sie fügten sich daher nach der Revolution in den Umkreis der Idéologues ein, deren gesellschaftliches und wissenschaftliches Konzept ihren Auffassungen entgegenkam. Denn wie bereits erwähnt hatte Destutt de Tracy mit der Idéologie den Versuch unternommen, eine Wissenschaft von der psychischen wie physischen Entstehung der menschlichen Ideen zu entwerfen, die in ihren exakten Methoden den Naturwissenschaften wie der Zoologie in nichts nachstehen sollte. ${ }^{77}$ Für die Idéologues war zivilisatorischer Fortschritt in erster Linie ein gesellschaftliches Phänomen, das nur über tradierende Zeichensysteme wie etwa Symbole, die Sprache oder Bilder ermöglicht wurde. ${ }^{78}$ Bei der Lektüre der Äußerungen eines Destutt de Tracy scheint es durchaus nicht zu weit gegriffen, zu behaupten, dass sich hier der vormoderne magische Glaube an die Wirksamkeit der Zeichen in eine wissenschaftliche Theorie verkehrt habe.

Die Kultiviertheit drückte sich für beide Gruppen insbesondere in der Rezeption und Produktion der tradierenden Zeichensysteme "Kunst" und »Wissenschaft« aus - Felder, in denen sich die neue Elite des nachrevolutionären Frankreichs fand und verband. Aus der Betrachtung der Korrespondenzpartner und Mitglieder des Salons der Constance de Salm deutet sich bereits an, dass das enzyklopädische Projekt der Idéologues unter Napoleon zwar institutionell gescheitert, aber informell keineswegs vollkommen am Ende war. ${ }^{79}$ Bedenkt man die oben

73 Vgl. die Aufschlüsselung des Namens bei Jean L. Proteau, Charles Dupaty: un magistrat-philosophe du Siècle des Lumières, Rochefort 1989, 24.

$74 \mathrm{Zu}$ der Ausrichtung der Loge und der Einschätzung des Stellenwerts der Schönen Künste in ihren Statuten siehe Louis Amiable, Une loge maçonnique d'avant 1789. La R $\therefore$ M $\therefore$ Les Neuf Sœurs, Paris 1897, 32, Permalink: http://n2t.net/ark:/13960/t7sn12755 (Zugriff vom 25.05.2014).

75 Siehe zu diesen Angaben sowie zum angeführten Zitat die Auszüge aus den Dokumenten des Archivs der Loge bei Ders., Une loge maçonnique d'avant 1789 (wie Anm. 74, Kap. VII), 33.

76 Vgl. Ders., Une loge maçonnique d'avant 1789 (wie Anm. 74, Kap. VII), 39.

77 Vgl. Dräxler, Die Idéologie in Deutschland (wie Anm. 60, Kap. VII), 23-34.

78 Siehe Ders., Die Idéologie in Deutschland (wie Anm. 60, Kap. VII), 23-34.

79 Siehe in diesem Sinne auch die Untersuchungen Thomas Niedings zum »juste milieu«: Thomas Nieding, Ökonomietheorie als Beitrag zum `juste milieu«? Der `Traité d'économie politique`von 
angeführte und in anderem Zusammenhang getroffene Aussage Pierre Molliers, dass die Freimaurerei des Premier Empire für Napoleon ein >ideologisches Instrument ' geworden war, und berücksichtigt zudem, dass Archichancelier Cambacérès im Vorfeld des Premier Empire den Begriff der »science sociale« entscheidend prägte ${ }^{80}$ stellt sich hier auch in Hinblick auf die bereits genannte Verknüpfung mit bedeutenden Freimaurer-Logen wie der Loge Les Neuf Sœurs die Frage, ob sich innerhalb der Freimaurerei des Premier Empire einige Ideen der Idéologues gehalten hatten, die dem Selbstverständnis der neuen Elite entgegenkamen. Stellte die Freimaurerei im napoleonischen Kaiserreich doch ohnehin ein Gegengewicht zur katholischen Kirche und damit zum metaphysischen Überbau der alten Elite dar. Für viele Mitglieder des Salons ließe sich diese Frage folglich bejahen.

Der Salon de Salm - der sich zudem eine Zeitlang in der Pariser rue du bac, einem bekannten Treffpunkt einiger Idéologues, befunden hatte - wirkt aus heutiger Sicht zwar nicht unbedingt wie eine Freimaurerloge unter Leitung der Constance de Salm, wie Robert Bied meinte ${ }^{81}$ jedoch unter Berücksichtigung des oben dargestellten Panoramas zumindest wie eine Reminiszenz an den Salon der Minette Helvetius. Die Freimaurerei stellte somit nur eine optionale Verlängerung dieser Salonkultur dar, der man sich nur anschließen konnte, sofern man sich auf die esoterischen Traditionsketten der freimaurerischen Geschichte einlassen wollte. ${ }^{82}$ Bereits Marc Regaldo betonte in seiner ausführlichen Darstellung der Geschichte der »Décade philosophique«, in der er auch die personalen Zusammenhänge der Zeitschrift mit der zeitgenössischen Freimaurerei sowie insbesondere der Loge Les Neuf Sœurs besprach, richtigerweise, dass die Philosophie für alle Beteiligten im Vordergrund stand und insofern weniger der Einfluss der Freimaurerei auf die »Décade« zu untersuchen sei als vielmehr der Einfluss der zeitgenössischen Philosophie auf die Freimaurerei. ${ }^{83}$ Es darf zu dieser Anmerkung Regaldos der für die philosophischen Überlegungen der Idéologues nicht unwichtige Bereich der Naturwissenschaften hinzugedacht werden.

Die folgende Untersuchung des freimaurerischen Umfeldes Joseph zu SalmReifferscheidt-Dycks im Premier Empire kann nur unter Berücksichtigung dieses

Jean Baptiste Say, in: Gudrun Gersmann/Hubertus Kohle (Hg.), Frankreich 1800. Gesellschaft, Kultur, Mentalitäten, Stuttgart 1990, 134-141, hier 140. Demnach blieben die Idéologues auch unter den Entwicklungen im Premier Empire ihren Ansichten verpflichtet.

80 Dierse führt an, dass eine Rede Cambacérès' vom 25.02.1798 womöglich die erste Nennung des Begriffs der »science sociale« enthält. Siehe hierzu die Ausführungen bei Ders., Die Anfänge der sscience socialer (wie Anm. 51, Kap. VII), 113f.

81 Vgl. hierzu Bied, Le rôle d'un salon littéraire (wie Anm. 4, Kap. VII), hier 159. Siehe zur rue du bac das entsprechende Kapitel bei Picavet, Les Idéologues (wie Anm. 50, Kap. VII), $31 \mathrm{f}$.

82 Dass dies nicht bei allen Beiträgern der Décade der Fall war, zeigt etwa der bei Regaldo erwähnte Auszug aus einem »Décade«-Artikel Chabeaussières vom 10. Fructidor des Jahres IX. In Bezug auf die antiken Mysterien bemerkte Chabeaussière hier, dass diese "n'avaient rien de commun avec nos momeries maçonniques et nos loges d'illuminés". Zitiert nach Regaldo, Un millieu intellectuel (wie Anm. 50, Kap. VII), 308. Regaldo erwähnt auf Seite 309 auch die Mitarbeit des zeitweiligen Freimaurergegners Cadet de Gassicourt an der »Décade«.

83 Siehe Ders., Un millieu intellectuel (wie Anm. 50, Kap. VII), 299-314, hier insb. $312 f$. 
wichtigen Befundes geschehen, da er sich weitestgehend mit den oben erwähnten Forschungsmeinungen deckt und auch in Hinblick auf die Fragestellung dieser Studie von großer Wichtigkeit ist. Besonderer Aufmerksamkeit bedarf dabei zudem die beiläufige Bemerkung Chappeys, dass mit der Umstellung des Wissenschaftssystems um 1804 auch die Wendungen der "médecine philosophique» sowie des "sacerdoce médical " mehr und mehr aus den medizinischen Abhandlungen verschwanden. ${ }^{84} \mathrm{Im}$ freimaurerischen Bereich trat gerade mit dem Jahr 1804 eben das Philosophische und Priesterliche mit dem hermetisch-alchemistischen Rit écossais philosophique der seit 1802 sich erholenden schottischen Maurerei in Frankreich wieder auf den Plan. Für dieses System engagierte sich Joseph zu Salm-Reifferscheidt-Dyck.

\section{VII.4 Joseph zu Salm-Reifferscheidt-Dycks Weg durch die Hochgrad- freimaurerei im Paris des Premier Empire - ein Überblick}

Die Jahre 1808/1809 sollten für Joseph zu Salm-Reifferscheidt-Dyck in verschiedener Hinsicht eine ereignisreiche Zeit sein. Wie bereits erwähnt, war er im April 1808 durch Napoleon in den Rang eines Chevalier d'Empire in den neugeschaffenen Verdienstadel des französischen Kaiserreichs aufgenommen worden, dem im Jahr darauf die Erhebung zum Comte de l'Empire und die Erlaubnis zur Einrichtung eines Familienmajorats folgte. ${ }^{85}$ In das Jahr seiner Erhebung in die Noblesse d'Empire fällt auch der erste sichere Beleg für seine Mitgliedschaft in einer Freimaurerloge: Am 20.06.1808 wurde er bei der erst im Jahr zuvor unter der Aufsicht des Grand Orient installierten und 1808 in das Hochgradsystem des Rit écossais philosophique übergegangenen Loge Les Commandeurs du Mont Thabor in Paris affiliiert. ${ }^{86}$ Die in der Quelle vermerkte »affiliation « beweist zum einen, dass Joseph Salm-Reifferscheidt-Dyck bereits vor diesem Zeitpunkt in den Bund aufgenommen worden sein muss, da eine affiliation eine Mitgliedschaft in einer anderen

84 Vgl. Chappey, La Société des Observateurs de l'homme (wie Anm. 54, Kap. VII), 401.

85 Vgl. Sachse, Als in Dyck Kakteen blühten (wie Anm. 2, Kap. I), 81f.; Schönfuß, Noblesse d’Empire (wie Anm. 23, Kapitel VI); Mara Keferstein, Die Einrichtung eines Majorats und die Ernennung zum Comte d'Empire, aus: Netzbiographie: Joseph zu Salm-Reifferscheidt-Dyck (1773-1861), in: his toricum-estudies.net, [01.05.2014], http://www.historicum-estudies.net/epublished/netzbiographie/ franzoesische-zeit/majorat (Zugriff vom 01.05.2014).

86 Vgl. die Angaben bei Bied, Le rôle d'un salon littéraire (wie Anm. 4, Kap. VII), hier 138f. Der Hinweis auf die affiliation ist im Logentableau des Jahres 1810 verzeichnet. Siehe Tableau des Membres de la R $\therefore$ L $\therefore$ Ecos $\therefore$ de St. Jean sous le titre distinctif des Commandeurs du Mont Thabor, Paris, 22.02.1810, in: BnF, FM2 65bis, Loge et Chapitre Commandeurs du Mont Thabor, Tableaux, fol. 82. $\mathrm{Zu}$ einem Überblick über den Weg Salm-Dycks durch die napoleonische Freimaurerei ohne Einordnung in Bezug auf das hier behandelte Thema sei nochmals verwiesen auf Martin Otto Braun, Mitgliedschaft in Freimaurer-Logen, aus Netzbiographie: Joseph zu Salm-Reifferscheidt-Dyck (1773-1861), in: historicum-estudies.net, [01.05.2014], http://www.historicum-estudies.net/epub lished/netzbiographie/franzoesische-zeit/freimaurerei (Zugriff vom 19.07.2014). 
Loge voraussetzte. Zum anderen ging seine Aufnahme in die Noblesse d'Empire interessanterweise mit seinem Anschluss an die Hochgradfreimaurerei einher.

Auch wenn hierin kein kausaler Zusammenhang gesehen werden muss, sind sowohl die Erhebung in die Noblesse d'Empire als auch das Engagement innerhalb der Freimaurerei ein weiterer Beweis für den Willen Joseph Salm-Reifferscheidt-Dycks, sich in die veränderten Herrschaftsbedingungen im Rheinland so gut wie möglich einzufügen. Wie bereits oben erwähnt, konnte er in der Zeit des Premier Empire eine Reihe von wichtigen Ämtern einnehmen. So war er bereits 1803 von Napoleon zum Präsidenten der Kantonalversammlung von Elsen im Arrondissement Köln ${ }^{87}$ ernannt worden und fungierte ab 1804 als Kanzler der vierten Kohorte der Légion d' honneur mit Sitz auf Schloss Brühl. ${ }^{88}$ In Anbetracht dieses steilen Aufstiegs ist man geneigt zu sagen, dass seine ähnlich eindrucksvolle Karriere innerhalb der französischen Hochgradfreimaurerei nur die folgerichtige Fortsetzung seines Aufstiegs in der profanen Welt war. So bearbeitete er innerhalb der Freimaurerei - auch aufgrund der oben genannten engen Zusammenhänge der schottischen Systeme, die sich zum Teil aufeinander beriefen - neben dem Rit écossais philosophique den Ritus des Royal Ordre d'Heredom de Kilwinning sowie den Rite écossais ancien accepté. Im Archiv des Schlosses Dyck haben sich bis heute die - zum Teil sehr eindrucksvollen - Urkunden der Aufnahmen in verschiedene Grade dieser Systeme erhalten. Mit Hilfe anderer Dokumente lassen sich auch weitere Stationen und Ämter nachweisen, die im Folgenden kursorisch nachgezeichnet werden sollen.

87 Siehe Thea Fiegenbaum, Die Kantonalspräsidentschaft des Citoyen Salm (1803-1813), aus: Netzbiographie: Joseph zu Salm-Reifferscheidt-Dyck (1773-1861), in: historicum-estudies.net, [01.05.2014], http://www.historicum-estudies.net/epublished/netzbiographie/franzoesische-zeit/ kantonalspraesidentschaft (Zugriff vom 01.05.2014); Ernennung zum Präsidenten der Kantonalsversammlung (Elsen), 11. Juni 1803, Transkription Elisabeth Schläwe, aus: Netzbiographie: Joseph zu Salm-Reifferscheidt-Dyck (1773-1861), in: historicum-estudies.net, [01.05.2014], http://www.historicum-estudies.net/epublished/netzbiographie/transkriptionen/ernennungs urkunde-kantonspraesident-1803 (Zugriff vom 01.05.2014); Napoleon an den neuernannten Kantonspräsidenten, Bestimmungen zur Einberufung der Kantonsversammlung, 11. Juni 1803, Transkription Elisabeth Schläwe, aus: Netzbiographie: Joseph zu Salm-Reifferscheidt-Dyck (1773-1861), in: historicum-estudies.net, [01.05.2014], http://www.historicum-estudies.net/epublished/netzbio graphie/transkriptionen/schreiben-an-kantonspraesidenten-1803 (Zugriff vom 01.05.2014).

88 Vgl. Sabine Graumann, Französische Verwaltung am Niederrhein. Das Roerdepartement 17981814 (Düsseldorfer Schriften zur Neueren Landesgeschichte und zur Geschichte NordrheinWestfalens, 27), Essen 1990, 93f.; Sachse, Als in Dyck Kakteen blühten (wie Anm. 2, Kap. I), 81f.; Martin Otto Braun, Kanzler der vierten Kohorte der napoleonischen Ehrenlegion, aus: Netzbiographie: Joseph zu Salm-Reifferscheidt-Dyck (1773-1861), in: historicum-estudies.net, [01.05.2014], http://www.historicum-estudies.net/epublished/netzbiographie/franzoesische-zeit/legion-dhon neur (Zugriff vom 01.05.2014); Dekret Napoleons über die Aufnahme des Sieur de Salm-Dyck als Kanzler der 4. Kohorte in die Ehrenlegion, 16. August 1806, Transkription Elisabeth Schläwe, aus: Netzbiographie: Joseph zu Salm-Reifferscheidt-Dyck (1773-1861), in: historicum-estudies.net, [01.05.2014], http://www.historicum-estudies.net/epublished/netzbiographie/transkriptionen/ kanzler-der-ehrenlegion-1806 (Zugriff vom 01.05.2014). 


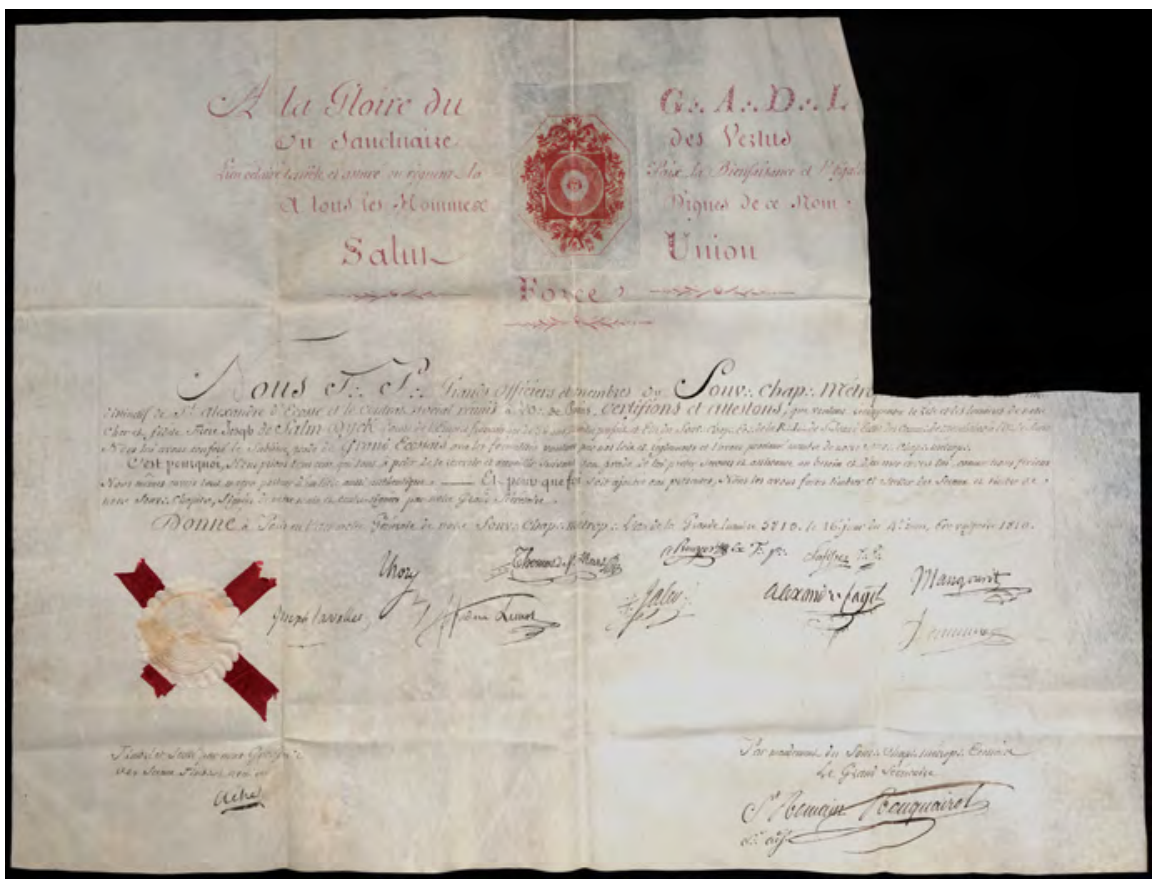

Abbildung 20: Urkunde zur Ernennung Joseph Salm-Dycks zum Grand Écossais im Rit écossais philosophique, 1810 (Bildnachweis: ASD, Dyck 4 - Kart. 49/5; Bildrecht/Werk: Grafen WolffMetternich zur Gracht; Foto: LVR-Archivberatungs- und Fortbildungszentrum).

Für das Jahr 1810 ist die Aufnahme Josephs in den Grad eines Grand Écossais im Rit écossais philosophique bezeugt. ${ }^{89}$ Im darauf folgenden Jahr 1811 wurde er sowohl in den ersten wie in den zweiten Grad (genannt Chevalier Garde de la Tour) des Royal Ordre d'Heredom de Kilwinning im Pariser Hochgradkapitel Du Choix aufgenommen. ${ }^{90}$ Sein nom de guerre, der jedem Rezipienten im Zuge der Aufnahme in diesen freimaurerischen Ritter-Orden verliehen wurde, lautete »Joseph

89 Siehe Abb. 20 bzw. Urkunde zur Ernennung des Fürsten Joseph zum Grand-Écossais der Freimaurer, Paris, 1810, in: ASD, Dyck4 - Kart. 49/5. Zu den Inhalten des Grades siehe Rit écossais philosophique, Cahier du Grade de Grand Écossais, Paris, 12.04.1813, in: BnF, FM4 683.

90 Diese Angaben finden sich in den zum Zeitpunkt der Veröffentlichung dieser Studie noch in der Vorbereitung auf eine Edition befindlichen Archivalien des Chapitre du Choix. Für die freundliche Übermittlung dieser Angaben danke ich Herrn Bernard Dat. Zum Grad des Chevalier Garde de la Tour, der wiederum die Suche nach dem verlorenen Meisterwort behandelte, siehe Rit d'Herodom, Garde de la Tour, o.O., o.D., in: BnF, FM4 824. Hierin bemerkte der Meister vom Stuhl zum Ende des Rituals: »Je sais combien il est dur pour une âme généreuse et sensible de vivre longtems dans l'esclavage; puis que vos yeux se sont ouverts au flambeau de la raison et que votre instruction devient une garantie pour l'avenir aller ...X... (le Caracteristique) soyez heureux et libre; mais sachez que si jamais vous rentrez dans le cachot de l'ignorance la lumière de la Maçonnerie s'éclipserait devant vous, pour vous replonger dans les peines de l'esclavage. « Rit d'Herodom, Garde de la Tour, o.O., o.D., in: BnF, FM4 824, fol. 5 f. 


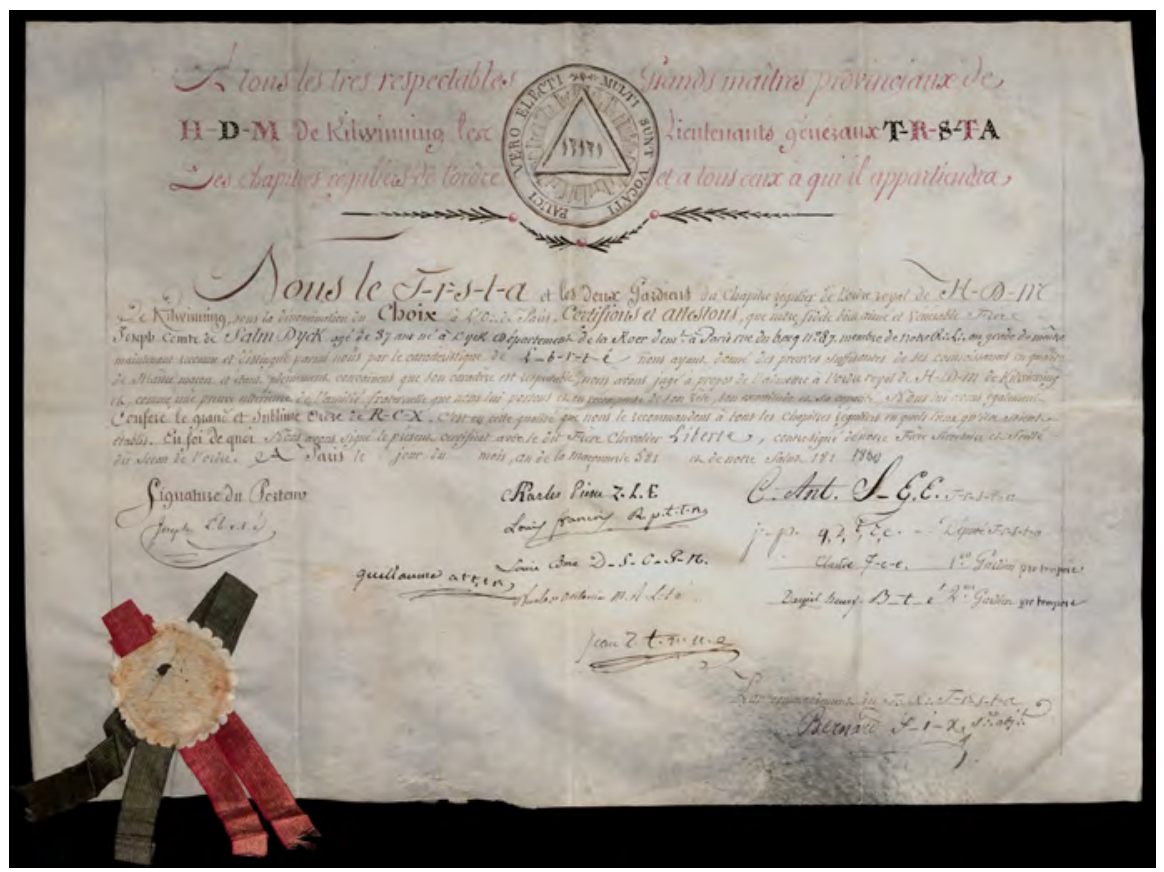

Abbildung 21: Urkunde zur Verleihung des Grades eines Chevalier Rose-Croix im Pariser Hochgradkapitel Du Choix, 1811 (Bildnachweis: ASD, Dyck4 - Kart. 49/1; Bildrecht/Werk: Grafen Wolff-Metternich zur Gracht; Foto: LVR-Archivberatungs- und Fortbildungszentrum).

Réputation «. ${ }^{91}$ Noch im selben Jahr erhielt er - ebenfalls im Hochgradkapitel Du Choix - den Grad des Chevalier Rose-Croix mit dem Beinamen "Joseph Liberté« zugesprochen..$^{92}$ Eine Anrede innerhalb eines Briefes des Aachener Freimaurers Josef von Fürth aus dem Jahr 1811, in der Joseph Salm-Reifferscheidt-Dyck mit der Wendung "G $\therefore \mathrm{I} \therefore$ du $32^{\mathrm{em}}$ dégrée au rit Ecos $\therefore$ anc $\therefore$ \& accep $\therefore$ « angesprochen

91 Vgl. die in Edition befindlichen Archivalien des Chapitre du Choix sowie Rit d'Herodom, Garde de la Tour, o.O., o.D., in: BnF, FM4 824.

92 Vgl. Abb. 21 bzw. Urkunde zur Aufnahme des Fürsten Joseph in den Freimaurer-Orden, Paris, 1811, in: ASD, Dyck4 - Kart. 49/1. Das im Findbuch und auf dem Schutzumschlag der Quelle maschinenschriftlich angegebene Jahr 1800 als Datum der Ausstellung ist falsch. Dies wird auch aus der Altersangabe Salm-Reifferscheidt-Dycks innerhalb der Quelle ersichtlich. Hier wird ein Alter von 37 Jahren bei der Ernennung zum Chevalier Rose-Croix angegeben, woraus sich - wie schon aus den Angaben zur Aufnahme in den ersten und zweiten Grad - auf das Jahr 1811 schließen lässt. Aufnahme des Grafen Joseph in den Freimaurer-Orden, 1800 [?], Transkription Elisabeth Schläwe, aus: Netzbiographie: Joseph zu Salm-Reifferscheidt-Dyck (1773-1861), in: historicum-estudies. net, [01.05.2014], http://www.historicum-estudies.net/epublished/netzbiographie/transkriptionen/ aufnahme-freimaurerorden-1800 (Zugriff vom 01.05.2014). Zum Grad selbst siehe Ordre Royal d'Écosse-Heredom de Kilwinning, Sublime grade de R $\therefore$ C $\therefore$ d'Heredom de Kilwinning, o.O., Anfang 19. Jh., in: BnF, FM4 828. 
wird, ${ }^{93}$ sowie die in späteren Briefen vorkommende Bezeichnung als Grand Inspecteur Inquisiteur Commandeur sowie als Mitglied des Souverain Tribunal Chef d'ordre en France bedürfen hier der Erläuterung. ${ }^{94}$

Der Grad eines Grand Inspecteur Commandeur oder auch Grand Inspecteur Inquisiteur Commandeur bildete den letzten von insgesamt sieben Graden des Rit écossais philosophique sowie gleichzeitig den 31. Grad des Rite écossais ancien accepté. ${ }^{95}$ Da Joseph zu Salm-Reifferscheidt-Dycks Aufnahme in den Grad eines Chevalier St. André, Fidèle Gardien du Trésor Sacré, Prince du Royal Secret, dem vorletzten von insgesamt 33 Graden des Rite écossais ancien accepté, für 1812 urkundlich belegt ist, muss aufgrund der oben erwähnten früheren Bezeichnung Salm-Dycks als »G $\therefore$ I $\therefore$ du 32 em dégré« aus dem Jahr 1811 davon ausgegangen werden, dass Salm-Reifferscheidt-Dyck beide Grade bereits im Jahr 1811 erhalten hatte, die Ausstellung der Urkunde für den 32. Grad im Rite écossais ancien accepté jedoch erst im Jahr 1812 erfolgte. ${ }^{96}$ Das Ritual des Grades eines Prince $d u$ Royal Secret stellte eine Art Rekapitulation der bisher durchlaufenen Grade und eine Synthese der in ihr vermittelten Symbole und Weisheiten dar, ${ }^{97}$ die in der Formel »SALIX NONIS TENGV « zusammengefasst wurde ${ }^{98}$ und - so darf hier gefolgert werden - auf die Unsterblichkeit der Seele sowie der innerhalb der >Kette

93 Vgl. Fürth an Joseph Salm-Dyck, Aachen, 12. Tag des 7. Monats 5811 (12.09.1811), in: ASD, Blaue Bände, Bd. 590, fol. 24r.

94 Siehe hierzu etwa einen Brief der Aachener Loge La Concorde aus dem Jahr 1813: Aachener Loge La Concorde an Joseph Salm-Dyck, Aachen, 24. Tag des 4. Monats 5813 (24.06.1813), in: ASD, Blaue Bände, Bd. 590, fol. 12r/v sowie fol. 13.

95 Zur Ordnung der Grade des Rit écossais philosophique siehe die Angaben in BnF, FR Nouv. Acq. 10956, Notes chronologiques pour servir à l' histoire de la Maçonnerie, o.O., o.D., fol. 30. Hier ist die Ordnung der Grade des Rit écossais philosophique wie folgt angegeben: Maître profane, Chevalier élu philosophe, Grand Écossais, Chevalier de l'anneaux lumineux, Chevalier de l'aigle blanc et noir, Grand Inspecteur Commandeur. Zur gleichzeitigen Verwendung des Grades eines Grand Inspecteur Commandeur als 31. Grad des Rite écossais ancien accepté siehe auch den ebenfalls zeitgenössischen Eintrag bei Claude Antoine Thory, Acta Latomorum, ou Chronologie de l'Histoire de la Franch-Maçonnerie Française et Étrangere, Bd. 1, Paris 1815, 318, Permalink: http://hdl.handle. net/2027/njp.32101061269328 (Zugriff vom 25.05.2014).

96 Vgl. Abb. 26 bzw. Urkunde zur Rangerhöhung des Freimaurer-Ordens für Fürst Joseph, Paris, 11.05.1812, in: ASD, Dyck4 - Kart. 49/6.

97 Siehe die Transkription des Grades in Anhang B dieser Studie. Vgl. hierzu auch Lennhoff/Posner/ Binder (Hg.), Internationales Freimaurer-Lexikon (wie Anm. 18, Kap. I), 676. Hier heißt es zum Grad u.a.: »Vor allem dient der XXXII. Grad der Rekapitulation und Synthese. In Dialogform zieht der Lehrgehalt aller Grade nochmals vorüber, wobei ein eigenartiger Plan eines Feldlagers zugrunde liegt, dessen Feldzeichen den einzelnen Graden entsprechen. Der zweite Teil des Rituals handelt von den Religionen und philosophischen Systemen aller Zeiten. Das Tiefste, das ihre - figürlich dargestellten - Stifter und Propheten gesprochen, das Gemeinsame ihrer Lehren, prägt sich, auf knappste Form gebracht, den Kandidaten ein. Ein Sockel bleibt leer. Er gemahnt an den noch ungeborenen Führer beim Tempelbau der Zukunft. Toleranz und Wahrheitsstreben sind das Leitmotiv dieses Grades.«

98 Sublime et Souverain Prince Du Royal Secret Grand Inspecteur, o.O., Anfang 19. Jh., in: BnF, FM4 817, insb. fol. 9v-10r. Aufgelöst wird diese Formel mit der Wortfolge: „Offrons en Présent à l'invincible Xercis notre incomparable et sacré trésor et nous serons victorieux." Der »unbesiegbare Xerxes« kann hier als Symbol für den Tod interpretiert werden, wohingegen der »heilige Schatz« sinnbildlich für die Seele stehen kann, die letztendlich über den Tod triumphieren soll. 


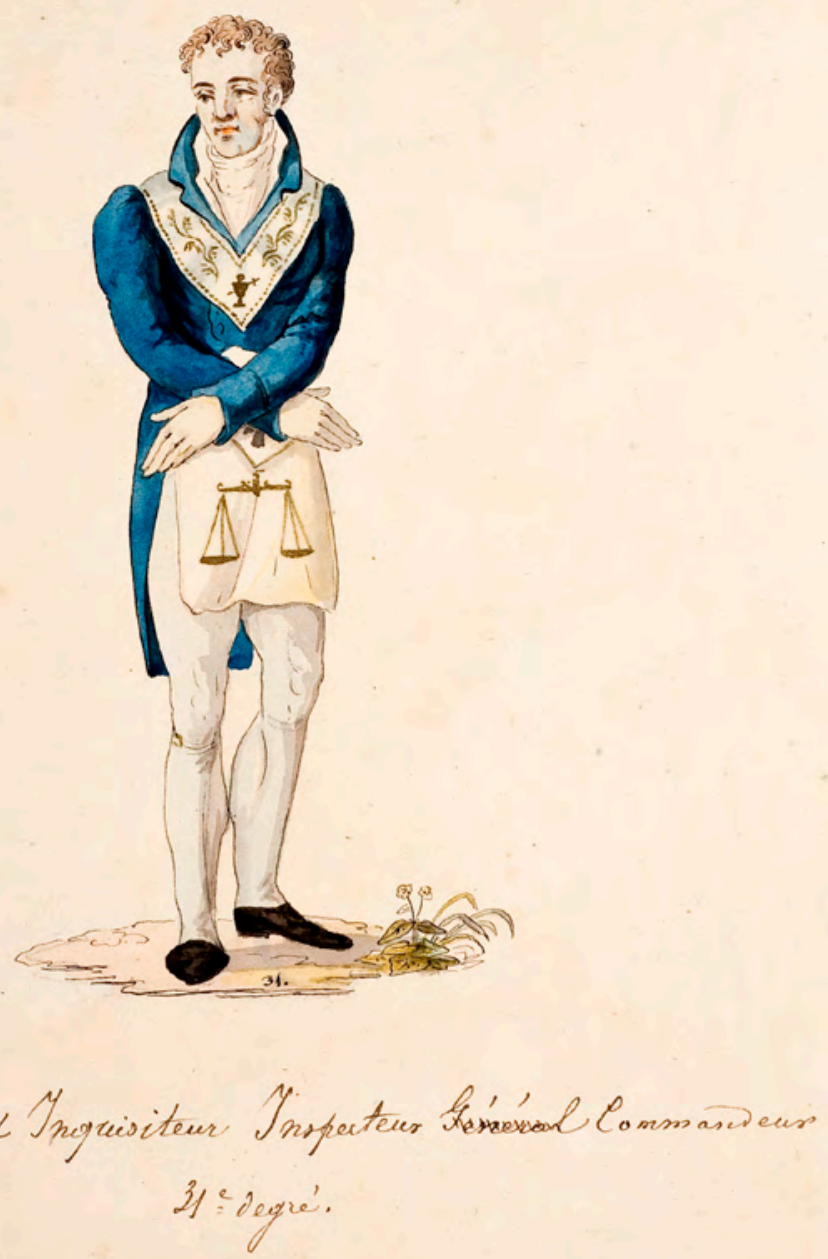

Abbildung 22: Rite Écoss. Anc. et Acc.: Décorations et Costumes II: Grand Inquisiteur Inspecteur Commandeur, $31^{\mathrm{e}}$ degré (= Amtsbekleidung eines Grand Inquisiteur), um 1800 (Bildrecht/Werk und Foto: From the collections of the Cultural Masonic Centre, The Hague). 


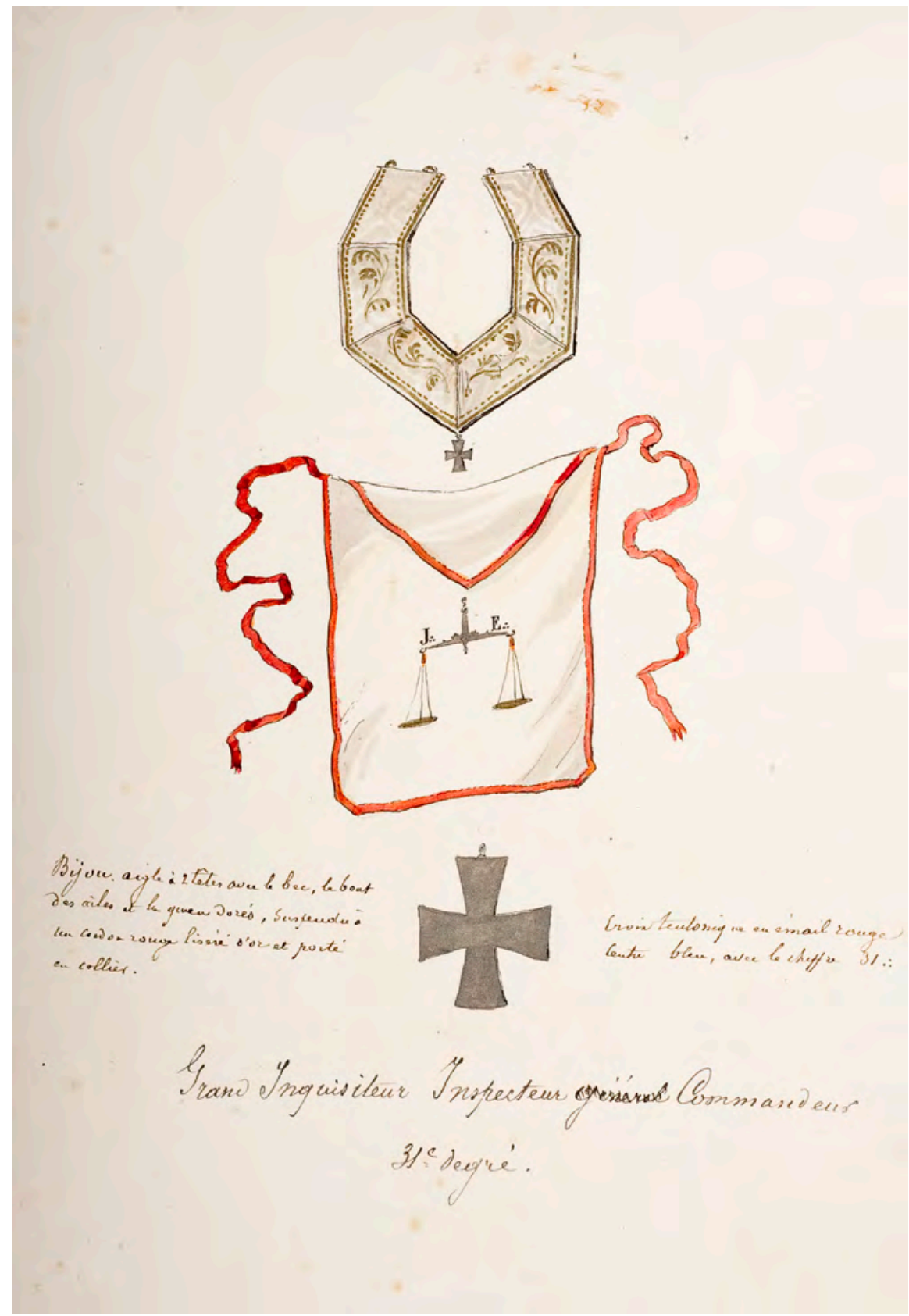

Abbildung 23: Rite Écoss. Anc. et Acc.: Décorations et Costumes II: Grand Inquisiteur Inspecteur Commandeur, 31 $1^{\mathrm{e}}$ degré (= Bijou und Schurz eines Grand Inquisiteur), um 1800 (Bildrecht/Werk und Foto: From the collections of the Cultural Masonic Centre, The Hague). 


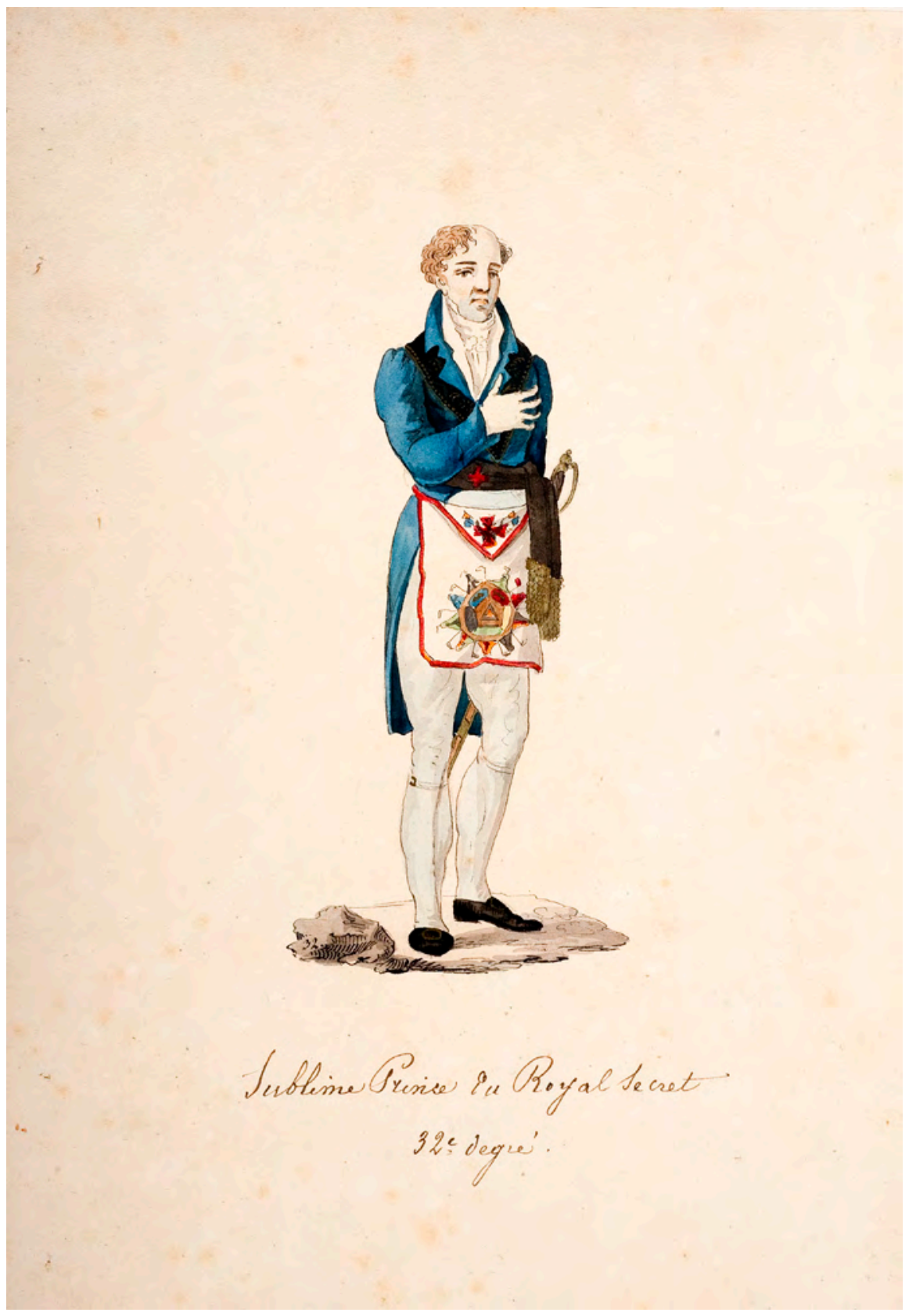

Abbildung 24: Rite Écoss. Anc. et Acc.: Décorations et Costumes II: Sublime Prince du Royal Secret, $32^{\mathrm{e}}$ degré (= Amtsbekleidung des Sublime Prince du Royal Secret), um 1800 (Bildrecht/ Werk und Foto: From the collections of the Cultural Masonic Centre, The Hague). 


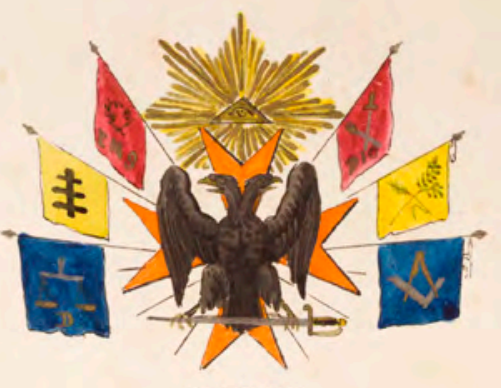

SEEAU

\section{des Sublives Phivees du Roval SECKeT}

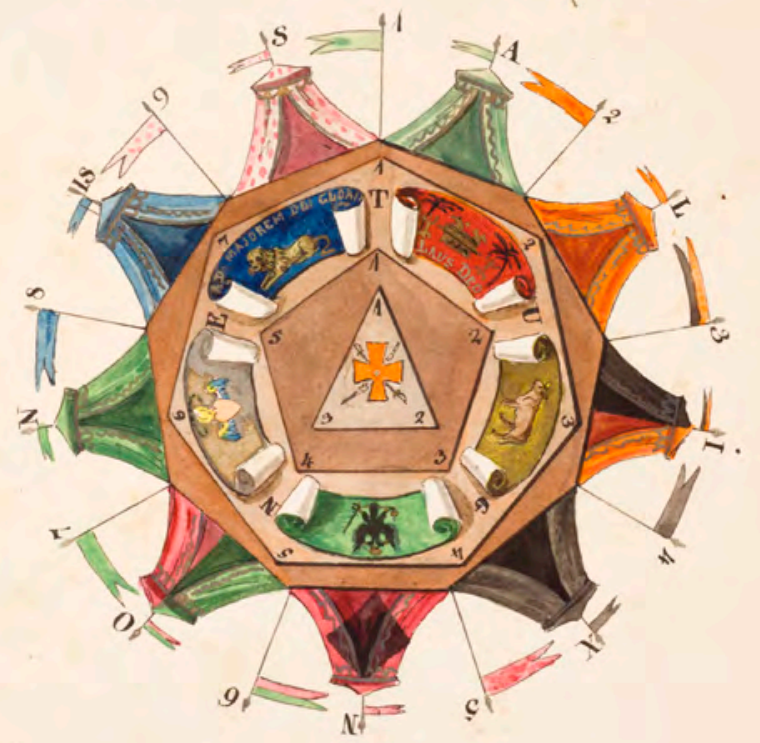

Srbteme Privice ou Poyal Vecrel

$$
32 \text { - iexyé }
$$

Abbildung 25: Rite Écoss. Anc. et Acc.: Décorations et Costumes II: Sublime Prince du Royal Secret, $32^{\mathrm{e}}$ degré (= Siegel eines Prince du Royal Secret), um 1800 (Bildrecht/Werk und Foto: From the collections of the Cultural Masonic Centre, The Hague). 


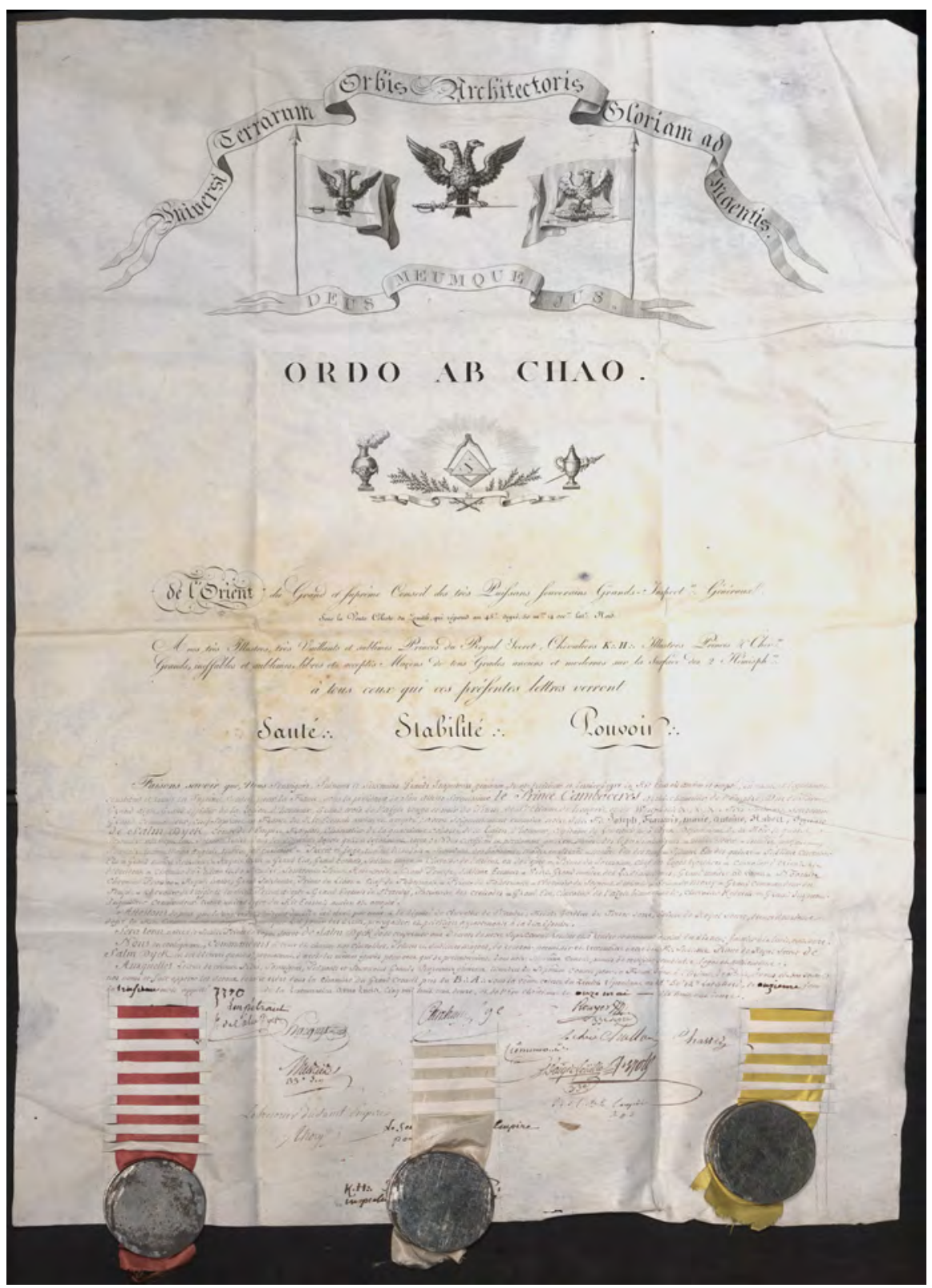

Abbildung 26: Durch die Inhaber des 33. Grades unterzeichnete Urkunde zur Aufnahme Joseph Salm-Dycks in den 32. Grad des Rite écossais ancien accepté, unter anderem mit Unterschriften von Thory, dem Secrétaire du Saint Empire pour la France Jean-Baptiste Pyron de Chaboulon (verdeckt unter dem mittleren Siegel) sowie Archichancelier Cambacérès, 1812 (Bildnachweis: ASD, Dyck4 - Kart. 49/6; Bildrecht/Werk: Grafen Wolff-Metternich zur Gracht; Foto: LVR-Archivberatungs- und Fortbildungszentrum). 
der Weisen « weitergegebenen läuternden Symbolsprache als einigendes Band aller Religionen und letztes Geheimnis der »königlichen Kunst« verwies. Der »Prinz des königlichen Geheimnisses « war somit Anwärter oder - genealogisch gedacht zukünftiger Erbe der leitenden Elite im 33. Grad des Systems.

Die Überschneidungen bzw. gegenseitigen Bedingungen der verschiedenen schottischen Systeme in der Zeit des Premier Empire, die auch bereits im Fall des Chevalier Rose-Croix des Systems des Royal Ordre d'Heredom de Kilwinning zu beobachten waren, können dabei nur auf das Bemühen der Anhänger des Systems des Rite écossais ancien accepté ab 1804 zurückgeführt werden, die verschiedenen schottischen Systeme zu einem zusammenhängenden System zu einigen, das sich sukzessive bis zum 33. Grad fortsetzte. Insofern waren einige Grade ambivalent in ihrer Systemzugehörigkeit, nicht aber in ihrer Legitimation als sechte schottische Grade. Dies drückt sich etwa auch noch in einer Ritualinstruktion für den Grad des Prince du Royal Secret vom Anfang des 19. Jahrhunderts des Rite écossais ancien accepté in den Archivbeständen des GOF aus. Hier heißt es zur stufenmäßigen Einordnung des Grades: » $25^{\mathrm{eme}}$ et dernier Dégrée/32 $2^{\mathrm{eme}}$ suivant quelques novateurs $\ll{ }^{99}$

Unabhängig von dieser komplexen Gemengelage verdeutlichen die von SalmReifferscheidt-Dyck eingenommenen hohen Grade bereits eindrücklich, dass Joseph mühelos in die ersten Kreise der Hochgradfreimaurerei des Premier Empire aufgestiegen war und bedeutende Positionen in verschiedenen Hochgradsystemen innehatte. Hierzu ist zu bemerken, dass der Aufstieg in bestimmte Hochgrade zum Teil nur einer zahlenmäßig begrenzten Gruppe und gegen ein entsprechendes Entgelt möglich war.

Den Aufstieg Salm-Reifferscheidt-Dycks in diese erste Charge beweist beispielsweise auch seine Anwesenheit bei der Installierung des dritten Kapitels des Royal Ordre d'Heredom de Kilwinning unter dem Namen St. Napoleon, die durch den Archichancelier Cambacérès persönlich am 24.04.1812 vorgenommen wurde. ${ }^{100}$ Hier fungierte Joseph Salm-Reifferscheidt-Dyck als Zweiter Großaufseher (Second Grand Surveillant). ${ }^{101}$ Neben ihm standen so bedeutende Freimaurer dieser Zeit wie Claude Antoine Thory (hier in der Funktion eines sogenannten T-R$S-T-A^{102}$ ), der Comte de Gavre (in der Funktion eines Grand Secrétaire), Fulcrand Michel d'Aigrefeuille (Grand Trésorier), Nicolas Antoine Massé de Cormeille (Député Grand Maréchal) oder Michel-Ange de Mangourit (Grand Porte Étendard)

99 Vgl. Sublime et Souverain Prince Du Royal Secret Grand Inspecteur, o.O., Anfang 19. Jh., in: BnF, FM4 817, fol. 1v.

100 Siehe hierzu die Besprechung sowie Quellenauszüge bei Pierre Girard-Augry, Le R $\therefore$ Chapitre de H.D.M. de Kilwinning sous la dénomination du Choix, Deuxième Chapitre de l'Ordre en France et le Premier à Paris, in: Travaux de Villard de Honnecourt 9 (1973), 30-40, hier 35-37.

101 Vgl. Ders., Le R $\therefore$ Chapitre de H.D.M. de Kilwinning (wie Anm. 100, Kap. VII), 36.

102 Das Kürzel »T-R-S-T-A« steht hier für »Thersata « und meint den Vorsitzenden der Arbeiten. Es bedeutet zu Deutsch »Zeitschauer«. Siehe hierzu die Ausführungen bei Frick, Licht und Finsternis (wie Anm. 61, Kap. V), 55. 
den rituellen Arbeiten vor. ${ }^{103}$ Der noble Anstrich des Ordens von Kilwinning, der bereits in seiner Namensgebung sowie den Bezügen zum Rittertum ersichtlich wurde, zeigte sich bei dem Bankett zur Installation des Kapitels St. Napoleon im Übrigen auch an einer pompösen Dekoration. ${ }^{104}$

Auch in anderen Pariser Logen sollte Salm-Reifferscheidt-Dyck wichtige Ämter einnehmen. So wurde er etwa im Jahr 1812 zum Deputierten der Aachener Loge beim GOF ernannt sowie für das Jahr 1813 zum Vénérable der Loge Les Commandeurs du Mont Thabor gewählt. ${ }^{105}$ Seine im Jahr 1814 ausgeübte Funktion eines Zweiten Aufsehers während einer regulären Sitzung des Chapitre du Choix verdient hier besondere Beachtung. ${ }^{106}$ Insbesondere diese letzte Erwähnung zeigt, dass Joseph Salm-Reifferscheidt-Dyck der französischen Hochgradfreimaurerei auch in politisch schwierigen Zeiten verbunden blieb.

Ohne Zweifel spielte, wie im Folgenden noch darzustellen sein wird, die Erweiterung seines zu politischen Zwecken nutzbaren Netzwerks im Premier Empire über das Mittel »Freimaurerei« eine nicht zu unterschätzende Rolle. Es muss jedoch hervorgehoben werden, dass gerade die Inhalte der französischen Hochgradsysteme und hier insbesondere des Rit écossais philosophique den privaten Interessen Joseph zu Salm-Reifferscheidt-Dycks entgegenkamen - wobei noch zu zeigen sein wird, dass das Politische und das Private oftmals untrennbar miteinander verwoben waren. Da sich in Bezug auf sein freimaurerisches Wirken vor allem seine Tätigkeit für den Rit écossais philosophique detaillierter betrachten lässt, soll im Folgenden das freimaurerische Umfeld, in dem Joseph Salm-Reifferscheidt-Dyck sich innerhalb dieses Systems bewegte, ausschnittsweise rekonstruiert werden. Hiermit soll eine Auskunft darüber gegeben werden, weshalb der Comte de l'Empire sich für den aus dem Ancien Régime herüberreichenden

103 Vgl. die Angaben bei Girard-Augry, Le R $\therefore$ Chapitre de H.D.M. de Kilwinning (wie Anm. 100, Kap. VII), hier 36. Zu den Biographien der hier genannten Freimaurer vgl. jeweils die Einträge in Mollier/Pinaud, L'état-major maçonnique (wie Anm. 3, Kap. VI).

104 In den von Girard-Augry wiedergegebenen Quellen heißt es hierzu: ") [...] le Grand Salon, destiné aux banquets, avait été converti en Grand Salon d'Honneur, orné de glaces dans lesquelles se répétaient neuf lustres, chacun de neuf étoiles Il était décoré, ainsi que les autres appartements destinés à recevoir A.S et les autres personnes qui l'accompagnaient depuis son palais, de meubles de la plus haute magnificence. Sur un fût de colonne de granit était le buste de A. Le Temple et les accessoires formaient, d'après les soins d'un architecte habile, un ensemble imposant de tenture et de draperie écossaises, rehaussé de broderies en métal le plus pur. Les avenues du Temple et de ses accessoires étaient couvertes de tapis et de décors de fleurs, de festons et de banderoles aux couleurs écossaises. Tout comportait le caractère d'une fête noble et majestueuse, préparée par une famille tendre et respectueuse pour le père le plus cher.« Zitiert nach GirardAugry, Le R. Chapitre de H.D.M. de Kilwinning (wie Anm. 100, Kap. VII), hier 36.

105 Vgl. Aachener Loge La Concorde an Grand Orient, Aachen, 3. Tag des 5. Monats 5812 (03.07.1812), 4. Tag des 12. Monats 5812 (04.02.1813) sowie vom 22. Tag des 11. Monats 5812 (22.01.1813), in: BnF, FM2 533, fol. 53-59. Die Installierung Salm-Dycks als Vénérable der Loge Commandeurs du Mont Thabor hatte laut dem Schreiben vom 04.02.1813 am 07.01.1813 in ihrem Tempel stattgefunden.

106 Diese Angaben finden sich ebenfalls in den noch unedierten Archivalien des Chapitre du Choix (wie Anm. 90, Kap. VII). 
hermetisch-alchemistischen Ritus interessieren konnte und inwiefern der Ritus in seiner gedanklichen Ausrichtung dem überkommenen aristokratischen Weltbild verbunden blieb.

\section{VII.5 Die Metempsychose als politische Fiktion - Alexandre Lenoirs Vor- lesungsreihe anlässlich der Convents philosophiques des Jahres 1812}

"Je travaille comme une démon. ${ }^{107}$ - Mit diesem ironischen Vergleich eröffnete der bekannte Kunstsammler der revolutionären und napoleonischen Zeit sowie Initiator des Musée des Antiquités et Monuments Français, Alexandre Lenoir (1762-1839), am 16.12.1812 einen Brief, der an den sintellektuellen Kopf $\triangleleft$ des Rit écossais philosophique, den Pariser Advokaten und Grand Administrateur sowie Garde perpétuel des archives, livres, manuscrits, médailles et objets d'art des Souverain Chapitre Métropolitain du Rit écossais philosophique en France Claude Antoine Thory (1759-1829) ${ }^{108}$ adressiert war. Lenoirs berühmt-berüchtigte Sammelleidenschaft für künstlerische Objekte äußerte sich auch in seinem Brief an Thory: "Je vous prie de m'envoyer le plut tôt possible les divinités indienne de votre cabinet, j'en ai le plus grand besoin pour mon travail..«109 Lenoir schlug Thory als Ausgleich für diesen Dienst eine Art Austausch von Kunstobjekten vor:

Je vous fais une collection d'antiquités egyptiennes. J'ai couru tous les cabinets et je sui parvenu à me procurer des originaux de toutes les varietés des dieux de ce peuple. Ainsi nous aurons a peu près toute la mythologie [...] egyptienne en figure. Le tout sans moule a frais commun. Le grand Osiris est coulé, voulez vous qu'on le porte chez vous ou voulez vous attendre que le tout soit fait? ${ }^{110}$

Wohlgemerkt verwendete Lenoir, der in seiner Unterschrift und bei der Angabe des Absenders durchaus auf sein offizielles Amt als Administrateur du Musée des monuments français Bezug nahm, hier die erste Person Plural, als er davon

107 Lenoir an Thory, Paris, 16.12.1812, in: BSB, Autographensammlung, Autograph Lenoir, Alexandre. In seiner Schrift La Franc-Maçonnerie rendue à sa véritable Origine ou l'antiquité de la Franc-Maçonnerie prouvée par l'explication des mystères anciens et modernes bespricht Lenoir ausführlich die indischen Dämonen. Siehe Alexandre Lenoir, La Franc-Maçonnerie rendue à sa véritable Origine ou l'antiquité de la Franc-Maçonnerie prouvée par l'explication des mystères anciens et modernes, Paris 2009 (Erstausgabe 1814), 79.

$108 \mathrm{Zu}$ diesen Angaben und einem Abriss seiner Biographie vgl. Mollier/Pinaud, L'état-major maçonnique (wie Anm. 3, Kap. VI), 270f. Zu einem Porträt Thorys siehe Abb. 27.

109 Lenoir an Thory, Paris, 16.12.1812, in: BSB, Autographensammlung, Autograph Lenoir, Alexandre.

110 Lenoir an Thory, Paris, 16.12.1812, in: BSB, Autographensammlung, Autograph Lenoir, Alexandre. Dass es tatsächlich zum Austausch von Statuen kam, beweist das »Annuaire maçonnique« des Rit écossais philosophique für das freimaurerische Jahr 5812, das sich im ASD erhalten hat. Hier heißt es nach der Auflistung einer Statue der ägyptischen Göttin Isis: „Cette statue a été donnée par le F $\therefore$ Lenoir." Annuaire Maçonnique pour l'Année 5812 (Freimaurerisches Jahrbuch für das Jahr 5812), Paris, 1812, in: ASD, Dyck 4 - Kart. 35/17, 118. 
sprach, dass bald die Kollektion der ägyptischen Götterwelt fertiggestellt sei. Bei der musealen Zusammenschau der Objekte, die nicht nur hinsichtlich der Thematik an das ehrgeizige Ziel des Publikationsprojekts eines Charles François Dupuis erinnerte, ${ }^{111}$ handelte es sich somit um eine Kooperation zwischen Lenoir und Thory und damit auch um eine Überschneidung eines staatlichen und eines freimaurerischen »Bildungsprojekts«.

Diese Überschneidung war dabei bereits seit mehreren Monaten äußerst fruchtbar und hatte ihren Niederschlag in einer Vorlesungsreihe Lenoirs im Zuge der sogenannten Convents philosophiques gefunden, die das Souverain Chapitre Métropolitain du Rit écossais philosophique en France ab dem 01.05.1812 in der Galerie der Archives générales du Rit écossais philosophique im hôtel de Bullion auf der rue Jean-Jacques Rousseau in Paris für Logen des Systems sowie korrespondierende Brüder-Freimaurer veranstaltete. ${ }^{112}$ Bei den Convents philosophiques handelte es sich um bereits im Ancien Régime innerhalb des Rit écossais philosophique durchgeführte freimaurerische Lehrveranstaltungen, deren Abhaltung durch die Revolution unterbrochen und nun durch die Initiative Lenoirs und Thorys fortgeführt worden war. ${ }^{113}$ Die Convents waren dabei nicht frei zugänglich, sondern richteten sich - wenn auch systemunabhängig - an Brüder höherer Grade. ${ }^{114}$ Claude Rétat zitiert hierzu folgende Äußerung Lenoirs aus einem

111 In der Beschreibung der Ausstellungsstücke des Museums im »Annuaire maçonnique« des Jahres 5812 hieß es zu Beginn: „Un planisphère dressé par M. DUPUIS, pour son grand ouvrage de l'origine de tous les cultes. Les noms et signes manuscrits sont de la propre main de ce savant. Il fit présent de ce monument au F $\therefore$ chevalier Lebreton, secrétaire perpétuel de la classe des beauxarts de l'Institut, ex-vénérable de la $\mathrm{R} \therefore \mathrm{L} \therefore \mathrm{E} . \therefore$ du Grand Sphinx, qui a bien voulu en faire hommage aux archives générales de l'ordre, le 25 mars 1811. « Annuaire Maçonnique pour l'Année 5812 (Freimaurerisches Jahrbuch für das Jahr 5812), Paris, 1812, in: ASD, Dyck 4 - Kart. 35/17, 116. Vgl. zur Beeinflussung des späten Rit écossais philosophique durch das Werk Dupuis auch die Ausführungen bei: Rétat, Revers la science (wie Anm. 61. Kap. VII), hier insb. 114-119.

112 Siehe hierzu Einladung des Souverain Chapitre Métropolitain, Paris, 20.04.1812, in: BnF, FM4 37, fol. 7. Diese befindet sich mit anderen Drucksachen vor handschriftlichen Ritualinstruktionen aus dem Jahr 1817. Siehe zu den Convents philosophiques des Rit écossais philosophique auch die kurzen Angaben im Allgemeinen Handbuch der Freimaurerei von Lenning. Hier heißt es: "Zur Weckung der Wissenschaftlichkeit hielt dieses System verschiedene Convente ab, in denen Vorlesungen gehalten wurden; z.B. las Lenoir [...] über die Beziehungen zwischen der Freimaurerei und den alten ägyptischen und griechischen Mysterien [...], de Viany über die allgemeine und besondere Geschichte der Freimaurerei, Leroux über Pneumatologie u.s.w.« Lenning, Allgemeines Handbuch der Freimaurerei (wie Anm. 4, Kap. V), 192. Der bei Lenning erwähnte Leroux veröffentlichte im Jahr 1825 eine Schrift mit dem Titel »Élémens de pneumatologie, ou anatomie des substances spirituelles«. Dieses Werk war leider nicht zugänglich. Eine sarkastische Kritik, die auch die inhaltlichen Bezüge des Werks zur Freimaurerei benennt bzw. im Zitat wiedergibt, findet sich in: Revue encyclopédique ou Analyse raisonnée des productions les plus remarquables dans les sciences, les arts industriels, la littérature et les beaux-arts; par une Réunion de Membres de l'Institut et d'autres hommes de lettres, Bd. 31, Paris 1826, 743-745, Permalink: http://hdl.handle.net/2027/hvd.hxjgsv (Zugriff vom 21.07.2014).

113 Siehe hierzu die Angaben in Claude Rétat, Un temple à côté du temple. Le "Muséum mystérieux" de Thory, in: Renaissance Traditionelle. Revue d'études maçonniques et symboliques 123-124 (2000), 222-254, hier 230.

114 Vgl. Rétat, Un temple à côté du temple (wie Anm. 113, Kap. VII), hier 230. 
Brief an die Brüder des Souverain Chapitre Métropolitain, die hier aufgrund ihrer Wichtigkeit für das richtige Verständnis der Konvente in großen Teilen ebenfalls angeführt sei:

[...] Ces assemblées, formées de frères pourvus de hauts grades, et déjà distingués dans l'ordre par des travaux scientifiques et des actes de philanthropie, se tiennent ordinairement dans un local où tout Maçon, à quelque rit qu'il appartienne, a le droit d'assister. On y discute les points les plus difficiles à résoudre dans la Franche-Maçonnerie, et on s'occupe de tout ce qui peut contribuer au bien de l'Ordre. De même les Mages en Perse, les Hiérophantes en Égypte, et les Philosophes de l'antiquité, à certaines époques de l'année, se réunissaient dans un local retiré, où ils dissertaient sur l'astronomie, sur la sphère, sur la morale et sur la manière de propager les lumières, pour le bonheur commun des hommes. ${ }^{115}$

Die Zulassungskriterien bestanden somit neben dem Erreichen eines hohen Grades in wissenschaftlichen Arbeiten und gemeinnützigen Taten. Bereits Rétat bemerkte, dass Lenoir die Konvente in einer aus der Antike herüberreichenden Traditionskette sah. Zusätzlich muss hier darauf hingewiesen werden, dass Lenoir in ihnen explizit eine Tradition einer geistigen Elite erblickte, der die Sorge um das Wohl der Menschheit anvertraut sei.

Es ist an dieser Stelle wichtig, sich - auch in Hinblick auf die wissenschaftlichen Interessen Joseph zu Salm-Reifferscheidt-Dycks - noch vor einer näheren Besprechung der Vorlesungsreihe Lenoirs die Geschichte und gedankliche Ausrichtung des Systems des Rit écossais philosophique zu vergegenwärtigen, die für das Anbändeln eines wissenschaftlich und künstlerisch Interessierten mit der Freimaurerei weitaus entscheidender waren. Vor allem bei Personen, die den revolutionären Ideen offen gegenübergestanden hatten, ist ein solches Engagement in dem aus dem Ancien Régime herüberreichenden Rit écossais philosophique erklärungsbedürftig. Wie bereits mehrfach erwähnt, stellte der Rit écossais philosophique ein hermetisch-alchemistisches Hochgradsystem dar, woraus sich nicht zwangsläufig eine gute >Passform $>$ zu nachrevolutionären Vorstellungen des gesellschaftlichen Zusammenlebens ergeben musste. Seine Ursprünge gingen in das Paris des Jahres 1776 zurück, als er durch einen Mediziner namens Boileau $(† 1802)$ in die ebenfalls neugegründete Mère Loge du Rit écossais philosophique eingeführt worden war. ${ }^{116}$ Boileau seinerseits stand unter dem Einfluss des bereits oben erwähnten Benediktinermönchs und Physiognomen Antoine-Joseph Pernety (1716-1801), der in einer Aristokratenloge Avignons zuvor den sogenannten Rite hermétique begründet hatte. ${ }^{117}$ Der Rite hermétique ist als eine direkte Vorläuferform des späteren Rit écossais philosophique zu sehen. Im Dunstkreis dieses

115 Zitiert nach Ders., Un temple à côté du temple (wie Anm. 113, Kap. VII), hier $230 f$.

$116 \mathrm{Zu}$ diesen Angaben siehe Frick, Die Erleuchteten (wie Anm. 3, Kap. IV), 505.

117 Vgl. Ders., Die Erleuchteten (wie Anm. 3, Kap. IV), 503f.; Viatte, Les sources occultes (wie Anm. 77, Kap. I), 92-98, insb. 93. Viatte erwähnt hier auch Pernetys Beschäftigung mit den Schriften eines Paracelsus und Helmont. 
Systems hatte Pernety weitere Gesellschaften gegründet, die der Verbreitung des Rite hermétique dienten.

Innerhalb dieser Studie sind vor allem zwei von Pernety gegründete Gesellschaften von Interesse. Noch vor seiner im Jahr 1768 unternommenen Flucht aus Avignon vor den Verfolgungen der Inquisition an den Hof Friedrichs II. von Preußen war die sogenannte Académie des Vrais Maçons entstanden. ${ }^{118}$ Daneben ist aber auch die 1770 von Pernety trotz seiner Abwesenheit innerhalb der Mère Loge Écossaise du Comtat Venaissin in Avignon ins Leben gerufene Académie des Sages von besonderer Bedeutung, da sich in späterer Zeit ein Hochgrad des Rit écossais philosophique auf diese hermetisch-alchemistische Akademie Pernetys beziehen sollte, die - laut der bei Frick zitierten Angabe des »Allgemeinen Handbuchs der Freimaurerei« - »einer angeblich von Ashmole nach der Lehre von Bacons `Nova Atlantis` gegründeten Gesellschaft nachgebildet war.«119 Die Anspielung auf die in Francis Bacons utopischem Roman "Nova Atlantis" erwähnte Gesellschaft "Salomon's House«, die innerhalb des Romans als eine Gesellschaft zur Erforschung des göttlichen Wirkens in der Natur beschrieben wird, ist durchaus bemerkenswert - wie in der weiter unten angeführten Besprechung der Etablierung der Académie in der Aachener Loge La Constance et la Concorde réunis noch zu zeigen sein wird. ${ }^{120}$

Mit dem Wiederaufleben der schottischen Maurerei in Frankreich um das Jahr 1802 und der Wiedererrichtung eines Souverain Chapitre Métropolitain du Rit écossais philosophique, das der Mère Loge écossais de France, sous la dénomination Saint-Alexandre d'Écosse et le Contrat Social angegliedert war, stellte der Rit écossais philosophique erneut ein durchaus prominentes Hochgradsystem dar. ${ }^{121}$ Es beinhaltete wie zur Zeit des Ancien Régime sieben Grade, die über die Prägung Boileaus und Pernetys immer noch hermetisches Gedankengut und insbesondere die Symbolsprache der Alchemie aufgriffen. So wurde als Ziel etwa im Grad eines Parfait Élu durchaus »létude de la Sagesse et la connoissance des Secrets de la Nature festgehalten. ${ }^{122}$ Von der »Blutsideologie« hatte man sich jedoch entfernt. ${ }^{123}$

118 Siehe zur Académie des Vrais Maçons zusammenfassend Frick, Die Erleuchteten (wie Anm. 3, Kap. IV), $504 f$.

119 Hierzu sowie zum Zitat aus dem Allgemeinen Handbuch der Freimaurerei siehe Ders., Die Erleuchteten (wie Anm. 3, Kap. IV), 504f. Siehe ferner zur Académie des Vrais Maçons Lennhoff/ Posner/Binder (Hg.), Internationales Freimaurer-Lexikon (wie Anm. 18, Kap. I), 59.

120 Siehe zur Aufgabe der Gesellschaft die entsprechenden Stellen im Original: Francis Bacon, NeuAtlantis, hg. von Jürgen Klein, Stuttgart 2003, 27f.

121 Vgl. die Beschreibung bei: Mollier, Naissance et essor (wie Anm. 33, Kap. VI), hier 74.

122 Rit écossais philosophique, Cahier du Grade de la Parfait Élu, o.O., 21.09.1813, in: BnF, FM4 681, fol. $9 f$.

123 Siehe hierzu Rit écossais philosophique, Cahier du Grade de la Parfait Élu, o.O., 21.09.1813, in: BnF, FM4 681, fol. 10r. Hier heißt es: »En effet, mes Freres, on ne doit éprouver les hommes que sous le rapport de la morale et des vertus civiles et maçonniques: Toutes les épreuves sanguinaires tiennent de la barbarie ou de la Superstition; et les Sages Ecossais doivent, en s'en abstenant, se distinguer de tous les Chapitres modernes." 
Bereits die Ausführungen zur Diskussion der Idéologues um eine science sociale zur Jahrhundertwende konnten aufzeigen, dass eine wissenschaftliche Beschäftigung mit der Symbolsprache bereits vor dem Anbruch des napoleonischen Kaiserreichs außerhalb der Freimaurerei intensiv weiter betrieben worden war. Auch innerhalb des Rit écossais philosophique des Premier Empire bildeten die pädagogischen Auswirkungen von Symbol und Ritus auf die menschliche Psyche - über den Umweg des aus dem Ancien Régime übernommenen alchemistischen Gedankengutes - offenbar noch einen Interessensschwerpunkt. In einer Instruktion für den Président du Souverain Chapitre Métropolitain du Rit écossais philosophique aus der Zeit des Premier Empire heißt es zum Zweck des Systems des Rit écossais philosophique zusammenfassend:

La Maçonnerie du Rit Ecossais philosophique a pour but les connoissances les plus élevées, et celles qui assuront à l'homme qui peut arriver à l'explication des simboles, un bonheur veritable et eternel. Semblable aux Pyramides d'Egypte, qui contenoirat des Hierogliphes qui donnoient la Clef de toutes les Sciences, notre Maçonnerie, depuis le Grade d'Apprentif jusques au dernier dégré conduit, pas à pas, ses sectaires à la découverte de la vérité. C'est une série divine, dont tous les anneaux se tiennent; et rien, pas même les Révolutions des Empires n'a pu les séparer. Les Ecossais ont été nos Maîtres, leurs descendants existent encore et nos peres tenoient d'eux les secrets qu'ils nous ont transmis. La Dépôt en est confié avec prudence à des hommes sages; s’il étoit violé, les symboles changeroient, mais l'art resteroit toujours. ${ }^{124}$

Die uralte Kunst einer ursprünglich in Stein gemeißelten Symbolsprache, die zur moralischen Perfektionierung des Menschen führen konnte und nur einer gebildeten, zur richtigen Anwendung und Auslegung der Symbole befähigten Elite zugänglich war, vermochte somit auch zur Zeit des Premier Empire im System des Rit écossais philosophique dessen Anhänger zu faszinieren. Die Vorstellung der Entschlüsselung der uralten Symbole sowie eines hiermit zusammenhängenden Urwissens, die auch bereits in der Freimaurerei des Ancien Régime vorhanden gewesen war, kann unter Berücksichtigung des Programms der Idéologie und nicht zuletzt der für das Premier Empire und seinen Kaiser typischen Ägyptomanie in diesem zeitlichen Kontext als eine wissenschaftliche Betätigung angesehen werden - jedoch unter anderen Voraussetzungen als noch im Ancien Régime. Dieser Bezug zu einer Wissenschaft der Symbolsprache klang in der oben genannten Instruktion für den Präsidenten eines Souverain Chapitre bereits in der Beschreibung seiner Aufgaben an. Innerhalb des Ritus sei demnach alles symbolisch und habe eine wissenschaftliche Bedeutung, deren weise Auslegung und Instruktion gegenüber den Adepten dem Präsidenten des Souverain Chapitre vorbehalten 
bleibe. ${ }^{125}$ Von dieser freimaurerischen Praxis der Anschauung und Auslegung einer Symbolsprache war es kein weiter Weg zu den Convents philosophiques und der von den Ausstellungsobjekten der Archive des Rit écossais philosophique untermalten Vorlesungsreihe Alexandre Lenoirs mit dem Titel »Sur les Rapports qui existent entre la Franche-Maçonnerie et les anciens Mystères des Egyptiens, des Grecs et des Peuples modernes «. ${ }^{126}$

Die Vorlesungsreihe erstreckte sich dabei auf acht Abende und wurde allem Anschein nach nachträglich in Lenoirs 1814 erschienene Studie »La Franc-Maçonnerie rendue à sa véritable Origine ou l'antiquité de la Franc-Maçonnerie prouvée par l'explication des mystères anciens et modernes « eingearbeitet. ${ }^{127}$ Am ersten Abend erläuterte Lenoir unter anderem die Zusammenhänge der Freimaurerei mit den Mysterien der alten Ägypter sowie den Eleusinischen Mysterien und entwickelte hieraus die These, dass alle Religionen von diesen abstammten. ${ }^{128}$ Ihren Kern sah Lenoir durch den Glauben an bestimmte "principes generaux « der Natur bestimmt. ${ }^{129}$ Am zweiten Abend der Vorlesungsreihe setzte sich Lenoir etwa eingehender mit einem Vergleich der Mysterien der Isis und der Ceres mit der Freimaurerei auseinander und erläuterte in diesem Zuge die Beschaffenheit und Natur der Seele sowie die Vorstellungen der Alten zu ihrer Läuterung. ${ }^{130}$ Zum Abschluss des Abends fasste er die Lehre der Metempsychose zusammen. ${ }^{131}$ Der dritte Abend war unter anderem dem biblischen Bericht über die Sintflut gewidmet. Wichtig scheint von den weiteren Abenden vor allem der vierte zu sein, da Lenoir hier nochmals auf die Vorstellung von der Unsterblichkeit der Seele zu sprechen kam. Im Dokument heißt es hierzu: »Il examine le dogme du jugement des âmes après la mort, selon les anciens, et prouve qu'il n'est qu'une fiction qui a l'astronomie pour base. ${ }^{132}$

Wiederum erscheint hier also - ähnlich wie bei dem aus politischen Gründen in Ungnade gefallenen Dupuis - die Astronomie als Basis aller Vorstellungen über die Metempsychose bzw. die Unsterblichkeit der Seele. Alle von Lenoir in seinen Vorlesungen beschriebenen Kulte der Alten trugen letztlich zu dem Ergebnis bei, das Lenoir am achten und letzten Abend formulierte und das entscheidend für seine Sicht auf das freimaurerische Ritual - insbesondere des Meistergrades - war. Dessen Ritual stellte demnach eine Allegorie der Phänomene des Sternenhimmels dar. Letztlich konnte als Ergebnis festgehalten werden, dass die Freimaurerei in di-

Instruction sur la maniere de conférer les Hauts-grades (Rit écossais philosophique), o.O., o.D., in: BnF, FM4 685, fol. 1v-2r.

126 Zum Titel vgl. Convent philosophique, Paris, 12.04.1812, in: BnF, FM4 37, fol. 7r.

127 Lenoir, La Franc-Maçonnerie rendue à sa veritable Origine (wie Anm. 107, Kap. VII).

128 Siehe hierzu Extrait Sommaire, Paris, 1812, in: BnF, FM4 37, fol. 8r.

129 Extrait Sommaire, Paris, 1812, in: BnF, FM4 37, fol. 8r.

130 Vgl. Extrait Sommaire, Paris, 1812, in: BnF, FM4 37, fol. 8r. Siehe hierzu auch Kapitel II, $₫$ IV in Lenoir, La Franc-Maçonnerie rendue à sa veritable Origine (wie Anm. 107, Kap. VII), $70 \mathrm{f}$.

131 Siehe Extrait Sommaire, Paris, 1812, in: BnF, FM4 37, fol. 8r.

132 Extrait Sommaire, Paris, 1812, in: BnF, FM4 37, fol. 8r. 
rekter Linie mit den alten Mysterien verwandt war, die bereits die Mager verwandt hatten, um ihr Volk anzuleiten und zur Tugend zu führen. ${ }^{133}$

Die Einweihung in die »Großen Mysterien«, zu denen für Lenoir auch die Freimaurerei gehörte, war somit immer noch - dies musste in einem Hochgradsystem nicht unbedingt überraschen - die Angelegenheit einer elitären »Priesterschaft «, die sich innerhalb der Convents in Form der in hohe Grade eingeweihten Brüder neu formierte. Die Eliten, die den gedanklichen Hintergrund der freimaurerischen bzw. auch jeglicher anderer Riten und Kulte erkannt hatten, leiteten die Menschen durch ihr Vorbild und durch die Überwachung eines ordnungsgemäßen Vollzugs der Riten zum harmonischen Zusammenleben einer Nation und zu tugendhaftem Verhalten an. Die in die höchsten Grade vorgedrungenen Freimaurer des Rit écossais philosophique des Premier Empire begriffen sich somit als vollends über diese Rolle der religiösen Kulte und Riten aufgeklärt. Die Frage nach der Wahrhaftigkeit der Metempsychose, deren Realität im Ancien Régime in alchemistisch experimentierenden Kreisen noch nachzuweisen versucht wurde, aber bereits im Gedicht von Constance de Salm vor der Revolution im Ungewissen lag, war bei Lenoir vollends mit dem Verweis in das Reich der Fiktion beantwortet worden.

Es wäre jedoch ein Trugschluss zu glauben, dass ihr Nutzen durch diesen Status zwangsläufig von den Zeitgenossen in Frage gestellt worden wäre. Das Gegenteil ist der Fall. Lenoir hatte sich bereits im Jahr 1810 in einem Vortrag vor der Académie celtique eingehend mit der Lehre der Metempsychose auseinandergesetzt. In diesem Vortrag, der verkürzt auch verschiedene antike Kulte besprach, wie sie auch Gegenstand der späteren Vortragsreihe für den Rit écossais philosophique waren, kam er in Bezug auf die »Fiktion der Metempsychose« zu dem Ergebnis, dass sie dennoch große Weisheit in sich barg. ${ }^{134}$ Die Weitergabe der Idee

133 Extrait Sommaire, Paris, 1812, in: BnF, FM4 37, fol. 8v. Hier heißt es: »Enfin, le Frère Lenoir examine le troisième grade de la Franche-Maçonnerie, dans lequel il trouve, par explication qu'il en donne, la répétition complette de la théorie des anciens mystères qu'il a développée dans son Cours: il prouve que les formules usitées dans ce grade, que sa composition même n'est qu'une image allégorique des phénomènes célestes qui frappent journellement nos regards, et que son invention est de toute antiquité. [...] Le Frère Lenoir passe ensuite à l'examen et à l'explication du grade d'élu, et termine son Cours par la récapitulation générale de toutes les matières qu'il a traitées, et il prouve que la Franche-Maçonnerie n'est qu'une imitation des anciens mystères; qu'elle renferme à elle seule, quand on sait bien la connaître, toutes les théories et toutes les doctrines mises au jour par les anciens Mages pour diriger les hommes dans le monde social et les conduire à la vertu."

134 Alexandre Lenoir, Observations critiques sur la Métempsycose, in: Académie Celtique, Mémoires de l'Académie celtique ou Mémoires d'antiquités celtiques, gauloises et françaises, Bd. 5, Paris 1810, 477-497, hier 497, Permalink: http://nbn-resolving.org/urn:nbn:de:bvb:12-bsb10534873-1 (Zugriff vom 25.05.2014). Hier heißt es: »Ne suffirait-il pas de se rendre compte de ses pays imaginaires pour lesquels les hierophantes expédiaient des passe-ports aux hommes après la vie? $\mathrm{Ne}$ suffirait-il pas enfin de réfléchir sur la nature des peines et des récompenses qui les y attendaient? Il n'y a point d'erreur indifférente, du moment qu'elle est adoptée par une nation entière. Que sera-ce donc d'une erreur adoptée par le monde entier pendant des siècles! Cependant, je dirai: les dépositaires de la science se virent souvent forcés d'employer des moyens obliques pour nous 
der Metempsychose durch eine Symbolsprache trug zur harmonischen Ordnung der Welt und zur Perfektionierung des Menschen auf dem Weg der Tugend bei und musste folgerichtig auch in Zukunft gewährleistet werden. Dies ist als Grund für die große Mühe zu sehen, die sich sowohl Lenoir mit seiner Vorlesungsreihe über die künstlerisch gestalteten Kultobjekte antiker Religionen als auch Thory gegeben hatte, dessen Wirken für den Rit écossais philosophique im Folgenden betrachtet werden soll. Wie oben gesehen, stellte die Freimaurerei im Denken beider Männer die Zusammenfassung der religiösen und kultischen Systeme der Menschheitsgeschichte dar. Der fiktionale Kern der Metempsychose konnte - bei richtiger Vermittlung, so die Annahme - zur Wohlfahrt der menschlichen Gesellschaft insgesamt beitragen.

Die Aufgabe des »wissenschaftlichen Ritus« des Rit écossais philosophique war es, die Wirkungsweise der Symbolsprache nicht in Hinblick auf die adlige »Blutsideologie«, sondern die Gesellschaft allgemein zu erforschen, diese Sprache zu perfektionieren und insgesamt ihr inhärent politisches Prinzip zu bewahren. Die Rückverfolgung der `Großen Kette der Riten`, der Sammlung ihrer missing links, die das kontinuierliche System von trial and error der menschlichen Zivilisationen repräsentierten, war eine der Antriebsfedern der Bemühungen des philosophischen Ritus im Premier Empire. Gerade in der Zeit nach der Französischen Revolution verband sich mit der Rückverfolgung des gesellschaftlichen Scheiterns die Hoffnung auf eine Perfektionierung der Grande Nation mit den exakten Mitteln der zeitgenössischen Wissenschaften.

Über seine Mitgliedschaft und seine Einnahme der höchsten Grade nahm auch Joseph zu Salm-Reifferscheidt-Dyck an dieser Suche teil und durfte sich als ein Zugehöriger dieser sesoterisch-politischen Elite` fühlen. Einer seiner engsten Korrespondenzpartner innerhalb des schottisch-philosophischen Ritus war der Kopf des Ritus, Claude Antoine de Thory. Das gemeinsame Engagement für das System des Rit écossais philosophique war jedoch nicht das einzige gemeinsame Interesse beider Männer. Sie teilten auch ihre Passion für das Wissensgebiet der Botanik.

\section{VII.6 Taxierte Seelen - Naturwissenschaftliche Analytik in ihrem Einfluss auf das zeitgenössische Verständnis des freimaurerischen Rituals in der Zeit des Premier Empire}

Der Garten des Schlosses Dyck am Niederrhein spiegelt bis heute die große Leidenschaft Joseph zu Salm-Reifferscheidt-Dycks für die Pflanzenwelt wider. Die intensive Beschäftigung mit botanischen Studien ist insofern wohl eine der auffäl-

transmettre des vérités utiles; c'est ce qui a fait dire à un penseur profond, que dans presque tous les ordres des préjugés, si les écrivains n'avaient pas consenti à passer pour fous, le monde en serait aujourd'hui moins sage." 
ligsten Tätigkeiten, denen Joseph zu Salm-Reifferscheidt-Dyck zu seinen Lebzeiten nachging. Wie bereits erwähnt, spielte die naturkundliche Ausbildung bereits im Ancien Régime eine hervorgehobene Rolle in der adligen Erziehung, die auch der Vergewisserung des eigenen Status in der Gesellschaft diente.

Aufgrund der veränderten gesellschaftlichen bzw. herrschaftlichen Rahmenbedingungen in der Lebenswelt Joseph zu Salm-Reifferscheidt-Dycks im Premier Empire ist es nahezu selbstverständlich, dass das botanische Interesse nicht mehr der Untermauerung einer exklusiven »Blutsideologie« des Adels dienen konnte. Die Debatten um Monogenismus und Klimatheorie bzw. den Ursprung und die Entwicklung der Menschheit waren mit Anbruch des 19. Jahrhunderts bekanntermaßen nicht zu einem Ende gelangt. Obgleich Buffon und die mit ihm verbundene Weltsicht im Zuge der Französischen Revolution im wahrsten Sinne des Wortes von ihrem Sockel gerissen worden waren, ${ }^{135}$ wurde seine »Histoire Naturelle bis über die Zeit der Revolution hinaus von Bernard Germain Comte de Lacépède fortgeführt. Fortan dominierte jedoch auch in der »Histoire Naturelle« eine stark durch Linné geprägte klassifizierende Methode, in der »der Materialismus Seite an Seite mit sozialen und ästhetischen Vorurteilen ${ }^{136}{ }^{136}$ stand - ein Umstand, der auch auf die physiognomischen Schriften von Literaten des Ancien Régime wie Pernety oder Lavater zurückzuführen war. Obgleich die Vorstellung von der großen, kontinuierlich aufsteigenden »Kette der Wesen « sowie die aristotelische Unterteilung der Natur in drei Reiche stärker in Zweifel gezogen wurde, war der Glaube an eine hierarchische Gliederung der Lebewesen nicht verschwunden, wenngleich die grassierende `Systemwut`, die den Wildwuchs der natürlichen Ordnung ein für allemal in die Nüchternheit wissenschaftlicher Sprache bannen sollte, bereits durch die Zeitgenossen kritisch beäugt wurde. ${ }^{137}$

Auch die Freimaurerei hatte sich im 18. Jahrhundert anfällig für immer neue Systeme gezeigt. Und so überrascht es nur wenig, dass die Diskussionen der Naturwissenschaftler zu Beginn des 19. Jahrhunderts ihren direkten Niederschlag in der Freimaurerei des Premier Empire und ihrer Sichtweise auf das freimaurerische Ritual fanden. So hat sich unter den Freimaurerreden der Aachener Loge La Concorde ein Vortrag erhalten, der im Dezember 1804 in der Pariser Loge L'Abeille gehalten worden war. ${ }^{138}$ Ihrem ungenannten Verfasser galt die Freimaurerei, deren eigenes Alter auf 500 Jahre eingeschätzt wurde, als eine Nachfolgerin der »mysteres d'Isis, d'Osiris, de Ceres et de Cybelle« sowie direkter noch der eleu-

135 Siehe hierzu Lepenies, Das Ende der Naturgeschichte (wie Anm. 38, Kap. I), 168. Lepenies erwähnt, dass die im Rathaus von Buffons Geburtsstadt Montbard befindliche Büste im Zuge der revolutionären Ereignisse aus dem Fenster geworfen wurde.

136 Mosse, Die Geschichte des Rassismus (wie Anm. 62, Kap. II), 46.

137 Siehe hierzu Peter F. Stevens, The Development of biological Systematics. Antoine Laurent de Jussieu, Nature and the Natural System, New York 1994, insb. 63-132.

138 Planche presentée a la R $\therefore \square$ de l'Abeille, Paris, 5804 (1804), in: GStA PK, FM 5.2.A2, Nr. 102, o.S. innerhalb der Akte. Im Folgenden wird die Seitenangabe innerhalb des hier ausgewerteten Dokuments angegeben. 
sinischen Mysterien. ${ }^{139}$ Mit Hilfe der Darstellungen des Astronomen Jean-Sylvain Bailly, Dupuis', des Historikers Boulanger sowie des Philosophen Volney sei es, so der Verfasser, möglich, sich über das System Klarheit zu verschaffen, das allen Religionen und Mysterien zugrunde liege und die Freimaurerei - ganz im Sinne Dupuis' - als ein »dépositaire des élémens de l'astronomie « erscheinen ließe. ${ }^{140}$

Der Redner ging jedoch noch einen Schritt weiter und kam auf das Verhältnis der Freimaurerei zu den exakten Wissenschaften und insbesondere den Naturwissenschaften im Sinne eines Linné und Buffon bzw. ihrer wissenschaftlichen Nachfahren zu sprechen. Die wissenschaftliche Analyse galt ihm als Kern jeglicher Wissenschaft und insbesondere der modernen Medizin, die durch die Arbeiten des Mediziners Barthez, des Psychiaters Pinel, des Anatoms Bichat und Cabanis' von einer lediglich beobachtenden Kunst zu einer analytischen Wissenschaft emporgestiegen sei. ${ }^{141}$ Deutlich kann in der Rede die Stoßrichtung der Idéologues und der science sociale bemerkt werden, da der Verfasser davon ausging, dass auch alle anderen Wissensgebiete, wie die Sprache oder die Gesetzgebung, nun allmählich der Analyse unterworfen werden könnten. ${ }^{142}$ Einzig der regulären Freimaurerei war es jedoch aus Sicht des Orateurs bislang vorbehalten geblieben, die analytische Methode erfolgreich auf den einzelnen Menschen angewandt zu haben. ${ }^{143} \mathrm{Um}$ dies zu illustrieren, wählte er den direkten Vergleich mit einem Botaniker, der in einer Familie von Pflanzen durch die Analyse ihrer spezifischen Eigenschaften die nächstkleinere Einheit der Klasse (»classe«) aufstelle, um dann unter den verschiedenen »Rassen« (»espèces«) diese Klasse in Geschlechter (»genres«) und ihre Varietäten einzuteilen. ${ }^{144}$

139 Planche presentée a la R $\therefore \square$ de l'Abeille, Paris, 5804 (1804), in: GStA PK, FM 5.2.A2, Nr. 102, 1-5.

140 Planche presentée a la R $\therefore \square$ de l'Abeille, Paris, 5804 (1804), in: GStA PK, FM 5.2.A2, Nr. 102, $5 f$.

141 Vgl. Planche presentée a la R $\therefore \square$ de l'Abeille, Paris, 5804 (1804), in: GStA PK, FM 5.2.A2, Nr. 102, 8f. Hier heißt es: »Jusqu'ici je n'ai considéré la Franc-Maçonnerie que comme une institution propre à nous rappeler les initiations anciennes et les bases de la théorie pythagoricienne; j'oserai l'envisager sous un plus vaste rapport, et avancer qu'elle possède le type sur lequel on a basé les méthodes sublimes des sciences naturelles. Il est une vérité qui n'est admise en Europe que depuis 20 ans environ, c'est que l'analyse est la clé de toutes les sciences, et qu'il n'y a point de sciences sans analyse. Et en effet, M $\therefore$ F $\therefore$, le beau systême de Linnée, celui de Buffon et de ses illustres continuateurs, la méthode sublime de Lavoisier, n'ont point d'autre fondement que l'analyse. La médecine qui jusqu'à nos jours n'a été qu'un art d'observation, est enfin devenue par les travaux de Barthez, de Pinel, de Bichat et de Cabanis, une science analytique. Ce siècle qu'on peut avec raison nommer le siècle des lumières, ne devra son éclat qu'à l'analyse appliquée aux diverses connaissances humaine. L'entendement, les langues, la législation, peuvent être soumis au même moyen, et déjà de profonds écrivains ont commencé ces heureuses applications; mais dans quel Etat, sous quel Gouvernement s'est-on servi de l'analyse pour apprécier les hommes individuellement? Nulle part, si ce n'est dans les Loges maçonniques régulière..."

142 Vgl. Planche presentée a la R $\therefore \square$ de l'Abeille, Paris, 5804 (1804), in: GStA PK, FM 5.2.A2, Nr. 102, 8f.

143 Siehe Planche presentée a la R. $\square$ de l'Abeille, Paris, 5804 (1804), in: GStA PK, FM 5.2.A2, Nr. 102, 8f.

144 Vgl. Planche presentée a la R $\therefore \square$ de l'Abeille, Paris, 5804 (1804), in: GStA PK, FM 5.2.A2, Nr. 102, 10. Hier heißt es: »Un botaniste, par exemple, choisit dans une famille de plantes, celles qui réunissent le plus de caractères distinctifs, et il en forme une classe. Dans cette classe, il trouve entre les plantes plusieurs espèces qui n’ont pas tous les caractères qui appartiennent à la classe, et il en 


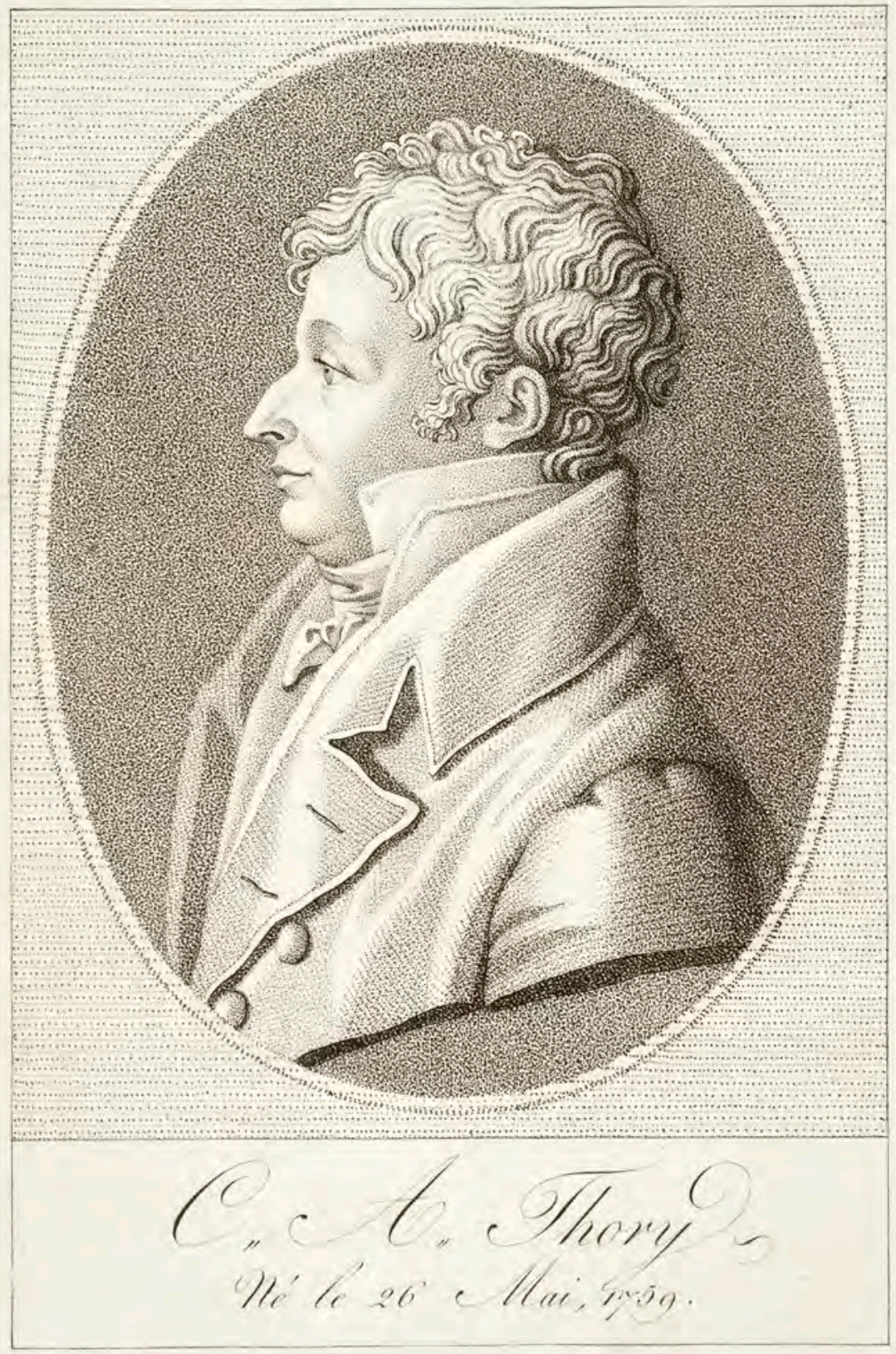

Abbildung 27: N.N., Claude Antoine Thory, né le 26 mai 1759 (= Frontispiz zu Thorys »Histoire de la fondation du Grand Orient de France»), 1812 (Bildrecht/Foto: From the collections of the Cultural Masonic Centre, The Hague). 
Dasselbe Prinzip wandten demnach auch die Inhaber der Hochgrade auf ihre Brüder an, indem sie diese mit Hilfe des freimaurerischen Rituals auf ihre moralische Qualität bzw. ihren Charakter hin analysierten und nach Maßgabe ihrer Fähigkeiten und dem hieraus zu erwartenden Nutzen für den Orden und die Gesellschaft einteilten. ${ }^{145}$ Die Anlehnung an die buffonsche Naturgeschichte und mehr noch die linnésche Taxonomie mit ihren Begrifflichkeiten von »Gattung» und »Art« brachte die Freimaurerei des Premier Empire und ihr Gradsystem dabei in das Fahrwasser der weiterhin schwelenden Diskussion um die Existenz und Einteilung menschlicher »Rassen«.

Auch innerhalb des Rit écossais philosophique waren eine derartig gelagerte Einteilung sowie die naturwissenschaftlichen Beiträge Linnés nicht fremd. Wie bereits erwähnt stellte Claude Antoine Thory den >intellektuellen Kopf^ des Ritus dar. Neben der Freimaurerei fiel Thory im profanen Leben durch seine botanischen Studien insbesondere zu Rosen-Gewächsen auf. ${ }^{146}$ Hierbei arbeitete er unter anderem mit dem bekannten Zeichner Pierre-Joseph Redouté (1759-1840) zusammen, der auch Joseph zu Salm-Reifferscheidt-Dyck um das Jahr 1800 Zeichenunterricht gegeben hatte und als Anreger seiner Vorliebe für Sukullenten gilt. ${ }^{147}$

Thorys Stellung als Garde perpétuel des archives, livres, manuscrits, médailles et objets d'art des Souverain Chapitre Métropolitain du Rit écossais philosophique en France verlangte ihm zunächst eine Reihe von Fertigkeiten ab, die nicht direkt parallel zur Botanik lagen. Neben der Zugehörigkeit zu den "plus hauts degrées philosophiques, même supérieurs à celui de membre de l'académie des $\mathrm{V} \therefore \mathrm{M} \therefore$ « schrieb die Ordnung für das Grand Suprême et Souverain Tribunal des Grand Inquisiteurs Inspecteurs Commandeurs, Chef d'ordre en France die Kenntnis des Lateinischen und anderer alten Sprachen, der freimaurerischen Medaillen und Kunstobjekte sowie die Kenntnis der Geschäfte des Ordens in Frankreich und dem Ausland vor. ${ }^{148}$ Außerdem sollte er mit Logen aller Systeme im In- und

forme des genres; et enfin dans ces genres, il reconnaît des plantes qui lui offrent des différences remarquables et il les appelle variétés. C'est ainsi que tout se distingue, que rien ne se confond et que le savant lève peu à peu le voile de la nature.«

145 Vgl. Planche presentée a la R $\therefore \square$ de l'Abeille, Paris, 5804 (1804), in: GStA PK, FM 5.2.A2, Nr. 102, 10f. Hier heißt es: »De même les Maçons parvenus aux plus hauts grades par la recherche constante de la vérité, classent leurs collaborateurs en raison de leurs facultés; et si les épreuves qu'ils leur font subir sont dirigées par un esprit purent maçonnique, ces épreuves sont une véritable analyse morale, qui donnent une connaissance parfaite du caractère de l'initié et des services que l'ordre et la société peuvent attendre de lui."

146 Vgl. hierzu bspw.: Claude Antoine Thory, Rosa Candolleana seu Descriptio Novæ Speciei Generis Rosaæ, dicata Pyr.-Aug. de Candolle, Parisiis 1819, Permalink: http://nbn-resolving.org/ urn:nbn:de:bvb:12-bsb10303615-1 (Zugriff vom 25.05.2014).

147 Zum Zeichenunterricht Joseph zu Salm-Reifferscheidt-Dycks bei Redouté vgl. Ernst Wunschmann, Salm-Reifferscheid [sic!], Josef, in: Allgemeine Deutsche Biographie, Bd. 30, Leipzig 1890, 255-257, http://www.deutsche-biographie.de/pnd118750992.html?anchor=adb (Zugriff vom 16.10.2012).

148 Lois du S $\therefore$ T $\therefore$ des GG $\therefore$ I $\therefore$ I $\therefore$ C $\therefore$, o.O., o.D., in: BnF, FM1 300 (MF 33620), fol. 32f. Hier heißt es: "L'archiviste général doit bien connoître la langue latine et avoir des notions sur les langues anciennes, les médailles et objets d'arts relatifs à la Maçonnerie. Il doit être instruit à fond des 
Ausland korrespondieren, um seine Sammlung zu erweitern. ${ }^{149}$ Aus dieser Vorschrift ergibt sich durch das eingeforderte kunsthistorische Wissen nicht nur die Erklärung für das anscheinend leichte Zusammenwirken von Thory und Lenoir im Zuge der Convents philosophiques, sondern auch eine Positionierung Thorys als bildungsmäßige `Schnittstelle zwischen dem Rit écossais philosophique und anderen Freimaurer-Systemen.

Sammelpunkt der konservatorischen Bemühungen Thorys waren - dies klang in der Einladung der Convents philosophiques bereits an - Museum, Archiv und Bibliothek des Rit écossais philosophique im Pariser hôtel de Bullion. Diese bedürfen einer besonderen Erwähnung, da es sich hierbei nicht um Stätten handelte, die lediglich freimaurerische Dokumente und Objekte verwahrten, sondern die in ihrem Bestand sehr weitgefächert waren und insbesondere auf die Vermittlung an die außerhalb des freimaurerischen Raums gelegene profane Öffentlichkeit zielten.

Ihr Inhalt setzte sich neben den explizit auf das Sachgebiet der Freimaurerei ausgerichteten Schriften und Objekten deshalb etwa auch aus den Kunst- und Kultgegenständen des indischen, ägyptischen, römischen und griechischen Altertums zusammen, die auch für Lenoir von so großem Interesse gewesen waren. ${ }^{150}$ Zudem enthielt die in insgesamt sechs Sektionen unterteilte Bibliothek neben Schriften zu verschiedenen Mysterienbünden, Zahlenmagie, Astrologie, Magie und Metaphysik auch Bände zur Chemie und Transmutation von Metallen. ${ }^{151}$ Außerdem existierte ein "cabinet de physique et d'histoire naturelle «. ${ }^{152}$ Das Museum blieb jedoch nicht nur Freimaurern vorbehalten, sondern stand auch Profanen offen und wurde durch den von zeitgenössischen Besuchern als "très communicatif« beschriebenen Thory bei Interesse erläutert. ${ }^{153}$ Claude Rétat, der auf diesen wichtigen Umstand verweist, zitiert hierzu auch einen Auszug aus einer Quelle, die als Grund für diese »Redseligkeit« Thorys sowie die Öffnung des Museums den Wunsch nach Vermittlung der Idee der Freimaurerei in das »Herz

affaires de l'ordre en France et dans l'Etranger, entretenir une Correspondance avec les maçons de tous les rits et de tous les pays; pour en obtenir des ouvrages et des manuscrits propres à augmenter ses collections."

149 Vgl. Lois du S $\therefore$ T $\therefore$ des GG $\therefore$ I $\therefore$ I $\therefore$ C $\therefore$, o.O., o.D., in: BnF, FM1 300 (MF 33620), fol. $32 f$.

150 Siehe zur komplizierten Geschichte des Verbleibs des Archivs nach Thorys Tod sowie zu Teilen von dessen Inhalt insb. Rétat, Un temple à côté du temple (wie Anm. 113, Kap. VII), hier 223-229.

151 Siehe hierzu die Angaben bei Collaveri, La franc-maçonnerie de Bonaparte (wie Anm. 21, Kap. VI), 106-108. Aus unbekannten Gründen meint Collaveri, dass das Museum nicht demselben Zweck diente wie die Bibliothek. Dem kann hier in Anbetracht der Studien Claude Rétats sowie des oben zitierten Briefes Lenoirs nicht zugestimmt werden.

152 Rétat, Un temple à côté du temple (wie Anm. 113, Kap. VII), hier insb. 223.

Ders., Un temple à côté du temple (wie Anm. 113, Kap. VII), hier 227. 
des Profanen« angibt. ${ }^{154}$ Der »wahre« Freimaurer galt ihm demnach als ein »ami des hommes, le philosophe de toutes les contrées, le savant de tous les siècles. « ${ }^{155}$

In dieser letzten Aussage, die die verschiedenen gesellschaftlichen Rollen des "wahren Freimaurers" benennt, wird verständlich, weshalb auch die exakten Wissenschaften, wie etwa die Botanik, im Interessensgebiet Thorys, aber auch Joseph Salm-Reifferscheidt-Dycks, mit der Freimaurerei zusammengehen konnten. Folgerichtig finden sich auch in der privaten Bibliothek Thorys Schriften zur Freimaurerei und antiken Philosophie Seite an Seite mit zahlreichen botanischen Schriften sowie den Werken Linnés. ${ }^{156}$

Es versteht sich fast von selbst, dass auch innerhalb des Rituals des ohnehin durch die Alchemie des Ancien Régime geprägten Rit écossais philosophique die Beobachtung der Pflanzen bereits im ersten Hochgrad des Maître parfait dem Adepten als Tradition des Ordens dargelegt wurde. ${ }^{157}$ Der Wille zur universalen Gelehrtheit und die Anstrengung für die Vermehrung des Wissens wurden auch innerhalb des Rit écossais philosophique zum Maßstab für den persönlichen Wert eines Menschen. Wie aus den Untersuchungen Claude Rétats ersichtlich wird, spielte die genaue Einordnung der Brüder nach ihren Fähigkeiten in verschiedene Klassen auch im Rit écossais philosophique bei der Erteilung der Grade eine Rolle. Demnach sollte erst den Brüdern in den Hochgraden, die ihrerseits von einer zweiten in eine dritte und letzte Klasse aufstiegen, das wahre Ziel des Ordens, nämlich die Erforschung sämtlicher Geheimnisse der Natur, bekannt werden. Der dritten und letzten Klasse, die in den sogenannten Chapitres des Grands Aigles blancs et noirs zusammengefasst wurde und aus den besonders wissbegierigen Brüdern bestand, war es zudem vorbehalten, aufgrund ihrer

154 In der von Rétat wiedergegebenen Quelle heißt es: „S'il était possible qu'un profane fût introduit dans ce Muséum mystérieux, son imagination le reporterait peut-être vers ces sanctuaires égyptiens, sources sacrées des arts, des sciences et des connaissances humaines, dans lesquelles l'initié avait la faculté de puiser les lumières qu'il reportait ensuite dans le monde; de simple curieux qu'il serait d'abord en entrant, il deviendrait bientôt Maçon dans le cœur, et prendrait la résolution de s'attacher à un ordre que tant d'objets palpables rendent intéressant à ses yeux. Que serait-ce, s'il lui était permis de feuilleter cette multitude de livres, d'ouvrages historiques, moraux ou scientifiques? C'est alors qu'il serait convaincu que le véritable Maçon est l'ami des hommes, le philosophe de toutes les contrées, le savant de tous les siècles.« Zitiert nach Ders., Un temple à côté du temple (wie Anm. 113, Kap. VII), hier 227f.

155 Ders., Un temple à côté du temple (wie Anm. 113, Kap. VII), $227 f$.

156 Siehe hierzu insb. den Abdruck des Auktionskatalogs der Bibliothek Thorys bei Jacques Tuchendler, Les livres et les objets d'art de Claude Antoine Thory, in: Renaissance Traditionelle. Revue d'études maçonniques et symboliques 157-158 (2010), 2-47, hier insb. 5-15 sowie 20f. Interessant scheinen hier auch die auf Seite 15 vermerkten Autographen innerhalb der Bibliothek, unter denen sich unter anderem die Namen Cambacérès, Lacépède, Dupuis, Gall, Denon, Millin, Guillotin und Lucien Bonaparte finden.

157 Vgl. hierzu den Ritualtext in Instruction sur la manière de conférer les Hauts-grades (Rit écossais philosophique), o.O., o.D., in: BnF, FM4 685, fol. 3v. Hier heißt es: »Le Président demande au Candidat, s'il n'attache pas quelque sens à ce mot si simple en lui même? Il attend sa réponse, et finit par lui dire, que tout est simbolique dans la Maçonnerie; que l'art consiste dans l'explication des simboles et son but, leur application. Il ajoute, que nos Peres, par ce mot, ont voulu indiquer l’Etude du Regne végétal.« 
Dignität und ihres angehäuften Wissens ihre eigene Meinung über die Freimaurerei zu äußern. ${ }^{158}$

Doch auch innerhalb der Chapitres des Grands Aigles blancs et noirs gab es eine Unterteilung in drei Grade bzw. hier Tempel genannt: Chevalier du Soleil (1. Tempel), Chevalier de l'anneau lumineux (2. Tempel), Chevalier de l'Aigle blanc et noir (3. Tempel). ${ }^{159}$ Die Convents philosophiques stellten dabei eine besondere Versammlungsform dieser freimaurerischen Elite dar, wobei die freimaurerischen Gepflogenheiten beiseitegelassen wurden und auch ausgewählte Brüder anderer Riten zur Teilnahme zugelassen werden konnten. ${ }^{160}$ Die Veranstaltungen mussten laut dem Reglement durch einen Bruder aus der Klasse der Professeurs geleitet werden, welche den Grad des Chevalier de l'Aigle blanc et noir innehaben mussten und während des Convents das alleinige Rederecht besaßen. ${ }^{161}$

Die Brüder der anderen beiden Tempel wurden Auditeurs genannt und durften während der gesamten Sitzung nicht das Wort ergreifen. ${ }^{162}$ Auch zu den zu verhandelnden Themen bestanden Vorschriften und Empfehlungen. So tauschte man sich während der Convents über die Wissensgebiete »chimie, haute chimie, de Goétie, de Théurgie, de Psychologie, de Pneumatologie; en un mot, de toutes les parties des sciences que l'on nomme occultes ou secrètes « aus. ${ }^{163}$ Diese Gebiete wurden als die "haute science" aufgefasst, mit der sich nur besonders wissbegierige und als solche »erleuchtete« Brüder befassen durften, die zur Leitung der Gemeinschaft bestimmt sein sollten. ${ }^{164}$

Die Zulassung von ausgewählten Brüdern anderer Riten galt dabei als eine besondere Offenheit der Gründer des Systems des Rit écossais philosophique, die richtigerweise erkannt hätten, dass der Drang, sich dieses Wissen anzueignen, nicht nur Brüdern des Rit écossais philosophique, sondern auch anderen Frei-

158 Siehe hierzu die Ausführungen bei Rétat, Un temple à côté du temple (wie Anm. 113, Kap. VII), hier 237f. Rétat, der zahlreiche Auszüge aus den Quellen anführt, bemerkt hierzu: »Les jeunes recrues trop légères, produit de `ces temps modernes‘, peuvent participer aux formes maçonniques jusqu'au grade de Maître. Les hommes qui, sans scruter le ‘fond ‘ de la maçonnerie, montrent beaucoup de zèle et une grande connaissance des ıformes matérielles«, vont dans une seconde classe: ils y rentrevoient $<$ le but du Rite, >l'étude de la Nature [...] comme celle des hautes sciences et des artsı. Enfin les 'Maçons animés du désir de tout savoir, de tout connaître; [les] hommes curieux de s'instruire dans des sciences au-dessus de la portée des savants ordinaires`, forment une troisième classe, destinée au Chapitre des Grands Aigles blancs et noirs, qui se divise lui-même en trois Temples, qu'ils parcourent successivement. 'C'est là qu'ils peuvent, selon leurs désirs, s'instruire dans la Science maçonnique, même la professer.«"

$159 \mathrm{Zu}$ dieser Einteilung vgl. Chapitre des Grands Aigles blancs et noirs, Paris, 20. Tag des 1. Monats 5787 (20.03.1787), in: BnF, FM4 37, fol. 68r; Anneau Lumineux, Rit écossais philosophique, Paris, 07.09.1812, in: BnF, FM4 687, fol. 2. Letztgenannte Ritualinstruktion wurde von Thory verfasst.

160 Vgl. die Angaben bei: Rétat, Un temple à côté du temple (wie Anm. 113, Kap. VII), hier 234 und 238.

161 Ders., Un temple à côté du temple (wie Anm. 113, Kap. VII), hier 233.

162 Ders., Un temple à côté du temple (wie Anm. 113, Kap. VII).

163 Vgl. zu diesen Ausführungen sowie zum Quellenzitat Ders., Un temple à côté du temple (wie Anm. 113, Kap. VII), hier 238.

164 Vgl. Ders., Un temple à côté du temple (wie Anm. 113, Kap. VII), hier 238. 
maurern eigen war. ${ }^{165}$ Claude Rétat bezeichnet die Convents, die eines eigentlichen freimaurerischen Rituals entbehrten, daher treffend als eine "maçonnerie hors formes maçonniques «. ${ }^{166}$ Bereits hier kann festgestellt werden, dass innerhalb des Rit écossais philosophique zwischen der Wahrung "höherer Erkenntnis« zur Schaffung einer über das Wohl der Gesellschaft wachenden Elite und einer - von eher traditionell gesinnten Freimaurern als Vulgarisation aufgefassten - Verbreitung eines wie auch immer definierten »freimaurerischen Geistes « in die profane Gesellschaft hinein ein kurioser Zwiespalt bestand.

Dieser Zwiespalt kann nur durch die offenbar innerhalb der Mitglieder vorherrschende Annahme erklärt werden, dass der Drang zur Forschung durch die Konfrontation mit Ritus und Symbol bei einem Menschen ausgelöst werden konnte und ihn zur Suche nach der Aufklärung des »Geheimnisses« und über diese zu seiner moralischen Perfektionierung anleiten sollte - oder, wie es in einer Logenrede der Commandeurs du Mont Thabor aus dem Jahr 1814 hieß:

Les vieux Maç $\therefore$ répètent continuellement: Nous cherchons sans cesse. En effet, il y a toujours à trouver et à découvrir, même pour ceux qui en savent le plus, dans ce champ si étroit en apparence et si vaste en réalité. Tous nos regards, tous nos soins, toute notre application doivent donc tourner vers ce point si essentiel, qui renferme les dogmes, et où se trouve consacrée la doctrine, ame de notre institution. ${ }^{167}$

Wissenschaft wurde hier zur Urreligion einer Elite der Menschheit erhoben. In Verbindung mit der oben wiedergegebenen Rede aus dem Jahr 1804 können die Grade des Rit écossais philosophique daher nur als eine Übertragung der naturwissenschaftlichen Taxonomie auf das freimaurerische System betrachtet werden. Anhand der Entwicklungen in der Aachener und Kölner Loge des Rit écossais philosophique wird noch zu zeigen sein, dass hierüber ein solcher Einfluss auch im Rheinland spürbar und folgenreich sein sollte.

Joseph zu Salm-Reifferscheidt-Dyck durfte sich in diesem Denken aufgrund seiner hohen Grade und seines wissenschaftlichen Dranges als Zugehöriger zu einer besonders »erleuchteten« Klasse der Menschheit fühlen, die über den durch

165 Siehe hierzu die Auszüge aus den Quellen bei Ders., Un temple à côté du temple (wie Anm. 113, Kap. VII), 238. Hier heißt es u.a.: "Quoique les connaissances comprises dans ce cadre ne soient pas tellement inhérentes à la franche-maçonnerie philosophique, que l'on ne puisse pas les apprendre ailleurs, il est néanmoins vrai de dire, que les hommes réunis sous les formes maçonniques en général, ont toujours pris un goût particulier pour certaines connaissances, qu'ils ont repoussées souvent, en les recontrant dans des livres profanes. Les frères anciens n'ont pas même regardé ces connaissances comme devant nécessairement faire l'objet de l'étude des maçons professant le rit philosophique; ils ont, suivant leurs principes, laissé sur ce point une entière liberté aux membres de l'association. «Zitiert nach Ders., Un temple à côté du temple, 238.

166 Ders., Un temple à côté du temple (wie Anm. 113, Kap. VII), 238.

167 Discours Prononcé dans la R $\therefore$ L $\therefore$ des Commandeurs du Mont-Thabor; Par le F $\therefore$ Bailleul, Off: du G $\therefore$ O $\therefore$ de France, en son Gr $\therefore$ Ch $\therefore$ Gén $\therefore$, Séance du 18. Jour du 6. Mois, l'an de la V $\therefore$ L $\therefore$ 5814, Paris, 18.08.1814, in: GOF, 5477, 11. 
die Naturwissenschaften ergänzten Wissensbestand der Freimaurerei die für ihre "Geheimnisse" empfänglichen Seelen und letztlich eine gesamte Nation zur moralischen Perfektionierung zu führen vermochte. Seine Bildung über die Religionen, Riten und Philosophien der Menschheit, deren aus freimaurerischer Sicht wichtigste Bestandteile ihm insbesondere noch während des 32. Grades des Rite écossais ancien accepté zusammenfassend vermittelt worden waren, zielte zwar darauf, ihn von der Fiktionalität der Lehren, wie der Metempsychose, zu überzeugen. Die freimaurerischen Riten konnten ihm aber paradoxerweise dennoch als ein nützliches Hilfsmittel zur Führung menschlicher Gesellschaften erscheinen. Sie allein sollten es ermöglichen, den moralischen Stand eines Menschen zu analysieren, ihn entsprechend seiner Anlagen zu klassifizieren und mit ihren erzieherischen Mitteln zu einer höheren Reife zu führen. Denn der Glaube an die weiter fortschreitende, stufenweise erfolgende zivilisatorische Perfektionierung der Menschheit - dies ist in allen freimaurerischen Texten dieser Zeit offensichtlich - war nach wie vor vorhanden. Er artikulierte sich in einer »ästhetischen Erziehung " und - hiermit aufs engste zusammenhängend - über den Glauben an die Wissenschaft.

Obgleich die Ausrichtung auf einen »divine moteur « immer noch fester Bestandteil dieses Denkens war, war an die Stelle des Gottes, der die Menschen in ihre gesellschaftliche Stellung einsetzt, eine besondere Klasse der Menschheit selbst getreten, die mit Hilfe der Wissenschaft ihre Mitmenschen analysieren, klassifizieren und ihnen entsprechend ihrer individuellen Eignung Aufgaben bzw. ihre Stellung in der Gesellschaft zuteilen sollte.

Mit diesem hochtrabenden Selbstbild verband sich gleichzeitig die ebenfalls immer wieder geäußerte Forderung nach Verschwiegenheit, Bescheidenheit und Nächstenliebe. Im Folgenden soll unter diesem Aspekt auf die Pariser Loge Les Commandeurs du Mont Thabor eingegangen werden, da ihre Untersuchung nicht nur das Umfeld Joseph zu Salm-Reifferscheidt-Dycks weiter erhellt, sondern auch eingehender die Überschneidung der profanen mit der freimaurerischen Ebene über die Gebiete Wissenschaft und Künste illustriert und die karitative Ausrichtung der Loge sichtbar macht. Die Entwicklungen und Zusammenhänge in der Pariser Loge stellen zudem die Grundlage für das Verständnis der späteren Vorgänge im Rheinland dar.

\section{VII.7 "... et prendre racine dans leur âme." - Das gedankliche und personale Umfeld Joseph zu Salm-Reifferscheidt-Dycks in der Pariser Loge Les Commandeurs du Mont Thabor}

Die Aufnahme in eine Freimaurerloge durfte im Premier Empire, in dem auf französischem Boden mit der Schaffung der Noblesse d'Empire durch Napoleon auch Adelstitel erneut eingeführt worden waren, wieder als Ehre aufgefasst werden. Die im Jahr 1807 begründete Pariser Loge Les Commandeurs du Mont Thabor, deren 
Name sowohl an den in der Bibel erwähnten Berg der Verklärung Jesu als auch an den dortigen Sieg Napoleons im April 1799 erinnern sollte, ${ }^{168}$ hatte dabei als ihren Vénérable d'honneur mit Bernard Germain de Lacépède niemand geringeren als den Grand Chancelier der Légion d'honneur gewählt. ${ }^{169}$ Es handelte sich also um eine Person, die bereits auf profanem Gebiet an Ehrauszeichnungen kaum mehr $\mathrm{zu}$ überbieten war.

Eine Untersuchung Molliers zu dieser bedeutenden Pariser Loge des Rit écossais philosophique konnte zeigen, dass die Wahl Lacépèdes wohl nicht völlig zufällig getroffen worden war. Mollier konstatierte, dass ein Viertel der Logengründer der Légion d'honneur und hier eine Vielzahl insbesondere der Grande Chancelerie angehörte, wie auch die Führungsspitze der Légion selbst zu großen Teilen mit Freimaurern besetzt war. ${ }^{170}$ Joseph zu Salm-Reifferscheidt-Dyck fügte sich in diese Reihe ein, war er doch im Jahr 1804 zum Kanzler der vierten Kohorte der Ehrenlegion ernannt worden und wurde als solcher auch in der Loge geführt. ${ }^{171}$ Er stand in dieser Funktion mit dem Comte de Lacépède in regem Schriftverkehr, worüber umfangreiche Bestände im Familienarchiv Auskunft geben. ${ }^{172}$

Wie bereits gesehen, war Bernard Germain de Lacépède auch in Hinsicht auf seine naturwissenschaftlichen Forschungen keine unbedeutende Person. Er verband so wiederum die beiden Interessenfelder Freimaurerei und Naturwissenschaften miteinander, die, wie gezeigt, besonders im Rit écossais philosophique eine hervorgehobene Stellung einnahmen. Michel Ange de Mangourit, im Jahr

168 Eine Erklärung des Namens gibt der Redner der Loge Michel Ange de Mangourit anlässlich der Installation der Loge im Jahr 1808. Hierin klingen deutlich die Bezüge zur Sichtweise der Religionen als Spiegel der Astronomie an. Siehe hierzu Commandeurs du Temple du Mont Thabor, Discours de l'Orateur Mangourit, Paris, 1809, in: GOF, 5477, 41-54, hier 46f. Zander erwähnt, dass die Verklärung Christi auf dem Berg Thabor auch immer wieder als Textbeleg für reinkarnatorische Ideen in der Bibel angeführt wird. Das Vorkommen derartiger Ideen in der Bibel ist nach Zander jedoch nicht haltbar. Vgl. Zander, Geschichte der Seelenwanderung (wie Anm. 77 Kap. I), 119-122. Es ist in Bezug auf den Namen der Loge sowie die hierzu gegebenen Ausführungen Mangourits, die auch eine gedankliche Brücke zur Astronomie schlagen, jedoch durchaus möglich, dass eine solche Verbindung des Christentums zur Fiktion der Metempsychose durch die Logenmitglieder gesehen wurde.

169 Vgl. hierzu Pierre Mollier, Les débuts de la Légion d'honneur et la franc-maçonnerie, in: Ders. (Hg.), La Franc-maçonnerie sous l'Empire (wie Anm. 43, Kap. VI), 61-78, hier 70. Mollier verweist hier auch auf eine Rede Rogers zur Symbolik der Sonnenwendfeiern und Äquinoktien in Zusammenhang mit dem Johannestag. In der Rede seien, so Mollier, deutlich die Einflüsse Dupuis' sowie die Lehren der Idéologues ersichtlich. Ein Porträt Lacépèdes (Öl auf Leinwand von Jean-Baptiste Paulin Guérin nach dem Original von Louis Hersent, 1842) findet sich unter: commons. wikimedia. org/wiki/File\%3AB_G_de_Lac\%C3\%A9p\%C3\%A8de.jpg (Zugriff vom 05.08.2014).

170 Vgl. Ders., Les débuts de la Légion d'honneur (wie Anm. 169, Kap. VII), hier 67-69.

171 Vgl. hierzu die Angaben im Tableau der Loge aus dem Jahr 1810: Tableau des Membres de La R $\therefore$ L $\therefore$ Écoss $\therefore$ De St. Jean sous le titre distinctif des Commandeurs du Mont Thabor, Paris, 22.02.1810, in: BnF, FM2 65bis, fol. 82.

172 Zum Schriftverkehr mit Lacépède siehe Korrespondenz mit Lacépède, Bernard, Germain (1756-1826, Comte, Großkanzler der Ehrenlegion, Staatsminister), 1804-1813, in: ASD, Dyck4 - Kart. 6/102 sowie Korrespondenz mit Lacépède, Bernard, Germain (1756-1826, Comte, Großkanzler der Ehrenlegion, Staatsminister), 1804-1810, in: ASD, Dyck4 - Kart. 6/103. Hierbei handelt es sich um insgesamt 216 Briefe aus der Hand Lacépèdes und 147 Konzepte Joseph zu SalmReifferscheidt-Dycks. Die Freimaurerei spielte innerhalb des Schriftverkehrs keine Rolle. 
1808 Redner der Loge Les Commandeurs du Mont Thabor, wandte sich daher bei seiner Rede anlässlich der Installation der Loge direkt an seine Brüder und betonte folgerichtig die sich aus der naturwissenschaftlichen Expertise ergebende geradezu priesterliche Stellung des anwesenden und die Installationsarbeit leitenden Lacépède: "Votre Vénérable d'honneur, revêtu du sacerdoce des sciences naturelles et du pontificat des récompenses nationales, n’a point dédaigné la houlette d'un troupeau dont les brebis se repaissent du parfum des fleurs... « ${ }^{173}$ Stach der >Hohepriester Lacépède als Naturforscher durch seine Tätigkeit als Fortführer der »Histoire Naturelle« Buffons und Mitglied sowie zeitweilig Präsident der Société des Observateurs de l'homme hervor, war sein freimaurerischer Werdegang nicht minder beeindruckend. ${ }^{174}$ Neben verschiedenen hohen Ämtern für den GOF in der Zeit des Premier Empire bestand die wichtigste Station wohl in der Mitgliedschaft in der bereits erwähnten Künstler-Loge Les Neuf Sœurs, an deren Wiedererrichtung Lacépède im Jahr 1805 ebenfalls maßgeblich beteiligt war. $^{175}$

Es muss aufgrund der Fortführung der buffonschen »Histoire Naturelle« erwähnt werden, dass sich Lacépèdes naturwissenschaftliche Methodik eindeutig an Linné orientierte und insofern kein Konflikt mit der Ausrichtung der Société des Observateurs de l'homme entstand, die sich ebenfalls zur Aufgabe gemacht hatte, die verschiedenen "variétés de l'espèce humaine « zu untersuchen. ${ }^{176}$ Dies bedeutete für die Zeitgenossen, die verschiedenen Völker insbesondere in ihren kulturellen und geschichtlichen Unterschieden zu analysieren, obwohl physische Unterschiede beim Menschen nach wie vor interessierten und der Glaube an die Klimatheorie noch nicht gänzlich verschwunden war. ${ }^{177}$ Die belletristische Naturgeschichte Buffons wurde hier somit durch Gelehrte wie Lacépède zur Naturgeschichte in historisch-wissenschaftlichem Sinne.

Dass die historische Erforschung der Ursprünge des französischen Volkes auch für die Mitglieder freimaurerischer Logen sowie insbesondere der Loge Les Commandeurs du Mont Thabor von entscheidender Bedeutung war, zeigt auch die zahlen- wie funktionsmäßig nicht unbedeutende Mitgliedschaft aus ihren Reihen bzw. auch Brüdern anderer Logen des Rit écossais philosophique in der Académie

173 Commandeurs du Temple du Mont Thabor Discours de l'Orateur Mangourit, Paris, 1809, in: GOF, 5477, 41-54, hier 44.

174 Siehe zur Präsidentschaft die Angabe bei Chappey, La Société des Observateurs de l'homme (wie Anm. 54, Kap. VII), 12.

$175 \mathrm{Zu}$ seinem freimaurerischen Werdegang vgl. insb. die Beiträge Amiables und Molliers: Amiable, Une loge maçonnique d'avant 1789 (wie Anm. 74, Kap. VII), 293-295; Mollier, Les débuts de la Légion d'honneur (wie Anm. 169, Kap. VII), hier 62-67; Ders./Pinaud, L'état-major maçonnique (wie Anm. 3, Kap. VI), 179-182.

176 Zum Programm der Société in Bezug auf die Erforschung der »Varietäten « siehe Chappey, La Société des Observateurs de l'homme (wie Anm. 54, Kap. VII), 336-360.

177 Vgl. Chappey, La Société des Observateurs de l'homme (wie Anm. 54, Kap. VII), $344 f$. 
celtique. ${ }^{178}$ Neben den Logen-Brüdern Joseph zu Salm-Reifferscheidt-Dycks, der selbst nicht Mitglied der Académie war, finden sich unter ihren Mitgliedern neben zahlreichen Bretonen einige Besucher des durch die Idéologues beeinflussten Salons der ebenfalls aus der historischen Bretagne stammenden Constance - inklusive des »Décade«-Gründers Ginguené. ${ }^{179}$ Auch aus diesem Grund muss hier näher auf die Académie eingegangen werden.

Die Académie celtique, die später in Société des Antiquaires de France umbenannt werden sollte, war im Jahr 1805 gegründet worden. Im Nachklang zur Französischen Revolution, die von den Zeitgenossen auch als Ende der Fremdherrschaft einer ursprünglich germanischen Adelskaste über das französische Volk aufgefasst worden war, wollte sie sich verstärkt den Ursprüngen der französischen Nation widmen, deren Wiege man insbesondere in Frankreichs Nordwesten bzw. der Bretagne vermutete. ${ }^{180}$ Im Zentrum dieser Forschungen standen dabei nicht nur die Sprache und die steinernen Kultobjekte der gallisch-keltischen Vorfahren, sondern darüber hinaus auch - als Reaktion auf die Schriften des Cercle social um den Freimaurer und Jesuitenfeind Nicholas de Bonneville - die Anleitung des Volkes durch die Druiden und ihre Religion, die Bonneville in der bekannten Traditionskette mit den >kosmischen Religionen` des Altertums in Indien oder Ägypten sah. ${ }^{181}$

Es handelte sich bei derlei Konstruktionen Bonnevilles und später auch der Académie celtique jedoch nicht um ein beliebiges Interesse an der Vorgeschichte des französischen Volkes. Vielmehr kam es hierbei aus Sicht der Zeitgenossen Salm-Dycks auf die Stellung der Druiden innerhalb der archaischen Gesellschaft an, die als Naturkundige das Volk zu führen und durch religiöse Kulthandlungen, aber auch Feste oder Musik, auf dem »Weg der Tugend « zu halten vermochten. ${ }^{182}$ Die Zeugnisse dieser Kultur, von der man annahm, dass sie durch das Christentum unterdrückt worden war, vermutete man daher folgerichtig nicht nur in den monumentalen steinernen Kultobjekten oder mittelalterlichen Erzählungen wie etwa der Artuslegende und der - aus dieser Perspektive - an den Zodiakalkreis erinnernden Tafelrunde der Ritter, sondern auch in Sprache, Festen und Liedgut

178 Vgl. hierzu die Angaben bei Jean-Yves Guiomar, La revolution et les origines celtiques de la France, in: Annales historiques de la Révolution Française 287 (1992), 63-85, hier insb. 76-78 sowie 85. Guiomar erwähnt hier in Bezug auf die Brüder des Rit écossais philosophique die Bretonen Jacques Cambry (1749-1807), Mangourit und Joseph Lavallée. Außerdem wird Lenoir erwähnt, der nach Cambrys Tod auch die Präsidentschaft in der Académie übernahm.

179 Ginguené war Gründungsmitglied der Académie. Siehe Guiomar, La revolution et les origines celtiques (wie Anm. 179, Kap. VII), hier 79. Zu einer Untersuchung der Bedeutung der »Blutsideologie« bzw. der Vorstellung der »Rasse« in der Bretagne siehe jüngst Christopher H. Johnson, Class Dimensions of Blood, Kinship, and Race in Brittany, 1780-1880, in: Johnson [u.a.] (Hg.), Blood \& Kinship (wie Anm. 50, Kap. II), 196-226.

180 Vgl. hierzu die Angaben bei Guiomar, La revolution et les origines celtiques (wie Anm. 179, Kap. VII), hier 63 sowie 80.

181 Vgl. hierzu Ders., La revolution et les origines celtiques (wie Anm. 179, Kap. VII), hier 63-65.

182 Siehe hierzu die bei Guiomar zitierten Textstellen aus den Schriften Bonnevilles oder Cambrys: Ders., La Révolution et les origines celtiques (wie Anm. 179, Kap. VII), hier insb. 64 sowie 67. 
der so oft vernachlässigten Kultur des »einfachen Volkes «. ${ }^{183}$ Gerade in den »coutumes `singulières«, ১bizarres`, ‘absurdes` et même 'grotesques « ${ }^{184}$ vermuteten die Mitglieder der Académie die Überlieferungen der unterdrückten Vorfahren. Wohlgemerkt war es auch hier Aufgabe einer geistigen Elite, diese Überreste zu erkennen und ihre ursprüngliche Bedeutung für die Ordnung des Gemeinwesens herauszuarbeiten.

Der hinter dem `folkloristischen` Forschungsinteresse liegende Impetus betonte die Wichtigkeit dieser besonders ursprünglichen Riten für die Beherrschung bzw. tugendhafte Ausrichtung des Volkes. Er ist insofern als profane Parallele zur Erforschung der Geschichte der Freimaurerei innerhalb des Rit écossais philosophique zu sehen und scheint selbst mit den mythisch-genealogischen Rückführungen der "semence occulte" des adligen Blutes noch gedanklich in entfernter Verbindung zu stehen. Freilich lag der Fokus der Académie auf den Ursprüngen der Nation im Gesamten und somit nicht auf dem Ursprung einzelner Familien.

Innerhalb der Loge Les Commandeurs du Mont Thabor war nicht nur der erste Präsident der Académie celtique - und damit Vorgänger Alexandre Lenoirs - Jacques Cambry vertreten, sondern auch Joseph Lavallée, ebenfalls Mitglied der Académie und Chef der fünften Division der Légion d'honneur. ${ }^{185}$ Besondere Beachtung verdient hier aber der Sekretär der Académie celtique Michel Ange de Mangourit, der sich vor den Commandeurs im Jahr 1809 in seiner "Éloge Funèbre « auf Cambry rühmen konnte, gemeinsam mit ihm und dem Philologen und Altertumsforscher Éloi Johanneau (1770-1851) die Académie celtique im Jahr 1805 begründet zu haben. ${ }^{186}$

Der aus einer adligen Familie Rennes stammende Bretone Mangourit war ein Revolutionär der ersten Stunde mit liberalen gesellschaftlichen Einstellungen und hatte sich bereits im Vorfeld der Revolution als Schreiber bissiger Pamphlete den Unmut der Regierung der Provinz Bretagne zugezogen. ${ }^{187}$ Im Jahr 1792 war er

183 Siehe hierzu Ders, La Révolution et les origines celtiques (wie Anm. 179, Kap. VII), hier 67-69; Marie-Jeanne Durry, Lacadémie celtique et la chanson populaire, in: Revue de littérature comparée 9 (1929), 62-73; Mollier, Les débuts de la Légion d'honneur (wie Anm. 169, Kap. VII), hier 74f.

184 Nicole Belmont, L'Académie celtique et George Sand. Les débuts des recherches folkloriques en France, in: Romantisme 9 (1975), 29-38, hier 31.

185 Vgl. die Angabe bei Mollier, Les débuts de la Légion d'honneur (wie Anm. 169, Kap. VII), hier 75f. Mollier erwähnt hier auch den Einfluss der Idéologues auf Lavallée sowie die Académie.

186 Siehe hierzu Commandeurs du Mont-Thabor, Rit ecossais philosophique. Fête funèbre votée le $2^{\mathrm{e}}$ du $9^{\mathrm{e}}$ de l'an de la G.L. 5808, et célébrée le $27^{\mathrm{e}}$ du $12^{\mathrm{e}}$, même année (E.V., 27 février 1809), en mémoire du R. commandeur-fondateur Jacques de Cambry, Mont-Thabor, 5809 (1809), in: GON, 125.B.31, 40f., Permalink: http://gallica.bnf.fr/ark:/12148/bpt6k841578v (Zugriff vom 25.05.2014). Hier berichtete Mangourit: »Depuis longues années, je m’occupais d'antiquités celtiques. Un semblable, mais plus fructueux dévouement animait M. Johanneau, l'un des savans estimés de cette capitale. Je lui fis part de mon désir de rassembler les explorateurs de la Gaule; il en parla à $\mathrm{M}$. de Cambry; nous nous réunîmes tous les trois: et l'académie Céltique fut fondée."Eine Anmerkung verweist dabei auf das Jahr 1805 als Gründungsjahr.

187 Erwähnenswert ist hier seine Haltung zum Wahlrecht in den französischen Kolonien. In Bezug auf die Beteiligung von dunkelhäutigen Menschen an den Wahlen zitiert Alderson eine für die damalige Zeit durchaus liberale Äußerung Mangourits: »They are not less than men, [...] the way 
zum französischen Botschafter im amerikanischen North Carolina, in South Carolina und Georgia ernannt worden. ${ }^{188}$ Bis zum Jahr 1799 verblieb Mangourit in politisch-diplomatischen Ämtern, beendete dann jedoch aufgrund von Differenzen mit Napoleon seine Karriere und trat nach 1800 vor allem als Autor geschichtlicher Werke und Theaterstücke in Erscheinung. ${ }^{189}$ Erwähnenswert ist seine Beschreibung des hannoverschen Staates, in der er sich nicht nur als Kenner der gelehrten und vor allem naturwissenschaftlichen Einrichtungen der Gegend erwies, sondern dem Leser auch eine Beschreibung der Sitten der Einwohner sowie der alten Götter der Sachsen bieten wollte. ${ }^{190}$ Er beschrieb in diesem Zuge unter anderem auch die »Albernheit« der Hexensagen um den Blocksberg bzw. Brocken, die er als Konstrukt auf den »Trümmern der Druidenreligion « verstanden haben wollte. ${ }^{191}$ Mangourit gab hierin also bereits einen ersten Vorgeschmack auf die Projekte des zum Zeitpunkt der Veröffentlichung noch nicht reorganisierten Umfeldes des Rit écossais philosophique bzw. der Académie celtique.

Auch innerhalb der Freimaurerei konnte Mangourit auf eine bewegte Geschichte zurückblicken, wobei ihm seine `kreative Ader`durchaus zugutegekommen sein mochte. ${ }^{192}$ So war er im Jahr 1776 Begründer eines Hochgradsystems namens Suprêmes Élus de la Vérité. ${ }^{193}$ Diese `Gründertätigkeit` nahm er im Premier Empire wieder auf. Sie kann dabei am besten illustrieren, inwiefern künstlerische Neuschöpfung und historische Forschung innerhalb einer Neugründung freimaurerischer Riten aktiv wurden.

Es ist hierbei zunächst wichtig zu erwähnen, dass auch in der Loge Les Commandeurs du Mont Thabor das Erbe der Druiden immer wieder zur Sprache kam. ${ }^{194}$ In Anbetracht der Logenreden wird deutlich, dass dabei eine hierarchisch organisierte Kultform als Mittel zur Anleitung des Volkes angesehen wurde. Es

of alleviating the harshness of slavery, if one does not want to destroy it and render the planters more human, would be to accord the blacks as well as the whites the faculty of being elector." Siehe Robert J. Alderson, Jr., This Bright Era of Happy Revolutions. French Consul Michel Ange Bernard Mangourit and International Republicanism in Charleston 1792-1794, Columbia, 2008, 39f. Zu dem Konflikt mit der Provinz-Regierung sowie seinen politischen Aktivitäten während der Französischen Revolution von 1789 siehe Ders., This Bright Era of Happy Revolutions, 38-40.

188 Vgl. Ders., This Bright Era of Happy Revolutions (wie Anm. 187, Kap. VII), 40.

189 Vgl. hierzu die Angaben bei Ders., This Bright Era of Happy Revolutions (wie Anm. 187, Kap. VII), 173. Demnach hielt Napoleon Mangourit nicht nur von weiteren diplomatischen Ämtern fern, sondern verhinderte auch eine berufliche Tätigkeit im akademischen Umfeld.

190 Siehe hierzu Michel Ange Bernard Mangourit, Der Hannöversche Staat in allen seinen Beziehungen. Geschildert in den Jahren 1803 und 1804, Hamburg 1805, insb. 299f., Permalink: http:// nbn-resolving.org/urn:nbn:de:bvb:12-bsb10020396-0 (Zugriff vom 25.05.2014).

191 Vgl. Ders., Der Hannöversche Staat (wie Anm. 190, Kap. VII), 300.

192 Mangourits Engagement innerhalb der Freimaurerei wird in Aldersons Untersuchung nur knapp erwähnt. Siehe Alderson, This Bright Era of Happy Revolutions (wie Anm. 187, Kap. VII), 38 und 173.

193 Siehe hierzu sowie zu einer Transkription des letzten Grades dieses Systems in André Dore, Aperçus sur le rite des Sublimes Élus de la Vérité, in: Chroniques d'histoire maçonnique 25-26 (1980), 48-57.

194 Siehe hierzu etwa Discours Prononcé dans la R $\therefore$ L $\therefore$ des Commandeurs du Mont-Thabor; Par le F $\therefore$ Bailleul, Off $\therefore$ du G $\therefore$ O $\therefore$ de France, en son Gr $\therefore$ Ch $\therefore$ Gén $\therefore$, Séance du 18. Jour du 6 . Mois, l'an de la V $\therefore$ L $\therefore$ 5814, Paris, 18.08.1814, in: GOF, 5477, 3. 
kann auch aufgrund von Zuschreibungen an einzelne Mitglieder wie der oben zitierten "Priesterschaft" eines Lacépède davon ausgegangen werden, dass die Mitglieder der Loge sich als Nachfolger der Druiden in einer >Kette der Weisen empfanden. Der Entwurf neuer Rituale spiegelte insofern auch diese Annahme einer besonders hohen Kultivierung der eigenen Person und damit Befähigung zur Anleitung anderer wider. Das Wissen über die Natur und daraus abgeleitet über die >richtige< Erziehung der Menschheit war dieser Elite vorbehalten.

Nur infolge eines solchen Denkens ist die Gründung des Souverain Chapitre Métropolitain des Dames écossaises de la Colline du Mont Thabor im Jahr 1809 durch die Loge Commandeurs du Mont Thabor zu verstehen. Hierbei handelte es sich um eine Loge für Frauen, die auf die Initiative Michel Ange de Mangourits hin ins Leben gerufen worden war und unter seiner Leitung arbeitete. Sie war jedoch keine Adoptionsloge im eigentlichen Sinne - wie eine von beiden Geschlechtern besuchte Loge genannt wurde. Bereits im Ancien Régime hatte es sogenannte Adoptionslogen gegeben, in denen Männer und Frauen, nicht selten adliger Abstammung, gemeinsam freimaurerisch arbeiteten. ${ }^{195}$ Zwar hatte die Adoptionsmaurerei im Ancien Régime aufgrund der gemeinsamen Vergesellschaftung von Frauen und Männern keinen einfachen Stand gehabt, da sie oft als anrüchig diffamiert wurde; sie lebte jedoch in den vornehmen Kreisen im Paris des Premier Empire wieder auf. ${ }^{196}$

Mangourit hatte eigene Rituale für die neue Frauenloge entworfen. ${ }^{197}$ In Hinblick auf ihre Wirkung in die profane Welt hatte sich die Logengemeinschaft zur Aufgabe gemacht:

>Bedürftigen Personen weiblichen Geschlechts von guter Aufführung Beistand, Brod und Arbeit zu geben, ihnen zunächst beizustehen, dann sie zu trösten, und sie vermittelst Wohltaten und Hoffnung vor dem Aufgeben guter Grundsätze und den Foltern der Verzweiflung zu bewahren $<.{ }^{198}$

Das Affiliationspatent der Damenloge war dabei nicht nur von ihm, sondern auch von Joseph zu Salm-Reifferscheidt-Dyck sowie einem nicht näher benannten Prinzen von Hohenzollern unterzeichnet worden. ${ }^{199}$ Die innerhalb dieser Frauenloge arbeitenden Schwestern teilten sich vom Einweihungsgrad dabei insofern in die kleinen und großen Mysterien auf, als neben den eigentlichen Aufnahme-

195 Eine Aufsatzsammlung jüngeren Datums zu diesem Thema, die einen guten Überblick gibt, besteht in: Alexandra Heidle/Jan A.M. Snoek (Hg.), Women's Agency and Rituals in Mixed and Female Masonic Orders (Texts and Studies in Western Esotericism, 8), Leiden/Boston 2008.

196 Siehe hierzu die zusammenfassenden Bemerkungen bei Collaveri, La franc-maçonnerie de Bonaparte (wie Anm. 21, Kap. VI), $93 \mathrm{f}$.

197 Vgl La franc-maçonnerie de Bonaparte (wie Anm. 21, Kap. VI), $93 f$.

198 Zitiert nach Kloss, Geschichte der Freimaurerei (wie Anm. 28, Kap. VI), 540. Zu Teilen der französischen Ausführung vgl. Collaveri, La franc-maçonnerie de Bonaparte (wie Anm. 21, Kap. VI), 94.

199 Vgl. die Angaben bei Frick, Licht und Finsternis (wie Anm. 61, Kap. V), 29f. Frick entnahm diese Angaben bei Kloss. Zu den Bemerkungen Kloss' siehe Kloss, Geschichte der Freimaurerei (wie Anm. 28, Kap. VI), insb. 539-541. 
graden Hochgrade existierten, »deren Erteilung in den höchsten geschichtlichen und philosophischen Stufen sich der Général Chef d'Ordre Mangourit selbst vorbehielt. $\ll^{200}$

Bei Durchsicht des Protokollbuchs der Loge fällt der hohe Anteil künstlerischer Darbietungen der Mitglieder auf. Am 15.05.5811 ${ }^{201}$ wurde etwa die 26-jährige Cécile Delétang in die Loge aufgenommen. ${ }^{202}$ An die Aufnahme, die - wie die Erwähnung eines schüchternen Charakters des weiblichen Geschlechts im Allgemeinen zeigt - offenbar durchaus von gewissen Erwartungshaltungen an den Charakter der weiblichen Adeptin geprägt war, schloss sich eine Vielzahl künstlerischer Darbietungen an, wie Gedichtrezitationen und musische Darbietungen, an denen sich auch die neue Schwester Delétang beteiligte. ${ }^{203}$ Bevor die Gemeinschaft gegen Mitternacht auseinanderging, schloss man den Abend mit einer karitativen Spende an die Armen. Dieser Eintrag kann als typisch für die Vergesellschaftung innerhalb der Loge gesehen werden.

Auch in der Korrespondenz mit Joseph zu Salm-Reifferscheidt-Dyck berichtete Mangourit dem zu Zeiten des Schriftverkehrs nicht in Paris weilenden Salm-Dyck über die neuesten Entwicklungen in der freimaurerischen Sphäre der Hauptstadt sowie die künstlerischen Darbietungen innerhalb der Loge. ${ }^{204}$ Innerhalb eines Briefes vom 28.08.1811 klagte Mangourit: »Je régrétte toujours, et je suis loin dêtre le seul plaintif, de ce qu'un beau et aimable Génie, ne fait pas Sour Constance du Thabor. ${ }^{205}$ Mangourit, der Salm-Dyck im Anschluss an diese Äußerung über die Entwicklungen auf literarischem Gebiet in Paris Auskunft gab, war somit durchaus daran interessiert, auch Constance de Salm als Schwester zu gewinnen. Der Brief Mangourits zeigt deutlich, dass die künstlerische Tätigkeit der Frau Joseph zu Salm-Reifferscheidt-Dycks für die freimaurerische Sphäre höchst interessant war. Es war aber wohl gerade die Hierarchie innerhalb des Ordens, die seine Frau Constance davon abhielt, sich der Frauenloge anzuschließen. Der selbstbewusst agierenden Feministin dürfte die hintergründig nach wie vor vorhandene dominierende Stellung der männlichen Loge zuwider gewesen sein. Es darf stark bezweifelt werden, dass die auch öffentlich für die Rechte der Frauen eintretende Constance von sich annahm, der moralischen Führung durch einen Mann zu bedürfen.

Das Ehepaar Salm-Dyck genoss dennoch, wie zu erwarten, einen hohen Stellenwert, wie auch folgende Äußerung Mangourits gegenüber Joseph Salm-Dyck verdeutlicht:

200 Frick, Licht und Finsternis (wie Anm. 61, Kap. V), 30.

201 Hierbei handelt es sich offenbar nicht um eine exakte Umrechnung in eine freimaurerische Zeitform, sondern lediglich um die Umrechnung der Jahresangabe, also 15.05.1811.

202 Registre de la Dame Secrétaire G $\therefore$ du Souverain Chapitre Métropolitain des Dames écossaises du Mont Thabor, Paris, Eintrag vom 15.05.5811 (15.05.1811), in: BnF, Baylot FM3 2, fol. $42 f$.

203 Registre de la Dame Secrétaire G. du Souverain Chapitre Métropolitain des Dames écossaises du Mont Thabor, Paris, Eintrag vom 15.05.5811 (15.05.1811), in: BnF, Baylot FM3 2, fol. 43f.

204 Mangourit an Joseph Salm-Dyck, Paris, 28.08.1811, in: ASD, Blaue Bände, Bd. 590, fol. $26 \mathrm{v}$.

205 Mangourit an Joseph Salm-Dyck, Paris, 28.08.1811, in: ASD, Blaue Bände, Bd. 590, fol. $26 \mathrm{v}$. 
Enfin Monsieur le Comte, je me rejouis de tant de beaux jours précurseurs des mauvais qui vous forcerent de revenir, aussi que Madame, avec les amis de la ville par éxcéllence. Revenez nous avec des rivaux du goût et de faire des Van Spandonc [sic!] et des Redouté; et ramenez nous la Divinité qui chante les fleurs et la nymphe qui l'accompagne de son luth. ${ }^{206}$

Innerhalb der Logen versammelte sich somit kein beliebiger Teil der Gesellschaft, sondern - ähnlich wie in der Loge Les Neuf Sœurs des Ancien Régime - jener Teil, der durch künstlerisches und wissenschaftliches Engagement als besonders kultiviert erscheinen konnte. Hierbei ist die Divergenz zwischen innerer, elitärer Mitgliederauswahl und äußerem, karitativem Ziel offensichtlich. Der ausgezeichnete Kenner der französischen Freimaurerei der napoleonischen Zeit François Collaveri fällte daher in seiner Studie ein in großen Teilen zutreffendes Urteil über die Damenloge der Commandeurs, welches in dieser Form wohl auch auf die Herrenloge zutrifft: „C'était une création inspirée de sentiments généreux, mais prétentieuse, et qui n'avait de commun avec la maçonnerie que le nom. « ${ }^{207}$

Dem ersten Teil dieser Äußerung Collaveris kann hier vollkommen zugestimmt werden. Die Commandeurs waren eine sich elitär gebärdende Gesellschaft. In Bezug auf den letzten Teil muss hier jedoch der Blickwinkel der Zeitgenossen eingenommen werden. Gerade in der von Collaveri bemerkten Divergenz drückte sich für die Zeitgenossen offenbar das ıinnere Geheimnis` des 'wahren Freimaurers aus. Die hohe Kultiviertheit oder Zivilisiertheit, die sich in der künstlerischen Darbietung bzw. wissenschaftlichen Produktion der Mitglieder innerhalb der Loge entfalten sollte, galt zutiefst als Ausdruck und Teil ihres Selbstverständnisses. In diesem Selbstverständnis hatte die Vorstellung von einer strikten gesellschaftlichen Hierarchie das Ancien Régime überlebt, in der nur die ১begabten` Personen zur Anleitung der Rangniederen befähigt waren. Der geheimnisvolle Geist, der in der »Blutsideologie« des Ancien Régime insbesondere den Adel für Lehren empfänglicher machen sollte, war im Premier Empire gewissermaßen aus dem Blut herausgetreten und den Zeitgenossen $>$ zu Kopf gestiegen $\prec$. An die Stelle einer durch Genealogien auf eine zahlenmäßig kleine Kaste begrenzte »Ideologie des Blutes« trat eine stärker, wenn doch nicht völlig entgenealogisierbare »Ideologie des Intellekts «, der sich in seiner historischen Begründung auf eine weitergefasste Elite innerhalb einer Nation beziehen ließ. Denn an der Wurzel der Tugend sollten fortan nicht mehr ausschließlich Lebensbilder individueller Vorfahren, sondern vielmehr Weisheiten und Bilder einer seit jeher auf das Kollektiv des Volkes bzw. der Nation wirkenden »Priesterschaft der Hochkultur« stehen.

Aus Sicht der Freimaurer des Rit écossais philosophique bedeutete dies unter anderem, dass die >Hochkultivierten ` den weniger Kultivierten als eine solche `Priesterkaste zu mehr Bildung und Kunstsinn emporhelfen konnten, dass

206 Mangourit an Joseph Salm-Dyck, Paris, 28.08.1811, in: ASD, Blaue Bände, Bd. 590, fol. 26v. Bei Spandonk handelt es sich wie bei Redouté um einen bekannten zeitgenössischen Blumenmaler. 


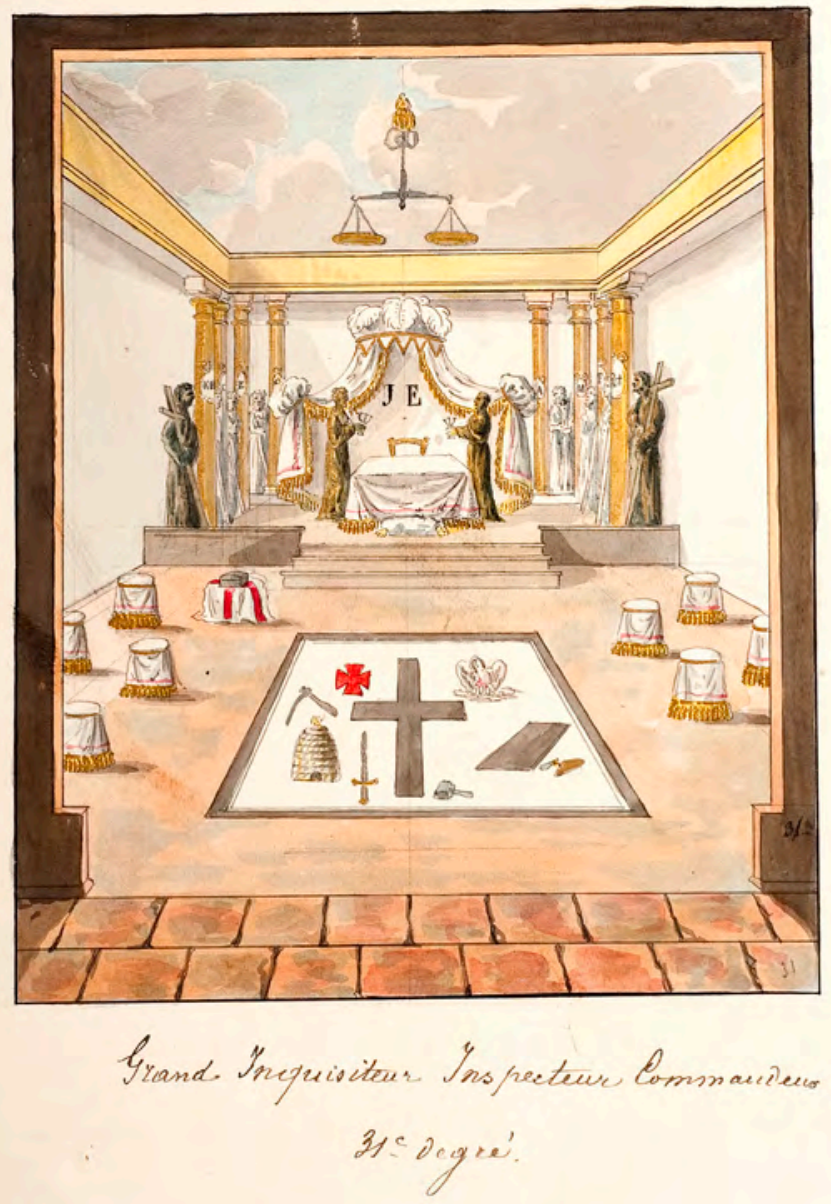

Abbildung 28: Rite Écoss. Anc. et Acc.: Décorations et Costumes II: Grand Inquisiteur Inspecteur Commandeur, $31^{\text {e }}$ degré (= Dekoration der Loge im 31. Grad), um 1800 (Bildrecht/Werk und Foto: From the collections of the Cultural Masonic Centre, The Hague). 


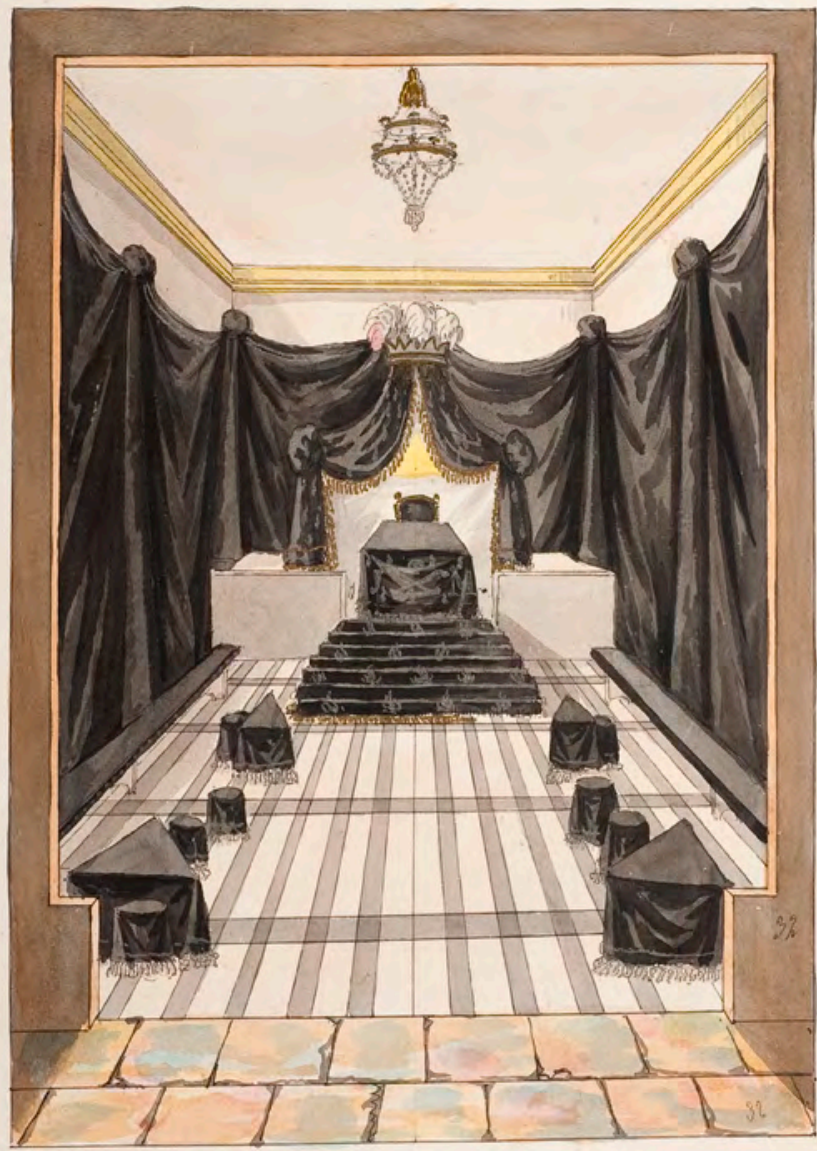

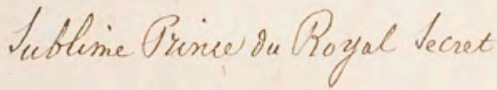

$$
\begin{aligned}
& \text { 32. degré, }
\end{aligned}
$$

Abbildung 29: Rite Écoss. Anc. et Acc.: Décorations et Costumes II: Sublime Prince du Royal Secret, $32^{\mathrm{e}}$ degré (= Dekoration der Loge im 32. Grad), um 1800 (Bildrecht/Werk und Foto: From the collections of the Cultural Masonic Centre, The Hague). 


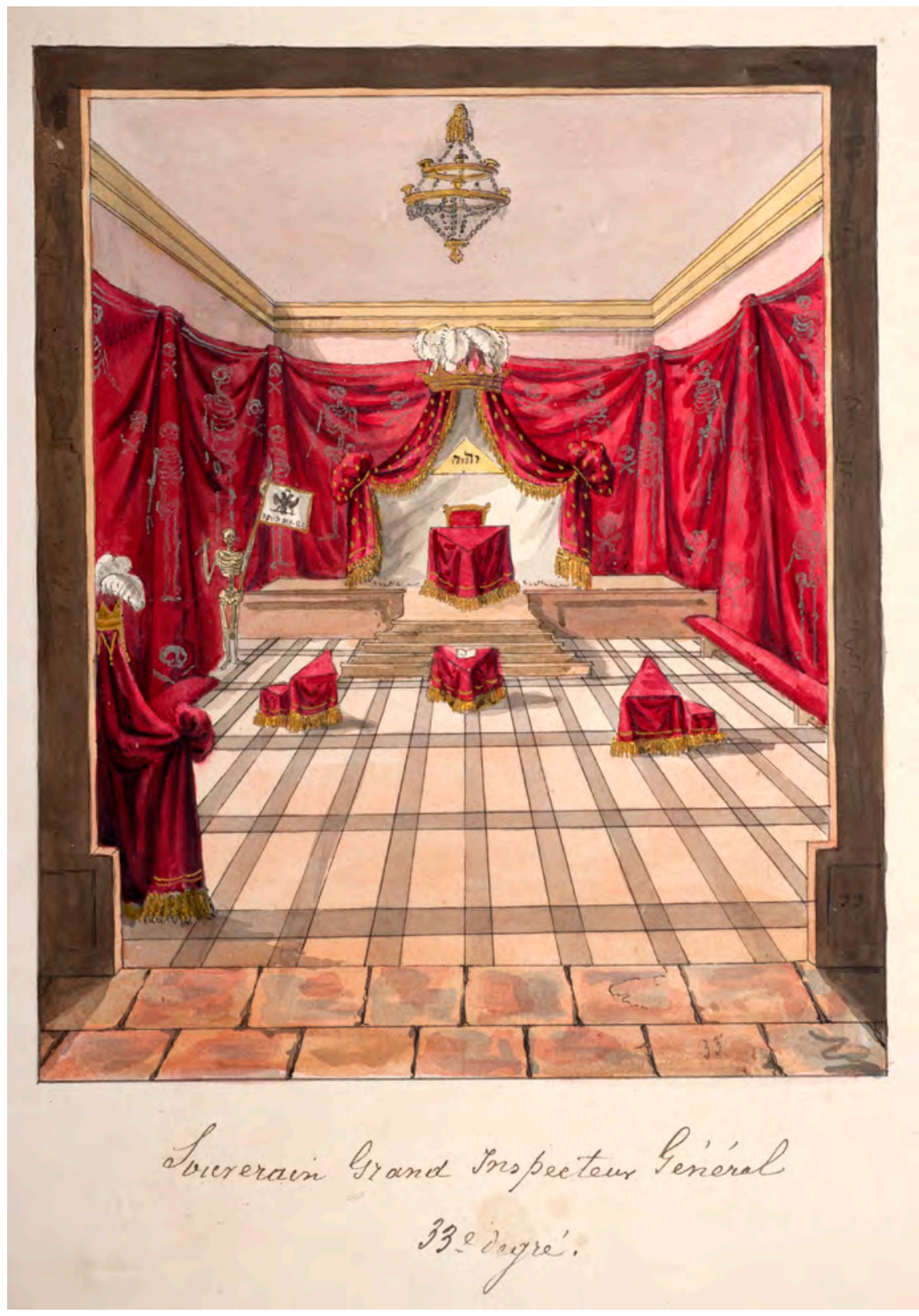

Abbildung 30: Rite Écoss. Anc. et Acc.: Décorations et Costumes II: Souverain Grand Inspecteur Général, $33^{\mathrm{e}}$ degré (= Dekoration der Loge im 33. Grad), um 1800 (Bildrecht/Werk und Foto: From the collections of the Cultural Masonic Centre, The Hague). 
die Reichen den Armen Spenden darbrachten, dass ein Mann der Vorsteher und -denker eines Frauenordens war. Die Ausrichtung auf das Bedürftige hin ist insofern interessant, als sie sich mit dem in der Académie celtique zu bemerkenden analytischen Interesse an der »Volkskultur « von Seiten der gehobenen Schichten der Bevölkerung verband. Dieses Interesse sollte wie die Betonung der analytischen Methode in der Pariser Freimaurerei des beginnenden 19. Jahrhunderts der gesamtgesellschaftlichen Perfektionierung dienen und war - wie oben gezeigt vor allem auf den gedanklichen Einfluss der Idéologues zurückzuführen. In den Gesellschaften, in denen sich die freimaurerische mit der staatlichen Sphäre überschnitt, ist diese Ausrichtung auf die Perfektionierung der Gesellschaft daher immer mitzudenken.

So wies der Bruder Antoine Bailleul, Mitglied der Loge Le Centre des Amis sowie officier des GOF in einer Rede im Jahr 1814 in der Loge Les Commandeurs du Mont Thabor auf eben diesen Umstand hin. Für Bailleul stand fest, dass es auf die Frage »Où allons-nous? « nur die Antwort geben konnte »A la perfection! « ${ }^{208}$ Das Wissen um die symbolischen Handlungen und Organisationsformen der Vorfahren, wie etwa um die »organisation toute mystérieuse des Druides «, ${ }^{209}$ das sich in der Freimaurerei bewahrt hatte, war dabei von essentieller Wichtigkeit. Die aus der oben bereits geschilderten Traditionskette hergeleitete Freimaurerei teilte sich für Bailleul in zwei Bereiche auf: den symbolischen sowie den administrativen. ${ }^{210}$ Letzterer war für jede Gesellschaft notwendig, da: »Toute société, toute reunion a besoin de règles d'organisation qui établissent une hiérarchie, une subordination, et d'après lesquelles chaque membre doit diriger sa conduite dans les devoirs et les fonctions qu'il a à remplir. « ${ }^{211}$ Obgleich Bailleul den administrativen Teil der freimaurerischen Arbeit nicht unterschätzen mochte, hielt er ihren symbolischen Bereich für wichtiger, denn:

Cette partie embrasse les cérémonies emblématiques qui composent les travaux symb $\therefore$; sage et heureuse combinaison qui ne pouvait naître que dans des temps et dans des contrées où tout ce qui touchait aux rapports entre l'homme et le G $\therefore$ A $\therefore$ de l'Univers, entre l'homme et tout ce qui brille au

208 Discours Prononcé dans la R $\therefore$ L $\therefore$ des Commandeurs du Mont-Thabor; Par le F $\therefore$ Bailleul, Off: $\therefore$ du G $\therefore$ O $\therefore$ de France, en son Gr $\therefore$ Ch $\therefore$ Gén $\therefore$, Séance du 18. Jour du 6. Mois, l'an de la V $\therefore$ L $\therefore$ 5814, Paris, 18.08.1814, in: GOF, 5477, 4. Zur Biographie Bailleuls vgl. die Angaben bei Mollier/Pinaud, L'état-major maçonnique (wie Anm. 3, Kap. VI), 82f.

209 Vgl. Discours Prononcé dans la R $\therefore$ L $\therefore$ des Commandeurs du Mont-Thabor; Par le F $\therefore$ Bailleul, Off. du G $\therefore$ O $\therefore$ de France, en son Gr $\therefore$ Ch $\therefore$ Gén $\therefore$, Séance du 18. Jour du 6. Mois, l'an de la V $\therefore$ L $\therefore$ 5814, Paris, 18.08.1814, in: GOF, 5477, 3 .

210 Vgl. Discours Prononcé dans la R $\therefore$ L $\therefore$ des Commandeurs du Mont-Thabor; Par le F $\therefore$ Bailleul, Off. $\therefore$ du G $\therefore$ O $\therefore$ de France, en son Gr $\therefore$ Ch $\therefore$ Gén $\therefore$, Séance du 18. Jour du 6. Mois, l'an de la V $\therefore$ L $\therefore$ 5814, Paris, 18.08.1814, in: GOF, 5477, 7.

211 Discours Prononcé dans la R $\therefore$ L $\therefore$ des Commandeurs du Mont-Thabor; Par le F $\therefore$ Bailleul, Off: du G $\therefore$ O $\therefore$ de France, en son Gr $\therefore$ Ch $\therefore$ Gén $\therefore$, Séance du 18. Jour du 6. Mois, l'an de la V $\therefore$ L $\therefore$ 5814, Paris, 18.08.1814, in: GOF, 5477, 7f. 
ciel ou décore la nature, entre l'homme et ses semblables, était présenté sous le voile des allégories les plus ingénieuses. ${ }^{212}$

Den Freimaurern kam es zu, das Wissen um diese Symbolsprache zu besitzen und insbesondere andere Menschen hierüber aufzuklären: »Notre art est de les entendre [die Symbole, Anm. d. Verf.]; notre plus digne, notre plus précieux emploi, d'y faire participer les autres hommes, en les éclairent, en les rendant dignes de s'associer à nos augustes travaux. ${ }^{213}$ Diese Dignität konnte nur über den bekannten stufenweisen Prozess und durch die Anleitung der weisen Meister zur Perfektion gebracht werden. Zum Ende seiner Rede betonte Bailleul:

Je crois cependant pouvoir encore ajouter que leur méthode de donner ces importantes conaissances, ne consiste point dans des explications orales, qui ne feraient que glisser sur les superficies; mais à diriger avec habilité, avec mesure, en un mot avec une sage réserve, l'esprit des FF $\therefore$ qui parcourent les divers gr $\therefore$ symb $\therefore$, dans le dessin de leur faire découvrir eux-mêmes les significations; de telle sorte qu'elles puissent produire une plus forte impression sur leur intelligence, se graver plus profondement, et prendre racine dans leur âme. ${ }^{214}$

Es ist eben diese Aufsichts- und Führungsrolle über die administrative wie über die symbolische Anleitung der untergebenen Brüder, die Joseph zu Salm-Reifferscheidt-Dyck nicht nur in Paris bei der Loge Les Commandeurs du Mont Thabor, sondern auch für die rheinischen Logen erfüllte. Ihm, der im maurerischen Jahr 5812 zum Vénérable der Loge Les Commandeurs du Mont Thabor gewählt worden war, ${ }^{215}$ kam aus der freimaurerischen Perspektive der Zeit innerhalb des Ordens die - durchaus in gewisser Weise parallel zu seinem Interesse für die Botanik zu sehende - Aufgabe zu, durch die geeigneten >symbolischen Samen ‘ den Intellekt seiner Brüder anzuregen und durch eine weise und maßvolle Anleitung großzuziehen, auf dass die vermittelten Weisheiten in ihren Seelen >Wurzeln ‘ schlugen. Im großen Zusammenhang gedacht, war die Freimaurerei für ihn wie für seine Freimaurerbrüder somit ein pädagogisches Projekt, das eine Nation bzw. eine menschliche Gesellschaft über die Symbolsprache moralisch vollkommener machen konnte. Eine Führungsrolle innerhalb dieses Ordens einzunehmen, konnte somit auch für die Identität einer Person aus einem zuvor zur Herrschaft qua Geburt bestimmten Stand attraktiv sein - ohne dem Gedankengut der Revolution

212 Discours Prononcé dans la R $\therefore$ L $\therefore$ des Commandeurs du Mont-Thabor; Par le F $\therefore$ Bailleul, Off: du G $\therefore$ O $\therefore$ de France, en son Gr $\therefore$ Ch $\therefore$ Gén $\therefore$, Séance du 18. Jour du 6. Mois, l'an de la V $\therefore$ L $\therefore$ 5814, Paris, 18.08.1814, in: GOF, 5477, 8.

213 Discours Prononcé dans la R $\therefore$ L $\therefore$ des Commandeurs du Mont-Thabor; Par le F $\therefore$ Bailleul, Off $\therefore$ du G $\therefore$ O $\therefore$ de France, en son Gr $\therefore$ Ch $\therefore$ Gén $\therefore$, Séance du 18. Jour du 6. Mois, l'an de la V $\therefore$ L $\therefore$ 5814, Paris, 18.08.1814, in: GOF, 5477, 8f.

214 Discours Prononcé dans la R $\therefore$ L $\therefore$ des Commandeurs du Mont-Thabor; Par le F $\therefore$ Bailleul, Off: du G $\therefore$ O $\therefore$ de France, en son Gr $\therefore$ Ch $\therefore$ Gén $\therefore$, Séance du 18. Jour du 6. Mois, l'an de la V $\therefore$ L $\therefore$ 5814, Paris, 18.08.1814, in: GOF, 5477, $10 \mathrm{f}$.

215 Vgl. Mangourit an Joseph Salm-Dyck, Paris, 07.01.1813, in: ASD, Blaue Bände, Bd. 590, fol. 51v. Die Wahl hatte demnach am 28. Tag des 9. Monats 5812 (28.11.1812) stattgefunden. 
vollständig den Rücken zu kehren. Das System lag auf einer eigenartigen Schnittstelle zwischen den magischen, hermetisch-alchemistischen Vorstellungswelten des Ancien Régime und den modernen naturwissenschaftlichen Systemen der Idéologues.

Im folgenden Kapitel soll diese Führungsposition Joseph zu Salm-Reifferscheidt-Dycks innerhalb des Rit écossais philosophique im Rheinland näher beleuchtet werden.

\section{VII.8 Die Akademie der "wahren Maurer" - Joseph zu Salm- Reifferscheidt-Dyck als Vermittler des Rit écossais philosophique}

Um die Verbindungen mit Paris wie dem Rheinland nicht abreißen zu lassen, führten Joseph zu Salm-Reifferscheidt-Dyck und seine Frau Constance nicht nur intensive schriftliche Korrespondenzen, sondern absolvierten auch eine Vielzahl strapaziöser Reisen zwischen den verschiedenen Zentren. Die Präfekturstadt des Roerdepartements, Aachen, war hierbei des Öfteren ein Zielort, dessen freimaurerisches Leben wohl auch aufgrund der zahlreichen Kurgäste florierte. ${ }^{216}$ Anders als im französischen Kernland war die Freimaurerei im Rheinland mit der Revolution nicht vollkommen zum Erliegen gekommen. ${ }^{217}$ Und auch die aus den veränderten Herrschaftsbedingungen nach 1794 resultierenden rituellen Umstellungen dürften in den Aachener Logen nicht als gravierend empfunden worden sein, hatte die Aachener Loge La Constance doch bereits im Ancien Régime den Rit écossais philosophique angenommen. ${ }^{218}$ In der französischen Zeit bearbeitete sie nach dem offiziellen Anschluss an den GOF zunächst im Jahr 1799 das hierin gängige Hochgradsystem des Rite français. ${ }^{219}$

Eine Logenspaltung im Jahr 1803 führte dazu, dass neben der Constance die Loge La Concorde entstand. ${ }^{20}$ Dieser wichtigsten Aachener Loge gehörten im Laufe ihres Bestehens neben französischen Beamten auch mehrere Präfekten des Roerdepartements an, namentlich Jean Charles Joseph Laumond, Alexandre de

216 Siehe hierzu etwa August Pauls, Die Gräfin Remusat als Aachener Kurgast, in: Zeitschrift des Aachener Geschichtsvereins 54 (1932), 142-160, hier insb. 158-160. Zum Zusammenhang von Kurorten und Freimaurerei siehe ferner Ute Lotz-Heumann, Unterirdische Gänge, oberirdische Gänge, Spaziergänge. Freimaurerei in deutschen Kurorten des 18. Jh.s, in: Monika NeugebauerWölk (Hg.), Arkanwelten im politischen Kontext (Aufklärung, 15), Hamburg 2003, 159-186.

217 Vgl. Mettele, Bürgertum in Köln (wie Anm. 46, Kap. VI), 95.

218 Siehe hierzu auch die entsprechende Datierung der Erteilung des Ritus auf den 15.12.1782 in den Unterlagen zur Reinstallierung der Loge im ASD: Auszug aus dem Protokollbuch der Aachener Loge La Concorde, Aachen, 17. Tag des 4. Monats 5812 (12.06.1812), in: ASD, Blaue Bände, Bd. 590, fol. 30r.

219 Vgl. die Angaben bei August Pauls, Annalen der Aachener Freimaurerei. Festschrift zum 175. Stiftungsfest der Aachener Johannisloge »Zur Beständigkeit und Eintracht«, Frankfurt a.M. 1949, 67f.

220 Zur Logenspaltung siehe August Pauls, Festschrift zum 125. Stiftungsfeste der Johannisloge »Zur Beständigkeit und Eintracht« im O $\therefore$ von Aachen, Aachen 1903, 61. 
Lameth sowie Jean Charles François Ladoucette. ${ }^{221}$ Es ist bereits bekannt, dass die mitgliedsstärkere Loge La Concorde im Jahr 1812 einen erneuten Rituswechsel zum Rit écossais philosophique vollzog: Der freimaurerische Historiograph August Pauls bezeichnete diese Angliederung noch in der Rückschau im Jahr 1903 als »eine schwere maurerische Verirrung « und meinte, man müsse »erstaunt sein über den Dünkel der Kapitelmitglieder, die glaubten, als >schottische Philosophen können «. ${ }^{222}$ Er beklagte jedoch auch das weitgehende Fehlen von Unterlagen zu dieser Zeit der Loge. ${ }^{223}$

Die Dokumente im Archiv Schloss Dyck zeigen auf, dass diese »maurerische Verirrung « in den Rit écossais philosophique maßgeblich auf den Kontakten und der sicherlich in zeitlicher und finanzieller Hinsicht nicht unaufwendigen Reisetätigkeit Joseph zu Salm-Reifferscheidt-Dycks nach Aachen beruhte. Die Loge setzte sich zu nicht geringen Teilen aus Aachener Fabrikanten, Kaufleuten und Juristen zusammen, die zum Teil direkt in den Beamtenapparat des Premier Empire involviert waren. ${ }^{224}$ So war auch der Meister vom Stuhl der Loge für das Jahr 1812, Chevalier Josef von Fürth, neben seiner Tätigkeit als fabricant de draps im Amt eines Conseiller de la préfecture de la Roer. ${ }^{225}$ Fürth war es auch, der den Rituswechsel in vorheriger Beratung mit Joseph zu Salm-Reifferscheidt-Dyck initiierte und am 12.09.1811 diesen über die Dringlichkeit des Vorhabens informierte. ${ }^{226}$ Die innerhalb des Schreibens verwendeten Formulierungen zeigen auf, dass es bereits vorher ein Treffen zwischen beiden Akteuren gegeben hatte, bei dem das Vorhaben des Rituswechsels besprochen worden war. Der Brief verdeutlicht insofern die `Expertenfunktion` des Dycker Schlossherrn.

Die Dringlichkeit des Vorhabens, die Fürth in seinem Brief betonte, lag dabei wohl auch in einer möglichen Rangerhöhung der Concorde zu einer logenrechtlich höhergestellten Provinzialloge begründet. ${ }^{227}$ Dies geht aus den Fragen über die konkreten Folgen eines Rituswechsels hervor, die das Aachener Kapitel zunächst beantwortet haben wollte und die Fürth im Anschluss an seinen Brief an Joseph Salm-Reifferscheidt-Dyck auf einem gesonderten Blatt formulierte. In diesem Antrieb glichen also die Zustände innerhalb der Freimaurerei unter

221 Vgl. die Angaben bei Ders., Festschrift zum 125. Stiftungsfeste (wie Anm. 220, Kap. VII), 65-68.

222 Ders., Festschrift zum 125. Stiftungsfeste (wie Anm. 220, Kap. VII), 68f.

223 Vgl. Ders., Festschrift zum 125. Stiftungsfeste (wie Anm. 220, Kap. VII), 69.

224 Siehe hierzu etwa das Mitgliederverzeichnis aus dem Jahr 1813: Tableau des FF $\therefore$ qui composent la L $\therefore$ de St $\therefore$ Jean sous le titre distinctif de la Concorde à l'O $\therefore$ d'Aix-la-Chapelle, Aachen, 10. Tag des 11. Monats 5812 (10.01.1813), in: BnF, FM2 533, fol. 71-73. Salm-Reifferscheidt-Dyck erscheint hierin an erster Stelle.

225 Siehe hierzu die Mitgliederlisten der Concorde aus den Jahren 1803 und 1812: in: BnF, FM2 533, fol. 10v sowie fol. 71r.

226 Fürth an Joseph Salm-Dyck, Aachen, 12. Tag des 7. Monats 5811 (12.09.1811), in: ASD, Blaue Bände, Bd. 590, fol. 24r.

227 Vgl. Fürth an Joseph Salm-Dyck, Aachen, 12. Tag des 7. Monats 5811 (12.09.1811), in: ASD, Blaue Bände, Bd. 590, fol. 25. Hier heißt es: »Auront elles l'esperance de devenir $\square$ provincial? - quel sont les attributions d'une $\square$ prov $\therefore$ ? Quel seroit le rayon supposé de sa jurisdiction?« 
Napoleon durchaus noch der Lage im Ancien Régime. Joseph zu Salm-Reifferscheidt-Dyck konnte in dieser Frage aufgrund seiner hervorgehobenen Stellung innerhalb des Systems vermitteln. Er leitete die Fragen an Claude Antoine Thory weiter, der sie in einem auf den 27.09.1811 datierten Schreiben an Joseph zu Salm-Reifferscheidt-Dyck offenbar zur Zufriedenheit der Aachener Brüder beantwortete, ${ }^{228}$ denn am 25.09.1812 konnte das Protokoll der bereits im Juni erfolgten feierlichen Reinstallierung der Loge im Rit écossais philosophique brieflich an Salm-Reifferscheidt-Dyck zur Weiterreichung an die Pariser Mère Loge übersandt werden. ${ }^{229}$ Bei dieser Gelegenheit teilten die Brüder Joseph zu Salm-Reifferscheidt-Dyck mit, dass er zu ihrem Deputierten beim Grand Orient ernannt worden war. ${ }^{230}$ Salm-Dyck wurde zudem als Ehrenmitglied in der Loge

228 Siehe Thory an Joseph Salm-Dyck, Paris, 27.09.1811, in: ASD, Blaue Bände, Bd. 590, fol. $27 \mathrm{f}$.

229 Vgl. Aachener Loge La Concorde an Joseph Salm-Dyck, Aachen, 25. Tag des 7. Monats 5812 (25.09.1812), in: ASD, Blaue Bände, Bd. 590, fol. 29r. Innerhalb des Protokolls heißt es: »Le V $\therefore$ ble, après avoir ouvert les Trav $\therefore$ de la manière usitée, a fait donner lecture du dernier tracé qui avait principalement rapport aux Elections des Dign $\therefore$, lequel a été sanctionné par un applaudissement mac $\therefore$ Il a ensuite été procedé à l'installation des nouveaux dign $\therefore$ avec toutes les cérémonies d'usages. Le $\mathrm{V} \therefore$ ble annonce que le but principal de la Reunion de jour solemnel, avait non seulement pour motif la célébration de la fête de notre Patron, mais aussi celle dela réinstallation de notre Att $\therefore$ au Rit Ec $\therefore$ Ph $\therefore$. L'illustre F $\therefore$ Comte de Salm-Dyck, Grand Insp $\therefore$ teur du Rit Ec $\therefore$ $\mathrm{Ph} \therefore$ a été annoncé et reçu au milieu des plus vifs applaudissements. Le $\mathrm{V} \therefore$ ble lui a exprimé au nom dela $\mathrm{R} \therefore$ le plaisir qu'elle avait de le récévoir dans son sein en lui temoignant sa réconnaissance de ses soins pour la réinstallation au Rit Ec $\therefore \mathrm{Ph} \therefore$ et sa solicitude pour la prospérité de cet Att $\therefore$ L'illustre F $\therefore$ Comte de Salm-Dyck a répondu d'une manière extrémement flateuse, en assurant qu'il continuerait ses soins pour tout ce qui pourrait être agréable et fructueux a la R : $\square$. Il a ensuite réquis l'Enrégistrément de son Diplôme de Grand Inspecteur attaché à la R $\therefore$ Q Métrop $\therefore$ du Rit Ec $\therefore$ Ph $\therefore$ en France, au Livre d'Arch $\therefore$ ce qui a été fait immediatement. Il a été procedé a l'initiation d'un Candidat qui a été réçu avec toutes les formalités réquisses. Le $\mathrm{R} \therefore \mathrm{F} \therefore$ Orateur a prononcé un morceau d'arch $\therefore$ rétraçant particulièrement au nouveau réçu les dévoirs des Mac $\therefore$ dans ce discours rélatif a la célébration de notre réinstallation au Rit $\mathrm{Ec} \therefore \mathrm{Ph} \therefore$ et à la fête de St. Jean; il l'a terminé en payant un tribut d'Eloge à l'illustre F $\therefore$ Comte de Salm-Dyck pour la protection particulière qu'il a bien voulu accorder a ce $\mathrm{R} \therefore$ Att $^{\mathrm{r}} \therefore$ et en le priant d'etre notre interprête près dela Mere $\square$ pour lui exprimer nos sentiments de gratitude. L'illustre F $\therefore$ Comte de Salm-Dyck ayant demandé d'avoir son Nom inscrit parmi ceux des Membres de cette $\mathrm{R} \therefore$ Q , cette demande a été acceuillie avec le plus vif entousiasme et la plus grande satisfaction." Protokoll der Aachener Loge La Concorde, Aachen, 17. Tag des 4. Monats 5812 (12.06.1812), in: ASD, Blaue Bände, Bd. 590, fol. 30f.

230 Vgl. Aachener Loge La Concorde an Joseph Salm-Dyck, Aachen, 25. Tag des 7. Monats 5812 (25.09.1812), in: ASD, Blaue Bände, Bd. 590, fol. 29r. Die Angabe zur Ernennung befindet sich auf der vom Betrachter aus unteren linken Ecke des Briefes. Zu einer kurzen Skizze der Vorgänge um die Ernennung vgl. auch einen Auszug aus dem »Livre d'Architecture « der Concorde in: Extrait du Livre d'architecture, Aachen, 3. Tag des 5. Monats 5812 (03.07.1812), in: BnF, FM2 533, fol. 53. Demnach hatte ein in den Aufzeichnungen nicht namentlich genanntes Mitglied Joseph zu SalmReifferscheidt-Dyck für dieses Amt vorgeschlagen. 
geführt. ${ }^{231}$ Ein Gedicht zur Reinstallierung stellte ihn folgerichtig als einigende Vaterfigur der $»$ Logenfamilie« dar. ${ }^{232}$

Die in dieser Rolle gedanklich intendierte autoritäre Funktion äußerte sich tatsächlich auch in seinen freimaurerischen Ämtern. Als Grand Inspecteur und Deputiertem bei der Pariser Mutterloge kam Joseph zu Salm-Reifferscheidt-Dyck eine besondere Aufsichtsfunktion für den Vollzug der Rituale in der Aachener Loge zu. Dies verdeutlicht eine Rede aus dem Jahr 1813 zum neuen Ritus, die in den Akten der Aachener Loge im GStA PK verwahrt wird. Der nicht genannte Redner ${ }^{233}$ schwor seine Brüder dabei auf die besondere Ernsthaftigkeit der Rituale des Rit écossais philosophique ein und verwies gleichzeitig auf die >Bringschuld der Brüder gegenüber dem Inspektoren Salm-Dyck. ${ }^{234}$ Die besonderen Ehrbezeugungen, die man von Seiten der Brüder der Aachener Loge La Concorde Joseph zu Salm-Reifferscheidt-Dyck bei verschiedenen Gelegenheiten angedeihen ließ, zeugen somit auch von seiner Autorität in der Arkanwissenschaft.

Hinsichtlich der oben besprochenen Convents philosophiques ist es interessant zu sehen, dass die Aachener Loge sich im Anschluss an ihre Reinstallierung um die Errichtung eines für die Durchführung eines Convents notwendigen Chapitre des Grands Aigles blancs et noirs bemühte. Thory hatte gegenüber Joseph SalmReifferscheidt-Dyck zuvor erklärt, dass für eine Rangerhöhung zur Provinzialloge die Errichtung eines solchen Chapitres unter anderem nach einer Zahlung von 300 Francs an die Mutterloge vonnöten war. ${ }^{235}$ Die Akten im Archiv Schloss Dyck

231 Vgl. Tableau des FF $\therefore$ qui composent la L $\therefore$ de St $\therefore$ Jean sous le titre distinctif de la Concorde à l'O $\therefore$ d'Aix-la-Chapelle, Aachen, 10. Tag des 11. Monats 5812 (10.01.1813), in: BnF, FM2 533, fol. 71 .

232 Vgl. Hommage au T $\therefore$ C $\therefore$ F $\therefore$ Comte de Salm Dick Vénérable de la $\square$ Concorde à l'O $\therefore$ Aix-laChapelle. Le Jour de son Installation et de la Fete de St. Jean d'été, o.O., o.D., in: ASD, Blaue Bände, Bd. 590, fol. 15. Hier heißt es: »Par lui dans cet Atelier/ Tout a reçu une nouvelle vie,/ C'est lui qui ranime chaque ouvrier/ Rien que par sa Présence cherie./ De tous Malheurs, de tous Souçis,/ Grands Dieux! Préservez sa Carrière,/ Qu'il vive pour nous voirs unis/ Tant que nous verrons la Lumière.//Autour de lui, comme ses Enfants,/ Nous ne faisons qu'une Famille/ De frères, de maçons triomphans,/ Au sein desquels la joie petille./ Si le Ciel écoute nos vœux,/ s'il accomplit notre Prière/ nous verrons Salm-Dick heureux/ Tant que nous verrons la Lumière.//« ASD, Blaue Bände, Bd. 590, fol. 15v.

233 Die Loge La Concorde besaß im freimaurerischen Jahr 5812 drei Redner. Aus diesem Grund kann hier nicht mit Sicherheit gesagt werden, wer die Rede verfasste und vortrug. Vgl. Tableau des FF $\therefore$ qui composent la L $\therefore$ de St $\therefore$ Jean sous le titre distinctif de la Concorde à l'O $\therefore$ d'Aixla-Chapelle, Aachen, 10. Tag des 11. Monats 5812 (10.01.1813), in: BnF, FM2 533, fol. 71r.

234 Der Redner erwähnt innerhalb seines Vortrages: "Le rit Ecc $\therefore$ Phil $\therefore$ dans ce Trav $\therefore$ Simb $\therefore$ ne differe que fort peu avec le rit francais, que nous avons professé [...]. Une raison [...] d'observer avec autant plus de precision toutes ces petites manes qui doivent nous distinguer aujourd' hui \& prouver par la a l'ill $\therefore$ F $\therefore$ qui viendra inspectér nos Travaux aux Comte de Salm-Dik, que nous ambitionons de nous rendre dignes de la Bienveillance de la protection \& de l'amitié qu'il nous à temoigné [...]. D'abord l'ordre, le silence, la regularité qui doivent regner sur les colones sont les premieres qualités caracteristiques des $\mathrm{L} \therefore \mathrm{L} \therefore$ de notre nouveau Rit. Je ne pourois donc assez vous recommander de vous conduire en consequence - [...]. « Rede über den Rit écossais, o.O., 1813/14, in: GStA PK, FM 5.2.A2, Nr. 102 (ohne Folioangabe im Dokument).

235 Vgl. Thory an Joseph Salm-Dyck, Paris, 27.09.1811, in: ASD, Blaue Bände, Bd. 590, fol. $27 \mathrm{f}$. 
offenbaren dabei, wie sehr die Hoffnungen der Aachener Brüder, eine Provinzialloge zu werden, wiederum an die Person Joseph Salm-Reifferscheidt-Dycks geknüpft waren. ${ }^{236}$ Bereits im Vorfeld der für die Loge wichtigen Installierung eines Chapitre des Grands Aigles blancs et noirs berichtete Fürth Salm-Dyck über seine andauernden Proben des diesbezüglichen Rituals. ${ }^{237}$ Die Erteilung des elitären Chapitre erfolgte schließlich im September 1812. ${ }^{238}$ Die Präfekturstadt Aachen besaß somit auch in freimaurerischer Hinsicht eine wichtige Stellung.

Bei der Auswahl zukünftiger Brüder für das Kapitel wurde - den Quellen nach zu urteilen - sehr streng vorgegangen. Die für die Zulassung zum Chapitre des Grands Aigles blancs et noirs bestimmten Brüder wurden dabei zunächst durch Fürth ausgewählt und diese Auswahl durch Salm-Reifferscheidt-Dyck bestätigt. ${ }^{239}$ Dies geht aus einem Schreiben Fürths an Joseph zu Salm-Reifferscheidt-Dyck hervor, in dem es heißt:

$[\ldots]$ tres Ill $\therefore$ Fr $\therefore$ l'observance stricte \& rigoureuse que nous devons mettre dans le choix des membres, qui composeront le Chap $\therefore$ de G $\therefore$ A $\therefore$ B $\therefore$ et $\mathrm{N} \therefore$ m’a engagé d'écrire la lettre confidentielle si inclusee au F $\therefore$ Thory. Veuillez la parcourir et proteger ma demande, si vous approuvez le princip qui l'a dicté. ${ }^{240}$

Diese Zeilen lassen klar die strikte Unterordnung und Weisungsgebundenheit Fürths gegenüber Joseph zu Salm-Reifferscheidt-Dyck erkennen.

In Ergänzung hierzu illustriert die in dem beigelegten Schreiben an Thory durch Fürth an den Tag gelegte Haltung, wie sehr die in Paris zu bemerkende analytische Sichtweise des freimaurerischen Rituals im Rheinland angekommen war. In seinem Schreiben an Thory begründete Fürth das strikte Vorgehen bei der Auswahl der Mitglieder mit folgenden Worten:

236 Siehe hierzu etwa Aachener Loge La Concorde an Joseph Salm-Dyck, Aachen, 10. Tag des 7. Monats 5812 (10.09.1812), in: ASD, Blaue Bände, Bd. 590, fol. 45r. Hier wird ein Auszug aus dem Sitzungsbuch des Kapitels wiedergegeben, in dem es unter anderem heißt: "Considérant que notre atel $\therefore$ pourra par la suite et par anciennité et par les soins et la bienveillance de notre T $\therefore$ I $\therefore$ F $\therefore$ Comte de Salm, Grand Inspecteur, devenir L $\therefore$ provinciale."

237 Vgl. Fürth an Joseph Salm-Dyck, Aachen, 05.08.1812, in: ASD, Blaue Bände, Bd. 590, fol. 54r. Hier heißt es: »[...] j'etudie matin et soir à fin de paraitre comme un maçon fort instruit dans ma nouvelle qualité d'installateur [...].«

238 Vgl. die Angabe bei Pauls, Festschrift zum 125. Stiftungsfeste (wie Anm. 220, Kap. VII), 69; Ders., Annalen der Aachener Freimaurerei (wie Anm. 219, Kap. VII), 81f. Demnach konnte Pauls noch auf ein auf den 17.09.1812 datiertes und u.a. von Thory unterschriebenes Patent zurückgreifen. Bestätigt wird die Errichtung aber auch durch zwei Briefe Fürths im ASD, die auf September und Oktober 1812 datieren und um die Konstitution kreisen. Pauls erwähnte, dass die Installierung am 08.10.1812 in der Versammlung der Mutterloge in Paris bekannt gegeben wurde. Siehe zu den beiden Briefen: Fürth an Joseph Salm-Dyck, Frankfurt a.M., 16.10.1812, in: ASD, Blaue Bände, Bd. 590, fol. 55; Fürth an Joseph Salm-Dyck, Aachen, 08.09.1812, in: ASD, Blaue Bände, Bd. 590, fol. 57. In dem Brief, der auf den 08.09.1812 datiert, bemerkt Fürth u.a. gegenüber Joseph SalmReifferscheidt-Dyck: "Je viens d'installer le Chap $\therefore$ d'apres vos instructions \& compte d'avoir incessament la satisfaction de vous envoyer le proces verbal de cette operation [...]."

239 Vgl. Fürth an Joseph Salm-Dyck, Frankfurt a.M., 16.10.1812, in: ASD, Blaue Bände, Bd. 590, fol. $55 \mathrm{f}$.

240 Fürth an Joseph Salm-Dyck, Frankfurt a.M., 16.10.1812, in: ASD, Blaue Bände, Bd. 590, fol. 55v. 
Parmis les $\mathrm{F} \therefore \mathrm{F} \therefore$ composent le Chap $\therefore$ il y en a qui sont pénétrés des veritables principes de notre Ill $\therefore$ institution, d'autres paroissent froids et inaccessibles à l'enthousiasme qui anime la plus part des FF $\therefore$ composant le Chap $\therefore$ depuis que nous avons formes la douee et l' heureuse alliance avec la mère $\mathrm{L}: \therefore$ Ecoss. . - Je ne me permetterai pas de pretendre qu'ils n'ambitionent pas de participer à l'honneur et à la Confiance que nous sollicitons, mais il ne suffit pas de le desirer il faut d'après moi s'en rendre digne par le zèle \& par la constance dans nos Travaux. ${ }^{241}$

Beide Schreiben illustrieren eindrücklich die innerhalb des Ritus geforderte Einhaltung der Unterordnung bzw. des Gehorsams. Die Einhaltung dieser Kriterien - so darf hier gefolgert werden - galt letztlich als Ausweis der persönlichen Zivilisiertheit und hatte entscheidenden Einfluss auf die Auswahl der zur Führung des Ordens bestimmten freimaurerischen Elite. Auch hierin konnte vieles noch an die Organisation freimaurerischer Hochgradorden des Ancien Régime erinnern.

Neben dem elitären Kapitel existierte - ähnlich wie in Köln - jedoch auch eine profane Gesellschaft. ${ }^{242}$ Dies geht ebenfalls aus einem Schreiben Josef von Fürths an Joseph zu Salm-Reifferscheidt-Dyck anlässlich der Genehmigung der Zusammenlegung der beiden Aachener Logen im Jahr 1813 hervor. Hier heißt es: »Les mac $\therefore$ membres de la $\mathrm{L} \therefore$ de la Constance, deviennent par leur reunion, membres nés de la Société Prof $\therefore$ établie au local de la L $\therefore$ de la Concorde. ${ }^{243}$ In dieser Hinsicht glich also die Lage in der Präfekturstadt den Verhältnissen in Köln. Wie bereits oben im Zusammenhang der - aus Sicht einiger zeitgenössischer Freimaurer skandalösen - Vorgänge in Köln geschildert, hatte sich die dort ansässige Loge Le Secret des trois Rois im Jahr 1811 in zwei Sektionen aufgeteilt, deren zu karnevalistischen `Entgleisungen neigender Teil, die Sektion Charlemagne, sich ebenfalls mit Hilfe Joseph zu Salm-Reifferscheidt-Dycks dem Rit écossais philosophique anschloss und später unter dem Namen La Naissance du Roi de Rome bei der Mutterloge in Paris geführt wurde. Angesichts der profanen Société in Aachen und der Pariser Projekte eines Thory, die durch eine offenere Haltung gegenüber Profanen auf eine Begeisterung für den Bund zielten, muss dieses Zusammengehen nicht überraschen, sondern stellt sich als durchaus konsequent dar. Auch das Geschlecht der Salmen war dabei bereits seit längerem in der Kölner Freimaurerei bekannt, hatte sich doch mit Prince Emanuel de Salm-Salm und mit dem herzoglich-badischen Major Altgraf Joseph Franz zu Salm-Reifferscheidt-Kraut-

241 Fürth an Joseph Salm-Dyck, Frankfurt a.M., 16.10.1812, in: ASD, Blaue Bände, Bd. 590, fol. 56.

242 Eine erste Tendenz zur deutlicheren Öffnung gegenüber Nichtfreimaurern in Aachen findet sich in dem seit 1784 - und damit bereits in der Zeit der Zugehörigkeit der Loge zum Rit écossais philosophique - für die Loge La Constance belegten »Freimaurer-Cloup«, in dem auch Profane Zugang hatten. Später richtete auch die Concorde - wie oben erwähnt - ein ähnliches Etablissement ein. Laut den Angaben bei August Pauls konnten Nichtfreimaurer hier gegen eine Gebühr Zeitungen lesen, Billard spielen oder kegeln - deutliche Mitgliedergewinne konnte die Loge durch diese Annäherung jedoch nicht erzielen. Vgl. hierzu die Angaben bei Pauls, Annalen der Aachener Freimaurerei (wie Anm. 219, Kap. VII), $78 f$.

Fürth an Joseph Salm Dyck, Aachen, 25.12.1813, in: ASD, Blaue Bände, Bd. 590, fol. 8v. 
heim (geb. 1778) zeitweilig die zum Teil fernere, zum Teil nähere Verwandtschaft der Loge angeschlossen. ${ }^{244}$ Die freimaurerische Verbindung "Köln/Aachen « war ebenfalls seit längerem etabliert, wie etwa die Beziehungen der Concorde zur Kölner Dreikönigsloge zeigen. ${ }^{245}$

Salm-Reifferscheidt-Dyck unterhielt über seine freimaurerische Tätigkeit in Köln einen direkten Kontakt zu einem nicht unbedeutenden Teil der Kölner "Werteelite ${ }^{246}$ und konnte über die Vermittlung des Rit écossais philosophique in diesem Feld auch Einfluss auf diese nehmen. Präsident des Hochgradkapitels der Loge war im Jahr 1813 Jean Philippe Heimann. ${ }^{247}$ Unter den 14 Brüdern, die im selben Jahr den Grad eines Grand Écossais besaßen, finden sich nicht nur sein Vater Fréderic-Charles Heimann, ${ }^{248}$ sondern auch Bernard Boisserée, ${ }^{249}$ ein Bruder der bekannten Kölner Kunstsammler Sulpiz und Melchior Boisserée, der bekannte Kölner Jurist Erich-Heinrich Verkenius sowie mit Baron Franz-Ludwig von Harff (1747-1814) ein Freimaurer aus der vormals adligen, nun in den neuen napoleonischen Adel aufgenommenen und - ähnlich wie im Fall Joseph zu SalmReifferscheidt-Dycks - mit einem Majorat bedachten rheinischen Familie Harff zu Dreiborn. ${ }^{250}$

244 Siehe hierzu die Angaben bei Dotzauer, Die Mitglieder der Kölner Freimaurerloge (wie Anm. 179, Kap. V), hier 226f. Der General in spanischen Diensten, Prince Emanuel de Salm-Salm, war demnach im Jahr 1775 in den Logenlisten eingetragen. Altgraf Joseph Franz zu Salm-Reifferscheidt-Bedburg bzw. -Krautheim findet sich im Jahr 1808 als abwesendes Mitglied. Zu seiner Identifikation, die sich über den bei Dotzauer erwähnten Majorstitel ergibt, siehe die Angaben in Gothaischer genealogischer Hofkalender nebst diplomatisch-statistischem Jahrbuche auf das Jahr 1750, Sieben und Achtzigster Jahrgang, Gotha 1850, 190, Permalink: http://nbn-resolving. org/urn:nbn:de:bvb:12-bsb10620158-2 (Zugriff vom 18.07.2014). Er ist demnach ein Bruder des Fürsten Franz Wilhelm zu Salm-Reifferscheidt-Krautheim (1772-1831), mit dem Fürst Joseph im Zuge der Mediatisierungsfrage in Kontakt stand.

245 Siehe hierzu Dotzauer, Freimaurergesellschaften am Rhein (wie Anm. 56, Kap. I), 199.

246 Zum Ausdruck der »Werteelite« siehe Müller, Köln von der französischen zur preußischen Herrschaft (wie Anm. 7, Kap. VI), 255. Müller versteht hierunter die aus etwa 200 bis 250 Familien bestehende Oberschicht Kölns. Hierunter fallen vor allem die Höchstbesteuerten, aber auch die "Notabeln in Literatur, Wissenschaften und Künsten".

247 Vgl. die Angaben in Tableau des Off. Dign $\therefore$ et des FF $\therefore$ Qui composent la R $\therefore \square$ de St.-Jean d'Écosse, sous le Titre distinctif de la Naissance du Roi de Rome à l'Or. de Cologne, Cologne 5813 (1813), in: GON, 212.D.33.

248 Siehe Tableau des Off $\therefore$ Dign $\therefore$ et des FF $\therefore$ Qui composent la R $\therefore \square$ de St.-Jean d'Écosse, sous le Titre distinctif de la Naissance du Roi de Rome à l'Or $\therefore$ de Cologne, Cologne 5813 (1813), in: GON, 212.D.33, 13. Zu einer biographischen Besprechung der Mitglieder der Familie Heimann in der Loge Le Secret des trois Rois siehe Dotzauer, Die Mitglieder der Kölner Freimaurerloge (wie Anm. 179, Kap. V), hier 167-169.

249 Dotzauer erwähnt außerdem Wilhelm Boisserée als Mitglied der Dreikönigsloge. Siehe Ders., Die Mitglieder der Kölner Freimaurerloge (wie Anm. 179, Kap. V), hier 173.

250 Vgl. Tableau des Off $\therefore$ Dign $\therefore$ et des FF $\therefore$ Qui composent la R $\therefore \square$ de St.-Jean d'Écosse, sous le Titre distinctif de la Naissance du Roi de Rome à l'Or $\therefore$ de Cologne, Cologne 5813 (1813), in: GON, 212.D.33, 13f. Zum Titel eines Barons sowie zur Verleihung des Majorats an Harff siehe L[ouis] Rondonneau, Institution des Majorats et de la Légion d'honneur, ou Receuil chronologique des Sénatus-consultes, des Lois, des Décrets, des Avis du Conseil d'État et des Lettres-patentes, concernant l'institution des Titres, Dignités et Majorats, Paris 1811, 358f., http://books. google.de/books?id=70Zkm-Ihs6MC (Zugriff vom 25.05.2014). Zu seiner Biographie siehe die 
Im Grad eines Élu parfait finden sich insgesamt vier Brüder, von denen Charles-Antoine Farina, aus der Familie der Kölnisch Wasser-Hersteller, ${ }^{251}$ sowie Jacques-Conrad Herstatt ${ }^{252}$ besonders hervorstechen. ${ }^{253}$ Auch unter den 14 Brüdern im Grad eines Maître parfait finden sich die Namen bekannter Kölner Familien. Neben Friedrich Herstatt und Adolf Steinberger, in den Jahren 1823 bis 1848 Oberbürgermeister der Stadt Köln, sowie Philippe Joseph Lenné, Bruder des mit Joseph zu Salm-Reifferscheidt-Dyck auf botanischem Gebiet eng zusammenarbeitenden Peter Joseph Lenné, finden sich drei Vertreter von Zweigen der Familie Dumont $^{254}$ - wobei die Mitgliedschaft des Verlegers Marcus Dumont-Schauberg in der symbolischen Loge der La Naissance du Roi de Rome bereits oben angeführt wurde.

Über ein Mitglied der Familie Dumont lässt sich erweisen, wie sehr der Rit écossais philosophique danach strebte, eine Wirkung in der Stadtbevölkerung zu erzielen und Projekte, die dies bewerkstelligen sollten, innerhalb des Netzwerks der korrespondierenden Logen zu vermitteln. So empfahl Jean Philippe Heimann dem Repräsentanten bei der Pariser Mutterloge, de Saint-Romain Rouquairol, ${ }^{255}$ in einem Brief des Jahres 1812 ein musikalisches Projekt des zu diesem Zeitpunkt in Paris weilenden Bruders Dumont. ${ }^{256}$ Ein derartiges Projekt muss in der Kölner Loge nicht überraschen, in der laut der Klage der Agrippinen karnevalistische »Orgien $\aleph^{257}$ gefeiert wurden. Zudem spielte die Musik traditionell eine wichtige

Angaben bei Joseph Strange, Beiträge zur Genealogie der adligen Geschlechter, Zweites Heft, Cöln 1865, 57, Permalink: http://nbn-resolving.org/urn:nbn:de:bvb:12-bsb10703981-8 (Zugriff vom 25.05.2014). Demnach war Harff unter anderem in den Malteser-Ritterorden sowie den kurpfälzischen Löwenorden aufgenommen worden. Er bekleidete außerdem die Ämter eines Kammerherrn am Mainzer Kurfürstenhof sowie des Direktors des Jülicher Landtags zu Düsseldorf. Seine Belehnung mit Dreiborn durch Karl Theodor erfolgte im Jahr 1779.

251 Vgl. Dotzauer, Die Mitglieder der Kölner Freimaurerloge (wie Anm. 179, Kap. V), hier $162 f$.

252 Vgl. Ders., Die Mitglieder der Kölner Freimaurerloge (wie Anm. 179, Kap. V), hier 169-171.

253 Siehe Tableau des Off $\therefore$ Dign $\therefore$ et des FF $\therefore$ Qui composent la R $\therefore \square$ de St.-Jean d'Écosse, sous le Titre distinctif de la Naissance du Roi de Rome à l'Or $\therefore$ de Cologne, Cologne 5813 (1813), in: GON, 212.D.33, 14.

254 Vgl. Dotzauer, Freimaurergesellschaften am Rhein (wie Anm. 56, Kap. I), 199-206, hier 156-160.

255 Saint-Romain Rouquairol wurde im Verzeichnis von 1813 als Ehrenmitglied geführt. Siehe Tableau des Off: $\therefore$ Dign $\therefore$ et des FF $\therefore$ Qui composent la R $\therefore \square$ de St.-Jean d'Écosse, sous le Titre distinctif de la Naissance du Roi de Rome à l'Or $\therefore$ de Cologne, Cologne 5813 (1813), in: GON, 212.D.33, 3.

256 Heimann erwähnt: »Permettez nous de Vous recommander en même temps le F $\therefore$ Dumont, [...]. Ce jeune F $\therefore$ jouit parmi nous d'une estime et d'une activité dans les devoirs de son état, par son zèle ardent pour le soutien d'une branche importante de nos institutions pour les indigents, d'un institut musical, dont il peut le mieux vous expliquer les détails Enfin par le donneur de son caractère et sa franchise. « Siehe zu diesem Zitat Sektion Agrippina an Grand Orient, Köln, 3. Tag des 3. Monats 5812 (03.05.1812), in: BnF, FM2 535 (MF 4589) (ohne Folioangabe im Dokument). Der Brief befindet sich am Beginn des Dokuments.

257 Sektion Agrippina an Grand Orient, Köln, 10. Tag des 11. Monats 5809 (10.01.1810), in: BnF, FM2 535 (MF 4589), fol. 107f. Hier heißt es in Bezug auf die Sektion Charlemagne: »Au contraire ceux qui se sont éloignés de l'arche sainte, ceux qui ont méprisé les plus simples maximes de l'Economie ont préféré l'Ostentation à la modestie, le désordre et les orgies aux rigueurs, mais sages règlement des Agappes Maçonnique.» 
Rolle innerhalb des freimaurerischen Lebens, wie etwa auch die um 1800 aufgelegten Liederbücher der Dreikönigsloge beweisen. ${ }^{258}$ Wie im Ausblick auf die preußische Zeit noch zu zeigen sein wird, ist in den karnevalistischen Sitzungen eine weitere Ausformung des bereits oben angesprochenen Wirkens auf die Bevölkerung zu sehen, die sich die in den Logen versammelte Notabelnelite zur Aufgabe gemacht hatte. Im Anschluss hieran kann die in den Studien Klaus Müllers und Gisela Metteles bereits besprochene Musikalische Gesellschaft als ein ähnlich gelagertes Projekt betrachtet werden, ${ }^{259}$ deren Gründer Erich-Heinrich Verkenius, Adolf Steinberger und der Musikprofessor Jean-Jacques Almenräder ebenfalls zum Mitgliederbestand der La Naissance du Roi de Rome zählten. Mettele konnte bereits auf die Überschneidung der verschiedenen Gesellschaften hinsichtlich ihrer Mitglieder hinweisen. ${ }^{260}$ In der vorliegenden Studie kann in Ergänzung hierzu festgestellt werden, dass einige der Projekte direkt dem Bildungsauftrag der Freimaurerlogen in der Zeit des Premier Empire bzw. den innerhalb der Logen des Rit écossais philosophique gepflegten und mit den zeitgenössischen Naturwissenschaften in enger Verbindung stehenden Ansichten über die ideale geistige Erziehung der Nation entsprangen. Derartige Projekte fanden auch über Empfehlungen innerhalb des freimaurerischen Korrespondenznetzwerks ihre Verbreitung.

Wie oben bereits erläutert, waren derartig weit gehende >Ausflüge $<$ in die profane Welt längst nicht bei allen Freimaurern gern gesehen. Es ist wohl letztlich auf die Vermittlertätigkeit Joseph Salm-Reifferscheidt-Dycks für den in dieser Hinsicht liberalen Rit écossais philosophique zurückzuführen, dass sich liberale Tendenzen, wie sie in den karnevalesken Sitzungen der affiliierten Sozietät der Loge La Naissance du Roi de Rome zu beobachten waren, derartig über die Logengemeinschaft entfalten konnten. ${ }^{261}$ Nur aus dieser Perspektive ist die

258 Vgl. hierzu Dotzauer, Freimaurergesellschaften am Rhein (wie Anm. 56, Kap. I), $208 \mathrm{f}$.

259 Zur Gründung der Musikalischen Gesellschaft in Köln durch Verkenius, Dumont, Steinberger und Almenräder vgl. die Angaben bei Mettele, Bürgertum in Köln (wie Anm. 46, Kap. VI), 102-107; Müller, Köln von der französischen zur preußischen Herrschaft (wie Anm. 7, Kap. VI), 372-374. Müller betont, dass Verkenius im Mittelpunkt der Reorganisation des musikalischen Lebens in Köln zu Beginn des 19. Jh.s stand. In Bezug auf die oben erläuterte Thematik sind auch die bei Mettele zitierten Stellen aus dem Vorwort der Statuten der Musikalischen Gesellschaft beachtenswert, die das Bewusstsein ihrer Mitglieder für den »Leib/Seele«-Dualismus klar zum Ausdruck bringen und die Musik als wohltätig für den Menschen ansehen, da diese »das ganze sinnlich-geistige Wesen des Menschen in Anspruch nimmt, nicht einseitig den Geist oder den Körper reizt, sondern sich der ganzen Natur bemächtigt, durch die Gefühle die Einbildungskraft, und durch die Einbildungskraft tiefe Gefühle erregt." Sie habe daher nichts Unedles an sich und wirke nur auf die Moral, nicht auf »das thierische Gefühl«. Siehe hierzu: Mettele, Bürgertum in Köln (wie Anm. 46, Kap. VI), 106f.

260 Vgl. hierzu insgesamt Ders., Bürgertum in Köln (wie Anm. 46, Kap. VI), 101-107.

261 Dabei ist es interessant zu sehen, dass es hinsichtlich der musikalischen und karnevalesken Unternehmungen durchaus starke Parallelen zu den Logen in Paris gegeben hatte. Einige der Lieder der Kölner Loge waren auf die Melodien französischer Vaudevilles getextet worden. Vgl. hierzu Dotzauer, Freimaurergesellschaften am Rhein (wie Anm. 56, Kap. I), 208f. In der Hauptstadt des Premier Empire formierten sich zu Beginn des 19. Jh.s die sogenannten Vaudeville-Gesell- 
Wichtigkeit der Anbindung der Logen über Mittlerpersonen, wie eben Joseph zu Salm-Reifferscheidt-Dyck, richtig zu verstehen. Um den Kontakt in die Hauptstadt Paris und zu den Entwicklungen der dort ansässigen Mutterloge zu halten, war man - neben der Reisetätigkeit eigener Brüder ${ }^{262}$ - zwingend auf die guten Kontakte des Repräsentanten bei der Mutterloge angewiesen. Joseph zu SalmReifferscheidt-Dyck erschien hier wohl auch aufgrund seines ständigen Pendelns als die richtige Wahl.

Denn ohne Zweifel hatte sich die Sichtweise auf die Bedeutung der freimaurerischen Rituale und den Umgang mit diesen in der französischen Metropole im Vergleich zum Ancien Régime stark gewandelt. Dieser Wandel, der hier anhand des Umfelds Joseph zu Salm-Reifferscheidt-Dycks innerhalb des Rit écossais philosophique untersucht wurde, war teilweise derart, dass auch die Brüder des philosophischen Ritus bei der Praktizierung einiger aus dem Ancien Régime übernommener Riten wortwörtlich das Lachen überkam. Dieser Umstand findet sich in einem Schreiben Thorys an Joseph zu Salm-Reifferscheidt-Dyck zusammengefasst. ${ }^{263}$ Gegenstand des auf den 23.06.1813 datierenden Schreibens war die Übermittlung einer bereits oben angesprochenen besonderen freimaurerischen Einrichtung in das Rheinland: der Académie de la Sagesse bzw. Académie des Vrais Maçons. Salm-Reifferscheidt-Dyck hatte im Vorfeld dieses Briefes diese freimaurerische Einrichtung für das Aachener Kapitel erbeten. ${ }^{264}$ Thory, der in

schaften, die sich mit der Darbietung oft humorvollen Liedguts zwar an die Kultur der unteren Volksklassen anlehnten, jedoch von den gehobenen Schichten als »amateurs « bevölkert wurden. Diese Entwicklung ist in Teilen als Parallele zur Ausrichtung der Académie celtique zu sehen, die sich in ihren Forschungen zur »Volkskultur« bekanntermaßen dem populären Liedgut zuwandte. Auch Constance de Salm stand mit einigen Gründern dieser Vaudeville-Gesellschaften in Kontakt, und von Joseph Salm-Reifferscheidt-Dyck ist in einem Brief der Constance de Salm überliefert, dass er heimlich zum privaten Amüsement in der sonntäglichen Messe VaudevilleTexte las. In diesem Bereich kamen sich Freimaurerei und »Volkskultur« in der französischen Zeit also wiederum sehr nahe. Zur Entwicklung der Vaudeville-Gesellschaften im Frankreich des späten 18. und frühen 19. Jh. siehe vor allem den Sammelband Herbert Schneider (Hg.), Chanson und Vaudeville. Gesellschaftliches Singen und unterhaltende Kommunikation im 18. und 19. Jh. (Schriften der Saarländischen Universitäts- und Landesbibliothek, 6), St. Ingbert 1999. Zum Zusammenhang zwischen der Académie celtique und der Erforschung französischer Volkslieder siehe insb. Durry, L'académie celtique et la chanson (wie Anm. 183, Kap. VII), 62-73. Zum Interesse des Fürsten Joseph zu Salm-Reifferscheidt-Dyck an Vaudevilles siehe die Bemerkungen bei Bied, Le rôle d'un salon littéraire (wie Anm. 4, Kap. VII), hier 136.

262 Ein interessanter Fall der Reisetätigkeit eines Aachener Bruders findet sich im »Livre d'architecture « der Mutterloge für das Jahr 1814. Demnach reiste der Bruder Frohnheuser nach Paris, nahm an mehreren Sitzungen der Mutterloge teil und übersetzte einige Werke der Bibliothek von der deutschen in die französische Sprache. Im selben Jahr ist außerdem Louis Alexandre Gautier, Redner der Aachener Loge, in der Pariser Mutterloge anwesend. Siehe hierzu Livre d'architecture Mère Loge Écoss. de France, Paris, Einträge vom 11. Tag des 1. Monats 5814 (11.03.1814), vom 8. Tag des 2. Monats 5814 (08.04.1814) sowie vom 13. Tag des 3. Monats 5814 (13.05.1814), in: BnF, FM1 295 (MF 33616), fol. 198f.

263 Vgl. Thory an Joseph Salm-Dyck, Paris, 23.06.1813, in: ASD, Blaue Bände, Bd. 590, fol. 48v-49.

264 Die Académie de la Sagesse oder auch Académie des Sages Vrais Maçons war offenbar eine unabhängig vom System der regulären Kapitelgrade existierende Einrichtung für die Brüder in der höchsten Klasse des Ritus. Siehe hierzu insb. Abb. 31 und Abb. 32 sowie die Besprechung von 


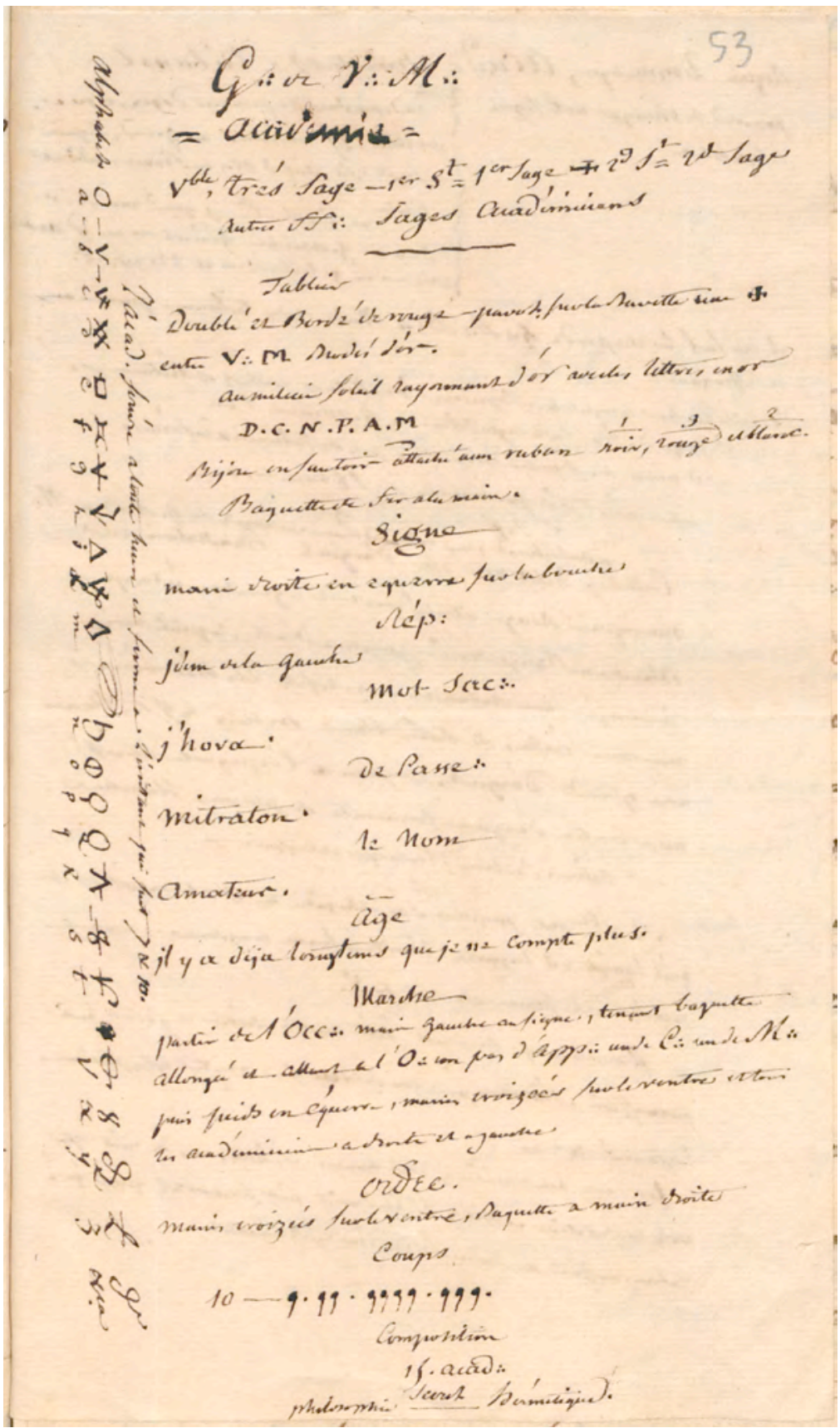

Abbildung 31: Ritualinstruktion der Académie de Vrais Maçons, Vorderseite (Bildnachweis: ASD, Blaue Bände, Bd. 590, fol. 53r; Bildrecht/Werk: Grafen Wolff-Metternich zur Gracht; Foto: LVR-Archivberatungs- und Fortbildungszentrum). 


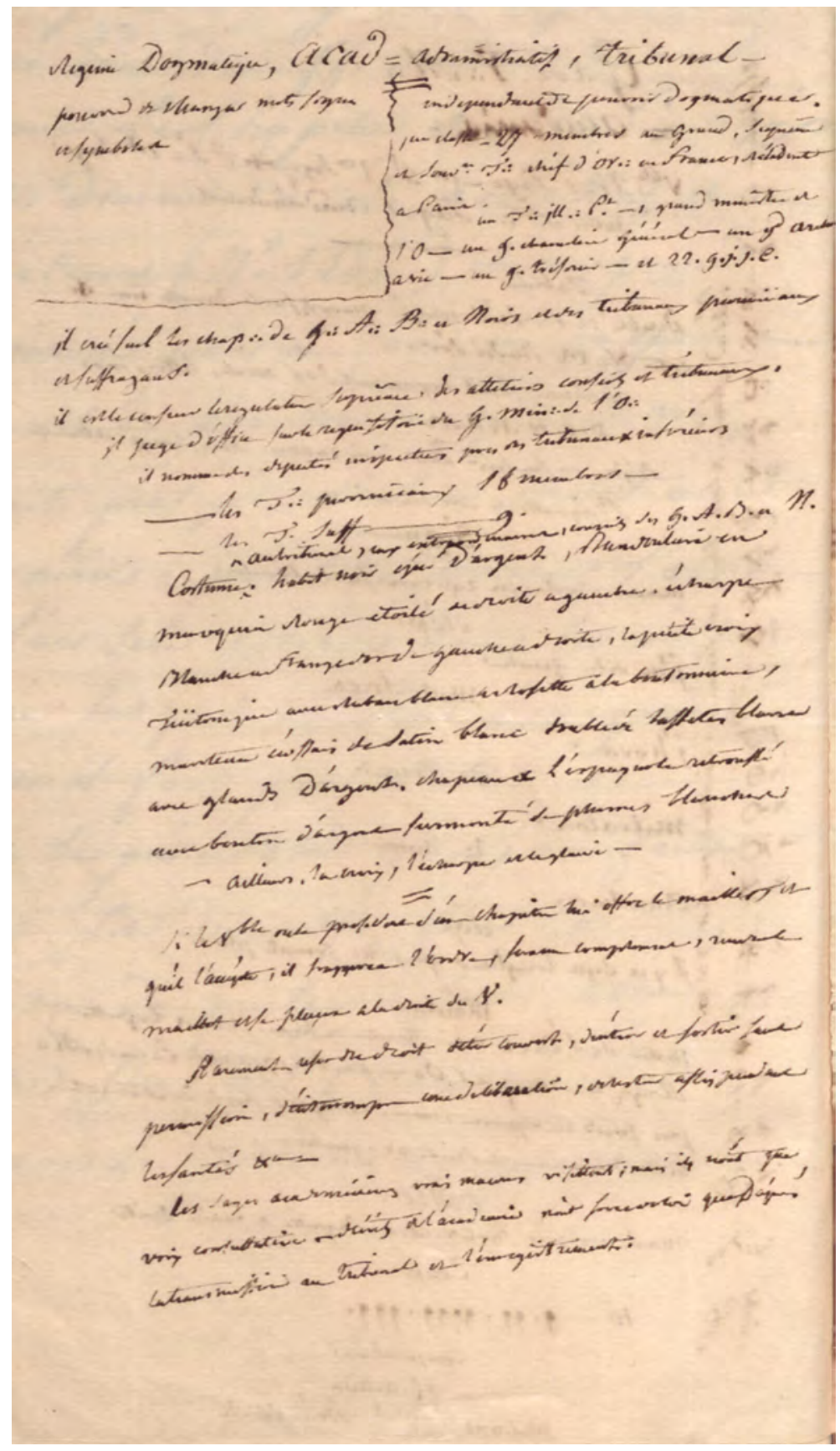

Abbildung 32: Ritualinstruktion der Académie de Vrais Maçons, Rückseite (Bildnachweis: ASD, Blaue Bände, Bd. 590, fol. 53v; Bildrecht/Werk: Grafen WolffMetternich zur Gracht; Foto: LVR-Archivberatungs- und Fortbildungszentrum). 
seinem Schreiben wiederum den vorbildlichen Einsatz Joseph zu Salm-Reifferscheidt-Dycks für die Verbreitung des Ritus im Rheinland lobte, kam anschließend auch auf den alchemistischen Inhalt des Grades zu sprechen:

Vous n'ignoré pas que le grade de l'académie de la Sagesse est un Rapport de tous les emblêmes maçonniques à l'alchimie. Cette Science était fort à la mode dans le temps de l'institution du Regime philosophique, et ses auteurs ont du présenter ce but final aux adeptes qui l'ont accueilli avec empressement. Depuis on a perdu petit à petit ces idées qu'on a considerées comme chimeriques, et le grade de la Sagesse a eu moins de partisans; [...]. Les gens raisonnables ont pensé qu'il était ridicule de se rassembler pour disserter sur les moyens de faire de l' [Wort durch Siegelabdruck verdeckt; ১or «?, Anm. d. Verf.] on a tout abandonné apeuprès depuis vingt cinq ans. ${ }^{265}$

Trotz seiner offenbar als überholt geltenden alchemistischen Inhalte, die noch aus dem Ancien Régime stammten, lebte der Grad in der Praxis zur Zeit des Premier Empire wieder auf. Die vormals ernste Angelegenheit war jedoch zur Komödie verkommen, wie Thorys anschließende Kommentierung verdeutlicht:
M. D’Aigrefeuille qui était président de l'académie de Montpellier a cherché a renouer à Paris; nous avons eu quelque assemblées; mais en conscience nous ne pouvions nous regarder sans rire. Au peu de zèle qu'on apporte à ce sujet, je crois entrevoir que le temps de cet niaiserie est passé et que les hommes s'adonneront a quelque chose de plus satisfaisant. ${ }^{266}$

Diese kurzen Passagen fügen sich cum grano salis in die oben gegebene Schilderung der Verhältnisse in der Kölner Freimaurerei ein. Nicht alle freimaurerischen Rituale, die man aus der Zeit des Ancien Régime übernommen hatte, verdienten es mehr, ernst genommen zu werden oder der Geheimhaltung zu unterliegen.

Bereits im Zuge der vorrevolutionären Konvente der Philaleten in Paris war ernsthaft diskutiert worden, inwiefern auch humoristische Vereinigungen, wie das Anfang des 18. Jahrhunderts in Frankreich entstandene, damals exklusiv aristokratische Régiment de la Calotte, unter dem Stichwort einer »franc-maçonnerie du rire $«^{267}$ mit in die Kette der Vorläuferformen der Freimaurerei einbezogen wer-

Mollier in Ders., Contribution à l'étude du grade de Chevalier du Soleil, IV. Le Chevalier du Soleil et la Maçonnerie hermétique, in: Renaissance Traditionelle. Revue d'études maçonniques et symboliques 107/108 (1996), 231-246, hier insb. 236-239; Henrik Bogdan, From Darkness to Light. Western Esoteric Rituals of Initiation, Göteborg 2003, 148-163. In den »Loix du Souverain Tribunal des Grand Instructeurs Inquisiteurs Commandeurs « wird der Grad der Académie ebenfalls erwähnt und seine Unabhängigkeit und hohe Stellung erläutert. Siehe hierzu Lois du S $\therefore$ T $\therefore$ des GG $\therefore$ I $\therefore$ I $\therefore$ C $\therefore$, o.O, o.D., in: BnF, FM1 300 (MF 33620), fol. 34f.

265 Thory an Joseph Salm-Dyck, Paris, 23.06.1813, in: ASD, Blaue Bände, Bd. 590, fol. 48v-49.

266 Thory an Joseph Salm-Dyck, Paris, 23.06.1813, in: ASD, Blaue Bände, Bd. 590, fol. 49.

$267 \mathrm{Zu}$ diesem Ausdruck sowie der Besprechung des »Régiment de la Calotte « auf den Konventen der Philaleten in Paris vgl. Charles Porset, Les Philalèthes et les Convents de Paris. Une politique de la folie, Paris 1996, 500f. Allgemein zur Geschichte des aristokratischen Regiments sowie zu sei- 
den sollten. ${ }^{268}$ Collaveri bemerkt in seinen Untersuchungen beiläufig, dass jedoch selbst der in Bezug auf die freimaurerische Geheimhaltungspflicht recht liberale Thory in seiner 1815 erschienenen Darstellung der Geschichte der Freimaurerei nur die Ritter der Tafelrunde, ${ }^{269}$ nicht aber die humoristischen und gastronomischen Gesellschaften unter die Vorläufer der Freimaurerei rechnete. ${ }^{270}$ Vertreter radikalerer Positionen hinsichtlich der Profanierung der freimaurerischen Geheimnisse taten dies aber durchaus. So zählt ein französisches Dokument aus der Zeit des Premier Empire unter der Überschrift »Notes Chronologiques pour servir à l'histoire de la Maçonnerie« explizit auch humoristische Vereinigungen auf, wie den »Ordre de la coupe« oder die »Mère-folle« zu Dijon. ${ }^{271}$ Eben hierin lag die Krux, die in preußischer Zeit klar zu Tage treten sollte und sich offenbar verselbstständigte. Während sich einige Hochgrad-Freimaurer des Rit écossais philosophique in ihrem Sendungsbewusstsein merklich der profanen Welt öffneten, hegte der konservative Teil der Freimaurerei kein Verständnis für derartig weit gehende `volksnahe< Reformen.

Wegen seines großen und insofern liberalen Einsatzes für die Aachener Loge wurde Joseph Salm-Reifferscheidt-Dyck noch in den letzten Jahren der französischen Herrschaft eine besondere Ehre innerhalb des nun beide Aachener Logen unter dem Namen La Constance et la Concorde réunis vereinigenden Ateliers zuteil. Die Aachener Brüder wählten ihn zum Nachfolger Josef von Fürths im Amt des Vénérable der Loge. Ein Entwurf eines Schreibens bzw. einer Rede Joseph Salm-Reifferscheidt-Dycks zeigt dabei, dass er zunächst aufgrund der zahlreichen offiziellen Belastungen hin- und hergerissen war, ob er das Amt annehmen oder ablehnen sollte. ${ }^{272}$ Sein Zögern in dieser Angelegenheit verdeutlicht, dass es

ner Bedeutung in der durchaus hintergründigen »Lachkultur« des 18. Jh.s: Antoine de Baecque, Les éclats du rire. La culture des rieurs au XVIII ${ }^{e}$ siècle, Paris 2000, insb. 23-55.

268 Auch Lessing war bereits der Ansicht gewesen, dass die gastronomischen Tischgesellschaften der Vorzeit zu den Vorläufern der Freimaurerei zu zählen seien. Vgl. hierzu die Besprechung von Lessings Ernst und Falk bei Maurice, Freimaurerei um 1800 (wie Anm. 33, Kap. I), 48.

269 Vgl. Thory, Acta Latomorum (wie Anm. 95, Kap. VII), Bd. 2, 244, Anm. 1, Permalink: http://hdl. handle.net/2027/njp.32101061269286 (Zugriff vom 25.05.2014).

270 Vgl. Collaveri, La franc-maçonnerie de Bonaparte (wie Anm. 21, Kap. VI), 106.

271 Siehe hierzu Notes chronologiques pour servir à l'histoire de la Maçonnerie, o.O., o.D., in: BnF, FR Nouv. Acq. 10956, fol. 19 bzw. 21. Ergänzend hierzu sei auf folgende Schrift verwiesen, die sich ebenfalls für eine teilweise Profanierung der freimaurerischen Gesellschaftsformen einsetzt: Chansonnier Maç $\therefore$ et Prof $\therefore$, dédié aux Francs-Maç de l'O de Paris et des OO $\therefore$ étrangers, par le F $\therefore$ Aze, K $\therefore$ D $\therefore$, Orateur de la respectable L $\therefore$ d'Isis; Deputé au G $\therefore$ O $\therefore$ de son Chap $\therefore$, et de la $L \therefore$ des Amis-réunis, à l'O $\therefore$ de Tarare; Capitaine en non-activité, Chevalier de la Légion d'honneur, Paris 1822, insb. V-VII, Permalink: http://gallica.bnf.fr/ark:/12148/bpt6k5544334c (Zugriff vom 24.05.2014).

272 Innerhalb des Entwurfs heißt es: »Mes F $\therefore$, Les reglements du Rit qui nous professons ordonnent qu'aucun Vénérable ne pourra être portagé deux années de suite dans ses fonctions et quoiqu'une longue éxpérience ait consacré toute l'utilité de cette disposition, nous sommes plus frappés aujourd'hui de sa severité que de sa profonde Sagesse - en effet, M. F., le vœu le plus unanime [...] appellé l'ill $\therefore$ F $\therefore$ de Furth a conserve un maillet qui entre ses mains a acquis chaque année un nouveau dégré de Gloire, si votre soumission a nos statuts ne vous en fait une loi de vous occuper d'un autre choix - Dans cette circonstance vos suffrages m’ont désigné pour remplacer ce digne 
für den Comte de l'Empire durchaus mit einigen Anstrengungen verbunden war, zusätzlich zu seinen mannigfaltigen Staatsämtern den Anforderungen innerhalb der freimaurerischen Sphäre gerecht zu werden. Joseph Salm-Reifferscheidt-Dyck entschloss sich jedoch letztlich dazu, Amt und Würde innerhalb der Loge zu übernehmen, und bezeugte hierdurch seinen freimaurerischen Eifer. In der Programmordnung für die Feier des Johannisfests für das maurerische Jahr 5813 war auch die Installierung als Vénérable der Loge unter $\$ 13$ vorgesehen. Hier hieß es:

Après l'introduction de toutes les Deputations, les trois Maîtres de Ceremonies, se plaieront entre les deux Surveillants \& le prémier annoncera a haute Voie l'arrivée de l'illustre Fr $\therefore$ Comte de Salm, grand Inspect $\therefore$, nouvel élu à la prémière dignité de la $\square$. Le Vénérable fera repeter cette annonce par les Surveillants \& ordonnera qu'il y soit applaudi par une triple batterie \& fanfare. Il enverra les trois maîtres de Ceremonie, accompagnés de neuf étoiles, pour introduire cet illustre Fr.., Son introduction se fera sous la Voute d'Astres \& maillets battant. Les Fr. Art $\therefore$ éxécuteront pendant cette Ceremonie l'Air. Ou peut on être mieux. Il sera conduit au coté droit du Vénérable en éxercice. ${ }^{273}$

Im Anschluss hieran wurde Joseph Salm-Reifferscheidt-Dyck zu einem Sessel in der Mitte der Loge geleitet, wo er den rechten Arm hob und bei seiner Ehre schwor, seine gesamte Kraft für die freimaurerischen Arbeiten und den Erhalt der Harmonie innerhalb des Ordens und der Loge einzusetzen. ${ }^{274}$

Die Ernennung Fürths im selben Jahr zum Grand Inspecteur Inquisiteur Commandeur zeigt in Ergänzung hierzu, dass sich das System des Rit écossais philo-

$\mathrm{F} \therefore-[\ldots]$ vous avez rendu justice pleine et entière aux sentiments d'attachement et d'intérêt que je porte a cet attelier, vous pourriez néanmoins vous être trompés en me supposant des talents maçonniques que je ne possede pas, et une habitude de presider a vos travaux que mes nombreuses occupations civiles ne m'ont pas permis d'acquerir. - Quoiqu'il en puisse être, j'ai pensé que mon premier devoir etait celui de me rendre a vos désirs, et laissant de côté toute autre consideration, j'ai mis toute ma confiance dans votre indulgence, $\mathrm{M} \therefore \mathrm{F} \therefore$, et dans le concours des lumières et du zèle de tant de dignitaires illustres dont je me vois entouré - Je prie donc chacun de vous de recevoir en particulier mes remerciements les plus sincères par la confiance qu'il m'a témoignée, et les assurances les plus franches de l'attachement fraternel que je lui porte - avec votre assistance j'ose me flatter de remplir tous les engagements qu j'ai contracté de maintenir pendant le cours de cette année maçonnique, les splendeurs de cet atelier, et d'ajouter encore un gloire nouvelle, a celle dont il brille déjà -.» Entwurf des Grafen Salm-Dyck, o.O., o.D., in: ASD, Blaue Bände, Bd. 590, fol. 16-18. Durch die im Folgenden geschilderten Ereignisse ist der Entwurf auf 1813 datierbar.

273 Programme pour la Celebration de la fête de la St. Jean d'Été 5813, o.O., 5813 (1813), in: ASD Blaue Bände, Bd. 590, Art. 13, fol. 20-23, hier fol. 21r. Es handelte sich bei dem hier erwähnten Lied vermutlich um das Lied "Où peut on être mieux qu'au sein de sa famille«, das für die wiederhergestellte Monarchie Frankreichs in der Restaurationszeit zu einiger Bedeutung gelangen sollte. Innerhalb des Textes wird die Wichtigkeit des Gedenkens an die Lebensweise der Vorfahren betont. Da sich das Lied hier jedoch auf die "Familie« der Logengemeinschaft bezog, ist aus der Verwendung des Lieds nicht auf eine Gegnerschaft zu Napoleon bzw. eine vorweggenommene Unterstützung der Bourbonen zu schließen.

274 Vgl. Programme pour la Celebration de la fête de la St. Jean d'Été 5813, o.O., 5813 (1813), in: ASD, Blaue Bände, Bd. 590, Art. 18, fol. 20-23, hier fol. 21v. 
sophique zum Ende des napoleonischen Regimes um die Person Joseph zu SalmReifferscheidt-Dycks immer stärker im Rheinland etablieren konnte, da nun auch in Bezug auf den Rang innerhalb des Ordens unter ihm rangierende Freimaurer vorhanden waren, die administrative Tätigkeiten für den weiteren Ausbau übernehmen konnten. In diesem Zuge muss hier auch die Korrespondenztätigkeit der beiden Logen erwähnt werden, da sie für die Ausstrahlung des Systems in nicht zum Rit écossais philosophique gehörende Logen von einiger Wichtigkeit gewesen sein dürfte. So stand die Kölner Loge nachweislich mit der Loge St. Joachim in Düsseldorf sowie den Frères Courageux in Bonn in Korrespondenz und schickte Abordnungen von Brüdern zu ihren Feierlichkeiten. ${ }^{275}$

Die Pläne zur Errichtung eines Chapitre de Kilwinning bestätigen diesen administrativen Ausbau, ${ }^{276}$ waren derartige Kapitel doch notwendig, um den aus Sicht des Rit écossais philosophique nur von einem Chapitre de Kilwinning gültig zu verleihenden Rosenkreuzergrad zu vergeben. Ob diese Pläne tatsächlich noch umgesetzt werden konnten, darf aufgrund der Kriegsereignisse im Zuge der »Befreiungskriege « und der hieraus auch in freimaurerischer Hinsicht resultierenden allmählichen Ablösung der Rheinlande von Frankreich bezweifelt werden. ${ }^{277}$ Wie bereits erwähnt, hielt Joseph zu Salm-Reifferscheidt-Dyck - der wohl ebenfalls noch im Jahr 1813, nach einer Mitteilung Thorys zu urteilen, zum Inspektor des Rit écossais philosophique über die Gebiete »Ourthe, Meuse inférieure et rhin et moselle « benannt worden war ${ }^{278}$ - jedoch auch in dieser kritischen Phase Kontakte nach Paris und zur Pariser Freimaurerei. Insgesamt war jedoch mit dem Ende des napoleonischen Regimes auch die Zeit seines großen Engagements für die Freimaurerei vorüber, wie der folgende Ausblick in die preußische Zeit des Rheinlandes verdeutlichen kann.

275 Im Logentableau ist der Bruder Théodore Lenzen zudem als Repräsentant der Kölner Loge in der Düsseldorfer Loge St. Joachim erwähnt. Siehe Tableau des Off $\therefore$ Dign $\therefore$ et des FF $\therefore$ Qui composent la R $\therefore \square$ de St.-Jean d'Écosse, sous le Titre distinctif de la Naissance du Roi de Rome à l'Or $\therefore$ de Cologne, Cologne 5813 (1813), in: GON, 212.D.33, 2 sowie 12. Zum Hinweis auf die Abordnungen siehe Zum Heiligen Joachim, Protokolle I, Düsseldorf, Eintrag vom 24. Tag des IV. Monats 5812 (24.06.1812), in: GStA PK, 5.2.D48, Nr. 128 (ohne Folioangabe im Dokument). Hier werden die Brüder Reynier, Bemberg, Dumont, Schmitz und Lenné als besuchende Brüder der Kölner Loge La Naissance du Roi de Rome in der Loge St. Joachim erwähnt.

276 Vgl. Thory an Joseph Salm-Dyck, o.O., o.D., in: ASD, Blaue Bände, Bd. 590, fol. 59. Im historischen Kontext der Ereignisse auf 1813 datierbar.

277 Ein Hinweis auf diese Ablösungstendenzen könnte bereits in der im Jahr 1814 bei der Pariser Mutterloge beantragten, etwas doppeldeutigen Namensänderung der Kölner Loge in »Amis de la Patrie « bestehen - obgleich hier entgegenzuhalten ist, dass noch im selben Schreiben die Anfragen für den Grad eines Grand Inspecteur Inquisiteur Commandeur für Jean Philippe Heimann sowie eine Mitteilung seitens Thorys über die erforderlichen Schritte und die zu zahlende Gebühr für ein tribunal des Grands Inspecteurs enthalten sind. Vgl. Schriftstück des Deputierten der Loge La Naissance du Roi de Rome beim GOF, o.O, 1814, in: BnF, FM2 535 (MF 4589), fünfte Seite auf Mikrofilm (ohne Folioangabe im Dokument). Klaus Müller erwähnt, dass Maximilian von Kempis die Lage für Frankreich in den Kölner Gesellschaften des Jahres 1813 als äußerst schlecht einschätzte. Vgl. Müller, Köln von der französischen zur preußischen Herrschaft (wie Anm. 7, Kap. VI), 90.

278 Siehe Thory an Joseph Salm-Dyck, o.O., o.D., in: ASD, Blaue Bände, Bd. 590, fol. 59. Im historischen Kontext der Ereignisse auf 1813 datierbar. 


\title{
VIII. An den Grenzen der Wissenschaft - ein Ausblick
}

\begin{abstract}
Mais après avoir fait ainsi la part incontestable d'une cause première et extra-naturelle, il faut se hâter de rentrer dans les limites des sciences naturelles: Rien ici ne dépasse celles de notre intelligence, et en remontent logiquement, comme vous le faites, du connu à l'inconnu, les problèmes en apparance les plus insolubles deviennent abordables.
\end{abstract}

— Fürst Joseph zu Salm-Reifferscheidt-Dyck an Alphonse-Pyrame de Candolle, $1855^{1}$

Es ist gerade der auf den ersten Blick banal erscheinende Befund der Verbindungen der Freimaurerei zu svolksnahen Vereinigungen, der im Hinblick auf das nachlassende Interesse des rheinischen Adels an der Freimaurerei als Vergesellschaftungsform nicht zu vernachlässigen ist. In Bezug auf den rheinischen Adel wog abseits der mit 1789 stärker grassierenden Verschwörungstheorien besonders schwer, dass infolge einer sich 'volksnah' gebenden Freimaurerei Bezüge zu besonders >ursprünglichen « Elementen eines spezifisch adligen »kulturellen Gedächtnisses « innerhalb der französischen Freimaurerei immer schwerer glaubhaft zu konstruieren und im Sinne einer Aufwertung oder Fundierung der eigenen Selbstsicht zu nutzen waren. Im Gegenteil versuchten Teile der französischen Freimaurer - wie oben gesehen - gerade die Riten des reinfachen Volkes` zu erforschen und sie in Beziehung zur Freimaurerei bzw. zur Nation im Gesamten zu setzen.

So übermittelte die in der niederrheinischen Provinz gelegene Erleuchtete Monds-Universität und Berittene Akademie der Künste und Wissenschaften zu Dülken Salm-Dyck noch um das Jahr 1830 ein großformatiges Aufnahmediplom, auf dem die Einweihung eines - durch das »junge Licht« des Neumonds erleuchteten - Kandidaten in die »Geheimnisse« dieser Gesellschaft abgebildet war. ${ }^{2}$ Die im Dülkener Diplom abgebildete Aufnahmezeremonie, die am linken Bildrand durch Minerva, die Göttin der Weisheit, bewacht wurde, erinnerte durchaus an freimaurerische Gepflogenheiten, wobei in der rechten Bildhälfte ein Narr mit Schelle durch ein offenes Fenster störend in die feierliche Einweihung hineinplatzte. Joseph zu Salm-Reifferscheidt-Dyck dürfte die Dülkener Akademie bereits über volkskundliche Publikationen seiner französischen Logenbrüder bekannt

1 Salm-Dyck an de Candolle, o.O., 28.10.1855, in: ASD, Dyck4 - Kart. 2/16, fol. 2r.

2 Abb. 33 und 34. Er erhielt laut der auf den 19. Tag des 4. jungen Lichtes des Jahres 5782 datierenden Urkunde den Titel eines "Monds-Doctors« sowie »Ritters des jungen Lichtes« sowie den »Windmühlenorden mit zwei Flügeln« zugesprochen. Siehe hierzu Dülkener Akademie an Joseph Salm-Dyck, Dülken, 19. Tag des 4. jungen Lichtes des Jahres 5782 (um 1830), in: ASD, Blaue Bände, Bd. 594, fol. 155-159. Siehe hierzu auch die Erwähnung bei Heinrich Goossens, Die Dülkener Narrenakademie oder »Die erleuchtete Mondsuniversität und berittene Akademie der Künste und Wissenschaften«, Dülken 1901, 111. 
gewesen sein. ${ }^{3}$ Rund um eine Windmühle, den Sitz der Dülkener Akademie, ritten die Monds-Doktoren und -Professoren - die vornehmlich Angehörige der einheimischen Honoratiorenschicht waren - zum akademischen Neujahr auf Steckenpferden und machten sich mit ihren eigenartigen Ritualen und Diplomen über den Dünkel des Adels und der Gelehrten ihrer Zeit lustig. Das erklärte Ziel bei ihren Zusammenkünften war es - bei Verbannung jeglicher politischer oder religiöser Erörterung -, die bei jedem »Bruder « vorhandenen Leidenschaften zum Ausgleich zu bringen, also sowohl dem Sinn als auch dem Unsinn unter dem Einfluss des lunaticus spiritus seinen Raum zu geben. ${ }^{4}$ Wie man sich hierbei bereits denken kann, war dieser Spaß durchaus hintergründiger, als es auf den ersten Blick scheinen mag. Er rief so nach der Wiederaufrichtung der Akademie in den 1820er Jahren unter dem Eindruck der Karlsbader Beschlüsse Nachforschungen der preußischen Regierung auf den Plan, die die Gründung eines politischen Geheimbundes vermutete. ${ }^{5}$ Diese Vermutung war nicht völlig unbegründet, befan-

3 Die eigentümliche Dülkener Gesellschaft war bereits durch Josephs Aachener Logenbruder und Korrespondenzpartner seiner Frau, den Präfekten Ladoucette, in einer im Jahr 1818 veröffentlichten Reisebeschreibung der Jahre 1813/14 erwähnt worden. Vgl. Jean Charles François de Ladoucette, Voyage fait en 1813 et 1814 dans les pays entre Meuse et Rhin, suivi de notes, avec une carte géographique, Paris 1818, 135, Permalink: http://nbn-resolving.org/urn:nbn:de:bvb:12-bsb10469005-7 (Zugriff vom 25.05.2014); Arie Nabrings, Die Dülkener Narrenakademie, Düsseldorf 2003, 28. Nabrings weist auf die große Ähnlichkeit zu einem früheren Bericht des zeitweiligen Unterpräfekten des Arrondissements Kleve, Anton Joseph Dorsch, hin. Dorsch war in französischer Zeit Freimaurer in der Aachener Loge La Constance. Zu Dorschs Logenmitgliedschaft in Aachen sowie seiner Zugehörigkeit zum Orden der Illuminaten vgl. Dotzauer, Freimaurergesellschaften am Rhein (wie Anm. 56, Kap, I), 202. Aufgrund der bereits seit dem 18. Jh. bestehenden Bekanntheit Dülkens als »Narrenstadt « ist es nicht unwahrscheinlich, dass die Dülkener Gesellschaft auch den Kölner Freimaurern der Sektion Charlemagne und ihren karnevalesken Versammlungen, in denen die freimaurerischen Amtsbezeichnungen durch die Namen profaner Berufe ersetzt worden waren, als Vorbild gedient hatte. Vgl. zu Dülkens Ruf als Narrenstadt: Nabrings, Die Dülkener Narrenakademie (wie Anm. 3, Kap. VIII), 26-33. Noch den Aachener und Kölner Karnevalisten der 1820er Jahre galt die Dülkener Akademie und Mondsuniversität gemeinsam mit dem auf eine adlige Stiftung aus dem Jahr 1381 zurückgehenden Klever Narrenorden als Vorläufer ihrer eigenen Projekte. Zu den Bezügen des Kölner Rosenmontagszugs von 1825 und 1826 auf die Dülkener Gesellschaft siehe vor allem Michael Euler-Schmidt/Marcus Leifeld, Der Kölner Rosenmontagszug 1823-1948, Köln 2007, 27-29.

4 Vgl. Nabrings, Die Dülkener Narrenakademie (wie Anm. 3, Kap. VIII), 56-58. Dass sich die Dülkener Narren dabei mehr oder weniger scherzhaft in der langen Reihe der >traditionellen Geheimgesellschaften - aber wie die Logen des Rit écossais philosophique mit einer deutlichen Hinwendung zur Öffentlichkeit - sahen, wird aus dem Vorwort ihrer humoristischen Aufsatzsammlung deutlich. Siehe hierzu den »Vorspann « in Heinrich Weimann (Hg.), Kuriosa der berittenen Akademie der Künste und Wissenschaften, Bd. 1, Krefeld 1828, Vorspann, Permalink: http:// nbn-resolving.org/urn:nbn:de:bvb:12-bsb10578013-9 (Zugriff vom 25.05.2014) sowie Ders. (Hg.), Kuriosa der berittenen Akademie der Künste und Wissenschaften, Bd. 2, Krefeld 1829, hier insb. Vorspann, Permalink: http://resolver.staatsbibliothek-berlin.de/SBB000063E000000000 (Zugriff vom 22.07.2014).

5 Vgl. zu den Nachforschungen der preußischen Regierung, die die Gesellschaften in Dülken, Linnich, Düren sowie den Kölner Karnevalsverein betrafen: Christina Frohn, »Löblich wird ein tolles Streben, Wenn es kurz ist und mit Sinn«. Karneval in Köln, Düsseldorf und Aachen 1823-1914, Diss., Bonn 1999, 64, http://nbn-resolving.org/urn:nbn:de:hbz:5-02121 (Zugriff vom 25.05.2014). 
den sich unter den leitenden Mitgliedern doch auch Freimaurer, die bereits in französischer Zeit Logen besucht hatten und insofern als Parteigänger des napoleonischen Regimes bzw. liberalen Gedankenguts gelten konnten. ${ }^{6}$

Die seit den 1820er Jahren in den Diplomen und Einladungen der Dülkener Akademie und Mondsuniversität zahlreich auftretende Symbolik, ${ }^{7}$ wie Halbmond, Sonne, Hammer oder musivisches Pflaster, war insofern wohl nicht zufällig dem Geheimbundwesen entlehnt und fand sich auch bei mit ihr korrespondierenden humoristischen Vereinigungen dieser Zeit wieder. ${ }^{8}$ Insbesondere der Mond stand dabei bekanntlich in dem Ruf, das Närrische im Menschen hervorzubringen, und so datierte etwa das oben erwähnte Diplom des Fürsten Joseph zu Salm-Reifferscheidt-Dyck auf den »19. Tag des 4. jungen Lichtes [Neumond, Anm. d. Verf.] des Jahres 5782« - eine Datierung, die durchaus als scherzhafte Umkehrung der in der französischen Freimaurerei üblichen Angabe »an de la vrai lumière« gesehen werden kann. In diesem eigenartigen Bezug auf den Mondkalender liegt im Übrigen eine schlüssige Erklärung für die bis heute so ‘geheimnisumwobene` Narrenzahl »11«, ${ }^{9}$ die sich im gesamten rheinischen Karneval verbreitete: Das Mondjahr

6 Mit dem Schweizer Mediziner Johann Jakob Meyer, der als Präsident der Gesellschaft fungierte, und dem Gold- und Silberbearbeiter Mathias Anton Cornely fanden sich unter den Gründern der Akademie tatsächlich zwei ehemalige Freimaurer in leitenden Positionen, die in der Düsseldorfer Loge St. Joachim bzw. ihrer Nachfolgerin, der Loge Zu den drei Verbündeten, gearbeitet hatten. Letztere stand - wie oben erwähnt - mit den rheinischen Logen des Rit écossais philosophique in enger Verbindung. Siehe hierzu die Mitgliederverzeichnisse der Düsseldorfer Logen Zum Heiligen Joachim bzw. ihrer Nachfolgerin Zu den drei Verbündeten: Sammlung Guntrum, Akten II, Nr. 38, in: LAV NRW, Abt. Rheinland, (ohne Folioangabe im Dokument). Zu Meyer siehe auch Goossens, Die Dülkener Narrenakademie (wie Anm. 2, Kap. VIII), 34f.

7 Vgl. hierzu insb. die Ausführungen bei Dieter Pesch, Die Dülkener Narrenakademie, in: Rheinisch-westfälische Zeitschrift für Volkskunde 16 (1969), 105-122, hier insb. 114-116.

8 Abb. 35. Zu erwähnen sind hier etwa die durch Mitglieder der Dülkener Akademie in Düren gegründete Wurm-Messer-Gilde und die Linnicher Eiertipperei. Trotz der derb wirkenden Namen der letzteren Gesellschaften handelte es sich ebenfalls um Honoratioren-Clubs. Die Kerzen bzw. freimaurerischen "Lichter « unter dem Baldachin in Abb. 7 werden in der Abb. 35 personalisiert. Diese Ersetzung wird nur verständlich, wenn man die freimaurerische Bedeutung der »drei Lichter « beachtet. Die Lichter können hier sinnbildlich für Winkelmaß, Zirkel und Buch, aber auch für den Meister vom Stuhl sowie die beiden Aufseher stehen. Das männliche, »impulsgebende« Symbol des »Stabes« sowie das weibliche, »empfangende« Symbol des Kelches des Rosenkreuzergrades aus Abb. 14 wird auch in der Urkunde der Dülkener Gesellschaft (Abb. 33 und 34) aufgegriffen. Siehe hierzu Lennhoff/Posner/Binder (Hg.), Internationales Freimaurer-Lexikon (wie Anm. 18, Kap. I), 513f. Zu den oben erwähnten Narren-Gesellschaften siehe die Besprechung von Helmut A. Crous in Ders., »Dülken gab den Anstoss«. Gründungen in Düren, Linnich und Aachen, in: Kuriosa der Dülkener Narrenakademie, Mühlenheft 31 (1986), 16-20.

9 Siehe zum Mondkalender der Akademie: Mondkalender der Dülkener Narrenakademie für die Jahre 1820-1899, Dülken, o.D., in: Stadtarchiv Viersen, Fremdarchivalien, Nr. 78. Innerhalb des Kalenders wurden die Daten für Neu- und Vollmondphasen berechnet sowie das Datum der Osterfeierlichkeiten. Siehe zum Ausstehen einer schlüssigen Erklärung für die Narrenzahl »11« den Hinweis bei Frohn, Löblich wird ein tolles Streben (wie Anm. 5, Kap. VIII), 102f.; Matthias von der Bank/Hildegard Brog/Marcus Leifeld, »Freiheit und Gleichheit im Narrenthum«. Das Bild Napoleons und Frankreichs im rheinischen Karneval des 19. Jh.s, in: Kerstin Theis/Jürgen Wilhelm (Hg.), Frankreich am Rhein. Die Spuren der »Franzosenzeit« im Westen Deutschlands, Köln 2009, 95-117, hier 104. 


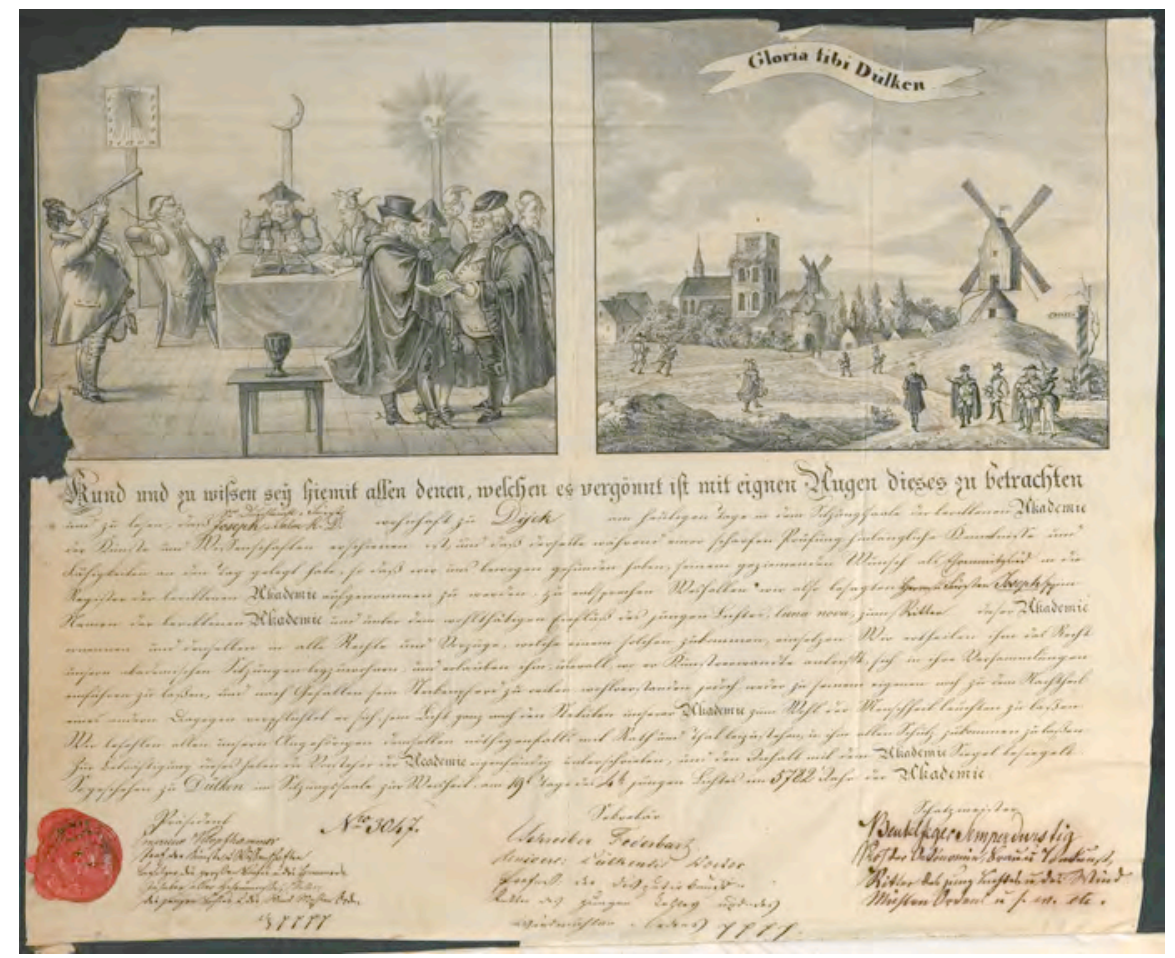

Abbildung 33: Urkunde zur Ernennung Joseph zu Salm-Reifferscheidt-Dycks zum Ritter in der Berittenen Akademie der Künste und Wissenschaften zu Dülken, um 1830 (Bildnachweis: ASD, Blaue Bände, Bd. 594; Bildrecht/Werk: Grafen Wolff-Metternich zur Gracht; Foto: LVR-Archivberatungs- und Fortbildungszentrum).

ist bekanntlich genau 11 Tage kürzer als das Sonnenjahr und so zeigten auch die in den Diplomen der Dülkener Akademie abgebildeten Sonnenuhren mitunter die Zahl 11 « durch einen Schattenkegel an.

Angesichts derartiger Persiflagen ${ }^{10}$ dürfte jedoch leicht verständlich sein, weshalb die Freimaurerei dem Großteil des rheinischen Adels in preußischer Zeit kein

10 Für eine Persiflage sprach sich bereits Nabrings aus. Vgl. Nabrings, Die Dülkener Narrenakademie (wie Anm. 3, Kap. VIII), 64. Dass es bei den Persiflagen des frühen 19. Jh.s auch um die bereits in der französischen Zeit aufgekommene Frage der Öffnung des Geheimraums ging, zeigt eine 1827 erschienene Schrift Carl Petraschs sowie des ehemaligen Illuminaten und Freimaurers in der Kölner Loge Le Secret des trois Rois Johann Wilhelm Brewer über den mittelalterlichen Klever Narrenorden. Die Autoren brachten hierin den adligen Narrenorden und die Dülkener Akademie in eine Reihe mit humoristisch-karnevalesken Gesellschaften wie der bereits in den französischen Freimaurer-Dokumenten erwähnten Mère-folle de Dijon und dem Régiment de la Calotte. Vgl. Carl Petrasch/Johann Wilhelm Brewer, Der Narren=Orden zu Cleve, dessen Entstehen, die Namen der sämmtlichen Stifter desselben, und die Abbildung des von Ihnen getragenen Ehrenzeichens, Köln 1827. Carl Petrasch findet sich auch unter den Ehrenmitgliedern der Dülkener Akademie: Statuten für die berittene Akademie der Künste und Wissenschaften zu Dülken, Dül- 


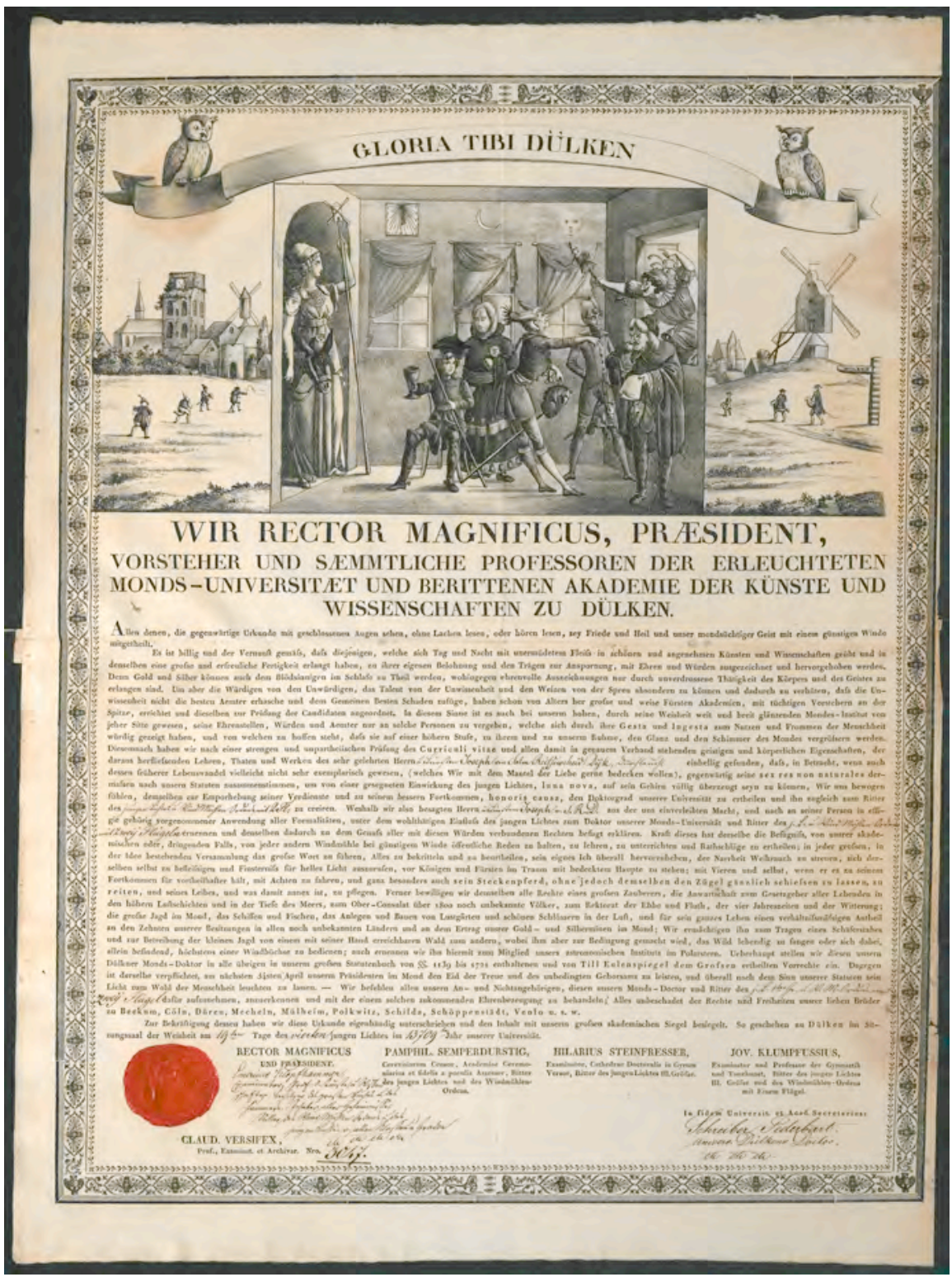

Abbildung 34: Aufnahmeurkunde Joseph zu Salm-Reifferscheidt-Dycks in die Berittene Akademie der Künste- und Wissenschaften zu Dülken, um 1830 (Bildnachweis: ASD, Blaue Bände, Bd. 594; Bildrecht/Werk: Grafen Wolff-Metternich zur Gracht; Foto: LVR-Archivberatungs- und Fortbildungszentrum). 


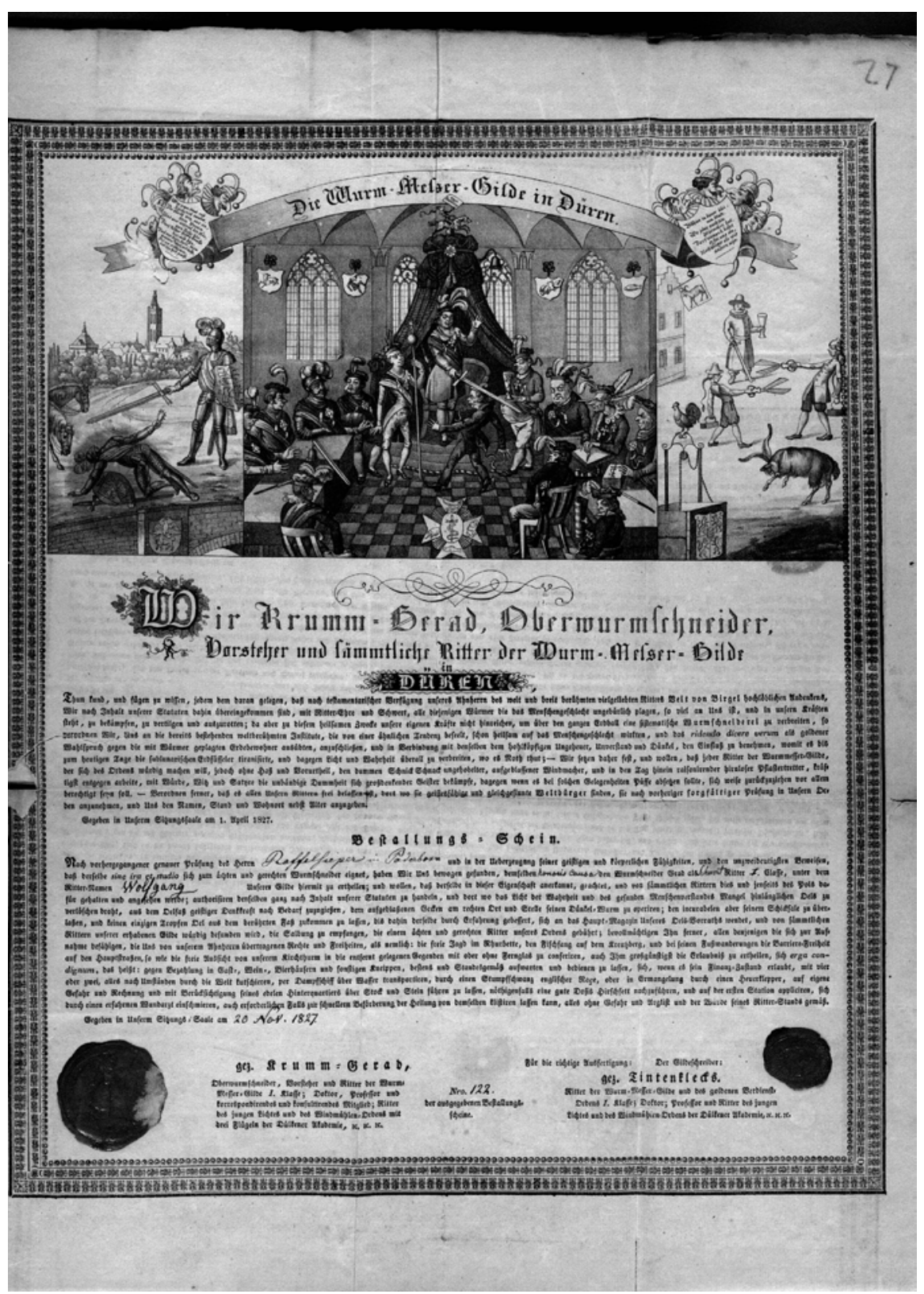

Abbildung 35: Aufnahmeurkunde Peter Johann Raffelsiepers in die Dürener Wurm-MesserGilde, 20.09.1827 (Bildrecht/Werk und Foto: Narrenakademie Dülken). 
Forum mehr bot, das als würdig betrachtet werden konnte, seine Mitglieder zu einem standesgemäßen Verhalten anzuleiten. Da mit der Freimaurerei eine Erziehungsfunktion zusammenhing, dürfte es vor allem die mit derartigen Tendenzen einhergehende Profanierung der freimaurerischen Gebräuche und Geheimnisse in Anschluss an die napoleonische Zeit gewesen sein, die die Freimaurerei aus Sicht des Adels als "Schule der Tugend « überflüssig, wenn nicht gar unmöglich werden ließ. In Zeiten, in denen Kölner Brüder mit den freimaurerischen Geheimnissen von einer verruchten Kneipe zur nächsten tingelten $^{11}$, war schließlich auch die letzte Mystifikation der Grenze des freimaurerischen Arkanraums profaniert. Die Freimaurerei hatte sich in den Augen vieler von einer >Akademie der Tugend $<$ in eine >Akademie der Narren verwandelt.

Das Fundament für diesen Umbruch in die "Zeit des Zweifelns" - um eine in der Studie Stefan-Ludwig Hoffmanns zur preußischen Freimaurerei aufgegriffene Bezeichnung aus dem Jahr $1840 \mathrm{zu}$ verwenden - war spätestens durch den Konvent in Wilhelmsbad angelegt und verstärkte sich seitdem zunehmend, bis die Vorgänge in der Zeit der Karlsbader Beschlüsse ihre Krise erreichen sollten. ${ }^{12}$ Das persönliche Verhältnis des Dycker Schlossherrn zur Freimaurerei deckt sich in dieser politisch schwierigen Zeit mit der allgemeinen Lage des Bundes, die im gesamten preußischen Land - zu welchem das Rheinland nach den Besitzergreifungspatenten König Wilhelms III. aus dem Jahr 1815 auch offiziell zählte - eine mehrjährige Phase der Stagnation hervorrief. Der Umbruch der Mächte brachte jedoch einen schlechten Boden nicht nur für Geheimbünde mit sich, sondern auch für die Mitglieder der im Ancien Régime zum rheinischen Adel zählenden und beim Einmarsch der Franzosen nicht emigrierten Familien. Für sie bedeutete das Ende der französischen Herrschaft den erneuten Kampf um die volle Anerkennung ihrer rechtlichen und gesellschaftlichen Position - so auch für Joseph zu Salm-Reifferscheidt-Dyck. Im Kampf um die Anerkennung seiner Rechte als Adliger unter preußischer Regierung sollte der 1816 gefürstete Joseph zu SalmReifferscheidt-Dyck schließlich - ebenso wie viele seiner rheinischen Standes-

ken 1826, in: Privatbesitz Narrenakademie Dülken, Akte Raffelsieper, 53. Siehe zum Klever Narrenorden und einer Abbildung des Gründungspatents der adligen Mitglieder auch: Rainer Hoymann, Der Narrenorden. Vor 625 Jahren wurde am 12.11.1381 die "geselscap van den gecken« in Kleve gegründet, http://web.archive.org/web/20060110184318/http://www.heimat-kleve.de/geschichte/ narrenorden_16.01.2005/narrenorden.htm (Zugriff vom 19.07.2014).

11 In Ergänzung zu den Auszügen der bereits oben zitierten Quelle heißt es im Brief vom 23.02.1810: "Je dois vous instruire que depuis huit jours la Section Charlemagne a quitté son Local où elle avait déjà fait de grandes dépenses et se trouve dans le moment sans Local pour ses travaux. Elle erre de Cabaret en Cabaret où l'on convoque pour une soirée, les Frères qui sont dans la plus grande incertitude sur le choix d'un local et cependant ils préfèrent cette conduite ridicule a l'avantage de venir travailler tranquillement et en fierté avec nous.« Siehe hierzu Kölner Dreikönigsloge an Grand Orient, Köln, 23. Tag des 12. Monats 5809 (23.02.1810), in: BnF, FM2 535 (MF 4589), fol. 117.

12 Dotzauer erwähnt, dass die Regierungen nach 1815 die Mitgliedschaft von Beamten in Freimaurerlogen skeptisch beäugten. Die preußische Regierung versuchte, nach Dotzauer, auch die Namen der in Logen aktiven Beamten zu erfahren. Vgl. Dotzauer, Freimaurergesellschaften am Rhein (wie Anm. 56, Kap. I), 245. 
genossen - zumindest in Teilen Erfolg haben. ${ }^{13}$ Im Jahr 1826 wurden durch die königliche »Kabinettsordre wegen Wiederherstellung der Adelsrechte in den am linken Rheinufer gelegenen Preußischen Provinzen« der Geburtsadel in den Rheinprovinzen sowie wenige Zeit später das mit diesem einhergehende Recht auf Familienfideikommisse erneut eingerichtet. ${ }^{14}$

Wie sich an dem obigen Beispiel jedoch erahnen lässt, gab der Dycker Fürst seine durchaus liberalen gesellschaftlichen Einstellungen der französischen Zeit bzw. das Festhalten an dem nach wie vor in der preußischen Rheinprovinz geltenden französischen Recht nicht auf, ${ }^{15}$ wenngleich auch er vor dem preußischen König vehement, wenn auch vergeblich auf seine Anerkennung als Standesherr bestand. ${ }^{16}$ Dieses Paradox, das nur durch seine Erfahrungen in der Aristokratenschicht des Premier Empire zu erklären ist, spiegelt sich in der Zeit nach 1815 auch in seinem Kontakt zu recht gegensätzlichen Vereinen und gesellschaftlichen Zusammenschlüssen wider - deren Vergesellschaftungsformen sich zum Teil eben-

13 Siehe hierzu Hans-Werner Langbrandtner, Die Standeserhöhung zum preußischen Fürsten, aus: Netzbiographie: Joseph zu Salm-Reifferscheidt-Dyck (1773-1861), in: historicum-estudies.net, [01.05.2014], http://www.historicum-estudies.net/epublished/netzbiographie/preussische-zeit/ standeserhoehung (Zugriff vom 01.05.2014); Ders., Der rheinische Adel im Provinziallandtag der preußischen Rheinprovinz, aus: Netzbiographie: Joseph zu Salm-Reifferscheidt-Dyck (17731861), in: historicum-estudies.net, [01.05.2014], http://www.historicum-estudies.net/epublished/ netzbiographie/preussische-zeit/provinziallandtag (Zugriff vom 01.05.2014); Antwort auf Gesuch um Erhebung in den Fürstenstand, 15. Januar 1815, Transkription Elisabeth Schläwe, aus: Netzbiographie: Joseph zu Salm-Reifferscheidt-Dyck (1773-1861), in: historicum-estudies.net, [01.05.2014], http://www.historicum-estudies.net/epublished/netzbiographie/transkriptionen/gesuch-umstandeserhebung-1815 (Zugriff vom 01.05.2014); Abschrift des Fürstendiploms, 28. Mai 1816, Transkription Elisabeth Schläwe, aus: Netzbiographie: Joseph zu Salm-Reifferscheidt-Dyck (1773-1861), in: historicum-estudies.net, [01.05.2014], http://www.historicum-estudies.net/epublished/netzbio graphie/transkriptionen/fuerstendiplom-1816 (Zugriff vom 01.05.2014).

14 Vgl. Carl Heiner Beusch, Adlige Standespolitik im Vormärz: Johann Wilhelm Graf von MirbachHarff (1784-1849) (Historia profana et ecclesiastica, 3), Diss., Münster/Hamburg/London 2001, 325-327.

15 Siehe hierzu auch Hans-Werner Langbrandtner, Politische Rolle im Provinziallandtag der preußischen Rheinprovinz, aus: Netzbiographie: Joseph zu Salm-Reifferscheidt-Dyck (1773-1861), in: his toricum-estudies.net, [05.06.2014], http://www.historicum-estudies.net/epublished/netzbiographie/ preussische-zeit/politische-rolle (Zugriff vom 21.11.2014); Promemoria zur Verfassungsfrage, 28. Januar 1831 [Entwurf], Transkription Elisabeth Schläwe, aus: Netzbiographie: Joseph zu Salm-Reifferscheidt-Dyck (1773-1861), in: historicum-estudies.net, [01.05.2014], http://www.historicum-estudies. net/epublished/netzbiographie/transkriptionen/promemoria-entwurf-1831 (Zugriff vom 01.05.2014).

16 Im preußischen Landtag setzte er sich etwa des Öfteren für liberale Reformen wie eine repräsentative Verfassung, Pressefreiheit oder Judenemanzipation ein - wenngleich ihm dies bei seinen Standesgenossen, insb. bei dem Freiherrn und 1840 in den preußischen Grafenstand erhobenen Johann Wilhelm von Mirbach-Harff (1784-1849), einen schlechten Ruf einbrachte und ihn »des Liberalismus anrüchig« machte. Vgl. hierzu Bremer, Die reichsunmittelbare Herrschaft Dyck (wie Anm. 2, Kap. I), 234-245 sowie Sachse, Als in Dyck Kakteen blühten (wie Anm. 2, Kap. I), 9194. Sachse führt an, dass König Friedrich Wilhelm III. ihm die Fürstenwürde aus Gnade verlieh. Seinen Anspruch auf eine Anerkennung als Standesherr konnte Joseph zu Salm-ReifferscheidtDyck demnach nicht erlangen. Siehe auch jüngst Hans-Werner Langbrandtner, Bemühungen um Anerkennung als preußischer Standesherr, aus: Netzbiographie: Joseph zu Salm-ReifferscheidtDyck (1773-1861), in: historicum-estudies.net, [01.05.2014], http://www.historicum-estudies.net/ epublished/netzbiographie/preussische-zeit/standesherrschaft (Zugriff vom 01.05.2014). 
falls deutlich an freimaurerische Gepflogenheiten anlehnten - wie etwa der im Umfeld des Wiener Kongresses entstandenen exklusiv adligen Gesellschaft Die Kette ${ }^{17}$ oder seinem Umgang mit liberal gesinnten Nichtadligen in Casinogesellschaften. ${ }^{18}$

Im Gegensatz zu den liberalen Tendenzen setzte die Vergesellschaftung des Gros des rheinischen Adels im Vormärz auf eine deutliche Abgrenzung zum 'gemeinen Volkı. Dies wird etwa im Fall der im Jahr 1837 durch Johann Wilhelm von Mirbach-Harff im Verbund mit anderen Vertretern rheinischer Adelsfamilien gegründeten Genossenschaft des rheinischen ritterbürtigen Adels sowie der nur wenige Jahre später eingerichteten Rheinischen Ritterakademie auf Schloss Bedburg ersichtlich. ${ }^{19}$ Mirbach-Harff sah etwa immer noch eine Ahnenprobe als unersetzliches Kriterium bei Nobilitierungen durch den preußischen König an, da er zutiefst von der Konstanz der "gottgewollten Ungleichheit « in der Natur überzeugt war und auf den altbekannten Topos des Tugend-Adels rekurrierte. ${ }^{20}$ Wie Heinz Reif zeigen konnte, trat in der Zeit des Vormärz gerade im preußischen Rheinland und in Westfalen das Reformkonzept des "katholischen Edelmannes" in den Vordergrund. ${ }^{21}$ Dessen esoterische Züge - im Sinne der obigen Ergebnisse für das Ancien Régime - sind nur schwer zu übersehen und waren auch als deutliche Abgrenzung gegenüber den Adelskonzepten des Freimaurers vom Stein bzw. dem Protestantismus zu werten. ${ }^{22}$ Aus diesen Projekten wird jedoch vor allem ersichtlich, dass ein Teil des rheinischen Adels auch weiterhin von seiner grund-

17 Siehe hierzu Horst Conrad, Die Kette. Eine Standesvereinigung des Adels auf dem Wiener Kongreß (Vereinigte Westfälische Adelsarchive Sonderveröffentlichung, 3), Münster 1979; Reif, Adelserneuerung und Adelsreform (wie Anm. 13, Kap. I), 203-230, hier insb. 207f.; Conrad sieht bei der Gesellschaft Die Kette durchaus starke Anleihen bei der Freimaurerei. Die Kette nahm den Fürsten, vermutlich aufgrund seiner engen Bindung an Frankreich, jedoch nicht auf. Siehe Dipper, Der rheinische Adel (wie Anm. 11, Kap. I), hier 100f. Das Festhalten an adligen Traditionen kann durchaus auch in Salm-Dycks Verhältnis zur Jagd gesehen werden. Vgl. Martin Otto Braun, Zwischen Repräsentation und Verantwortung — die Jagd, aus: Netzbiographie: Joseph zu Salm-Reifferscheidt-Dyck (1773-1861), in: historicum-estudies.net, [05.06.2014], http://www.his toricum-estudies.net/epublished/netzbiographie/preussische-zeit/jagdleidenschaft (Zugriff vom 21.11.2014).

18 Vgl. hierzu die Aufnahmeurkunde in die Casino-Gesellschaft in Berlin für das Jahr 1816: Admission pour Monsigneur en qualite de Membre du Casino à Berlin 1816, de Membre honoreuri [sic!] de l'athenée 1807, Berlin, 1816, in: ASD, Dyck4 - Kart. 35/7.

19 Siehe zur Genossenschaft des rheinischen ritterbürtigen Adels: Anton Freiherr von Salis-Soglio, Ritterrat (Hg.), Die Genossenschaft des rheinischen ritterbürtigen Adels 1837-1937. Festschrift zur Erinnerung an den hundertsten Jahrestag ihrer Gründung, Schloß Gemünden (Hunsrück) 1937.

20 Vgl. hierzu wie zu dem angeführten Zitat die ausführliche Besprechung bei Beusch, Adlige Standespolitik (wie Anm. 14, Kap. VIII), 112f. Nach den bei Beusch zitierten Ausführungen bestand Mirbach-Harff interessanterweise darauf, dass erst die vierte Generation der Nachfahren Neunobilitierter zum Preußischen Landtag zugelassen werden könne. Dies erinnert durchaus an die oben angeführten Theorien eines Loyseau im 17. Jahrhundert.

21 Zum Reformkonzept des »katholischen Edelmannes« und zu seiner Bedeutung für den rheinischen und westfälischen Adel vgl. die Ausführungen bei: Reif, Adelserneuerung und Adelsreform (wie Anm. 13, Kap. I), hier 209-211.

22 Die Adelsvorstellungen Mirbach-Harffs waren bereits um das Jahr 1815 mit den gemäßigten Positionen eines Freiherrn vom Stein kollidiert. Siehe hierzu Beusch, Adlige Standespolitik (wie Anm. 13, Kap. VIII), 105-120. 
sätzlichen Vorrangstellung aufgrund 'geheimnisvoller innerer sittlicher und tugendhafter Vorzüge überzeugt war. ${ }^{23}$ Hinter einem derartigen Weltbild wirkte der Wille, das in der französischen Zeit des Rheinlands profanierte >Geheimnis der Adligkeit $\prec$ zu alten Würden zurückzuführen. Die »Erinnerungsgruppe ${ }^{24}$ des rheinischen »Uradels«, die sich selbst als erste Stütze des Landes betrachtete, glich in der Zeit des Vormärz gerade durch die relative Konstanz ihrer Abgrenzungsmechanismen und in der anhaltenden Pflege eines überholt anmutenden Geschichts-, aber auch Selbstbildes paradoxerweise mehr und mehr den als Verschwörern gegen das Allgemeinwohl gebrandmarkten Geheimbünden. ${ }^{25}$

In den Naturwissenschaften war mit den Studien eines Jean-Baptiste de Lamarck (1744-1829) und spätestens mit »On the Origins of Species« (1858) eines Charles Darwin (1809-1882) eine gottgefällige Lebensführung als bedeutendster Garant für die Dominanz bzw. Höherentwicklung der menschlichen »Rasse« mehr denn je in Zweifel gezogen worden. Die in der wissenschaftlichen Öffentlichkeit dominierende Frage war nun die nach den sharten materiellen bzw. modern wissenschaftlich-verifizierbaren Gesetzen der Selektion der >Besten einer Art - den Glauben an ihre stetige Perfektionierung nach wie vor eingeschlossen. Der Naturforscher Joseph zu Salm-Reifferscheidt-Dyck beteiligte sich folgerichtig nicht mehr an den Unternehmungen seiner auf der adligen »Blutsideologie« beharrenden Standesgenossen, sondern widmete sich bis zu seinem Lebensende verstärkt botanischen Studien und unterhielt ein dichtes Korrespondenznetzwerk mit gelehrten Gesellschaften und Naturwissenschaftlern wie etwa dem Forschungsreisenden Karl Philipp Friedrich von Martius (1794-1868) ${ }^{26}$

23 Bereits zum Ende des Krisenjahres 1814 hatte sich Johann Wilhelm von Mirbach-Harff in seinem Tagebuch davon überzeugt gezeigt, dass eine »alle Hindernisse überwältigende Kraft im Volk" durch eine "geringe Anzahl von Edlen« verkündet werden könne. Diese machten demnach den »Kern des Volkes aus « und sollten sich »durch alle Provinzen [...] kennen, und in gewisser Verbindung stehen. «Ein solcher Edelmann konnte demnach »durch die Zauberkraft seines Wesens jenen schaffenden Geist auf andre« übertragen. »Zur Bewunderung und zum Erstaunen derjenigen, die alles nur in den dicken Formen und in den groben Werkzeugen sahen und den geheimen innern Weg der Natur nicht kennen, [...].« Johann Wilhelm, Tagebuch, o.O., Eintrag vom 13.11.1814, in: Gräflich Mirbachsches Archiv, 182/4.

24 Matzerath, Adelsprobe an der Moderne (wie Anm. 76, Kap. I), 13-25.

25 Ein in dieser Hinsicht vielsagendes Bild der sogenannten »rheinischen Autonomen« zeichnete der Schriftsteller und Liberale Karl Gutzkow (1811-1878) in einem um 1840 verfassten Brief. Hierin besprach er unter anderem die rigiden Zulassungspraktiken und inneren Sanktionsformen dieser »stillschweigend geschlossenen Corporation«, die bei der Aufnahme neuer Mitglieder auf einer 16er-Ahnenprobe bestand. Karl Gutzkow, Briefe aus Paris, Erster Theil, Leipzig 1842, 26f., Permalink: http://nbn-resolving.org/urn:nbn:de:bvb:12-bsb10422172-1 (Zugriff vom 25.05.2014).

26 Siehe hierzu etwa die Korrespondenz mit Karl Friedrich Philipp von Martius aus den Jahren 18271856. Martius bat hierin den Fürsten u.a., eine Einschätzung seiner Studien zur brasilianischen Pflanzenwelt zu geben. Siehe Korrespondenz mit Martius, Karl Friedrich (1794-1856, Konservator Botanischer Garten München, Hofrat), in: ASD, Dyck4 - Kart. 7/119. Vgl. zu den anthropologischen Forschungen Martius' auch Frederik Schulze, Konzepte von Physiognomie und Rasse bei Martius, in: Contingêntia 2 (2008), Permalink: http://nbn-resolving.org/urn:nbn:de:hebis:30:3-250583 (Zugriff vom 17.12.2012). Zu dem ausgebreiteten Korrespondenzwesen Salm-Dycks mit wissenschaftlichen Akademien vgl. Martin Otto Braun, Berlin, Paris, St. Louis. Eine Vermessung seines wissenschaft- 


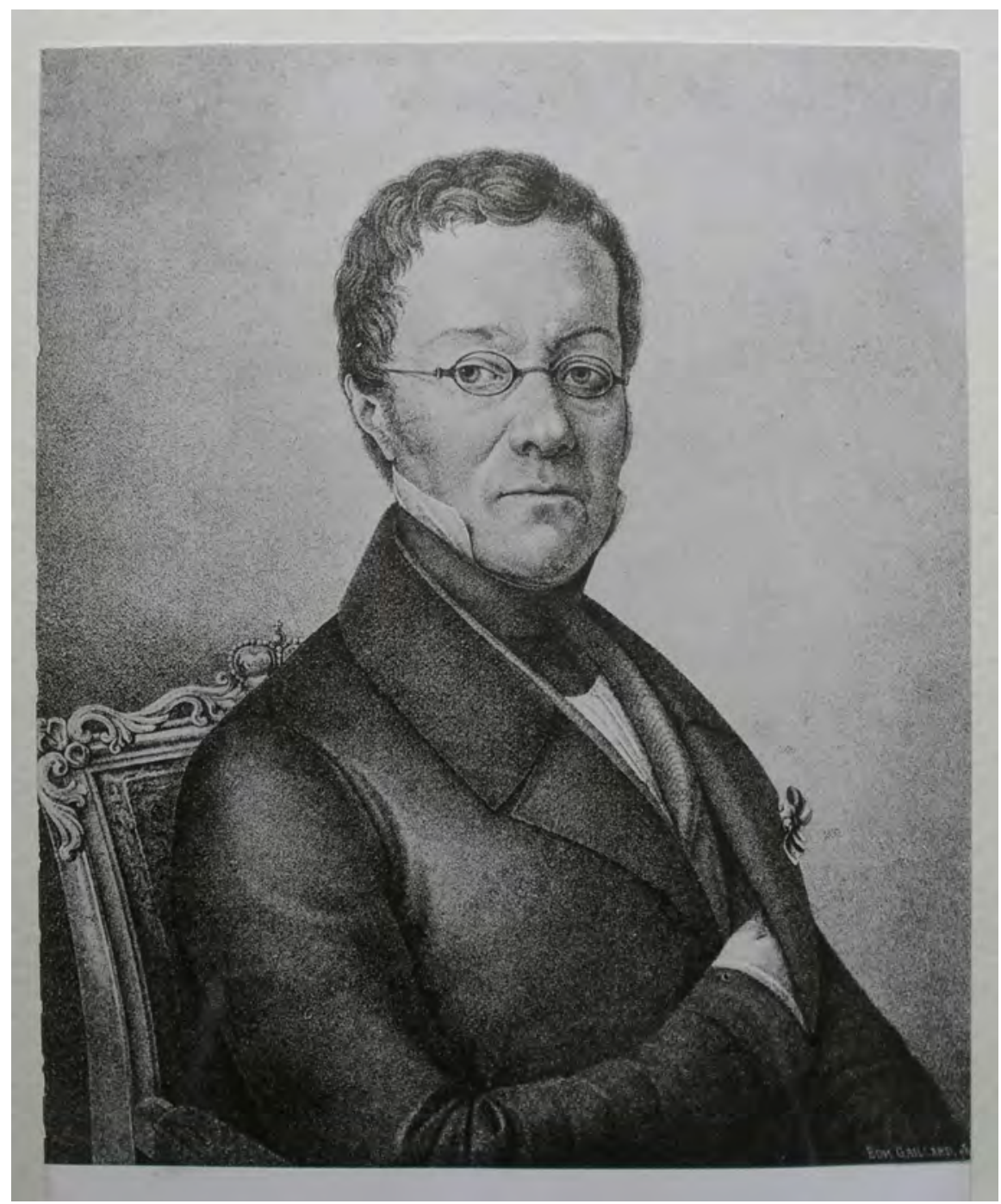

Abbildung 36: W. Eskuchen, Joseph zu Salm-Reifferscheidt-Dyck als Gelehrter, Stich, nach 1820 (Bildnachweis: ASD; Bildrecht/Werk: Grafen Wolff-Metternich zur Gracht; Foto: M.O. Braun). 
oder dem bekannten Botaniker und Prärassisten Alphonse Pyrame de Candolle $(1806-1893){ }^{27}$

Denn wie Letzterer zum Ende seiner im Jahr 1855 veröffentlichten Abhandlung mit dem Titel »Géographie botanique raisonnée ${ }^{28}$ feststellte, war die botanische Forschung nur der erste Schritt der Wissenschaft bei der Suche nach dem Fundamentalgesetz der Schöpfung. ${ }^{29}$ Die Beantwortung der Frage nach dem bisherigen Verlauf und dem weiteren Fortgang der Evolution der organisierten Lebewesen galt ihm in diesem Zuge als Endzweck, gleichzeitig aber auch als nahezu unmögliche Aufgabe. ${ }^{30}$ In einem Brief an Alphonse de Candolle aus dem Jahr 1855 zeigte sich der Dycker Fürst diesbezüglich wesentlich optimistischer: Nachdem man einen ersten und übernatürlichen Ursprung der Schöpfung unzweifelhaft nachgewiesen habe, gelte es umso dringlicher, in die Grenzen der Naturwissenschaften zurückzukehren, denn nichts bliebe in der Welt der menschlichen Intelligenz verborgen, und so lagen auch die Erkenntnis der Ursprünge der "race humain « und die Gesetze ihrer Entwicklung wieder im Bereich des Möglichen. ${ }^{31}$

lichen Netzwerks, aus: Netzbiographie: Joseph zu Salm-Reifferscheidt-Dyck (1773-1861), in: histo ricum-estudies.net, [05.06.2014], http://www.historicum-estudies.net/epublished/netzbiographie/ franzoesische-zeit/wissenschaftliche-akademien (Zugriff vom 21.11.2014). Ein Porträt Martius' (Lithographie von E. Porrens, 1850) findet sich unter: commons.wikimedia.org/wiki/File:Carl_ Friedrich_Philipp_von_Martius.jpg (Zugriff vom 02.08.2014).

27 Vgl. zu Alphonse de Candolle: Semjon R. Mikulinskij/Lyudmila Artemyevna Markova/Boris Anatol'evič Starostin, Alphonse de Candolle (Biographien bedeutender Biologen, 3), Jena 1980; Mosse, Die Geschichte des Rassismus (wie Anm. 62, Kap. II), 82. Zum engen Kontakt Salm-Dycks zum Vater, Augustin Pyrame de Candolle, der auch zu den Besuchern des Salons der Constance zählte, sowie seinem Einfluss auf die botanischen Studien des Dycker Schlossherrn vgl. Sachse, Als in Dyck Kakteen blühten (wie Anm. 2, Kap. I), 179f. Eine Aufnahme Alphonse de Candolles (Fotografie, unbekannt, 1866) findet sich unter: commons.wikimedia.org/wiki/File:Pyrame_de_ Candolle,_Alphonse_Louis,_BNF_Gallica.jpg (Zugriff vom 02.08.2014).

28 Alphonse Pyrame de Candolle, Géographie botanique raisonnée ou exposition des faits principaux et des lois concernant la distribution géographique des plantes de l'époque actuelle, 2 Bde., Paris/ Genève 1855, Permalink: http://gallica.bnf.fr/ark:/12148/bpt6k98177m bzw. http://gallica.bnf.fr/ ark:/12148/bpt6k98178z (Zugriff vom 24.05.2014).

29 Ders., Géographie botanique raisonnée (wie Anm. 28, Kap. VII), Bd. 2, 1336-1338. Hier heißt es: »Il est impossible, en effet, de ne pas sentir une influence mystérieuse, inexplicable, celle de la distribution première des classes, familles, genres, espèces, races, en un mot, des formes plus ou moins analogues, au moment de leur apparition. [...] La marche régulière de la science devrait être: $1^{\circ}$ de constater au moyen de la distribution géographique des groupes et de l'influence des conditions extérieures, ce qui s'explique par les circonstances actuelles; $2^{\circ}$ de chercher dans les autres phénomênes ce qui peut s'expliquer par des causes secondaires dans chaque partie du monde et à chaque époque; $3^{\circ}$ de déduire de là ce qui constitue la loi principale de sucession et de distribution géographique des êtres organisés. Je me suis efforcé dans cet ouvrage d'étudier le premier point, en ce qui concerne les végétaux. Le second dépend du progrès graduel de la géologie et de la paléontologie. Le troisième est le dernier mot de la science, qui ne sera peut-être jamais prononcé, à cause de l'insuffisance de nos moyens d'observation et de l'arrivée tardive de l'homme sur le théâtre des phénomènes qu'il voudrait comprendre et expliquer."

30 Vgl. Ders., Géographie botanique raisonnée (wie Anm. 28, Kap. VII), Bd. 2, 1336-1338.

31 Joseph Salm-Reifferscheidt-Dyck an de Candolle, o.O., 28.10.1855, in: ASD, Dyck4 - Kart. 2/16, fol. 3v-4r. Hier heißt es: »Je partage toutes vos opinions sur la création des êtres organisés, et sur leur origine multiple: leur naissance successive me semble pareillement demontrée, et l'on pourrait 
Diese im Jahr 1855 geäußerte kühne Überzeugung des Fürsten von der völligen Erkenntnisfähigkeit des Menschen in Bezug auf sämtliche Gesetze der Schöpfung und eines Vordringens bis an die letzten Grenzen der Naturwissenschaften erinnert in ihrem absoluten Anspruch noch an die Gedankenwelt des Rit écossais philosophique in der napoleonischen Zeit und sollte auch auf Alphonse de Candolle abfärben. ${ }^{32}$ Ein Goldenes Zeitalter und die Perfektionierung der Menschheit schienen in diesem ebenfalls deutlich esoterische Züge tragenden Glauben an die >Erlöserrolle` der modernen Naturwissenschaften nach wie vor möglich.

Die Freimaurerei passte sich diesem Wandel ebenfalls an und erlebte - auch unter dem Eindruck der 1840 erfolgten Einweihung des preußischen Kronprinzen Wilhelm in die Freimaurerei und seines darauffolgenden Engagements an der Spitze der preußischen Freimaurerei ${ }^{33}$ - eine erneute Konjunktur. Sie befeuerte im Laufe des 19. Jahrhunderts die insofern nicht weniger esoterische Selbstsicht der Eliten bürgerlich dominierter Nationen, die erneut auf ihre Auserwähltheit hoffen durften. Die Frage nach dem Ursprung und der perfekten Ordnung menschlicher Gemeinwesen blieb parallel zu den geschichts- und naturwissenschaftlichen Entwicklungen auch in den sich im Verlaufe des 19. Jahrhunderts stärker national als kosmopolitisch gebärdenden Freimaurerlogen aktuell, die nun - gemeinsam mit ähnlichen Tendenzen in der Erforschung der Sprachen - die Ursprünge der menschlichen Zivilisation und damit der »Königlichen Kunst« im indischen Kulturraum suchten. ${ }^{34}$

se demander seulement, s'il est necessaire d'admettre chaque fois l'intervention directe du créateur, ou si la sagesse regler d'avance un enchainement de causes et d'effets qui devait amener la naissance successive dêtres d'une organisation de plus en plus parfaite? Nous arriverions ainsi jusquà l'apparition de l'homme sur notre planète; ce couronnement de l'œuvre de la création, et je ne pense pas que ce soit pousser trop loin d'orgueil de notre race que de la croire sortie immédiatement de la main du créateur. - Mais après avoir fait ainsi la part incontestable d'une cause première et extra-naturelle, il faut se hâter de rentrer dans les limites des sciences naturelles: Rien ici ne dépasse celles de notre intelligence, et en remontent logiquement, comme vous le faites, du connu à l'inconnu, les problèmes en apparance les plus insolubles deviennent abordable. Votre idée la plus lumineuse est celle de faire remonter les formes actuelles des êtres organisés à une époque anterieure aux dernières révolutions géologiques, et même à l'apparition de la race humaine."

32 Vgl. zu de Candolle: Schütz, Rassenideologien (wie Anm. 59, Kap. II), 51. De Candolle wollte letztendlich unter dem Eindruck der Schriften eines Charles Darwin nochmals die gesellschaftliche Vorrangstellung des Adels bzw. bestimmter Nationen mit Hilfe naturwissenschaftlicher Verfahren begründen. Vgl. zu dieser Schrift auch die ausführlichen Darstellungen bei Mikulinskij/Markova/ Starostin, Alphonse de Candolle (wie Anm. 27, Kap. VIII), 122-183.

33 Siehe zur Aufnahme des Prinzen Wilhelm am 22.02.1840 in sämtliche preußischen Lehrarten sowie ihrer Folgewirkung: Lennhoff/Posner/Binder (Hg.), Internationales Freimaurer-Lexikon (wie Anm. 18, Kap. I), 399; Hoffmann, Die Politik der Geselligkeit (wie Anm. 24, Kap. I), $54 f$.

34 Vgl. hierzu etwa Rede über die Entstehung und die Entwicklung der Maurerei im Allgemeinen, in Belgien u. Verviers insbesondere, Verviers, 16. Tag des 5. Monats 5837 (16.07.1837), in: GStA PK, FM 5.2.A2, Nr. 103, fol. 1-12. Hier heißt es: „C'est dans l'Inde que l'histoire place le berceau de notre ordre; cette tradition nous parait très vraisemblable parceque le pays a été incontestablement habité avant tous les autres et par une conséquence forcée c'est là que les causes qui ont rendu l'institution nécessaire se sont d'abord fait sentir. Les hommes qui dans l'Inde établirent la première association furent appelés Brahmes ou Brachmanes. Bientôt ils devinrent puissans et ils formèrent dans l'Inde la caste sacerdotale: les Brahmes ne reconnaissaient qu'un seul Dieu, tout puissant 
Es ist jedoch unwahrscheinlich, dass Fürst Joseph zu Salm-Reifferscheidt-Dyck in seinen letzten Lebensjahren nochmals eine Loge betrat. ${ }^{35}$ Zwar finden sich im Dycker Archiv weitere Zeugnisse für den Kontakt Joseph zu Salm-ReifferscheidtDycks zur Freimaurerei, jedoch keine Indizien für ein direktes Wirken in den

infini; ils admettaient l'immortalité de l'âme et après la mort la récompense ou le châtiment du bien et du mal que l'on avait fait pendant la vie. Ils établirent des épreuves sévères pour éloigner la masse des aspirans. Malheureusement un usage funeste corrompit bientôt l'institution et la fit dégénérer en un instrument de tyrannie. Les fils des adeptes furent admis dans le corps des prêtres avec de faibles épreuves, on en vint bientôt jusqu'à substituer totalement les droits du sang à ceux du mérite. L'ordre des Brahmes ne forma plus qu'une caste héréditaire tenant par suite a ses privilêges dans son intérêt privé et occupée uniquement du soin de se défendre contre une destruction inévitable qui ont été le résultat de la propagation des lumières en maintenant les peuples dans l'ignorance. Le G $\therefore$ A $\therefore$ de l'U $\therefore$ voulut que l'Égypte hérita de l'institution qui s'était alterée dans l'Inde.« Rede über die Entstehung und die Entwicklung der Maurerei im Allgemeinen, in Belgien u. Verviers insbesondere, Verviers, 16. Tag des 5. Monats 5837 (16.07.1837), in: GStA PK, FM 5.2.A2, Nr. 103, fol. 4r. Trotz einer nicht verwunderlichen Aussprache des belgischen Freimaurers gegen Tyrannei und »Blutsideologie« sticht doch das Festhalten an einer durch strenge Prüfungen gewährten Exklusivität des Bundes ins Auge. So sah der Redner trotz einer offenbar grundsätzlich gewollten kosmopolitischen Ausbreitung der Freimaurerei zum Zwecke des Fortschritts der Menschheit den Bund zuallererst als eine nationale Einrichtung: "La Séparation absolue qui existe d'ordinaire entre les savans, les gens de la haute classe et la bourgoisie est le plus grand obstacle aux progrès intellectuels et la civilisation d'une nation. La Franc-Mac. l'a senti elle a reconnu que le développement de l'Ésprit humain exigeait la réunion des diverses facultés de l'homme, l'emploi de toutes les forces que trop souvent dans la vie profane on sépare ou individualise. Aussi elle a sû dans ses réunions opérer une fusion et rapprocher de l'enthousiasme de l'artiste, l'érudition du savant, le coup d'œil si prompt et la décision si sûre de l'homme actif; de ce rapprochement est résulté cet échange si facile, si rapide des impressions intellectuelles dont les conséquences sont immenses pour la propagation des lumières. C'est par là que se sont infiltrés dans toutes les classes de la société les principes de cette philosophie sublime, qui pénétrant l'enveloppe du monde sensible [...] «. Rede über die Entstehung und die Entwicklung der Maurerei im Allgemeinen, in Belgien u. Verviers insbesondere, Verviers, 16. Tag des 5. Monats 5837 (16.07.1837), in: GStA PK, FM 5.2.A2, Nr. 103, fol. 11v-12r. Aufschlussreich in Bezug auf das Verhältnis der englischen Freimaurerei zur Mitte des 19. Jh.s zum indischen Kulturraum: Jessica Harland-Jacobs, All in the family. Freemasonry and the British Empire in the Mid-Nineteenth Century, in: The journal of British studies 42 (2003), 448-482. Die Autorin bestreitet zwar die Wichtigkeit von »blood ties«, erläutert aber den trotz der freimaurerischen Familienmetaphorik vorhandenen, durchaus durch "rassische» Vorstellungen bedingten Dünkel der englischen Freimaurer gegenüber ihren indischen »Brüdern«. Letzteren war aus Sicht der englischen Freimaurer dieser Zeit durch das Mittel der Freimaurerei dabei zu helfen, kulturelle bzw. zivilisatorische Fortschritte zu erzielen. Harland-Jacobs hält fest, dass »the admission of indigenous candidates never became commonplace." Sie erwähnt ferner: "[...] the United Grand Lodge [...] conceptualized the difference between Indians and Britons in terms of racial categories. « Siehe hierzu Dies., All in the family, hier insb. 467-482. Zur Installierung der Loge Les Philadelphes in Verviers im Jahr 1811 durch Brüder der Aachener Concorde siehe Pauls, Annalen der Aachener Freimaurerei (wie Anm. 219, Kap. VII), 80f. Siehe ferner zum angespannten Verhältnis der deutschen Freimaurerei des 19. Jh.s zur Freimaurerei Frankreichs: Hoffmann, Die Politik der Geselligkeit (wie Anm. 24, Kap. I), 282-345; Reinalter, Die Freimaurer (wie Anm. 18, Kap. I), 25-27. Zur Installierung der Loge Les Philadelphes in Verviers im Jahr 1811 durch Brüder der Aachener Concorde siehe Pauls, Annalen der Aachener Freimaurerei (wie Anm. 238, Kap. VII), 80f.

35 Vgl. Sachse, Als in Dyck Kakteen blühten (wie Anm. 2, Kap. I) 145; Karl Emsbach, Tod in Nizza. Zum Ableben von Fürst und Altgraf Joseph zu Salm-Reifferscheidt-Dyck, in: Jahrbuch für den Rhein-Kreis Neuss 2013 (2012), 74-81. 
rheinischen Logen. ${ }^{36}$ Ein Eintrag in einem Protokollbuch aus den Beständen der Aachener Loge Zur Beständigkeit und Eintracht über die Präsenz des "Ehrenmeisters und Ehrengroßmeisters « Joseph zu Salm-Reifferscheidt-Dyck bei einer Logenarbeit im Lehrlingsgrad am 23.03.1822 lässt darauf schließen, dass seine Besuche nach der napoleonischen Zeit zur Seltenheit geworden waren. ${ }^{37}$ Er wandte sich vielmehr noch im Alter von 85 Jahren dem katholischen Glauben wieder $\mathrm{zu}^{38}$ und trieb bis in seine letzten Tage hinein seine botanischen Studien voran. ${ }^{39}$ Trotz dieser Distanz zur Freimaurerei wurde der Name Joseph zu Salm-ReifferscheidtDycks in den rheinischen Logen nicht vergessen. Die Aachener Loge Zur Beständigkeit und Eintracht verzeichnete in ihrem Logenverzeichnis von 1861/62 das Ausscheiden des Bruders Salm-Dyck durch den Eingang in den »ewigen Osten «. ${ }^{40}$

36 Die Logen des Rheinlands klagten ihrerseits über mangelnde Besucherzahlen. Dies legt etwa eine Veröffentlichung der Aachener Loge Zur Beständigkeit und Eintracht vom 30. Tag des dritten Monats 5820 nahe, in der aufgrund mangelnder Teilnahme der Brüder an den Logenarbeiten eine Generalversammlung einberufen wurde. Siehe Schreiben Zur Beständigkeit und Eintracht, Aachen, 30. Tag des dritten Monats 5820 (30.05.1820), in: GStA PK, FM 5.2.A2, Nr. 101, o.S. Die Zeugnisse des Kontakts Salm-Dycks zur Freimaurerei beziehen sich auf verschiedene Nachrichten von Logen. Im Mitgliederverzeichnis der Kölner Loge Zum Vaterländischen Verein aus dem Jahr 1817 wurde er nach wie vor in der Position eines Ehrenmitglieds geführt. Vgl. hierzu das Mitgliederverzeichnis der Kölner Loge Zum Vaterländischen Verein aus dem Jahr 1817: Mitgliederverzeichnis der Kölner Loge Zum Vaterländischen Verein, Köln, 1. Tag des 8. Monats 5817 (01.10.1817), in: ASD, Blaue Bände, Bd. 590, fol. 2r-3v. Es liegen jedoch auch Einladungen zu Johannisfesten oder die Information über karitative Aktivitäten der Kölner Loge vor. Siehe hierzu etwa ASD, Blaue Bände, Bd. 590, fol. 61r-77v. Es finden sich Einladungen von Logen an den Fürsten bis in das Jahr 1846. Siehe Brief der Mönchengladbacher Freimaurerloge Vorwärts, Mönchengladbach, 18.08.5846 (18.08.1846), in: ASD, Dyck4 - Kart. 30/34; Einladung der Düsseldorfer Freimaurerloge Zu den drei Verbündeten zu einem Fest in Schloss Benrath, Düsseldorf, 10.07.1838, in: ASD, Dyck4 - Kart. 30/33.

37 Der Eintrag ist zudem das letzte Zeugnis eines Logenbesuches Joseph Salm-Reifferscheidt-Dycks. Er lautet: »Der E $\therefore$ Großmeister von Salm ergriff das Wort, sprach seinen Danck für den Beweiß der Liebe nach einer so langen Abwesenheit aus und wie sehr es ihn freue noch in den Herzen der ihm theuren BB. zu leben. « Protokollbuch der Aachener Loge Zur Beständigkeit und Eintracht, Aachen, Eintrag vom 23.03.1822, in: GStA PK, FM 5.2.A2, Nr. 85, 122r.

38 Vgl. hierzu Sachse, Als in Dyck Kakteen blühten (wie Anm. 2, Kap. I), 148f.; Bernd Klesmann, Religiosität, aus: Netzbiographie: Joseph zu Salm-Reifferscheidt-Dyck (1773-1861), in: histori cum-estudies.net, [01.05.2014], http://www.historicum-estudies.net/epublished/netzbiographie/ ancien-regime/religiositaet (Zugriff vom 01.05.2014). Bereits unter dem Eindruck der Kölner Wirren hatte sich das Ehepaar Salm-Reifferscheidt-Dyck im Jahr 1841 kirchlich trauen lassen.

39 Vgl. den Nachruf auf Salm-Dyck in Wochenschrift des Vereines zur Beförderung des Gartenbaues in den Königlich Preussischen Staaten für Gärtnerei und Pflanzenkunde 19 (1861), hier 145f., http:// www.biodiversitylibrary.org/item/24591\#page/7/mode/lup (Zugriff vom 25.05.2014).

40 Siehe hierzu die im Geheimen Staatsarchiv Preußischer Kulturbesitz verwahrten Logenmatrikel, die bis in das Jahr 1862 ausgewertet wurden: Logenmatrikel der Loge Zur Beständigkeit und Eintracht, Aachen 1861/62, in: GStA PK, FM 5.2.A2, Nr. 26/1 sowie 26/2. 



\section{Fazit}

Die vorliegende Studie ging dem Verhältnis des rheinischen Adels zur Freimaurerei in der "Sattelzeit" nach. Hierbei zeigte sie die Bedeutung des Verbindungspunkts einer esoterischen Position der Adelsbegründung bzw. eines esoterischen Diskurses zur »Rassengenese« in Bezug auf die Freimaurerei des Ancien Régime auf. Diese Position basierte zunächst auf der Vorstellung, die geistig-seelischen Ursprünge der menschlichen »Rasse« über genealogische Aufstellungen bis zu ihren Ursprüngen zurückverfolgen zu können. Das Bild des Stammbaums, übertragen auf das menschliche Gemeinwesen, implizierte dabei durch die gedankliche Verbindung zu einem Wurzelgeflecht und den Verästelungen einer Krone bereits einen mit dem Fortschritt der Zeit angenommenen Unterschied zwischen einzelnen Gruppen der Gesellschaft.

Auch die Abhängigkeit des pflanzlichen Wachstums von der Einwirkung des Sonnenlichts konnte offenbar noch um die Wende zum 18. Jahrhundert mit der philosophischen Strömung des Sensualismus und den Forschungen eines Isaac Newton, der in seinen "Opticks ${ }^{1}$ noch der Durchdringung des menschlichen Körpers durch den unsichtbaren spiritus ${ }^{2}$ im Licht nachging, auf den Menschen übertragen werden. Die durch die Vorstellungswelten der Alchemie beeinflussten Teilaspekte der Studien Newtons sind hierbei jedoch nur als Ausläufer älterer Traditionen $\mathrm{zu}$ sehen. So konnte in der vorliegenden Untersuchung gezeigt werden, dass speziell das adlige Blut bereits zu Beginn der Frühen Neuzeit auf der Grundlage einer durch das hermetisch-alchemistische Weltbild und den Paracelsismus beeinflussten Medizin als eine Art `flüssiges Gedächtnis` galt, das die "tugendhaften Samen« bzw. die insbesondere bildlich erfahrenen »Lebensgeister" der Vorfahren in sich aufzunehmen vermochte. Durch diese "Lebensgeister «, die innerhalb der gesamten Natur und durch sie im einzelnen Menschen wirkten, sollte sich der auf eine Perfektionierung der Welt hin gerichtete göttliche Schöpfungsplan vollziehen.

Da hierbei ein Abfall von Gott bzw. eine untugendhafte Lebensführung prinzipiell als eine Gefährdung für den Erhalt des eigenen Standes wie der Familie in der göttlichen Ordnung gelten konnte, wurde eine fromme Erziehung als Garant für die künftige Erlangung des Seelenheils und die weitere Verfeinerung des Blutes angesehen. Auf der Annahme, einer langen Kette tugendhafter Ahnherren zu entstammen, fußte daher der Glaube des Adels, im >Wurzelgeflecht der Menschheit eine hervorgehobene bzw. besonders widerstandsfähige »Rasse« auszumachen,

1 Sir Isaac Newton, Opticks: or a treatise of the reflections, refractions, inflections and colours of the light, 4. Aufl., London 1730 (Erstausgabe 1704), Permalink: n2t.net/ark:/13960/t3ws8zp9j (Zugriff vom 12.08.2014). Zur kritischen Einstellung Newtons gegenüber der Seelenwanderung siehe insbesondere seine abschließenden Bemerkungen, in denen er nochmals die Wichtigkeit der noachidischen Urreligion - vor ihrem Verfall - hervorhebt. Siehe hierzu insbesondere Newton, Opticks, $381 f$.

2 Vgl. hierzu Fischer, Isaac Newton und das verlorene Wissen (wie Anm. 65, Kap. III), insb. 54f. 
die in der menschlichen Gesellschaft wegen ihrer geblütsmäßig gespeicherten Anlagen zur Tugend durch göttliche Vorsehung zur Herrschaft auserkoren war.

Diese Vorstellungen um die adlige »Blutsideologie« verbanden sich unter dem Eindruck der zahlreicher in die Logen Aufnahme findenden Adligen zu Beginn des 18. Jahrhunderts mit der Geschichtsschreibung und dem symbolisch aufgeladenen Ritualwesen der ersten englischen Großloge, das in der Folge - in Anknüpfung an die bereits seit der Antike bekannte Erinnerungskunst und der im Zuge des 18. Jahrhunderts viel diskutierten Lehre der Metempsychose - von den Zeitgenossen als elaboriertes, insbesondere auf einprägsamen Ritualen beruhendes Erziehungssystem zur Tugendhaftigkeit interpretiert werden konnte. Über diese ,Wissenschaft der Tugend`, die von Adligen wie Bürgerlichen gleichermaßen innerhalb wie außerhalb der Loge spekulativ erforscht wurde, sickerten hintergründig auch die »rassischen« Vorstellungen des Adels allmählich in den Arkanraum der Freimaurerei ein. Da im Arkanraum der Loge auch Bürgerliche diese >Wissenschaft` vorantrieben, wurde eine weitergehende Annäherung von Teilen der esoterischen Position der Adelsbegründung auf das Bürgertum möglich. Hierunter sind insbesondere solche Bestandteile zu summieren, die sich auf die Empfänglichkeiten für Lehren bzw. einer von Gott geschenkten `Begabung` oder »feinen Seele« konzentrierten. Die letztlich nicht mehr exklusiv auf den Adel begrenzbare seelisch-geistige Auserwähltheit führte - wie im Falle der Düsseldorfer Adelsloge La Parfaite Amitié verdeutlicht werden konnte - im Rheinland des Ancien Régime untergründig zur Verschärfung gegenseitiger Standesvorbehalte und einem Konkurrenzkampf in Bezug auf die »Herrschaft über die Gemüter«.

Die Untersuchung des freimaurerischen Umfelds Joseph zu Salm-Reifferscheidt-Dycks in der Zeit des napoleonischen Premier Empire zeigte den Wandel dieses Verhältnisses nach den Ereignissen der Französischen Revolution auf. Innerhalb des ursprünglich ebenfalls hermetisch-alchemistisch geprägten Hochgradsystems des Rit écossais philosophique, das sich unter dem Einfluss Intellektueller im Umkreis der Idéologues als ein explizit wissenschaftliches Freimaurersystem präsentierte, blieb die Vorstellung von einer auserwählten ıwissenden Elite < erhalten. Hier berief man sich jedoch nicht mehr auf den Adel des Blutes, sondern vielmehr auf eine allgemeinere Kategorie, die man mit dem von Dieter A. Binder bereits in Bezug auf die Rittergrade verwendeten Begriff des »Adels des Geistes $\aleph^{3}$ oder, im vorliegenden Fall besser ausgedrückt, des »Adels des Intellekts« umschreiben kann. Diesem »Adel des Intellekts « kam es durch seine jeweilige >Begabung $<\mathrm{zu}$, die Gesellschaft bzw. die Nation insbesondere durch die Förderung der Wissenschaften und schönen Künste moralisch emporzuheben und zu einem »Goldenen Zeitalter « zu führen.

Ein Ausblick in die preußische Zeit konnte zudem verdeutlichen, dass sich beide Positionen - also sowohl adlige »Blutsideologie « als auch »Adel des Intellekts« - bis in das 19. Jahrhundert hinein hielten, wobei die Krise der Freimau- 
rerei zu Beginn des 19. Jahrhunderts nicht nur durch die politischen Umstände der Zeit verursacht worden war, sondern auch durch die innerhalb der französischen Freimaurerei des Premier Empire schwelende Diskussion um eine gezielte Verbreitung freimaurerischer $>$ Erkenntnisse $<$ in den profanen Bereich hinein. Der Rückzug des rheinischen Adels aus den Logen um 1800 erklärte sich insbesondere durch diese vor allem in den naturgeschichtlichen Diskussionen außerhalb der freimaurerischen Sphäre vorbereitete Transformation des esoterischen Diskurses der »Rassengenese« hin zu einer stärkeren Übertragung auf gesamte Völker und Nationen. Während also das auf der Vorstellung der Einprägung von Bildern in das Blut basierende »Geheimnis der Rasse ${ }^{4}$ in seiner nationalen Transformation allem Anschein nach in der »bürgerlichen Gesellschaft « des 19. Jahrhunderts mehr und mehr an Bedeutung gewann, folgten konservativ denkende Adlige durchaus ebenfalls der eigentümlichen Logik des Diskurses, wenn Sie ihre überkommenen Vorstellungen von der Qualität des adligen Blutes zukünftig stärker in exklusiven Adelsgesellschaften pflegten.

Vor diesem Ergebnis scheinen sich für das 19. Jahrhundert die Begriffe "Adel « und »Bürgertum«, was ihre diskursiven bzw. gesellschaftlichen Abgrenzungsmechanismen anbelangt, in zunehmender Weise als dichotome Größen aufzulösen. Sie bleiben - ebenso wie die Freimaurerei - >schwammig ‘, da sie - um das Bild der »Wurzel« weiter aufzugreifen - die vielfältigen, sich ändernden Einflüsse und Innovationen ihres diskursiven Umfeldes raufsogen<, um sie im Sinne der Aufrechterhaltung der "esoterischen Ursprungskette der eigenen "Erinnerungsgruppe» in das eigene Selbstbild einzufügen. Beide Begriffe ließen sich somit fortan nutzen, um gesellschaftliche Auserwähltheit gegenüber ıandersartigen` Gruppen gesellschaftlich zu manifestieren - also jenen, die über vermeintlich `falscher oder unzureichende Mittel verfügten, sich an diesem zur Schau gestellten Sinn für die erzieherische Wirkmächtigkeit von Symbolik und Ästhetik zu beteiligen, der sich insbesondere in der Aneignung, Produktion und Weitergabe wissenschaftlicher, literarischer, architektonischer und künstlerischer Werke ausdrückte. ${ }^{5}$ Die vormals in den mythischen Stammbäumen des Adels und der Geschichte der Freimaurerei illustrierte Förderung der Tugend und der Aufrechterhaltung des Friedens durch eine adlige "Rasse" war zur Aufgabe einer `wissenden Tugendelite innerhalb einer Nation geworden. Diese vermochte es, ihre Vorrangstellung in den gesellschaftlich geführten Diskursen um »Rasse« und geistiger >Begabung auch fortan auf Grundlage medizinisch bzw. naturwissenschaftlich sfundierter Feststellungen zu behaupten. Der deutliche esoterische Gehalt dieses Diskurses um >Begabung $<$ und eines hieraus resultierenden >Wachstums $<$ bzw. >Fortschritts der Menschheit scheint dabei noch in Teilen bis in die Gegenwart nachzuwirken.

4 Mosse, Geschichte des Rassismus (wie Anm. 62, Kap. II), 118-135.

5 Hier ließe sich für die Moderne an die soziologischen Konzepte Pierre Bourdieus zum »kulturellen Kapital« und seiner Wendungen der »cultural pedigrees« und »titles of cultural nobility« anknüpfen. Siehe hierzu insb. Pierre Bourdieu, Distinction. A Social Critique of the Judgement of Taste, 2. Aufl., London/New York 2010. 
Die vorliegende Studie vertritt somit die These, dass die hier anhand des Zusammengehens von adliger "Blutsideologie" und Freimaurerei herausgearbeitete Transformation des "Esoterischen « eine Beantwortung der von Monika Neugebauer-Wölk aufgeworfenen Frage nach der anhaltenden Attraktivität der Freimaurerei in der sogenannten bürgerlichen Gesellschaft bietet. Das »Esoterische« zeigte sich insbesondere innerhalb der frühneuzeitlichen Vorstellungen zur "Rassengenese", die sich zur Moderne hin stärker mit dem Gedanken der »Nation« verbanden, als überaus anpassungsfähiges »Diskurselement«. Der Glaube des Adels an eine auf Grundlage des Blutes historisch konstruierte Auserwähltheit wurde innerhalb und außerhalb der Freimaurerlogen am Vorabend der Moderne mehr oder weniger mühelos von der Hoffnung der neuen Eliten auf ein »Goldenes Zeitalter« der Menschheit durch die Naturwissenschaften bzw. die menschliche Intelligen $z^{6}$ und die hieraus entspringenden gesellschaftlichen bzw. kulturellen Leistungen als Anzeiger der `Begabung`ersetzt.

Aufgrund des beschränkten Untersuchungsrahmens ergibt sich zur breiteren Stützung dieser These weiterer Forschungsbedarf zur Ausprägung dieser Vorstellungen sowohl in Bezug auf den Adel anderer Regionen als auch auf andere Geheimgesellschaften des 19. und 20. Jahrhunderts. Es gilt dabei weiterhin die längerfristigen Einflüsse inner- und, wichtiger noch, außereuropäischer Geistesströmungen, die sich im Sinne des »Esoterischen « in Europa im Mittelalter und der Frühen Neuzeit vermischten, in ihren gegenseitigen Annäherungen, Abgrenzungen und Veränderlichkeiten aufzudecken. Ferner bleibt im Hinblick auf die Katastrophen des 20. Jahrhunderts verstärkt danach zu fragen, inwiefern das "Esoterische« sowie die hier aufgezeigte Vorstellung einer über die Einprägung von Bildern wirksamen »Rassengenese« im Denken an staatlicher Macht beteiligter Eliten Konjunkturen durchlief. Dies insbesondere deshalb, weil jüngst Stephan Malinowski in Anlehnung an Hannah Arendt in Erinnerung rief, dass es insbesondere »bürgerliche Intellektuelle» waren, die in der Moderne auf der "Blutsideologie« als Kriterium des gesellschaftlichen Vorzugs bestanden ${ }^{7}$ und bereits Mosse auf den »starken mystischen Impuls« innerhalb des modernen Rassismus

$6 \mathrm{Zu}$ der offenbaren Fokussierung esoterischer Diskurse auf das Hirn in der Moderne siehe Robert Matthias Erdbeer, Paläopoiesis/Paleofiction. Kognitionspoetik und `Erlebenswissenschaft، bei Laßwitz und Hörbiger, in: Monika Neugebauer-Wölk/Renko Geffarth/Markus Meumann (Hg.), Aufklärung und Esoterik (wie Anm. 71, Kap. I), 461-503, hier 500. Verwiesen sei hier auch auf ein vielversprechendes Forschungsprojekt Susanne Schregels, das derzeit an der Universität zu Köln unter dem Titel »Intelligenz. Zur Geschichte einer sozialen Unterscheidung (GB, D ca. 1880-1990)« entsteht. Siehe eine Skizze des Projekts unter http://artes.phil-fak.uni-koeln.de/19543. html?\&L=1 (Zugriff vom 25.05.2014).

7 Stephan Malinowski, Vom blauen zum reinen Blut. Antisemitische Adelskritik und adliger Antisemitismus 1871-1944, in: Jahrbuch für Antisemitismusforschung 12 (2003), 147-169, hier insb. 149-151. Siehe hier auch die bleibende Wichtigkeit der Vorstellung der Metempsychose bei führenden Nationalsozialisten wie Heinrich Himmler. Vgl. zur »völkischen Esoterik« jüngst auch Eugen Semrau, Erleuchtung und Verblendung. Einflüsse esoterischen Gedankenguts auf die Entwicklung der Wiener Moderne (Quellen und Darstellungen zur europäischen Freimaurerei, 13), Innsbruck/ Wien/Bozen 2012, insb. 139-172. 
verwies. ${ }^{8}$ Es hat den Anschein, als sei dies ein bislang nur ungenügend beachteter Ansatzpunkt für die Erforschung des langfristigen Einflusses des "Esoterischen «, der sich in den verschiedensten Bereichen der modernen Kultur zum Teil verdeckt, zum Teil offensichtlicher erhielt.

Im Verlauf der Untersuchungen zeichnete sich dabei bereits ab, dass die in dieser Studie aufgezeigte esoterische Form der Adelsbegründung bzw. der »Rassengenese « nicht nur für den Adel von besonderer Bedeutung im Hinblick auf die Festigung familiärer Identitäten und sozialer Abgrenzungsmechanismen war, sondern auch im Hinblick auf die in bürgerlichen bzw. neunobilitierten Familien der Frühen Neuzeit wie des 19. Jahrhunderts anzutreffenden rigiden Praktiken der Heiratspolitik - bei der nicht vorschnell einzig von wirtschaftlichen Interessen ausgegangen werden sollte - sowie ihre starke Übernahme der symbolischen Repräsentationspraktiken des Adels. ${ }^{9}$ Es bleibt darüber hinaus danach zu fragen, $\mathrm{ob}$ »Bildung « und die Förderung von »Bildung« innerhalb des Bürgertums dabei noch auf der oben erläuterten Vorstellung einer Einprägung und Vererbbarkeit von bildhaften Lebensgeistern bzw. einer modernen Weiterentwicklung dieses Gedankens basierten. Die Analyse der Wechselwirkungen und Transformationen des »Esoterischen« innerhalb der gesellschaftlichen Diskurse der Frühen Neuzeit wie der Moderne scheint daher weiterhin erforderlich, um die Mechanismen sozialer Ausgrenzung in ihrer historischen Entwicklung besser verstehen zu können.

8 Mosse, Geschichte des Rassismus (wie Anm. 62, Kap. II), 118.

9 Siehe hierzu etwa jüngst Ines Heisig, Die Unternehmerfamilie von Heyl in Worms. Aspekte privater Kulturförderung im Kaiserreich, in: Gabriele B. Clemens/Malte König/Marco Meriggi (Hg.), Hochkultur als Herrschaftselement. Italienischer und deutscher Adel im langen 19. Jahrhundert, Berlin/Boston 2011, 233-262. 



\section{Anhang}

\section{A Tabellarische Übersicht rheinischer adliger Freimaurer 1765-1815}

Die folgende Tabelle beruht sowohl auf den Angaben einschlägiger Forschungsliteratur als auch archivalischen Auswertungen. ${ }^{1}$ Es werden in der Regel nur solche adligen Freimaurer aufgeführt, die sich Familien des sogenannten rheinischen "Uradels« zuordnen lassen. Ausnahmen von dieser Regel beruhen auf der Bedeutung der jeweiligen Vertreter für den im Fließtext dargestellten Kontext. So wurden etwa einige Familienvertreter der Familien von Hatzfeld sowie von StaëlHolstein, deren Ursprünge außerhalb des geographischen Untersuchungsraums verortet werden können, aufgrund ihrer Anbindung an das Kurfürstentum Köln bzw. das Herzogtum Jülich-Berg in die Auflistung übernommen. Die Vertreter nobilitierter Familien bzw. Patriziergeschlechter wie von Francken-Sierstorff, von Buschmann, von Klespé, von Löwenich ebenso wie eingewanderte Familien wie La Valette St. George, von der Leyen oder die aus Preußen stammende Familie der Grafen von Borcke ${ }^{2}$ wurden nicht aufgeführt. Weibliche Personen des rheinischen Adels konnten nicht in Logen nachgewiesen werden. Als einziger - wenngleich unsicherer Hinweis - darauf, dass auch weibliche Vertreterinnen des rheinischen Adels in Freimaurerlogen verkehrten, ist die Erwähnung einer "Madame La Comtesse de Quad-Wickerad, née a Nyvenheim« in einer Rede Michel-Ange de Mangourits innerhalb des "Livre d'architecture« der Mère Loge des philosophischen Ritus St. Alexandre d'Ecosse le Contrat Social réunis. Diese soll einer in den 1780er Jahren gegründeten Nimwegener Adoptionsloge angehört haben, die durch den Prinzen Ludwig von Waldeck als maître-dirigeant sowie »S.A.R. Ma-

1 Die in der Tabelle angegebenen Daten beruhen auf Angaben in: Abafi, Geschichte der Freimaurerei in Österreich-Ungarn (wie Anm. 6, Kap. VII); Dotzauer, Bonner aufgeklärte Gesellschaften (wie Anm. 193, Kap. V); Ders., Die Mitglieder der Kölner Freimaurerloge (wie Anm. 179, Kap. V); Dotzauer, Freimaurergesellschaften am Rhein (wie Anm. 56, Kap. I); Gerlach, Die Logen zwischen mittlerer Oder und Niederrhein (wie Anm. 56, Kap. I); Gerlach, Die Logen in Pommern, Preußen und Schlesien (wie Anm. 56, Kap. I); Hansen, Quellen zur Geschichte des Rheinlandes (wie Anm. 181, Kap. V); Pauls, Festschrift zum 125. Stiftungsfeste (wie Anm. 220, Kap. VII); Pauls, Düsseldorfer Freimaurerei (wie Anm. 2, Kap. V); Schuler, Die St. Johannis-Freimaurerloge "Zur wahren Eintracht» (wie Anm. 211, Kap. V); N.N., Verzeichniss der Mitglieder der gerechten u. vollkommenen Freimaurer Loge Libanon zu den drei Cedern im Orient von Erlangen: Am Johannisfeste 5818, Erlangen 1818, Permalink: http://nbn-resolving.org/urn:nbn:de:bvb:12bsb10678162-9 (Zugriff vom 25.05.2014); ASD, Dyck4 - Blaue Bände, Bd. 590; Zur Beständigkeit und Eintracht, Aachen, Logenmatrikel, in: GStA PK, FM 5.2.A2, Nr. 26/1 sowie 26/2; Loges Aix-la-Chapelle, Dossier Aix-la-Chapelle, Loge de la Concorde, in: BnF, FM2 533; Loges Aix-laChapelle, Bonn, Coblence, Loge La Constance, in: BnF, FM2 534; Loge Cologne, in: BnF, FM2 536 (MF4590).

2 Siehe zu der ursprünglich aus Preußen stammenden Familie der Grafen von Borcke bereits Erich Hubbertz, Zwei Jahrhunderte Freimaurerei am Niederrhein. Geschichte der Freimaurerloge PAX INIMICA MALIS in Emmerich (Emmericher Forschungen, 1), Kleve 1979, hier insb. 71-74. 
dame la Princesse d'Orange et de Nassau « geleitet worden sein soll. ${ }^{3}$ Trotz der Unwägbarkeiten wurden die Angaben zu ihrer Mitgliedschaft in der Tabelle aufgeführt.

Die Tabelle erhebt keinen Anspruch auf Vollständigkeit, da nicht ausgeschlossen werden kann, dass Mitgliedschaften bereits innerhalb des Untersuchungszeitraums nicht offiziell in den Logenmatrikeln verzeichnet werden sollten oder in Zukunft aus bislang nicht ausgewerteten Beständen europäischer Logen weitere Personen bzw. Daten zu ergänzen sind.

3 Rede Michel Ange de Mangourits über Affaire de la Mère Loge Union Royale de la Haye (à propos de Tenues d'adoption) 1808-1809, Paris, o.D., in: BnF, FM1 289 (MF 33609), fol. 61-77. Siehe zur Nimwegener Loge auch C. Lenning, Allgemeines Handbuch der Freimaurerei, Bd. 2, 2. Aufl., Leipzig 1865, 257 sowie 440, Permalink: http://nbn-resolving.org/urn:nbn:de:bvb:12-bsb10435410-4 (Zugriff vom 25.05.2014). 


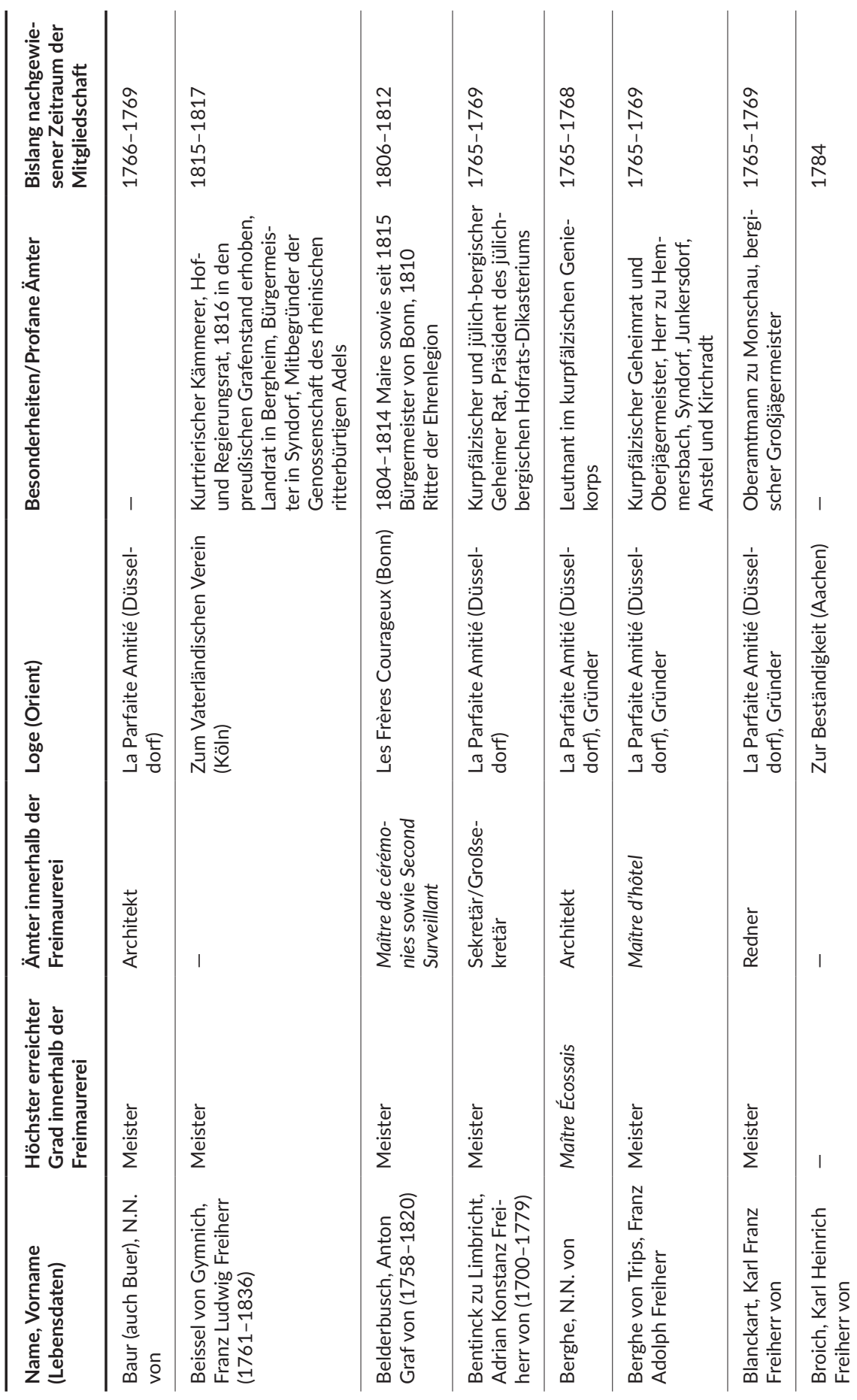




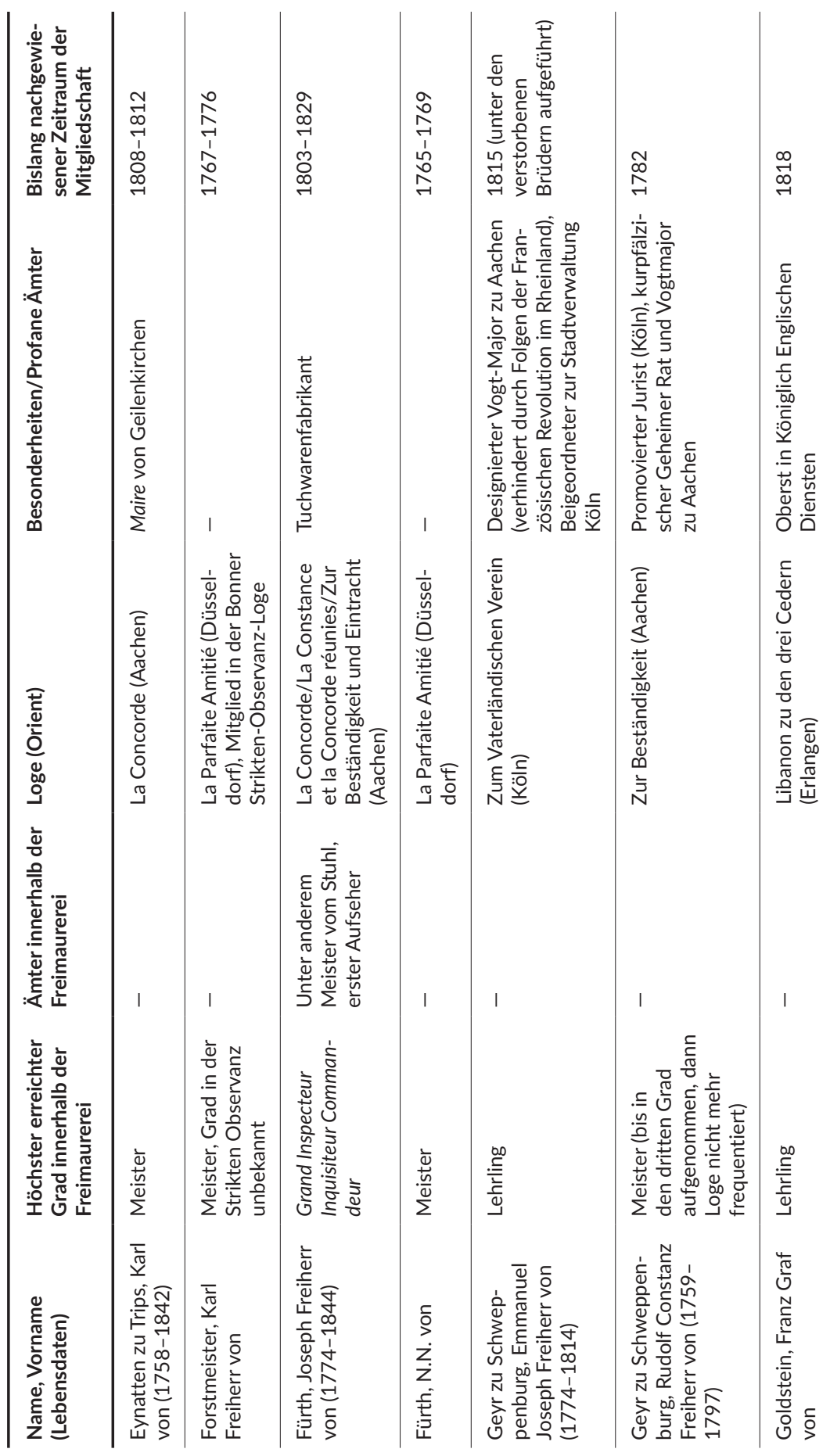




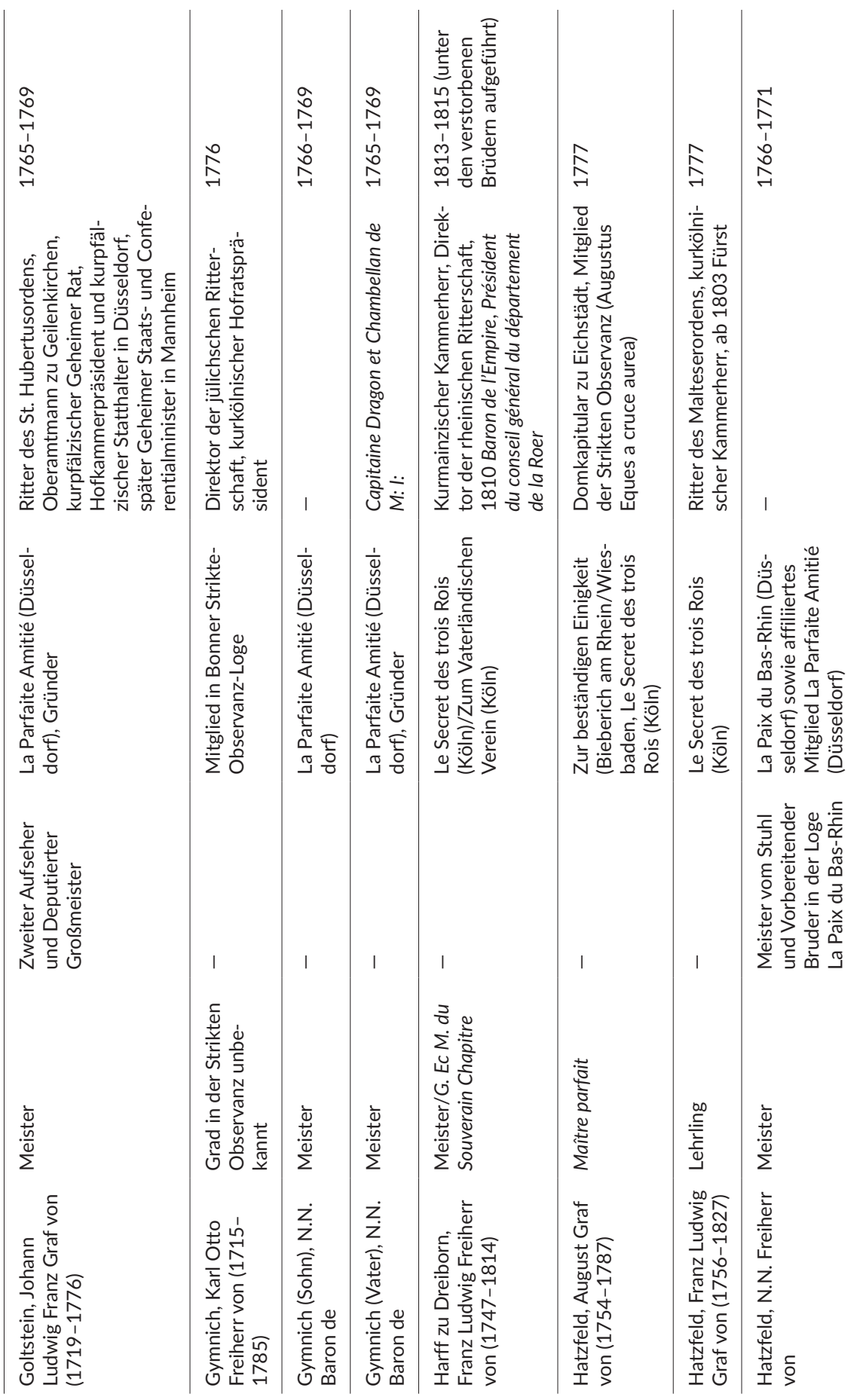




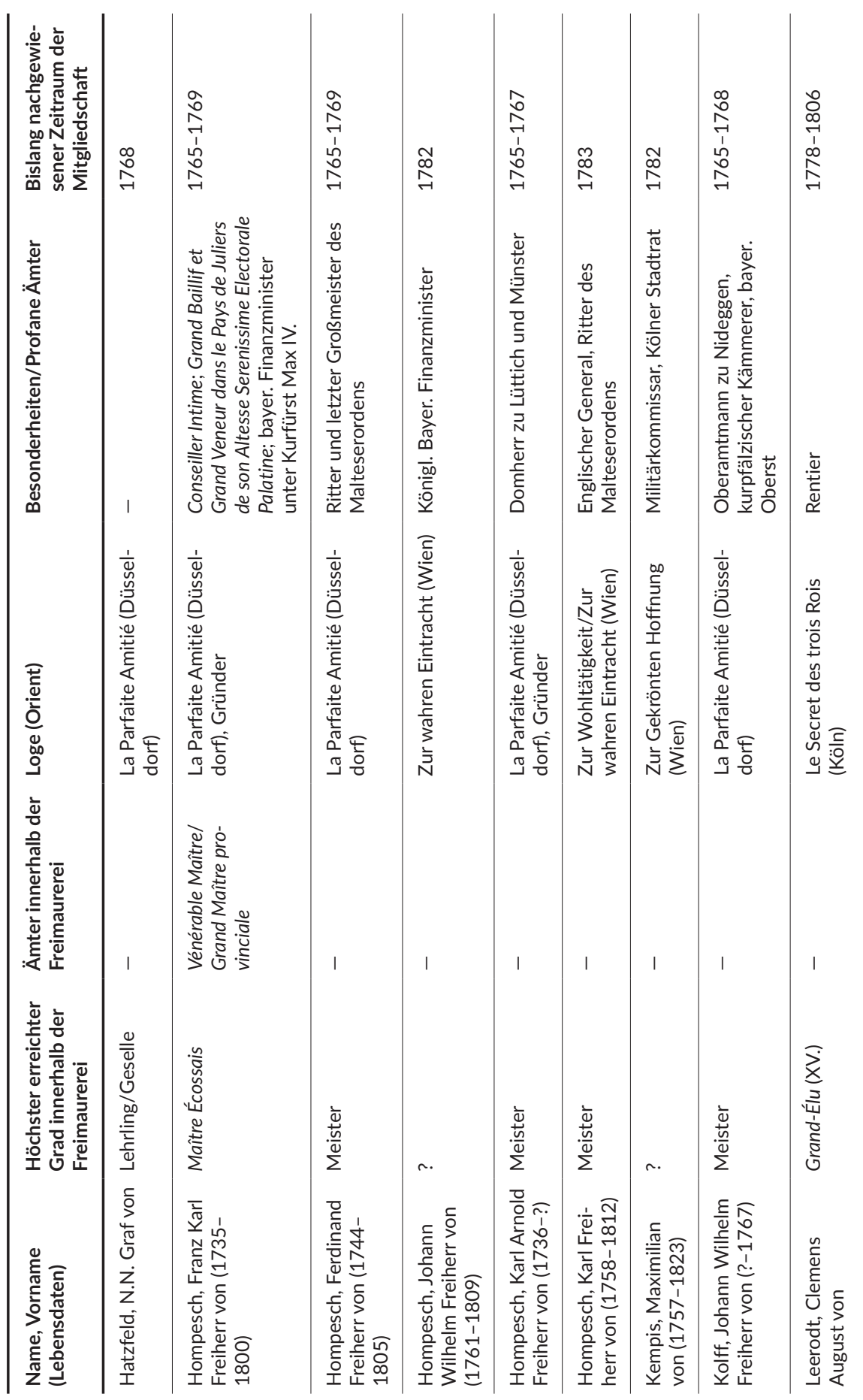




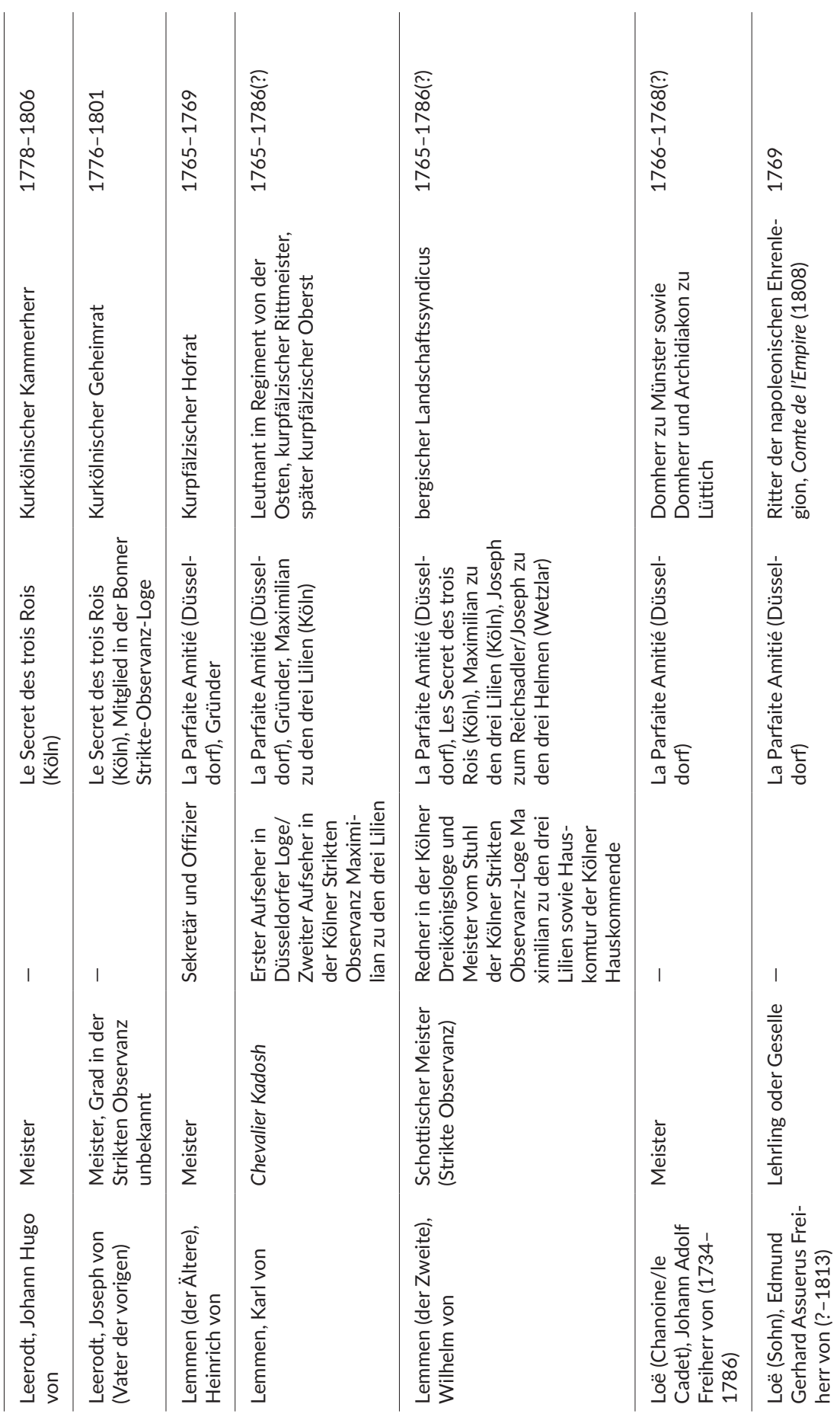




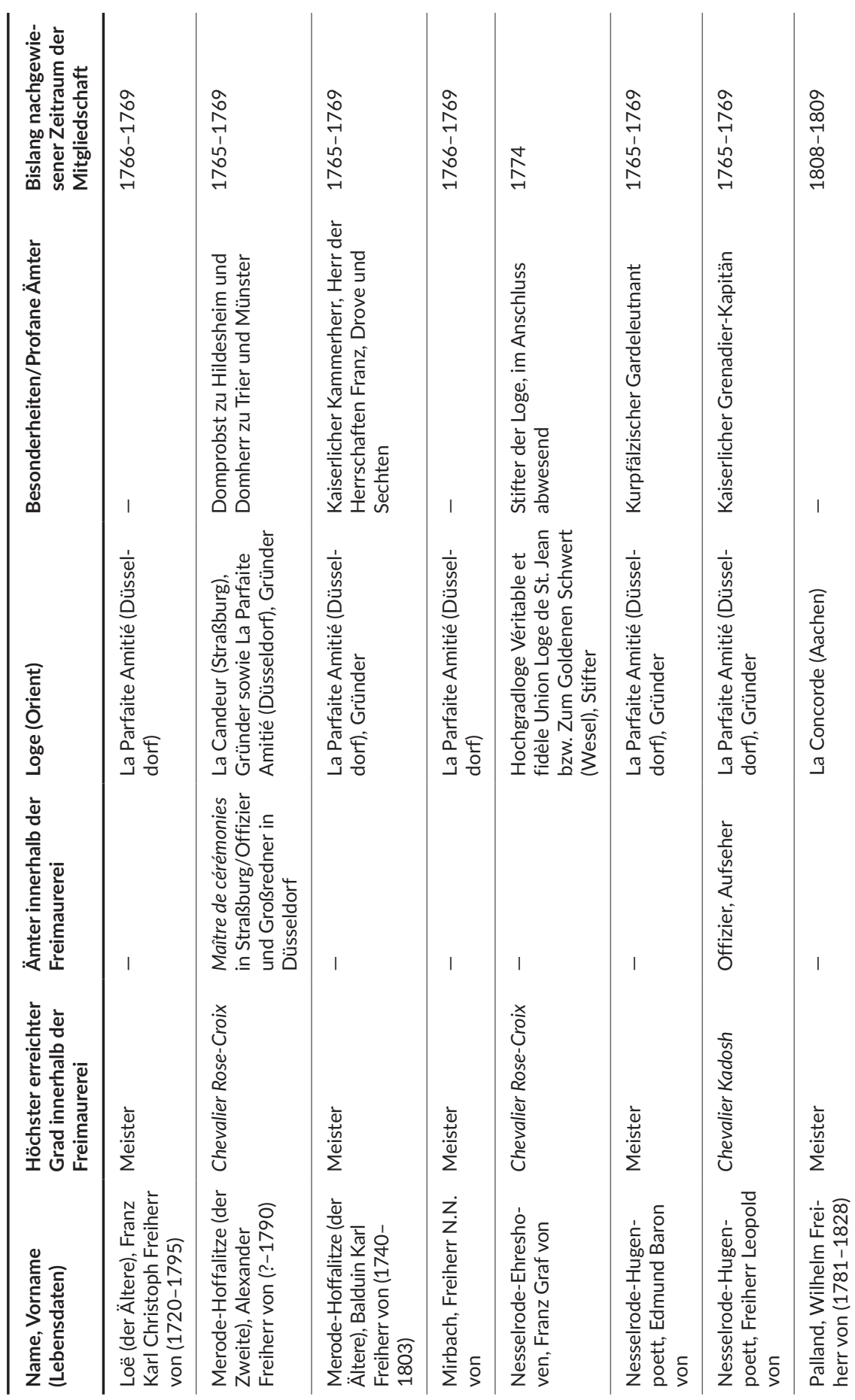




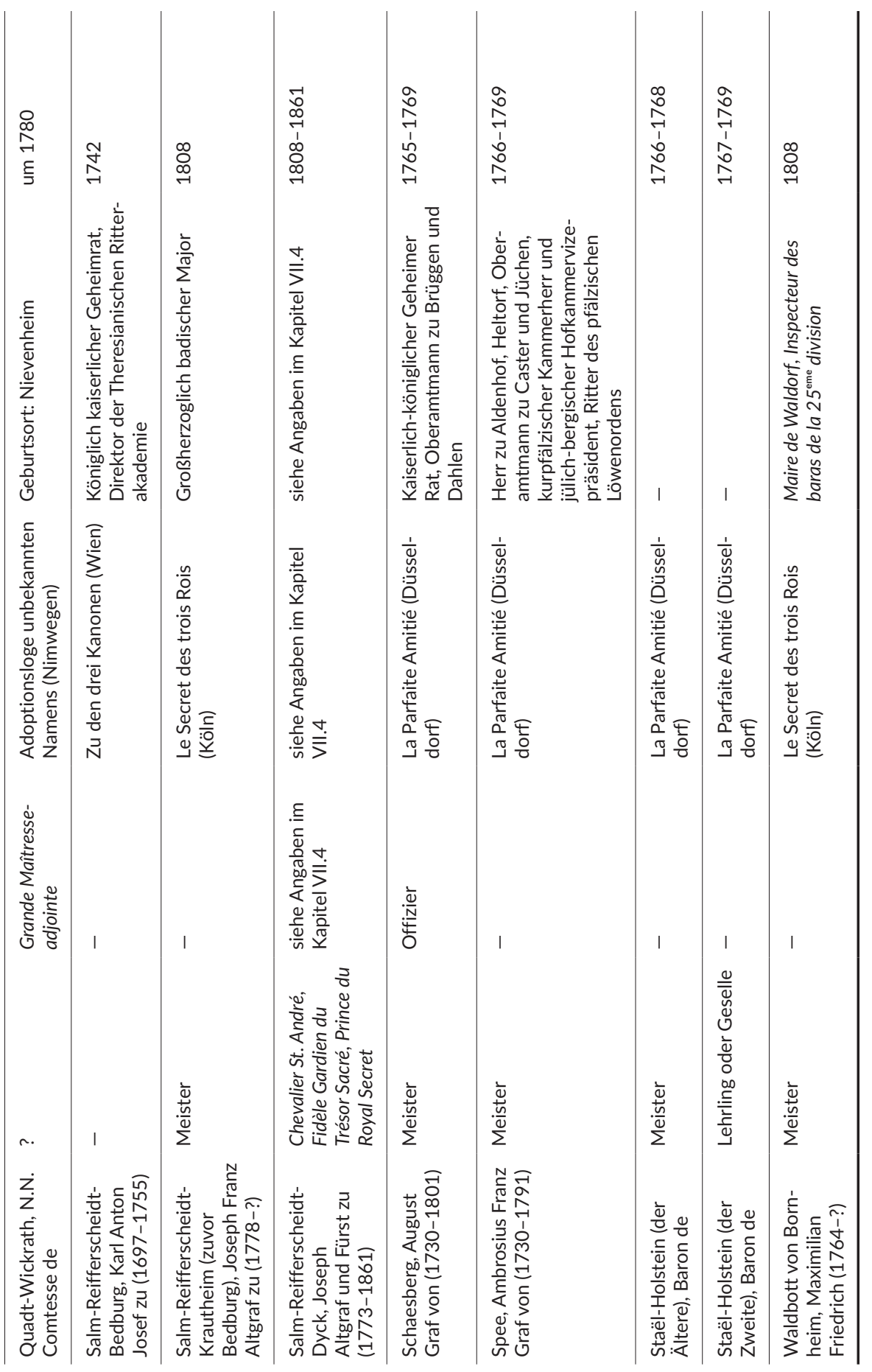




\section{B Transkription: Discours Historique des 32. Grades des Rite ancien accepté}

\section{Sublime et Souverain Prince Du Royal Secret Grand Inspecteur, " $25^{\text {me }}$ et dernier dégré $-32^{\mathrm{me}}$ suivant quelques novateurs ${ }^{4}$}

\section{Discours Historique du Grade De Royal Sécret}

Parvenu par vos travaux au Sanctuaire de la maçonnerie franche et acceptée; délivré des emblemes de l'obeissance; destiné à commander et Regir un ordre celebre et nombreux repandu sur les deux hemispheres, vous allez voir à découvert nos mystères les plus augustes: vous allez entendre en abregé l'histoire de notre association et vous y verrez tracé par la main de la Sagesse meme les principes qui doivent vous guider dans les fonctions honnorables que ce nouveau grade vous impose.

L'écossais de la Perféction et le Prince de Jerusalem vous ont instruit du sort de la maçonnerie sous Salomon; sous ses successeurs pendant la Captivité et sous Nehimius chargé de la construction du $2^{\text {me }}$ temple.

Vous voyez au $2^{\text {me }}$ chapitre du $2^{\text {me }}$ livre des Machabées historique du feu sacré caché par Jeremie et rétrouvé par Nehemie. Ce furent les maçons unis depuis la Captivité aux levites et qui desormais ne formeront plus qu'un seul corps avec eux qui transmirent ses précieux renseignemens indiquant le lieu ou le feu sacré avait été celé.

Vous trouverez Joseph dans l'histoire des maçons et des Levites sous Herode le Grand ou ils furent emloyés à la construction du $3^{\text {me }}$ temple et a celle du chateau d'Hérodom dont les maçons Ecossais datent encore aujourd'huy leurs patentes.

Uni par les memes Dogmes menant le meme genre de vie que les esséncéns et les thirapeutes ils suivirent en grande partie la doctrine de Saint Jean Baptiste et de Saint Jean l'evangeliste qui furent successivement leurs chefs. Ils réçurent alors dans leur sein la plus grande partie des premiers pères de l'église dont les ecrits contiennent leurs vrayes connaissances ésotériques ou mystérieuses.

Vous pouvez lire Saint Justin, Saint Denys l'aréopagiste, Saint Clément d'aléxandrie, Eusebe, le Juif Philon, et plusieurs autres contemporains; vous y trouverés des passages frappants et convaincants de l'intime liaison des premiers mysteres du christianisme avec ceux de la maçonnerie.

Après la déstruction du $3^{\text {me }}$ temple par Titus les maçons les plus unis aux thirapeutes et aux Esséncens chrétiens se rétirerent dans la thébaide ou ils prirent le titre de Kadosch ou Saint, de la cette longue suite des Pères du Desert. Dans la liste des premiers chrétiens qui ont illustré l'église primitive, ils ne cessèrent de cultiver dans leur Rétraite les connaissances que leurs ancètres leur avaint transmises en y

4 Sublime et Souverain Prince Du Royal Secret Grand Inspecteur, o.O., Anfang 19. Jh., in: BnF, FM4 817 , fol. $10 \mathrm{v}-13 \mathrm{r}$. 
joignant celle de la science des anciens mystères dont Hermés trismégiste; orphée, porphire, Jambliche, Proclus, et autres nous ont laissé une partie de la doctrine sécrete: c'est à eux que nous devons la consérvation des hautes sciences et leur rénaissance chez les arabes ou ils formerent les guebres, les avicennes, les Rhasses, et les averhois.

Rétirés du monde ils attendirent pendant la longue domination des mahométans le moment du triomphe de la vraye Réligion. Les croisades arriverent ils se lièrent avec les chevaliers des Temple de Jérusalem célébres par leur humilité leur charité leur zèle pour la Foy et l'exercice de toutes les vertus chrétiennes: ils leurs transmirent leur sciences et les agregerent à leurs associations. C'est par eux que ces connaissances furent portées en occident ou ils formerent par la Suite un Saint Thomas d'acquin, un christian Rozen Kreuzer fondateur des RR.. CC.., un Pic de la Mirandole, un Chancellier Bacon et tant d'autres Grands hommes qui ont illustré la maçonnerie franche et acceptée.

Lordre des Templiers fut détruit; une grande partie des chevaliers orientaux se retirèrent dans les deserts de la thibaide, ou leurs successeurs cultivent encore aujourd'huy les sciences que leurs ancetres leur ont laissé en heritage. Daumont et plusieurs autres chevaliers occidentaux se retirèrent en Ecosse deguisés en maçons ou ils se reunirent aux chevaliers de Saint André ordre qui s'etait formé dans la Palestine de Gentils hommes Ecossais et qui avaient conservé des liaisons intimes avec les templiers: ils leur transmirent une partie de leurs documens de l'ordre sauvés du naufrage Réprirent le nom de maçons libres et acceptés pour jouir suivant les loix décosse connue contraire de metier du droit de Bourgeoisie et pour cacher cette continuation de lordre aux yeux des prophanes.

Jacques VI, Roy D'écosse et d'angleterre transporta la Grande loge à Edimbourg et réunit les deux corps des architectes et des maçons acceptés, il en fut grand maître comme les Roys d'écosse ses prédécesseurs et ses successeurs chefs de la famille des Stuards.

La maçonnerie se repandit dans toute l'europe à pas de Geants. Tout ce qu'il y eut d'hommes éclairés et instruits voulurent se faire initier dans ces nouveaux mystères suite des anciennes initations de l'égypte, de la Palestine et de la Grèce. Des lors les loges se multiplierent; mais les secrets de l'ordre, sa véritable histoire se trouvent Resserrer entre peu de personnes qui lies par un serment Religieux convinrent de n'en accorder la connaissance qu'a ceux qui auraient mérité par leurs travaux de posseder ces importantes traditions.

Vous faites partie illustre Frère Grand Inspecteur Général de cette puissance; nous avons droit d'attendre de vous que vous [...] employrez les éminents pouvoirs qui vous sont conferés au Bien Général et a la plus grande splendeur de l'ordre; et que nous n'aurons jamais a nous repentir de vous avoir appellé a l'exercice de ce devoir suprème." 
Note très intéressante qui ne concerne en Rien l'ancien Grade de Grand Inspecteur Royal Sécret et dont le Paragraphe suivant n'est connu que depuis 1804 époque du Concordat

Le Prince Charles Edouard dernier Rejetton des Stuards désigne à sa mort Fréderic le Grand Roy de Prusse pour Grand Maître et luy communique l' historique de l'ordre que vous venez d'entendre.

Il sera facile aux novateurs de propager cette prétendue désignation de deux chefs aussy Recommandables; mais si maçons nouvellement appelés au sublime Grade de Grand Inspecteur du Royal Sécret se laissent entraines a cette fausse annoncé les anciens maçons toujours fermes dans les vrays Principes se tiendront sur leurs Gardes sur les innovations et comme Gardiens des Réglémens de l'ordre ils veilleront par tous leurs moyens a ce que leurs jeunes successeurs ne soient pas égarés. C'est un devoir sacré pour eux qu'ils ne se dispenséront pas de Remplir. 


\section{Freimaurerische Abkürzungen}

Académie des $\mathrm{V} \therefore \mathrm{M} \therefore$

Air :

Att:

C $\therefore$

Chap $\therefore$ de G $\therefore$ A $\therefore$ B $\therefore$ et $N \therefore$

Command $\therefore$

Dign :

E $\therefore$ Großmeister

E.V.

$\mathrm{F} \therefore / \mathrm{FF} \therefore / \mathrm{F} \therefore \mathrm{F} \therefore$

Fr. Art.

G. A. d. L./G $\therefore$ A $\therefore$ de l'Univers

$\mathrm{G} \therefore \mathrm{M} \therefore$

Gr:

Gr $\therefore$ Ch $\therefore$ Gén $\therefore$

Gr $\therefore$ I $\therefore$

Gr $\therefore$ II $\therefore$ II $\therefore$ CC $\therefore$

Gr $\therefore$ L $\therefore$

G. L.

$\mathrm{K} \therefore \mathrm{D} \therefore$

$\mathrm{L} \therefore /[\therefore] / \square / \mathrm{LL} \therefore$

Livre d'Arch $\therefore$

Maç.:

Mad :

$\mathrm{M} \therefore \mathrm{F} \therefore$

$\mathrm{O} \therefore / \mathrm{OO} \therefore$

Off:

$P \therefore$

Prof:

Prov:

Rit Ecos $\therefore$ anc $\therefore$ \& accep $\therefore$

Rit Ec. $\therefore$ Ph $\therefore$

$\mathrm{R} \therefore$ Métrop $\therefore$ du Rit Ec $\therefore$ Ph $\therefore$

Souv :

$\mathrm{S} \therefore \mathrm{T} \therefore$ des GG $\therefore \mathrm{I} \therefore \mathrm{I} \therefore \mathrm{C} \therefore \mathrm{C} \therefore$

St. $\therefore$ Jean

$\mathrm{T} \therefore \mathrm{C} \therefore \mathrm{F} \therefore$

Trav :

Tr $\therefore$ ill $\therefore$ et Ch $\therefore$ Fr $\therefore$

$\mathrm{V} \therefore$

$\mathrm{V} \therefore \mathrm{T} \therefore \mathrm{R} \therefore \mathrm{F} \therefore$

$\square$
Académie des Vrais Maçons

Air

Attelier

Chapitre

Chapitre de Grand Aigle Blanc et Noir

Commandeur

Digne

Ehren Großmeister

Ère vulgaire

Frère/Frères

Frère Artisan

Grand Architecte de l'Univers

Grand Maître

Grand oder Grade

Grand Chapitre Général

Grand Inspecteur

Grands Inspecteurs Inquisiteurs Commandeurs

Grande Loge

Grande Lumière

Kadosh

Loge/Logen bzw. Loge/Loges

Livre d'Architecture

Maçon

Madame

Mon Frère

Orient bzw. Orients

Officiers

Planche

Profane

Provinciale

Rit Écossais ancien \& accepté

Rit écossais philosophique

Respectable Mère Loge Métropolitain du

Rit écossais philosophique

Souverain

Souverain Tribunal des Grands

Inspecteurs Inquisiteurs Commandeurs

Saint Jean

Très Cher Frère

Travaux

Très illustre et Cher Frère

Vénérable

Vénérable Très Respectable Frère

Mère Loge 



\section{Quellenverzeichnis}

\section{Ungedruckte Quellen}

\section{Archiv Schloss Dyck (ASD)}

Bestände des 19. Jahrhunderts: Allgemeine Verwaltung, Nr. 66, „Geschichten der Salmer«, 1780.

Dyck4 - Kart. 2/16, Korrespondenz mit Alphonse de Candolle (1806-1862, Botaniker, Genf, Paris).

Dyck4 - Kart. 6/102, Korrespondenz mit Bernard Germain Lacépède (1756-1826, Comte, Großkanzler der Ehrenlegion, Staatsminister), 1804-1813.

Dyck4 - Kart. 6/103, Korrespondenz mit Bernard Germain Lacépède (1756-1826, Comte, Großkanzler der Ehrenlegion, Staatsminister), 1804-1810.

Dyck4 - Kart. 7/119, Korrespondenz mit Karl Friedrich Martius (1794-1856, Konservator Botanischer Garten München, Hofrat).

Dyck4 - Kart. 30/33, Einladung der Düsseldorfer Freimaurerloge Zu den drei Verbündeten zu einem Fest in Schloss Benrath, Düsseldorf, 10.07.1838.

Dyck4 - Kart. 30/34, Brief der Mönchengladbacher Freimaurerloge Vorwärts, Mönchengladbach, 18.08.5846 (18.08.1846).

Dyck 4 - Kart. 35/17, Annuaire Maçonnique pour l'Année 5812 (Freimaurerisches Jahrbuch für das Jahr 5812), Paris, 1812.

Dyck4 - Kart. 35/7, Admission pour Monseigneur en qualité de Membre du Casino à Berlin 1816, de Membre honoreuri de l'athenée 1807, Berlin, 1816.

Dyck 4 - Kart. 49/1, Urkunde zur Aufnahme des Fürsten Joseph in den Freimaurer-Orden, Paris, 1811.

Dyck4 - Kart. 49/5, Urkunde zur Ernennung des Fürsten Joseph zum Grand-Écossais der Freimaurer, Paris, 1810.

Dyck4 - Kart. 49/6, Urkunde zur Rangerhöhung des Freimaurer-Ordens für Fürst Joseph, Paris, 11.05.1812.

Dyck4 - Blaue Bände, Band 590, 1811-1820.

Dyck4 - Blaue Bände, Band 594.

\section{Archiv Schloss Gracht (ASG)}

Akten, Nr. 545, Reisetagebuch (»Annotations et journal sur mes Voiages«) von Johann Ignaz Wolff-Metternich, 1760-1763.

\section{Orde van Vrijmetselaren onder het Grootoosten der Nederlanden, Cultureel Maçonniek Centrum Prins Frederik, Den Haag (GON)}

Sign. 2336-10, Mitgliederlisten Loge La Parfaite Amitié, Düsseldorf, 1765-1769.

Sign. 2402-23, Schriften zur Konstituierung Loge La Parfaite Amitié, Düsseldorf, 1765-1767. 
125.B.31, Commandeurs du Mont-Thabor, Rit écossais philosophique. Fête funèbre votée le $2^{\mathrm{e}}$ du $9^{\mathrm{e}}$ de l'an de la G.L. 5808, et célébrée le $27^{\mathrm{e}}$ du $12^{\mathrm{e}}$, même année (E.V., 27.02. 1809), en mémoire du R. commandeur-fondateur Jacques de Cambry, Mont-Thabor, Paris 5809 (1809), BnF-Digitalisat unter Permalink: http://gallica.bnf.fr/ark:/12148/ bpt6k841578v (Zugriff vom 25.05.2014).

212.D.33, Tableau des Off $\therefore$ Dign $\therefore$ et des FF $\therefore$ Qui composent la R $\therefore \square$ de St.-Jean d'Écosse, sous le Titre distinctif de la Naissance du Roi de Rome à l'Or $\therefore$ de Cologne, Cologne 5813 (1813).

240.C.53, Chevalier de l'Aigle du Pélican de Rose-Croix de St. André, ou le Parfait Maçon, c'est-à-dire: le Chev. de l'Aigle Souv. de Rose-Croix de Strasbourg 1760.

\section{Bibliothèque du Grand Orient de France, Paris (GOF)}

Sign. 5311, Commandeurs du Temple du Mont Thabor Rit Écossais Philosophique a l'O : de Paris, Paris 5809 (1809).

Sign. 5477, Loges de Paris.

\section{Bibliothèque Méjanes, Aix-en-Provence (BM)}

MS 1188 (417), Anecdotes de la vie de messire André de Ramsay, chevalier, baron, ou plus tost baneret d'Écosse, dictés par lui-même peu de jours avant sa mort, pressé par les instances réitérées de son épouze, Digitalisat: http://www.e-corpus.org/eng/ref/88281/ Ms_1188_(417)/(Zugriff vom 15.07.2014).

\section{Bibliothèque nationale de France, Manuscrit, Paris (BnF)}

FM1 289 (MF 33609), Papiers Comte de Valence et Archives Internes Mère Loge Écossais de France, 1807-1813.

FM1 289 (MF 33610), Papiers Comte de Valence et Archives Internes Mère Loge Écossais de France, 1807-1813. (= zweiter Teil)

FM1 295 (MF 33616), Livre d'architecture Mère Loge Écoss. de France.

FM1 300 (MF 33620), Lois du S $\therefore$ T $\therefore$ des GG $\therefore$ I $\therefore$ I $\therefore$ C $\therefore$.

FM2 58bis, Loge La Candeur, Paris, Tableaux, 1775-1782.

FM2 65bis, Loge et Chapitre Commandeurs du Mont Thabor, Tableaux, 1807-1808 et 1827. FM2 533, Loges Aix-la-Chapelle, Dossier Aix-la-Chapelle, Loge de la Concorde.

FM2 534, Loges Aix-la-Chapelle, Bonn, Coblence, Loge La Constance.

FM2 535 (MF 4589), Loge Cologne, 1812-1814.

FM2 536 (MF 4590), Loge Cologne.

Baylot FM3 2, Registre de la Dame Secrétaire G $\therefore$ du Souverain Chapitre Métropolitain des Dames écossaises du Mont Thabor, Paris, 1809-1819.

FM4 37, Rituel du Grade de Grand Inquisiteur Inspecteur Commandeur (précédé des statuts généraux des Tribunaux des GG $\therefore$ II $\therefore$ II $\therefore$ Comm $\therefore$ ), o.O., um 1817. 
FM4 681, Rit écossais philosophique, Cahier du Grade de la Parfait Élu, o.O., 21.09.1813.

FM4 683, Rit écossais philosophique, Cahier du Grade de Grand Écossais, Paris, 12.04.1813.

FM4 685, Instruction sur la maniere de conférer les Hauts-grades (Rit écossais philosophique), o.O., o.D.

FM4 687, Anneau Lumineux, Rit écossais philosophique, Paris, 07.09.1812.

FM4 817, Sublime et Souverain Prince du Royal Sécret Grand Inspecteur, o.O., Anfang 19. Jahrhundert.

FM4 824, Rit d'Herodom, Garde de la Tour, o.O., o.D.

FM4 828, Ordre Royal d'Écosse-Heredom de Kilwinning, Sublime grade de R $\therefore$ C. d'Heredom de Kilwinning, o.O., Anfang 19. Jahrhundert.

FR Nouv. Acq. 10956, Notes chronologiques pour servir à l' histoire de la Maçonnerie, o.O., o.D.

\section{Bibliothèque nationale et universitaire de Strasbourg (BnuS)}

MS 5437, Registre des Procès-Verbaux de la Loge de La Candeur constitutée mère des loges du Grand Orient de Strasbourg, Straßburg.

\section{Bayerische Staatsbibliothek München, Autographensammlung (BSB)}

Autograph Lenoir, Alexandre, Mediennummer HS005426191, Paris, 16.12.1812.

\section{Geheimes Staatsarchiv Preußischer Kulturbesitz, Berlin (GStA PK)}

FM 5.2.A2, Nr. 26/1 sowie 26/2, Zur Beständigkeit und Eintracht, Aachen, Logenmatrikel. FM 5.2.A2, Nr. 85, Zur Beständigkeit und Eintracht, Aachen, Protokollbuch, 1819-1822. FM 5.2.A2, Nr. 101, Zur Beständigkeit und Eintracht, Aachen, Vorträge, 1779-1838.

FM 5.2.A2, Nr. 102, Zur Beständigkeit und Eintracht, Französische Logenreden der Loge La Concorde, Aachen, 1804-1813.

FM 5.2.A2, Nr. 103, Zur Beständigkeit und Eintracht, Sammlung von Dokumenten und Reden, Aachen, 1816-1858.

FM 5.2.D48, Nr. 128, Zum Heiligen Joachim, Düsseldorf, Protokolle I, 1812-1815.

FM 5.2.D48, Nr. 165, Düsseldorfer Freimaurerei im 18. Jahrhundert nach den Akten des

Groß-Orients der Niederlande.

\section{Gräflich Mirbachsches Archiv}

182/4, Johann Wilhelm, Tagebuch, o.O., Oktober 1814. 


\section{Landesarchiv Nordrhein-Westfalen, Abteilung Rheinland, Düsseldorf (seit 05.05.2014 Duisburg) (LAV NRW)}

Sammlungen, Guntrum, Akten II, Nr. 38, Freimaurer.

\section{Privatbesitz der Narrenakademie Dülken}

Akte Raffelsieper.

\section{Stadtarchiv Viersen}

Fremdarchivalien, Nr. 78, Mondkalender der Dülkener Narrenakademie für die Jahre 1820-1899.

\section{Gedruckte Quellen}

Anderson, James, Royal Genealogies: Or, The Genealogical Tables of Emperors, Kings and Princes, From ADAM to these Times, In Two Parts, London 1732, BSB-Digitalisat nur für registrierte BSB-Nutzer - unter Permalink: http://opacplus.bsb-muenchen.de/ metaopac/search?oclcno $=220046302 \& \mathrm{db}=100$, Digitalisat mit Volltext: http://books. google.de/books?id=yrqeY839bMwC (Zugriff vom 15.07.2014).

Archiv für Geographie, Historie, Staats- und Kriegskunst 7 (1816), BSB-Digitalisat mit Volltext unter Permalink: http://nbn-resolving.org/urn:nbn:de:bvb:12-bsb10530589-8, Digitalisat mit Volltext: http://books.google.de/books?id=5i8OAAAAYAAJ (Zugriff vom 25.05.2014).

Bonnet, Charles, Traité d'Insectologie, ou Observations sur les Pucerons, Bd. 1, Paris 1745, BSB-Digitalisat mit Volltext unter Permalink: http://nbn-resolving.org/ urn:nbn:de:bvb:12-bsb10306750-6, BnF-Digitalisat unter Permalink: http://gallica. bnf.fr/ark:/12148/bpt6k991457, Digitalisat mit Volltext: http://books.google.de/books ?id=7r6Jy-5m8MAC (Zugriff vom 24.05.2014).

Buffon, Georges Louis Leclerc, Comte de/Louis Jean Marie Daubenton, Histoire Naturelle, Générale et Particulière, avec la description du Cabinet du Roi, Bd. 1, Paris 1749, BnFDigitalisat unter Permalink: http://gallica.bnf.fr/ark:/12148/bpt6k97490d (Zugriff vom 24.05.2014).

Boulainvilliers, Henri de, Essais sur la noblesse de France contenans une dissertation sur son origine \& abaissement, Amsterdam 1732, BSB-Digitalisat mit Volltext unter Permalink: http://nbn-resolving.org/urn:nbn:de:bvb:12-bsb10306750-6, Digitalisat mit Volltext: http://books.google.de/books?id=TQlbAAAAQAAJ (Zugriff vom 24/05/2014).

Cabanis, Pierre-Jean Georges, Lettre sur un passage de la Décade Philosophique, et en général sur la Perfectibilité de l'esprit humain, in: La Décade philosophique, littéraire et politique 21 (AN VII de la République Française, 30. Germinal), hier 149-159, 
BnF-Digitalisat unter Permalink: http://gallica.bnf.fr/ark:/12148/bpt6k423985j (Zugriff vom 25.04.2014).

Candolle, Alphonse Pyrame de, Géographie botanique raisonnée ou exposition des faits principaux et des lois concernant la distribution géographique des plantes de l'époque actuelle, 2 Bde., Paris/Genève 1855, BSB-Digitalisate mit Volltext unter Permalink: http://nbn-resolving.org/urn:nbn:de:bvb:12-bsb10476976-5 bzw. http://nbn-resolving. org/urn:nbn:de:bvb:12-bsb10306750-6, BnF-Digitalisate unter Permalink: http://gallica. bnf.fr/ark:/12148/bpt6k98177m bzw. http://gallica.bnf.fr/ark:/12148/bpt6k98178z, Digitalisate mit Volltext: http://books.google.de/books?id=xjA-AAAAcAAJ bzw. http:// books.google.de/books?id=7TA-AAAAcAAJ (Zugriff vom 24.05.2014).

Chansonnier Maç $\therefore$ et Prof $\therefore$, dédié aux Francs-Maç. de l'O $\therefore$ de Paris et des OO $\therefore$ étrangers, par le F $\therefore$ Aze, $\mathrm{K} \therefore \mathrm{D} \therefore$, Orateur de la respectable L $\therefore$ d'Isis; Deputé au $\mathrm{G} \therefore \mathrm{O} \therefore$ de son Chap $\therefore$, et de la $\mathrm{L} \therefore$ des Amis-réunis, à l'O $\therefore$ de Tarare; Capitaine en non-activité, Chevalier de la Légion d'honneur, Paris 1822, BnF-Digitalisat mit Volltext unter Permalink: http://gallica.bnf.fr/ark:/12148/bpt6k5544334c, Digitalisat mit Volltext: http://books.google.de/books?id=syyRoojlxEEC (Zugriff vom 24.05.2014).

Gutzkow, Karl, Briefe aus Paris, Erster Theil, Leipzig 1842, BSB-Digitalisat mit Volltext unter Permalink: http://nbn-resolving.org/urn:nbn:de:bvb:12-bsb10422172-1, Digitalisat mit Volltext: http://books.google.de/books?id=B-NdAAAAIAAJ (Zugriff vom 25.05.2014).

Helmont, Franciscus Mercurius van, Zweyhundert mit gebührender Bescheidenheit vorgestellte Fragen/ Betreffend die Lehre von der Wieder=Kehr der menschlichen Seelen/ und wie solche mit der Wahrheit des Christentums überein komme, o.O. 1686, Digitalisat der Staatsbibliothek zu Berlin unter Permalink: http://resolver.staatsbibliothek-berlin. de/SBB000063F600000000 (Zugriff vom 25.05.2014).

Helmont, Ioanne Baptista van/Francisco Mercurio van Helmont, Ortus Medicinæ. Id est, Initia physicæ inaudita. Progressus medicinæ novus, in morborum ultionem, ad vitam longam, Amsterdam 1652, BSB-Digitalisat mit Volltext unter Permalink: http:// nbn-resolving.org/urn:nbn:de:bvb:12-bsb10055180-6, Digitalisat mit Volltext: http:// books.google.de/books?id=uLubZKrl62QC (Zugriff vom 24.05.2014).

Helmont, Johann Baptista von, Aufgang der Artzney-Kunst/ Das ist: Noch nie erhörte Grund-Lehren von der Natur/ zu einer neuen Beförderung der Artzney-Sachen/ so wol Die Kranckheiten zu vertreiben/ als Ein langes Leben zu erlangen. Geschrieben von Johann Baptista von Helmont/ auf Merode/ Royenborch/ Oorschot/ Pellines/ etc. Erbherrn, Sulzbach 1683, BSB-Digitalisat unter Permalink: http://nbn-resolving.org/ urn:nbn:de:bvb:12-bsb10869856-0, Digitalisat mit Volltext: http://books.google.de/ books?id=4TFFAAAAcAAJ (Zugriff vom 24.05.2014).

Hübner, Johann, Kurze Fragen aus der Genealogie, Nebst denen darzu gehörigen Tabellen, zur Erläuterung Der Politischen Historie zusammen getragen, Und bey dieser zweyten Auflage bis auf gegenwärtige Zeit continuieret, Leipzig 1712, BSB-Digitalisat mit Volltext unter Permalink: http://nbn-resolving.org/urn:nbn:de:bvb:12-bsb10428228-2, Digitalisat mit Volltext: http://books.google.de/books?id=O5VAAAAAcAAJ (Zugriff vom 25.05.2014).

Jacobi, Friedrich Heinrich, Woldemar, Erster Theil, Königsberg 1794, Digitalisat der Staatsbibliothek zu Berlin unter Permalink: http://resolver.staatsbibliothek-berlin.de/ SBB00006BFB00010000, Digitalisat mit Volltext: http://books.google.de/books?id= 3GEHAAAAQAAJ (Zugriff vom 25.05.2014).

Ladoucette, Jean Charles François de, Voyage fait en 1813 et 1814 dans les pays entre Meuse et Rhin, suivi de notes, avec une carte géographique, Paris 1818, BSB-Digitalisat mit 
Volltext unter Permalink: http://nbn-resolving.org/urn:nbn:de:bvb:12-bsb10469005-7, Digitalisat mit Volltext: http://books.google.de/books?id=yGpCAAAAcAAJ (Zugriff vom 25.05.2014).

Lenoir, Alexandre, Observations critiques sur la Métempsycose, in: Académie Celtique, Mémoires de l'Académie celtique ou Mémoires d'antiquités celtiques, gauloises et françaises, Bd. 5, Paris 1810, 477-497, BSB-Digitalisat mit Volltext unter Permalink: http:// nbn-resolving.org/urn:nbn:de:bvb:12-bsb10534873-1, Digitalisat mit Volltext: http:// books.google.de/books?id=brRf4nk3rdYC (Zugriff vom 25.05.2014).

Linné, Carl von, Des Ritters Carl von Linné Pflanzensystem nach seinen Klassen, Ordnungen, Gattungen und Arten mit den Erkennungs und Unterscheidungszeichen, 14. Aufl., Wien 1786, BSB-Digitalisat mit Volltext unter Permalink: http://nbn-resolving.org/ urn:nbn:de:bvb:12-bsb10302318-7, Digitalisat mit Volltext: http://books.google.de/ books?id=UUE-AAAAcAAJ (Zugriff vom 25.05.2014).

Loen, Johann Michael von, Der Adel, Ulm 1752, Internet Archive-Digitalisat mit Volltext unter Permalink: http://n2t.net/ark:/13960/t3mw2d04t, BSB-Digitalisat unter Permalink: http://nbn-resolving.org/urn:nbn:de:bvb:12-bsb10920565-6, Digitalisat mit Volltext: http://books.google.de/books?id=EqpQAAAAcAAJ (Zugriff vom 25.05.2014).

Loyseau, Charles, Cinq livres du droict des offices, avec le livre des seigneuries, et celui des ordres, 2. Aufl., Paris 1613, BnF-Digitalisat unter Permalink: http://gallica. bnf.fr/ark:/12148/bpt6k118300j, Digitalisat mit Volltext: http://books.google.de/ books?id=sPiQq1NZ1zAC (Zugriff vom 22.05.2014).

Mangourit, Michel Ange Bernard de, Der Hannöversche Staat in allen seinen Beziehungen. Geschildert in den Jahren 1803 und 1804, Hamburg 1805, BSB-Digitalisat unter Permalink: http://nbn-resolving.org/urn:nbn:de:bvb:12-bsb10020396-0, Digitalisat mit Volltext: http://books.google.de/books?id=5XkAAAAAcAAJ (Zugriff vom 25.05.2014).

Monceau, Henri Louis Duhamel du/Charles René Fourcroy de Ramecourt/Jean-Gaffin Gallon, Descriptions des arts et métiers, faites ou approuvées par Messieurs de l'Académie royale des sciences de Paris, Bd. 4: L'Art du Tuilier et du briquetier, Paris 1763, Digitalisat mit Volltext: http://books.google.de/books?id=xkO2-sSfR10C (Zugriff vom 25.05.2014).

Monceau, Henri Louis Duhamel du, Traité Général des Pesches, et Histoire des Poissons qu'elles fournissent, tant pour la subsistance des hommes, que pour plusieurs autres usages qui ont rapport aux Arts et au Commerce, Bd. 2, Paris 1772, BnF-Digitalisat unter Permalink: http://gallica.bnf.fr/ark:/12148/btvlb8626558w (Zugriff vom 25.05.2014).

Newton, Sir Isaac, Opticks: or a treatise of the reflections, refractions, inflections and colours of the light, 4. Aufl., London 1730, Internet Archive-Digitalisat mit Volltext unter Permalink: n2t.net/ark:/13960/t3ws8zp9j, Transkription bei Projekt Gutenberg: http://www.gutenberg.org/files/33504/33504-h/33504-h.htm, weitere Transkriptionen bzw. Digitalisate des Originals bei Newton Project bzw. Cambridge Digital Library: http://www.newtonproject.sussex.ac.uk/prism.php?id=1 (Zugriff vom 12.08.2014).

Newton, Sir Isaac, The Chronology of Ancient Kingdoms Amended, London 1728, HathiTrust-Digitalisat mit Volltext unter Permalink: http://hdl.handle.net/2027/ mdp.39015007005500, Transkription bei Projekt Gutenberg: http://www.gutenberg.org/ ebooks/15784, weitere Transkriptionen bei Newton Project: http://www.newtonproject. sussex.ac.uk/prism.php?id=1 (Zugriff vom 15.07.2014).

N.N., Chymische Hochzeit: Christiani Rosencreutz Anno 1459, Straßburg 1616, Digitalisat des Göttinger Digitalisierungszentrums unter Permalink: http://resolver.sub. 
uni-goettingen.de/purl?PPN661910350, Digitalisat mit Volltext: http://books.google.de/ books?id=BXYvAQAAMAAJ (Zugriff vom 24.05.2014).

N.N., Das Schloß zur Dyk [sic!], mit der neuen botanischen Anlage, und dem alten Rittersaale, in: Gesellschaft von Freunden des Vaterlandes (Hg.), Vaterländische Blätter, den Bewohnern des Niederrheins gewidmet, Zweiter Band, Erstes Heft, Düsseldorf 1814, 35-42, Digitalisat der Universitäts- und Landesbibliothek Düsseldorf unter Permalink: http://nbn-resolving.org/urn:nbn:de:hbz:061:1-97846 (Zugriff vom 19.07.2014).

N.N., Hugo Franz Altgraf von Salm-Reifferscheidt-Krautheim, in: Joseph Freiherr von Hormayr (Hg.), Taschenbuch für die vaterländische Geschichte, 29. Jahrgang der gesammten und 11. der neuen Folge, Leipzig 1840, 523-596, BSB-Digitalisat mit Volltext unter Permalink: http://nbn-resolving.org/urn:nbn:de:bvb:12-bsb10009920-5, Digitalisat mit Volltext: http://books.google.de/books?id=6qO6AAAAIAAJ (Zugriff vom 21.07.2014).

N.N., Poésies de Madame La Princesse Constance de Salm, Bd. 2, 3. Aufl., Paris 1835, BnFDigitalisat mit Volltext unter Permalink: http://gallica.bnf.fr/ark:/12148/bpt6k5601159q (Zugriff vom 25.05.2014).

N.N., Verzeichniss der Mitglieder der Gerechten und vollkommenen St. Johannes $\square$ Zur Gekrönten Hoffnung im Orient von Wien, Wien 1792.

N.N., Verzeichnis der Mitglieder der gerechten u. vollkommenen Freimaurer Loge Libanon zu den drei Cedern im Orient von Erlangen: Am Johannisfeste 5818, Erlangen 1818, BSBDigitalisat unter Permalink: http://nbn-resolving.org/urn:nbn:de:bvb:12-bsb10678162-9, Digitalisat mit Volltext: http://books.google.de/books?id=n0tNAAAAcAAJ (Zugriff vom 25.05.2014).

Pérau, Gabriel Louis Calabre/Johann Leuchtbecher/Johann Erich Biester, L'Ordre des Francs-Maçons trahi, et le secret des Mopses revelé, Amsterdam 1745, HathiTrust-Digitalisat mit Volltext unter Permalink: http://hdl.handle.net/2027/ucm.5323780964, BSBDigitalisat mit Volltext unter Permalink: http://nbn-resolving.org/urn:nbn:de:bvb:12bsb10435606-1 (Zugriff vom 25.05.2014).

Petrasch, Carl/Johann Wilhelm Brewer, Der Narren=Orden zu Cleve, dessen Entstehen, die Namen der sämmtlichen Stifter desselben, und die Abbildung des von Ihnen getragenen Ehrenzeichens, Köln 1827.

Prichard, Samuel, Masonry Dissected, 20. Aufl., London 1770 [?] (Erstausgabe 1730), Internet Archive-Digitalisat mit Volltext unter Permalink: http://n2t.net/ark:/13960/ t4sj3xj9c, Digitalisat mit Volltext: http://books.google.de/books?id=4C9cAAAAQAAJ (Zugriff vom 25.05.2014).

Ramsay, Andrew Michael, Les Voyages de Cyrus, avec un Discours sur la Mythologie, 2 Bde., Amsterdam 1728, BSB-Digitalisate unter Permalink: http://nbn-resolving.org/ urn:nbn:de:bvb:12-bsb10748484-6 bzw. http://nbn-resolving.org/urn:nbn:de:bvb:12-bsb 10096583-7, Digitalisat beider Bände mit Volltext: http://books.google.de/books?id= jeMPAAAAYAAJ (Zugriff vom 25.05.2014).

Revue encyclopédique ou Analyse raisonnée des productions les plus remarquables dans les sciences, les arts industriels, la littérature et les beaux-arts; par une Réunion de Membres de l'Institut et d'autres hommes de lettres, Bd. 31, Paris 1826, HathiTrustDigitalisat mit Volltext unter Permalink: http://hdl.handle.net/2027/hvd.hxjgsv (Zugriff vom 25.05.2014).

Rondonneau, L[ouis], Institution des Majorats et de la Légion d'honneur, ou Receuil chronologique des Sénatus-consultes, des Lois, des Décrets, des Avis du Conseil d'État et des Lettres-patentes, concernant l'institution des Titres, Dignités et Majorats, Paris 1811, 
Digitalisat mit Volltext: http://books.google.de/books?id=ohNEAAAAcAAJ (Zugriff vom 25.05.2014).

Salm, Constance de, Eloge Historique de M. De La Lande; par M. ${ }^{\text {me }}$ la C. ${ }^{\text {tesse }}$ Constance de S., Paris 1810, BnF-Digitalisat mit Volltext unter Permalink: http://gallica.bnf.fr/ ark:/12148/bpt6k5613408b (Zugriff vom 25.05.2014).

Shelton, Maurice, An Historical and Critical Essay on the True Rise of Nobility, Political and Civil, London 1718, Internet Archive-Digitalisat mit Volltext unter Permalink: http://n2t.net/ark:/13960/t0zp51j1b, HathiTrust-Digitalisat mit Volltext unter Permalink: http://hdl.handle.net/2027/mdp.39015002445073 (Zugriff vom 25.05.2014).

Spangenberg, Cyriacius, Adels-Spiegel. Historischer ausführlicher Bericht: Was Adel sey und heisse / Woher er kome / Wie mancherley er sey / Und Was denselben ziere und erhalte / auch hingegen verstelle und schwäche. Desgleichen von allen Göttlichen / Geistlichen und weltlichen Ständen auff Erden / u. wie solches alles der Innhalt nach der Vorrede nahmhafftig und in der ordnung zeiget, Bd. 1, Schmalkalden 1591, Digitalisat der Universitätsbibliothek Heidelberg unter Permalink: http://digi. ub.uni-heidelberg.de/diglit/drwspangenberg1591, BSB-Digitalisat mit Volltext unter Permalink: http://nbn-resolving.org/urn:nbn:de:bvb:12-bsb10143826-2 (Zugriff vom 25.05.2014).

The Constitutions of the Free-Masons. Containing the History, Charges, Regulations, \&c. of that most Ancient and Right Worshipful FRATERNITY, London 5723/1723 (Faksimile, New York 1855), Internet Archive-Digitalisat mit Volltext unter Permalink: http:// n2t.net/ark:/13960/t22b8xx16 (Zugriff vom 18.07.2014).

Thomasii, Christian, Kurtzer Entwurff der Politischen Klugheit, sich selbst und anderen in allen Menschlichen Gesellschafften wohl zu rathen, Und zu einer gescheidten Conduite zu gelangen; Allen Menschen, Die sich klug zu seyn düncken, oder die noch klug werden wollen, zu höchstnöthiger Bedürffnis und ungemeinen Nutzen; Nebst einen ausführlichen Register, Franckfurth/Leipzig 1713, Digitalisat der Universitätsund Landesbibliothek Sachsen-Anhalt unter Permalink: http://nbn-resolving.de/ urn:nbn:de:gbv:3:1-341186 (Zugriff vom 25.05.2014).

Thory, Claude Antoine, Acta Latomorum, ou Chronologie de l'Histoire de la Franch-Maçonnerie Française et Étrangere, 2 Bde., Paris 1815, HathiTrust-Digitalisate mit Volltext unter Permalink: http://hdl.handle.net/2027/njp.32101061269328 bzw. http://hdl. handle.net/2027/njp.32101061269286, BSB-Digitalisat mit Volltext unter Permalink: http://nbn-resolving.de/urn:nbn:de:bvb:12-bsb10445986-1 bzw. http://nbn-resolving. de/urn:nbn:de:bvb:12-bsb10445987-6 (Zugriff vom 25.05.2014).

Thory, Claude Antoine, Rosa Candolleana seu Descriptio Novæ Speciei Generis Rosaæ, dicata Pyr.-Aug. De Candolle, Parisiis 1819, BSB-Digitalisat mit Volltext unter Permalink: http://nbn-resolving.de/urn:nbn:de:bvb:12-bsb10303615-1, Digitalisat mit Volltext: http://books.google.de/books?id=3Fs-AAAAcAAJ (Zugriff vom 25.05.2014).

Tschudi, Baron Théodore-Henri de, L'étoile flamboyante, ou la société des Francs-Maçons, Considérée sous tous les aspects, Bd. 2, À l'Orient 1785 (Erstausgabe 1766), BnF-Digitalisat unter Permalink: http://gallica.bnf.fr/ark:/12148/bpt6k29010v (Zugriff vom 25.05.2014).

Weimann, Heinrich (Hg.), Kuriosa der berittenen Akademie der Künste und Wissenschaften, Bd. 1, Krefeld 1828, BSB-Digitalisat mit Volltext unter Permalink: http:// nbn-resolving.de/urn:nbn:de:bvb:12-bsb10578013-9, Digitalisat mit Volltext: http:// books.google.de/books?id=o-xDAAAAcAAJ (Zugriff vom 25.05.2014). 
Weimann, Heinrich (Hg.), Kuriosa der berittenen Akademie der Künste und Wissenschaften, Bd. 2, Krefeld 1829, Digitalisat der Staatsbibliothek zu Berlin unter Permalink: http://resolver.staatsbibliothek-berlin.de/SBB000063E000000000 (Zugriff vom 22.07.2014).

Wochenschrift des Vereines zur Beförderung des Gartenbaues in den Königlich Preussischen Staaten für Gärtnerei und Pflanzenkunde 19 (1861), Biodiversity Heritage Library-Digitalisat mit Volltext: http://www.biodiversitylibrary.org/item/24591\#page/7/ mode/lup, Digitalisat mit Volltext: http://books.google.de/books?id=jydAAAAAcAAJ (Zugriff vom 25.05.2014).

\section{Quelleneditionen}

Abschrift des Fürstendiploms, 28. Mai 1816, Transkription Elisabeth Schläwe, aus: Netzbiographie: Joseph zu Salm-Reifferscheidt-Dyck (1773-1861), in: historicum-estudies. net, [01.05.2014], http://www.historicum-estudies.net/epublished/netzbiographie/tran skriptionen/fuerstendiplom-1816 (Zugriff vom 01.05.2014).

Alsted, Johann Heinrich, Encyclopædia, in: Jörg Jochen Berns/Wolfgang Neuber (Hg.), Documenta Mnemonica. Enzyklopädie- und Lexikonartikel zur Mnemonik, Bd. 2: Das enzyklopädische Gedächtnis der Frühen Neuzeit, Tübingen 1998, 143-188.

Antwort auf Gesuch um Erhebung in den Fürstenstand, 15. Januar 1815, Transkription Elisabeth Schläwe, aus: Netzbiographie: Joseph zu Salm-Reifferscheidt-Dyck (1773-1861), in: his toricum-estudies.net, [01.05.2014], http://www.historicum-estudies.net/epublished/netz biographie/transkriptionen/gesuch-um-standeserhebung-1815 (Zugriff vom 01.05.2014).

Aufnahme des Grafen Joseph in den Freimaurer-Orden, 1800 [?], Transkription Elisabeth Schläwe, aus: Netzbiographie: Joseph zu Salm-Reifferscheidt-Dyck (1773-1861), in: histo ricum-estudies.net, [01.05.2014], http://www.historicum-estudies.net/epublished/netz biographie/transkriptionen/aufnahme-freimaurerorden-1800 (Zugriff vom 01.05.2014).

Bacon, Francis, Neu-Atlantis, hg. von Jürgen Klein, Stuttgart 2003.

Charrière, Madame de, Lettres Neuchâteloises. Mistriss Henley. Le Noble, Genf 1908, Internet Archive-Digitalisat mit Volltext unter Permalink: http://n2t.net/ark:/13960/ t8jd5p53z (Zugriff vom 18.07.2014).

Corpus Hermeticum, Bd. 4: Fragments extraits de Stobée (XXIII-XXIX), hg. und übers. von André-Jean Festugière, Paris 1954.

Dekret Napoleons über die Aufnahme des Sieur de Salm-Dyck als Kanzler der 4. Kohorte in die Ehrenlegion, 16. August 1806, Transkription Elisabeth Schläwe, aus: Netzbiographie: Joseph zu Salm-Reifferscheidt-Dyck (1773-1861), in: historicum-estudies.net, [01.05.2014], http://www.historicum-estudies.net/epublished/netzbiographie/transkripti onen/kanzler-der-ehrenlegion-1806 (Zugriff vom 01.05.2014).

Dotzauer, Winfried (Hg.), Quellen zur Geschichte der deutschen Freimaurerei im 18. Jahrhundert unter besonderer Berücksichtigung des Systems der Strikten Observanz (Schriftenreihe der Internationalen Forschungsstelle »Demokratische Bewegungen in Mitteleuropa 1770-1850«, 3), Frankfurt a.M. [u.a.] 1991.

Erklärung des Friedensrichters zur Flucht der Maria Theresia von Hatzfeld, August 1801, Transkription Elisabeth Schläwe, aus: Netzbiographie: Joseph zu Salm-ReifferscheidtDyck (1773-1861), in: historicum-estudies.net, [01.05.2014], http://www.historicum- 
estudies.net/epublished/netzbiographie/transkriptionen/erklaerung-des-friedensrich ters-1801 (Zugriff vom 01.05.2014).

Ernennung zum Präsidenten der Kantonalsversammlung (Elsen), 11. Juni 1803, Transkription Elisabeth Schläwe, aus: Netzbiographie: Joseph zu Salm-Reifferscheidt-Dyck (1773-1861), in: historicum-estudies.net, [01.05.2014], http://www.historicum-estudies. net/epublished/netzbiographie/transkriptionen/ernennungsurkunde-kantonspraesi dent-1803 (Zugriff vom 01.05.2014).

Kaiserliche Großjährigkeitserklärung für Graf Joseph, 31. Mai 1793, Transkription Elisabeth Schläwe, aus: Netzbiographie: Joseph zu Salm-Reifferscheidt-Dyck (1773-1861), in: historicum-estudies.net, [05.06.2014], http://www.historicum-estudies.net/epublished/netz biographie/transkriptionen/grossjaehrigkeitserklaerung-1793 (Zugriff vom 21.11.2014).

Hansen, Joseph, Quellen zur Geschichte des Rheinlandes im Zeitalter der Französischen Revolution 1780-1801, Bd. 1, Bonn 1931.

Irmen, Hans-Josef (Hg.), Die Protokolle der Wiener Freimaurerloge »Zur wahren Eintracht" (1781-1785) (Schriftenreihe der Internationalen Forschungsstelle »Demokratische Bewegungen in Mitteleuropa 1770-1850«, 15), Frankfurt a.M. [u.a.] 1994.

Jacobi, Friedrich Heinrich, Discours Préliminaire zu Le Noble (1771), in: Ders., Kleine Schriften I: 1771-1783, hg. von Catia Goretzki/Walter Jaeschke (Friedrich Heinrich Jacobi: Werke, 4,1), Hamburg 2006, 9 f.

Jacobi, Friedrich Heinrich, Über die Lehre des Spinoza in Briefen an den Herrn Moses Mendelssohn, bearb. von Marion Lauschke (Philosophische Bibliothek, 517), Hamburg 2000.

Jolly, Claude (Hg.), Destutt de Tracy, Premiers écrits (1789-1794). Sur l'éducation et l'instruction publique, Euvres complètes I, Paris 2011.

Jolly, Claude (Hg.), Destutt de Tracy. Lettres à Joseph Rey 1804-1814 (Hautes Études Médiévales et Modernes, 82), Genève 2003.

Kopie der Reichskammergerichtsakten, April 1798 (in Auszügen), Transkription Elisabeth Schläwe, aus: Netzbiographie: Joseph zu Salm-Reifferscheidt-Dyck (1773-1861), in: his toricum-estudies.net, [01.05.2014], http://www.historicum-estudies.net/epublished/netz biographie/transkriptionen/prozessakten-in-auszuegen-1798 (Zugriff vom 01.05.2014).

Lamprecht, Jakob Friedrich, Rede, welche am Johannisfeste in der großen Loge der Freimäurer zu Berlin gehalten worden, in: Karlheinz Gerlach (Hg.), Berliner Freimaurerreden 1743-1804 (Schriftenreihe der Internationalen Forschungsstelle »Demokratische Bewegungen in Mitteleuropa 1770-1850«, 22), Frankfurt a.M. [u.a.] 1996, 11-16.

Lenoir, Alexandre, La Franc-Maçonnerie rendue à sa véritable Origine ou l'antiquité de la Franc-Maçonnerie prouvée par l'explication des mystères anciens et modernes, Paris 2009 (Erstausgabe 1814).

Lessing, Gotthold Ephraim, Werke, Bd. 8: Theologiekritische Schriften III. Philosophische Schriften, hg. von Herbert G. Göpfert, Darmstadt 1979.

Die alten Matrikeln der Universität Strassburg: 1621 bis 1793, Bd. 1: Die allgemeinen Matrikeln und die Matrikeln der philosophischen und theologischen Fakultät, bearb. von Gustav C. Knod, Strassburg 1897.

Napoleon an den neuernannten Kantonspräsidenten, Bestimmungen zur Einberufung der Kantonsversammlung, 11. Juni 1803, Transkription Elisabeth Schläwe, aus: Netzbiographie: Joseph zu Salm-Reifferscheidt-Dyck (1773-1861), in: historicum-estudies. net, [01.05.2014], http://www.historicum-estudies.net/epublished/netzbiographie/ transkriptionen/schreiben-an-kantonspraesidenten-1803 (Zugriff vom 01.05.2014). 
Promemoria zur Verfassungsfrage, 28. Januar 1831 [Entwurf], Transkription Elisabeth Schläwe, aus: Netzbiographie: Joseph zu Salm-Reifferscheidt-Dyck (1773-1861), in: historicum-estudies.net, [01.05.2014], http://www.historicum-estudies.net/epublished/ netzbiographie/transkriptionen/promemoria-entwurf-1831 (Zugriff vom 01.05.2014).

Schönberger, Otto (Hg.), Physiologus, Stuttgart 2001.

Vergil, Aeneis. Lateinisch-Deutsch, hg. von Johannes Götte, 5. Aufl., München 1980. 



\section{Literaturverzeichnis}

\section{Lexika, Biographien und genealogische Werke}

Ernst von Oidtman und seine genealogisch-heraldische Sammlung in der UniversitätsBibliothek zu Köln, bearb. von Herbert M. Schleicher (Veröffentlichungen der Westdeutschen Gesellschaft für Familienkunde e.V., 58-110), Bde. 1-18, Köln 1991-1999.

Fahne, Anton, Geschichte der Grafen, jetzigen Fürsten zu Salm-Reifferscheid, sowie ihrer Länder und Sitze: nebst derjenigen Familien, aus denen sie ihre Frauen genommen, Bd. 1, 2. Abt., Cöln 1866, BSB-Digitalisat mit Volltext unter Permalink: http:// nbn-resolving.de/urn:nbn:de:bvb:12-bsb10624325-0 (Zugriff vom 25.05.2014).

Gothaischer genealogischer Hofkalender nebst diplomatisch-statistischem Jahrbuche auf das Jahr 1750, Sieben und Achtzigster Jahrgang, Gotha 1850, BSB-Digitalisat mit Volltext unter Permalink: http://nbn-resolving.de/urn:nbn:de:bvb:12-bsb10620158-2, Digitalisat mit Volltext: http://books.google.de/books?id=E_RBAAAAcAAJ (Zugriff vom 18.07.2014).

Lennhoff, Eugen/Oskar Posner/Dieter Anton Binder (Hg.), Internationales FreimaurerLexikon, 5. überarbeitete und aktualisierte Aufl., München 2006.

Lenning, C., Allgemeines Handbuch der Freimaurerei, Bd. 1, Leipzig 1822.

Lenning, C., Allgemeines Handbuch der Freimaurerei, Bd. 2, 2. Aufl., Leipzig 1865, BSB-Digitalisat mit Volltext unter Permalink: http://nbn-resolving.de/urn:nbn:de: bvb:12-bsb10435410-4, Digitalisat mit Volltext: http://books.google.de/books?id= nRWAAAAcAAJ (Zugriff vom 25.05.2014).

Martin, Georges, Histoire et généalogie de la Maison de Merode, Lyon 1999.

Michaud, Louis Gabriel (Hg.), Biographie Universelle Ancienne et Moderne, ou Histoire, par ordre alphabétique, de la vie publique et privée de tous les hommes qui se sont fait remarquer par leurs écrits, leurs actions, leurs talents, leurs vertus ou leurs crimes, Bd. 14, Paris 1856, BnF-Digitalisat mit Volltext unter Permalink: http://gal lica.bnf.fr/ark:/12148/bpt6k51654t, Digitalisat mit Volltext: http://books.google.de/ books?id=zm1XAAAAYAAJ (Zugriff vom 25.05.2014).

Strange, Joseph, Beiträge zur Genealogie der adligen Geschlechter, Zweites Heft, Cöln 1865, BSB-Digitalisat unter Permalink: http://nbn-resolving.de/ urn:nbn:de:bvb:12-bsb10703981-8 (Zugriff vom 25.05.2014).

Wunschmann, Ernst, Salm-Reifferscheid, Josef, in: Allgemeine Deutsche Biographie, Bd. 30, Leipzig 1890, 255-257, http://www.deutsche-biographie.de/pnd118750992. html?anchor=adb (Zugriff vom 16.10.2012).

Zedler, Johann Heinrich, Grosses vollständiges Universal-Lexicon Aller Wissenschaften und Künste, Bde. 1-64, Halle/Leipzig 1732-1750, http://www.zedler-lexikon.de/ (Zugriff vom 25.05.2014).

Zedlitz-Neukirch, Freiherr Leopold von, Neues preußisches Adels-Lexicon oder genealogische und diplomatische Nachrichten von den in der preussischen Monarchie ansässigen oder zu derselben in Beziehung stehenden fürstlichen, gräflichen, freiherrlichen und adeligen Häusern, mit der Angabe ihrer Abstammung, ihres Besitzthums, ihres Wappens und der aus ihnen hervorgegangenen Civil- und Militärpersonen, Helden, Gelehrten und Künstler, Supplement Band oder des ganzen Werkes fünfter Band, Leipzig 1839, Internet Archive-Digitalisat mit Volltext unter Permalink: http://n2t.net/ 
ark:/13960/t13n2989z, HathiTrust-Digitalisat mit Volltext unter Permalink: http://hdl. handle.net/2027/hvd.hx3kn7, BSB-Digitalisat unter Permalink: http://nbn-resolving. de/urn:nbn:de:bvb:12-bsb10428662-1 (Zugriff vom 25.05.2014).

\section{Kataloge}

Bendel, Reinhold, Die Ableitung der Freimaurerei von den Steinmetzbruderschaften, Tempelritterorden und den älteren Rosenkreuzerbruderschaften, in: Joachim Berger/KlausJürgen Grün (Hg.), Geheime Gesellschaft. Weimar und die deutsche Freimaurerei, (Ausstellungskatalog: Weimarer Klassik, Schiller-Museum Weimar, 21.06.-31.12.2002), München/Wien 2002, 62-74.

Haller, Bertram, Aus der Bibliothek Fürstenberg-Stammheim, (Ausstellungskatalog: Stadtsparkasse Münster, 16.05.-27.05.1988) (Schriften der Universitätsbibliothek Münster, 1), Münster 1988.

Neugebauer-Wölk, Monika, Zur Konzipierung der bürgerlichen Gesellschaft. Freimaurerei und Esoterik, in: Joachim Berger/Klaus-Jürgen Grün (Hg.), Geheime Gesellschaft. Weimar und die deutsche Freimaurerei, (Ausstellungskatalog: Weimarer Klassik, SchillerMuseum Weimar, 21.06.-31.12.2002), München/Wien 2002, 80-89.

Raschke, Bärbel, Androgyne Arkangesellschaften und Freimaurerei. Entwicklungs- und Beziehungsprobleme aus der Perspektive hochadliger Frauen, in: Joachim Berger/ Klaus-Jürgen Grün (Hg.), Geheime Gesellschaft. Weimar und die deutsche Freimaurerei, (Ausstellungskatalog: Weimarer Klassik, Schiller-Museum Weimar, 21.06.31.12.2002), München/Wien 2002, 153-159.

Senator \& Hanstein, Auktion 66: Bibliothek Schloss Dyck und weitere wertvolle Bücher, Druckgraphik, Handzeichnungen, Autographen, 14.-15.09.1992, Köln 1992.

\section{Aufsätze, Monographien und Sammelbände}

Abafi, Lajos, Geschichte der Freimaurerei in Österreich-Ungarn, Bd. 1, Budapest 1890.

Agethen, Manfred, Geheimbund und Utopie. Illuminaten, Freimaurer und deutsche Spätaufklärung (Ancien Régime, Aufklärung und Revolution, 11), München 1984.

Alderson, Robert J., Jr., This Bright Era of Happy Revolutions. French Consul MichelAnge-Bernard Mangourit and International Republicanism in Charleston 1792-1794, Columbia 2008.

Alt, Peter-André/Volkhard Wels, Einleitung, in: Dies. (Hg.), Konzepte des Hermetismus in der Literatur der Frühen Neuzeit (Berliner Mittelalter- und Frühneuzeitforschung, 8), Göttingen 2010, 7-22.

Amiable, Louis, Une loge maçonnique d'avant 1789. La R $\therefore$ M $\therefore$ Les Neuf Sœurs, Paris 1897, Internet Archive-Digitalisat mit Volltext unter Permalink: http://n2t.net/ark:/13960/ t7sn12755 (Zugriff vom 18.07.2014).

Angelike, Karin, Louis-François Mettra. Ein französischer Zeitungsverleger in Köln (17701800) (Rheinisches Archiv, 145), Diss., Köln/Weimar/Wien 2002.

Anstey, Peter R., John Locke and Helmontian Medicine, in: Charles T. Wolfe/Ofer Gal (Hg.), The Body as Object and Instrument of Knowledge. Embodied Empiricism in 
Early Modern Science (Studies in History and Philosophy of Science, 25), Dordrecht [u.a.] 2010, 93-120.

Antonín, Luboš, Rájec nad Svitavou [Raitz], in: Handbuch der historischen Buchbestände in Deutschland. Digitalisiert von Günter Kükenshöner, hg. von Bernhard Fabian, Hildesheim 2003, [2003], http://fabian.sub.uni-goettingen.de/?Rajec_Nad_Svitavou (Zugriff vom 31.08.2012).

Antonsen, Jan Erik, Text-Inseln. Studien zum Motto in der deutschen Literatur vom 17. bis 20. Jahrhundert (Epistemata. Würzburger wissenschaftliche Schriften: Reihe Literaturwissenschaften, 258), Würzburg 1998.

Asch, Ronald G., Europäischer Adel in der Frühen Neuzeit. Eine Einführung, Köln/Weimar/Wien 2008.

Assmann, Aleida, Erinnerungsräume. Formen und Wandlungen des kulturellen Gedächtnisses, 3. Aufl., München 2006.

Assmann, Jan, Die Zauberflöte: Oper und Mysterium, München/Wien 2005.

Assmann, Jan, Das kulturelle Gedächtnis. Schrift, Erinnerung und politische Identität in frühen Hochkulturen, 6. Aufl., München 2007.

Aubert, Guillaume, Kinship, Blood and the Emergence of the Racial Nation in the French Atlantic World, 1600-1789, in: Christopher Howard Johnson [u.a.] (Hg.), Blood \& Kinship. Matter for metaphor from ancient Rome to the present, New York [u.a.] 2013, 175-195.

Babel, Rainer/Werner Paravicini (Hg.), Grand Tour. Adeliges Reisen und europäische Kultur vom 14. bis zum 18. Jahrhundert (Beihefte der Francia, 60), Ostfildern 2005, BSB-Digitalisat unter Permalink: http://nbn-resolving.org/urn:nbn:de:bvb:12-bsb00026833-7, Digitalisat mit Volltext: http://www.perspectivia.net/content/publikationen/bdf/babelparavicini_grand-tour (Zugriff vom 25.05.2014).

Bachmann Manuel/Thomas Hofmeier, Geheimnisse der Alchemie, Basel 1999.

Baecque, Antoine de, Les éclats du rire. La culture des rieurs au XVIIIe siècle, Paris 2000.

Bank, Matthias von der/Hildegard Brog/Marcus Leifeld, »Freiheit und Gleichheit im Narrenthum«. Das Bild Napoleons und Frankreichs im rheinischen Karneval des 19. Jahrhunderts, in: Kerstin Theis/Jürgen Wilhelm (Hg.), Frankreich am Rhein. Die Spuren der »Franzosenzeit« im Westen Deutschlands, Köln 2009, 95-117.

Bauer, Volker, Die gedruckte Ahnentafel als Ahnenformular. Zur Interferenz von Herrschafts-, Wissens- und Medienordnung in der Universalgenealogie des 17. Jahrhunderts, in: Elizabeth Harding/Michael Hecht (Hg.), Die Ahnenprobe in der Vormoderne: Selektion - Initiation - Repräsentation (Symbolische Kommunikation und gesellschaftliche Wertesysteme Schriftenreihe des Sonderforschungsbereichs 496, 37), Münster 2011, 125-156.

Baumgartner, Christian M., Strikte Observanz. Der hohe Orden vom heiligen Tempel zu Jerusalem. Ein vergangenes templerisches und freimaurerisches System. 1751-1782. Aufstieg und Fall, Jarplund/Weding 2007.

Baxmann, Inge, Monströse Erfindungskunst, in: Inge Baxmann/Michael Franz/Wolfgang Schäffner (Hg.), Das Laokoon-Paradigma. Zeichenregime im 18. Jahrhundert, Berlin 2000, 404-417.

Beaufort, W. H. de, Brief van V. Goens aan den Graaf van Rechteren, in: Bijdragen en mededeelingen van het Historisch Genootschap, Tiende Deel, Utrecht 1887, 458-461, Digitalisat der Digitale Bibliotheek voor de Nederlandse Letteren: http://www.dbnl.org/ tekst/_bij005188701_01/_bij005188701_01_0016.php (Zugriff vom 25.05.2014).

Beaurepaire, Pierre-Yves, L’Autre et le Frère. L'étranger et la franc-maçonnerie en France au XVIIIe siècle (Les Dix-Huitièmes Siècles, 23), Paris 1998. 
Beaurepaire, Pierre-Yves, Un creuset maçonnique dans l'Europe des Lumières: La Loge de la Candeur, orient de Strasbourg, in: Revue d'Alsace 124 (1998), 89-120.

Beaurepaire, Pierre-Yves, L'espace des francs-maçons. Une sociabilité européenne au XVIII' siècle, Rennes 2003.

Beaurepaire, Pierre-Yves, Quand les francs-maçons signent des traités diplomatiques: circulations et échanges maçonniques entre France et Angleterre (1765-1775), in: Ann Thomson [u.a.] (Hg.), Cultural Transfers. France and Britain in the long eighteenth century, London/Paris 2010, 71-84.

Beaurepaire, Pierre-Yves, Freimaurer. Fürstliche Protektion, Hoflogen und hugenottische Netzwerke, in: Bernd Sösemann/Gregor Vogt-Spira (Hg.), Friedrich der Große in Europa. Geschichte einer wechselvollen Beziehung, Stuttgart 2012, 97-111.

Belmont, Nicole, L'Académie celtique et George Sand. Les débuts des recherches folkloriques en France, in: Romantisme 9 (1975), 29-38.

Bender, Eva, Die Prinzenreise. Bildungsaufenthalt und Kavalierstour im höfischen Kontext gegen Ende des 17. Jahrhunderts (Schriften zur Residenzkultur, 6), Diss., Berlin 2011.

Bergengruen, Maximilian, Nachfolge Christi - Nachahmung der Natur. Himmlische und Natürliche Magie bei Paracelsus, im Paracelsismus und in der Barockliteratur (Scheffler, Zesen, Grimmelshausen) (Paradeigmata, 26), Hamburg 2007.

Berger, Joachim, Hercules Vinariensis. Aneignungen eines europäischen Mythos in der Frühen Neuzeit, in: Hellmut Th. Seemann (Hg.), Europa in Weimar. Visionen eines Kontinents (Jahrbuch der Klassik Stiftung Weimar 2008), Weimar 2008, 77-104.

Berman, Ric, The Foundations of Modern Freemasonry. The Grand Architects: Political Change and the Scientific Enlightenment, 1714-1740, Brighton/Portland 2012.

Bernhardt, Marcus, »Es sollten gleichsam Krieges=Schulen seyn vor dem Adel, daß man geschickte Krieges=Officierer hätte.» Die Gründung militärischer Bildungsanstalten im Rheinland des 18. Jahrhunderts, in: Frank Günter Zehnder/Werner Schälke, Eine Gesellschaft zwischen Tradition und Wandel: Alltag und Umwelt im Rheinland des 18. Jahrhunderts (Der Riss im Himmel. Clemens August und seine Epoche, 3), Köln 1999.

Bernheim, Alain, Ramsay et ses deux discours, Paris 2011.

Best, Wilhelm, Die Fürstenlogen von Saarbrücken. Zur Geschichte der Freimaurerei in Nassau-Saarbrücken (Monographien zur Kunst- und Kulturgeschichte der Saarregion, 10), Walsheim 2000.

Beusch, Carl Heiner, Adlige Standespolitik im Vormärz: Johann Wilhelm Graf von Mirbach-Harff (1784-1849) (Historia profana et ecclesiastica, 3), Diss., Münster/Hamburg/ London 2001.

Bied, Robert, Le rôle d'un salon littéraire au début du XIXe siècle: les amis de Constance de Salm, in: Revue de l'Institut Napoléon 113 (1977), 121-160.

Biedermann, Hans, Das verlorene Meisterwort. Bausteine zu einer Kultur- und Geistesgeschichte des Freimaurertums, 3. Aufl., Wien/Köln/Weimar 1999.

Bill, Claus Heinrich, Adelige Freimaurer in Mecklenburg 1750 bis 1850. Ein prosopographischer Überblick zu Logen und Edelleuten, in: Nobilitas. Zeitschrift für deutsche Adelsforschung 22 (2002), 1082-1122.

Binder, Dieter Anton, Die Freimaurer. Ursprung, Rituale und Ziele einer diskreten Gesellschaft, 2. Aufl., Freiburg/Basel/Wien 2006.

Binder, Dieter Anton, Die Freimaurer. Geschichte, Mythos und Symbole, Wiesbaden 2009.

Binder, Dieter Anton, Freimaurerei oder die Erziehung zum Gentleman, in: Mitteilungen des Österreichischen Staatsarchivs 55 (2011), 333-353. 
Bitterli, Urs, Die »Wilden« und die »Zivilisierten«. Grundzüge einer Geistes- und Kulturgeschichte der europäisch-überseeischen Begegnung, München 1976.

Bloch, Marc, Die wundertätigen Könige, München 1998 (Erstausgabe 1924).

Böhmer, Leopold, Geschichte der Freimaurerei in Köln am Rhein von 1815 bis 1872 nebst Rückblicken auf ältere Epochen, Köln 1873.

Bogdan, Henrik, From Darkness to Light. Western Esoteric Rituals of Initiation, Göteborg 2003.

Boos, Heinrich, Geschichte der Freimaurerei. Ein Beitrag zur Kultur- und Literatur-Geschichte des 18. Jahrhunderts, 2. Aufl., Aarau 1906.

Böttcher, Nikolaus, Ahnenforschung in Hispanoamerika. "Blutsreinheit « und die CastasGesellschaft in Neu-Spanien im 18. Jahrhundert, in: Elizabeth Harding/Michael Hecht (Hg.), Die Ahnenprobe in der Vormoderne: Selektion - Initiation - Repräsentation (Symbolische Kommunikation und gesellschaftliche Wertesysteme Schriftenreihe des Sonderforschungsbereichs 496, 37), Münster 2011, 387-413.

Borchers, Stefan, Die Erzeugung des "ganzen Menschen«. Zur Entstehung von Anthropologie und Ästhetik an der Universität Halle im 18. Jahrhundert, Berlin/New York 2011.

Bourdieu, Pierre, Distinction. A Social Critique of the Judgement of Taste, 2. Aufl., London/New York 2010 (Erstausgabe 1979).

Brague, Rémi, Völkerwanderungen und Überschwemmungen. Die Flut als Metapher des Vergessens, in: Martin Mulsow/Jan Assmann (Hg.), Sintflut und Gedächtnis. Erinnern und Vergessen des Ursprungs, München 2006, 117-127.

Braun, Martin Otto, Ein Kavalier und sein soziales Netzwerk. Ausschnitte aus dem Journal der Bildungsreise des Reichsgrafen Johann Ignaz Wolff-Metternich zur Gracht (1740-1790), in: Rechtsrheinisches Köln. Jahrbuch für Geschichte und Landeskunde 35 (2010), 50-108.

Braun, Martin Otto, Franz Joseph Graf Wolff-Metternich zur Gracht (1710-1741). Karriereweg eines rheinischen Adligen am kurkölnischen Hof, in: Jahrbuch der Stadt Erftstadt 20 (2011), 66-76.

Braun, Martin Otto, »Arbeit am Ideal«. Reformpotentiale freimaurerischer Vergesellschaftung in Bezug auf den Rheinischen Adel der Sattelzeit (1750-1850), in: Zeitschrift für Internationale Freimaurerforschung 28 (2012), 77-80.

Braun, Martin Otto, Berlin, Paris, St. Louis. Eine Vermessung seines wissenschaftlichen Netzwerks, aus: Netzbiographie: Joseph zu Salm-Reifferscheidt-Dyck (1773-1861), in: historicum-estudies.net, [05.06.2014], http://www.historicum-estudies.net/epublished/ netzbiographie/franzoesische-zeit/wissenschaftliche-akademien (Zugriff vom 21.11.2014).

Braun, Martin Otto, Kanzler der vierten Kohorte der napoleonischen Ehrenlegion, aus: Netzbiographie: Joseph zu Salm-Reifferscheidt-Dyck (1773-1861), in: historicumestudies.net, [01.05.2014], http://www.historicum-estudies.net/epublished/netzbiogra phie/franzoesische-zeit/legion-dhonneur (Zugriff vom 01.05.2014).

Braun, Martin Otto, Mitgliedschaft in Freimaurer-Logen, aus Netzbiographie: Joseph zu Salm-Reifferscheidt-Dyck (1773-1861), in: historicum-estudies.net, [01.05.2014], http://www.historicum-estudies.net/epublished/netzbiographie/franzoesische-zeit/ freimaurerei (19.07.2014).

Braun, Martin Otto, Zwischen Repräsentation und Verantwortung - die Jagd, aus: Netzbiographie: Joseph zu Salm-Reifferscheidt-Dyck (1773-1861), in: historicum-estudies.net, [05.06.2014], http://www.historicum-estudies.net/epublished/netzbiographie/preussi sche-zeit/jagdleidenschaft (Zugriff vom 21.11.2014).

Braun, Martin Otto, »Quel titre font-il que j'y prenne? « Die Entscheidung gegen die Emigration im Jahr 1794 und ihre langfristigen Folgen, aus: Netzbiographie: Joseph zu 
Salm-Reifferscheidt-Dyck (1773-1861), in: historicum-estudies.net, [05.06.2014], http:// www.historicum-estudies.net/epublished/netzbiographie/franzoesische-zeit/emigra tion (Zugriff vom 21.11.2014).

Braun, Rudolf, Konzeptionelle Bemerkungen zum Obenbleiben. Adel im 19. Jahrhundert, in: Hans-Ulrich Wehler (Hg.), Europäischer Adel 1750-1950 (Geschichte und Gesellschaft, 13), Göttingen 1990, 87-95.

Brecht, Martin/Friedhelm Ackva (Hg.), Geschichte des Pietismus, Bd. 2: Der Pietismus im 18. Jahrhundert, Göttingen 1995.

Bremer, Jakob, Die reichsunmittelbare Herrschaft Dyck der Grafen und jetzigen Fürsten zu Salm-Reifferscheidt, Grevenbroich 1959.

Bronsart von Schellendorff, Friedrich, Deutscher Adel und Freimaurerei, Wismar 1929.

Brömer, Rainer, The Nature of the Soul and the Passage of Blood through the Lungs. Galen, Ibn al-Nafīs, Servetus, İtaki, «Aț̣ār, in: Manfred Horstmanshoff/Helen King/Claus Zittel (Hg.), Blood, Sweat and Tears. The Changing Concepts of Physiology from Antiquity into Early Modern Europe (Interdisciplinary Studies in Early Modern Culture, 25), Leiden/Boston 2012, 339-362.

Buchholtz, Klaus-Dietwardt, Isaac Newton als Theologe. Ein Beitrag zum Gespräch zwischen Naturwissenschaft und Theologie, Witten 1965.

Buchwald, Jed Z./Diane Greco Josefowicz, The Zodiac of Paris. How an Improbable Controversy over an Ancient Egyptian Artifact Provoked a Modern Debate between Religion and Science, Princeton/New Jersey 2010.

Büchel, Jochen, Psychologie der Materie. Vorstellungen und Bildungsmuster von der Assimilation von Nahrung im 17. und 18. Jahrhundert unter besonderer Berücksichtigung des Paracelsismus (Epistemata. Würzburger Wissenschaftliche Schriften, Reihe Philosophie, 375), Diss., Würzburg 2005.

Bullock, Steven C., Revolutionary Brotherhood. Freemasonry and the Transformation of the American Social Order 1730-1840, Chapel Hill/London 1998.

Callot, Émile, Maupertuis: Le Savant et le Philosophe. Présentation et Extraits, Paris 1964.

Carl, Horst, Genossenschaft und Herrschaftsverdichtung. Zur politischen Kultur von Adelseinungen im Alten Reich, in: Ronald G. Asch/Dagmar Freist (Hg.), Staatsbildung als kultureller Prozess. Strukturwandel und Legitimation von Herrschaft in der Frühen Neuzeit, Köln 2005, 405-428.

Cavaignac, François, Légende templière et imaginaire maçonnique dans le théâtre profane en France au XIX ${ }^{\mathrm{e}}$ siècle, in: Alain de Keghel/Bernard Moisy (Hg.), Deux Siècles de Rite Écossais Ancien Accepté en France 1804-2004, Paris 2004, 143-161.

Chappey, Jean-Luc, La Société des Observateurs de l'homme (1799-1804). Des anthropologues au temps de Bonaparte, Diss., Paris 2002.

Christ, Kurt, Friedrich Heinrich Jacobi: Rousseaus deutscher Adept. Rousseauismus in Leben und Frühwerk Friedrich Heinrich Jacobis, Würzburg 1998.

Collaveri, François, La franc-maçonnerie des Bonaparte, 2. Aufl., Paris 2007.

Collaveri, François, Napoléon franc-maçon?, 2. Aufl., Paris 2003.

Conrad, Horst, Die Kette. Eine Standesvereinigung des Adels auf dem Wiener Kongreß (Vereinigte Westfälische Adelsarchive Sonderveröffentlichung, 3), Münster 1979.

Cook, Harold J., The Society of Chemical Physicians, the New Philosophy, and the Restoration Court, in: Bulletin of the History of Medicine 61 (1987), 61-77.

Coudert, Allison, The impact of the Kabbalah in the seventeenth Century. The Life and Thought of Francis Mercury van Helmont (1614-1698), Leiden [u.a.] 1998.

Crous, Helmut A., »Dülken gab den Anstoss«. Gründungen in Düren, Linnich und Aachen, in: Kuriosa der Dülkener Narrenakademie, Mühlenheft 31 (1986). 
Dachez, Roger, Histoire de la franc-maçonnerie française, Paris 2003.

Darnton, Robert, Der Mesmerismus und das Ende der Aufklärung in Frankreich, Frankfurt a.M. 1986 (Erstausgabe 1968).

De Beer, E. (Hg.), The Correspondence of John Locke, Bd. 5, Oxford 1979.

Dent, Edward Joseph, Mozarts Opern, Berlin 1922.

Devyver, André, Le sang épuré. Les préjugés de race chez les gentilshommes français de l’Ancien Régime (1560-1720), Bruxelles 1973.

Dierse, Ulrich, Die Anfänge der sscience sociale ihrem Umkreis, in: Gudrun Gersmann/Hubertus Kohle (Hg.), Frankreich 1800. Gesellschaft, Kultur, Mentalitäten, Stuttgart 1990, 104-121.

Dipper, Christof, Der rheinische Adel zwischen Revolution und Restauration, in: Helmuth Feigl/Willibald Rosner (Hg.), Adel im Wandel. Vorträge und Diskussionen des 11. Symposions des Niederösterreichischen Instituts für Landeskunde, Horn, 02.-05.07.1990 (Studien und Forschungen aus dem Niederösterreichischen Institut für Landeskunde, 15), Wien 1991, 91-116.

Dore, André, Aperçus sur le rite des Sublimes Élus de la Vérité, in: Chroniques d'histoire maçonnique 25-26 (1980), 48-57.

Dotzauer, Winfried, Bonner aufgeklärte Gesellschaften und geheime Sozietäten bis zum Jahr 1815 unter besonderer Berücksichtigung des Mitgliederbestandes der Freimaurerloge »Frères courageux« in der napoleonischen Zeit, in: Bonner Geschichtsblätter 24 (1971), 78-142.

Dotzauer, Winfried, Die Mitglieder der Kölner Freimaurerlogen, insbesondere der Loge »Le Secret des trois Rois", vom Ende des alten Reiches bis zu den Freiheitskriegen: Ein Beitrag zur Entwicklung der städtischen Gesellschaft vom Ancien régime zum Zeitalter Napoleons, in: Jahrbuch des kölnischen Geschichtsvereins 44 (1973), 123-231, Digitalisat der Universitäts- und Stadtbibliothek Köln: http://www.ub.uni-koeln.de/cdm4/document. php?CISOROOT=/_RHPER\&CISOPTR=17662\&REC=14 (Zugriff vom 25.05.2014).

Dotzauer, Winfried, Freimaurergesellschaften am Rhein. Aufgeklärte Sozietäten auf dem linken Rheinufer vom Ausgang des Ancien Régime bis zum Ende der napoleonischen Herrschaft (Veröffentlichungen des Instituts für geschichtliche Landeskunde an der Universität Mainz, 16), Wiesbaden 1977.

Dotzauer, Winfried, Zur Sozialstruktur der Freimaurerei in Deutschland, in: Helmut Reinalter (Hg.), Aufklärung und Geheimgesellschaften. Zur politischen Funktion und Sozialstruktur der Freimaurerlogen im 18. Jahrhundert (Ancien Régime, Aufklärung und Revolution, 16), München 1989, 109-150.

Dotzauer, Winfried, Freimaurergesellschaften im Rheingebiet. Die Anfänge der Freimaurerei im Westen des Alten Reiches, in: Helmut Reinalter (Hg.), Freimaurer und Geheimbünde im 18. Jahrhundert in Mitteleuropa, 4. Aufl., Frankfurt a.M. 1993.

Dotzauer, Winfried, Freimaurerei global (Quellen und Darstellungen zur europäischen Freimaurerei, 11), Innsbruck 2009.

Dräxler, Hans-Dietrich, Die Idéologie in Deutschland. Versuch der Rekonstruktion der Rezeption einer französischen wissenschaftlichen Theorie im Deutschland des frühen 19. Jahrhunderts, Münster 1996.

Dufraisse, Roger, Les notables de la rive gauche du rhin à l'époque napoléonienne, in: Revue d' histoire moderne et contemporaine 17 (1970), 758-776.

Dunkhase, Heinrich Helmut, Das Fürstentum Krautheim. Eine Staatsgründung um Jagst und Tauber 1802-1806 (1839), Diss., Würzburg 1967.

Durry, Marie-Jeanne, L'académie celtique et la chanson populaire, in: Revue de littérature comparée 9 (1929), 62-73. 
Düselder, Heike, Vom »Botanisieren « und der »Nützlichkeit der Natur«. Naturaneignung und Herrschaftsverständnis des Adels im Kontext von Kultur, Bildung und Ökonomie, in: Heike Düselder/Olga Weckenbrock/Siegrid Westphal (Hg.), Adel und Umwelt. Horizonte adeliger Existenz in der Frühen Neuzeit, Köln/Weimar/Wien 2008, 19-50.

Düselder, Heike/Olga Weckenbrock, Einführung, in: Heike Düselder/Olga Weckenbrock/ Siegrid Westphal (Hg.), Adel und Umwelt. Horizonte adeliger Existenz in der Frühen Neuzeit, Köln/Weimar/Wien 2008, 1-16.

Ebeling, Florian, Das Geheimnis des Hermes Trismegistos. Geschichte des Hermetismus von der Antike bis zur Neuzeit, 2. Aufl., München 2009.

Ebersold, Günther, Louise von Hompesch (1775/1777-1801) und ihre Familie. Eine Frau zwischen Tradition und Revolution (Mannheimer historische Schriften, 2), UbstadtWeiher [u.a.] 2009.

Eckert, Georg, »True, Noble, Christian Freethinking«. Leben und Werk Andrew Michael Ramsays (1686-1743), Diss., Münster 2009.

Edighoffer, Roland, Die Rosenkreuzer, Sonderausgabe, München 2008.

Emsbach, Karl, Tod in Nizza. Zum Ableben von Fürst und Altgraf Joseph zu Salm-Reifferscheidt-Dyck, in: Jahrbuch für den Rhein-Kreis Neuss 2013 (2012), 74-81.

Erdbeer, Robert Matthias, Paläopoiesis/Paleofiction. Kognitionspoetik und >Erlebenswissenschaft ‘ bei Laßwitz und Hörbiger, in: Monika Neugebauer-Wölk/Renko Geffarth/ Markus Meumann (Hg.), Aufklärung und Esoterik: Wege in die Moderne (Hallesche Beiträge zur europäischen Aufklärung, 50), Berlin/Boston 2013, 461-503.

Espagne, Geneviève/Bénédicte Savoy (Hg.), Aubin-Louis Millin et l'Allemagne: Le Magasin encyclopédique. Les lettres à Karl August Böttiger (Europaea Memoria. Studien und Texte zur Geschichte der europäischen Ideen, Reihe 1: Studien, 41), Hildesheim/ Zürich/New York 2005.

Euler-Schmidt, Michael/Marcus Leifeld, Der Kölner Rosenmontagszug 1823-1948, Köln 2007.

Feddersen, Klaus C., Rituale des hohen Ordens zum heiligen Tempel zu Jerusalem, auch Strikte Observanz genannt, weltlicher Zweig nebst Ordensregeln und vielen Abbildungen aus dem Jahr 1764, Flensburg 1999.

Fehrenbach, Elisabeth, Geschichtsinteressen des Adels. Freiherr vom Stein und die Gründung der "Gesellschaft für ältere deutsche Geschichtskunde», in: Dieter Hein/Klaus Hildebrand/Andreas Schulz (Hg.), Historie und Leben. Der Historiker als Wissenschaftler und Zeitgenosse, Festschrift für Lothar Gall zum 70. Geburtstag, München 2006, 645-656.

Fiegenbaum, Thea, Die Kantonalspräsidentschaft des Citoyen Salm (1803-1813), aus: Netzbiographie: Joseph zu Salm-Reifferscheidt-Dyck (1773-1861), in: historicum-estudies. net, [01.05.2014], http://www.historicum-estudies.net/epublished/netzbiographie/ franzoesische-zeit/kantonalspraesidentschaft (Zugriff vom 01.05.2014).

Figalla, Karin, Gärung, in: Claus Priesner/Dies. (Hg.), Alchemie. Lexikon einer hermetischen Wissenschaft, München 1998, 143f.

Fischer, Klaus, Isaac Newton und das verlorene Wissen der Alten. Auf der Suche nach den inneren Kräften der Natur, in: Richard van Dülmen/Sina Rauschenbach (Hg.), Denkwelten um 1700. Zehn intellektuelle Profile, Köln/Weimar/Wien 2002, 41-62.

Fischer-Colbrie, Gerald, Die Mitgliederliste der Freimaurerloge "Zur gekrönten Hoffnung « aus Mozarts Sterbejahr aufgefunden, in: Mitteilungen der Internationalen Stiftung Mozarteum 3-4 (1993), 35-47.

Frick, Karl R. H., Die Erleuchteten. Gnostisch-theosophische und alchemistisch-rosenkreuzerische Geheimgesellschaften, Wiesbaden 2005. 
Frick, Karl R. H., Licht und Finsternis. Okkulte Geheimgesellschaften bis zur Wende des 20. Jahrhunderts, 2 Bde., Wiesbaden 2005.

Frie, Ewald, Adel um 1800. Oben bleiben?, in: zeitenblicke 4/3 (2005), [13.12.2005], http:// nbn-resolving.org/urn:nbn:de:0009-9-2457 (Zugriff vom 13.10.2014).

Frohn, Christina, »Löblich wird ein tolles Streben, Wenn es kurz ist und mit Sinn«. Karneval in Köln, Düsseldorf und Aachen 1823-1914, Diss., Bonn 1999, [1999], PDF-Datei der Universitäts- und Landesbibliothek Bonn mit Volltext unter Permalink: http:// nbn-resolving.org/urn:nbn:de:hbz:5-02121 (Zugriff vom 25.05.2014).

Geffarth, Renko D., Zirkel, Brüder, Unbekannte Obere. Zur inneren Struktur des Goldund Rosenkreuzerordens in Mittel- und Norddeutschland, in: Holger Zaunstöck/Markus Meumann (Hg.), Sozietäten, Netzwerke, Kommunikation. Neue Forschungen zur Vergesellschaftung im Jahrhundert der Aufklärung (Hallesche Beiträge zur Europäischen Aufklärung, 21), Tübingen 2003, 159-175.

Geffarth, Renko D., Religion und arkane Hierarchie. Der Orden der Gold- und Rosenkreuzer als Geheime Kirche im 18. Jahrhundert, Leiden 2007.

Gemoll, Br.[uder], Die Teilnahme des Adels und der Offiziere in den 3 preussischen Grosslogen, in: Schlesisches Logenblatt 20 (1900), o.S.

Gennep, Arnold van, Übergangsriten (Les rites de passage), Frankfurt a.M. 1986.

Gerlach, Karlheinz, Die Freimaurer im Alten Preußen 1738-1806. Die Logen zwischen mittlerer Oder und Niederrhein (Quellen und Darstellungen zur europäischen Freimaurerei, 8), Innsbruck 2007.

Gerlach, Karlheinz, Die Freimaurer im Alten Preußen 1738-1806. Die Logen in Pommern, Preußen und Schlesien (Quellen und Darstellungen zur europäischen Freimaurerei, 9), Innsbruck 2009.

Gerlach, Karlheinz, König Friedrich II. und die preußischen Freimaurer, in: Zeitschrift für Internationale Freimaurer-Forschung 28 (2012), 9-53.

Gersmann, Gudrun, Die Ehen, aus: Joseph zu Salm-Reifferscheidt-Dyck (1773-1861), in: historicum-estudies.net, [05.06.2014], http://www.historicum-estudies.net/epublished/ netzbiographie/franzoesische-zeit/ehen (Zugriff vom 21.11.2014).

Gersmann, Gudrun, Postrevolutionäre Netzwerke, aus: Netzbiographie: Joseph zu SalmReifferscheidt-Dyck (1773-1861), in: historicum-estudies.net, [01.05.2014], http://www. historicum-estudies.net/epublished/netzbiographie/franzoesische-zeit/netzwerke (Zugriff vom 01.05.2014).

Gersmann, Gudrun, Vorwort, aus: Netzbiographie: Joseph zu Salm-Reifferscheidt-Dyck (1773-1861), in: historicum-estudies.net, [01.05.2014], http://www.historicum-estudies. net/epublished/netzbiographie (Zugriff vom 01.05.2014).

Gersmann, Gudrun/Langbrandtner, Hans-Werner (Hg.), Adlige Lebenswelten im Rheinland. Kommentierte Quellen der Frühen Neuzeit (Vereinigte Adelsarchive im Rheinland e.V., 3), Köln/Weimar/Wien 2009.

Geuenich, Dieter/Otto Gerhard Oexle (Hg.), Memoria in der Gesellschaft des Mittelalters (Veröffentlichungen des Max-Planck-Instituts für Geschichte, 111), Göttingen 1994.

Geulen, Christian, Geschichte des Rassismus, München 2007.

Girard-Augry, Pierre, Le R $\therefore$ Chapitre de H.D.M. De Kilwinning sous la dénomination du Choix, Deuxieme Chapitre de l'Ordre en France et le Premier à Paris, in: Travaux de Villard de Honnecourt 9 (1973), 30-40.

Godsey, William D., Vom Stiftsadel zum Uradel. Die Legitimationskrise des Adels und die Entstehung eines neuen Adelsbegriffs im Übergang zur Moderne, in: Anja Victorine Hartmann/Małgorzata Morawiec/Peter Voss (Hg.), Eliten um 1800. Erfahrungshorizonte, Verhaltensweisen, Handlungsmöglichkeiten (Veröffentlichungen des Instituts 
für Europäische Geschichte Mainz, Abteilung für Universalgeschichte, 183), Mainz 2000, 371-391.

Goossens, Heinrich, Die Dülkener Narrenakademie oder »Die erleuchtete Mondsuniversität und berittene Akademie der Künste und Wissenschaften«, Dülken 1901.

Götz, Carmen, Friedrich Heinrich Jacobi im Kontext der Aufklärung. Diskurse zwischen Philosophie, Medizin und Literatur (Studien zum achtzehnten Jahrhundert, 30), Hamburg 2008.

Graf, Klaus, Ursprung und Herkommen. Funktionen vormoderner Gründungserzählungen, in: Hans-Joachim Gehrke (Hg.), Geschichtsbilder und Gründungsmythen, Würzburg 2001, 23-36, Digitalisat mit Volltext auf Freiburger Dokumentenserver unter Permalink: http://nbn-resolving.org/urn:nbn:de:hebis:30-1137987 (Zugriff vom 19.07.2014).

Graf, Klaus, Adel als Leitbild. Zur Geschichte eines Grundwerts in Spätmittelalter und früher Neuzeit, in: Horst Carl/Sönke Lorenz (Hg.), Gelungene Anpassung? Adelige Antworten auf gesellschaftliche Wandlungsvorgänge vom 14. bis zum 16. Jahrhundert (Schriften zur südwestdeutschen Landeskunde, 53), Ostfildern 2005, 67-81, Digitalisat mit Volltext auf Freiburger Dokumentenserver unter Permalink: http://nbn-resolving. org/urn:nbn:de:bsz:25-opus-56326 (Zugriff vom 25.05.2014).

Graumann, Sabine, Französische Verwaltung am Niederrhein. Das Roerdepartement 1798-1814 (Düsseldorfer Schriften zur Neueren Landesgeschichte und zur Geschichte Nordrhein-Westfalens, 27), Essen 1990.

Guiomar, Jean-Yves, La revolution et les origines celtiques de la France, in: Annales historiques de la Révolution Française 287 (1992), 63-85.

Gürtler, Heinz, Deutsche Freimaurer im Dienste napoleonischer Politik. Die Geschichte der Freimaurerei im Königreich Westfalen, Berlin 1942.

Gussone, Monika, Einstellung zu den sakralen Monumenten seiner Vorfahren, aus: Netzbiographie: Joseph zu Salm-Reifferscheidt-Dyck (1773-1861), in: historicum-estudies. net, [05.06.2014], http://www.historicum-estudies.net/epublished/netzbiographie/fran zoesische-zeit/monumente (Zugriff vom 21.11.2014).

Gussone,Monika,HochzeitinderFamilie, aus:Netzbiographie:JosephzuSalm-ReifferscheidtDyck (1773-1861), in: historicum-estudies.net, [05.06.2014], http://www.historicumestudies.net/epublished/netzbiographie/ancien-regime/hochzeit (Zugriff vom 21.11.2014).

Haddad, Elie, The Question of the Imprescriptibility of Nobility in Early Modern France, in: Matthew P. Romaniello/Charles Lipp (Hg.), Contested Spaces of Nobility in Early Modern Europe, Farnham 2011, 147-166.

Hammacher, Klaus/Hans Hirsch, Die Wirtschaftspolitik des Philosophen Jacobi (FichteStudien Supplementa, 1), Amsterdam/Atlanta 1993.

Hammermayer, Ludwig, Der Wilhelmsbader Freimaurer-Konvent von 1782. Ein Höheund Wendepunkt in der Geschichte der deutschen und europäischen Geheimgesellschaften (Wolfenbütteler Studien zur Aufklärung, V/2), Heidelberg 1980.

Hanegraaff, Wouter J., Esotericism and the Academy. Rejected Knowledge in Western Culture, Cambridge 2012.

Harding, Elizabeth/Michael Hecht (Hg.), Die Ahnenprobe in der Vormoderne: Selektion - Initiation - Repräsentation (Symbolische Kommunikation und gesellschaftliche Wertesysteme. Schriftenreihe des Sonderforschungsbereiches 496, 37), Münster 2011.

Harland-Jacobs, Jessica, All in the family. Freemasonry and the British Empire in the MidNineteenth century, in: The Journal of British Studies 42 (2003), 448-482.

Hartwig, Wolfgang, Eliteanspruch und Geheimnis in den Geheimgesellschaften des 18. Jahrhunderts, in: Helmut Reinalter (Hg.), Aufklärung und Geheimgesellschaften. 
Zur politischen Funktion und Sozialstruktur der Freimaurerlogen im 18. Jahrhundert (Ancien Régime, Aufklärung und Revolution, 16), München 1989, 63-86.

Hasselmann, Kristiane, Die Rituale der Freimaurer. Zur Konstitution eines bürgerlichen Habitus im England des 18. Jahrhunderts, Diss., Bielefeld 2009.

Heck, Kilian, Genealogie als Monument und Argument. Der Beitrag dynastischer Wappen zur politischen Raumbildung in der Neuzeit (Kunstwissenschaftliche Studien, 98), München/Berlin 2002.

Heck, Kilian/Bernhard Jahn (Hg.), Genealogie als Denkform in Mittelalter und Früher Neuzeit (Studien und Texte zur Sozialgeschichte der Literatur, 80), Tübingen 2000.

Heffernan, Michael, Edme Mentelle's Geographies and the French Revolution, in: David N. Livingstone/Charles W. J. Whithers (Hg.), Geography and Revolution, Chicago 2005, 273-303.

Heidle, Alexandra/Jan A.M. Snoek (Hg.), Women's Agency and Rituals in Mixed and Female Masonic Orders (Texts and Studies in Western Esotericism, 8), Leiden/Boston 2008.

Heinecke, Berthold, The Mysticism and Science of Johann Baptista van Helmont (15791644), in: Ambix 42 (1995), 65-78.

Heisig, Ines, Die Unternehmerfamilie von Heyl in Worms. Aspekte privater Kulturförderung im Kaiserreich, in: Gabriele B. Clemens/Malte König/Marco Meriggi (Hg.), Hochkultur als Herrschaftselement. Italienischer und deutscher Adel im langen 19. Jahrhundert, Berlin/Boston 2011, 233-262.

Henderson, George David, Chevalier Ramsay, London 1952.

Hering Torres, Max Sebastián, Rassismus in der Vormoderne: »Reinheit des Blutes « im Spanien der Frühen Neuzeit, Frankfurt a.M. 2006.

Hivert-Messeca, Yves, Portalis, Ministre des Cultes et des Rites ou la Théorie du Licol Doré, in: Pierre Mollier (Hg.), La franc-maçonnerie sous l'empire: Un âge d'or?, Paris 2007, $15-39$.

Hoffmann, Stefan-Ludwig, Die Politik der Geselligkeit. Freimaurerlogen in der deutschen Bürgergesellschaft 1840-1918 (Kritische Studien zur Geschichtswissenschaft, 141), Diss., Göttingen 2000.

Hombach, Rita, Der Park von Schloss Dyck, aus: Netzbiographie: Joseph zu Salm-Reifferscheidt-Dyck (1773-1861), in: historicum-estudies.net, [01.05.2014], http://www. historicum-estudies.net/epublished/netzbiographie/preussische-zeit/landschaftsgarten (Zugriff vom 01.05.2014).

Hombach, Rita, Die Pflanzensammlungen zu Dyck, aus: Netzbiographie: Joseph zu Salm-Reifferscheidt-Dyck (1773-1861), in: historicum-estudies.net, [01.05.2014], http://www.historicum-estudies.net/epublished/netzbiographie/franzoesische-zeit/ pflanzensammlung (Zugriff vom 01.05.2014).

Hombach, Rita, Botaniker, aus: Netzbiographie: Joseph zu Salm-Reifferscheidt-Dyck (1773-1861), in: historicum-estudies.net, [05.06.2014], http://www.historicum-estudies. net/epublished/netzbiographie/preussische-zeit/botanik (Zugriff vom 21.11.2014).

Hoymann, Rainer, Der Narrenorden. Vor 625 Jahren wurde am 12.11.1381 die "geselscap van den gecken" in Kleve gegründet, http://web.archive.org/web/20060110184318/ http://www.heimat-kleve.de/geschichte/narrenorden_16.01.2005/narrenorden.htm (Zugriff vom 19.07.2014).

Hubbertz, Erich, Zwei Jahrhunderte Freimaurerei am Niederrhein. Geschichte der Freimaurerloge PAX INIMICA MALIS in Emmerich (Emmericher Forschungen, 1), Kleve 1979.

Huber, Eva, Zur Sozialstruktur der Wiener Logen im Josephinischen Jahrzehnt, in: Helmut Reinalter (Hg.), Aufklärung und Geheimgesellschaften. Zur politischen Funktion und 
Sozialstruktur der Freimaurerlogen im 18. Jahrhundert (Ancien Régime, Aufklärung und Revolution, 16), München 1989, 173-188.

Huber, Eva, Sozialstruktur der Wiener Freimaurer 1780-1790, 2. Teil, Diss., Wien 1991.

Irmen, Hans-Josef, Mozart. Mitglied geheimer Gesellschaften, Zülpich 1988.

Jacob, Margaret C., The Radical Enlightenment: Pantheists, Freemasons and Republicans, London/Worcester 1981.

Jacob, Margaret C., Living the Enlightenment: Freemasonry and Politics in Eighteenth-Century Europe, Oxford 1991.

Jacob, Margaret C., Money, Equality, Fraternity: Freemasonry and the Social Order in Eighteenth-century Europe, in: Thomas L. Haskell, Richard F. Teichgraeber III (Hg.), The culture of the market. Historical Essays, Cambridge 1996, 102-135.

Javor, Martin, Slobodomurárske Hnutie V Českých Krajinách A V Uhorsku V 18. Storočí, Prešov 2009.

Johnson, Christopher H., Class Dimensions of Blood, Kinship, and Race in Brittany, 17801880, in: Ders. [u.a.] (Hg.), Matter for metaphor from ancient Rome to the present, New York [u.a.] 2013, 196-226.

Jordan, Stefan, Die Sattelzeit als Epoche, in: Klaus Erich Müller (Hg.), Historische Wendeprozesse. Ideen, die Geschichte machten, Freiburg 2003, 188-203.

Jordan, Stefan, Die Sattelzeit. Transformation des Denkens oder revolutionärer Paradigmenwechsel, in: Achim Landwehr (Hg.), Frühe Neue Zeiten. Zeitwissen zwischen Reformation und Revolution (Mainzer Historische Kulturwissenschaften, 2), Bielefeld 2012, 373-388.

Jung, Carl, Kaross und Kimono. »Hottentotten« und Japaner im Spiegel des Reiseberichts von Carl Peter Thunberg (1743-1828) (Beiträge zur Kolonial- und Überseegeschichte, 85), Diss., Stuttgart 2002.

Kaiser, Michael/Florian Schönfuß, Einführung, in: zeitenblicke 9/1 (2010), [10.06.2010], http://nbn-resolving.org/urn:nbn:de:0009-9-25200 (Zugriff vom 13.10.2014).

Kantorowicz, Ernst H., Die zwei Körper des Königs. Eine Studie zur politischen Theologie des Mittelalters, 2. Aufl., München 1994.

Katz, Jacob, Der Orden der Asiatischen Brüder, in: Helmut Reinalter (Hg.), Freimaurer und Geheimbünde im 18. Jahrhundert in Mitteleuropa, 4. Aufl., Frankfurt a.M. 1993, 240-283.

Keferstein, Mara, Die Einrichtung eines Majorats und die Ernennung zum Comte d'Empire, aus: Netzbiographie: Joseph zu Salm-Reifferscheidt-Dyck (1773-1861), in: historicum-estudies.net, [01.05.2014], http://www.historicum-estudies.net/epublished/ netzbiographie/franzoesische-zeit/majorat (Zugriff vom 01.05.2014).

Kiesel, Helmuth, »Bei Hof, bei Höll«. Untersuchungen zur literarischen Hofkritik von Sebastian Brant bis Friedrich Schiller, Tübingen 1979.

Kirchner, Thomas, Physiognomie als Zeichen. Die Rezeption von Charles Le Bruns Mensch-Tier-Vergleichen um 1800, in: Gudrun Gersmann/Hubertus Kohle (Hg.), Frankreich 1800. Gesellschaft, Kultur, Mentalitäten, Stuttgart 1990, 34-48.

Klausnitzer, Ralf, Geheimgesellschaften im Visier. Geisteswissenschaftliche "Gegnerforschung « 1933-1945 zwischen Verschwörungsparanoia und Versachlichung, in: Gerhard Kaiser/Matthias Krell (Hg.), Zwischen Resonanz und Eigensinn. Studien zur Geschichte der Sprach- und Literaturwissenschaften im 20. Jahrhundert (Studien zur Wissenschafts- und Universitätsgeschichte, 7), Heidelberg 2005, 71-112.

Klesmann, Bernd, Erfahrungen in Paris am Vorabend der Revolution, aus: Netzbiographie: Joseph zu Salm-Reifferscheidt-Dyck (1773-1861), in: historicum-estudies.net, 
[01.05.2014], http://www.historicum-estudies.net/epublished/netzbiographie/ancienregime/paris-um-1789 (Zugriff vom 01.05.2014)

Klesmann, Bernd, Religiosität, aus: Netzbiographie: Joseph zu Salm-Reifferscheidt-Dyck (1773-1861), in: historicum-estudies.net, [01.05.2014], http://www.historicum-estudies. net/epublished/netzbiographie/ancien-regime/religiositaet (Zugriff vom 01.05.2014).

Klier, Gerhard, Die drei Geister des Menschen. Die sogenannte Spirituslehre in der Physiologie der Frühen Neuzeit (Sudhoffs Archiv Beihefte, 50), Diss., Stuttgart 2002.

Kloss, Georg, Geschichte der Freimaurerei in Frankreich aus ächten Urkunden dargestellt. (1725-1830), Bd. 1: Von der Einführung der Freimaurerei in Frankreich bis zur Restauration des Königthums, Darmstadt 1852, HathiTrust-Digitalisat mit Volltext unter Permalink: http://hdl.handle.net/2027/hvd.32044105550289 (Zugriff vom 25.05.2014).

Knoop, Douglas/G.P. Jones, Die Genesis der Freimaurerei. Ein Bericht vom Ursprung und der Entwicklung der Freimaurerei in ihren operativen, angenommenen und spekulativen Phasen (Veröffentlichungen der Freimaurerischen Forschungsgesellschaft Quatuor Coronati e.V., Bayreuth), Bayreuth 1968.

Knoop, Douglas/G.P. Jones/Douglas Hamer (Hg.), Early Masonic Pamphlets, Manchester 1945.

Knust, Christine, Von Armsündertüchlein und Liebestränken. Blut als Heil- und Zaubermittel in Volksmedizin und Volksglauben, in: Dies./Dominik Groß (Hg.), Blut. Die Kraft des ganz besonderen Saftes in Medizin, Literatur, Geschichte und Kultur (Studien des Aachener Kompetenzzentrums für Wissenschaftsgeschichte, 7), Kassel 2010, 209-228.

Kodera, Sergius, The Art of the Distillation of `Spirits` as a Technological Model for Human Physiology. The Cases of Marsilio Ficino, Joseph Duchesne and Francis Bacon, in: Manfred Horstmanshoff/Helen King/Claus Zittel (Hg.), Blood, Sweat and Tears. The Changing Concepts of Physiology from Antiquity into Early Modern Europe (Interdisciplinary Studies in Early Modern Culture, 25), Leiden/Boston 2012, 139-170.

Koselleck, Reinhart, Einleitung, in: Otto Brunner/Werner Conze/Reinhart Koselleck (Hg.), Geschichtliche Grundbegriffe. Historisches Lexikon zur politisch-sozialen Sprache in Deutschland, Bd. 1, Stuttgart 1972, I-XXVII.

Koselleck, Reinhart, Kritik und Krise. Eine Studie zur Pathogenese der bürgerlichen Welt, Frankfurt a.M. 1973.

Kottmann, Klaus, Die Freimaurer und die Katholische Kirche (Adnotationes in Ius Canonicum, 45), Diss., Frankfurt a.M. 2009.

Kreutzmann, Marko, Zwischen ständischer und bürgerlicher Lebenswelt: Adel in SachsenWeimar-Eisenach 1770 bis 1830 (Veröffentlichungen der Historischen Kommission für Thüringen, 23), Diss., Köln/Weimar/Wien 2008.

Krzeszowiak, Tadeusz, Freihaustheater in Wien 1787-1801. Wirkungsstätte von W. A. Mozart und E. Schikaneder, Wien/Köln/Weimar 2009.

Küchler Williams, Christiane, Erotische Paradiese. Zur europäischen Südseerezeption im 18. Jahrhundert, Göttingen 2004.

Küntzel, Astrid, Fremde in Köln. Integration und Ausgrenzung zwischen 1750 und 1814 (Stadt und Gesellschaft. Studien zum rheinischen Städteatlas, 4), Diss., Köln/Weimar/ Wien 2008.

Küppers-Braun, Ute, Anmerkungen zum Selbstverständnis des hohen Adels - Katholische Hochadelsstifte als genossenschaftliche Kontrollinstanzen für Ebenbürtigkeit und Missheirat, in: zeitenblicke 4/3 (2005), [13.12.2005], http://nbn-resolving.org/ urn:nbn:de:0009-9-2438 (Zugriff vom 21.07.2014). 
Langbrandtner, Hans-Werner, Ahnenprobe und Aufschwörung, in: Gudrun Gersmann/ Hans-Werner Langbrandtner (Hg.), Adlige Lebenswelten im Rheinland. Kommentierte Quellen der Frühen Neuzeit (Vereinigte Adelsarchive im Rheinland e.V., 3), Köln/Weimar/Wien 2009, 178-186.

Langbrandtner, Hans-Werner, Bemühungen um Anerkennung als preußischer Standesherr, aus: Netzbiographie: Joseph zu Salm-Reifferscheidt-Dyck (1773-1861), in: historicum-estudies.net, [01.05.2014], http://www.historicum-estudies.net/epublished/ netzbiographie/preussische-zeit/standesherrschaft (Zugriff vom 01.05.2014).

Langbrandtner, Hans-Werner, Die Botanische Bibliothek auf Schloss Dyck, aus: Netzbiographie: Joseph zu Salm-Reifferscheidt-Dyck (1773-1861), in: historicum-estudies.net, [01.05.2014], http://www.historicum-estudies.net/epublished/netzbiographie/preussi sche-zeit/botanische-bibliothek (Zugriff vom 01.05.2014).

Langbrandtner, Hans-Werner, Der rheinische Adel im Provinziallandtag der preußischen Rheinprovinz, aus: Netzbiographie: Joseph zu Salm-Reifferscheidt-Dyck (1773-1861), in: historicum-estudies.net, [01.05.2014], http://www.historicum-estudies.net/epublished/ netzbiographie/preussische-zeit/provinziallandtag (Zugriff vom 01.05.2014).

Langbrandtner, Hans-Werner, Politische Rolle im Provinziallandtag der preußischen Rheinprovinz, aus: Netzbiographie: Joseph zu Salm-Reifferscheidt-Dyck (1773-1861), in: historicum-estudies.net, [05.06.2014], http://www.historicum-estudies.net/epublished/ netzbiographie/preussische-zeit/politische-rolle (Zugriff vom 21.11.2014).

Langbrandtner, Hans-Werner, Die Standeserhöhung zum preußischen Fürsten, aus: Netzbiographie: Joseph zu Salm-Reifferscheidt-Dyck (1773-1861), in: historicum-estudies. net, [01.05.2014], http://www.historicum-estudies.net/epublished/netzbiographie/ preussische-zeit/standeserhoehung (Zugriff vom 01.05.2014).

Langbrandtner, Hans-Werner/Maria Rößner-Richarz, Genealogie und Familiengeschichte, in: Gudrun Gersmann/Hans-Werner Langbrandtner (Hg.), Adlige Lebenswelten im Rheinland. Kommentierte Quellen der Frühen Neuzeit (Vereinigte Adelsarchive im Rheinland e.V., 3), Köln/Weimar/Wien 2009, 187-192.

Langbrandtner, Hans-Werner/Christine Schmitt, Aufbruch in die Moderne. Der Rheinische Adel in westeuropäischer Perspektive 1750-1850. Ein Forschungsprojekt des Deutschen Historischen Instituts Paris und der Archivberatung des Landschaftsverbandes Rheinland, in: Jahrbuch des Kreises Düren 2010 (2009), 119-125.

Langbrandtner, Hans-Werner/Monika Gussone, Bibliotheken und Musikalien als Spiegel adliger Bildung. Auf Spurensuche in rheinischen Adelsbibliotheken und -archiven, in: zeitenblicke 9/1 (2010), [10.06.2010], http://nbn-resolving.org/urn:nbn:de:0009-9-25171 (Zugriff vom 26.02.2012).

Le Bihan, Alain, Francs-maçons parisiens du Grand Orient de France (Fin du XVIII siècle) (Commission d'Histoire Économique et Sociale de la Révolution Française, Mémoires et Documents, 19), Paris 1966.

Le Forestier, René, Die templerische und okkultistische Maurerei im 18. und 19. Jahrhundert, 4 Bde., Leimen 1987-1992.

Leibetseder, Mathis, Die Kavalierstour. Adlige Erziehungsreisen im 17. und 18. Jahrhundert (Beihefte zum Archiv für Kulturgeschichte, 56), Köln/Weimar/Wien 2004.

Lepenies, Wolf, Das Ende der Naturgeschichte. Wandel kultureller Selbstverständlichkeiten in den Wissenschaften des 18. und 19. Jahrhunderts, München 1978.

Limpricht, Cornelia, Platzanlage und Landschaftsgarten als begehbare Utopien. Ein Beitrag zur Deutung der Templum-Salomonis-Rezeption im 16. und 18. Jahrhundert (Europäische Hochschulschriften, Reihe 28, Kunstgeschichte, 202), Frankfurt a.M. [u.a.] 1994. 
Lindert, Wilgert te, Aufklärung und Heilserwartung. Philosophische und religiöse Ideen Wiener Freimaurer (1780-1795) (Schriftenreihe der Internationalen Forschungsstelle »Demokratische Bewegungen in Mitteleuropa 1770-1850«, 26), Frankfurt a.M. [u.a.] 1998.

Lotz-Heumann, Ute, Unterirdische Gänge, oberirdische Gänge, Spaziergänge. Freimaurerei in deutschen Kurorten des 18. Jahrhunderts, in: Monika Neugebauer-Wölk (Hg.), Arkanwelten im politischen Kontext (Aufklärung, 15), Hamburg 2003, 159-186.

Lovejoy, Arthur O., Die große Kette der Wesen. Geschichte eines Gedankens, Frankfurt a.M. 1993.

Macsotay, Tomas, Suffering Bodies, Sensible Artists. Vitalist Medicine and the Visualising of Corporeal Life in Diderot, in: Manfred Horstmanshoff/Helen King/Claus Zittel (Hg.), Blood, Sweat and Tears. The Changing Concepts of Physiology from Antiquity into Early Modern Europe (Interdisciplinary Studies in Early Modern Culture, 25), Leiden/Boston 2012, 267-291.

Mahlert, Friedrich, Nachrichten über die Loge »Maximilian zu den drei Lilien« im Or. Cöln 1778-1784, in: Bundesblatt: Organ der Großen National-Mutterloge »Zu den Drei Weltkugeln« 15 (1915), 97-103.

Malinowski, Stephan, Vom blauen zum reinen Blut. Antisemitische Adelskritik und adliger Antisemitismus 1871-1944, in: Jahrbuch für Antisemitismusforschung 12 (2003), 147-169.

Mandelbrote, Scott, Isaac Newton and the Flood, in: Martin Mulsow/Jan Assmann (Hg.), Sintflut und Gedächtnis. Erinnern und Vergessen des Ursprungs, München 2006, 337-353.

Marburg, Silke/Josef Matzerath, Vom Stand zur Erinnerungsgruppe. Zur Adelsgeschichte im 18. und 19. Jahrhundert, in: Dies. (Hg.), Der Schritt in die Moderne: sächsischer Adel zwischen 1763 und 1918, Köln/Weimar/Wien 2001, 5-16.

Markley, Robert, Newton, Corruption, and the Tradition of Universal History, in: James E. Force/Richard H. Popkin (Hg.), Newton and Religion. Context, Nature and Influence (Archives Internationales d'Histoire des Idées, 161), Dordrecht 1999, 121-143.

Martin, Georges, Histoire et généalogie de la Maison de Merode, Lyon 1999.

Matzerath, Josef, Adelsprobe an der Moderne: Sächsischer Adel 1763-1866. Entkonkretisierung einer traditionalen Sozialformation (Vierteljahrschrift für Sozial- und Wirtschaftsgeschichte, Beiheft 183), Habil., Stuttgart 2006.

Maurice, Florian, Freimaurerei um 1800. Ignaz Aurelius Feßler und die Reform der Großloge Royal York in Berlin (Hallesche Beiträge zur Europäischen Aufklärung, 5), Tübingen 1997.

Maurice, Florian, Die Mysterien der Aufklärung. Esoterische Traditionen in der Freimaurerei?, in: Monika Neugebauer-Wölk (Hg.), Aufklärung und Esoterik (Studien zum 18. Jahrhundert, 24), Hamburg 1999, 274-287, Digitalisat mit Volltext: http://www.netz werk-freimaurerforschung.de/blog/wordpress/wp-content/uploads/2014/03/maurice 99_mysterien_der_auklaerung.pdf (Zugriff vom 15.07.2014).

Mauser, Wolfram, Geselligkeit. Zu Chance und Scheitern einer sozialethischen Utopie um 1750, in: Karl Eibl (Hg.), Entwicklungsschwellen im 18. Jahrhundert, Hamburg 1990, 5-36, Digitalisat mit Volltext auf Freiburger Dokumentenserver unter Permalink: http://nbn-resolving.org/urn:nbn:de:bsz:25-opus-67758 (Zugriff vom 25.05.2014).

Mauser, Wolfram, Konzepte aufgeklärter Lebensführung: literarische Kultur im frühmodernen Deutschland, Würzburg 2000.

Mauser, Wolfram, »Ich lasse den Freund dir als Bürgen«. Das Prinzip Vertrauen und die Freundschaftsdichtung des 18. Jahrhunderts, in: Ute Pott (Hg.), Das Jahrhundert der 
Freundschaft. Johann Wilhelm Ludwig Gleim und seine Zeitgenossen (Schriften des Gleimhauses Halberstadt, 3), Göttingen 2004, 11-20.

McClellan III, James E., Colonialism \& Science. Saint Domingue in the old regime, 2. Aufl., Chicago 2010.

Meier, Christian/Werner Conze, Adel, in: Otto Brunner/Werner Conze/Reinhart Koselleck (Hg.), Geschichtliche Grundbegriffe. Historisches Lexikon zur politisch-sozialen Sprache in Deutschland, Bd. 1, Stuttgart 1972, 1-48.

Mettele, Gisela, Bürgertum in Köln 1775-1870. Gemeinsinn und freie Association (Stadt und Bürgertum, 10), München 1998.

Meyer-Waarden, Paul Friedrich, Stephan Ludwig Jacobi: Begründer der künstlichen Besamung in der Fischzucht. Leben und Werk, Berlin 1972.

Mikulinskij, Semjon R./Lyudmila Artemyevna Markova/Boris Anatol'evič Starostin, Alphonse de Candolle (Biographien bedeutender Biologen, 3), Jena 1980.

Mollier, Pierre, Contribution à l'étude du grade de Chevalier du Soleil, IV. Le Chevalier du Soleil et la Maçonnerie hermétique, in: Renaissance Traditionelle. Revue d'études maçonniques et symboliques 107/108 (1996), 231-246.

Mollier, Pierre, Le grade maçonnique de Rose-Croix et le christianisme: enjeux et pouvoir des symboles, in: Politica Hermetica 11 (1997), 85-118.

Mollier, Pierre, Le grade maçonnique de Rose-Croix et le christianisme: enjeux et pouvoir des symboles, in: Alain de Keghel/Bernard Moisy (Hg.), Deux siècles de Rite Écossais Ancien Accepté en France: 1804-2004, Paris 2004, S. 170-193.

Mollier, Pierre, Naissance et essor du Rite Écossais Ancien Accepté en France 1804-1826, in: Alain de Keghel/Bernard Moisy (Hg.), Deux siècles de Rite Écossais Ancien Accepté en France: 1804-2004, Paris 2004, 71-113.

Mollier, Pierre, La chevalerie maçonnique. Franc-maçonnerie, imaginaire chevaleresque et légende templière au siècle des Lumières, Paris 2005.

Mollier, Pierre, Les débuts de la Légion d'honneur et la franc-maçonnerie, in: Ders. (Hg.), La Franc-maçonnerie sous l'Empire: Un âge d'or?, Paris 2007, 61-78.

Mollier, Pierre/Pierre-François Pinaud, L'état-major maçonnique de Napoléon. Dictionnaire biographique des dirigeants du Grand Orient de France sous le Premier Empire, À l'Orient 2009.

Morrison, Tessa, Isaac Newton's Temple of Solomon and his Reconstruction of Sacred Architecture, Basel 2011.

Mosse, George L., Die Geschichte des Rassismus in Europa, Frankfurt a.M. 1990.

Mulsow, Martin, Vernünftige Metempsychosis. Über Monadenlehre, Esoterik und geheime Aufklärungsgesellschaften im 18. Jahrhundert, in: Monika Neugebauer-Wölk (Hg.), Aufklärung und Esoterik (Studien zum achtzehnten Jahrhundert, 24), Hamburg 1999, 211-273.

Mulsow, Martin, Epilog: Das schnelle und das langsame Ende des Hermetismus, in: Ders. (Hg.), Das Ende des Hermetismus. Historische Kritik und neue Naturphilosophie in der Spätrenaissance (Religion und Aufklärung, 9), Tübingen 2002, 305-312.

Müller, Gerhard, Von der arkanen Sozietät zum bürgerlichen Verein. Die Freimaurerei in Weimar-Jena als Medium bürgerlicher Wertevermittlung (1744-1844), in: Hans-Werner Hand/Dieter Hein (Hg.), Bürgerliche Werte um 1800: Entwurf - Vermittlung - Rezeption, Köln 2005, 167-192.

Müller, Hans-Peter, Johann Beckmann und Carl von Linné. Anmerkungen zu einer prägenden Begegnung, in: Günter Bayerl/Jürgen Beckmann (Hg.), Johann Beckmann (1739-1811). Beiträge zu Leben, Werk und Wirkung des Begründers der Allgemeinen Technologie (Cottbuser Studien zur Geschichte, Technik, Arbeit und Umwelt, 9), Münster [u.a.] 1999, 87-104. 
Müller, Jan-Dirk, Gedechtnus. Literatur und Hofgesellschaft um Maximilian I. (Forschungen zur Geschichte der älteren deutschen Literatur, 2), München 1982.

Müller, Klaus, Unter pfalz-neuburgischer und pfalz-bayerischer Herrschaft, in: Hugo Weidenhaupt [u.a.] (Hg.), Düsseldorf: Geschichte von den Ursprüngen bis ins 20. Jahrhundert, Bd. 2, Düsseldorf 1988.

Müller, Klaus, Köln von der französischen zur preußischen Herrschaft 1794-1815 (Geschichte der Stadt Köln, 8), Köln 2005.

Müller-Wille, Staffan, Genealogie, Naturgeschichte und Naturgesetz, in: Kilian Heck/Bernhard Jahn (Hg.), Genealogie als Denkform in Mittelalter und Früher Neuzeit (Studien und Texte zur Sozialgeschichte der Literatur, 80), Tübingen 2000, 109-119.

Nabrings, Arie, Die Dülkener Narrenakademie, Düsseldorf 2003.

Neipperg, Reinhard Graf von, Kaiser und Schwäbischer Kreis (1714-1733). Ein Beitrag zu Reichsverfassung, Kreisgeschichte und kaiserlicher Reichspolitik am Anfang des 18. Jahrhunderts (Veröffentlichungen der Kommission für Geschichtliche Landeskunde in Baden-Württemberg, Reihe B, 119), Stuttgart 1991.

Neugebauer-Wölk, Monika, Esoterische Bünde und Bürgerliche Gesellschaft. Entwicklungslinien zur modernen Welt im Geheimbundwesen des 18. Jahrhunderts (Kleine Schriften zur Aufklärung, 8), Göttingen 1995.

Neugebauer-Wölk, Monika, Arkanwelten im 18. Jahrhundert - Zur Struktur des Politischen im Kontext von Aufklärung und frühmoderner Staatlichkeit, in: Dies. (Hg.), Arkanwelten im politischen Kontext (Aufklärung. Interdisziplinäres Jahrbuch zur Erforschung des 18. Jahrhunderts und seiner Wirkungsgeschichte, 15), Hamburg 2003, $7-65$.

Neugebauer-Wölk, Monika, Esoterik als Element freimaurerischer Geschichte und Geschichtsforschung, in: Quatuor Coronati Jahrbuch für Freimaurerforschung 40 (2003), 1-24, Digitalisat mit Volltext: http://www.netzwerk-freimaurerforschung.de/blog/ wordpress/wp-content/uploads/2014/03/neugebauer_woelk_jahrbuch2003.pdf (Zugriff vom 25.05.2014).

Neugebauer-Wölk, Monika, Zur Konstituierung historischer Religionsforschung 1974-2004, in: zeitenblicke 5/1 (2006), [04/04/2006], http://nbn-resolving.org/ urn:nbn:de:0009-9-2755 (Zugriff vom 08.01.2013).

Neugebauer-Wölk, Monika, Religion als Thema der Geschichtswissenschaft, in: Friedrich Wilhelm Graf/Friedemann Vogt (Hg.), Religion(en) deuten. Transformationen der Religionsforschung (Troeltsch-Studien, N.F., 2), Berlin/New York 2010, 259-280.

Neugebauer-Wölk, Monika, Esoterische Religiosität und ihre Bedeutung für die Freimaurerei, in: Quatuor Coronati Jahrbuch für Freimaurerforschung 47 (2010), 97-109.

Neugebauer-Wölk, Monika/Markus Meumann, Aufklärung - Esoterik - Moderne. Konzeptionelle Überlegungen zur Einführung, in: Monika Neugebauer-Wölk/Renko Geffarth/ Markus Meumann (Hg.), Aufklärung und Esoterik: Wege in die Moderne (Hallesche Beiträge zur europäischen Aufklärung, 50), Berlin/Boston 2013, 1-36.

Neumann, Ulrich, Rosenkreuzertum, in: Claus Priesner/Karin Figala (Hg.), Alchemie. Lexikon einer hermetischen Wissenschaft, München 1998, 306-308.

Nieding, Thomas, Ökonomietheorie als Beitrag zum `juste milieu<? Der >Traité d'économie politique r von Jean Baptiste Say, in: Gudrun Gersmann/Hubertus Kohle (Hg.), Frankreich 1800: Gesellschaft, Kultur, Mentalitäten, Stuttgart 1990, 134-141.

Nora, Pierre (Hg.), Erinnerungsorte Frankreichs, München 2005.

Nutz, Thomas, Varietäten des Menschengeschlechts. Die Wissenschaften vom Menschen in der Zeit der Aufklärung, Köln/Weimar/Wien 2009.

Obst, Helmut, Reinkarnation. Weltgeschichte einer Idee, München 2009. 
Oer, Rudolfine Freiin von, Landständische Verfassungen in den geistlichen Fürstentümern Nordwestdeutschlands, in: Dietrich Gerhard (Hg.), Ständische Vertretungen in Europa im 17. und 18. Jahrhundert (Veröffentlichungen des Max-Planck-Instituts für Geschichte, 27), Göttingen 1969, 94-119.

Oexle, Otto Gerhard, Memoria in der Gesellschaft und in der Kultur des Mittelalters, in: Joachim Heinzle (Hg.), Modernes Mittelalter. Neue Bilder einer populären Epoche, Frankfurt a.M./Leipzig 1994, 297-323.

Oexle, Otto Gerhard (Hg.), Memoria als Kultur (Veröffentlichungen des Max-Planck-Instituts für Geschichte, 121), Göttingen 1995.

Pagel, Walter, Joan Baptista van Helmont: Reformer of science and medicine (Cambridge Monographs on the History of Medicine), Cambridge 2002.

Pallot-Raguet, Marie-Thérèse, Correspondance de Constance de Salm (1795-1811). Édition critique, Diss., 2008 (unveröffentlicht).

Pauls, August, Festschrift zum 125. Stiftungsfeste der Johannisloge »Zur Beständigkeit und Eintracht« im O $\therefore$ von Aachen, Aachen 1903.

Pauls, August, Düsseldorfer Freimaurerei im 18. Jahrhundert. Mit einer Einleitung über die rheinische Freimaurerei während des 18. Jahrhunderts, Leipzig 1927.

Pauls, August, Die Gräfin Remusat als Aachener Kurgast, in: Zeitschrift des Aachener Geschichtsvereins 54 (1932), 142-160.

Pauls, August, Annalen der Aachener Freimaurerei. Festschrift zum 175. Geburtstag der Aachener Johannisloge »Zur Beständigkeit und Eintracht«, Frankfurt a.M. 1949.

Paulson Eigen, Sara, A Mother's Love, a Father's Line: Law, Medicine and the 18th-Century Fictions of Patrilineal Genealogy, in: Kilian Heck/Bernhard Jahn (Hg.), Genealogie als Denkform in Mittelalter und Früher Neuzeit (Studien und Texte zur Sozialgeschichte der Literatur, 80), Tübingen 2000, 87-107.

Pesch, Dieter, Die Dülkener Narrenakademie, in: Rheinisch-westfälische Zeitschrift für Volkskunde 16 (1969), 105-122.

Picavet, François, Les Idéologues. Essai sur l'histoire des idées et des théories scientifiques, philosophiques, religieuses, etc. en France depuis 1789, Diss., Paris 1891, BnFDigitalisat unter Permalink: http://gallica.bnf.fr/ark:/12148/bpt6k108222f (Zugriff vom 22.07.2014).

Piquet, Michel, Le grade de Rose-Croix: les sources du »Nec plus Ultra«, in: Renaissance Traditionelle. Revue d'études maçonniques et symboliques 110-111 (1997), 159-196.

Porset, Charles, Les Philalèthes et les Convents de Paris. Une politique de la folie, Paris 1996.

Priesner, Claus, Geschichte der Alchemie, München 2011.

Principe, Lawrence M., Lapis philosophorum, in: Claus Priesner/Karin Figala (Hg.), Alchemie. Lexikon einer hermetischen Wissenschaft, München 1998, 215-220.

Proteau, Jean L., Charles Dupaty: un magistrat-philosophe du siècle des Lumières, Rochefort 1989.

Quix, Christian, Die Frankenburg insgemein Frankenberg genannt und die Vogtei Burtscheid, Aachen 1829, BSB-Digitalisat mit Volltext unter Permalink: http://nbn-resolving. org/urn:nbn:de:bvb:12-bsb10013978-2, Digitalisat mit Volltext: http://books.google.de/ books?id=gdJYAAAAcAAJ (Zugriff vom 25.05.2014).

Rattansi, P.M., The Helmontian-Galenist Controversy in Restoration England, in: Ambix 12 (1964), 1-23.

Regaldo, Marc, Un milieu intellectuel: la Décade philosophique (1794-1807), 5 Bde., Diss., Paris 1976. 
Reif, Heinz, Westfälischer Adel: 1770-1860. Vom Herrschaftsstand zur regionalen Elite (Kritische Studien zur Geschichtswissenschaft, 35), Diss., Göttingen 1979.

Reif, Heinz, Adelserneuerung und Adelsreform in Deutschland 1815-1874, in: Elisabeth Fehrenbach (Hg.), Adel und Bürgertum in Deutschland 1770-1848 (Schriften des Historischen Kollegs, 31), München 1994, 203-230.

Reif, Heinz, Adel im 19. und 20. Jahrhundert (Enzyklopädie deutscher Geschichte, 55), München 1999.

Reif, Heinz, Einleitung, in: Heinz Reif (Hg.), Adel und Bürgertum in Deutschland, Bd. 1: Entwicklungslinien und Wendepunkte im 19. Jahrhundert (Elitenwandel in der Moderne, 1), 2. Aufl., Berlin 2008, 7-28.

Reinalter, Helmut, Die Freimaurer, Sonderausgabe, München 2008.

Reinalter, Helmut, Die historischen Ursprünge und die Anfänge der Freimaurerei. Legenden - Theorien - Fakten, in: Frank Jacob (Hg.), Geheimgesellschaften: Kulturhistorische Sozialstudien (Globalhistorische Komparativanalysen, 1), Würzburg 2013, 49-83.

Reinhard, Wolfgang, Freunde und Kreaturen. »Verflechtung« als Konzept zur Erforschung historischer Führungsgruppen. Römische Oligarchie um 1600 (Schriften der Philosophischen Fachbereiche der Universität Augsburg, 14), München 1979.

Rétat, Claude, Un temple à côté du temple. Le "Muséum mystérieux« de Thory, in: Renaissance Traditionelle. Revue d'études maçonniques et symboliques 123-124 (2000), 222-254.

Rétat, Claude, Revers la science. Aubin-Louis Millin, Alexandre Lenoir, in: Éric PerrinSaminadayar (Hg.), Rêver l'archéologie au XIXe siècle: de la science à l'imaginaire (Mémoires 23), Saint-Étienne 2001, 97-122.

Riegelmann, Hans, Die europäischen Dynastien in ihrem Verhältnis zur Freimaurerei. Historisch-politische Untersuchungen auf genealogischer Grundlage (Quellen und Darstellungen zur Freimaurerfrage, 4), Diss., Berlin 1943.

Rogalla von Bieberstein, Johannes, Adelsherrschaft und Adelskultur in Deutschland, Frankfurt a.M [u.a.] 1989.

Rogalla von Bieberstein, Johannes, Der Mythos von der Verschwörung. Philosophen, Freimaurer, Juden, Liberale und Sozialisten als Verschwörer gegen die Sozialordnung, Wiesbaden 2008.

Roos, Anna Marie, The Salt of the Earth. Natural Philosophy, Medicine, and Chymistry in England, 1650-1750 (History of Science and Medicine Library, 3), Leiden 2007.

Rößner-Richarz, Maria, Selbstzeugnisse als Quellen adliger Lebenswelten in der Sattelzeit. Eine Bestandsaufnahme, in: zeitenblicke 9/1 (2010), [10/06/2010], http://nbn-resolving. org/urn:nbn:de:0009-9-21027 (Zugriff vom 13.10.2014).

Rousseau, Paul, Der französische Ritus und die linksrheinischen Logen am Anfang des 19. Jahrhunderts, in: Quatuor Coronati Jahrbuch für Freimaurerforschung 22 (1985), 261-280.

Sachse, Margit, Als in Dyck Kakteen blühten... Leben und Werk des Dycker Schlossherrn Joseph Altgraf und Fürst zu Salm-Reifferscheidt-Dyck (1773-1861), Pulheim 2005.

Salis-Soglio, Anton Freiherr von, Ritterrat (Hg.), Die Genossenschaft des rheinischen ritterbürtigen Adels 1837-1937. Festschrift zur Erinnerung an den hundertsten Jahrestag ihrer Gründung, Schloß Gemünden (Hunsrück) 1937.

Santing, Catrien, >For the Life of a Creature is in the Blood (Leviticus 17:11). Some Considerations on Blood as the Source of Life in Sixteenth-Century Religion and Medicine and their Interconnections, in: Manfred Horstmanshoff/Helen King/Claus Zittel (Hg.), Blood, Sweat and Tears. The Changing Concepts of Physiology from Antiquity into 
Early Modern Europe (Interdisciplinary Studies in Early Modern Culture, 25), Leiden/ Boston 2012, 415-441.

Schiffmann, Gustav Adolf, Die Entstehung der Rittergrade in der Freimaurerei um die Mitte des 18. Jahrhunderts. Nach den ältesten freimaurerischen Hand- und Druckschriften, Leipzig 1882, BSB-Digitalisat unter Permalink: http://nbn-resolving.org/ urn:nbn:de:bvb:12-bsb00066046-7 (Zugriff vom 25.05.2014).

Schindler, Norbert, Freimaurerkultur im 18. Jahrhundert. Zur sozialen Funktion des Geheimnisses in der entstehenden bürgerlichen Gesellschaft, in: Robert M. Berdahl [u.a.] (Hg.), Klassen und Kultur. Sozialanthropologische Perspektiven in der Geschichtsschreibung, Frankfurt a.M. 1982, 205-262.

Schläwe, Elisabeth, Der junge Graf als Reiseliterat auf Kavalierstour, aus: Netzbiographie: Joseph zu Salm-Reifferscheidt-Dyck (1773-1861), in: historicum-estudies.net, [05.06.2014], http://www.historicum-estudies.net/epublished/netzbiographie/ancienregime/kavalierstour (Zugriff vom 21.11.2014).

Schlögl, Rudolf, Ansätze zu einer Sozialgeschichte des Paracelsismus im 17. und 18. Jahrhundert, in: Peter Dilg/Hartmut Rudolph (Hg.), Resultate und Desiderate der Paracelsus-Forschung (Sudhoffs Archiv Beihefte, 31), Stuttgart 1993, 145-162.

Schmid, Karl, Geblüt, Herrschaft, Geschlechterbewusstsein. Grundfragen zum Verständnis des Adels im Mittelalter (Vorträge und Forschungen, 44), Sigmaringen 1998.

Schneider, Hannah, »Unvergängliche Werke des Geistes und der Wissenschaft» - die Schriftstellerin Constance de Salm und ihr Ehemann, aus: Netzbiographie: Joseph zu Salm-Reifferscheidt-Dyck (1773-1861), in: historicum-estudies.net, [01.05.2014], http:// www.historicum-estudies.net/epublished/netzbiographie/preussische-zeit/werke (Zugriff vom 01.05.2014).

Schneider, Herbert (Hg.), Chanson und Vaudeville. Gesellschaftliches Singen und unterhaltende Kommunikation im 18. und 19. Jahrhundert (Schriften der Saarländischen Universitäts- und Landesbibliothek, 6), St. Ingbert 1999.

Schönfuß, Florian, Zur Aufnahme in Napoleons Noblesse d'Empire, aus: Netzbiographie: Joseph zu Salm-Reifferscheidt-Dyck (1773-1861), in: historicum-estudies.net, [05.06.2014], http://www.historicum-estudies.net/epublished/netzbiographie/franzoesische-zeit/no blesse-dempire (Zugriff vom 21.11.2014).

Schuler, Heinz, Die St. Johannis-Freimaurerloge »Zur wahren Eintracht«. Die Mitglieder der Wiener Elite-Loge 1781-1785, in: Genealogisches Jahrbuch 31 (1991), 5-41.

Schulze, Frederik, Konzepte von Physiognomie und Rasse bei Martius, in: Contingentia 2 (2008), Digitalisat mit Volltext der Universitätsbibliothek Frankfurt a.M. unter Permalink: http://nbn-resolving.org/urn:nbn:de:hebis:30:3-250583 (Zugriff vom 17.12.2012).

Schumacher, Nicole, Friedrich Heinrich Jacobi und Blaise Pascal: Einfluss - Wirkung Weiterführung, Diss., Würzburg 2003.

Schüttler, Hermann, Geschichte, Organisation und Ideologie der Strikten Observanz, München 1987.

Schüttler, Hermann, Die Mitglieder des Illuminatenordens 1776-1787/93 (Deutsche Hochschuledition, 18), München 1991.

Schüttler, Hermann, Zum Verhältnis von Ideologie, Organisation und Auswanderungsplänen im System der Strikten Observanz, in: Monika Neugebauer-Wölk/Richard Saage (Hg.), Die Politisierung des Utopischen im 18. Jahrhundert. Vom utopischen Systementwurf zum Zeitalter der Revolution (Hallesche Beiträge zur Europäischen Aufklärung, 4), Tübingen 1996, 143-168.

Schüttler, Hermann, Zwei freimaurerische Geheimgesellschaften des 18. Jahrhunderts im Vergleich: Strikte Observanz und Illuminatenorden, in: Erich Donnert (Hg.), Europa 
in der Frühen Neuzeit: Festschrift für Günter Mühlpfordt, Bd. 4: Deutsche Aufklärung, Köln/Weimar 1997, 521-544.

Schütz, Marco, Rassenideologien in der Sozialwissenschaft (Contacts: Sér. 2, Gallo-Germanica, 11), Diss., Bern [u.a.] 1994.

Schwartz, Michael, Leviathan oder Lucifer. Reinhart Kosellecks >Kritik und Krise ted, in: Zeitschrift für Religions- und Geistesgeschichte 45 (1993), 33-57.

Semrau, Eugen, Erleuchtung und Verblendung. Einflüsse esoterischen Gedankenguts auf die Entwicklung der Wiener Moderne (Quellen und Darstellungen zur europäischen Freimaurerei, 13), Innsbruck/Wien/Bozen 2012.

Serna, Pierre, Der Adlige, in: Michel Vovelle (Hg.), Der Mensch der Aufklärung, Essen 2004, 42-97.

Simmel, Georg, Zur Soziologie des Adels. Fragment aus einer Formenlehre der Gesellschaft, in: Ders., Individualismus der modernen Zeit und andere soziologische Abhandlungen, hg. von Otthein Rammstedt, Frankfurt a.M. 2008, 257-266.

Snoek, Jan A.M., On the Creation of Masonic Degrees. A Method and its Fruits, in: Antoine Faivre/Wouter J. Hanegraaf (Hg.), Western Esotericism and the Science of Religion (Gnostica, 2), Leuven 1998, 145-190.

Snoek, Jan A.M., Initiating Women in Freemasonry. The Adoption Rite (Aries book series, 13), Leiden 2012.

Sommer, Antje/Werner Conze, Rasse, in: Otto Brunner/Werner Conze/Reinhart Koselleck (Hg.), Geschichtliche Grundbegriffe. Historisches Lexikon zur politisch-sozialen Sprache in Deutschland, Bd. 5, Stuttgart 1984, 135-178.

Sonntag, Michael, »Gefährte der Seele, Träger des Lebens«. Die medizinischen Spiritus im 16. Jahrhundert, in: Gerd Jüttemann/Michael Sonntag/Christoph Wulff (Hg.), Die Seele. Ihre Geschichte im Abendland, Weinheim 1991, 165-179.

Soukup, Rudolf Werner, Chemie in Österreich: Bergbau, Alchemie und frühe Chemie. Von den Anfängen bis zum Ende des 18. Jahrhunderts, Bd. 1, Wien/Köln/Weimar 2007.

Stannek, Antje, Telemachs Brüder. Die höfische Bildungsreise des 17. Jahrhunderts (Geschichte und Geschlechter, 33), Frankfurt a.M. 2001.

Stevenson, David, The Origins of Freemasonry, 12. Aufl., Cambridge 2011.

Stevens, Peter F., The Development of biological Systematics. Antoine Laurent de Jussieu, Nature and the Natural System, New York 1994.

Sting, Stephan, Freundschaft als soziale Utopie - Zur Entstehung bürgerlicher Gesellungsformen im 18. Jahrhundert, in: Meike Sophia Baader/Johannes Bilstein/Christoph Wulf (Hg.), Die Kultur der Freundschaft. Praxen und Semantiken in anthropologisch-pädagogischer Perspektive, Weinheim/Basel 2008, 60-69.

Stollberg-Rilinger, Barbara, Gut vor Ehre oder Ehre vor Gut? Zur sozialen Distinktion zwischen Adels- und Kaufmannsstand in der Ständeliteratur der Frühen Neuzeit, in: Johannes Burkhardt (Hg.), Augsburger Handelshäuser im Wandel des historischen Urteils (Colloquia Augustana, 3), Berlin 1996, 31-45.

Stosch, Manfred von, Düsseldorfs »öffentliche Bibliotheque« 1770-1809, in: Gerhard Kurz (Hg.), Düsseldorf in der deutschen Geistesgeschichte (1750-1850), Düsseldorf 1984, 37-53.

Stuckrad, Kocku von, Was ist Esoterik? Kleine Geschichte des geheimen Wissens, München 2004.

Stuckrad, Kocku von, Überlegungen zur Transformation des esoterischen Diskursfeldes seit der Aufklärung, in: Monika Neugebauer-Wölk/Renko Geffarth/Markus Meumann (Hg.), Aufklärung und Esoterik: Wege in die Moderne (Hallesche Beiträge zur europäischen Aufklärung, 50), Berlin/Boston 2013, 96-112. 
Taute, Reinhold, Der Geburts-Adel in den deutschen Logen. Ein statistischer Beitrag von Br. R. Taute, Mitglied der Loge »Karl zu den drei Ulmen« in Ulm, in: Asträa. Taschenbuch für Freimaurer 10 (1891), 114-118.

Terpstra, Jan U., Eine niederländische Woldemar-Übersetzung. Ein Beitrag zum Problem der Rezeption Friedrich Heinrich Jacobis in den Niederlanden, in: Klaus Hammacher (Hg.), Friedrich Heinrich Jacobi. Philosoph und Literat der Goethezeit (Studien zur Philosophie und Literatur des 19. Jahrhunderts, 11), Frankfurt a.M. 1971, 301-318.

Toussaint, Gia, Blut im Flakon. Orientalische Fläschchen zur Präsentation des Blutes Christi im Mittelalter, in: Christine Knust/Dominik Groß (Hg.), Blut. Die Kraft des ganz besonderen Saftes in Medizin, Literatur, Geschichte und Kultur (Studien des Aachener Kompetenzzentrums für Wissenschaftsgeschichte, 7), Kassel 2010, 191-206.

Tuchendler, Jacques, À propos des archives de Claude Antoine Thory: de la légende à l' histoire, in: Renaissance Traditionelle. Revue d'études maçonniques et symboliques 145 (2006), 32-72.

Tuchendler, Jacques, Les livres et les objets d'art de Claude Antoine Thory, in: Renaissance Traditionelle. Revue d'études maçonniques et symboliques 157-158 (2010), 2-47.

Turner, Victor Witter, The ritual process: structure and anti-structure, London 1969.

Ulbricht, Otto, Mikrogeschichte. Menschen und Konflikte in der Frühen Neuzeit, Frankfurt a.M./New York 2009.

Van de Sande, Anton, Monarchy and Aristocracy as International Factors in Freemasonry. The Case of Prince Frederick of the Netherlands, 1816-1881, in: Equinox. Journal for research into freemasonry and fraternalism 1 (2010), 23-35.

Vasoli, Cesare, Der Mythos der »Prisci Theologi« als »Ideologie« der »Renovatio«, in: Martin Mulsow (Hg.), Das Ende des Hermetismus. Historische Kritik und neue Naturphilosophie in der Spätrenaissance (Religion und Aufklärung, 9), Tübingen 2002, 17-60.

Venturino, Diego, Race et histoire. Le paradigme nobiliaire de la distinction sociale au début du XVIII siècle, in: Sarga Moussa (Hg.), L'idée de »race« dans les sciences humaines et la littérature (XVIII ${ }^{e}$ et XIXe siècles), Paris/Budapest/Torino 2003, 19-38.

Viatte, August, Les sources occultes du Romantisme. Illuminisme - Théosophie 1770-1820, Bd. 1: Le Préromantisme, Paris 1928.

Walker Bynum, Caroline, Wonderful Blood. Theology and Practice in Late Medieval Northern Germany and beyond, Philadelphia 2007.

Weiland, Hermann, Chronik der vereinigten Johannisloge Minerva zum vaterländischen Verein und Rhenana zur Humanität im Or. Köln 1852-1902, Köln 1902.

Weitz, Karl Reinhold, Die preußische Rheinprovinz als Adelslandschaft. Eine statistische, sozialgeschichtliche und kulturräumliche Untersuchung zum frühen 19. Jahrhundert. Mit einer Karte, in: Rheinische Vierteljahrsblätter 38 (1974), 333-354.

Whittaker, Alfred, Karl Ludwig Giesecke, His Life, Performance and Achievements, in: Mitteilungen der Österreichischen Mineralogischen Gesellschaft 146 (2001), 451-479, Digitalisat mit Volltext der Faculty of Geo- and Atmospheric Sciences, University of Innsbruck: http://www.uibk.ac.at/mineralogie/oemg/bd_146/146_451-479.pdf (Zugriff vom 30.05.2014).

Whittaker, Alfred, Karl Ludwig Giesecke: His Albums and his likely involvement in the writing of the Libretto of Mozart's Opera The Magic Flute, in: Mitteilungen der Österreichischen Mineralogischen Gesellschaft 155 (2009), 321-332, Digitalisat mit Volltext der Faculty of Geo- and Atmospheric Sciences, University of Innsbruck: http://www.uibk. ac.at/mineralogie/oemg/bd_155/155_321-332.pdf (Zugriff vom 25.05.2014).

Wirth, Oswald, Le symbolisme hermétique dans ses rapports avec l'alchimie et la francmaçonnerie, 2. Aufl., Paris 1931. 
Wolfstieg, August, Werden und Wesen der Freimaurerei. 2. Abt.: Die Philosophie der Freimaurerei, Bd. 1, Berlin 1922.

Wolthaus, Martin, Die Ahnengalerie der Altgrafen und Fürsten zu Salm-ReifferscheidtDyck, aus: Netzbiographie: Joseph zu Salm-Reifferscheidt-Dyck (1773-1861), in: historicum-estudies.net, [01.05.2014], http://www.historicum-estudies.net/epublished/ netzbiographie/ancien-regime/ahnengalerie (Zugriff vom 01.05.2014).

Wrede, Martin, Zwischen Mythen, Genealogen und der Krone. Rivalisierende Familiengedächtnisse im französischen Hochadel des 17. Jahrhunderts: die Häuser Bouillon, Noailles und Bourbon, in: Zeitschrift für Historische Forschung 32 (2005), 17-43.

Wrede, Martin, Ohne Furcht und Tadel. Für König und Vaterland. Frühneuzeitlicher Hochadel zwischen Familienehre, Ritterideal und Fürstendienst (Beihefte der Francia, 75), Ostfildern 2012.

Wrede, Martin/Horst Carl (Hg.), Zwischen Schande und Ehre. Erinnerungsbrüche und die Kontinuität des Hauses. Legitimationsmuster und Traditionsverständnis des frühneuzeitlichen Adels in Umbruch und Krise (Veröffentlichungen des Instituts für Europäische Geschichte Mainz, 73), Mainz 2007.

Wulf, Christoph, Blut, Ritual und Imagination, in: Christina von Braun/Ders. (Hg.), Mythen des Blutes, Frankfurt a.M./New York 2007, 16-27.

Wunderlich, Heinke, Studienjahre der Grafen Salm-Reifferscheidt (1780-1791). Ein Beitrag zur Adelserziehung am Ende des Ancien Régime (Beiträge zur Geschichte der Literatur und Kunst des 18. Jahrhunderts, 8), Heidelberg 1984.

Yates, Frances Amelia, The Art of Memory, 19. Aufl., London 2012 (Erstausgabe 1966).

Zander, Helmut, Geschichte der Seelenwanderung in Europa. Alternative religiöse Traditionen von der Antike bis heute, Darmstadt 1999.

Ziegler, Joseph, The biology of the virtues in medieval and early Renaissance theology and physiognomy, in: Mariacarla Gadebusch Bondio/Andrea Bettels (Hg.), Im Korsett der Tugenden. Moral und Geschlecht im kulturhistorischen Kontext, Hildesheim [u.a.] 2013, 3-23.

Zimmermann, Rolf Christian, Das Weltbild des jungen Goethe. Studien zur hermetischen Tradition des deutschen 18. Jahrhunderts, Bd. 1: Elemente und Fundamente, 2. Aufl., München 2002. 



\section{Institutionen- und Logenregister}

A

Académie celtique, Paris 195, 208, 209, 210, 217

Académie des Vrais Maçons 192, 228

Adelspädagogium, Düsseldorf 115, 116

Agrippina, Sektion der Kölner

Dreikönigsloge 144, 145, 146, 226

Amis Philantropes, Brüssel 148

Archives générales du Rit écossais philosophique, Paris 190

Asiatische Brüder 141, 142, 160

C

Cercle social 208

Chapitre du Choix, Paris 179, 188

Chapitres des Grands Aigles blancs et noirs 202, 203, 222, 223

Charlemagne, Sektion der Kölner

Dreikönigsloge 144, 145, 146, 224

Commandeurs du Mont Thabor, Paris 150, 177, 188, 204, 205, 207, 209, 210, 211, 213, 217, 218

Convents philosophiques 190, 194, 201, 203, 222

Die Feinen 121

Die Kette 243

E

Erleuchtete Monds-Universität und Berittene Akademie der Künste und Wissenschaften zu Dülken 235, 236, 237

$\mathbf{F}$

Frères Courageux, Bonn 234

G

Gold- und Rosenkreuzer 112, 113, 114, 141, 158,160

Grand Orient de France 25, 135, 143, 144, $145,146,149,150,152,153,177,187,188$, 207, 217, 219, 221

Grande Loge de France 102, 105
Grande Loge Générale Écossaise de France 149

Grande Loge Provinciale de Hérédom 152

$\mathrm{H}$

Hermetische Brüder, Metz 105, 106

Hoher Orden vom Heiligen Tempel zu Jerusalem. siehe Strikte Observanz

\section{I}

Illuminaten 123, 138, 141, 142, 160

Institut national des sciences et arts, Paris 170

L

L'Abeille, Paris 197

L'Indissoluble, Den Haag 132

L'Innocence Reconnue, Paris 166

La Candeur, Straßburg 17, 102, 103, 104, 105

La Concorde, Aachen 197, 220, 222, 224

La Constance et la Concorde réunis, Aachen 192, 232

La Constance, Aachen 219, 224

La Naissance du Roi de Rome, Köln 146, 147, 154, 224, 226, 227

La Paix du Bas-Rhin, Düsseldorf 104, 115, 131,132

Le Centre des Amis, Paris 217

Le Secret des trois Rois, Köln 135, 143, 145, 146,224

Légion d'honneur 178, 206, 209

Les Neuf Sœurs, Paris 157, 174, 176, 207, 213

\section{M}

Maximilian zu den drei Lilien, Köln 134, 135,137

Mère Loge du Rit écossais philosophique, Paris 152, 154, 191

Mère Loge Écossaise de France, Paris 147

Mère Loge Écossaise du Comtat Venaissin, Avignon 192

Mère-folle de Dijon 232 
Musée des Antiquités et Monuments

Français, Paris 189

\section{$\mathrm{N}$}

Nationaltheater, Mannheim 124

Noble Society for the advancement of Hermetick Physick, London 87

0

Ordre de la coupe 232

P

Philaleten 140, 231

\section{$\mathbf{R}$}

Régiment de la Calotte 231

Rheinische Ritterakademie, Bedburg 243

Rite écossais ancien accepté 150, 178, 181, 187,205

Rite français 219

Rite hermétique 191, 192

Royal Ordre d'Heredom de

Kilwinning 150, 178, 187, 234

Royal Society, London 60, 73

\section{$\mathrm{S}$}

Saint-Alexandre d'Écosse, Paris 166, 192

Société d'histoire naturelle de Paris 171
Société des Observateurs de l'homme,

Paris 172, 207

Société des Philanthropes, Straßburg 137

Souverain Chapitre Métropolitain des

Dames Écossais de la Colline du Mont Thabor, Paris 211

Souverain Chapitre Métropolitain du Rit écossais philosophique en France 189, 191, 192, 193, 200

Souverain Tribunal Chef d'ordre en

France 181

Strikte Observanz 134, 135, 136, 137, 138, 158

Suprêmes Élus de la Vérité 210

\section{Z}

Zu den drei Kanonen, Wien 158

Zum vaterländischen Verein, Köln. siehe La Naissance du Roi de Rome

Zur aufgehenden Sonne, Brünn 158, 159

Zur Beständigkeit und Eintracht, Aachen 249

Zur Gekrönten Hoffnung, Wien 160, 161

Zur neugekrönten Hoffnung, Wien 160, 161

Zur wahren Eintracht, Wien 141, 162

Zur Wahrheit, Wien 160 


\section{Personen-, Sach- und Ortsregister}

A

Abstammung 8, 17, 19, 45, 47, 48, 63, 89, $100,147,211$

Adam, biblischer Menschenvater 13, 45, $46,55,80$

»Adel/Pferd «, Rassenvergleich 129

Adel des Intellekts 252

Adelsarchive 5, 24

Adelsloge 16, 17, 24, 101, 102, 103, 130, 131, 132,252

Adelspädagogium, Düsseldorf 115, 116

Adelsreform 7, 136

Adligkeit 23, 42, 50, 51, 74, 128, 244

Ägypten 35, 57, 174, 193, 208

Ahnengeister 87

Ahnenprobe 15, 118, 243

Ahnenreihe 43, 63, 78

Aigrefeuille, Fulcrand Michel de 187, 231

Alchemie 65, 69, 70, 71, 73, 75, 77, 95, 104, $105,112,113,142,159,160,192,202,231$, 251

Almenräder, Jean-Jacques 227

Anderson, James 8, 53, 54, 55, 56, 57, 58, $59,61,62,63,64,73,144$

Andreae, Johann Valentin 76, 77

anno mundi 2, 59

Antients 54

Archeus 82

ars memoriae $8,62,66,70,87$

Art, biologische 92, 93, 118, 200, 244

Ashmole, Elias 87

Astrologie 105, 201

Astronomie 157, 173, 194, 198

Atem 86, 122, 129

Ausprägung 52, 85, 88, 254

Avignon 191

B

Bacon, Francis 192

Bailleul, Antoine 217

Bailly, Jean-Sylvain 198

Barruel, Abbé 149

Barthélemy, André 171

Barthez, Paul Joseph 198
Begabung 252

Belling, Charles Léonore 143, 144

Bentinck, Christian Friedrich von 101

Bentinck van Rhoon, Willem 101

Bentinck zu Limbricht, von 101

Berghe von Trips 98

Berleburger Bibel 115

Bichat, Xavier 198

Bilder 82, 84, 175, 213, 254

Bildung 31, 32, 41, 48, 80, 122, 125, 168, 170, 205, 213, 255

Blanckart, Karl Franz von 100

Blanckart, Ludwig Anton von 125

Blanckart, von 98

Blocksberg/Brocken 210

Blut 41, 42, 43, 44, 45, 62, 63, 71, 76, 77, $82,84,85,86,88,108,109,110,122,129$, $133,213,251,253,254$

Blutsideologie, adlige $12,43,47,48,52$, $64,70,71,72,76,77,80,84,87,95,100$, $104,109,111,112,113,114,117,126,127$, $128,131,133,137,139,141,142,154,162$, $163,192,196,197,213,244,252,253,254$

Boileau 191, 192

Boisserée, Bernard 225

Boisserée, Melchior 225

Boisserée, Sulpiz 225

Bonaparte, Napoleon 100, 143, 147, 149, $152,153,154,173,174,175,176,177,178$, 205, 206, 210, 221

Bonnet, Charles 122, 123, 126

Bonneville, Nicholas de 208

Borcke, von 257

Born, Ignaz von 142

Botanik 12, 173, 196, 198, 200, 202, 218

Boulanger, Nicolas Antoine 198

Bretagne 164, 208, 209

Britannien 58, 90, 91

Brühl, Friedrich Aloys von 103

Brünn 129, 158, 159, 161

Brünner Fund 158

Brüssel 152

Buffon, Georges Louis Leclerc, comte de $46,48,93,118,119,120,197,198$ 
Buschmann, Peter Joseph von 134, 135

Buschmann, von 257

C

Cabanis, Pierre-Jean-Georges 168, 169, 175,198

Cambacérès, Jean-Jacques-Régis de 152, 176,187

Cambry, Jacques 209

Candolle, Alphonse Pyrame de 246, 247

Casaubon, Isaac 73

Caubray, Pierre Nicolas Riffe de 143

Charrière, Isabelle de. siehe Zuylen, Belle van

Chemie 201

Chevalier de l'Aigle 111

Chevalier de l'anneau lumineux 203

Chevalier de l'Orient 90, 94, 106, 107

Chevalier du Pélican 111

Chevalier du Soleil 203

Chevalier Garde de la Tour 179

Chevalier Rose-Croix 101, 105, 106, 108, 110, $111,112,150,180,187$

Christentum 11, 75, 88, 111, 115, 208

Christian August von Sulzbach 78

Chymische Hochzeit 76, 77

Cormeille, Nicolas Antoine Massé de 187

Corpus Hermeticum 72, 73, 74, 75, 76, 93

Cudworth, Ralph 73

D

Dämonologie 93, 159

Darwin, Charles 244

Décade philosophique, littéraire et politique $168,170,176,208$

Delétang, Cécile 212

Desaguliers, John Theophilus 54, 59, 60, 61

Destutt de Tracy, Antoine Louis 168, 172, 175

Diderot, Denis 170

Druiden 208, 210, 217

Dumont-Schauberg 146

Dumont-Schauberg, Marcus 226

Dupuis, Charles-François 173, 174, 190, 194, 198

Duval, Aumary 173
E

Einbildungen, geistige 84,85

Eindrücke, sinnliche $66,70,82,83,85$

Einprägungen, geistige $62,84,253,254$, 255

Elite $50,51,64,114,139,154,162,175,187$, 191, 193, 196, 203, 204, 209, 211, 213, $224,247,252,254$

Élu 103, 105, 192, 226

Élu des Quinze 143

England 8, 54, 59, 79, 87, 100, 129

Erinnerung 23, 34, 35, 83, 174

Erinnerungsräume $33,34,91$

Erkenntnis 49, 73, 74, 80, 92, 94, 139, 168, $173,204,246$

Erziehung 17, 32, 49, 91, 115, 116, 126, 128, $129,170,197,205,211,227,251$

Erziehung zum Gentleman 19, 20

Esoterische, das 21, 22, 23, 49, 50, 254, 255

Eucharistiefeier 109

$\mathbf{F}$

Faramund, König der Franken 2, 78

Farina 146

Farina, Charles-Antoine 226

Fénelon, François 89

Ferdinand von Braunschweig-

Wolffenbüttel 136

Forster, Georg 175

Forstmeister, Friedrich Karl von 137

Fortpflanzung 42, 61, 84

Fortschritt 13, 48, 109, 171, 175, 251, 253

Francken-Sierstorff, von 257

franc-maçonnerie du rire 231

Franklin, Benjamin 175

Frankreich 21, 44, 59, 72, 90, 91, 106, 147, $148,149,152,153,173,177,192,200,231$, 234

Franziska Dorothea von Sulzbach 113

Franz I. von Österreich 143

Französische Revolution 6, 24, 131, 142, $149,154,166,167,168,175,190,196,197$, 208, 218, 219, 252

Franz Stephan von Lothringen 60, 158

Freimaureredikt 160

Friedrich II. von Preußen 16, 192

Friedrich Ludwig von Hannover 60, 61, $62,63,65$ 
Friedrich Wilhelm III. von Preußen 5

Friedrich Wilhelm II. von Preußen 114

Fünf Punkte 68

Fürstenberg, Franz Friedrich Freiherr von 125

Fürth, Josef von 180, 220, 222, 223, 224, 232,233

\section{G}

Gall, Franz Joseph 172

Gallitzin, Anna Amalia von 125

Gavre, Léopold Joseph de 187

Gegnerforschung, nationalsozialistische 15

Gehirn, menschliches 83, 172

Geist 80, 123, 126, 169, 213

Geisterbeschwörung 159, 160

Gemüth 80,88

Genealogie 13, 50, 58, 61, 62, 63, 64

gentleman mason 8

Geometrie 55, 56

Geschichte der Freimaurerei 54, 55, 59, 90, $101,105,209,232,253$

Geschichtsphilosophie 123

Gesellschaft, bürgerliche 9, 14, 17, 18, 51, 253, 254

Giesecke, Karl Ludwig 161, 162, 167

Ginguené, Pierre Louis 168, 208

Goens, Rijklof Michael van 132

Gold 69, 70, 71, 95

Goltstein, Johann Ludwig von 100, 115, 116, $118,119,120,121,124,128,129,131,133$

Goltstein, von 98

Grand Écossais 179, 225

Grand Inspecteur Inquisiteur

Commandeur 147, 181, 233

Großbritannien 61

Große Kette der Wesen 42, 47, 74, 118, 122, 170, 197

Guillotine, Joseph-Ignace 175

Gymnich, Otto von 137

Gymnich, von 98, 100

\section{$\mathrm{H}$}

Ham, mythischer Urvater der Afrikaner 46, 57, 68

Harff, Franz-Ludwig von 225

Harff zu Dreiborn, von 225

Hatzfeld, Marie Therese von 166
Hatzfeld, von 98, 257

Heimann, Fréderic-Charles 225

Heimann, Jean Philippe 143, 147, 225, 226

Helmont, Franciscus Mercurius van 78, $79,80,86,87,88,110,113,115$

Helmont, Johann Baptist van $80,82,84$, $85,87,114$

Helvetius, Minette 174, 176

Herkunft 2, 17, 38, 45, 47, 49, 55, 68, 89, 118

Hermes Trismegistos 73, 75

Hermetik 8, 71, 105

Herrschaft über die Gemüter 131, 138, 252

Herstatt 146

Herstatt, Friedrich 226

Herstatt, Jacques-Conrad 226

Herz, menschliches 83, 111, 201

Hiram Abiff 57, 68, 78, 107

Hochgrade 11, 101, 113, 133, 152, 187, 200, 202, 212

Hochgradsysteme 11, 20, 22, 24, 71, 90, 95, $111,134,140,147,150,160,177,187,188$, 191, 192, 195, 219

Hochzeit, blutige 76, 77

Hohenzollern, Prinz von 211

Hompesch, Ferdinand von 100

Hompesch, Franz Karl von 100, 121, 124, $125,128,129,133,141$

Hompesch, Johann Wilhelm von 141

Hompesch, Karl Arnold von 100

Hompesch, Karl von 129, 141

Hompesch, Louise von 128, 129

Hompesch, von 98, 100, 129

honnête homme 85,97

Humboldt, Alexander von 167

Humoralpathologie 85

Hund und Altengrotkau, Karl Gotthelf von 135,137

\section{I}

Idéologie 168, 170, 175, 193

Idéologues 168, 170, 171, 172, 173, 174, 175, $176,193,198,208,217,219,252$

Indien 208, 247

Intelligenz 254

J

Jacob, Abbé 157 
Jacobi, Friedrich Heinrich 115, 116, 121, 122,

$123,124,125,126,127,128,129,130,132$

Jacobi, Johann Conrad 121

Jacobi, Stephan Ludwig 119, 120

Jafet, mythischer Urvater der Europäer 46, $57,63,64,68$

Jesus Christus 41, 88, 106, 108, 109, 111, 174, 206

Johanneau, Éloi 209

Johannisgrade 10,71

Joseph II. von Österreich 142, 160

K

Kabbala 78, 95, 113

Karl II. von England 87

Karl von Hessen-Kassel 136

Karlsbader Beschlüsse 236, 241

Karl Theodor von der Pfalz 132

Karl Theodor von Pfalz-Sulzbach 113

Karneval, rheinischer 237

Kavalierstour 19, 20, 34, 50, 90, 157, 160, 174

Kempis, Maximilian von 160

Kilwinning 90, 150, 188

Kirche, katholische 4, 174, 176

Klassifizierung 118, 172, 198

Klein, Dieudonné Louis 129

Klein, Jacques Louis 129

Klespé, von 257

Klimatheorie 117, 118, 197, 207

Klugheit, Kardinaltugend der 10, 36, 38, 66

Kompensationsthese 18, 20

Königliche Kunst 55, 56, 57, 64, 247

Königsegg-Rothenfels, Maximilian Friedrich von 135,137

Kore Kosmou 74, 93, 111

Körper 71, 73, 74, 76, 80, 93, 109, 123, 169

Kreuzritter 11, 90, 134

Küenburg, Graf von 159

Kulturelles Gedächtnis $33,34,35,36,56$, $136,137,235$

L

Lacépède, Bernard Germain de 197, 206, 207, 211

Ladoucette, Charles de 146, 220

La Fayette, Marie-Joseph Motier 175
Lalande, Joseph-Jérôme Lefrançais de 157, $159,167,173,174$

Lamarck, Jean-Baptiste de 244

Lameth, Alexandre de 220

Langlès, Louis-Mathieu 173

Laumond, Jean Charles Joseph 219

La Valette St. George, de 257

Lavallée, Joseph 209

Lavater, Johann Caspar 197

Lebens-Art 36, 37, 38

Lebensgeister 70, 84, 85, 86, 109, 111, 251, 255

Le Bret, Cardin 72

Leerodt, Joseph von 137

Lehrlingsgrad 10, 19, 66, 249

Leibniz, Gottfried Wilhelm 79

Lemmen, Karl von 134

Lemmen, von 98, 100

Lemmen, Wilhelm von 134, 135

Lenné 146

Lenné, Peter Joseph 226

Lenné, Philippe Joseph 226

Lenoir, Alexandre 189, 190, 191, 194, 195, 196, 201, 209

Leopold Maximilian von BraunschweigLüneburg 138

Le Sage, Georges-Louis 122

Lessing, Gotthold Ephraim 123, 124

Leyen, von der 257

Licht 82, 144, 235, 251

Lichterteilung, freimaurerische 67

Lichtheimat 73

Linné, Carl von 46, 47, 48, 93, 118, 139, 172, 197, 198, 200, 202, 207

Locke, John 87

Loen, Johann Michael von 38, 40, 41, 42, $43,72,85$

Loë, von 98,100

loi Dannou 170

Longueval, Bernhard von 134

Longueval, von 98

Löwenfeld, Bernhard Joseph Schleis von 113

Löwenich, von 257

Loyseau, Charles 72, 76, 77, 85

Ludwig XIV. von Frankreich 80

Ludwig XVI. von Frankreich 120

lunaticus spiritus 236 
Luria, Isaak ben 78

M

Magen, menschlicher 82

Magie 70, 95, 105, 142, 158, 201

Maître écossais 11

Maître parfait 202, 226

Malta 100

Mangourit, Michel-Ange de 187, 206, 209, 210, 211, 212, 257

Martini, Jean Paul 167

Martius, Karl Philipp Friedrich von 244

Maupertuis, Pierre-Louis Moreau de 117, 118

Maximilian IV. von Bayern 100

Medizin 87, 170, 173, 198, 251

Meiners, Christoph 117

Meistergrad 10, 67, 69, 71, 78, 88, 107, 129

Meisterwort 65, 68, 69

Mendelssohn, Moses 123

Menschenzucht 117, 118

Mentelle, Emde 167, 173

Merode-Hoffalize, Alexander von 101, 102, $105,113,114$

Merode-Hoffalize, Balduin Karl von 102

Merode-Hoffalize, Gottfried Arnold von 102

Merode-Motzfeld, von 80, 114

Merode, von 98, 100, 102, 114

Mesmerismus 159, 160

Metallveredelung 69, 112

Metempsychose, Lehre der 23, 88, 89, 92, 93, 94, 95, 109, 110, 111, 112, 113, 114, 115, $123,130,131,139,140,142,155,165,194$, $195,196,205,252$

Metternich, Wolf von 76

Mettra, Louis-François 137

Millin, Aubin-Louis 167, 171, 172, 173, 174

Mirbach-Harff, Johann Wilhelm von 243

Mirbach, von 98

Mnemosyne, griechische Göttin der Erinnerung 175

Moderns 54, 67

Monceau, Henri Louis Duhamel du 119, 120

Mondkalender 237

Monogenismus 45, 118, 197

Montagu, John Duke of 8, 54, 59, 60, 61
Montaleau, Roëttiers de 149

Mozart, Wolfgang Amadeus 161, 162

Mumm 146

Museum 171, 201

Mysterien 162, 173, 174, 194, 195, 198, 211

Mysterien, antike 162, 194, 195, 198

Mysterienprojekt, Wiener 162

Mystik 104

Mythos 34, 35

N

Narrenzahl »11« 237

Nation 154, 168, 171, 195, 196, 205, 208 , $209,213,218,227,235,247,252,253$, 254

Naturforscher 60, 93, 118, 119, 207, 244

Naturgeschichte 13, 23, 47, 48, 118, 172, 200, 207

Naturwissenschaften $12,13,22,23,49,125$, $140,142,159,162,167,169,171,175,176$, 198, 205, 206, 227, 244, 246, 247, 254

Nesselrode-Ehreshoven, Karolina Maria von 102

Nesselrode-Hugenpoett, von 98

Neuplatonismus 8,73

Neuplatonisten, Cambridger 73, 79

Newton, Sir Isaac 60, 64, 65, 92, 110, 251

Niederlande 31, 97, 98, 100

Nivellierung, ständische 9, 17, 104

Noah 46, 56, 57, 60, 68, 69, 91

Noblesse d'Empire 147, 148, 152, 177, 178, 205

Notarikon, INRI 108, 109

Nova Atlantis 192

O

Orange et de Nassau, Princesse de 258

Orléans, Elisabeth Charlotte von 80

P

Paracelsismus 251

Parfait Maçon 106, 107

Pasqually, Martinez de 105

Patronage 130

Payne, George 54

Pelikan, Symbol 76, 111

Perfektionierung 95, 170, 193, 196, 204, $205,217,244,247,251$ 
Pernety, Antoine-Joseph 105, 191, 192, 197

Philosophe Inconnu 112

philosophia perennis 50, 91, 93, 111

Philosophie 22, 41, 66, 73, 92, 125, 126, 128, $166,168,170,176,202$

Phrenologie 172

Physiologus 111

Pietismus 115

Pinel, Philippe 198

Pipelet, François 166

Pipelet, Jean-Baptiste 166

Planetenwanderung 123, 126

Platon 72, 93, 111

Polygenismus 45

Präformationslehre 47, 117, 126

Preußen 6, 192, 257

Prince du Royal Secret 181, 187

Protestantismus 243

Putrefactio. siehe Verwesung

Pythagoras 93, 111

Q

Quadt-Wickrath, von 257

\section{$\mathbf{R}$}

radix. siehe Rasse

Ramecourt, Charles-René Fourcroy de 120

Ramsay, Chevalier Andrew Michael 89, $90,91,92,93,94,111,124,150,157$

Rasse 13, 44, 45, 63, 72, 117, 128, 129, 130, $139,170,198,200,213,244,251,253$

Rassengenese 45, 84, 251, 253, 254, 255

Rassismus, moderner 254

Raynouard, François 173

Rechteren, von 132

Redouté, Pierre-Joseph 200, 213

Reifung, seelisch-charakterliche 10,66 , 67,70

Rey, Marc-Michel 127

Rheinland 5, 6, 7, 18, 21, 24, 25, 31, 104, 115, $137,142,153,155,166,178,204,205,219$, $223,228,233,234,241,243,252$

Rheinprovinz, preußische 5, 6, 242

Rittergrade 11, 16, 90, 95, 136, 252

Ritter vom Degen und vom

Rosenkreuz 105

Roerdepartement 6, 143, 148, 219

Rosenkreuz, Christian 76, 77
Rosenkreuzer 76, 87, 109

Rosenroth, Knorr von 78, 79

Rousseau, Jean-Jacques 126

\section{S}

Saint-Martin, Louis Claude de 105

Salm, Constance de 157, 164, 167, 168, 171, $172,173,174,175,176,195,212,219$

Salmo, Graf zu Ardennien 1, 63, 78

Salm-Reifferscheidt-Bedburg, Karl Anton Josef zu 158

Salm-Reifferscheidt-Bedburg, Sigismund zu 158

Salm-Reifferscheidt-Dyck, Franz Joseph zu 157

Salm-Reifferscheidt-Dyck, Joseph zu insb. ab 157

Salm-Reifferscheidt-Krautheim, Joseph Franz zu 225

Salm-Reifferscheidt-Raitz, Hugo Franz zu 159

Salm-Reifferscheidt-Raitz, Karl Anton zu 158, 159, 160, 161

Salm-Salm, Emanuel de 224

salomonischer Tempel 56, 57, 60, 66, 68, 107

Salomon, König 40, 54, 57, 68, 72, 91, 93, 94,111

Salomon's House 192

Salon 157, 164, 172, 174, 175, 176

Salz, volatiles 86,109

Samen, männlicher 82, 84

Samen, tugendhafte/geistige $42,49,85,88$, $110,218,251$

Sattelzeit 6, 7, 22, 23, 24, 25, 95, 251

Sayn-Wittgenstein-Berleburg, Casimir von 115

Schädel, menschliche 172

Schaesberg, August von 100

Schaesberg, von 98, 100

Schikaneder, Emanuel 162

Schirmer, François Xavier 143, 145

Schloss Bedburg 243

Schloss Bollheim 125

Schloss Brühl 178

Schloss Dyck 1, 13, 36, 38, 63, 158, 178, 196, 220, 222

Schloss Ehreshoven 24 
Schloss Raitz 159

Schottland 8, 90

science sociale 171, 176, 193, 198

Seele $10,40,41,71,73,74,77,78,80,83$, $88,91,93,109,115,121,123,126,129$, $130,131,141,169,181,194,252$

Seelenheil 95, 114, 130, 140, 251

Seelenlehre, platonische 75

Seelenrevolution 79, 92, 115, 142

Seelenverwandtschaft 98, 128

Seelenwanderungsdebatte $79,80,88,113$, $115,121,130$

Selbsterkenntnis 10, 74, 139

Selektion 244

Sem, mythischer Urvater der Völker des Nahen Ostens 46, 57, 68

Sensualismus 66, 251

Siebenjähriger Krieg 101, 103, 120

Sissonet, Anton 116, 117, 118, 130

Sophie von Hannover 79, 80

Spee, Ambrosius Franz von 125

Spee, von 98, 125

Spiegel zum Diesenberg, Franz Wilhelm von 137

Staël-Holstein, von 100, 257

Stammbaum 1, 13, 36, 50, 63, 78, 127, 148, 158,251

Stammsitz 31, 34

Steinberger, Adolf 226, 227

Stein, Heinrich Friedrich vom 243

St. Joachim, Düsseldorf 234

St. Napoleon, Paris 187, 188

Stuart, Charles Edward 89

Sündenfall $40,55,80,82$

Symbolik 10, 56, 106, 107, 109, 175, 181, 193, 218, 237, 253

Symbolsprache $91,94,187,192,193,196$, 218

\section{T}

Taxonomie 139, 200, 204

Templerlegende 105, 136, 137, 152, 173

Terreur 149

Théis, Alexandre de 167

Théis, de 164

Thiriart, Théodore François 144

Thomasius, Christian 36, 38, 168
Thory, Claude Antoine 187, 189, 190, 196, 200, 201, 202, 221, 222, 223, 224, 228, 232, 234

Tierzucht 120

Tod 68, 69, 78, 95, 108, 109, 129, 138, 162

Transmutation 95, 201

Tschudi, Théodore-Henri de 111, 112, 133

Tugend-Adel 41, 104, 243

Tugendhaftigkeit 10, 38, 40, 41, 42, 52, 252

U

Unsterblichkeit 20,121, 141, 181, 194

Uradel 55, 64, 102, 244, 257

Urchristentum 109

Urreligion, noachidische $51,60,64,65,88$, $89,91,95,204$

Ursprung 2, 11, 34, 37, 40, 41, 42, 45, 50, $54,55,56,84,197,209,235,246,247$, 251

Ursprungsfrage 13,45

Urwissen 8

V

Varietäten 198

Verbürgerlichung des Adels 14

Verdienstadel 177

Verdienstdiskurs 44

Veredelung, seelisch-charakterliche 10,49, 50,51

Vererbbarkeit 50, 131, 255

Verkenius, Erique Henry 143, 225, 227

Vernunftreligion 131

Verschwörungstheorien 149, 235

Verwesung 69, 78

Volney, Constantin François 198

Voltaire 122, 175

Vormärz 243

\section{W}

Wachstum 251, 253

Waldeck, Ludwig von 257

Weg der Tugend 10, 11, 48, 63, 196, 208

Weishaupt, Adam 138

Weyer, Henry Joseph 143

Wiedergeburt $68,70,74,77,80,88,89,94$, 162,165

Wilhelm III. von Preußen 241 
Wilhelmsbader Konvent 138, 140, 141, 159, 162,241

Willermoz, Jean-Baptiste 105

Willermoz, Pierre-Jacques 105

Wolff-Metternich zur Gracht 5, 24, 31, 32, 36,76

Wurzel 13, 63, 64, 82, 98, 213, 218, 251, 253

Z

Zahlenmagie 201

Zauberflöte, Die 161, 162

Zeichen 68, 82, 175

Zeit, Beschleunigung der 70

Zeitrechnung 2, 59

Zivilisation, menschliche 37, 55, 95, 247

Zoologie 48, 175

Zuylen, Belle van 127, 129 
Welche Rolle spielte das »Esoterische« für die Selbstsicht der adeligbürgerlichen Eliten beim Übergang zur Moderne? Dieser Frage geht die Studie Martin Otto Brauns mit dem Titel »An den Wurzeln der Tugend. Rheinischer Adel und Freimaurerei 1765-1815 « nach. Auf der Grundlage der mythischen Geschichtskonstruktionen von Genealogien des rheinischen Adels sowie des Geheimbunds der Freimaurerei zeichnet der Autor die parallel zu den Entwicklungen der Naturwissenschaften verlaufende Transformation der Vorstellung vom tugendhaften »Adel des Blutes " hin zum bürgerlichen »Adel des Intellekts" nach. Die Studie kann dabei zeigen, wie der esoterische Gehalt des frühneuzeitlichen Bildes von Wachstum und Fortschritt des Familienstammbaums sich um 1800 mehr und mehr auf die Konzepte »Nation« und »Volk» im Gesamten ausweitete. Das esoterische Denken hielt sich auf dieser Grundlage bis in die Moderne und sollte vorhandene rassische Vorstellungen adlig-bürgerlicher Eliten der "Sattelzeit» nachhaltig prägen.

Martin Otto Braun promovierte im Fach Neuere und Mittelalterliche Geschichte an der Universität zu Köln und war Doktorand in der Forschergruppe »Aufbruch in die Moderne. Der Rheinische Adel in westeuropäischer Perspektive 1750-1850 « des Deutschen Historischen Instituts Paris unter Leitung von Prof. Dr. Gudrun Gersmann. Er ist Autor und Mitherausgeber der durch die Fritz Thyssen Stiftung geförderten »Netzbiografie: Joseph zu Salm-Reifferscheidt-Dyck $(1773-1861) \ll$.

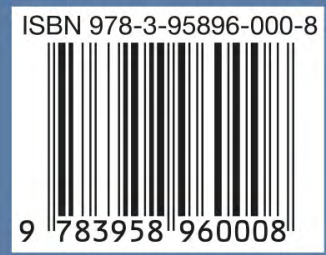

